\title{
RECEIVED
}

LOCKHEED WATINY JUL 031996

OSTI

ORNL/ER-366

ENVIRONMENTAL RESTORATION PROGRAM

\section{Waste Area Grouping 2 Phase I Task Data Report: Ecological Risk Assessment and White Oak Creek Watershed Screening Ecological Risk Assessment}

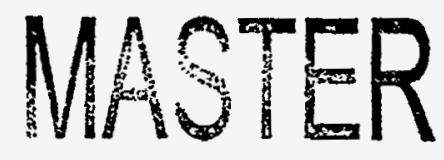

This document has been approved by the K-25 Site Technical Information Office for release to the public. Date: $5 / 3 / 96$ 
This report has been reproduced directly from the best available copy.

Available to DOE and DOE contractors from the Office of Scientific and Technical Information, P.O. Box 62, Oak Ridge, TN 37831; prices available from 423-576-8401 (fax 423-576-2865).

Available to the public from the National Technical Information Service, U.S. Department of Commerce, 5285 Port Royal Rd., Springfield, VA 22161. 
Energy Systems Environmental Restoration Program

Waste Area Grouping 2

Phase I Task Data Report:

Ecological Risk Assessment and

White Oak Creek Watershed Screening

Ecological Risk Assessment
R. A. Efroymson
B. L. Jackson
D. S. Jones
B. E. Sample
G. W. Suter II
C. J. E. Welsh

Date Issued-May 1996

Prepared for the

U.S. Department of Energy

Office of Environmental Management

under budget and reporting code EW 20

Environmental Management Activities at the

OAK RIDGE NATIONAL LABORATORY

Oak Ridge, Tennessee 37831-8169

managed by

LOCKHEED MARTIN ENERGY SYSTEMS, INC.

for the

U.S. DEPARTMENT OF ENERGY

under contract DE-AC05-84OR21400 


\section{Author Affiliations}

G. W. Suter, B. E. Sample, R. A. Efroymson, and D. S. Jones are members of the Environmental Sciences Division, Oak Ridge National Laboratory. C. J. E. Welsh is a member of the Health Sciences Research Division, Oak Ridge National Laboratory. B. L. Jackson is a member of the Computer Sciences and Mathematics Division. 


\section{PREFACE}

This report, Waste Area Grouping 2 Phase I Task Data Report: Ecological Risk Assessment and White Oak Creek Watershed Screening Ecological Risk Assessment (ORNL/ER-366), was prepared in accordance with requirements under the Comprehensive Environmental Response, Compensation, and Liability Act. This work was performed under Work Breakdown Structure 1.4.12.6.1.02.40.08.05 (Activity Data Sheet 3326). Publication of this document meets a project deliverable of May 15, 1996. This document is one of five reports issued in 1996 that provide follow-up information to the Phase I Remedial Investigation Report for Waste Area Grouping (WAG) 2 at the Oak Ridge National Laboratory. This report presents results of a screening ecological risk assessment for WAG 2 and, as far as available data permit, for other areas in White Oak Creek watershed. A screening assessment is intended to screen out chemicals that are not hazardous and receptors that are not at risk. A relatively small number of chemicals in water, sediment, and floodplain soils were identified as chemicals of potential ecological concern. However, no receptors could be screened out, and some tributaries and all upland areas except WAG 5 could not be assessed because of lack of data.

\section{DISCLAIMER}

This report was prepared as an account of work sponsored by an agency of the United States Government. Neither the United States Government nor any agency thereof, nor any of their employees, makes any warranty, express or implied, or assumes any legal liability or responsibility for the accuracy, completeness, or usefulness of any information, apparatus, product, or process disclosed, or represents that its use would not infringe privately owned rights. Reference herein to any specific commercial product, process, or service by trade name, trademark, manufacturer, or otherwise does not necessarily constitute or imply its endorsement, recommendation, or favoring by the United States Government or any agency thereof. The views and opinions of authors expressed herein do not necessarily state or reflect those of the United States Government or any agency thereof. 


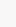




\section{CONTENTS}

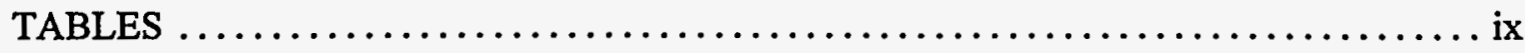

FIGURES $\ldots \ldots \ldots \ldots \ldots \ldots \ldots \ldots \ldots \ldots \ldots \ldots \ldots \ldots \ldots \ldots \ldots \ldots \ldots \ldots \ldots \ldots \ldots \ldots$

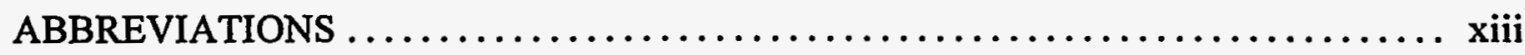

EXECUTIVE SUMMARY $\ldots \ldots \ldots \ldots \ldots \ldots \ldots \ldots \ldots \ldots \ldots \ldots \ldots \ldots \ldots \ldots \ldots \ldots \ldots \ldots$

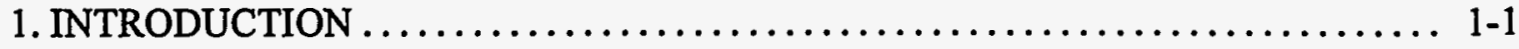

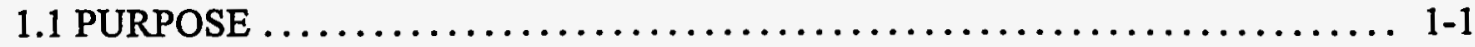

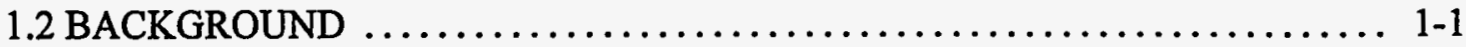

1.3 ORGANIZATION OF THE ECOLOGICAL RISK ASSESSMENT $\ldots \ldots \ldots \ldots \ldots$ 1-3

2. ECOLOGICAL PROBLEM FORMULATION $\ldots \ldots \ldots \ldots \ldots \ldots \ldots \ldots \ldots \ldots \ldots . . \ldots \ldots$

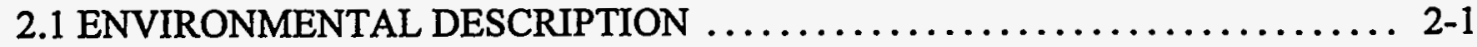

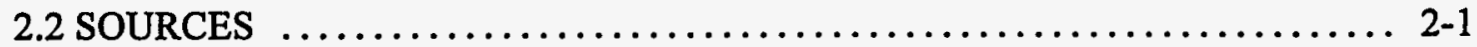

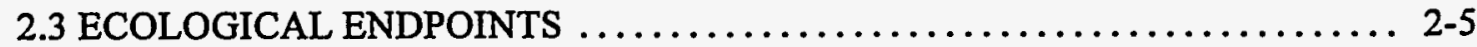

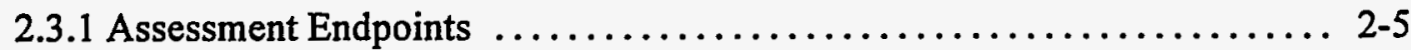

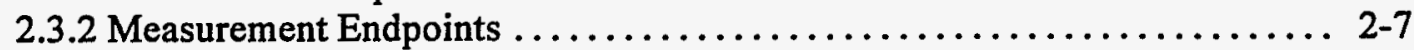

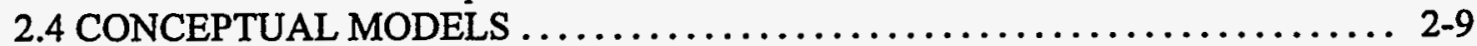

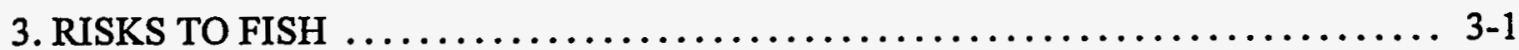

3.1 EXPOSURE ASSESSMENT FOR FISH $\ldots \ldots \ldots \ldots \ldots \ldots \ldots \ldots \ldots \ldots \ldots \ldots \ldots \ldots, 1$

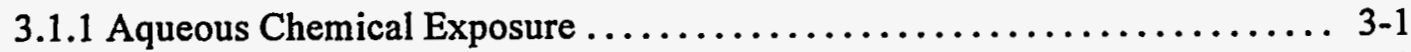

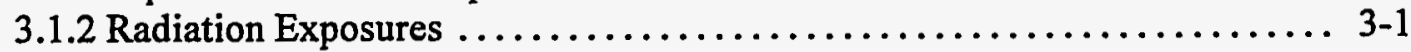

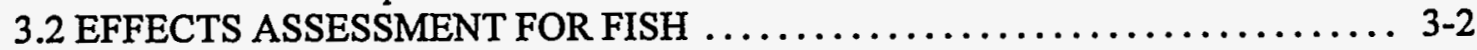

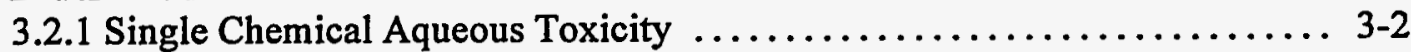

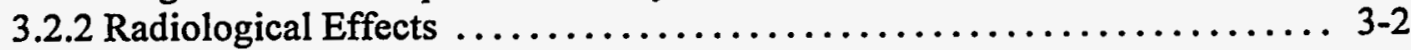

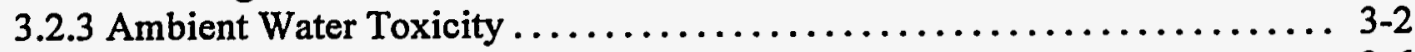

3.2.4 Fish Community Survey ........................... 3-6

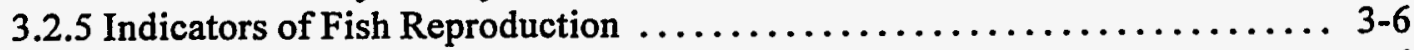

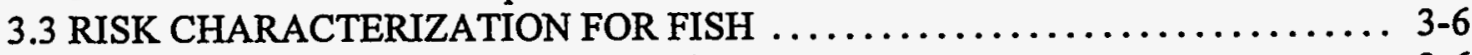

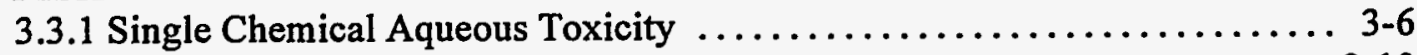

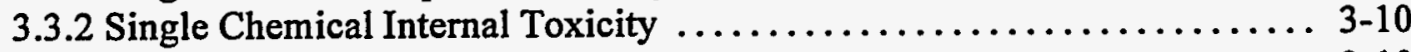

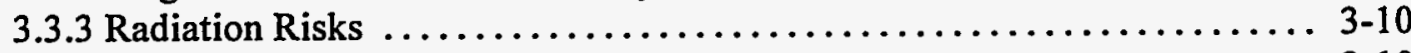

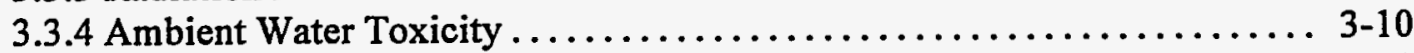

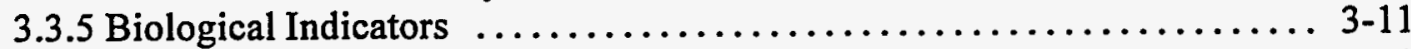

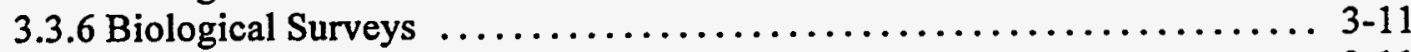

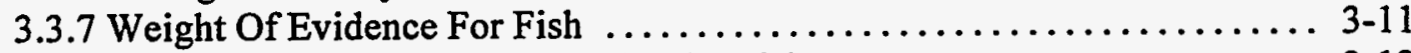

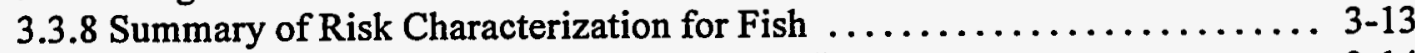

3.4 UNCERTAINTIES CONCERNING RISKS TO FISH $\ldots \ldots \ldots \ldots \ldots \ldots \ldots \ldots . . \ldots \ldots$

4. RISKS TO BENTHIC INVERTEBRATES $\ldots \ldots \ldots \ldots \ldots \ldots \ldots \ldots \ldots \ldots \ldots \ldots$. $4-1$

4.1 EXPOSURE ASSESSMENT FOR BENTHIC INVERTEBRATES . ........ 4-1

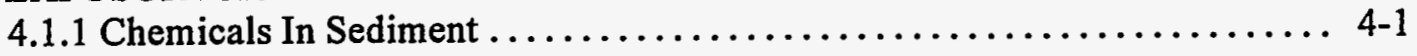


4.1.2 Sediment Radiation Exposures $\ldots \ldots \ldots \ldots \ldots \ldots \ldots \ldots \ldots \ldots \ldots . \ldots . . \ldots .4$

4.2 EFFECTS ASSESSMENT FOR BENTHIC INVERTEBRATES $\ldots \ldots \ldots \ldots \ldots .4$ 4-2

4.2.1 Single Chemical Sediment Toxicity ..................... 4-2

4.2.2 Invertebrate Community Surveys $\ldots \ldots \ldots \ldots \ldots \ldots \ldots \ldots \ldots \ldots . \ldots \ldots .4 .5$

4.3 RISK CHARACTERIZATION FOR BENTHIC INVERTEBRATES $\ldots \ldots \ldots \ldots$ 4-5

4.3.1 Single Chemical Sediment Toxicity ....................... 4-5

4.3.2 Sediment Radiation Characterization ...................... 4-8

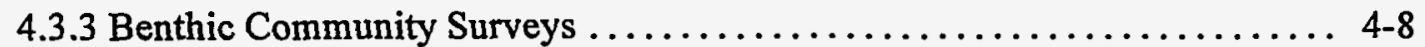

4.3.4 Weight of Evidence for Benthic Invertebrates $\ldots \ldots \ldots \ldots \ldots \ldots \ldots \ldots$ 4-8

4.4 UNCERTAINTIES CONCERNING RISKS

TO BENTHIC INVERTEBRATES $\ldots \ldots \ldots \ldots \ldots \ldots \ldots \ldots \ldots \ldots \ldots \ldots . \ldots \ldots$

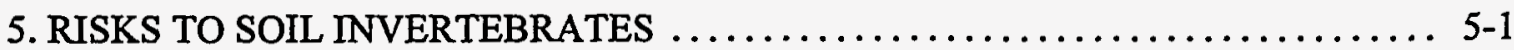

5.1 EXPOSURE ASSESSMENT FOR SOIL INVERTEBRATES $\ldots \ldots \ldots \ldots \ldots \ldots$. 5-1

5.2 EFFECTS ASSESSMENT FOR SOIL INVERTEBRATES ............ $5-1$

5.3 RISK CHARACTERIZATION FOR SOIL INVERTEBRATES $\ldots \ldots \ldots \ldots \ldots \ldots$.

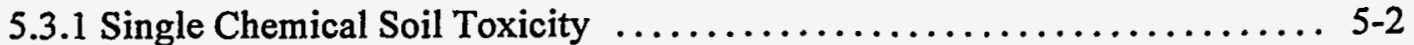

5.3.3 Summary of Risk Characterization for Soil Invertebrates ........... 5-3

5.4 UNCERTAINTIES CONCERNING RISKS TO SOIL INVERTEBRATES ..... $5-3$

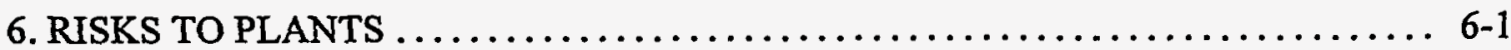

6.1 EXPOSURE ASSESSMENT FOR PLANTS $\ldots \ldots \ldots \ldots \ldots \ldots \ldots \ldots \ldots \ldots, 6-1$

6.1.1 Soil Exposures .................................. 6-1

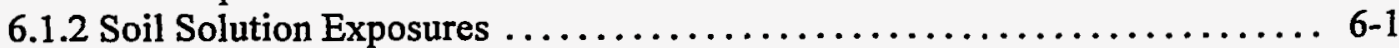

6.2 EFFECTS ASSESSMENT FOR THE PLANT COMMUNITY ${ }^{\prime} \ldots \ldots \ldots \ldots \ldots \ldots, 6-2$

6.3 RISK CHARACTERIZATION FOR THE PLANT COMMUNITY $\ldots \ldots \ldots \ldots \ldots$ 6-2

6.3.1 Single Chemical Soil and Solution Toxicity .................. 6-2

6.3.2 Summary of Risk Characterization for the Plant Community .......... 6-4

6.4 UNCERTAINTIES CONCERNING RISKS TO PLANTS .............. 6-4

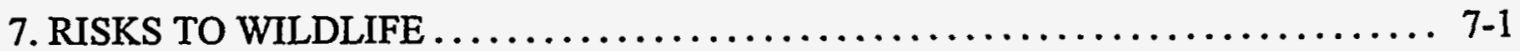

7.1 RISKS TO WILDLIFE FROM CHEMICALS $\ldots \ldots \ldots \ldots \ldots \ldots \ldots \ldots \ldots . \ldots \ldots, 2$

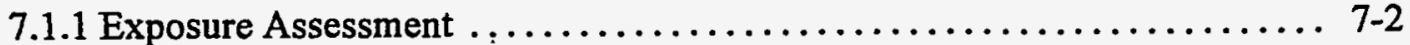

7.1.2 Chemical Effects Assessment for Wildlife .................... 7-6

7.1.3 Characterization Chemical Risks to Wildlife $\ldots \ldots \ldots \ldots \ldots \ldots \ldots \ldots$ 7-9

7.1.4 Uncertainties Concerning Risks to Wildlife ................. 7-31

7.2 RISKS TO PLANTS AND EARTHWORMS

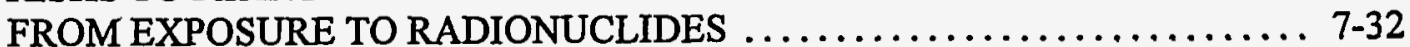

7.2.1 Exposure Assessment ............................. 7-32

7.2.2 Effects Levels for Radionuclides ..................... 7-38

7.2.3 Risk Characterization for Terrestrial Receptors

Exposed to Radionuclides .......................... 7-38

7.7.4 Uncertainties in the Radiological Risk Assessment ............. 7-40

8. SUMMARY AND CONCLUSIONS $\ldots \ldots \ldots \ldots \ldots \ldots \ldots \ldots \ldots \ldots \ldots \ldots \ldots \ldots \ldots \ldots$

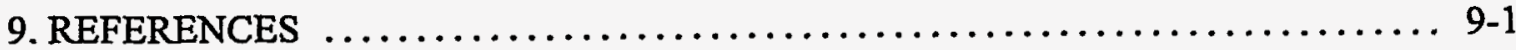


APPENDIX A.

Benthic Macroinvertegrate Community Study

of Waste Area Grouping 2 Deposition Areas

APPENDIX B.

Data Tables for Risks to Fish, Invertebrates, and Plants $\ldots \ldots \ldots \ldots \ldots \ldots \ldots \ldots$ B-1

APPENDIX C.

Data Tables for Risks to Wildlife

C-1 



\section{TABLES}

2.1 Definition of reaches in the White Oak Creek watershed

3.1 Descriptions of the ecotoxicological screening benchmarks for aquatic biota

3.2 Exposure factors for the radionuclides detected in WAG 2 sediment and surface water and their short-lived progeny

3.3 Results of screening of chemicals that exceed benchmarks in whole or filtered water for chemicals of potential ecological concern (COPECs)

3.4 Availability of biological data related to the fish community endpoint in the White Oak Creek watershed reaches

4.1 Descriptions of the ecotoxicological screening benchmarks for benthic biota exposed to contaminated sediments

4.2 Results of screening of chemicals that exceed benchmarks in sediments for COPECs

7.1 Metal concentration in hair of mink from the Oak Ridge Reservation and from off-site reference samples

7.2 Comparison of exposure distributions 



\section{FIGURES}

1.1 Map of White Oak Creek watershed and its tributaries $\ldots \ldots \ldots \ldots \ldots \ldots \ldots \ldots 1-2$

2.1 Map of White Oak Creek watershed with anthropogenic features

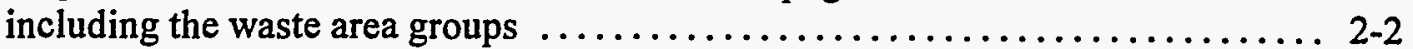

2.2 Map of the White Oak Creek watershed showing the stream reaches ......... 2-10

2.3 Conceptual model of the mechanisms of transport and exposure by which ecological receptors are exposed to contaminants in White Oak Creek, its tributaries, and its floodplain

2.4 Conceptual model of the mechanisms by which wide-ranging wildlife species are exposed to contaminants in White Oak Creek, its tributaries, and its floodplain ....................................... 7-10

7.1 Summary of lowest observed adverse effects level-based toxic units

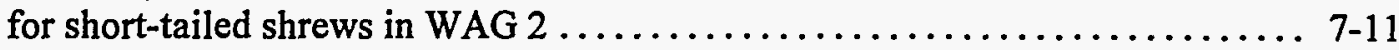

7.2 Summary of lowest observed adverse effects level-based toxic units

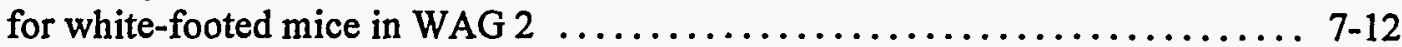

7.3 Summary of lowest observed adverse effects level-based toxic units

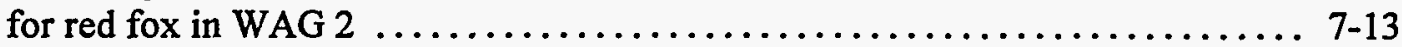

7.4 Summary of lowest observed adverse effects level-based toxic units

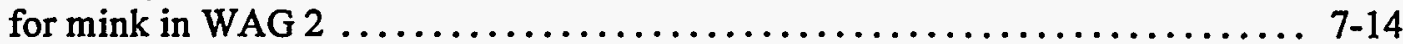

7.5 Summary of lowest observed adverse effects level-based toxic units for mink in WAG 2 (exposure through ingestion of fish only) $\ldots \ldots \ldots \ldots \ldots .7-15$

7.6 Summary of lowest observed adverse effects level-based toxic units

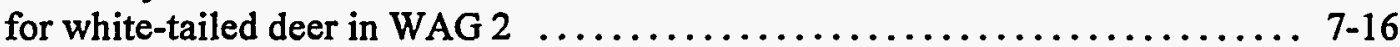

7.7 Summary of lowest observed adverse effects level-based toxic units

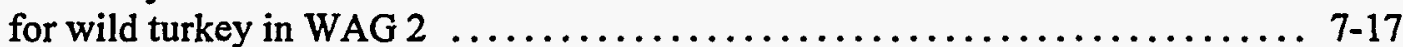

7.8 Summary of lowest observed adverse effects level-based toxic units

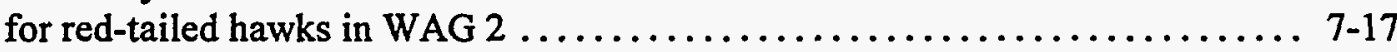

7.9 Summary of lowest observed adverse effects level-based toxic units for belted kingfisher in WAG 2 (exposure through ingestion of fish only) .... 7-18

7.10 Cumulative binomial probability of short-tailed shrews experiencing exposure to Aroclor-1260 in WAG 2 in excess of the lowest observed

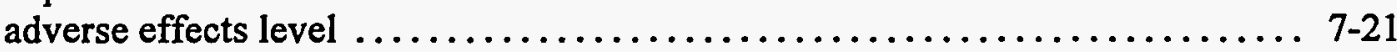

7.11 Cumulative binomial probability of short-tailed shrews experiencing exposure to cadmium in WAG 2 in excess of the lowest observed adverse effects level

7.12 Cumulative binomial probability of short-tailed shrews experiencing exposure to selenium in WAG 2 in excess of the lowest observed

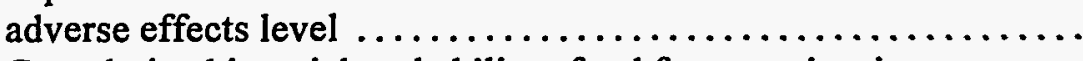

7.13 Cumulative binomial probability of red fox experiencing exposure to mercury in WAG 2 in excess of the lowest observed adverse

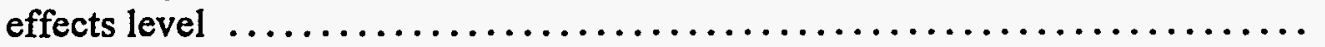

7.14 Cumulative binomial probability of belted kingfisher experiencing exposure to mercury in WAG 2 in excess of the lowest observed adverse

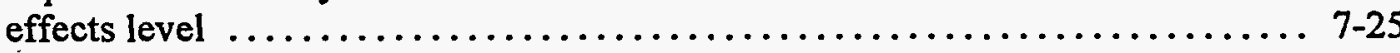

7.15 Cumulative binomial probability of wild turkey experiencing exposure to mercury in WAG 2 in excess of the lowest observed adverse effects level .... 



\section{ABBREVIATIONS}

$\begin{array}{ll}\text { BCV } & \text { Bear Creek Valley } \\ \text { BMAP } & \text { Biological Monitoring and Abatement Program } \\ \text { BWC } & \text { Background White Oak Creek } \\ \text { COPECs } & \text { chemicals of potential ecological concern } \\ \text { CV } & \text { chronic values } \\ \text { DOE } & \text { U.S. Department of Energy } \\ \text { DQO } & \text { Data Quality Objectives } \\ \text { EPA } & \text { U.S. Environmental Protection Agency } \\ \text { ER-L } & \text { effects range-low } \\ \text { EWC } & \text { White Oak Creek Embayment } \\ \text { FFA } & \text { Federal Facility Agreement } \\ \text { FY } & \text { fiscal year } \\ \text { HRT } & \text { Homogeneous Reactor Test } \\ \text { HQ } & \text { hazard quotient } \\ \text { IAEA } & \text { International Atomic Energy Agency } \\ \text { ICRP } & \text { International Council for Radiation Protection } \\ \text { IHP } & \text { Intermediate Holding Pond } \\ \text { LMB } & \text { Lower Melton Branch } \\ \text { LOAEL } & \text { lowest observed adverse effects level } \\ \text { LOEC } & \text { lowest observed effect concentration } \\ \text { LWC } & \text { Lower White Oak Creek } \\ \text { MWC } & \text { Middle White Oak Creek } \\ \text { NAWQ } & \text { National Ambient Water Quality Criteria } \\ \text { NCRP } & \text { National Council on Radiation Protection } \\ \text { NOAEL } & \text { no observed adverse effects level } \\ \text { NOEC } & \text { no observed effect concentration } \\ \text { NPDES } & \text { National Pollutant Discharge Elimination System } \\ \text { NWT } & \text { NorthwestTributary } \\ \text { ORNL } & \text { Oak Ridge National Laboratory } \\ \text { ORR } & \text { Oak Ridge Reservation } \\ \text { OU } & \text { operable unit } \\ \text { PAH } & \text { polycyclic aromatic hydrocarbons } \\ \text { PCB } & \text { polychlorinated biphenyl } \\ \text { PRL } & \text { probably effect level } \\ \text { RAC } & \text { Raccoon Creek } \\ \text { RI } & \text { remedial investigation } \\ \text { SAV } & \text { secondary acute value } \\ \text { SCV } & \text { secondary chronic values } \\ \text { TDEC } & \text { Tennessee Department of Environment and Conservation } \\ \text { TEL } & \text { threshold effect level } \\ \text { T\&E } & \text { threatened and endangered } \\ \text { UCL } & \text { upper confidence limit } \\ \text { TIE } & \text { toxicity identification and evaluation } \\ \text { UCB } & \text { upper confidence bound } \\ \text { UMB } & \text { Upper Melton Branch } \\ \text { WAG } & \text { Waste Area Grouping } \\ & \end{array}$


WOC

WOL

WS

W4T

IWC

White Oak Creek

White Oak Lake

West Seep

WAG 4 Tributary

WAG 1 White Oak Creek 


\section{EXECUTIVE SUMMARY}

This report presents an ecological risk assessment for Waste Area Grouping (WAG) 2 based on the data collected in the Phase I remedial investigation (RI). It serves as an update to the WAG 2 screening ecological risk assessment that was performed using historic data. In addition to identifying potential ecological risks in WAG 2 that may require additional data collection, this report serves to determine whether there are ecological risks of sufficient magnitude to require a removal action or some other expedited remedial process.

WAG 2 consists of White Oak Creek (WOC) and its tributaries downstream of the Oak Ridge National Laboratory (ORNL) main plant area, White Oak Lake (WOL), the White Oak Creek Embayment of the Clinch River, associated flood plains, and the associated groundwater. The WOC system drains the WOC watershed, an area of approximately $16.8 \mathrm{~km}^{2}$ that includes ORNL and associated WAGs. The WOC system has been exposed to contaminants released from ORNL and associated operations since 1943 and continues to receive contaminants from adjacent WAGs.

Since the WAG 2 program was planned, Federal Facility Agreement managers have decided to proceed with a remedial investigation for the WOC watershed. An early requirement of that activity is a screening ecological risk assessment for the watershed to identify hazards and data gaps. Since that assessment was needed at approximately the same time as the WAG 2 screening assessment and since the WAG 2 program is the primary source of data concerning the chemical composition of ambient media other than groundwater for the watershed, the assessments were combined. Therefore, this document used both WAG 2 program data and other data that was available to present a screening assessment of the WOC watershed. WAGs 5 and 6 and the WAG 1 surface impoundments have completed remedial investigations, and their results are not repeated here. Other WAGs have essentially no data concerning surface contamination, and they are scheduled for limited sampling and analysis.

This screening assessment is intended to indicate whether there are credible hazards to ecological endpoints in the WOC watershed due to contamination and whether there are data gaps that need to be filled. The following are conclusions concerning the hazards:

- Radionuclides in WAG 2 do not pose a hazard to fish or aquatic invertebrates. ${ }^{90} \mathrm{Sr}$ in three seeps exceed the screening benchmarks for aquatic life, but these seeps do not support communities of aquatic macroorganisms.

- Radionuclides in WAG 2 pose a hazard to terrestrial plants, wildlife, and soil invertebrates in all four reaches of WOC and in lower Melton Branch. Exposures were highest in the Intermediate Holding Pond (IHP) reach.

- The unfiltered water in all reaches exceeded water quality criteria and other toxicological benchmarks for aquatic life.

- Water from WOC adjacent to and below ORNL was toxic in a fish embryo-larval test but not in the standard subchronic tests.

- The fish community in WOC has low species richness, but this may be due to lack of recovery from past toxicity. However, the riffle invertebrate community that is exposed primarily to chemicals in water like the fish and has flying stages that should allow recovery also has low species richness. 
- $\quad$ Sediments from the IHP, Middle WOC (MWC), and Lower Melton Branch (LMB) are contaminated to levels that have been associated with toxic effects at other sites. Contaminants include metals, polycyclic aromatic hydocarbons, and polychlorinated biphenyls.

- The species richness of benthic invertebrates from WAG 2 sediments is lower than in background WOC sediments but not other reference streams. The exception is WOL, which has very low species richness. However, no comparable reference lakes were characterized.

- Chromium and mercury levels in IHP and Lower WOC (LWC) soils and mercury in MWC and $\mathrm{LMB}$ soils exceeded levels that were reported to be toxic to earthworms.

- Multiple metals were found in IHP, MWC, LWC, and LMB soils at concentrations that have been reported to be toxic to plants.

- Metals in seep waters in the WAG 4Tributary and West Seep reaches are at concentrations that have been reported to be toxic to plants.

- Hazards to wildlife were found in all WOC reaches. However, the hazards were greatest for mercury among chemicals, for IHP among reaches, and for shrews among species.

- Kingfishers from WOC show elevated levels of contaminants, and the one adult found had tissue levels of mercury and selenium that are indicative of toxicity. Mink from WOC do not appear to be contaminated.

The following are major uncertainties that could be addressed by additional data collection:

- Background concentrations need to be better characterized for the seeps, surface waters, sediments, and floodplain soils.

- The contamination of soil and biota on burial grounds other than WAGs 5 and 6 are unknown.

- The bioavailable concentrations of metals in WOC are unknown.

- The toxicity of soil and sediment in the watershed are unknown.

- The toxicity of water is unknown for some reaches and has been irregular in others.

- The fish communities have not been quantitatively characterized for the smaller tributaries.

- The chemical composition of fish is unknown for some tributaries and reaches.

- Because of the high selenium levels in a kingfisher, selenium levels should be characterized in fish.

In sum, plausible hazards exist in all reaches of WAG 2 and to all ecological endpoints. Radionuclides, organic chemicals, and metals are all implicated. However, none of the risk estimates or observations of the state of the watershed suggest that there is a need for an accelerated response. That is, no threatened or endangered species are at risk and no wetlands or other highly valued populations or ecosystems are experiencing catastrophic effects. Some parts of the watershed are uncharacterized and should be surveyed and sampled before the RI is completed. These results imply that a more complete data set should be assembled and used to prepare a definitive ecological risk assessment for the WOC watershed. 


\section{INTRODUCTION}

\subsection{PURPOSE}

This is one of five reports issued in 1996 that provide follow-up information to the Phase I Remedial Investigation (RI) Report for Waste Area Grouping (WAG) 2 at Oak Ridge National Laboratory (ORNL). The five reports address areas of concern that could cause immediate risk to public health at the Clinch River and ecological risk within WAG 2 at ORNL. The five reports that complete activities conducted as part of Phase I of the RI for WAG 2 are as follows:

- Waste Area Grouping 2, Phase I Task Data Report: Seep Data Assessment

- Waste Area Grouping 2, Phase I Task Data Report: Tributaries Data Assessment

- Waste Area Grouping 2, Phase I Task Data Report: Ecological Risk Assessment

- Waste Area Grouping 2, Phase I Task Data Report: Human Health Risk Assessment

- Waste Area Grouping 2, Phase I Task Data Report: Sediment Transport Modeling

In December 1990, the "Remedial Investigation Plan for Waste Area Grouping 2 at Oak Ridge National Laboratory" was issued (ORNL). The WAG 2 RI Plan was structured with a shortterm component to be conducted while up-gradient WAGs are investigated and remediated, and a long-term component that will complete the RI process for WAG 2 following remediation of up-gradient WAGs. RI activities for the short-term component were initiated with the approval of the U. S. Environmental Protection Agency (EPA), Region IV, and the Tennessee Department of Environment and Conservation (TDEC).

This report presents a screening ecological risk assessment for WAG 2 based on the data collected in the Phase I Remedial Investigation. It serves as an update to the WAG 2 screening ecological risk assessment that was performed using historic data (Suter 1992). In addition to identifying potential ecological risks in WAG 2 that may require additional data collection, it serves to determine whether ecological risks are of sufficient magnitude to require removal or some other expedited remedial process.

\subsection{BACKGROUND}

WAG 2 consists of White Oak Creek (WOC) and its tributaries downstream of the ORNL main plant area, White Oak Lake, the WOC embayment of the Clinch River and the associated flood plains, and the associated groundwater (Fig. 1.1). The WOC system drains the WOC watershed, an area of approximately $16.8 \mathrm{~km}^{2}$ that includes ORNL and associated WAGs. The WOC system has been exposed to contaminants released from ORNL and associated operations since 1943 and continues to receive contaminants from adjacent WAGs.

The WAG 2 RI Plan developed in 1990 was not a prototypical RI plan. It was recognized that full implementation of an RI was inappropriate while contaminants continue to enter the system. A phased effort was adopted in response to the need to take initial steps to protect the public and the environment and to characterize and assess risks associated with WAG 2 and the limitations imposed by changing contaminant input. 


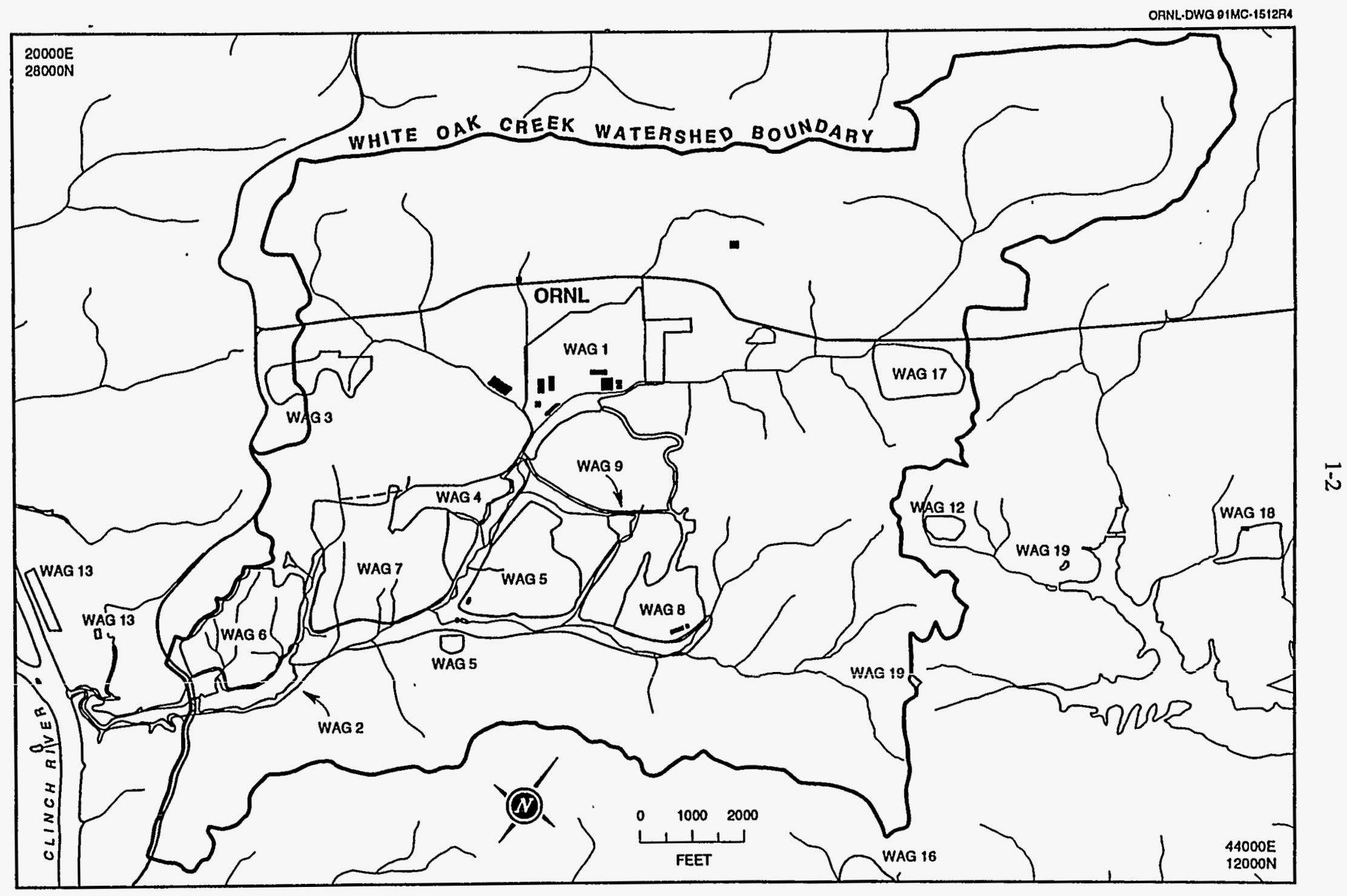

Fig. 1.1. Map of White Oak Creek and its tributaries. 
Three phases were initially identified: Phase I was the initial scoping activity to determine the need for early action; Phase II included interim activities during remediation of up-gradient WAGs to evaluate potential changes in the contamination status of WAG 2 that would necessitate revaluation of the need for early action; and Phase III would be completion of the Comprehensive Environmental Response, Compensation, and Liability Act process following remediation of the up-gradient WAGs. Field activities were initiated in fiscal year (FY) 1992 consistent with the RI Plan (ORNL 1990), and a report summarizing Phase I results to date was published in 1993 (DOE).

On June 20 and 21, 1994, a Data Quality Objectives (DQO) Workshop was held with representatives of the Department of Energy (DOE), EPA, and TDEC. The participants defined the nature and boundaries of the problems for the WAG 2 RI, determined decision criteria, and established inputs to be used for characterizing the site for decision-making purposes. During the workshop, the regulators made recommendations that would alter the initial WAG 2 RI plan. Consequently, the Federal Facility Agreement (FFA) managers from EPA, TDEC, and DOE directed that FY 1995 WAG 2 RI activities concentrate on meeting FFA requirements.

The FFA managers also directed that the WAG 2 RI be changed to a two-phase field program by eliminating Phase II activities and transferring needed elements into the newly formed ORNL Environmental Restoration Surface Water Program. A separate FY 1995 WAG 2 RI Work Plan was developed (DOE 1994) to replace previously identified planning and tasking documents. Emphasis was to be on analysis of existing data, data interpretation, and reporting of results. This document reports the results of the ecological risk assessment.

Finally, after the WAG 2 program was planned, the FFA managers decided to proceed with an RI for the WOC watershed. An early requirement of that activity is a screening ecological risk assessment for the watershed to identify hazards and data gaps. Since that assessment was needed at approximately the same time as the WAG 2 screening assessment and since the WAG 2 program is the primary source of data concerning the chemical composition of ambient media other than groundwater for the watershed, the assessments were combined. Therefore, this document used both WAG 2 program data and other data that were available to present a screening assessment of the WOC watershed. WAGs 5 and 6 and the WAG 1 surface impoundments have completed RIs, and their results are not repeated here. Other WAGs have essentially no data concerning surface contamination, and they are scheduled for limited sampling and analysis.

\subsection{ORGANIZATION OF THE ECOLOGICAL RISK ASSESSMENT}

This screening ecological risk assessment is organized in terms of the standard framework (EPA 1992). After a problem formulation the risks of chemicals to each of the ecological risk assessment endpoints are assessed separately (Sect. 3.7). Each includes an exposure assessment, effects assessment, characterization of risk, and characterization of uncertainty. Finally, ecological risks are summarized. The components of the assessment are explained in the following.

The problem formulation defines the scope and content of the assessment. It describes the site and potential contaminant sources, defines assessment and measurement endpoints, and presents the conceptual model. 
Exposure assessment characterizes the distribution in space and time of the concentrations of contaminants to which organisms are exposed. Risk from undetected chemicals was not assessed, as instructed by the FFA. Exposure calculations are performed for each reach.

Effects assessment characterizes the evidence concerning effects of contaminant exposure. The principal lines of evidence concerning effects are biological survey data that indicate the actual state of the receiving environment, media toxicity data that indicate whether the contaminated media are toxic under controlled conditions, bioindicator data that are biochemical and histological indications of the potential mechanisms and causes of effects, and single chemical toxicity data that indicate the toxic effects of the concentrations measured in site media.

Risk characterization is the phase of risk assessment in which the information concerning exposure and the information concerning the potential effects of exposure are integrated to estimate risks (the likelihood of effects given the exposure). Because this is a screening assessment, emphasis is placed on screening the chemical concentrations in ambient media against screening benchmark values. Procedurally, the risk characterization is performed for each assessment endpoint by (1) screening all measured contaminants against toxicological benchmarks and background concentrations if available, (2) considering the implications of other types of data for the hypothesis that a hazard exists that requires further assessment, (3) logically integrating the screening results with the other evidence to determine whether a credible hazard exists to the endpoint, and (4) listing and discussing the major uncertainties in the assessment. 


\section{ECOLOGICAL PROBLEM FORMULATION}

The problem formulation consists of describing the relevant features of the environment, describing the sources of contamination, identifying ecological endpoints, and summarizing that information in terms of a conceptual model of the hazard posed by the contaminants to the endpoint biota.

\subsection{ENVIRONMENTAL DESCRIPTION}

The environment considered in this assessment is the WOC watershed (henceforth, simply watershed) and in particular WAG 2 (Fig. 2.1). WAG 2 consists of Melton Branch and its floodplain below km 1.5 (just above the discharge from the High Flux Isotope Reactor) and WOC and its floodplain downstream of WAG 1 (km 3.45 at the 7500 Bridge).

The streams and floodplains of the watershed are divided into reaches, which are lengths of stream and associated floodplain that are relatively uniform with respect to exposure and ecology. The reaches within WAG 2 correspond to the areas defined for floodplain soil and sediment characterization (Ford et al. 1996). However, because this is also a preliminary assessment of the watershed, additional reaches are defined beyond the five WAG 2 reaches. These are defined in Table 2.1 and portrayed in Fig. 2.2. One stream that is not in the watershed, Raccoon Creek, is included because it was included in the WAG 2 Phase 1 program and it drains WAG 3 which is an ORNL site.

The reaches are divided into two categories. Mainstem reaches are those on WOC, including WOL, and tributaries are streams that feed WOC and are not ephemeral. Many of the water samples are from springs and small tributaries' sites, which include springs, seeps, and ephemeral tributaries. Each of these sites is associated with the reach to which it drains so that sources of chemicals can be identified, but its data are not averaged with the mainstem or tributary data.

No threatened or endangered species are known to occur in WAG 2, but some state -listed species (e.g., river otter) and federally listed species (e.g., bald eagle) are undergoing range expansions and may use WAG 2 in the future. Threatened or endangered species that are believed to occur on the Oak Ridge Reservation (ORR) are listed by Suter et al. (1996).

\subsection{SOURCES}

The proximate sources considered in this assessment are the contaminated water, sediment, and soil. The ultimate sources of contaminants are the National Pollutant Discharge Elimination System (NPDES) permitted point discharges at ORNL and releases from wastes in WAGs 1, 3-9, and 17. DOE's operations in the WOC watershed have included waste disposal, spills, and use of chemicals such as pesticides in the environment. 


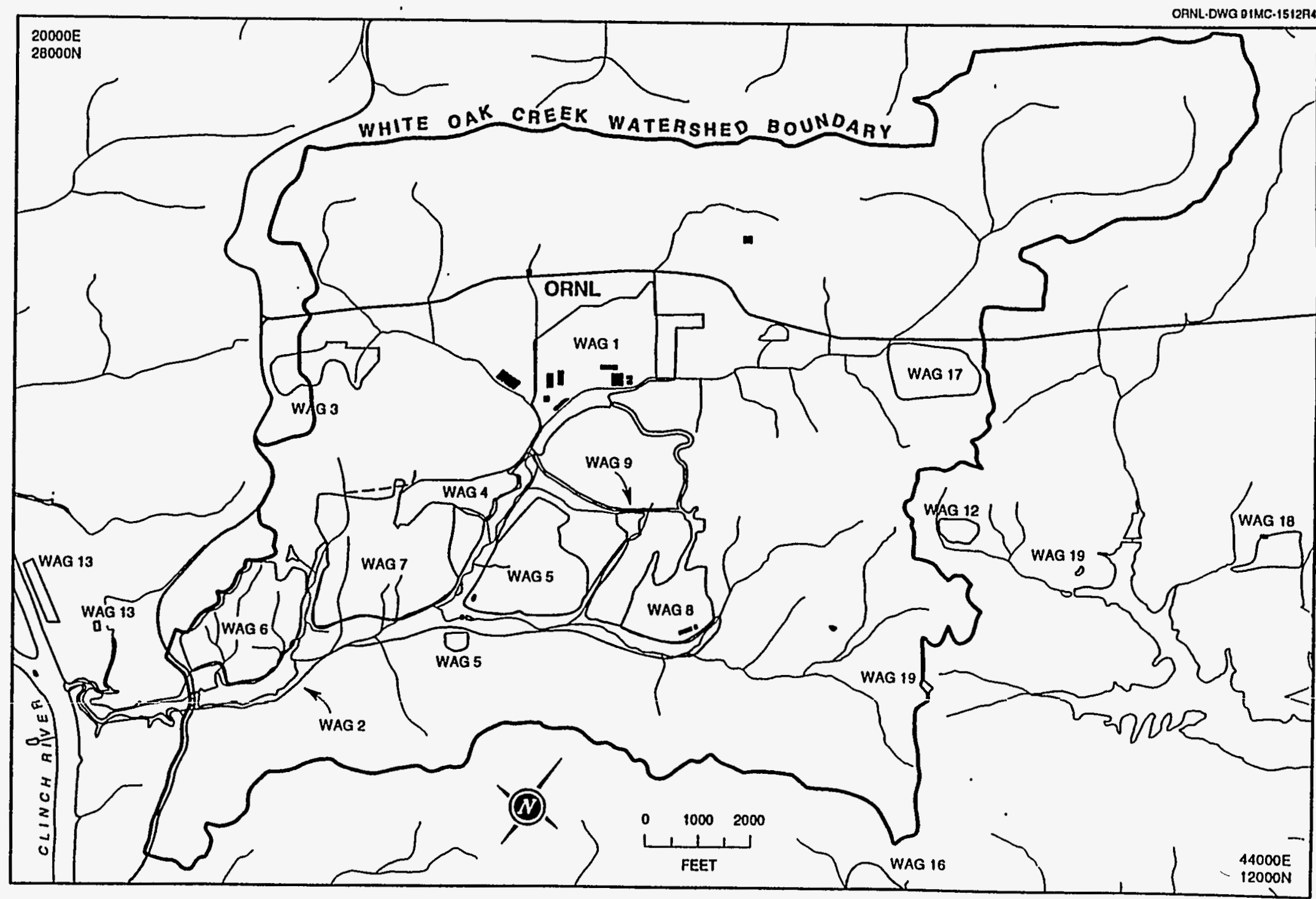

Fig. 2.1. A map of White Oak Creek watershed with anthropogenic features including the waste area groups. 
Table 2.1. Definition of reaches in the White Oak Creek watershed

\begin{tabular}{|c|c|}
\hline Reach code & Reach description \\
\hline BWC & Background White Oak Creek (WOC): upstream of WAG 1 \\
\hline IWC & $\begin{array}{l}\text { Waste Area Group (WAG) } 1 \text { WOC: the stream adjacent to WAG } 1 \text { and extending } \\
\text { downstream to the } 7500 \text { Bridge }\end{array}$ \\
\hline IHP & $\begin{array}{l}\text { Intermediate Holding Pond: The first WOC reach in WAG 2, extending from the } \\
7500 \text { Bridge to the confluence of the WAG } 4 \text { Tributary; it corresponds to the area of } \\
\text { the former Intermediate Holding Pond. }\end{array}$ \\
\hline MWC & Middle WOC: extends from the WAG 4 Tributary to Melton Branch \\
\hline LWC & Lower WOC: extends from the Melton Branch to White Oak Lake \\
\hline WOL & White Oak Lake \\
\hline EWC & $\begin{array}{l}\text { Embayment of WOC: extends from the dam at Route } 95 \text { to the coffer dam at the } \\
\text { confluence with the Clinch River }\end{array}$ \\
\hline UMB & $\begin{array}{l}\text { Upper Melton Branch: extends upstream from the Homogeneous Reactor Test } \\
\text { (HRT) Tributary }\end{array}$ \\
\hline LMB & Lower Melton Branch: extends downstream from the HRT Tributary \\
\hline $1 \mathrm{C}$ & $\begin{array}{l}\text { First Creek: flows through western ORNL and enters the lower end of the Northwest } \\
\text { Tributary }\end{array}$ \\
\hline $5 \mathrm{C}$ & Fifth Creek: flows through central ORNL and enters WOC \\
\hline NWT & Northwest Tributary: drains the eastern end of WAG 3 and far western ORNL \\
\hline W4T & WAG 4 Tributary \\
\hline HRT & $\begin{array}{l}\text { Homogeneous Reactor Test Tributary: the tributary of Melton Branch that drains } \\
\text { WAG } 9\end{array}$ \\
\hline WS & $\begin{array}{l}\text { West Seep: a small tributary located between WAGs } 6 \text { and } 7 \text { that directly enters } \\
\text { White Oak Lake }\end{array}$ \\
\hline $\mathrm{U}$ & $\begin{array}{l}\text { Unknown reach: two seeps that are not known to drain into any stream are assigned } \\
\text { this designation }\end{array}$ \\
\hline RAC & Raccoon Creek: outside the WOC watershed, drains WAG 3 \\
\hline
\end{tabular}


$2-4$

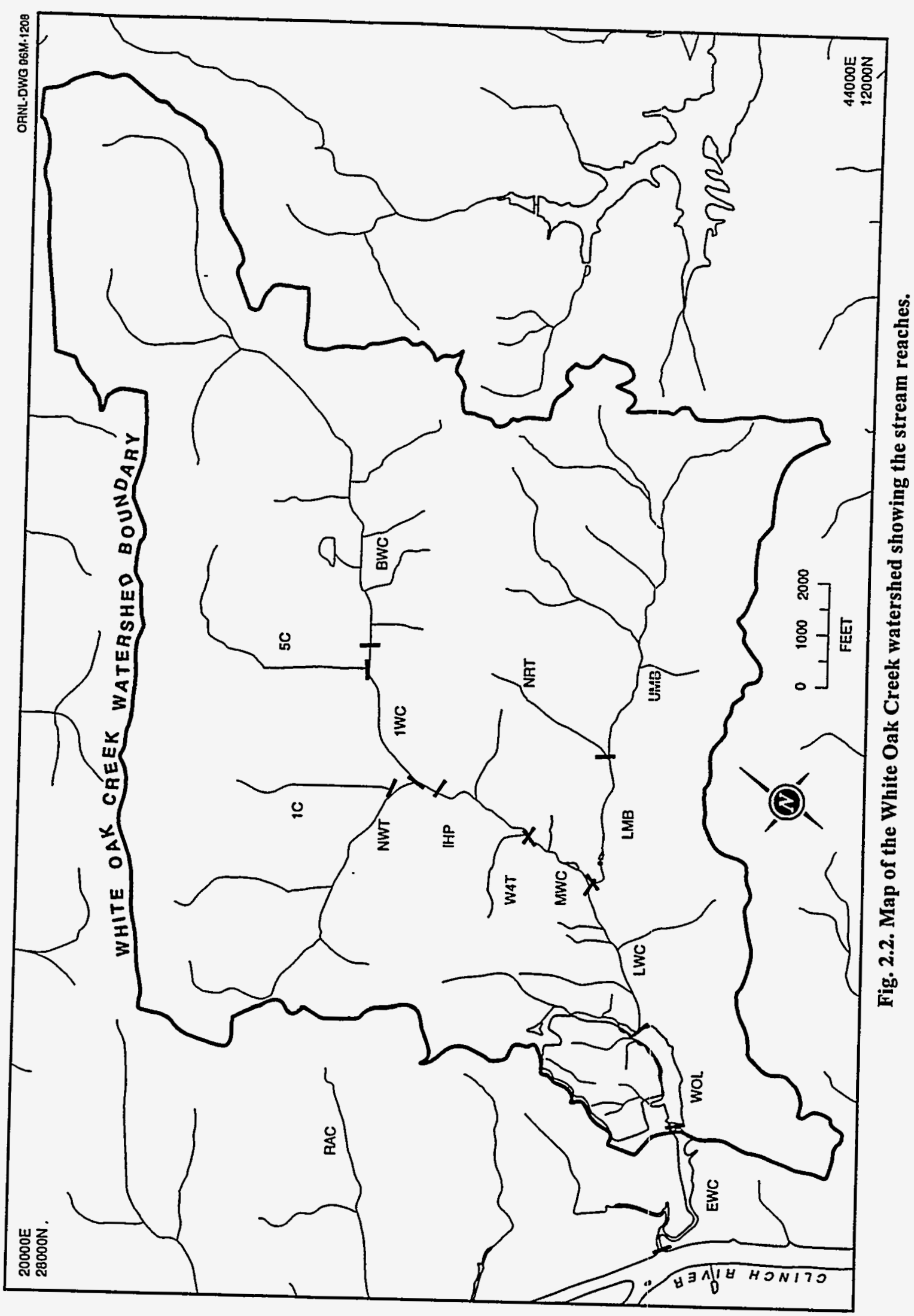


Chemicals of potential ecological concern (COPECs) for ecological risks have been identified in a previous screening assessment for WAG 2 (Blaylock et al. 1992). However, because the large number of COPECs, the revisions that have occurred in the ecological screening benchmarks, the questionable quality of the existing data used by Blaylock et al., and the new contaminant concentration data that have been obtained, chemicals are rescreened against benchmarks for this assessment.

\subsection{ECOLOGICAL ENDPOINTS}

The problem formulation must identify both the assessment endpoints, which are explicit statements of the characteristics of the environment that are to be protected, and the measurement endpoints, which are quantitative summaries of a measurement or series of measurements that are related to effects on an assessment endpoint.

\subsubsection{Assessment Endpoints}

The following assessment endpoints for aquatic and terrestrial risks have been selected for this assessment:

- $\quad$ reduction in species richness or abundance of fishes or increased frequency of gross pathologies in fish communities resulting from toxicity.

- reduction in species richness or abundance of benthic macroinvertebrate communities resulting from toxicity.

- reduction in abundance or production of earthworms resulting from toxicity.

- $\quad$ reduction in abundance or production of piscivorous wildlife populations (kingfisher and mink) resulting from toxicity.

- reduction in production of terrestrial plant communities resulting from toxicity.

- reduction in abundance or production of terrestrial wildlife populations (short-tailed shrew, white-footed mouse, red fox, red-tailed hawk) resulting from toxicity.

The ecological assessment endpoints have been selected based on DQO meetings that included representatives of DOE, EPA Region IV, and TDEC and the strategy for ecological risk assessment on the ORR, which was also a product of a DQO process (Suter et al. 1995).

The endpoints are chosen on the basis of ecological importance, policy or societal significance, susceptibility to toxic effects, and appropriateness of scale. All of these are self explanatory except for scale. An endpoint has appropriate scale for a site if toxic effects on the site could have a significant effect on the endpoint. For example, there is a distinct plant community on the WOC floodplain so properties of that community have an appropriate scale. However, the WOC watershed supports only a few kingfishers, which form a very small fraction of the biological population to which they belong. Therefore, individual kingfishers have an appropriate scale, but the kingfisher population does not. 
The following paragraphs explain the selected endpoints.

- The fish community is considered to be an appropriate endpoint community because it is ecologically and societally important, susceptible, and has a scale appropriate to the site. The societal importance is due to recreational fisheries; the ecological significance comes from the fact that much of the energy flow in temperate streams passes through fishes, and fishes are a major nutrient reservoir in those systems. In addition, the fish species in WAG 2 tend to move within an area smaller than the $O U$ and their movement is restricted by weirs and dams, so the scale is appropriate.

- The benthic invertebrate community is considered an appropriate endpoint community because it is highly susceptible and has a scale appropriate to the site. The high susceptibility is due to the association of these organisms with the sediment, which is the repository of most of the COPECs. In addition, the insects and crustaceans that dominate this community are sensitive to a variety of contaminants. Because these organisms are sedentary for all or most of their lives, their scale is highly appropriate to the scale of the site. Benthic invertebrates may also be ecologically important, but the importance of the invertebrates in the depositional areas is unclear.

- Soil invertebrates are considered to be an appropriate endpoint assemblage because they are susceptible and ecologically important and have an appropriate scale. The susceptibility results from their intimate exposure to contaminated soils including, in the case of earthworms, ingestion. The ecological importance is due to their role in litter degradation, nutrient cycling, and maintaining soil structure. The appropriate scale results from their low mobility; biological populations could occupy an area as small as the reaches defined for this assessment.

- The terrestrial plant community is considered an appropriate endpoint community because it is ecologically important, susceptible, and has a scale appropriate to the site. The ecological significance comes from the fact that the plant community is responsible for primary production. This community is susceptible because it would be directly exposed to the contaminants in the floodplain. Finally, the scale is appropriate because plants are immobile and because a distinct plant community occurs on the floodplain.

- Piscivorous and terrestrial wildlife species are considered appropriate because individuals are potentially sensitive due to food-web magnification of chemicals and because of the known sensitivity of some species (e.g., mink). The watershed has an appropriate scale for small mammals (i.e., mice and shrews) in that it could support: a biological population of those species. The watershed clearly does not support biological populations of birds or large (e.g., deer) or medium-sized (e.g., mink) mammals, but the regulators have decided that the organisms occurring in a watershed constitute a population for regulatory purposes.

Threatened and endangered species are not directly addressed in this assessment. This is because the other endpoint species are judged to be as sensitive or more sensitive than the endangered species that may come to use the site. In addition, because this is a screening assessment, it is conservative and affords the extra protection appropriate to T\&E species.

Wetlands are assumed to be protected by assessing the risks to plants in the small wetland areas associated with seeps. These wetlands should be more highly exposed than those associated with the streams. 


\subsubsection{Measurement Endpoints}

Three basic types of effects data are potentially available to serve as measurement endpoints: results of biological surveys, toxicity tests performed on media from the CR operable unit $(\mathrm{OU})$, and toxicity test endpoints for chemicals found in the OU. Measurement endpoints are presented in the following paragraphs.

\subsubsection{Fish}

Biological Survey Data. No fish survey data were collected by the WAG 2 program. However, results of Biological Monitoring Abatement Program (BMAP) surveys will be cited as supporting evidence. The BMAP measurement endpoints are assumed to be direct estimates of that assessment endpoint.

Biological Indicators Data. No fish bioindicators data were collected by the WAG 2 program. However, published results of the BMAP biological indicators task will be cited as supporting evidence. Frequencies of gross pathologies are a direct measure of one aspect of the assessment endpoint. Measures of fish fecundity in largemouth bass and bluegill provide an indication of the potential contribution of reproductive toxicity to community effects. Measures of the levels of physiological and histological condition in redbreast sunfish help to confirm that exposures have occurred and may suggest mechanistic connections between exposure and effects on the fish community.

Media Toxicity Data. No fish aqueous toxicity tests were conducted by the WAG 2 program. However, published results of the BMAP tests will be cited as supporting evidence. Test endpoints include reductions in growth and survivorship of larval fathead minnows and in fecundity and survivorship of Ceriodaphnia dubia (C. dubia) in 7-day tests of ambient water and reductions in hatching and larval survival and increases in terata in Japanese medaka (Oryzias latipes) eggs and larvae exposed to ambient water from shortly after fertilization to 48 hours posthatch. Responses that are statistically significantly different or are inhibited by $20 \%$ or greater relative to control or reference waters are assumed to be indicative of waters that are toxic to fish.

Single Chemical Toxicity Data. Chronic toxicity thresholds for freshwater fish are expressed as chronic EC20s or chronic values (CVs). These test endpoints correspond to the assessment endpoint for this community. That is, the sensitivity distribution of the test species is assumed to approximate the distribution of OU species, and exceeding the CVs and EC2Os is assumed to correspond to $20 \%$ or greater reductions in abundance, with some uncertainty.

\subsubsection{Benthic invertebrates}

Biological Survey Data. Benthic invertebrate survey data were collected by the WAG 2 program from areas in which fine sediments had been deposited. In addition, results of BMAP surveys of benthic invertebrates in riffles will be cited as supporting evidence. The measurement endpoints for both surveys are assumed to be direct estimates of that assessment endpoint.

Media Toxicity Data. Sediment toxicity tests planned for WAG 2 could not be performed because of concerns for worker safety.

Single Chemical Toxicity Data. Chronic toxicity thresholds for freshwater invertebrates expressed as chronic EC20s or CVs. These test endpoints correspond to the assessment endpoint 
for this community. That is, the sensitivity distribution of the test species is assumed to approximate the distribution of OU species, and exceeding the CVs and EC20s is assumed to correspond to $20 \%$ reductions in population abundance or greater, with some uncertainty. Toxic concentrations in ambient sediments reported by the state of Florida. Two types of values were extracted from that data set: (1) thresholds for modification of benthic invertebrate community properties based on co-occurrence analyses, which are assumed to correspond to the assessment endpoint.; (2) thresholds for lethality in toxicity tests of contaminated sediments, which are also assumed to correspond to the assessment endpoint effect but with greater uncertainty due to the extrapolation to the field.

\subsubsection{Piscivorous wildlife}

Biological Survey Data. Kingfisher reproduction was surveyed in WAG 2 and reference areas. Assuming that the kingfishers in the watershed constitute a population, this is a direct measure of the assessment endpoint for avian piscivores.

Media Toxicity Data. None were performed.

Single Chemical Toxicity Data. Chronic toxicity thresholds for contaminants of concern in birds and mammals gave greater weight to data from long-term feeding studies with wildlife species. Preference was given to tests that included reproductive endpoints. After allometric scaling for the endpoint species, these test endpoints are assumed to correspond to effects on individuals that could result in exceeding the population-level assessment endpoint. An extrapolation must be made to populations if effects on individuals are estimated to occur. In addition, body burdens of a kingfisher were compared to concentrafions associated with toxic effects on birds.

\subsubsection{Terrestrial wildlife}

Biological Survey Data. None were performed.

Media Toxicity Data. None were performed.

Single Chemical Toxicity Data. Chronic toxicity thresholds for contaminants of concern in birds and mammals gave greater weight to data from long-term feeding studies with wildlife species. Preference was given to tests that included reproductive endpoints. After allometric scaling for the endpoint species, these test endpoints are assumed to correspond to effects on individuals that could result in exceeding the population-level assessment endpoint. An extrapolation must be made to populations if effects on individuals are estimated to occur.

\subsubsection{Terrestrial plants}

Biological Survey Data. None.

Media Toxicity Data. None.

Single Chemical Toxicity Data. This includes EC20s for growth or production of vascular plants or equivalent chronic toxicity thresholds for contaminants of concern in soil. These test endpoints are assumed to correspond to the assessment endpoint for this community. That is, the sensitivity distribution of the test species is assumed to approximate the distribution of species 
that would colonize Clinch River dredge spoil; exceeding the test endpoints is assumed to correspond to $20 \%$ reductions in abundance or productivity with some uncertainty; and a distinct plant community is assumed to occur on a spoil disposal area.

\subsubsection{Soil invertebrates}

Biological Survey Data. Earthworms were collected by the WAG 2 program in a manner that produces only presence/absence information.

Media Toxicity Data. Earthworm toxicity tests planned for WAG 2 could not be performed because of concerns for worker safety.

Single Chemical Toxicity Data. Chronic toxicity thresholds for earthworms have been obtained from the literature. These test endpoints vary in their relevance, but they are assumed to correspond to the assessment endpoint for this assemblage if they include sublethal responses.

\subsubsection{Threatened and endangered species}

Biological Survey Data. None.

Media Toxicity Data. None.

Single Chemical Toxicity Data. The same chronic toxicity thresholds for contaminants of concern in invertebrates, fish, birds and mammals used as measurement endpoints for other species are used with the T\&E species but are interpreted in the risk characterization so as to provide the higher level of protection specified in the assessment endpoint.

\subsection{CONCEPTUAL MODELS}

Conceptual models are graphical representations of the relationships among sources of contaminants, ambient media, and the endpoint biota. Figure 2.3 shows a conceptual model for the streams and floodplains of the WOC watershed. Figure 2.4 shows a conceptual model for wide-ranging wildlife that utilize the streams and floodplains as well as upland areas and nearby aquatic habitat. The exposure pathways shown are those that are included in the assessment. Note that different benthic invertebrate assemblages are exposed to water and sediments. That is, the invertebrates inhabiting soft sediments in depositional areas are assumed to be exposed to chemicals in those sediments and their pore water with negligible exposure to free water and invertebrates inhabiting the rocky substrates of riffles are assumed to be primarily exposed to chemicals in water. These conceptual models are derived from the generic models developed for the ORR and are discussed in detail in the strategy document for ecological risk assessment on the ORR (Suter et al. 1995). 


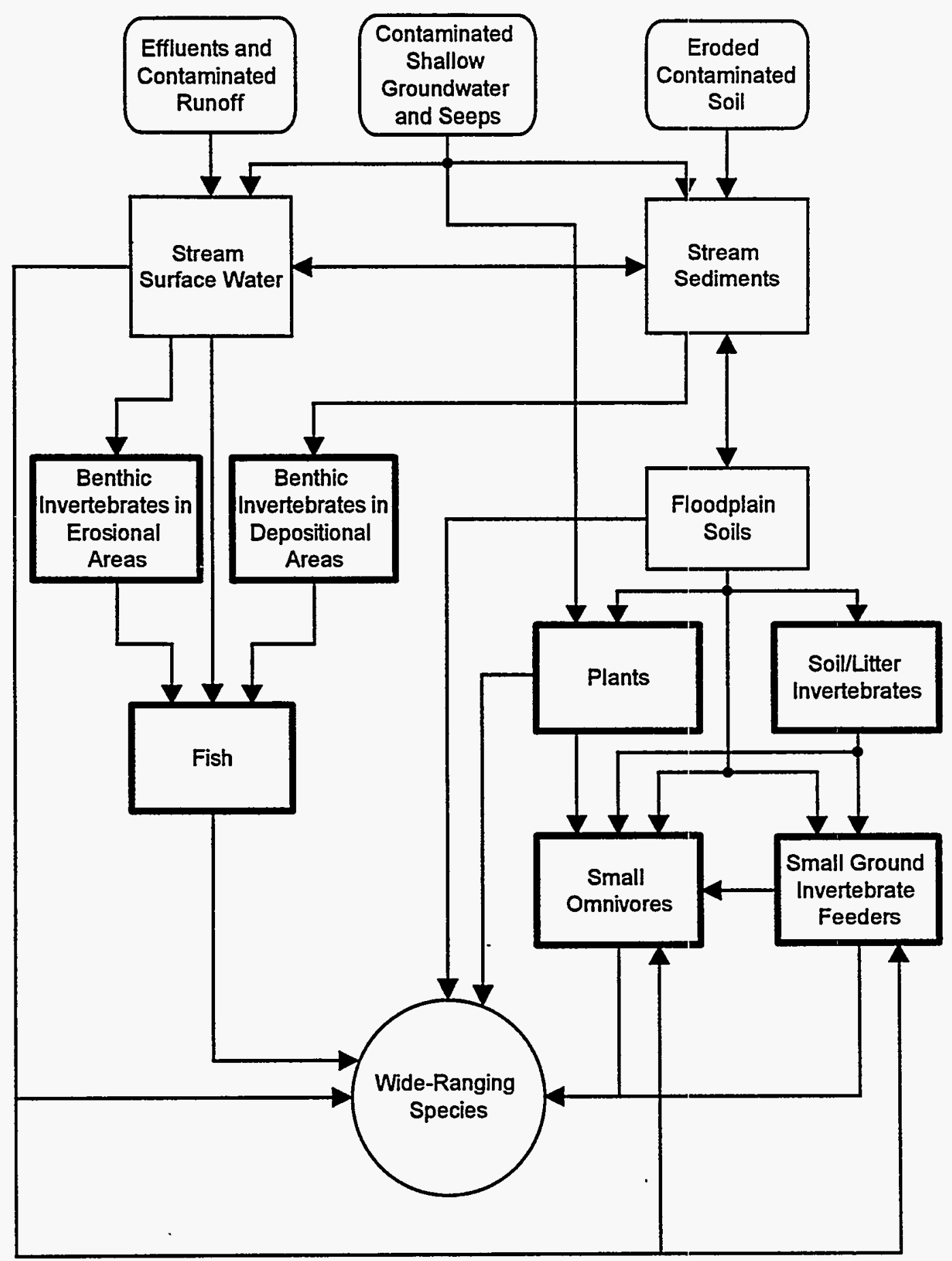

Fig. 2.3. Conceptual model of the mechanisms of transport and exposure by which ecological receptors are exposed to contaminants in White Oak Creek, its tributaries, and its floodplain. 


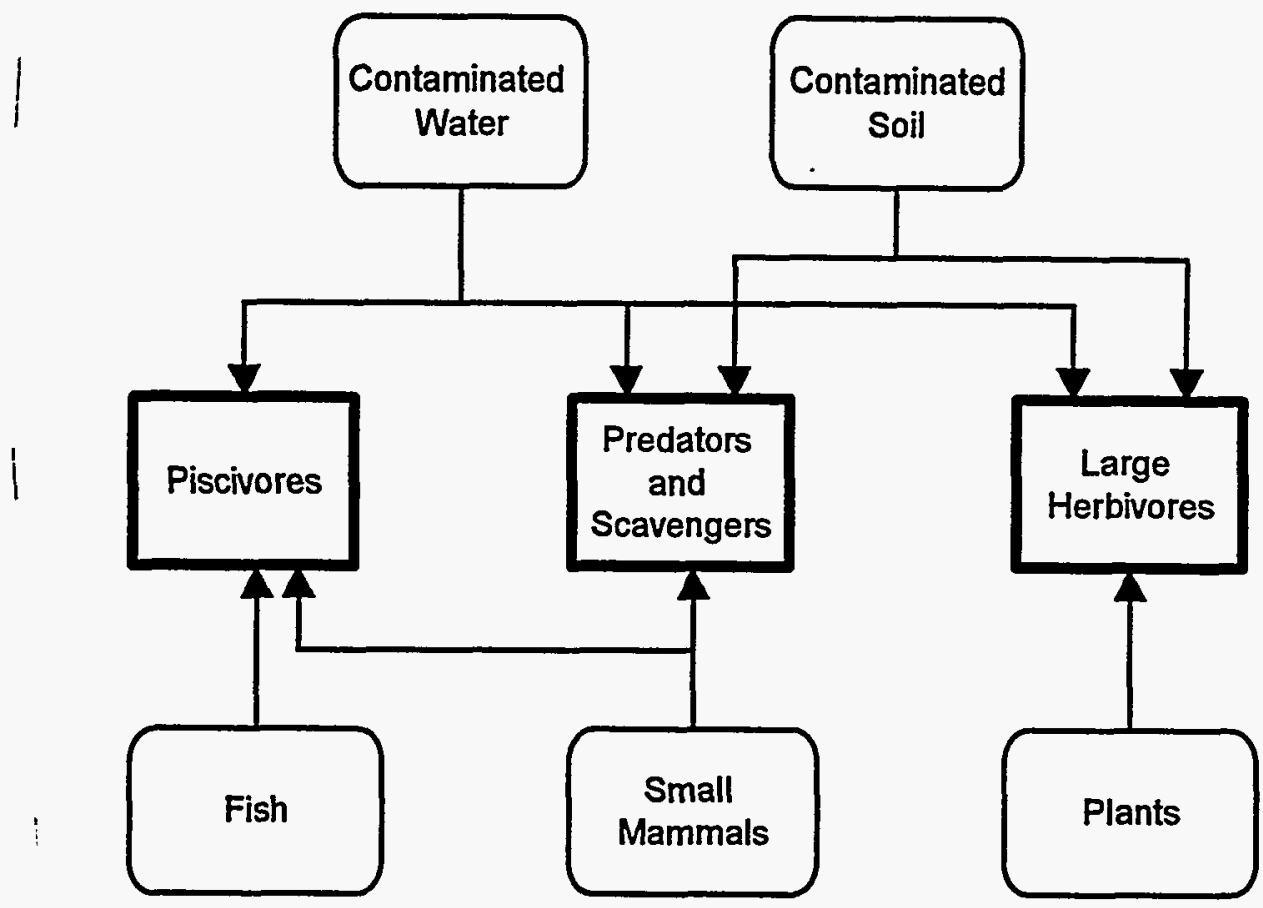

Fig. 2.4. Conceptual model of the mechanisms by which wide-ranging wildlife species are exposed to contaminants in White Oak Creek, its tributaries, and its floodplain. 


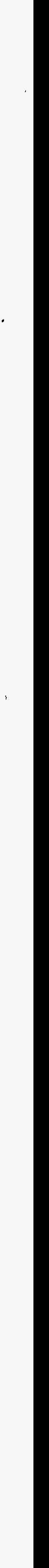




\section{RISKS TO FISH}

\subsection{EXPOSURE ASSESSMENT FOR FISH}

\subsubsection{Aqueous Chemical Exposure}

Fish are exposed primarily to contaminants in water. Contaminants in water may come from upstream aqueous sources including the permitted outfalls, runoff, and the numerous seeps sampled and analyzed by the WAG 2 RI program. They may also come from internal cycling including exchange of materials between the surface water and contaminated sediments and exchange of contaminants between the biota and the water column. The consensus of the scientific community and of the EPA Office of Water is that aquatic biota should be assumed to be exposed to the dissolved fraction of the chemicals in water because that is the bioavailable form (Prothro 1993). However, EPA Region IV prefers to use total concentrations as conservative estimates of the exposure concentration. Therefore, total concentrations of metals are used in the exposure assessment for fish.

Because water in the OU is likely to be more variable in time than in space because of the rapid replacement of water, the mean water concentration within a subreach is an appropriate estimate of the chronic exposure experienced by fishes. The upper $95 \%$ confidence limit on the mean is an appropriately conservative estimate of this exposure for use in the contaminant screening. No distinction was made between storm flow and base flow samples in this screening analysis.

Many of the chemical concentrations in water were below analytical detection limits. Chemicals that were not detected in any sample in a reach were eliminated. If a reach contained some detects and some nondetects for a chemical, the product limit estimator was used to estimate the mean and its variance.

\subsubsection{Radiation Exposures}

Exposures to radionuclides are expressed as the dose rate received by the organism. The total dose rate is the sum of the internal and external dose rates, which are a function of exposure to the radionuclide and the characteristics of the radiation. Radiation exposures of fish in surface water are likely to be driven by internal exposures, especially for alpha emitters such as $U^{234}$ and $\mathrm{Th}^{230}$ (Blaylock et al. 1993). Internal dose rates are based on the concentrations of the radionuclide in the organism, which were estimated by multiplying the water concentration times the biological concentration factors provided in Blaylock et al. (1993). External dose rates are based on the concentrations of the radionuclides in the surrounding water. Because the radiation exposure rate is expressed as absorbed dose per unit time (rads per day), the dose rates for each isotope and pathway can be added to determine the total dose rate.

As with estimates of aqueous chemical exposure, the $95 \%$ upper confidence limit (UCL)on the mean is an appropriately conservative estimate of exposure for use in the screening. As with chemical exposures, total concentrations of radionuclides were used in the radiation exposure assessment for fish. This results in conservative estimates of the internal dose and realistic estimates of external dose. 


\subsection{EFFECTS ASSESSMENT FOR FISH}

\subsubsection{Single Chemical Aqueous Toxicity}

The screening benchmarks for aquatic biota are taken from Suter and Mabrey (1994). Because there are no standard screening benchmarks, sets of alternative benchmarks (described in Table 3.1) were calculated for each chemical. The benchmark preferred by the regulatory agencies is the chronic National Ambient Water Quality Criteria (NAWQC), but they are available for relatively few industrial chemicals. Secondary chronic values (SCV), which are conservative estimates of chronic NAWQC, were calculated for chemicals that do not have NAWQC. Other benchmarks are included to provide greater assurance of detecting all COPECs.

NAWQC that are functions of water hardness are corrected for site-specific conditions. For purposes of screening, we chose conditions that would constitute reasonable maximum toxicity, defined as conditions that would persist for seven days. This was a hardness of approximately 100 $\mathrm{mg} / \mathrm{L}$ (Blaylock et al. 1992).

\subsubsection{Radiological Effects}

The recommended acceptable dose rate to natural populations of aquatic biota is $1 \mathrm{rad} / \mathrm{d}$ (NCRP 1991). Although there are no standard screening benchmarks for radionuclide concentrations in surface water, Blaylock et al. (1993) provide formulas and exposure factors estimating the dose rates to representative aquatic organisms. These formulas were used to calculate the water concentration that results in a total dose rate of $1 \mathrm{rad}$ per day to a small fish for each radionuclide detected in the water samples from Bear Creek Valley (BCV). The exposure factors used in this assessment are from Blaylock et al. (1993) and are presented in Table 3.2. The screening values include internal and external exposures from the detected isotope and all shortlived daughter products. All major alpha, beta, and gamma emissions for each isotope were included, and the absorbed fraction of each was estimated from the graphs provided in Blaylock et al. (1993). Internal exposures from radionuclides in water were estimated using the biological concentration factors for the detected parent isotopes.

\subsubsection{Ambient Water Toxicity}

Toxicity tests of WAG 2 water are performed by the ORNL BMAP and are presented in their annual reports. The tests employed include the standard 7-day tests of growth and survival in fathead minnow larvae and fecundity and survival of Ceriodaphnia dubia and an early life stage test with Japanese medaka eggs and larvae. The standard tests did not show any aqueous toxicity in the last two years reported, 1992 and 1993. However, the more sensitive medaka embryo-larval test consistently showed toxicity in water collected adjacent to or downstream of ORNL relative to upstream and control waters (Ashwood 1994). Attempts to identify the causal agent determined that mortality was not affected by 0.1 micron filter to eliminate pathogens or by treatment with sodium thiosulfate to eliminate chlorine. However, toxicity was completely eliminated by filtration with activated charcoal, a nonspecific treatment for aqueous contaminants. Finally, in situ toxicity tests were conducted with caged snails (Elimia clavaeformis) exposed for seven days. Although snails are benthic invertebrates, they are discussed here because they were exposed to water and not sediment. Snails were killed in lower fifth creek in October 1992 and in WOC adjacent to ORNL in June and October 1992 (Ashwood 1993). 
Table 3.1. Descriptions of the ecotoxicological screening benchmarks for aquatic biota

\begin{tabular}{|c|c|c|}
\hline Benchmark & Abbreviation & Description \\
\hline Acute National Ambient Water Quality Criteria & NAWQC_ACU & $\begin{array}{l}\text { Current national criteria for protection of aquatic life from lethal effects in } \\
\text { episodic exposures. }\end{array}$ \\
\hline $\begin{array}{l}\text { Chronic National Ambient Water Quality } \\
\text { Criteria }\end{array}$ & NAWQC_CHR & $\begin{array}{l}\text { Current national criteria for protection of aquatic life from lethal and } \\
\text { sublethal effects in extended exposures. Criteria for uses of aquatic life } \\
\text { (i.e., fish consumption) are not included. }\end{array}$ \\
\hline Secondary acute value & S_ACU_V & $\begin{array}{l}\text { Values estimated with } 80 \% \text { confidence to not exceed the unknown acute } \\
\text { NAWQC. Used when data are inadequate to calculate the acute criterion. }\end{array}$ \\
\hline Secondary chronic value & S_CHR_V & $\begin{array}{l}\text { Values estimated with } 80 \% \text { confidence to not exceed the unknown chronic } \\
\text { NAWQC. Used when data are inadequate to calculate the chronic } \\
\text { criterion. }\end{array}$ \\
\hline Lowest chronic value for fish & LCV_FISH & $\begin{array}{l}\text { The lowest value, from acceptable fish chronic toxicity tests, of the } \\
\text { geometric mean of the lowest observed effect concentration (LOEC) and } \\
\text { the no observed effect concentration (NOEC). }\end{array}$ \\
\hline Lowest chronic value for daphnids & LCV_DAPH & $\begin{array}{l}\text { The lowest value, from acceptable daphnid chronic toxicity tests, of the } \\
\text { geometric mean of the LOEC and the NOEC. }\end{array}$ \\
\hline $\begin{array}{l}\text { Lowest chronic value for nondaphnid } \\
\text { invertebrates }\end{array}$ & LCV_ND & $\begin{array}{l}\text { The lowest value of the geometric mean of the LOEC and the NOEC from } \\
\text { acceptable chronic toxicity tests of nondaphnid invertebrate species. }\end{array}$ \\
\hline Lowest plant value & LCV_AQPL & $\begin{array}{l}\text { The lowest value from an acceptable daphnid chronic toxicity test of the } \\
\text { geometric mean of the LOEC and the NOEC. }\end{array}$ \\
\hline Lowest Test EC20 for fish & LTV_FISH & $\begin{array}{l}\text { The lowest value, from acceptable fish chronic toxicity tests, of the lowest } \\
\text { concentration causing at least a } 20 \% \text { reduction in the weight of young per } \\
\text { female or the weight of young per egg. }\end{array}$ \\
\hline
\end{tabular}


Table 3.1 (continued)

\begin{tabular}{ccc}
\hline Benchmark & Abbreviation & Description \\
\hline Lowest test EC20 for daphnids & LTV_DAPH & $\begin{array}{l}\text { The lowest value from an acceptable daphnid chronic toxicity test of the } \\
\text { lowest concentration causing at least a 20\% reduction in the product of } \\
\text { survivorship, growth, and fecundity. }\end{array}$ \\
\hline
\end{tabular}

Note: More details are presented by Suter and Mabrey (1994). 
Table 3.2. Exposure factors for the radionuclides detected in WAG 2 sediment and surface water and their short-lived progeny

\begin{tabular}{|c|c|c|c|c|c|c|c|c|c|c|}
\hline \multirow[b]{2}{*}{ Radionuclide } & \multirow[b]{2}{*}{$\mathbf{K} \mathbf{d}^{\mathbf{b}}$} & \multirow[b]{2}{*}{$\begin{array}{c}\text { Biological } \\
\text { Concentration } \\
\text { Factor }\end{array}$} & \multicolumn{4}{|c|}{ Emission Energies (MeV) } & \multicolumn{3}{|c|}{ Absorption Factors } & \multirow[b]{2}{*}{$\begin{array}{l}\text { Gamma for } \\
\text { Small Fish }\end{array}$} \\
\hline & & & $\begin{array}{c}\text { Average } \\
\text { Alpha }\end{array}$ & $\underset{\text { Beta }}{\text { Maximum }}$ & $\begin{array}{c}\text { Average } \\
\text { Beta }\end{array}$ & $\begin{array}{l}\text { Average } \\
\text { Gamma }\end{array}$ & $\begin{array}{c}\text { Beta for } \\
\text { Small } \\
\text { Invertebrates }\end{array}$ & $\begin{array}{l}\text { Beta for } \\
\text { Small } \\
\text { Fish }\end{array}$ & $\begin{array}{l}\text { Gamma for } \\
\text { Small } \\
\text { Invertebrates }\end{array}$ & \\
\hline Cesium-137+Barium-137m & 1000 & 2000 & & $1.17 \mathrm{e}+00$ & $2.52 \mathrm{e}-01$ & $5.96 \mathrm{e}-01$ & 0.6 & 0.99 & 0.003 & 0.015 \\
\hline Cobalt- 60 & 45 & 300 & & $1.48 \mathrm{e}+00$ & $9.65 \mathrm{e}-02$ & $2.50 \mathrm{e}+00$ & 0.5 & 0.98 & 0.002 & 0.01 \\
\hline Hydrogen-3 & N/A & 1 & & $1.80 \mathrm{e}-02$ & $5.68 \mathrm{e}-03$ & & 1 & 1 & & \\
\hline Strontium-90+ Yttrium-90 & 35 & 60 & & $2.79 e+00$ & $1.13 \mathrm{e}+00$ & $1.69 \mathrm{e}-06$ & 0.25 & 0.83 & 0.4 & 0.6 \\
\hline Curium-244 & 2000 & 30 & $5.89 \mathrm{e}+00$ & & $8.59 \mathrm{e}-03$ & $1.70 \mathrm{e}-03$ & 1 & 1 & 0.4 & 0.6 \\
\hline Thorium-232 & 150000 & 100 & $4.07 e+00$ & & $1.25 \mathrm{e}-02$ & $1.33 \mathrm{e}-03$ & 1 & 1 & 0.4 & 0.6 \\
\hline Radium-228 & & & & & $1.69 \mathrm{e}-02$ & $4.14 \mathrm{e}-09$ & 1 & 1 & 0.4 & 0.6 \\
\hline Actinium-228 & & & & & $4.60 \mathrm{e}-01$ & $9.30 \mathrm{e}-01$ & 0.95 & 1 & 0.003 & 0.015 \\
\hline Thorium-228 & 150000 & 100 & $5.49 \mathrm{e}+00$ & & $2.05 \mathrm{e}-02$ & $3.30 \mathrm{e}-03$ & 1 & 1 & 0.4 & 0.6 \\
\hline Radium-224 & & & $5.78 \mathrm{e}+00$ & & & & & & & \\
\hline Radon-220 & & & $6.40 \mathrm{e}+00$ & & $8.19 e-06$ & $3.85 \mathrm{e}-04$ & 1 & 1 & 0.4 & 0.6 \\
\hline Polonium-216 & & & $6.91 \mathrm{e}+00$ & & $1.61 \mathrm{e}-07$ & $1.69 \mathrm{e}-05$ & 1 & 1 & 0.4 & 0.6 \\
\hline Lead-212 & & & & & $1.75 e-01$ & $1.48 \mathrm{e}-01$ & 1 & 1 & 0.002 & 0.012 \\
\hline Bismuth-212 & & & $2.22 \mathrm{e}+00$ & $5.80 \mathrm{e}-01$ & $4.69 \mathrm{e}-01$ & $1.85 c-01$ & 0.95 & 1 & 0.002 & 0.012 \\
\hline Polonium-212 & & & $8.95 e+00$ & $2.25 e+00$ & & & 0.3 & 0.89 & & \\
\hline Americium-241 & 700 & 30 & $5.57 e+00$ & & $5.19 e-02$ & $3.24 \mathrm{e}-02$ & 1 & 1 & 0.01 & 0.05 \\
\hline
\end{tabular}


Table 3.2 (continued)

\begin{tabular}{|c|c|c|c|c|c|c|c|c|c|c|}
\hline \multirow[b]{2}{*}{ Radionuclide" } & \multirow[b]{2}{*}{$\mathbf{K} \mathbf{d}^{\mathbf{b}}$} & \multirow[b]{2}{*}{$\begin{array}{c}\text { Biological } \\
\text { Concentration } \\
\text { Factor }^{c}\end{array}$} & \multicolumn{4}{|c|}{ Emission Energies (MeV) } & \multicolumn{3}{|c|}{ Absorption Factors } & \multirow[b]{2}{*}{$\begin{array}{l}\text { Gamma for } \\
\text { Small Fish }\end{array}$} \\
\hline & & & $\begin{array}{c}\text { Average } \\
\text { Alpha }\end{array}$ & $\underset{\text { Beta }}{\text { Maximum }}$ & $\begin{array}{c}\text { Average } \\
\text { Beta }\end{array}$ & $\begin{array}{l}\text { Average } \\
\text { Gamma }\end{array}$ & $\begin{array}{c}\text { Beta for } \\
\text { Small } \\
\text { Invertebrates }\end{array}$ & $\begin{array}{l}\text { Beta for } \\
\text { Small } \\
\text { Fish }\end{array}$ & $\begin{array}{c}\text { Gamma for } \\
\text { Small } \\
\text { Invertebrates }\end{array}$ & \\
\hline Uranium-233 & 450 & 10 & $4.89 \mathrm{e}+00$ & & $6.08 \mathrm{e}-03$ & $1.31 \mathrm{e}-03$ & 1 & 1 & 0.4 & 0.6 \\
\hline Uranium-238 & 450 & 10 & $4.26 e+00$ & & $1.00 \mathrm{e}-02$ & $1.36 \mathrm{e}-03$ & 1 & 1 & 0.4 & 0.6 \\
\hline Thorium-234 & & & & & $5.92 \mathrm{e}-02$ & $9.34 \mathrm{e}-03$ & 1 & 1 & 0.4 & 0.6 \\
\hline Protactinium-234m & & 10 & & $2.29 e+00$ & $8.20 \mathrm{e}-01$ & $1.13 \mathrm{e}-02$ & 0.3 & 0.87 & 0.2 & 0.5 \\
\hline Plutonium-238 & 4500 & 30 & $5.58 \mathrm{e}+00$ & & $1.06 \mathrm{e}-02$ & $1.81 \mathrm{e}-03$ & 1 & 1 & 0.4 & 0.6 \\
\hline Uranium-234 & 450 & 10 & $4.84 \mathrm{e}+00$ & & $1.32 \mathrm{e}-02$ & $1.73 e-03$ & 1 & 1 & 0.4 & 0.6 \\
\hline Thorium-230 & 150000 & 100 & $4.74 \mathrm{e}+00$ & & $1.46 \mathrm{e}-02$ & $1.55 \mathrm{e}-03$ & 1 & 1 & 0.4 & 0.6 \\
\hline Uranium-235 & 450 & 10 & $4.47 e+00$ & & $4.80 e-02$ & $1.54 \mathrm{e}-01$ & 1 & 1 & 0.002 & 0.012 \\
\hline Thorium-231 & & & & & $1.63 \mathrm{e}-01$ & $2.55 \mathrm{e}-02$ & 1 & 1 & 0.03 & 0.15 \\
\hline
\end{tabular}

Sources: Soil-water partitioning coefficients are from Baes et al. (1984), biological concentration factors are from IAEA (1982), emission energies are from ICRP (1983), and absorbed fractions were estimated from graphs in Blaylock et al. (1993).

a Designations of parent radionuclides and short-lived progeny are taken from Tables A.1 and A.2 in Blaylock et ai. (1993). For naiuraily occurring alpha decay series, the parent is listed first, and progeny are listed immediately below in order of occurrence.

${ }^{B}$ Soil-water partition coefficients are presented only for parent isotopes detected in WAG 2 sediments.

' Biological concentration factors are presented only for parent isotopes detected in WAG 2. 


\subsubsection{Fish Community Survey}

Analysis of fish population and community survey data provides a direct measure of impacts of human activities on aquatic ecosystems. The following results are taken from the most recent ORNL BMAP report (Ashwood 1993). The species composition of the fish community in the WOC watershed is stable at 13 species, which is less than other local streams. It is missing two families (Catastomidae and Percidae) and five genera (Lythruras, Luxilus, Notropis, Noturus, and Phoxinus) that historically occurred in the stream.

\subsubsection{Indicators of Fish Reproduction}

Reproduction and indicators of reproduction were monitored in redbreast sunfish from 1989 to 1993. Indicators of reproductive condition of female redbreast sunfish improved over the period monitored until they nearly equal background values. However, reproductive success was highly variable with apparent reproductive failure occurring in lower WOC during the last reported year of monitoring. Since this failure was not associated with poor reproductive condition of the female fish prior to spawning, effects on the embryos or larvae were said to be the likely cause (Ashwood 1994).

\subsection{RISK CHARACTERIZATION FOR FISH}

\subsubsection{Single Chemical Aqueous Toxicity}

All chemicals detected in stream waters were screened against benchmarks. This was done by dividing the $95 \%$ UCL concentration (or maximum if the UCL could not be calculated because the chemical was detected only once) by each of the aqueous screening benchmarks (Table B.1). Chemicals that exceeded benchmarks were eliminated as COPECs if their UCL did not exceed twice the mean background concentration. EPA Region IV recommends this screening criterion. The reader should be aware that this practice in combination with the practice of using total metal concentrations, which is required by EPA Region IV, is potentially anticonservative because the concentration of particulate metal is being doubled along with the bioavailable dissolved fraction. This is potentially important because metals leached from wastes would be likely to be in soluble forms (e.g., chlorides or nitrates) that are potentially toxic, whereas, background concentrations of many metals in unfiltered water are likely to be predominately in the form of relatively insoluble minerals (e.g., sulfides or oxides), which are relatively nontoxic. If contamination doubled the bioavailable metal over background, this would not necessarily double the total metal concentration. The results of the screening are summarized in Table 3.3, and the COPECs for fish and chemicals that exceed NAWQC are in the following paragraphs.

In addition to stream waters, the WAG 2 program sampled waters from seeps and small ephemeral tributaries (Hicks 1996). Because these sites do not support fish communities, they are not assessed for risks to this endpoint. However, it is important to know which of these sources is contributing to risks in the streams. In addition, the state of Tennessee is concerned with whether the seep waters exceed water quality standards; therefore, the UCM or maximum concentrations for all chemicals detected in each seep are compared to their chronic NAWQCs or SCV (Table B.2). The use of the regulatory standard (NAWQC) or an estimate of the standard (SCV) addresses the regulatory concern and provides a means of highlighting those seeps that have high concentrations relative to toxicity without suggesting that the seeps support communities of fish and macroinvertebrates like the streams. 
Table 3.3. Results of screening of chemicals that exceed benchmarks in whole or filtered water for chemicals of potential ecological concern (COPECs)

\begin{tabular}{|c|c|c|c|}
\hline Chemical & COPEC & Reason for Inclusion or Rejection & \\
\hline Aluminum & Yes & $\begin{array}{l}\text { Exceeds chronic National Ambient Water Quality Criteria (NAWQC) in all reaches and acute NAWQC in White } \\
\text { Oak Lake (WOL) and Raccoon Creek Tributary reach (RAC). The chronic criterion is also exceeded in background } \\
\text { water. Upper confidence limit (UCL) concentrations exceed twice background ( } 0.34 \mathrm{mg} / \mathrm{L} \text { ) in } 1 \mathrm{C} \text {, WAG } 1 \text { White } \\
\text { Oak Creek (1WC), Northwest Tributary (NWT), RAC, West Seep (WS), and WOL; and the WOL mean exceeds } \\
\text { twice background. It is entirely possible that the elevated Al is due to high particulate matter. }\end{array}$ & \\
\hline Barium & Yes & $\begin{array}{l}\text { Exceeds the secondary chronic values (SCV) in all reaches and the secondary acute value (SAV) in Background } \\
\text { White Oak Creek (BWC), Lower White Oak Creek (LWC), Waste Area Group } 4 \text { (W4T), and WS, but no other } \\
\text { benchmarks. The upper confidence limit (UCL) concentration in BWC and both the mean and UCL concentrations } \\
\text { in W4T exceed the twice background concentration }(0.004 \mathrm{mg} / \mathrm{L}) \text {. }\end{array}$ & \\
\hline Berylium & No & $\begin{array}{l}\text { Exceeds the LTV daphnids but no other benchmarks in all reaches. That benchmark is apparently below the local } \\
\text { background due to the compounding of effects across life stages in its derivation. }\end{array}$ & $\underset{\infty}{\omega}$ \\
\hline Boron & No & $\begin{array}{l}\text { The Bo UCL exceeds the LTV for Daphnids in all reaches but no other benchmark. The LTV for Daphnids is much } \\
\text { lower than other benchmarks for Bo. It is judged to be anomalous. }\end{array}$ & \\
\hline Cadmium & Yes & $\begin{array}{l}\text { The Cd UCL concentration in W4T exceeds the chronic NAWQC, and the mean exceeds the lowest chronic value } \\
\text { (CV) for daphnids. However, none of the concentrations exceed twice background }(0.01 \mathrm{mg} / \mathrm{L}) \text {. }\end{array}$ & \\
\hline Calcium & No & $\begin{array}{l}\text { The Ca UCL concentration in NWT and RAC slightly exceeds the CV for Daphnia but Ca would occur as nontoxic } \\
\text { carbonates in those circumneutral and moderately hard streams rather than the toxic form (chloride) used in the test. }\end{array}$ & \\
\hline Chromium & Yes & $\begin{array}{l}\text { The UCL exceeds the acute and chronic NAWQC, and the mean exceeds the chronic NAWQC in WOL. The WOL } \\
\text { mean and the LMB UCL exceed the daphnid lowest CV. However, none of the concentrations exceed twice } \\
\text { background }(0.02 \mathrm{mg} / \mathrm{L}) \text {. }\end{array}$ & \\
\hline Cobalt & Yes & $\begin{array}{l}\text { Exceeds the SCV in WS and Upper Melton Branch (UMB) and the daphnid LCV in WS in the one sample from } \\
\text { each site in which it was detected. However, none of the concentrations exceed twice background }(0.04 \mathrm{mg} / \mathrm{L}) \text {. }\end{array}$ & \\
\hline
\end{tabular}




\section{Table 3.3 (continued)}

\begin{tabular}{|c|c|c|}
\hline Chemical & COPEC & Reason for Inclusion or Rejection \\
\hline Copper & Yes & $\begin{array}{l}\text { Mean exceeds the chronic NAWQC in water from LWC, UMB, and W4T and exceeds the lowest CV for daphnids } \\
\text { in all reaches where it was detected. However, none of the concentrations exceed twice background }(0.023 \mathrm{mg} / \mathrm{L}) \text {. }\end{array}$ \\
\hline Iron & No & $\begin{array}{l}\text { Means exceeds chronic NAWQC in WS and WOL, and the daphnid LCV all reaches but BWC. However, none of } \\
\text { the concentrations exceed twice background }(0.81 \mathrm{mg} / \mathrm{L}) \text {. }\end{array}$ \\
\hline Lead & Yes & $\begin{array}{l}\text { Means in BWC and Intermediate Holding Pond (IHP) and the UCL in WOL exceed the chronic NAWQC. However, } \\
\text { none of the concentrations exceed twice background }(0.014 \mathrm{mg} / \mathrm{L}) \text {. }\end{array}$ \\
\hline Manganese & Yes & $\begin{array}{l}\text { Means in LMB, NWT, W4T, and WS exceed the SCV, and those in RAC and WS exceed the SAV and the lowest } \\
\text { chronic values (CVs) for fish and daphnids. Mean concentrations exceed twice background }(0.21 \mathrm{mg} / \mathrm{L}) \text { in RAC, } \\
\text { W4T, and WS. }\end{array}$ \\
\hline Nickel & Yes & $\begin{array}{l}\text { Means exceed daphnid and plant LCVs in LMB, W4T, and WS. However, none of the concentrations exceed twice } \\
\text { background }(0.04 \mathrm{mg} / \mathrm{L}) \text {. }\end{array}$ \\
\hline Silver & Yes & $\begin{array}{l}\text { Each of the single detected values at BWC, IHP, and W4T exceeds the SCV and lowest CVs for daphnids and fish. } \\
\text { Silver was not detected at the background site. }\end{array}$ \\
\hline Zinc & Yes & $\begin{array}{l}\text { Mean in } 1 \text { WC and the UCL in UMB exceed the chronic NAWQC. Lowest CVs for daphnids, fish, and plants } \\
\text { exceeded in } 1 \text { WC, IHP, UMB, and WOL. Only the UCL in } 1 \text { WC exceeds twice background }(0.22 \mathrm{mg} / \mathrm{L}) \text {. }\end{array}$ \\
\hline Carbon disulfide & Yes & Exceeds the SCV in LMB, M.C., RAC, UMB, and WS. No background for organics. \\
\hline
\end{tabular}


The following text discusses those chemicals that meet all criteria for COPECs or all criteria except for the exceedence of twice background (Table 3.3). Those metals that exceed NAWQC but not background are retained in spite of the criteria because background needs to be better defined for the watershed and because of the potential problem, discussed above, of background particulate concentrations masking increases in bioavailable metals.

Aluminum. Aluminum is not known to be toxic in circumneutral streams, and one must suspect that the high concentrations are due to particulate aluminum. However, aluminum concentrations in streams clearly exceed background, so it cannot be eliminated. All but five of the 27 seeps exceed the NAWQC for Al, and RS-3a exceeds it by more than a factor of 100 .

Barium. The exceedences of the SAV and SCV might be attributable to the conservatism of those benchmarks, which is a result of the poorly defined toxicity of this metal. However, the concentrations in W4T are quite high relative to background as well as benchmarks and therefore pose a credible risk to fish and other aquatic organisms. BTT, SW4-1, and SW4-2 are significant barium sources on W4T, with SW4-2 exceeding the SCV by more than a factor of 100 .

Cadmium. Although cadmium does not occur at concentrations exceeding twice background in W4T and in two seeps (RS-3a and SW5-4, neither of which feeds W4T), it exceeds the chronic NAWQC.

Chromium. Although chromium does not occur at concentrations exceeding twice background, it exceeds the acute and chronic NAWQC in WOL and in the following seeps: East Seep, RS-3a, SW7-3, and WAG 4 T2A.

Copper. Although copper does not occur at concentrations exceeding twice background, it exceeds the chronic NAWQC in LWC, UMB, and W4T.

Carbon disulfide. Carbon disulfide was seldom detected in streams. The highest observed concentration, which is from approximately a factor of 100 lower than the lowest observed toxic concentration. The exceedence of the SCV in the screening assessment is attributable to the large safety factors used with minimal data sets. Carbon disulfide exceeds the SCV in 22/33 seeps; but it is a natural constituent of ground water, and the concentrations are not exceptionally high. Hence, there appears to be negligible risk to aquatic biota from carbon disulfide

Manganese. The exceedences of the SCV in six reaches might be attributable to the conservatism of that benchmark, which is a result of the poorly defined toxicity of this metal. However, the concentrations in RAC, W4T, and WS exceed the SAV and chronic toxic concentrations for aquatic life. Seeps SW4-1 and SW7-1 are a conspicuous contributors of manganese to the W4T and WS.

Nickel. Nickel exceeded chronically toxic concentrations in $\mathrm{MBB}$, W4T, and WS. Nickel in seep SW4-2, which feeds reach W4T, is much higher than at any other location and exceeds the chronic NAWQC by more than a factor of 50 .

Silver. The combination of a detection limit that is barely lower than the lowest $\mathrm{CV}$, the failure to detect silver at the background site, and the small toxicity data set make interpretation of the hazard posed by silver uncertain. However, there is no basis for rejecting it as a COPEC. Silver was detected in only two seeps, RS-3A and SW2-4. 
Zinc. The mean concentration of zinc exceeds the chronic NAWQC, and the UCL exceeds twice background in the vicinity of ORNL (reach $1 \mathrm{WC}$ ). Therefore it is a clear COPEC. Zinc concentrations are not high in seeps except for SW9-2 which exceeds the chronic NAWQC. However, it feeds HRT, which does not have high zinc concentrations. This, and the fact that zinc was not detected above ORNL (reach BWC), suggests that the source of zinc is an effluent or an unidentified seep in the vicinity of ORNL.

Chemicals that were detected in water but for which no benchmarks are available are also of concern. They are silicon and cis-1,2-dichloroethene.

\subsubsection{Single Chemical Internal Toxicity}

Mercury. Mercury concentrations in largemouth bass, but not sunfish, increased from a mean of 0.11 to $0.57 \mathrm{mg} / \mathrm{kg}$ wet weight during the period 1988-1992 for unknown reasons (Ashwood 1994). The maximum concentrations in largemouth bass in the last two reported years $(0.70$ and $0.71 \mathrm{mg} / \mathrm{kg}$ in 1991 and 1992) exceeded the $0.66 \mathrm{mg} / \mathrm{kg}$ concentration that corresponded to a CV for fathead minnows but was well below the value for brook trout $(5.6 \mathrm{mg} / \mathrm{kg})$. The median concentration for largemouth bass and all concentrations for bluegill and redbreast sunfish were below $0.66 \mathrm{mg} / \mathrm{kg}$.

PCBs. PCBs have been detected in sunfish, largemouth bass, and channel catfish in WOC with the highest concentrations found in channel catfish from the embayment (reach EWC) (Ashwood 1994). However, both mean and maximum concentrations in catfish in 1993 were below the concentration of PCB-1242 that reduced growth and caused liver hypertrophy in channel catfish at a body burden of $14.3 \mathrm{mg} / \mathrm{kg}$ (Hansen et al. 1976).

\subsubsection{Radiation Risks}

The concentrations of detected radionuclides were compared with the screening values for small fish. A hazard quotient (HQ) was calculated for each radionuclide by dividing the $95 \%$ UCL concentration by the screening value. The screening value is the concentration resulting in a total dose rate of $1 \mathrm{rad} / \mathrm{d}$ from the major emissions of the measured parent radionuclide and all short-lived progeny. At each location the HQs for all detected radionuclides were summed. Radionuclides present a significant risk if the sum of HQs for a site exceeds 1.0. Table B.3 details the exposure estimates (95\% UCL), screening values, and HQs for individual radionuclides for all radionuclides detected at each location. Based on these results, radionuclides in BCV surface water appear to present a negligible risk to fish. That is, the individual and sum of $H Q$ s were $<1.0$ at all reaches for which data are available. Seeps and small ephemeral tributaries do not support communities of fish or other aquatic macroorganisms. However, they were also screened to determine whether they were significant sources. Although seeps SW2-6 and -7 and SW5-4 exceeded the screening benchmark for strontium-90, the nearby reaches are far below the benchmark so they are not contributing to a significant risk to aquatic life.

\subsubsection{Ambient Water Toxicity}

Water from the watershed was found to be lethal to snails and to medaka embryos and larvae. Snails were tested only in the vicinity of ORNL, and toxicity was attributed to chlorine on the basis of correlation. Medaka toxicity was tested in WOC but not its tributaries (Ashwood 1993). Toxicity was not observed above WAG 1 but occurred consistently downstream (Ashwood 1994). In the period 1991-1993 the lowest survival $(<10 \%)$ was at the WOL weir. This pattern is 
consistent with an accretion of contaminants in the creek. Since water was not chemically analyzed in conjunction with the toxicity tests and the toxicity identification and evaluation (TIE) was not completed, it is not possible to determine which contaminants may be responsible for the toxicity. However, preliminary TIE results indicate that a chemical other than chlorine was responsible.

In contrast, WOC water was not found to be toxic in the 7-day fathead minnow and C. dubia tests. This lack of response relative to the snail test was attributed to the insensitivity of the standard static renewal test to volatile chemicals such as chlorine (Ashwood 1993). The lack of response relative to medaka may be attributed to the inherent sensitivity of medaka or the longer duration of the medaka test and the inclusion of two life stages.

\subsubsection{Biological Indicators}

Results of the studies of histological, physiological, and reproductive indicators are presented by Ashwood (1994). Although these indicators show improvement, reproductive indicators for redbreast sunfish can not be interpreted as indicative of effects on the fish community endpoint; they are suggestive of inhibited reproduction in individuals of one species.

\subsubsection{Biological Surveys}

Surveys of the fish community in WOC indicate a significant loss of species and no recent improvement. Although it seems likely that the original loss was due to contaminants, it is not clear that the current contaminant levels would cause the same effect. The dam and numerous weirs inhibit movement of fish and may be preventing recovery of the community which would otherwise occur.

\subsubsection{Weight Of Evidence For Fish}

The weighing of evidence is performed by asking the following questions concerning each reach in the watershed:

- Is the fish community less species-rich or abundant than would be expected?

- Do individual fish display injuries that are indicative of significant toxic effects?

- Is the water toxic to aquatic organisms?

- Does that water contain chemicals in toxic amounts?

- Do the fish contain chemicals in toxic amounts?

- What factors account for apparent discrepancies in the results?

- What is the likelihood that the fish community is at least $20 \%$ less species rich or abundant than it would be in the absence of contamination?

The available evidence for each reach is summarized below. However, some lines of evidence are not available for every reach due to lack of data (Table 3.4). 
Table 3.4 Availability of biological data related to the fish community endpoint in the White Oak Creek watershed reaches

\begin{tabular}{lcccccc}
\hline Reach & $\begin{array}{c}\text { Fish } \\
\text { community }\end{array}$ & $\begin{array}{c}\text { Standard } \\
\text { tests }\end{array}$ & $\begin{array}{c}\text { Medaka } \\
\text { test }\end{array}$ & $\begin{array}{c}\text { Snail } \\
\text { test }\end{array}$ & $\begin{array}{c}\text { Redbreast } \\
\text { bioindicators }\end{array}$ & $\begin{array}{c}\text { Fish } \\
\text { bioaccumulation }\end{array}$ \\
\hline EWC & & & & & & $\mathrm{X}$ \\
WOL & & & $\mathrm{X}$ & & $\mathrm{X}$ & $\mathrm{X}$ \\
LWC & $\mathrm{X}$ & $\mathrm{X}$ & & $\mathrm{X}$ & $\mathrm{X}$ \\
M.C. & $\mathrm{X}$ & $\mathrm{X}$ & $\mathrm{X}$ & & & \\
IHP & $\mathrm{X}$ & $\mathrm{X}$ & $\mathrm{X}$ & & $\mathrm{X}$ \\
1WC & $\mathrm{X}$ & $\mathrm{X}$ & $\mathrm{X}$ & $\mathrm{X}$ & \\
BWC & $\mathrm{X}$ & $\mathrm{X}$ & $\mathrm{X}$ & $\mathrm{X}$ & & $\mathrm{X}$ \\
LMB & $\mathrm{X}$ & $\mathrm{X}$ & & & & \\
UMB & $\mathrm{X}$ & $\mathrm{X}$ & & & & \\
WS & & & & & $\mathrm{X}$ \\
W4T & & & & & \\
HRT & & & & & \\
NWT & $\mathrm{X}$ & $\mathrm{X}$ & & & \\
RAC & & & & & \\
1C & $\mathrm{X}$ & & & & \\
5C & $\mathrm{X}$ & & & & \\
\hline
\end{tabular}

Source: Ashwood 1993, 1994

\subsubsection{Mainstem reaches}

White Oak Creek Embayment (EWC). The WAG 2 program did not sample this reach and biological data are not available. Its water quality would be expected to be similar to WOL but with some dilution from the Clinch River.

White Oak Lake (WOL). Because there are no good reference lakes for WOL, the effects on the fish community of the lake cannot be directly evaluated. WOL effluent water has been lethal to medaka embryos and larvae. WOL water exceeds $\mathrm{NAWQC}$ values for $\mathrm{Al}, \mathrm{Cr}, \mathrm{Fe}$, and $\mathrm{Pb}$ as well as levels of $\mathrm{Ba}, \mathrm{Cu}, \mathrm{Mn}$, and $\mathrm{Zn}$ that are toxic to aquatic life.

Lower White Oak Creek (LWC). Reach LWC has a depauperate fish community relative to similar streams; it has experienced reproductive failures of redbreast sunfish, and its waters have been lethal to medaka embryos and larvae. LWC water exceeds chronic NAWQCs for aluminum and copper and contains potentially toxic concentrations for barium and iron. 
Middle White Oak Creek (MC). Reach MC has a depauperate fish community relative to similar streams. It has experienced reproductive failures of redbreast sunfish, and its waters have been lethal to medaka embryos and larvae. MC water exceeds the chronic NAWQC for aluminum and has potentially toxic concentrations for $\mathrm{Ba}, \mathrm{Cu}, \mathrm{Fe}$, and carbon disulfide.

Intermediate Holding Pond (IHP). Reach IHP has a depauperate fish community relative to similar streams. Its waters have been lethal to medaka embryos and larvae. LWC water exceeds the chronic NAWQC for aluminum and lead and has potentially toxic concentrations for $\mathrm{Ba}, \mathrm{Cu}$, $\mathrm{Fe}, \mathrm{Ag}$, and $\mathrm{Zn}$.

WAG1 White Oak Creek (1WC). Reach 1 WC has a depauperate fish community relative to similar streams, and its waters have been lethal to medaka embryos and larvae and to snails. 1WC water exceeds the chronic NAWQC for aluminum and lead and contains potentially toxic concentrations for $\mathrm{Ba}, \mathrm{Cu}, \mathrm{Fe}, \mathrm{Ag}$, and $\mathrm{Zn}$. Chlorinated effluents have been a source of severe episodic toxicity in this reach.

Background White Oak Creek (BWC). Reach BWC waters have not been found to be toxic. BWC water exceeds the chronic NAWQC for aluminum and lead and has potentially toxic concentrations for $\mathrm{Ba}, \mathrm{Cu}$, and $\mathrm{Ag}$.

Lower Melton Branch (LMB). Reach LMB has a depauperate fish community relative to similar streams. Reach LMB water exceeds the chronic NAWQC for aluminum and contains potentially toxic concentrations for $\mathrm{Ba}, \mathrm{Cr}, \mathrm{Cu}, \mathrm{Fe}, \mathrm{Mn}, \mathrm{Ni}$, and carbon disulfide.

Upper Melton Branch (UMB). Reach UMB has a depauperate fish community relative to similar streams. Reach UMB water exceeds the chronic NAWQC for $\mathrm{Al}, \mathrm{Cu}$, and $\mathrm{Zn}$ as well as containing potentially toxic concentrations for $\mathrm{Ba}, \mathrm{Cr}, \mathrm{Co}, \mathrm{Fe}$, and carbon disulfide.

\subsubsection{Tributary reaches}

West Seep (WS). WS water exceeds the chronic NAWQC for aluminum and iron as well as containing potentially toxic concentrations for $\mathrm{Ba}, \mathrm{Co}, \mathrm{Cu}, \mathrm{Mn}, \mathrm{No}$, and carbon disulfide.

WAG 4 Tributary (W4T). W4T water exceeds the chronic NAWQC for $\mathrm{Al}, \mathrm{Cd}$, and $\mathrm{Cu}$ as well as containing potentially toxic concentrations for $\mathrm{Ba}, \mathrm{Cr}, \mathrm{Fe}, \mathrm{Mn}, \mathrm{No}$, and $\mathrm{Ag}$.

Homogeneous Reactor Test Tributary (HRT). HRT water exceeds the chronic NAWQC for aluminum as well as containing potentially toxic concentrations for $\mathrm{Cr}, \mathrm{Cu}$ and $\mathrm{Fe}$.

Northwest Tributary (NWT). Reach NWT has a depauperate fish community relative to similar streams. NWT water exceeds the chronic NAWQC for aluminum as well as having potentially toxic concentrations for $\mathrm{Ba}, \mathrm{Cu}, \mathrm{Fe}$, and $\mathrm{Mn}$.

Raccoon Creek (RAC). RAC water exceeds the chronic NAWQC for aluminum as well as containing potentially toxic concentrations for $\mathrm{Cu}, \mathrm{Fe}, \mathrm{Mn}$, and carbon disulfide.

\subsubsection{Summary of Risk Characterization for Fish}

Because this is a screening assessment, the goal of the risk characterization is to determine whether risks to fish can be eliminated as an issue or whether there is a credible hazard that 
should be assessed further. Even if the NAWQC for $\mathrm{Al}$ is set aside as inappropriate to this site, credible NAWQCs and CVs are exceeded in nearly all reaches. The toxicity to medaka embryos and larvae provides important supporting evidence that waters in WOC are toxic to fish. The low species richness of the stream is consistent with effects but could have physical causes. Although all of these lines of evidence are consistent with a hazard to fish, the evidence is not conclusive. The high metal concentrations could be nonbioavailable, the medaka could be much more sensitive than any of the fish species native to the stream, and the low species richness could be due to physical barriers to recovery. In particular, it should be noted that three years have passed since the collection of the most recent biological data that were available for this assessment. At that time, the bioindicators data suggested that the condition of fish in WOC was improving and was approaching that of fish in reference streams. It is possible that the fish community has largely recovered and that toxicity would no longer be observed in WOC at this time.

\subsection{UNCERTAINTIES CONCERNING RISKS TO FISH}

The following issues constitute the major sources of uncertainty in the risk assessment for the fish community.

The bioavailable concentrations of chemicals in water are unknown. In assessments that included analyses of filtered as well as unfiltered water, concentrations of $\mathrm{Al}$ and some other metals that were above criteria in the unfiltered water were shown to be associated with particles (i.e., not bioavailable).

The toxicity of water in seven reaches is unknown.

The high observed mortality in medaka embryos and larvae are believed to constitute toxic effects that would result in significant effects on the fish community. However, this test is sensitive and has not been validated against biological survey data at sites where clear toxic effects are occurring and fish community properties are clearly related to toxic effects as has been done with the standard 7-day tests. 



\section{RISKS TO BENTHIC INVERTEBRATES}

\subsection{EXPOSURE ASSESSMENT FOR BENTHIC INVERTEBRATES}

\subsubsection{Chemicals In Sediment}

Benthic invertebrates are exposed to contaminants in water or sediments. Those benthic invertebrates that inhabit riffles live on rocks and organic debris and are primarily exposed to contaminants in water. As with fish, exposures of benthic invertebrates to water are conservatively estimated as total concentrations, although actual exposures are best estimated by dissolved phase concentrations. Benthic invertebrates that inhabit the soft sediments of pools are exposed to contaminants in the sediments. Two different expressions of sediment contamination are used in ecological risk assessments: whole sediment concentrations and filtered pore water concentrations. The use of pore water is based on the assumption that chemicals associated with the solid phase are largely unavailable and therefore sediment toxicity can be estimated by measuring or modeling the pore water concentration. This is the approach the EPA uses to calculate sediment quality criteria. Whole sediment concentrations do not account for effects of sediment properties on bioavailability; however, they are required by EPA Region IV and may provide a better estimate of risk for highly particle-associated chemicals, which may not be detectable in pore water.

Benthic invertebrates are exposed to surface sediments and not to deep sediments. In a compromise between realism and the desire to include data for all analytes, a maximum interval of 0 to 50 centimeters was used. Analyses of cores with a depth greater than 50 centimeters were discarded, and core sections other than the surface section were discarded.

Because sediment is likely to be more variable in space than in time (due to its relative immobility) and because the organisms are relatively immobile, it is not appropriate to think of benthic invertebrates as averaging their exposures to sediment over space or time. Therefore, the median sediment concentration is an appropriate measure of the central tendency of the contaminant data. An appropriate conservative estimate of this exposure for use in the contaminant screening is the maximum.

As with water, many of the chemical concentrations in sediments are below analytical detection limits. Chemicals that were not detected in any sample in a reach were eliminated. If a reach contained some detects and some nondetects for a chemical, the product limit estimator was used to estimate the mean, which is reported for reference.

Ford et al. (1996) presented a complete description of the sediment sampling and analysis in WAG 2. Note that sediment samples from the lower W4T were aggregated with the IHP samples and that samples from WS were aggregated with LWC samples for consistency with that report.

\subsubsection{Sediment Radiation Exposures}

Exposures to radionuclides are expressed as the dose rate received by the organism. As with radiation exposures in surface water, the total dose rate is the sum of the internal and external dose rates, which are a function of exposure to the radionuclide and the characteristics of the radiation. Radiation exposures to benthic invertebrates immersed in sediments are likely to be 
driven by external exposures to contaminated sediments. The exception is for alpha emitters, such as uranium-234 and thorium-230. Internal dose rates are based on the concentrations of the radionuclide in the organism, which is a function of bioavailabilty. Pore water concentrations are assumed to best estimate the bioavailable fraction in sediments, and standard sediment to benthic invertebrate transfer factors are not available. Therefore, the concentration in benthic invertebrates was estimated by using the measured sediment concentrations and the soil-water partition coefficients (Kd) from Baes et al. (1984) to estimate the sediment pore water concentrations. Concentrations in the organism were then estimated based on the biological concentration factors provided in Blaylock et al. (1993). Because the radiation exposure rate is expressed as absorbed dose per unit time ( $\mathrm{rads} / \mathrm{d}$ ), the dose rates for each isotope and pathway can be added to determine the total dose rate.

\subsection{EFFECTS ASSESSMENT FOR BENTHIC INVERTEBRATES}

\subsubsection{Single Chemical Sediment Toxicity}

Because there are no standard screening benchmarks and sediment quality criteria for only a few chemicals, sets of alternative sediment benchmarks were derived for each chemical (Table 4.1). Whole sediment concentrations are compared to these alternative benchmarks. The use of multiple benchmarks provides greater assurance of detecting all COPECs. Sediment quality criteria are corrected for site-specific conditions. Sediment benchmarks derived using the equilibrium partitioning method are calculated using location-specific percent organic carbon.

\subsubsection{Radiological effects}

The recommended acceptable dose rate to natural populations of aquatic biota is $1 \mathrm{rad} / \mathrm{d}$ (NCRP 1991). Although there are no standard screening benchmarks for radionuclide concentrations in sediments, Blaylock et al. (1993) provide formulas and exposure factors estimating the dose rates to representative aquatic organisms. These formulas were used to calculate the sediment concentration that results in a total dose rate of $1 \mathrm{rad} / \mathrm{d}$ to a small invertebrate for each radionuclide detected in the sediment samples from BCV. The exposure factors used in this assessment are from Blaylock et al. (1993) and are presented in Table 3.2. The benchmarks include internal and external exposures from the detected isotope and all short-lived daughter products. All major alpha, beta, and gamma emissions for each isotope were included; and the absorbed fraction of each was estimated from the graphs provided in Blaylock et al. (1993). Conservatism was practiced by assuming the representative invertebrate was immersed in the sediments at all times. Internal exposures from radionuclides in sediments were estimated using the soil-water partition coefficients and biological concentration factors for the detected parent isotopes. 
Table 4.1 Descriptions of the ecotoxicological screening benchmarks for benthic biota exposed to contaminated sediments

\begin{tabular}{|c|c|c|}
\hline Benchmark & Abbreviation & Description \\
\hline Effects Range-Low & ER_L & $\begin{array}{l}\text { The tenth percentile of estuarine sediment concentrations reported to be } \\
\text { associated with some level of toxic effects. }\end{array}$ \\
\hline Effects Range-Median & ER_M & $\begin{array}{l}\text { The fiftieth percentile of estuarine sediment concentrations reported to be } \\
\text { associated with some level of toxic effects. }\end{array}$ \\
\hline Region IV Benchmark & REG_IV & $\begin{array}{l}\text { The higher of two values, the EPA Contract Laboratory Program Practical } \\
\text { Quantification Limit (CLP PQL) and the Effects Value which is the lower } \\
\text { of the ER-L and the Florida NOEL. }\end{array}$ \\
\hline Threshold Effect Level & TEL & $\begin{array}{l}\text { The geometric mean of the fifteenth percentile of reported concentrations } \\
\text { which were associated with some level of effects and the fiftieth percentile } \\
\text { of reported concentrations which were associated with no adverse effects. } \\
\text { All data are for marine and estuarine sediments. }\end{array}$ \\
\hline Probable Effect Level & PEL & $\begin{array}{l}\text { The geometric mean of the fiftieth percentile of reported concentrations } \\
\text { which were associated with some level of effects and the eighty-fifth } \\
\text { percentile of reported concentrations which were associated with no } \\
\text { adverse effects. All data are for marine and estuarine sediments. }\end{array}$ \\
\hline National Sediment Quality Criteria & EPASQC_A & $\begin{array}{l}\text { Sediment quality criteria based on toxicity in water expressed as chronic } \\
\text { water quality criteria (recalculated after adding some benthic species) and } \\
\text { partitioning of the contaminant between organic matter ( } 1 \% \text { of sediment by } \\
\text { weight) and pore water. Sediment quality criteria were adjusted to the site- } \\
\text { specific percent total organic matter content. }\end{array}$ \\
\hline Equilibrium Partitioning Benchmark & EQPSQB_A & $\begin{array}{l}\text { Benchmarks derived in the same manner as sediment quality criteria except } \\
\text { that the expression of aqueous toxicity is the chronic NAWQC or the } \\
\text { secondary chronic value, and site-specific percent organic matter is used. }\end{array}$ \\
\hline
\end{tabular}


Table 4.1 (continued)

\begin{tabular}{lcl}
\multicolumn{1}{c}{ Benchmark } & Abbreviation & \multicolumn{1}{c}{ Description } \\
\hline $\begin{array}{l}\text { Ontario Ministry of the Environment } \\
\text { Lowest Effect Level }\end{array}$ & LEL_MOE & $\begin{array}{l}\text { Concentrations determined by the Ontario MOE to constitute thresholds for } \\
\text { toxic effects in Ontario sediments. }\end{array}$ \\
$\begin{array}{l}\text { Ontario Ministry of the Environment } \\
\text { Severe Effect Level }\end{array}$ & SEL_MOE & $\begin{array}{l}\text { Concentrations determined by the Ontario MOE to constitute thresholds for } \\
\text { severe toxic effects in Ontario sediments. }\end{array}$ \\
$\begin{array}{l}\text { Region V Benchmark for nonpolluted } \\
\text { sediments }\end{array}$ & REG_V_L & $\begin{array}{l}\text { A concentration determined to constitute background for sediments in } \\
\text { Illinois. }\end{array}$ \\
$\begin{array}{l}\text { Region V Benchmark for heavily } \\
\text { polluted sediments }\end{array}$ & REG_V_M & $\begin{array}{l}\text { A concentration determined to constitute the upper bound of moderately } \\
\text { polluted sediments relative to background sediments in Illinois. }\end{array}$ \\
Apparent Effect Threshold & AET & $\begin{array}{l}\text { A concentration above which toxic effects occurred at all sites in Puget } \\
\text { Sound. }\end{array}$ \\
\hline
\end{tabular}

Note: More details are presented by Hull and Suter (1994), Long et al. (1995), MacDonald (1994), and Region IV (1994). The last five benchmarks are used only when none of the first seven are available 


\subsubsection{Invertebrate Community Surveys}

\subsubsection{Sediment communities}

Surveys of benthic invertebrates in soft sediments behind weirs and dams were performed in 1995 (Appendix A). The surveys were conducted in large part to determine whether dredging these sediments to maintain pool depth would destroy communities that had any particular ecological value. However, they serve to indicate the effects of sediment contamination more generally including natural pools where sediments accumulate. The survey included two weirs on WOC within WAG 2, two on Melton Branch, and two sites in WOL. These were compared to reference pools behind weirs on upper First Creek, WOC above ORNL, and Clear Creek. The locations are described in Appendix A. The results are somewhat confounded by differences in sediment characteristics among the weirs. The reference weirs tended to have more coarse particulate organic matter (detritus) and less silt than the weirs in WAG 2. This is not surprising given the silt that would be expected to enter the streams from construction and remediation activities at ORNL. The two WOL sites are different from all of the weirs in the depth of water and associated physical characteristics.

The lowest taxonomic richness was found in WOL ( 4 taxa per sample), and the highest was found in background WOC ( 15 taxa/sample) and upper Clear Creek ( $\sim 12$ taxa/sample). The other two reference weirs and the WAG 2 weirs all had ( $\sim 9-11$ taxa/sample). Since chironomid midge larvae made up most of the taxa identified, they were tabulated separately and gave the same pattern of relative taxonomic richness. Hence, although taxonomic richness varies by more than a factor of three among sites, the difference could be attributed to physical habitat differences as well as contamination.

\subsubsection{Riffle communities}

Surveys of benthic invertebrates in riffles were performed beginning in 1987 with the last reported results from 1992 (Ashwood 1994). At that time, the taxonomic richness of all invertebrates and particularly of the Ephemeroptera, Plecoptera, and Trichoptera (EPT) was severely reduced at sites on WOC adjacent to and downstream of ORNL. They were also reduced in lower First and Fifth Creeks and in Melton Branch relative to reference sites. However, they were elevated in lower NWT relative to the upstream reference site. These comparisons of upstream and downstream sites are confounded by habitat differences as with the soft sediment communities. However, the differences in substrate are not as great, and because riffle communities have been much more studied than soft sediment communities, it is possible to judge which differences are attributable at least in part to contamination. Therefore, it can be judged with some confidence, that the reduced taxonomic richness was not due simply to stream habitat gradients (Ashwood 1994).

\subsection{RISK CHARACTERIZATION FOR BENTHIC INVERTEBRATES}

\subsubsection{Single Chemical Sediment Toxicity}

Screening against benchmarks. Chemicals detected in whole sediments were screened against benchmarks and evaluated as COPECs. An HQ was calculated for each chemical by dividing the maximum concentration by the sediment benchmarks (Table B.5). Chemicals that exceeded any benchmark (e.g., HQ>1) were examined further to determine whether they were 
Table 4.2. Results of screening of chemicals that exceed benchmarks in sediments for COPECs

\begin{tabular}{|c|c|c|}
\hline Chemical & COPEC & Reason for Inclusion or Rejection \\
\hline 2-methylnaphthalene & No & $\begin{array}{l}\text { Detected only in two reaches and only one and two samples; it barely exceeds the effects range-low (ER-L) in } \\
\text { one sample. }\end{array}$ \\
\hline Acenaphthene & Yes & $\begin{array}{l}\text { Exceeds all benchmarks in Middle White Oak Creek (MWC) and multiple benchmarks in Intermediate Holding } \\
\text { Pond (IHP) and Lower White Oak Creek (LWC). }\end{array}$ \\
\hline Anthracene & Yes & Exceeds all benchmarks in MWC and multiple benchmarks in IHP and LWC. \\
\hline Aroclor $-12 x x$ & & See PCBs \\
\hline Arsenic & Yes & $\begin{array}{l}\text { Exceeds the threshold effect level (TEL) in all reaches and the ER-L in all but LMB but not the ER-M or PRE } \\
\text { in any reach. }\end{array}$ \\
\hline Barium & Yes $^{a}$ & Exceeds both Region $V$ benchmarks \\
\hline Benzo(a)anthracene & Yes & Exceeds multiple benchmarks in IHP and MWC \\
\hline Benzo(a)pyrene & Yes & Exceeds multiple benchmarks in IHP and MWC \\
\hline Cadmium & Yes & Exceeds multiple benchmarks in IHP and MWC \\
\hline Chromium & Yes & Exceeds the ER-L in IHP and LMB \\
\hline Chrysene & Yes & Exceeds multiple benchmarks in IHP and MWC \\
\hline Copper & Yes & Exceeds multiple benchmarks in IHP, LMB, LWC, and MWC \\
\hline Dibenz(a,h)anthracene & Yes & Exceeds the ER-L and TEL in IHP and MWC and the PEL in IHP, but detected in only one sample/reach. \\
\hline Fluoranthene & Yes & Exceeds the ER-L and TEL in IHP and MWC and the TEL in LWC. \\
\hline Fluorene & Yes & Exceeds the ER-L and PEL in IHP and MWC. \\
\hline Iron & Yes $^{2}$ & Exceeds the Ontario MOE's SEL. \\
\hline Lead & Yes & $\begin{array}{l}\text { Exceeds the ER-L and TEL in IHP and MWC and barely exceeds the Region IV value in LWC and the PEL in } \\
\text { MWC. }\end{array}$ \\
\hline
\end{tabular}


Table 4.2 (continued)

\begin{tabular}{|c|c|c|}
\hline Chemical & COPEC & Reason for Inclusion or Rejection \\
\hline 2-methylnaphthalene & No & $\begin{array}{l}\text { Detected only in two reaches and only one and two samples; it barely exceeds the effects range-low (ER-L) in } \\
\text { one sample. }\end{array}$ \\
\hline Acenaphthene & Yes & $\begin{array}{l}\text { Exceeds all benchmarks in Middle White Oak Creek (MWC) and multiple benchmarks in Intermediate Holding } \\
\text { Pond (IHP) and Lower White Oak Creek (LWC). }\end{array}$ \\
\hline Anthracene & Yes & Exceeds all benchmarks in MWC and multiple benchmarks in IHP and LWC. \\
\hline Aroclor $-12 x x$ & & See PCBs \\
\hline Manganese & Yes" $^{*}$ & Exceeds MOE benchmarks in all reaches. \\
\hline Mercury & Yes & Exceeds multiple benchmarks in all reaches but particularly high in IHP and MWC. \\
\hline Nickel & Yes & Exceeds multiple benchmarks in all reaches \\
\hline PCB, total & Yes & Exceeds multiple benchmarks in all reaches but particularly high in IHP and MWC. \\
\hline Phenanthrene & Yes & Exceeds multiple benchmarks in IHP, LWC and MWC but particularly high in MWC. \\
\hline Pyrene & Yes & Exceeds the ER-L in IHP, and MWC \\
\hline Silver & Yes & Exceeds multiple benchmarks in IHP and MWC. \\
\hline Zinc & Yes & Exceeds multiple benchmarks in IHP, LMB, and MWC. \\
\hline
\end{tabular}

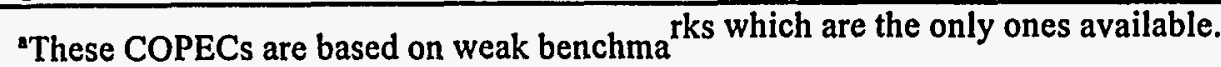


credible COPECs (Table 4.2). Only 2-methylnaphthalene could be eliminated without comparison to background and a more detailed evaluation of their distribution among reaches and the relevant effects data. These comparisons will be included in the White Oak Creek watershed RI.

Chemicals that were detected in sediment but for which no benchmarks are available are also of concern. They are aluminum, benzo(p)fluoranthene, benzo(g, $h, I)$ perylene, benzo(k)fluoranthene, beryllium, boron, butylbenzylphthalate, carbazole, cobalt, indeno $(1,2,3-$ cd)pyrene, lithium, methoxychlor, molybdenum, osmium, selenium, strontium, thallium, tin, and hexachlorobenzene.

\subsubsection{Sediment Radiation Characterization}

The concentrations of detected radionuclides were compared with the screening values for small invertebrates immersed in sediments. An HQ was calculated for each radionuclide by dividing the measured concentration by the screening value. The screening value is the concentration resulting in a total dose rate of $1 \mathrm{rad} / \mathrm{d}$ from the major emissions of the measured parent radionuclide and all short-lived progeny. A total dose rate to small invertebrates at each site was calculated by summing the $\mathrm{HQ}$ s for all detected radionuclides. Radionuclides present a significant risk to benthic invertebrates if the sum of HQs for a site exceeds 1.0. Table B.5 details the detected concentrations, screening values, HQs for individual raclionuclides, and the sum of HQs for all radionuclides detected at each site. Based on these results, radionuclides in BCV sediments appear to present a negligible risk to benthic invertebrates. That is, the individual and sum of HQs were considerably $<1.0$ at all locations.

\subsubsection{Benthic Community Surveys}

The benthic community survey data cannot be directly related to the chemical analyses because WOL and the community reference sites were not subject to chemical analyses and because differences in the sampling would tend to obscure patterns. The communities in the four pools on WOC and MB within WAG 2 had total taxonomic richnesses that were within the range of reference communities although not as high as the best site on upper WOC (Appendix A). The only indication of a contaminant effect in the soft sediment community is chironomid taxonomic richness (by far the most abundant taxon) in MWC (the most contaminated sediment), which was lower than in reference pools.

\subsubsection{Weight of Evidence for Benthic Invertebrates}

PCBs (both totals and Arochlor mixtures), 10 polycyclic aromatic hydrocarbons (PAHs), and 12 metals were found at concentrations high enough to indicate a hazard to benthic invertebrates. Sediment toxicity is unknown. Community surveys in depositional areas do not indicate a large effect of contamination except possibly in WOL, but they are confounded by habitat differences. Sediment chemical concentrations at most benthic community survey sites are unknown and were not available for most tributaries. Hence, the sediments are contaminated, but the benthic community is not clearly different from reference communities; or in the case of WOL, the community is different, but contaminant levels are not known.

The communities of riffles have low species richness below ORNL, which is likely to be primarily due to contaminants in water (Chap. 3). The dominance of this mode of exposure is the reason that riffle invertebrate communities are monitored to determine whether water quality goals are being met (Ashwood 1994). However, the feeding habits of some species expose them 
to the small amount of particulate material that is deposited in such areas so sediment contamination may make a small contribution to this effect.

\subsection{UNCERTAINTIES CONCERNING RISKS TO BENTHIC INVERTEBRATES}

The following issues are believed to constitute the major sources of uncertainty in the risk assessment for the benthic invertebrate assemblage.

- The benchmarks against which the sediment concentrations are screened are from studies of estuaries and large lakes that may differ considerably in their physical and ecological properties from the steams being assessed.

- The toxicity of the sediments is unknown.

- The chemical concentrations in WOL and in most tributaries are unknown.

- Chemical concentrations in sediments from most of the benthic invertebrate survey sites are unknown. 


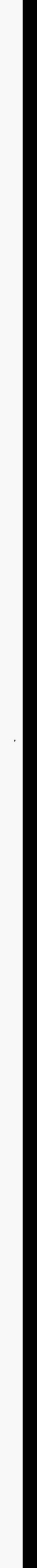




\section{RISKS TO SOIL INVERTEBRATES}

This chapter addresses risks from chemical soil invertebrates, which are represented by earthworms. Radiological risks to earthworms are presented in this report along with other terrestrial endpoints.

\subsection{EXPOSURE ASSESSMENT FOR SOIL INVERTEBRATES}

Earthworms absorb a variety of inorganic and organic soil contaminants through both feeding in soil and litter and burrowing in soil. It is assumed that these organisms represent highly exposed soil invertebrates. It is not possible or necessary to distinguish the exposure of earthworms to solid, liquid, and gaseous phases of the soil. Both in toxicity tests and the field, earthworms integrate exposures to all soil components by all uptake routes.

The bioavailability of the contaminants in soil and decomposing plant litter are controlled by soil, litter, and analyte characteristics; however, current knowledge is not sufficient to allow the prediction of bioavailability based on soil variables. An exception is the association of extremes in $\mathrm{pH}$ and metal availability (van Gestel 1992).

It is assumed that the earthworms spend their entire life span in soil with contaminant levels represented by the $0.5 \mathrm{~m}$ depth of soil sampled. The assumption is reasonable, though organisms feeding on well-decomposed organic material near the surface may be exposed to different quantities of organic chemicals than worms feeding on litter pulled down into burrows in the subsoil (Curl et al. 1987). Few earthworms are found in waterlogged soils so exposure to seeps is not considered. Because earthworms and other soil invertebrates may spend their entire lives at a single sampling location, the maximum detected contaminant concentrations were screened against toxicity benchmarks, as described in Sect. 5.2.1. These concentrations are used to assess potential negative impacts of contaminated soils on soil invertebrate populations.

\subsection{EFFECTS ASSESSMENT FOR SOIL INVERTEBRATES}

Toxicity tests and biological surveys were not performed at these sites. Earthworms were sampled, but quantitative surveys were not performed. Thus the only line of evidence in the risk assessment is the screening against benchmarks, described in the following paragraphs. Where benchmarks were not available, risks could not be evaluated.

Contaminant concentrations in soils were compared to toxicological benchmarks for earthworms in order to screen out chemicals that do not constitute a hazard to soil invertebrates and therefore do not require detailed risk characterization. Chemicals that were not screened out because the maximum detected concentrations were greater than benchmarks may potentially pose significant risks to soil invertebrates. References used for the derivation of benchmarks were reports of toxicity tests of individual chemicals in laboratory, greenhouse, or field settings. Tests conducted with natural soils in the laboratory were assumed to represent the exposures of worms in floodplain soils. However, chemicals freshly added to soils in toxicity tests may be more bioavailable than the chemical forms that occur in field soils. Only experiments in which earthworms were exposed to soil (natural or artificial mixture of natural components), soil/litter microcosms, or manure were considered. Twenty percent reduction in growth, reproduction, or 
activity was used as the threshold for significant effects to be consistent with other screening benchmarks for ecological risk assessment and because the FFA parties adopted this level of effects for ecological endpoints (Suter et al., 1995).

The method used for deriving soil benchmarks are described in Will and Suter (1995a). Screening benchmarks for toxic effects of contaminants present in WAG 2 soils are presented with the hazard quotients in Table B.6. Benchmarks were not available for any of the organic compounds detected in the floodplain, except n-nitrosodiphenylamine.

\subsection{RISK CHARACTERIZATION FOR SOIL INVERTEBRATES}

The evidence concerning risks to soil invertebrates consists of analyses of inorganic, organic, and radionuclide contaminants in soil. This single line of evidence is summarized in the following text. Toxicity tests and quantitative biological surveys were not available.

\subsubsection{Single Chemical Soil Toxicity}

Contaminants of potential ecological concern (COPECs) for soil invertebrates in the WAG 2 floodplain were identified by comparing maximum concentrations in soil at each location to the following: (1) twice the mean background for soils from WAG 5 (DOE 1995); and (2) available benchmarks for toxicity to soil invertebrates (Will and Suter 1995a). Maximum detected concentrations in soil are used for screening purposes because earthworms and other soil invertebrates are relatively immobile and can therefore be exposed to the maximum concentration during the course of their lifetimes (Suter et al. 1995). If both background and benchmark criteria were exceeded, the contaminant was identified as a COPEC. he magnitude of exceedence of a benchmark is described by the hazard quotient, the maximum concentration in soil divided by the toxicity benchmark concentration. If background criteria were not available, exceedence of a benchmark was sufficient for the COPEC designation. Benchmarks, maximum concentrations of analytes at each sample location exceeding background for which benchmarks are available, and hazard quotients for the contaminants are given in Table B.6. The major COPECs for soil invertebrates were mercury and chromium. Mercury and chromium are among the few chemicals for which the benchmarks for toxicity to soil invertebrates is lower than the phytotoxicity benchmarks.

Intermediate Holding Pond. The maximum detected concentrations of chromium, mercury, and nickel were 100,800 , and 2 times the benchmarks for toxicity to earthworms.

Lower White Oak Creek. The maximum detected concentrations of chromium and mercury were 200 and 50 times the benchmarks for toxicity to earthworms. Although the maximum detected concentration of zinc is apparently equivalent to the benchmark if a single significant digit is used, the concentration of $190 \mathrm{mg} / \mathrm{kg}$ is lower than the benchmark concentration of 200 $\mathrm{mg} / \mathrm{kg}$. Also, the mean concentration of zinc in the soils of the IHP reach was about half that of the benchmark concentration. Thus, zinc is not a COPEC for toxicity to soil invertebrates.

Middle White Oak Creek. The maximum detected concentration of mercury was 30 times the benchmark for toxicity to earthworms.

Lower Melton Branch. The maximum detected concentration of mercury was 20 times the benchmark for toxicity to earthworms. 
The strength in the literature toxicity line of evidence is in its ability to relate the concentration of a single contaminant in soil to observed effects. The screening is most useful if the chemical species and bioavailability of contaminants in WAG 2 floodplain soils are comparable to those of the chemical in laboratory toxicity tests in other soils. In these soils, the fractions of mercuric chloride, methyl mercury, mercuric sulfide, and some others were not determined. Thus, the hazard quotients for mercury may be quite conservative.

\subsubsection{Summary of Risk Characterization for Soil Invertebrates}

As in any screening assessment, potential hazard is indicated by the exceedence of toxicological benchmarks. COPECs for soil invertebrates in the WAG 2 floodplain include chromium, mercury and nickel. Further studies, such as toxicity tests (or other measures of bioavailability) and chemical speciation of mercury, would be advisable before concluding that these contaminants constitute hazards to soil invertebrates.

\subsection{UNCERTAINTIES CONCERNING RISKS TO SOIL INVERTEBRATES}

The following factors create uncertainty in assessing the risk posed by the potential contaminants of concern in soils:

'Bioavailability' of elements. The extraction methods used during sample collection may remove from the soil quantities of elements and compounds greater than those that are extracted from soil as they pass through the gut of the earthworm or those that are adsorbed dermally.

Variable response to contaminants. Various earthworm and other soil invertebrate species and earthworm growth stages tolerate contaminants to different degrees. The literature from which benchmarks were derived is not necessarily based on experiments using earthworm species known to be representative of those occurring in the soils of WAG 2.

Multiple contaminant exposure. Toxicity benchmark concentrations are derived from experiments in which earthworms are exposed to single contaminants. Typical soils of the WAG 2 expose earthworms to multiple contaminants which may not be adequately assessed on the basis of literature-derived benchmarks.

Lack of benchmarks for some metals and most organic compounds. Little research has been conducted on the toxic effects of the organic compounds, other than pesticides. Thus, it is not possible to assess the risk to earthworm populations posed by many of the analytes found in the soils.

Chemical speciation. Earthworm toxicity benchmarks for metals are often derived from studies with a single species of a contaminant. 



\section{RISKS TO PLANTS}

This chapter addresses risk from chemicals to plants. Radiological risks to plants are assessed along with other terrestrial endpoints.

\subsection{EXPOSURE ASSESSMENT FOR PLANTS}

Vegetation growing in the WAG 2 floodplain is exposed to contaminants in soil and potentially in shallow groundwater near seeps and intermittent tributaries.

\subsubsection{Soil Exposures}

Concentrations of analytes in the soil derived from double acid extractions (nitric and hydrochloric) generally representing the total potential reservoir of contaminants, not the concentrations to which plants are exposed at any one time. Some metals are more readily available for uptake by plants than others, depending on the solubility and species of the compound, interactions with soil constituents (organic matter and clay) and with other contaminants, and mechanisms for bioaccumulation in particular plant species. Organic contaminants may interact strongly with soil organic matter and therefore only be partially available for plant uptake.

Contaminants have vertical distributions in soil that reflect interactions between the soil and the contaminant, controlled by the chemical and physical characteristics of the soil and the quantity and chemical characteristics of the contaminant. The exposure of plant roots to a contaminant in the soil depends on these abiotic factors and the growth characteristics of individual plants, such as rooting depth and density. Deep-rooted trees and shallow-rooted grasses may be exposed to different concentrations of contaminants, depending on the location of the source. In the absence of data on root distribution, it is assumed that the plants are rooted within the zone from which the soil was sampled for analysis.

Two other routes of exposure cannot be addressed because of a lack of data. These are exposure to volatile organic compounds in the air above and in the soil and contaminants in dust particles deposited on above-ground plant parts. These routes are assumed to contribute negligibly to plant exposure in the WAG 2 floodplain.

\subsubsection{Soil Solution Exposures}

Plants growing in seep areas are exposed to contaminants in the aqueous phase. Numerous seeps, springs, or intermittent tributaries in the WAG 2 floodplain were sampled for contaminants. It is assumed that the roots of plants near the springs may be exposed to water containing contaminants at similar concentrations. Although the discharge in many of these seeps is seasonal and heightened during rainfall, we make the conservative assumption that plants growing at these locations are exposed to contaminants in the water throughout the year. We also assume that the entire root systems of plants growing in seep areas are exposed to contaminants and that this type of exposure is the only significant source for the plants.

Filtered water samples from seeps are better representations than unfiltered samples of concentrations to which plants are exposed. Samples for this assessment were not filtered; thus the data are conservative estimates of exposure. 


\subsection{EFFECTS ASSESSMENT FOR THE PLANT COMMUNITY}

Contaminant concentrations in soils and springs were compared to toxicological benchmarks (Will and Suter 1995b) in order to screen out chemicals that do not constitute a hazard to plants and therefore do not require detailed risk characterization. Tests conducted in natural soils in the laboratory were assumed to be representative of the exposure of plants to contaminants measured in floodplain soils, with the possibility that chemicals freshly added to soils in literature toxicity tests may be more bioavailable than contaminants in WAG 2 soils. Tests conducted in nutrient and mineral solutions are the best available representation of exposures of plants to contaminants in the vicinity of seeps and springs.

Benchmarks were not available for numerous organic contaminants, including polycyclic aromatic hydrocarbons.

\subsection{RISK CHARACTERIZATION FOR THE PLANT COMMUNITY}

The evidence concerning risks to the plant community consists of analyses of inorganic, organic and radionuclide contaminants in soil. This single line of evidence is summarized in the following text. Toxicity tests and biological surveys were not available.

\subsubsection{Single Chemical Soil and Solution Toxicity}

COPECs for terrestrial plants in the WAG 2 floodplain were identified by comparing maximum detected site concentrations of soil to the following: (1) twice the mean background for soils from WAG 5 (DOE 1995) and (2) available benchmarks for toxicity to terrestrial plants (Will and Suter 1995b). The screening of maximum concentrations against benchmarks is intended to protect plants that spend their entire lives in a single, highly contaminated location. If both background and benchmark criteria were exceeded, the contaminant was identified as a COPEC. The magnitude of exceedence of a benchmark is described by the hazard quotient, the maximum concentration in soil divided by the toxicity benchmark concentration. If background criteria were not available, exceedence of a benchmark was sufficient for the COPEC designation. Benchmarks for plants growing in soils, maximum concentrations of analytes at each reach exceeding background and for which benchmarks are available, and hazard quotients for the contaminants are given in Table B.7.

COPECs for plants potentially exposed to water from seeps and springs were identified by a similar comparison of contaminant concentrations with background and toxicity benchmarks (Table B.8).

\subsubsection{Terrestrial plants}

The screening of contaminant concentrations in soil against phytotoxicity benchmarks is provided in Table B.7.

Intermediate Holding Pond. The maximum detected concentrations of boron, chromium, lead, lithium, and manganese were 20,70,2,20, and 8 times the phytotoxicity benchmarks (i.e., concentrations causing toxic effects when added to surface soil). Mercury, molybdenum, nickel, silver, and zinc were detected at $300,3,10,8$, and 3 times the benchmarks. 
Lower White Oak Creek. The maximum detected concentrations of boron, chromium, lithium, manganese, mercury, molybdenum, silver, and zinc were $20,100,8,3,20,2,3$, and 4 times the phytotoxicity benchmarks. Lead and selenium were detected at concentrations only slightly above benchmarks (hazard quotient of 1 if appropriate significant figures were used).

Middle White Oak Creek. The maximum detected concentrations of boron, lithium, mercury, molybdenum, selenium, silver, and zinc were $20,7,8,2,2,2$, and 2 times the phytotoxicity benchmarks.

Lower Melton Branch. The maximum detected concentrations of antimony, boron, lithium, manganese, mercury, and molybdenum were $600,2,20,10,20,7$, and 4 times benchmarks. Selenium and thallium were detected at concentrations only slightly above benchmarks (hazard quotient of 1 if appropriate significant figures were used).

The strength of the literature toxicity line of evidence is in its ability to relate the concentration of a single contaminant in soil to observed effects. The screening is most useful if the chemical species and bioavailability of contaminants in WAG 2 floodplain soils are comparable to those of the chemicals in laboratory toxicity tests in other soils. In these soils, the fractions of mercuric chloride, methyl mercury, mercuric sulfide, and others were not determined. Thus, the hazard quotients for mercury may be conservative.

\subsubsection{Plants exposed to seeps and springs}

The screening of contaminant concentrations in soil solution against phytotoxicity benchmarks is provided in Table B.8.

Embayment of White Oak Creek. The maximum detected concentration of aluminum at WOCET was 8 times the benchmark for plants in solution.

Homogeneous Reactor Test Tributary. The maximum detected concentration of aluminum in SW9-2 was 7 times the plant benchmark concentration for aluminum in solution.

Intermediate Holding Pond. No contaminants were detected above plant benchmarks in seeps or tributaries.

Lower Melton Branch. The maximum detected concentration of manganese at MID. DRAIN. was slightly above the benchmark for plants in solution. No contaminants were detected above plant benchmarks for the following seeps or tributaries: MBTRIB-3, SW2-5, SW5-2, and SW5-4.

Lower White Oak Creek. The maximum detected concentrations of aluminum from the East Seep, SW7-3, SW7-5, SW7-6, and WCTRIB-1 were 10,4, 10, 4, and 5 times the plant solution benchmark. No other contaminants were detected above background and benchmarks in seeps in this region.

Middle White Oak Creek. No contaminants were detected above plant benchmarks in seeps or tributaries.

Upper Melton Branch. No contaminants were detected above plant benchmarks in seeps or tributaries. 
Unknown reach. The maximum detected concentration of iron in SW2-7 was 2 times the plant solution benchmark.

WAG 4 Tributary. The maximum detected concentrations of arsenic and iron at SW4-1 were 6 and 3 times the plant solution benchmarks. The maximum detected concentration of nickel in SW4-2 was 50 times the plant solution benchmark. Aluminum was detected at 5 times the phytotoxicity benchmark in both WAG 4 MS1 and WAG 4 T2A. Chromium was detected at a concentration slightly above the plant solution benchmark in WAG4 T2A. No contaminants were detected above benchmarks in BTT.

West Seep. The maximum detected concentrations of aluminum and arsenic, chromium, and iron in RS-3A were 90, 20,2, and slightly greater than 1 times the benchmark for toxicity to plants in solution. Aluminum was detected in RS-3B at up to 7 times the benchmark. Manganese in SW7-1 and aluminum and cobalt in SW7-2 were detected at 2,3, and 2 times the phytotoxicity benchmark.

Aluminum and iron. Of the contaminants detected at seeps and springs at concentrations above benchmarks, aluminum and iron are unlikely to be of ecological concern. In unfiltered water, both of these contaminants are significantly associated with the particulate fraction, which is wholly or largely unavailable to plants. Also, aluminum and iron are typically found at high background concentrations (twice the mean background is $0.34 \mathrm{mg} / \mathrm{kg}$ for Al and $0.81 \mathrm{mg} / \mathrm{kg}$ for $\mathrm{Fe}$ ) in this region.

\subsubsection{Summary of Risk Characterization for the Plant Community}

As in any screening assessment, potential hazards are indicated by the exceedence of toxicological benchmarks. COPECs for the plant community exposed to soils in the WAG 2 floodplain include: boron, chromium, lead, lithium, manganese, mercury, molybdenum, nickel, selenium, silver, thallium, and zinc. COPECs for the plant community exposed to seeps or springs in the WAG 2 floodplain include: arsenic, chromium, cobalt, manganese, and nickel. Further studies, such as toxicity tests (or other measures of bioavailability) and chemical speciation of mercury, would be advisable before concluding that these contaminants constitute hazards to the plant community.

\subsection{UNCERTAINTIES CONCERNING RISKS TO PLANTS}

The following factors create uncertainty in assessing the risk posed by the contaminants of potential concern in WAG 2 soils, seeps, and springs.

Bioavailability of elements in soil. The extraction methods used may remove from the soil quantities of chemicals greater than are available to plants. The double-acid extraction removes the exchangeable fraction of metals thereby giving a concentration that reflects the total potential pool of contaminants, not that to which the plant is exposed at any one time. Estimates of exposure are confounded by the concentration- and species-dependent synergistic and antagonistic interactions between metals during uptake by roots and inside plants.

Bioavailability of elements in groundwater and springs. Concentrations of contaminants such as aluminum in whole, unfiltered groundwater are probably higher than the concentrations 
bioavailable to plants. In unfiltered water samples (i.e., containing soil and organic particles), acidification will bring into solution metals strongly bound to this particulate matter.

Variable response to toxicants. Various plant species and plant growth stages tolerate contaminants to different extents. The literature from which benchmarks were derived is not based on experiments using plants found in ecosystems representative of Bear Creek Valley. It is difficult to extrapolate from largely agricultural crops in early growth stages used in most of the published literature to trees and the varied ground vegetation found at WAG 2.

Multiple contaminant exposure. Because of our lack of understanding of the complex interactions between contaminants, benchmark levels are necessarily derived from experiments in which plants are exposed to single contaminants. Typical soils in WAG 2 expose plants to multiple contaminants which may not be adequately assessed on the basis of literature-derived benchmarks.

Lack of benchmarks for some metals and most organic compounds. Little research has been conducted on the phytotoxic effects of the organic compounds. Thus, it is not possible to assess the risk to plant growth posed by some of the analytes found in the Bear Creek Valley soils.

Chemical speciation. The analytical techniques did not generally differentiate among species of chemicals present in the soil which have variable toxicity to plants. 



\section{RISKS TO WILDLIFE}

Risks from radionuclides and nonradionuclides (e.g., organic and inorganic chemicals) were estimated for small mammals, piscivores, and wide-ranging wildlife species within WAG 2. Because the methods for risk estimation differ greatly between radionuclide and nonradionuclide contaminants, each is addressed separately. Risks to wildlife from chemicals are presented in Sect. 7.1; risks from radionuclides to wildlife, terrestrial plants, and earthworms are presented in Sect. 7.2.

\subsection{RISKS TO WILDLIFE FROM CHEMICALS}

\subsubsection{Exposure Assessment}

Wildlife may be exposed to contaminants through ingestion of food, soil, and water. In this assessment, exposure through ingestion of food, soil, and water was estimated using exposure models (described in the following paragraphs. For areas where there was insufficient data to assess complete exposure, exposure through water was assessed by comparing unfiltered water concentrations to water benchmarks for wildlife (see Sect 7.1.2.1). Contaminant exposure through ingestion was estimated for small mammals (short-tailed shrew and white-footed mouse), wide-ranging species (white-tailed deer, wild turkey, red-tailed hawk, and red fox) and piscivores (mink and belted kingfisher). Exposure estimates were calculated using soil and soil-biota uptake factors for small mammals, earthworms, and herbaceous, canopy, and browse vegetation. Uptake factors for small mammals and herbaceous, canopy, and browse vegetation were derived from data from 15 locations within the Bear Creek watershed (four within BCOU1 and 11 within the Bear Creek floodplain). Uptake factors for earthworms were derived from data from Bear Creek, WAG 5 and two locations within WAG 2. Exposure to piscivores was assessed using fish data from eight locations in the WOC watershed.

\subsubsection{Oral Ingestion Exposure Model}

Oral exposure to contaminants experienced by wildlife may come from multiple sources. They may consume contaminated food (either plant or animal), drink contaminated water, or ingest soil or sediment. Soil or sediment ingestion may be incidental while foraging or grooming or purposeful to meet nutrient needs. The total oral exposure experienced by an individual is the sum of the exposures attributable to each source and may be described as follows:

$$
\text { Etotal } \approx \text { Efood }+ \text { Ewater }+ \text { Esoil, }
$$

where

$E_{\text {total }}=$ total exposure from all pathways,

$E_{\text {food }}=$ exposure from food consumption,

$\mathrm{E}_{\text {water }}=$ exposure from water consumption,

$E_{\text {soil }}=$ exposure from soil consumption.

For exposure estimates to be useful in the assessment of risk to wildlife, they must be expressed in terms of a body weight-normalized daily dose or $\mathrm{mg}$ contaminant per $\mathrm{kg}$ body weight per day $(\mathrm{mg} / \mathrm{kg} / \mathrm{d})$. Exposure estimates expressed in this manner may then be compared to toxicological 
benchmarks for wildlife, such as those derived by Opresko et al. (1995), or to doses reported in the toxicological literature. Estimation of the daily contaminant dose an individual may receive from a

$$
E_{i}=\sum_{i=1}^{m} p_{i k}\left(\frac{I R_{i} \times C_{i j k}}{B W}\right)
$$

particular medium for a particular contaminant may be calculated using the following equation: where

$E_{\mathrm{j}}=\quad$ total exposure to contaminant $(\mathrm{j})(\mathrm{mg} / \mathrm{kg} / \mathrm{d})$,

$\mathrm{m}=$ total number of ingested media (e.g., food, soil, or water),

$\mathrm{IR}_{\mathrm{i}}=$ ingestion rate for medium $(\mathrm{I})(\mathrm{kg} / \mathrm{d}$ or $\mathrm{L} / \mathrm{d})$,

$\mathrm{p}_{\mathrm{ik}}=$ proportion of type $(\mathrm{k})$ of medium (I) consumed (unitless),

$\mathrm{C}_{\mathrm{ij}}=$ concentration of contaminant $(\mathrm{j})$ in type (k) of medium $(\mathrm{I})(\mathrm{mg} / \mathrm{kg}$ or $\mathrm{mg} / \mathrm{L})$,

$\mathrm{BW}=$ body weight of endpoint species $(\mathrm{kg})$.

Exposure estimates were calculated for all contaminants detected in soil or water from WAG 2. Because wildlife are mobile, their exposure is best represented by the mean contaminant concentration in media. To be conservative, the $95 \%$ UCL is used in exposure estimates. These data were used in the initial exposure estimates. Exposure estimates for contaminants that may present a risk to wildlife [based upon comparisons to no observed adverse effects levels (NOAELs) and lowest observed adverse effects levels (LOAELs)] were recalculated using Monte Carlo simulations. (Note: because the purpose of the initial exposure estimate is to be conservative and to identify COPECs, the $95 \%$ UCL was used regardless of whether or not the value exceeded the maximum observed value. Overestimates of exposure that may occur at the screening level are addressed through the use of Monte Carlo simulation).

\subsubsection{Piscivore exposures}

Exposure of mink and belted kingfisher to mercury and PCBs in fish from WOC was estimated at eight locations within the watershed (and one reference location outside that watershed) as part of the Preliminary Oak Ridge Reservation-wide Ecological Risk Assessment (Sample et al. 1995). Estimates for mink and kingfisher are presented in Tables C.1 and C.2 . Additional detail on these exposure estimates may be found in Sample et al. (1995).

\subsubsection{Soil-biota uptake factors}

Contaminant concentrations in biota were not available for WAG 2. To estimate contaminant concentrations in biota, we used uptake factors developed as part of the Bear Creek RI. Summary statistics for the biota uptake factors are presented in Table C.3. Uptake factors for small mammals, canopy, browse, and herbaceous vegetation were developed exclusively with data from the Bear Creek assessment. In addition to the Bear Creek data, data from two samples in WAG 2 and six from WAG 5 were used to develop the earthworm uptake factors. Contaminant concentrations in biota were estimated by multiplying the biota type-specific uptake factor by the soil concentration. 


\subsubsection{Contaminant concentrations in media}

Contaminant concentrations in soil and water are needed to estimate exposure. Soil and water data were aggregated into four reaches: IHP, MWC, LWC, and LMB. Definitions of the bounds of these reaches may be found in Table 2.1 .

Summary statistics) for contaminants detected in soil and water from WAG 2 are presented in Appendix C. For comparison, estimates of exposure to inorganic analytes were generated for all endpoints using the $2 \times$ mean background soil and water concentrations obtained from the WAG 5 RI.

\subsubsection{Exposure modeling using point estimates}

Initial estimates of exposure of piscivorous wildlife to contaminants were performed for each of the four reaches using point estimates of parameters in the exposure model. Species-specific parameters necessary to estimate exposure using Eq. 1 are listed in Tables C.4 through C.11.

In estimating contaminant exposure experienced by short-tailed shrew, the following assumptions were made:

- $\quad$ body weight $=0.015 \mathrm{~kg}$;

- food consumption $=0.009 \mathrm{~kg} / \mathrm{d}$ (fresh weight);

- $\quad$ soil consumption $=0.00117 \mathrm{~kg} / \mathrm{d}$ (dry weight);

- $\quad$ water consumption $=0.033 \mathrm{~L} / \mathrm{d}$;

- diet consists $100 \%$ of earthworms or soil invertebrates;

- contaminant concentration in earthworms is representative of that in other invertebrate prey.

To estimate contaminant exposure experienced by white-footed mouse, the following assumptions were made:

- body weight $=0.022 \mathrm{~kg}$;

- food consumption $=0.0034 \mathrm{~kg} / \mathrm{d}$ (fresh weight);

- $\quad$ soil consumption $=0.000068 \mathrm{~kg} / \mathrm{d}$ (dry weight);

- water consumption $=0.0066 \mathrm{~L} / \mathrm{d}$;

- diet consists $50 \%$ of earthworms or soil invertebrates and $50 \%$ herbaceous plant material;

- contaminant concentration in earthworms is representative of that in other invertebrate prey.

To estimate contaminant exposure experienced by white-tailed deer, the following assumptions were made:

- $\quad$ body weight $=56.5 \mathrm{~kg}$;

- food consumption $=1.74 \mathrm{~kg} / \mathrm{d}$ (fresh weight);

- $\quad$ soil consumption $=0.0348 \mathrm{~kg} / \mathrm{d}$ (dry weight);

- $\quad$ water consumption $=3.7 \mathrm{~L} / \mathrm{d}$;

- diet consists $33 \%$ of browse plants, $33 \%$ canopy plants, and $33 \%$ herbaceous plant material.

To estimate contaminant exposure experienced by red fox, the following assumptions were made:

- $\quad$ body weight $=4.5 \mathrm{~kg}$;

- food consumption $=0.45 \mathrm{~kg} / \mathrm{d}$ (fresh weight); 
- $\quad$ soil consumption $=0.0126 \mathrm{~kg} / \mathrm{d}$ (dry weight);

- water consumption $=0.38 \mathrm{~L} / \mathrm{d}$;

- diet consists $80.8 \%$ of small mammals and birds, $10.4 \%$ browse plant material, and $8.8 \%$ earthworms or other invertebrates;

- contaminant concentration in small mammals is representative of that in other vertebrate prey;

- contaminant concentration in earthworms is representative of that in other invertebrate prey.

To estimate contaminant exposure experienced by red-tailed hawk, the following assumptions were made:

- $\quad$ body weight $=1.126 \mathrm{~kg}$;

- food consumption $=0.109 \mathrm{~kg} / \mathrm{d}$ (fresh weight);

- $\quad$ soil consumption $=0 \mathrm{~kg} / \mathrm{d}$ (dry weight);

- $\quad$ water consumption $=0.064 \mathrm{~L} / \mathrm{d}$;

- diet consists $100 \%$ of small mammals and other vertebrates;

- contaminant concentration in small mammals is representative of that in other vertebrate prey.

To estimate contaminant exposure experienced by mink, the following assumptions were made:

- $\quad$ body weight = $1 \mathrm{~kg}$;

- food consumption $=0.137 \mathrm{~kg} / \mathrm{d}$ (fresh weight);

- water consumption $=0.099 \mathrm{~L} / \mathrm{d}$;

- diet consists $54.6 \%$ of fish or other aquatic prey and $45.4 \%$ small mammals;

- contaminant concentration in fish is representative of that in other aquatic prey.

To estimate contaminant exposure experienced by kingfisher, the following assumptions were made:

- $\quad$ body weight $=0.148 \mathrm{~kg}$;

- food consumption $=0.75 \mathrm{~kg} / \mathrm{d}$ (fresh weight);

- water consumption $=0.016 \mathrm{~L} / \mathrm{d}$;

- diet consists $100 \%$ of fish.

To estimate contaminant exposure experienced by wild turkey, the following assumptions were made:

- $\quad$ body weight $=5.8 \mathrm{~kg}$;

- food consumption $=0.174 \mathrm{~kg} / \mathrm{d}$ (fresh weight);

- $\quad$ soil consumption $=0.0162 \mathrm{~kg} / \mathrm{d}$ (dry weight);

- water consumption $=0.19 \mathrm{~L} / \mathrm{d}$;

- diet consists $90.3 \%$ of plant material and $9.7 \%$ invertebrates;

- contaminant concentration in earthworms is representative of that in other invertebrate prey.

Using Eq. 3 and the assumptions and data described above, we made point estimates of exposure to contaminants within each of the four WAG 2 reaches and the background for each endpoint (Tables C.12 through C.20).

\subsubsection{Exposure modeling using Monte Carlo simulations}

Employing point estimates for the input parameters in the exposure model does not take into account the variation and uncertainty associated with the parameters and therefore may over or under 
estimate the contaminant exposure that endpoints may receive. In addition, calculating the model using point estimates produces a point estimate of exposure. This estimate provides no information concerning the distribution of exposures or the likelihood that individuals within the watershed will actually experience potentially hazardous exposures. To incorporate the variation in exposure parameters and to provide a better estimate of the potential exposure experienced by wildlife in WAG 2, the exposure model was re-calculated using Monte Carlo simulations.

Monte Carlo simulation is a resampling technique frequently used in uncertainty analysis in risk assessment (Hammonds et al. 1994). In practice, distributions are assigned to input parameters in a model; and the model is recalculated many times to produce a distribution of output parameters (e.g., estimates of contaminant exposure). Each time the model is recalculated, a value is selected from within the distribution assigned for each input parameter. As a result, a distribution of exposure estimates is produced that reflects the variability of the input parameters.

For all endpoints, Monte Carlo simulations were performed for the entire WAG 2 area. The percentiles of the resulting exposure distributions represent the likelihood that an individual within the modeled area will experience a given exposure level. It was assumed that each sampling location contributed equally to the overall mean exposure (i.e., individuals within each watershed do not preferentially forage at any one location within the watershed). While this assumption is not likely to be ecologically correct (foraging effort and therefore exposure is likely to be biased toward those locations with the most abundant food), data were not available to estimate the preferential use at each sampling location.

Simulations were performed for each contaminant where comparison of point estimates of exposure to LOAELs produced HQs 21 for at least one location (LOAELs are presented in Sect 7.1.2.; Screening of exposure estimates against LOAELs is presented in Sect. 7.1.3.).

Distributions were used for the following parameters in the exposure model: contaminant concentrations in soil and water and soil-biota uptake factors. All distributions were assumed to be normal. Because these wildlife are mobile, the contaminant concentration they are exposed to on a daily basis is best represented by the average concentration instead of the entire distribution. The standard error of the mean was used to describe variation in the average contaminant concentration.

Monte Carlo simulations were performed using the @Risk software. Samples from each distribution were selected using latin hypercube sampling. The number of iterations, or recalculations, of each exposure simulation was determined by the convergence criteria set in the software. Under these criteria, iterations are performed until the between-iteration percent change in the percentiles, mean, and standard deviation is below $1.5 \%$ (i.e., the percentile, mean, and standard deviation for the latest iteration is less than $1.5 \%$ different than the those from the previous iteration). Using this convergence criterion, from 600 to 2500 model iterations were performed for each exposure estimate. Monte Carlo estimates of contaminant exposures are presented in Table C.19.

\subsubsection{Chemical Effects Assessment for Wildlife}

\subsubsection{Single chemical toxicity data}

Single chemical toxicity data consist of no observed adverse effects levels (NOAELs) and lowest observed adverse effects levels (LOAELs) of toxicity studies reported in the literature. NOAELs and LOAELs for wildlife endpoints were estimated from these data using the allometric methods outline in Opresko et al. (1995). This methodology for toxicity extrapolation is equivalent to that the EPA 
uses in their carcinogenicity assessments and Reportable Quantity documents for adjusting from animal data to an equivalent human dose. Using the allometric scaling factor recommended in EPA (1995), the equation for estimating mammalian NOAELs and LOAELs was:

$$
N O A E L_{w}=N O A E L_{t}\left(\frac{b w_{t}}{b w_{w}}\right)^{1 / 6}
$$

where NOAEL $_{t}$ and NOAEL ${ }_{w}$ represent NOAELs for a mammalian test species and wildlife species, respectively. Toxicity values for birds were estimated using the scaling factor derived from Mineau (1996) where:

$$
N O A E L_{w}=N O A E L_{t}\left(\frac{b w_{t}}{b w_{w}}\right)^{0}=N O A E L_{t}(1)=N O A E L_{t}
$$

To evaluate the potential risk that contaminants in water may present, water benchmarks were derived according to the methods outline in Opresko et al. (1995). NOAEL's and LOAEL's and water benchmarks were derived for all seven endpoints. Experimental information used to estimate mammalian benchmarks and NOAEL's and LOAEL's for mammalian endpoints are presented in Tables C.20 and C.21. NOAELs and LOAELs for avian endpoints are listed in Table C.22. Water benchmark values for all endpoints are listed in Table C.23.

\subsubsection{Biological surveys}

Mink Survey. Stevens (1995) investigated bioaccumulation of mercury in mink on the ORR in 1993 through 1995. The methods used in the mink survey, while indicating that mink are present on the Reservation, cannot be used to estimate abundance or density on mink on the ORR. A total of four male mink were live-trapped over the course of 6073 trapnights (trapnight=one trap set for $24 \mathrm{~h}$ ). One juvenile was captured along East Fork Poplar Creek, two adults were captured along Bear Creek, and one adult was captured along WOC. Captured mink were fitted with an intraperitoneal radio transmitter (to monitor movements and home range) and were released. Prior to release, samples of hair were collected for metals analysis. An additional eight roadkill mink (five male and three female) were collected from the ORR and surrounding areas of Roane and Anderson counties. While one roadkill sample (a male) was collected on a bridge over Bear Creek and was assumed to be a resident of Bear Creek, all others were collected off the ORR and were used as referencesResults of metals analysis are presented in Table 7.1.

Radiotelemetry data on home ranges and movements were obtained for 3 mink —one each from the East Fork Poplar Creek, Bear Creek, and WOC watersheds. Mean ( \pm standard deviation) home range for these three individuals was found to be $7.5 \pm 3 \mathrm{~km}$ of stream. The entire home range of the East Fork Poplar Creek mink was in a highly urbanized area; it included all of upper East Fork inside the Oak Ridge Y-12 Plant and all areas of East Fork upstream of the Oak Ridge Turnpike-Illinois Avenue intersection. The home range of the WOC mink included all of WOC from the headwater tributaries to the Clinch River, including the X-10 facility. This individual was observed to use dens within the X-10 facility and moved through the facility on several occasions. 
Table 7.1. Metal concentrations in hair of Mink from the Oak Ridge Reservation and from off-site reference samples*

\begin{tabular}{lcccccc}
\hline \multicolumn{1}{c}{ Site } & $\mathrm{N}$ & $\mathrm{Hg}$ & $\mathrm{Se}$ & $\mathrm{As}$ & $\mathrm{Cd}$ & $\mathrm{Pb}$ \\
\hline East Fork Poplar Creek & 1 & 104 & 0.69 & $\mathrm{ND}^{\mathrm{b}}$ & $\mathrm{ND}$ & 0.33 \\
Bear Creek & 3 & $10.97 \pm 3.42$ & $1.88 \pm .1 .41$ & $0.15 \pm 0.09$ & $0.04 \pm .0 .02$ & $0.97 \pm 1.28$ \\
White Oak Creek & 1 & 8.8 & 1 & $\mathrm{ND}$ & $\mathrm{ND}$ & 0.37 \\
Offsite & 7 & $5.15 \pm 3.43$ & $1.11 \pm 0.25$ & $0.22 \pm 0.31$ & $0.04 \pm 0.02$ & $0.7 \pm 0.31$ \\
\hline $\begin{array}{l}\text { "Mean } \pm \text { standard deviation } \mathrm{mg} / \mathrm{kg} \text { dry weight } \\
\text { bD = Not Detected }\end{array}$ & & & & & &
\end{tabular}

Belted Kingfisher Survey. A field monitoring effort (Baron and Ashwood 1996) was initiated in 1994 to evaluate population parameters and contaminant bioaccumulation by belted kingfisher on the ORR. Areas surveyed included: WOC, WOL, WOL embayment, Melton Branch, Poplar Creek, portions of East Fork Poplar Creek (within the Y-12 Plant to downstream of Lake Reality and approximately 1 mile east of the confluence of Poplar Creek), and portions of Bear Creek.

Methods. Nest burrows were monitored for nesting activity. If activity were observed, samples of feathers and eggshells were collected. In addition to specimens collected from the burrows, three carcasses of adult kingfishers were found on the ORR (two from East Fork Poplar Creek and one from WOC). These carcasses were necropsied, and organs were extracted and analyzed for metals and radionuclides. Additional detail concerning methods are reported in Baron and Ashwood (1996).

Results. During April-July of 1994, a total of 27 potential kingfisher burrows were identified on the ORR, 11 of which contained swallow nests. Twenty-five of these burrows were found on the Clinch River. One kingfisher burrow, containing a single unhatched kingfisher egg, was found on WOC (downstream of WOC $\mathrm{km} \mathrm{3.5).}$

One active burrow, containing a clutch of six to seven eggs, was found on the Clinch River. This burrow was later abandoned with no sign of the eggs or the parents. Another burrow, containing six nestlings was located on the Clinch River approximately 12 miles upstream of all DOE contaminant outfalls. It was, therefore, considered uncontaminated. Three weeks following the initial observation of this burrow, three nestlings had fledged and three had died. Feathers were collected and analyzed. Results of residue analysis for eggshells and feathers from nestlings are presented in Table C.24; results for adult carcasses are presented in Table C.25.

Nestling feathers collected from the burrow on the Clinch River, upstream of ORR outfalls (Table C.24), contained relatively low levels of metal and radioactive contaminants. Feathers from the carcasses of three fledglings accumulated similar concentrations of $\mathrm{As}, \mathrm{Cd}, \mathrm{Pb}, \mathrm{Se}$, and $\mathrm{Hg}$. Mercury concentrations in feathers were approximately $1 \mathrm{mg} / \mathrm{kg}$. Mercury concentrations found in fish downstream of the nesting site are approximately $0.04 \pm 0.01 \mathrm{mg} / \mathrm{kg}$ (Peterson et al. 1994). Thus, biomagnification is occurring in kingfishers foraging in up-gradient areas of the ORR. However, these feather concentrations are much lower than those found in adult kingfishers on the ORR. While selenium concentrations in nestling feathers appear high, they are similar to selenium levels in adult kingfishers (Table C.25) and mink and raccoons collected at reference locations (Ashwood et al. 1994). The fourth feather sample presented in Table C.24 (CRU) represents a mixture of feathers 
retrieved from the three nestlings. This sample was analyzed to provide additional information on the variability of chemical concentrations within the feathers.

A burrow on the Clinch River contained fragments of egg shells and fish vertebrae from regurgitant. Analysis of the egg shells indicated that minimal metal contamination was present (CRD, Table C.24). Another burrow on WOC contained an unhatched kingfisher egg (WOC, Table C.24). Metal concentrations in this egg were similar to that for the Clinch River egg, except for cesium- 137 . The presence of this radionuclide in the egg indicates that the parent kingfisher bioaccumulated cesium-137 from foraging within WOC or a nearby surface impoundment (cesium-137 is a typical contaminant of this stream and the impoundments).

In at least one kingfisher from the $\mathrm{ORR},{ }^{137} \mathrm{Cs}, \mathrm{Cd}, \mathrm{Pb}, \mathrm{Se}$, and $\mathrm{Hg}$ were each detected (Table C.25). Arsenic was analyzed for but was not detected. Feathers of adult kingfishers contained elevated mercury (Table C.25) relative to feathers from the nestlings (Table C.24). The greatest burdens of $\mathrm{Hg}$, $\mathrm{Se}, \mathrm{Pb}$, and $\mathrm{Cs}-137$ were observed in the bird from the WOC watershed (bird 3; Table C.25 ). In contrast, cadmium levels were higher in the birds from East Fork Poplar Creek (birds 1 and 2) than in the WOC bird (Table C.25).

\subsubsection{Characterization Chemical Risks to Wildlife}

Risk Characterization integrates the results of the exposure assessment (Sect. C.1.1) and effects assessment (Sect. C.1.2) to estimate risks (the likelihood of effects given the exposure) based on each line of evidence and then applies a weight of evidence inference logic to determine the best estimate of risk to each assessment endpoint. In an ideal risk assessment, there are three lines of evidence: literature-derived single chemical toxicity data (which indicate the toxic effects of the concentrations measured in site media); biological surveys of the affected system (these indicate the actual state of the receiving environment); and toxicity tests with ambient media (these indicate the toxic effects of the concentrations measured in site media). With the exception of the biosurvey data for mink and belted kingfisher (Sect 7.1.2.2), only one line of evidence was available to assess risk to wildlife in WAG 2- that is single chemical toxicity data.

\subsubsection{Single chemical toxicity data}

Exposure estimates generated by the exposure model (see Sect. 7.1.1) produced by both point estimates of parameter values and Monte Carlo simulation represent exposure at the individual level. The exposure estimates using point estimates of parameter values at each reach are used to identify COPECs and locations that contribute significantly to risk. In contrast, the WAG 2-wide exposure distributions generated by Monte Carlo simulation represent the likelihood that an individual within the WAG will experience a particular exposure.

Two types of single chemical toxicity data are available with which to evaluate wildlife contaminant exposure: NOAELs and LOAELs. NOAELs are used to screen exposure estimates generated from point estimates of exposure parameters; if the estimate is greater than the NOAEL, adverse effects are possible and additional evaluation is necessary. LOAELs are compared to the exposure distribution generated by the Monte Carlo simulation. If the LOAEL is lower than the 80th percentile of the exposure distribution, there is a $>20 \%$ likelihood that individuals within the modeled location are experiencing contaminant exposures that are likely to produce adverse effects. By combining measured or literature-derived population density data with the likelihood or probability of exceeding the LOAEL, the magnitude of population-level impacts may be estimated. 
Screening Point Estimates of Exposure. To determine if the contaminant exposures experienced by wildlife in each reach and throughout WAG 2 are potentially hazardous, the dietary contaminant exposure estimates (generated using point estimates of parameter values; see Tables C.1 and C.2, and C.12 through C.18) were compared to estimated NOAELs and LOAELs for these species (Tables C.21 and C.22). To quantify the magnitude of hazard, an HQ was calculated, where $\mathrm{HQ}=$ exposure/NOAEL or LOAEL. HQs greater than 1 indicate that individuals may be experiencing exposures that are in excess of NOAELs or LOAELs. While exceeding the NOAEL suggests that adverse effects are possible, exceeding the LOAEL suggests that adverse effects are likely. HQs for all endpoints are presented along with the point estimates of exposure in Tables C.1 and C.2, and C.12 through C.18

While exposure of shrews (Table C.12), mice (Table C.13), deer (Table C.14), fox (Table C.15), and turkey (Table C.17) exceeded both NOAELs and LOAELs for aluminum in all four reaches, all WAG 2 estimates for each endpoint were less than that at the background. Because exposures to aluminum were less than background and background exposure is assumed to be nonhazardous, aluminum was dropped as a contaminant of concern for wildlife.

Mercury was the dominant contaminant presenting risks to wildlife in WAG 2. Mercury exposure in WAG 2 exceeded NOAELs, LOAELs, and background for all endpoints within all reaches (except for deer, where LOAELs were exceeded only within the IHP area, and turkey, where LOAELs were not exceeded in the LMB area). The next most important contaminants presenting risks were PCBs and selenium, which presented risks to shrews (Table C.12), mice (Table C.13), and fox (Table C.15). In general, few other contaminants presented significant risks. With the exception of short-tailed shrews, only one to at most four contaminants were identified as presenting risks to any endpoint. In the case of shrews, seven contaminants contributed significant risks (Table C.12).

The spatial distribution of contamination and potential risks to wildlife in WAG 2 are illustrated in Figs. 7.1 through 7.9. These figures display the sum of the LOAEL-based HQs (e.g., sum of toxic units or $\Sigma T U$ s) for those contaminants where at least one LOAEL-based HQ $>1$ was obtained. For all endpoint species, the greatest risks were identified in the mainstem of WOC. The highest $\Sigma T U s$ are in the IHP area. $\Sigma T$ TS decline with increasing distance downstream (IHP>MWC $>$ LWC). Risks in the $\mathrm{LMB}$ were consistently lower than that in all three WOC reaches. The spatial patterns of contaminant risk were comparable for all endpoint species.

Screening Monte Carlo Simulation Estimates of Exposure. To incorporate the variation present in the parameters employed in the exposure model, Monte Carlo simulations were performed for the exposure estimates of each species to analytes where at least one LOAEL-based HQ $>1$ was observed. For all endpoints, simulations were performed only at the WAG 2-wide level. The mean, standard deviation, and 80th percentile of the simulated exposures are presented in Table C.19.

By superimposing NOAEL and LOAEL values on the exposure distributions generated from the Monte Carlo simulation, the likelihood of an individual experiencing potentially hazardous exposures can be estimated, and the magnitude of risk may be determined. Interpretation of the comparison of exposure distributions to NOAELs and LOAELs is described in Table 7.2. 

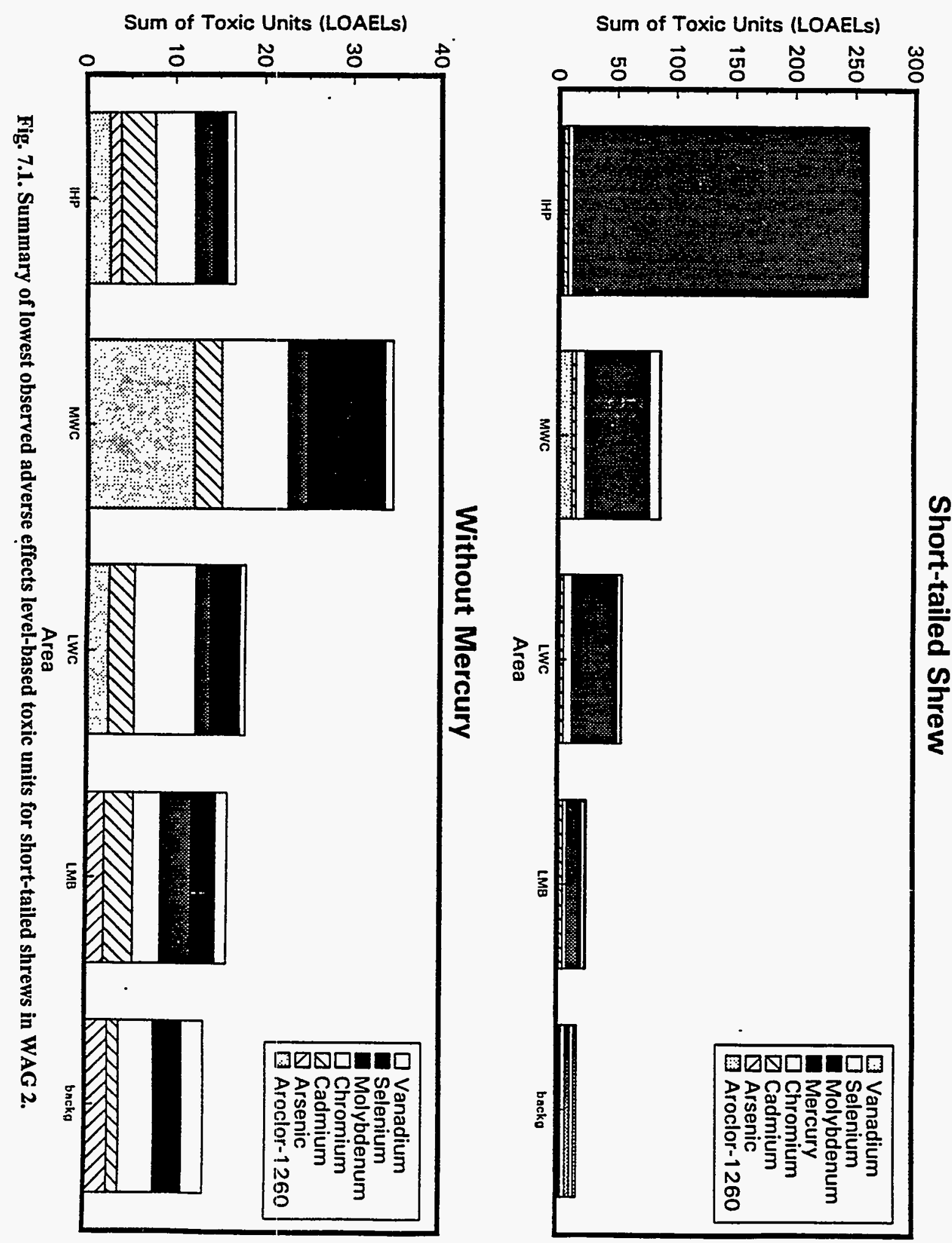


\section{White-footed Mouse}

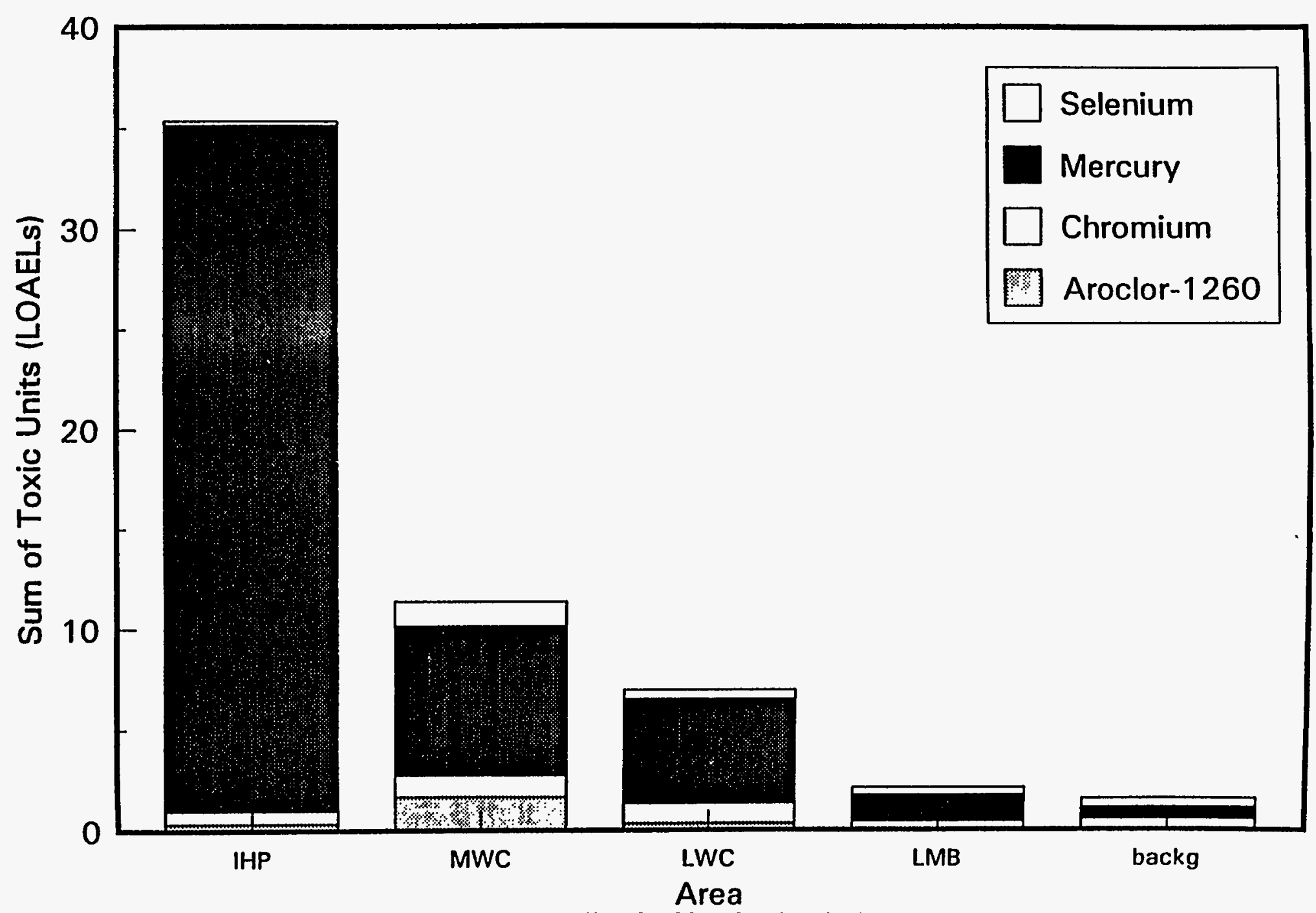




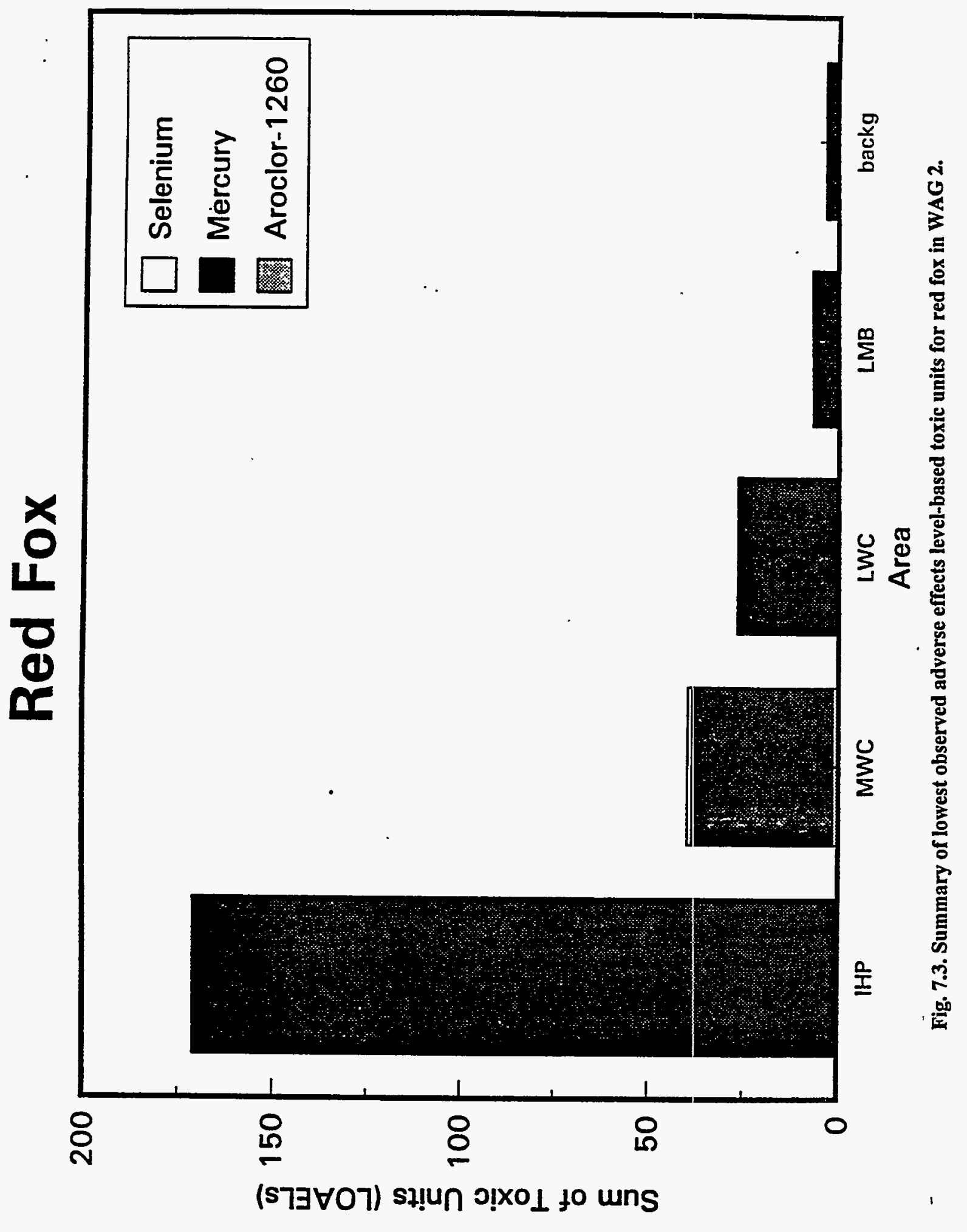




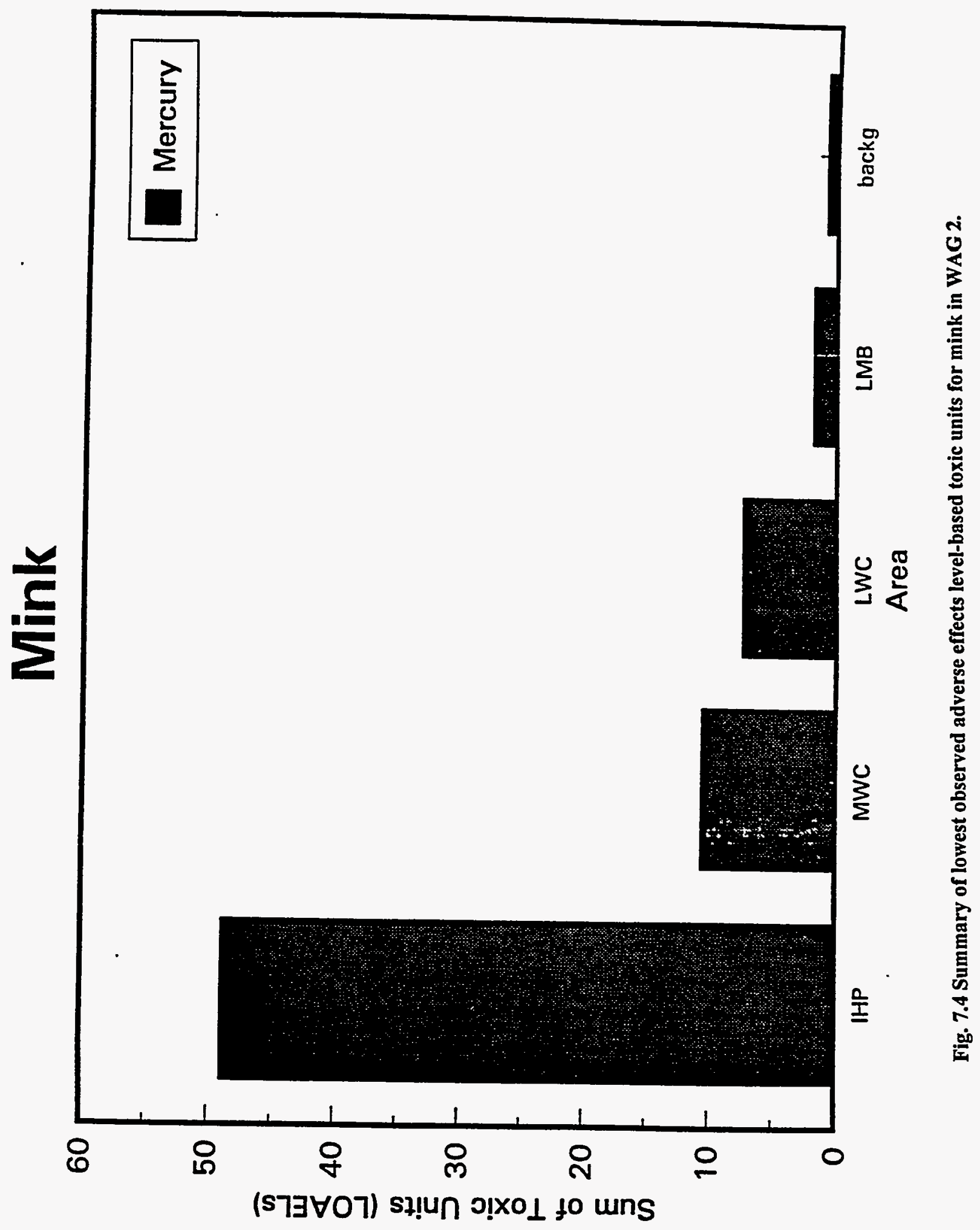




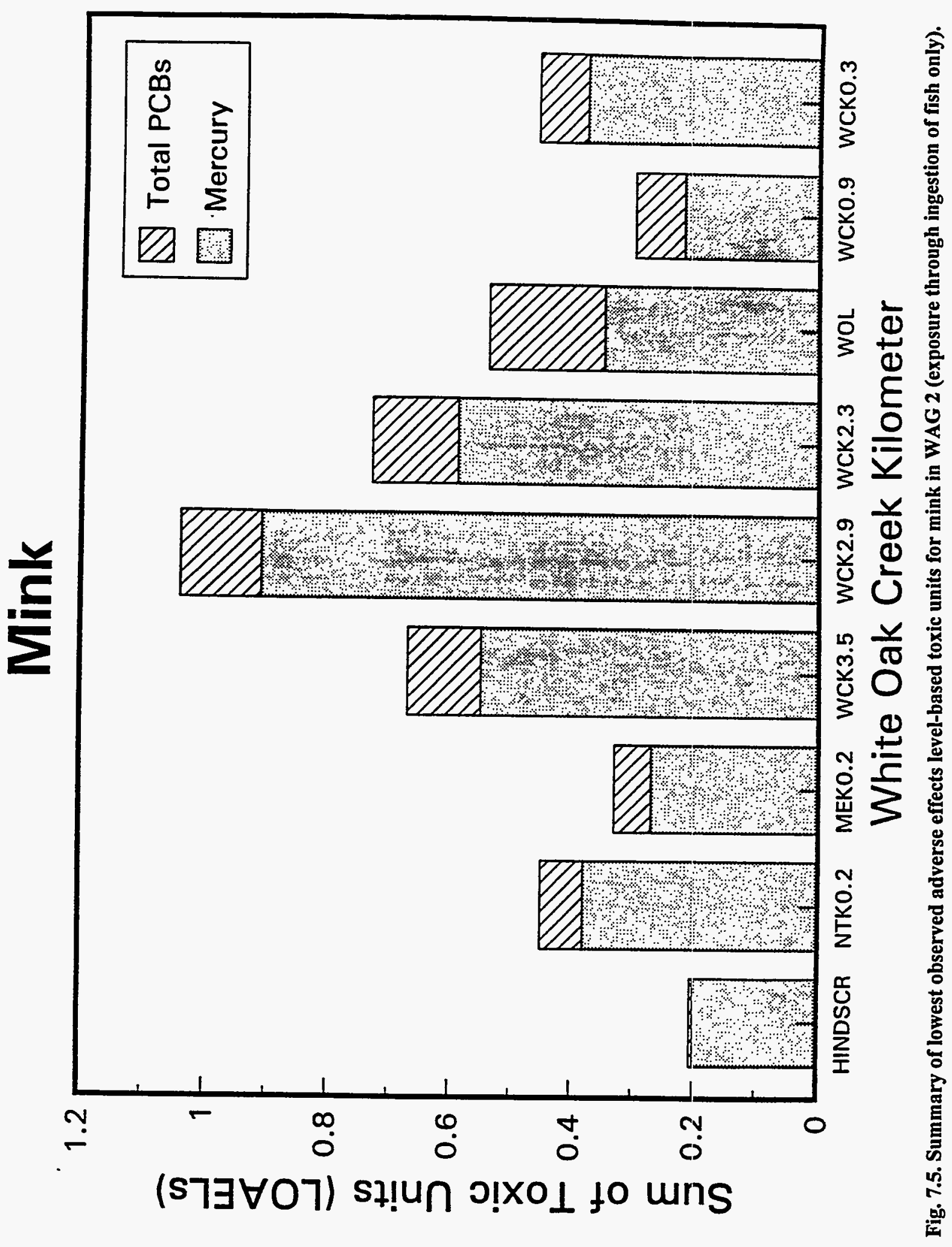




\section{White-tailed Deer}

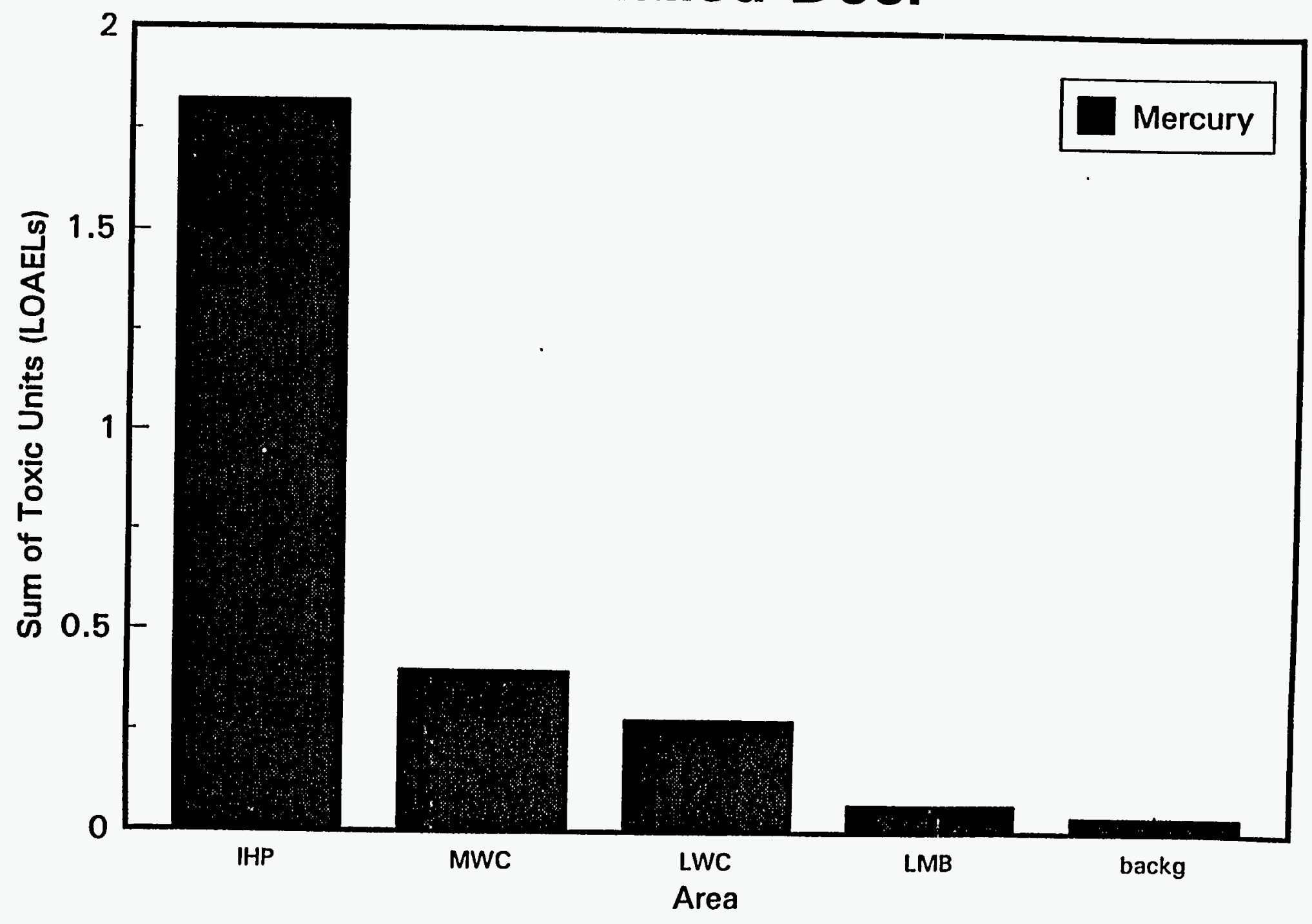

Fig. 7.6. Summary of lowest observed adverse effects level-based toxic units for white-tailed deer in WAG 2. 


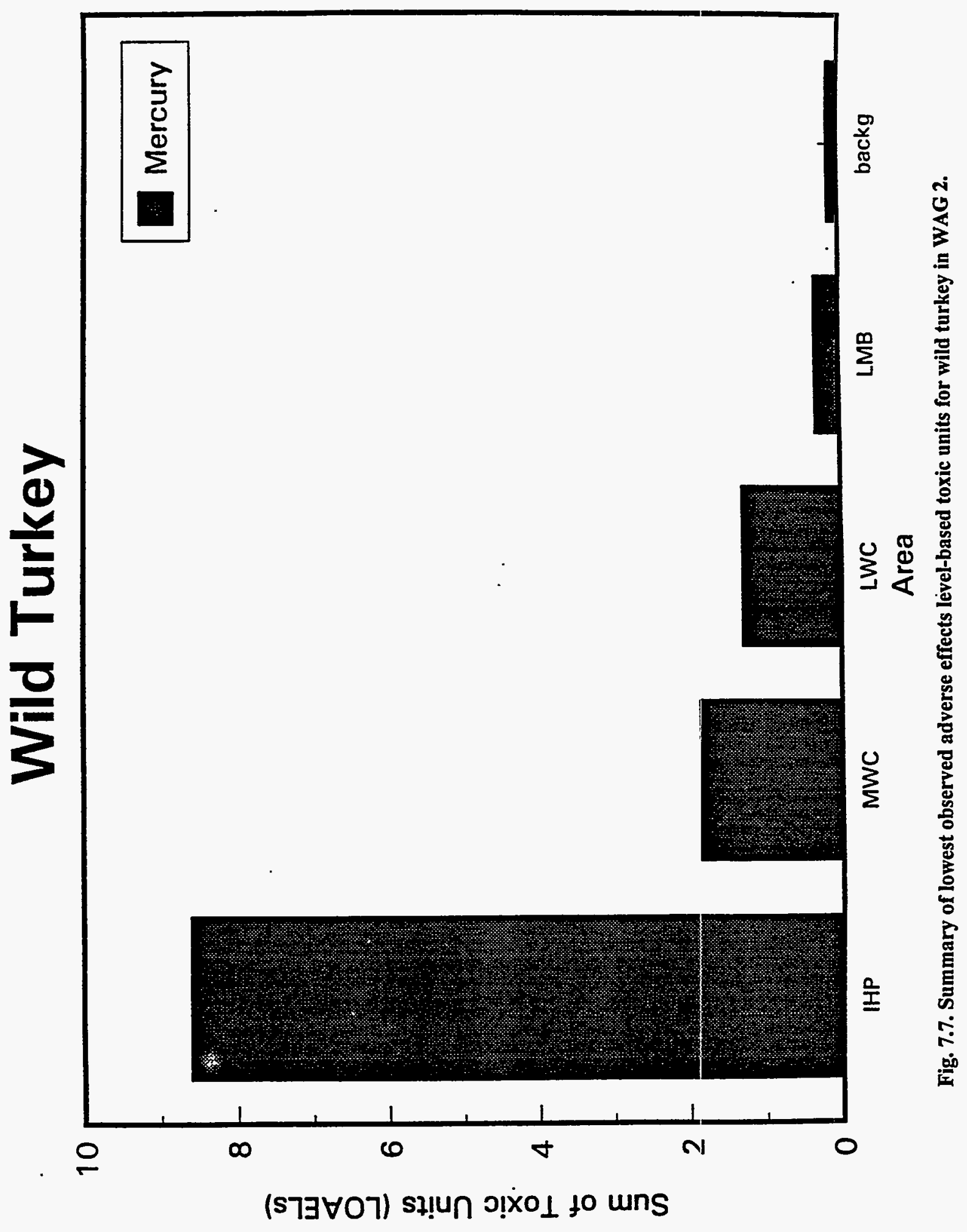




\section{Red-Tailed Hawk}

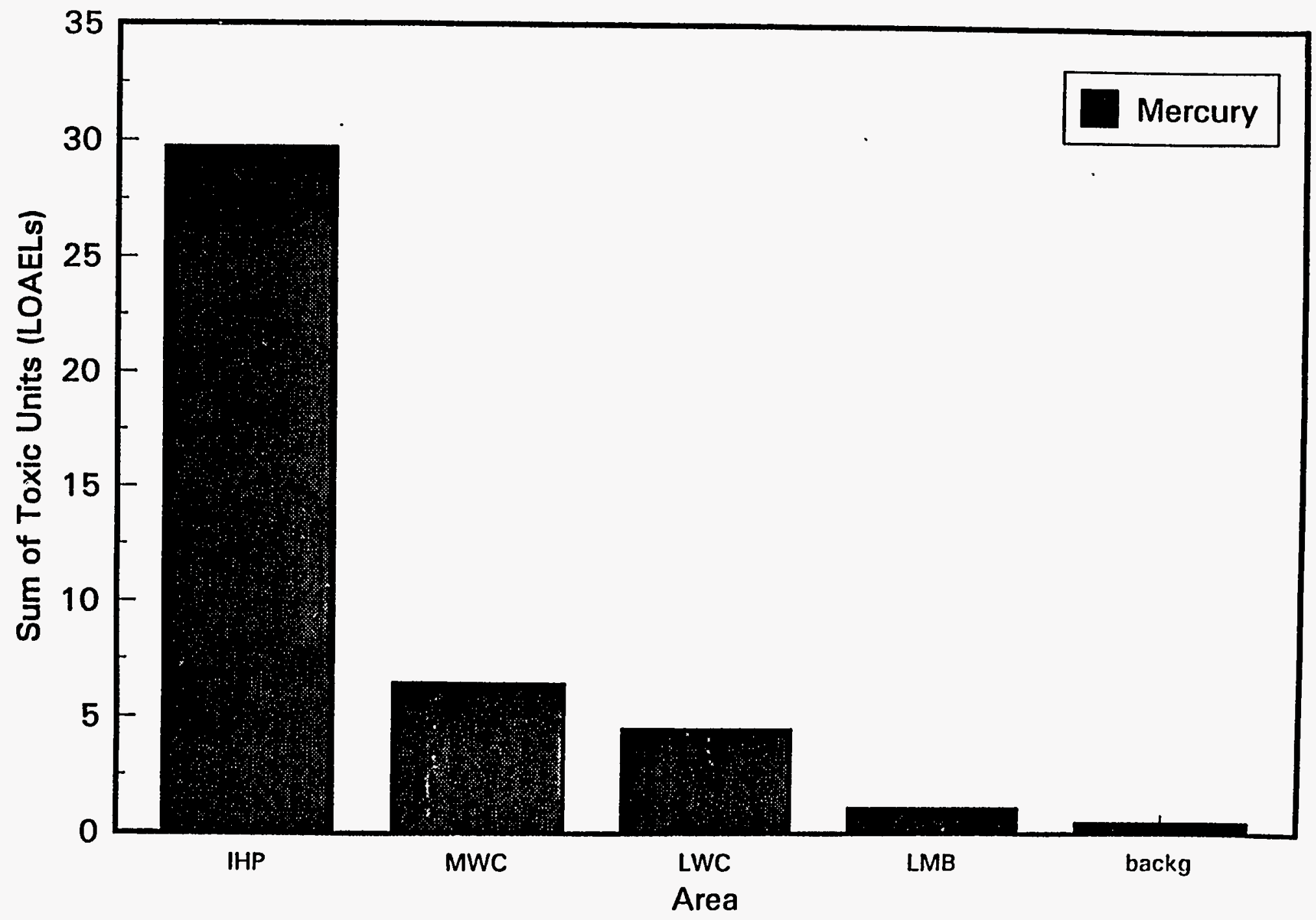

Fig. 7.8. Summary of lowest observed adverse effects level-based toxic units for red-tailed hawks in WAG 2. 


\section{Belted Kingfisher}

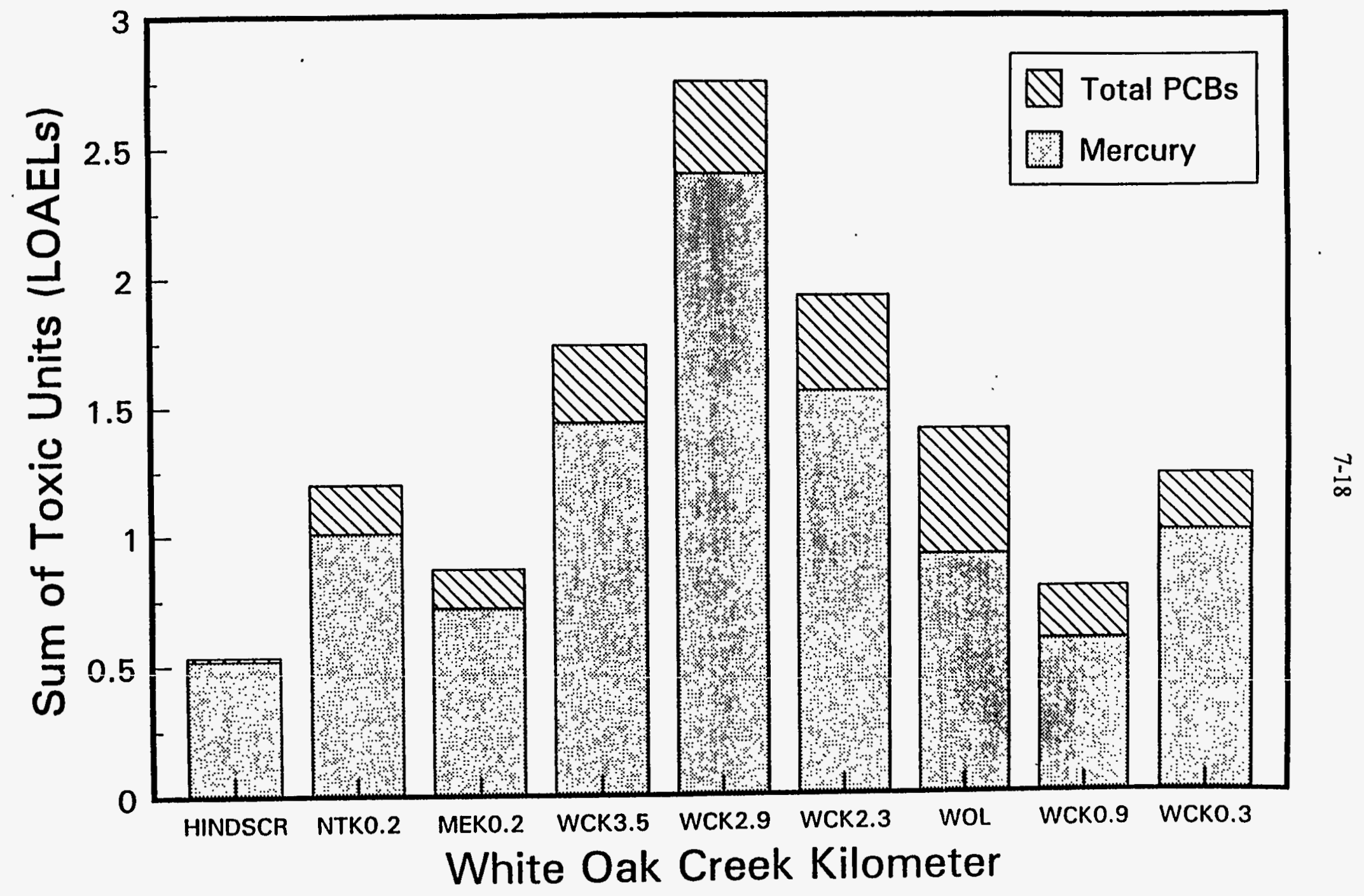

Fig. 7.9. Summary of lowest observed adverse effects level-based toxic units for belted kingfisher in WAG 2 (exposure through ingestion of fish only). 
Table 7.2. Comparison of exposure distributions

\begin{tabular}{lll}
\multicolumn{1}{c}{ Comparison } & \multicolumn{1}{c}{ Meaning } & \multicolumn{1}{c}{ Risk-based Interpretation } \\
\hline $\begin{array}{l}\text { NOAEL>80th percentile of } \\
\text { exposure distribution }\end{array}$ & $\begin{array}{l}\text { less than } 20 \% \text { of exposures }> \\
\text { NOAEL }\end{array}$ & $\begin{array}{l}\text { Individual- and population-level adverse } \\
\text { effects are highly unlikely }\end{array}$ \\
$\begin{array}{l}\text { NOAEL<80th } \\
\text { percentile<LOAEL }\end{array}$ & $\begin{array}{l}\text { More than } 20 \% \text { of exposures } \\
\text { > NOAEL, but less than } \\
20 \% \text { of exposures }>\text { LOAEL }\end{array}$ & $\begin{array}{l}\text { Individuals experiencing exposures at the } \\
\text { high end of the distribution may experience } \\
\text { adverse effects, but those effects are } \\
\text { unlikely to significantly contribute to }\end{array}$ \\
& & $\begin{array}{l}\text { effects on the Oak Ridge Reservation } \\
\text { (ORR) population. }\end{array}$ \\
& More than 20\% of & $\begin{array}{l}\text { Effects on some individuals are likely and } \\
\text { they may contribute significantly to effects } \\
\text { on the ORR population. }\end{array}$ \\
\hline
\end{tabular}

Note: NOAEL=no observed adverse effects level; LOAEL=lowest observed adverse effects level

To evaluate the likelihood and magnitude of population-level effects on wildlife, literaturederived population density data (expressed as number of individuals/ ha or $\mathrm{km}$ of stream) were combined with hectares of suitable habitat (within WAG 2) to estimate the number of individuals of each endpoint species expected to be present in the watershed. For the terrestrial species (shrew, mice, deer, fox, turkey and hawk), habitat preferences follow those reported in the Preliminary Reservationwide Ecological Risk Assessment (Sample et al. 1995). These habitat preferences were compared to the habitat types identified in WAG 2 in Washington-Allen et al. (1995). Because streams are the preferred habitats for mink and kingfisher, the length of White Oak Creek and its tributaries was assumed to represent suitable habitat. The estimated abundance of wildlife endpoint species is reported in Table C.26.

The number of individuals within WAG 2 likely to experience exposures >LOAELs can be estimated using cumulative binomial probability functions (Dowdy and Wearden 1983). Binomial probability functions are estimated using the following equation:

$$
b(y ; n ; p)=\left(\begin{array}{l}
n \\
y
\end{array}\right) p^{y}(1-p)^{n-y}
$$

where

$y=$ the number (or percent) of individuals experiencing exposures $>$ LOAEL,

$\mathrm{n}=$ total number (or percent) of individuals within the watershed,

$\mathrm{p}$ = probability of experiencing an exposure in excess of the LOAEL,

$b(y ; n ; p)=$ probability of $y$ individuals out of a total of $n$, experiencing an

exposure $>$ LOAEL, given the probability of exceeding the LOAEL $=p$.

Solving Eq. 8 for $\mathrm{y}=0$ to $\mathrm{y}=\mathrm{n}$ generates a cumulative binomial probability distribution, which can be used to estimate the number of individuals within WAG 2 who are likely to experience adverse effects.

Binomial probability distributions were generated only for contaminant-endpoint combinations where the percent of the exposure distribution exceeding the LOAEL was $20 \%$ to $80 \%$ (these values 
are reported in Table C.19). If the percent of the exposure distribution exceeding the LOAEL was $<20 \%$, it was assumed that no individuals within the area of interest were experiencing adverse effects. Conversely, if the percent of the exposure distribution exceeding the LOAEL was $>80 \%$, it was assumed that all individuals within the area of interest were experiencing adverse effects. Exposure estimates for six contaminant-endpoint combinations met the $20 \%$ to $80 \%$ exceedance criterion: PCB, cadmium, and selenium exposure to shrews and mercury exposure to fox, kingfisher, and turkey. Figures 7.10 through 7.15 graphically display the cumulative binomial probability distributions for each contaminant-endpoint combination. The total numbers of individuals for each endpoint species estimated to be experiencing adverse effects within WAG 2 are summarized in Table C.27.

Based on the Monte Carlo analysis, comparison to background exposure estimates, and binomial distribution analysis, the following conclusions may be made:

- Because $<20 \%$ of the WAG 2 populations are estimated to be experiencing exposures $>$ LOAEL, the following contaminants do not present significant risks:

\begin{tabular}{ll}
\hline Endpoint & \multicolumn{1}{c}{ Analytes } \\
\hline Short-tailed shrew & $\mathrm{As}, \mathrm{Ba}, \mathrm{Cu}, \mathrm{Mn}, \mathrm{Mo}, \mathrm{Ni}, \mathrm{V}$, and $\mathrm{Zn}$ \\
White-footed mouse & Aroclor-1260, Cr, and Se \\
Red fox & Aroclor-1260 and Se \\
Mink & $\mathrm{Hg}$ (exposure through fish consumption only) \\
White-tailed deer & $\mathrm{Hg}$ \\
\hline
\end{tabular}

- Because $>\mathbf{2 0 \%}$ of the WAG 2 shrew population is estimated to be experiencing exposures $>$ LOAEL, Aroclor-1260, cadmium, chromium, mercury, and selenium present a significant risk to shrews in WAG 2;

- Because $>20 \%$ of the populations are estimated to be experiencing exposures $>$ LOAEL, mercury presents a significant risk to white-footed mice, red fox, mink, belted kingfisher, red-tailed hawk, and wild turkey in WAG 2.

Screening Point Estimates of Exposure: Surface Water. To evaluate the potential risk that contaminants in surface water present to wildlife in reaches and seeps vhere total exposure was not estimated (due to lack of surface soil data), the $95 \%$ UCLs for concentrations in unfiltered water were compared to NOAEL and LOAEL water benchmarks for all species. HQs (water concentration/benchmark value) were calculated for all species. Comparisons of reach concentrations to NOAEL benchmarks are presented in Table C.28. NOAEL-based screening benchmarks were not exceeded within any reach, indicating that exposure to surface water within these WOC watershed reaches does not contribute to risk. These screening results indicated that exposure to seep water within the WOC watershed does not contribute to risk.

Comparisons of seep concentrations to NOAEL and LOAEL benchmarks are presented in Tables C.29 and C.30. Only one contaminant (aluminum) at one seep (RS-3A) exceeded NOAEL benchmarks (Table C.29); the LOAEL benchmarks, however were not exceeded (Table C.30). At all other seeps for all other analytes, NOAEL-based benchmarks were not exceeded. 


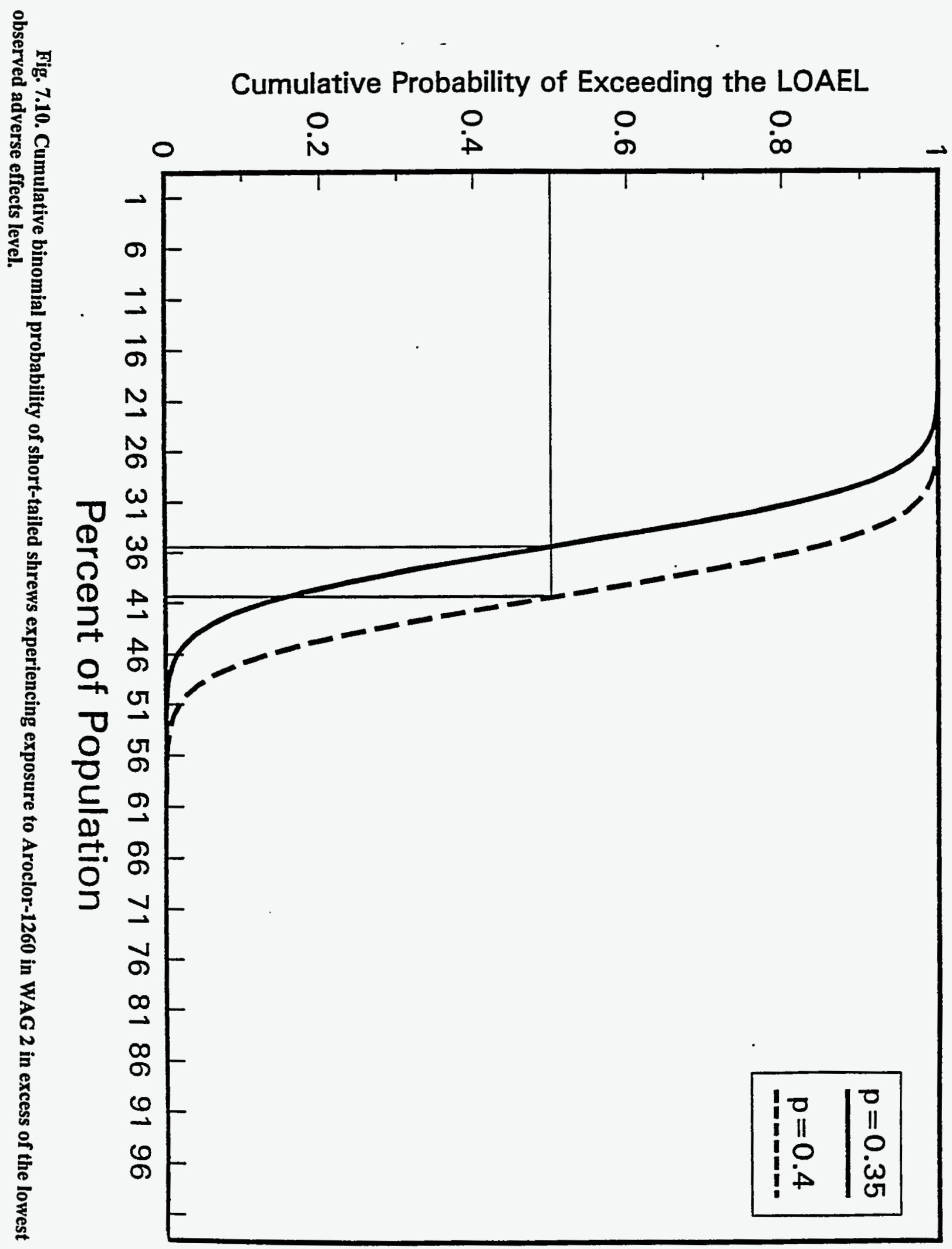




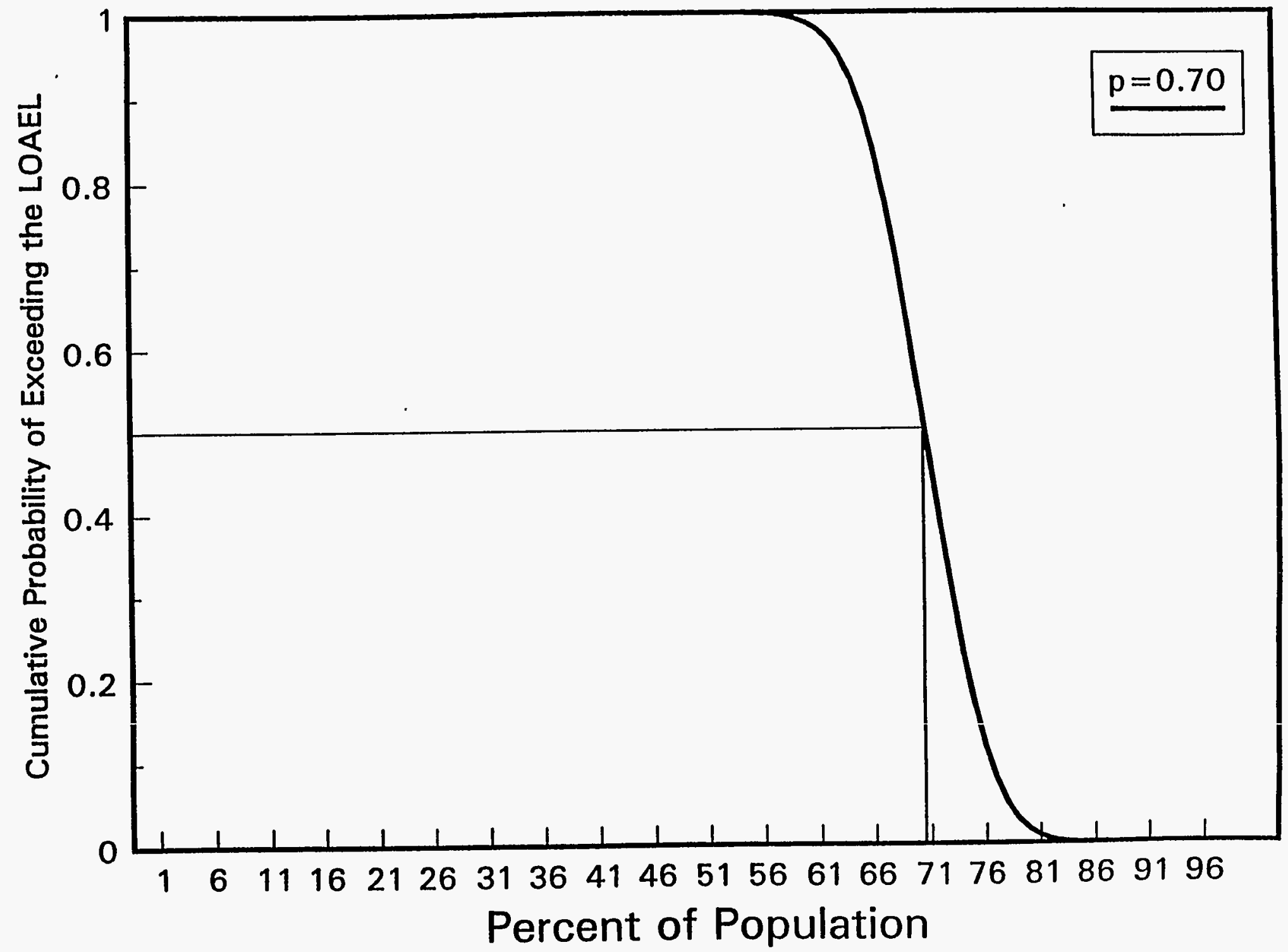

Fig. 7.11. Cumulative binomial probability of short-tailed shrews experiencing exposure to cadmium in WAG 2 in excess of the lowest observed adverse. effects level. 


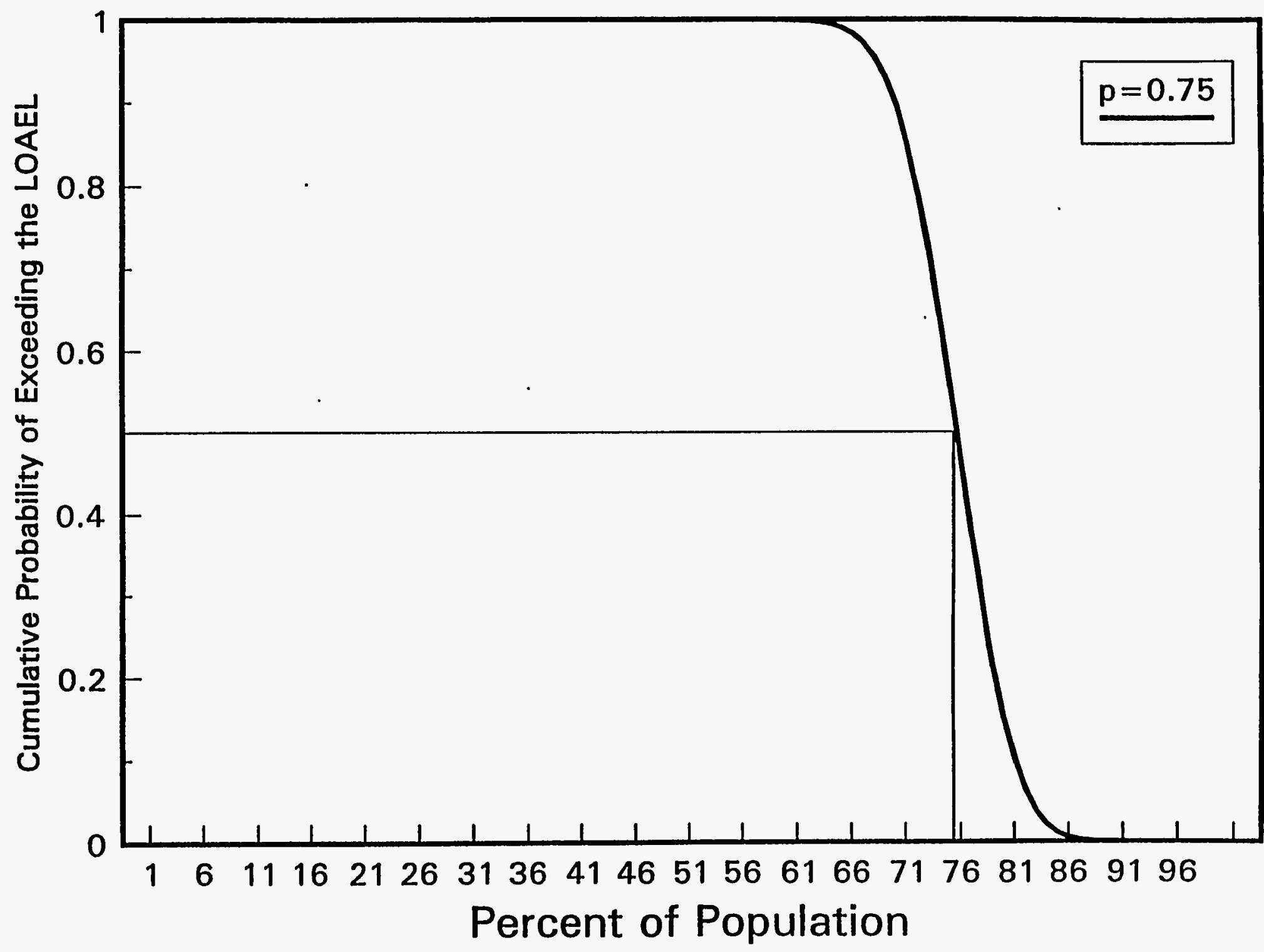

Fig. 7.12. Cumulative binomial probability of short-tailed shrews experiencing exposure to selenium in WAG 2 in excess of the lowest observed adverse effects level. 


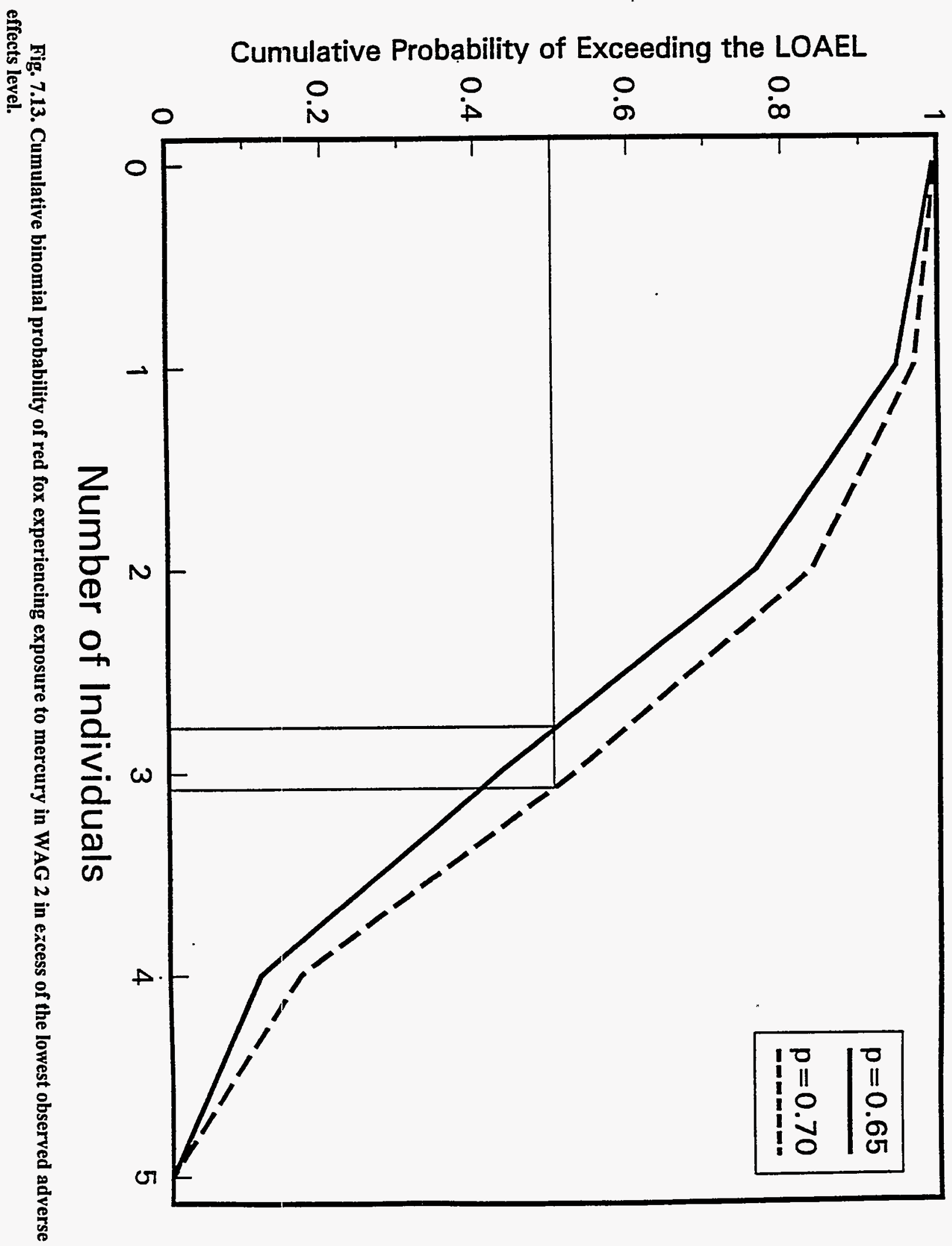

$t z-L$ 


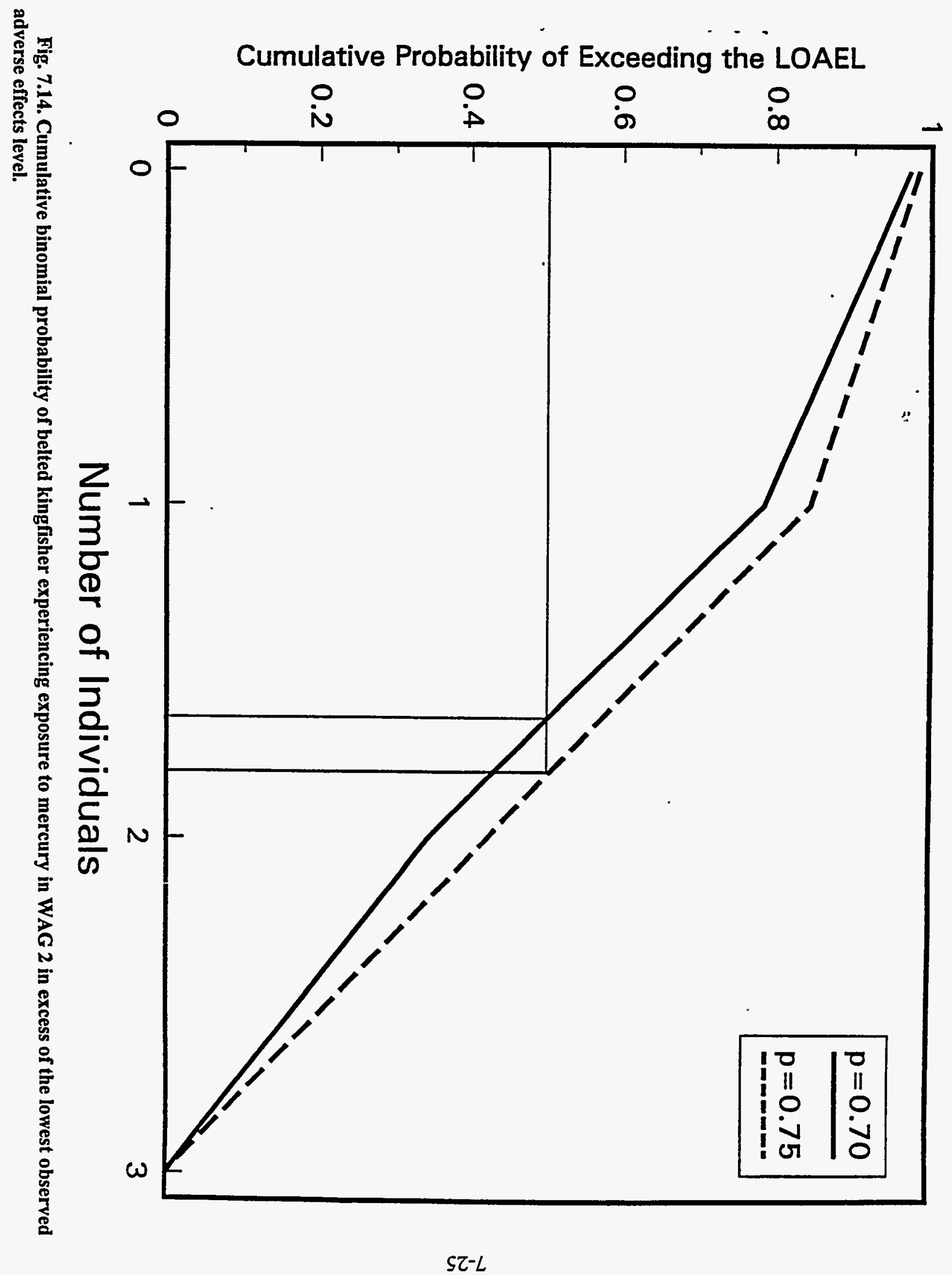




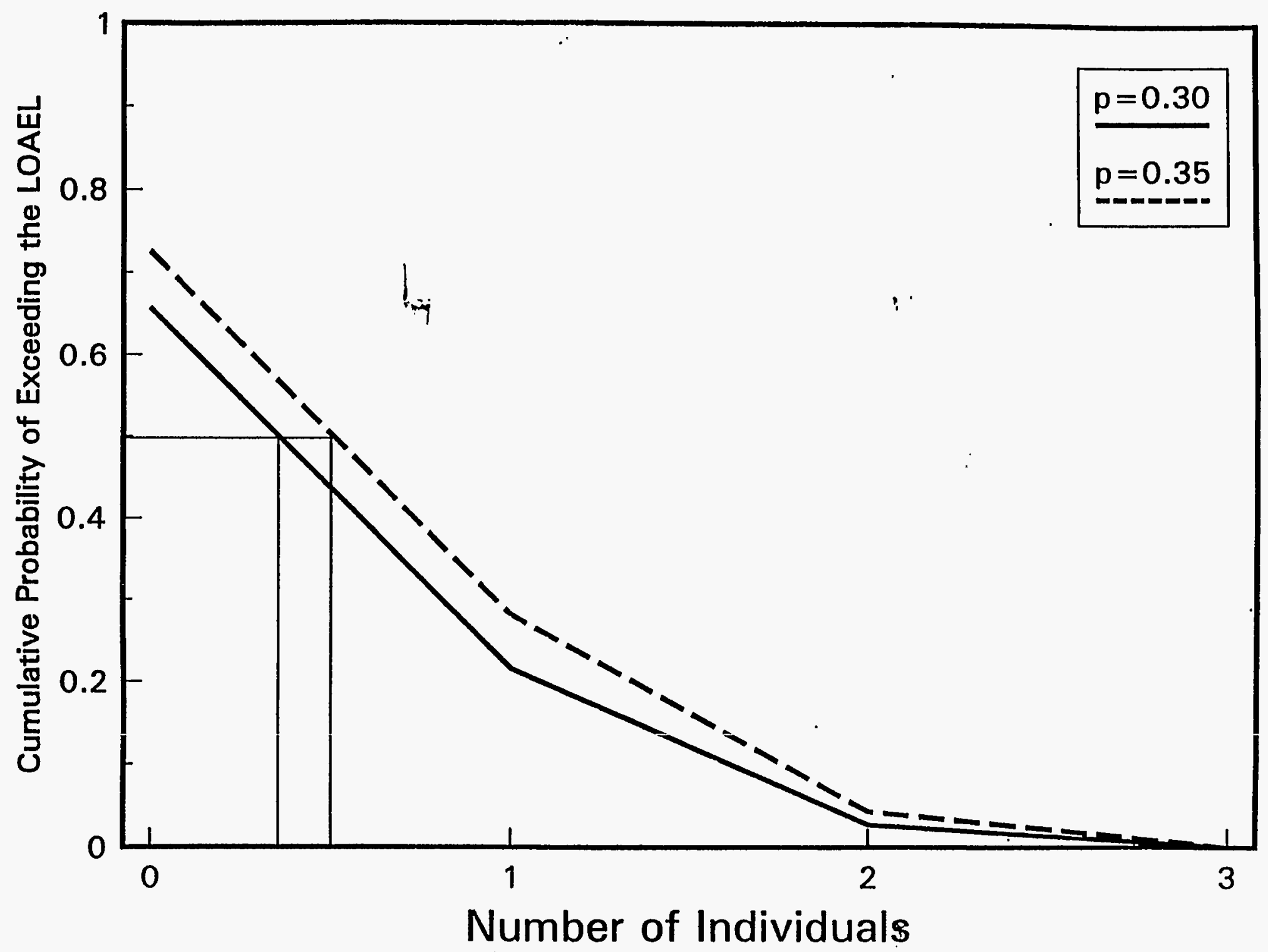

Fig. 7.15. Cumulative binomial probability of wild turkey experiencing exposure to mercury in WAG 2 in excess of the lowest observed adverse effects level. 


\subsubsection{Effects of retained contaminants}

Cadmium. The mammalian NOAELs and LOAELs for cadmium were derived from a study of mice fed cadmium for multiple generations. (Schroeder and Mitchner 1971). Consumption of 2.518 $\mathrm{mg} / \mathrm{kg}-\mathrm{d}$ cadmium impaired reproduction and caused the exposed line to die out before the third generation. Only one dose level was tested. The study was considered to represent a chronic exposure; therefore, a subchronic-chronic correction factor was not employed. A NOAEL was estimated using a LOAEL-LOAEL correction factor of 0.1 . The $0.25 \mathrm{mg} / \mathrm{kg}$-d exposure was considered to be a chronic NOAEL; the $2.5 \mathrm{mg} / \mathrm{kg}$-d exposure was considered to be a chronic LOAEL. Based on the results of Schroeder and Mitchner (1971), shrews experiencing exposure 2 LOAEL are likely to display impaired reproduction.

Chromium. The mammalian NOAEL for chromium was based on a study of rats fed $\mathrm{Cr}^{\text {t6 }}$ in water for one year (Mackenzie et al. 1958). No adverse effects were observed at the highest dose of 3.28 $\mathrm{mg} / \mathrm{kg}$-d. The study was considered to represent a chronic exposure; therefore, a subchronic-chronic correction factor was not employed. The $3.28 \mathrm{mg} / \mathrm{kg}$-d exposure was considered to be a chronic NOAEL. The mammalian LOAEL for chromium was based on a study of rats fed $\mathrm{Cr}^{+6}$ in water for 3 months (Steven et al. 1976). Mortality significantly increased among rats consuming $131.4 \mathrm{mg} / \mathrm{kg}-\mathrm{d}$. The study was considered to represent a subchronic exposure, therefore a subchronic-chronic correction factor was employed. The $13.14 \mathrm{mg} / \mathrm{kg}$-d exposure was considered to be a chronic LOAEL. Based on the results of Steven et al. (1976), shrews experiencing exposure $\geq$ LOAEL are likely to display increased mortality.

Mercury. For the purposes of this assessment, it is assumed that $100 \%$ of the mercury to which wildlife is exposed consists of methyl mercury.

Both the avian NOAEL and LOAEL are based upon a study of mallard ducks fed methyl mercury for three generations (Heinz 1979). The study was considered to represent a chronic exposure, and a subchronic-chronic correction factor was not employed. The only dose level administered, 0.064 $\mathrm{mg} / \mathrm{kg}-\mathrm{d}$, caused hens to lay fewer eggs, lay more eggs outside of the nest box, and produce fewer ducklings. This dose level was considered to be an LOAEL. Because an experimental NOAEL was not established, the NOAEL was estimated using an LOAEL-NOAEL correction factor of 0.1 . Based on the results of Heinz (1979), kingfisher, red-tailed hawks, and turkey experiencing exposure $z$ LOAEL are likely to display impaired reproduction.

The fox and mink NOAELs and LOAELs for mercury were derived from a study of mink fed methyl mercury for $93 \mathrm{~d}$ (Wobeser et al. 1976). While consumption of $0.247 \mathrm{mg} / \mathrm{kg}$-d methyl mercury resulted in significant mortality, weight loss, and behavioral impairment, no effects were observed at the $0.15 \mathrm{mg} / \mathrm{kg}$-d exposure level. The $0.15 \mathrm{mg} / \mathrm{kg}$-d exposure was considered to be an NOAEL and the $0.247 \mathrm{mg} / \mathrm{kg}$-d exposure was considered to be an LOAEL. Because the study was subchronic in duration $(<1 \mathrm{yr}$ ), a subchronic-chronic correction factor was applied (NOAEL $=0.015$, LOAEL $=0.025$ ). Based on the results of Wobeser et al. (1976), shrews, mice, fox, and mink experiencing exposure $z$ LOAEL are likely to display increased mortality, weight loss, and behavioral impairment.

PCBs. The mammalian NOAEL and LOAEL for PCBs were derived from a study of mink fed Aroclor 1254 for $4.5 \mathrm{mo}$. (Aulerich and Ringer 1977). While consumption of $0.69 \mathrm{mg} / \mathrm{kg}$-d of Aroclor 1254 reduced kit survivorship, no effects were observed at the $0.14 \mathrm{mg} / \mathrm{kg}-\mathrm{d}$ exposure level. The 0.14 $\mathrm{mg} / \mathrm{kg}$-d exposure was considered to be a chronic NOAEL; the $0.69 \mathrm{mg} / \mathrm{kg}$-d exposure was considered to be a chronic LOAEL. Based on the results of Aulerich and Ringer (1977), shrews experiencing exposure $\geq$ LOAEL are likely to display reduced survivorship of young. 
Selenium. The mammalian NOAELs and LOAELs for selenium were derived from a study of mice fed selenium for three generations. (Schroeder and Mitchner 1971). Consumption of $0.76 \mathrm{mg} / \mathrm{kg}-\mathrm{d}$ selenium resulted in reduced reproductive success, and increased incidence of runts and failure to breed. Only one dose level was tested. The study was considered to represent a chronic exposure; therefore, a subchronic-chronic correction factor was not employed. An NOAEL was estimated using an LOAEL-LOAEL correction factor of 0.1 . The $0.076 \mathrm{mg} / \mathrm{kg}$-d exposure was considered to be a chronic NOAEL; the $0.76 \mathrm{mg} / \mathrm{kg}$-d exposure was considered to be a chronic LOAEL. Based on the results of Schroeder and Mitchner (1971), shrews experiencing exposure $z$ LOAEL are likely to display impaired reproduction.

\subsubsection{Biological surveys}

Mink Survey. Results of the mink survey (see Sect. 7.1.2.2.1) indicate that mink are present on the ORR and within WAG 2, have large home ranges, and do not avoid the industrial facilities on the ORR. The methods employed in the study do not allow numbers or density of mink to be determined. Concentrations of metals in hair of the single mink collected from WAG 2 were comparable to that from mink collected offsite.

Kingfisher Survey. Results of the kingfisher survey (see Sect. 7.1.2.2.2) indicate that contaminants are being accumulated by both juveniles and adult birds. While contaminants in eggshells and nestling feathers indicate exposure, there is insufficient information to evaluate the toxicological significance of this contamination.

The toxicological significance of the tissue concentrations in adult kingfisher was evaluated by comparison of burdens and effects levels reported in other bird species. This comparison suggests that it is unlikely that cadmium or lead in the kingfisher from WOC contribute significantly to risk. Leach et al. (1979) observed a 50\% reduction in egg production among chickens consuming a diet containing $48 \mathrm{mg} / \mathrm{kg}$ cadmium. Cadmium concentrations in the livers and kidneys of these birds were $100 \mathrm{mg} / \mathrm{kg}$ and $40 \mathrm{mg} / \mathrm{kg}$. Cadmium concentrations in healthy birds from unpolluted areas ranged from 0.1 to 32 $\mathrm{mg} / \mathrm{kg}$ in liver and 0.3 to $137 \mathrm{mg} / \mathrm{kg}$ in kidney (Furness 1996). In comparison, cadmium concentrations in the kidney $(1.53 \mathrm{mg} / \mathrm{kg})$ and liver $(0.9 \mathrm{mg} / \mathrm{kg})$ of the kingfisher collected from the WOC watershed were significantly less than concentrations associated with reproductive impairment and at the low end of the ranges observed among healthy birds from unpolluted areas. Lead concentrations in the kidney $(0.42 \mathrm{mg} / \mathrm{kg})$ and liver $(0.4 \mathrm{mg} / \mathrm{kg})$ of the WOC kingfisher were approximately one order of magnitude lower than the minimal level at which overt toxicity is observed in birds (3 to $6 \mathrm{mg} / \mathrm{kg}$ )(Frenson 1996), suggesting that lead accumulation is unlikely to be contributing to risks to kingfishers.

In contrast to cadmium and lead, selenium and mercury burdens may present a hazard to WOC kingfishers. The concentration of selenium in the liver of Bird 3 (from WOC; $7.5 \mathrm{mg} / \mathrm{kg}$ ) is less than the $10 \mathrm{mg} / \mathrm{kg}$ toxicity threshold recommend by Heinz (1996), but greater than the $3 \mathrm{mg} / \mathrm{kg}$ reproductive impairment threshold, suggesting the potential for reproductive impairment. Mercury concentrations of 49 to $125 \mathrm{mg} / \mathrm{kg}$ in kidney and 4.6 to $91 \mathrm{mg} / \mathrm{kg}$ in liver have been reported for freeliving birds found dead or dying (Thompson 1996). Nephrotoxicity and kidney lesions occur in birds at mercury concentrations in kidney of 5 to $13 \mathrm{mg} / \mathrm{kg}$ (Nicholson and Osborn 1983). While mercury concentrations in the kidney $(26.8 \mathrm{mg} / \mathrm{kg})$ and liver $(17.6 \mathrm{mg} / \mathrm{kg})$ of the WOC kingfisher were generally lower than concentrations associated with mortality, the kidney concentration exceeds nephrotoxic levels, suggesting that mercury accumulation may be causing kidney damage to White Oak Creek kingfishers. 


\subsubsection{Weight of evidence}

Short-tailed Shrews. One line of evidence, literature toxicity data, was available to evaluate potential risk to short-tailed shrews in WAG 2. Point estimates of exposure indicated that 18 contaminants exceeded NOAELs with 16 also exceeding LOAELs (Table C.12). Monte Carlo simulation of exposure and comparison of these estimates to NOAELs and LOAELs (Table C.19) and calculation of binomial probability distributions (Table C.27) suggest that Aroclor-1260, cadmium, chromium, mercury, and selenium present significant risks to the shrew population in WAG 2.

White-footed Mice. One line of evidence, literature toxicity data, was available to evaluate potential risk to white-footed mice in WAG 2. Point estimates of exposure indicated that ten contaminants exceeded NOAELs with five also exceeding LOAELs (Table C.13). Monte Carlo simulation of exposure and comparison of these estimates to NOAELs and LOAELs (Table C.19) and calculation of binomial probability distributions (Table C.27) suggest that only mercury presents a significant risk to the mouse population in WAG 2.

White-tailed Deer. One line of evidence, literature toxicity data, was available to evaluate potential risk to white-tailed deer in WAG 2. Point estimates of exposure indicated that seven contaminants exceeded NOAELs with two also exceeding LOAELs (Table C.14). Monte Carlo simulation of exposure and comparison of these estimates to NOAELs and LOAELs (Table C.19) and calculation of binomial probability distributions (Table C.27) suggest that no contaminant presents a significant risk to the deer population in WAG 2.

Red Fox. One line of evidence, literature toxicity data, was available to evaluate potential risk to red fox in WAG 2. Point estimates of exposure indicated that 12 contaminants exceeded NOAELs with 3 also exceeding LOAELs (Table C.15). Monte Carlo simulation of exposure and comparison of these estimates to NOAELs and LOAELs (Table C.19) and calculation of binomial probability distributions (Table C.27) suggest that only mercury presents a significant risk to the fox population in WAG 2.

Red-tailed Hawk. One line of evidence, literature toxicity data, was available to evaluate potential risk to red-tailed hawk in WAG 2. Point estimates of exposure indicated that three contaminants exceeded NOAELs with one also exceeding LOAELs (Table C.16). Monte Carlo simulation of exposure and comparison of these estimates to NOAELs and LOAELs (Table C.19) and calculation of binomial probability distributions (Table C.27) suggest that only mercury presents a significant risk to the hawk population in WAG 2.

Wild Turkey. One line of evidence, literature toxicity data, was available to evaluate potential risk to wild turkey in WAG 2. Point estimates of exposure indicated that three contaminants exceeded NOAELs with two also exceeding LOAELs (Table C.17). Monte Carlo simulation of exposure and comparison of these estimates to NOAELs and LOAELs (Table C.19) and calculation of binomial probability distributions (Table C.27) suggest that only mercury presents a significant risk to the turkey population in WAG 2.

Mink. Two lines of evidence, biological survey data and literature toxicity data, were available to evaluate potential risks to mink within WAG 2 . The biological survey data indicate that mink are present within WAG 2; but due to the sampling methods employed, estimates of the abundance of the mink population cannot be made from these data. Residue analysis indicates that mink in WAG 2 have contaminant concentrations in hair similar to that in mink from offsite. 
Point estimates of exposure indicated that four contaminants exceeded NOAELs with two also exceeding LOAELs (Tables C.1 and C.18). Monte Carlo simulation of exposure and comparison of these estimates to NOAELs and LOAELs (Table C.19) and calculation of binomial probability distributions (Table C.27) suggest that only mercury presents a significant risk to the mink population in WAG 2.

Belted Kingfisher. Two lines of evidence, biological survey data and literature toxicity data, were available to evaluate potential risks to belted kingfisher within WAG 2. The biological survey data indicate that kingfisher are present and may be reproducing within WAG 2; but due to the sampling methods employed, estimates of the abundance of the kingfisher population cannot be made from these data. Limited residue analysis indicates that kingfisher in WAG 2 have selenium and mercury burdens in liver and kidney that may impair reproduction (selenium) or be nephrotoxic (mercury).

Point estimates of exposure indicated that mercury exceeded NOAELs and LOAELs, while PCBs exceeded NOAELs only (Table C.2). Monte Carlo simulation of exposure and comparison of these estimates to NOAELs and LOAELs (Table C.19) and calculation of binomial probability distributions (Table C.27) suggest that only mercury presents a significant risk to the kingfisher population in WAG 2.

The limited mercury body burden data corroborate the results of exposure assessment for mercury; therefore, the weight of evidence suggests that mercury presents risks to kingfisher within WAG 2. Because fish from WOC were not analyzed for selenium, the literature toxicity line of evidence is unavailable. The weight of evidence for selenium, therefore, is based solely on the body burden data, which suggest that selenium may present a risk to kingfisher within WAG 2.

\subsubsection{Uncertainties Concerning Risks to Wildlife}

Limited Sample Sizes. Because contaminant body burden data for belted kingfisher in WOC watershed are limited to one observation, conclusions based upon this clata point should be viewed with caution. This single observation may not be representative of body burdens present in other kingfisher from WOC.

Bioavailability of Contaminants. Bioavailability of contaminants was assumed to be comparable between soil and water from WAG 2 and the diets used in the literature toxicity tests. Because bioavailability may not be comparable, exposure estimates based upon the contaminant concentrations may either under- or overestimate the actual contaminant exposure experienced.

Extrapolation from Published Toxicity Data. While published toxicity studies are available for mink, there are no published data for the other endpoints. To estimate toxicity of contaminants at the site, it was necessary to extrapolate from studies performed on test species (i.e., mallard ducks, ring-necked pheasant, and rats). While it was assumed that toxicity could be estimated as a function of body size, the accuracy of the estimate is not known. For example, hawks or kingfisher may be more or less sensitive to contaminants than ducks or pheasants due to factors other than metabolic rate.

Additional extrapolation uncertainty exists for those contaminants for which data consisted of only LOAELs or tests were subchronic in duration. For either case, an uncertainty factor of 10 was employed to estimate NOAELs or chronic data. The uncertainty factor of 10 may either over- or underestimate the actual LOAEL-NOAEL or subchronic-chronic relationship. 
Toxicity of PCBs to piscivorous wildlife was evaluated using toxicity data from studies on Aroclor 1254. Because toxicity of PCB congeners can vary dramatically, the applicability of data for Aroclor 1254 is unknown.

Variable Food Consumption. While food consumption by wildlife was assumed to be similar to that reported for the same or related species in other locations, the validity of this assumption cannot be determined. Food consumption by wildlife in WAG 2 may be greater or less than that reported in the literature, resulting in either an increase or decrease in contaminant exposure.

Single Contaminant Tests vs Exposure to Multiple Contaminants in the Field. While wildlife in WAG 2 are exposed to multiple contaminants concurrently, published toxicological values only consider effects experienced by exposures to single contaminants. Because some contaminants to which wildlife are exposed can interact antagonistically, single contaminant studies may overestimate their toxic potential. Similarly, for those contaminants that interact additively or synergistically, single contaminant studies may underestimate their toxic potential.

Inorganic Forms or Species Present in the Environment. Toxicity of metal species varies dramatically depending upon the valence state or form (organic or inorganic) of the metal. For example, asenic (III) and methyl mercury are more toxic than arsenic (V) and inorganic mercury, respectively. The available data on the contaminant concentrations in media do not report which species or form of contaminant was observed. Because benchmarks used for comparison represented the more toxic species/forms of the metals (particularly for arsenic and mercury), if the less toxic species/form of the metal were actually present in media from WAG 2, potential toxicity at the sites may be overestimated.

Uptake Factors. Soil to biota uptake factors specific to WAG 2 were unavailable. Therefore, it was assumed that the uptake factors developed as part of the Bear Creek assessment were applicable. Due to the differing geologies and histories between WAG 2 and Bear Creek, the Bear Creek uptake factors may over- or underestimate the actual biota concentrations in WAG 2.

Contaminant Concentrations in Unanalyzed Food Types. Uptake factors were not available for all food types consumed by the endpoint species. It was assumed that the uptake factors for food types for which we had data were representative of that for those without data. Due to the different life histories of among food types, contaminant burdens are likely to differ from the measured data. Therefore, an assumption of comparability among food types may either over- or underestimate exposure.

Monte Carlo Simulation. In performing Monte Carlo simulations, distributions must be assigned to parameters. Because wildlife are mobile, the mean of the contaminant concentration is likely to best represent their exposure. or this report, the contaminant concentrations in fish were assumed to be normally distributed.

\subsection{RISKS TO PLANTS AND EARTHWORMS FROM EXPOSURE TO RADIONUCLIDES}

\subsubsection{Exposure Assessment}

Native biota may receive external radiation exposure from radionuclides in air, water, soil, sediment, and other biota, such as vegetation or earthworms. Organisms also receive internal radiation 
exposure from radionuclides ingested via food and water and from radionuclides absorbed through the skin and respiratory organs (IAEA 1976, Blaylock and Trabalka 1978). Evaluation of the resulting radiation doses received by biota requires quantitative information on the radionuclides to which they are exposed. In all cases the radiation source must be known in terms of the quantity of each specific radionuclide and the corresponding energy released per disintegration. Special corrections for factors that may affect exposures are applied when appropriate.

Radiation dose rates (mrad/d) were calculated for plants, earthworms, and representative terrestrial and semiaquatic wildlife species in the WOC watershed using methodology adapted from Blaylock et al. (1993), Baker and Soldat (1992), and DOE (1995b). The methodology was modified to address site-specific conditions and receptors. Current condition dose rates from internal exposures via ingestion of food and soil and inhalation of dust were evaluated, as were dose rates from external exposures via soil.

The representative terrestrial and semiaquatic wildlife selected as endpoints for the radiological assessment were the same as those for the chemical data assessment: short-tailed shrew, white-footed mouse, wild turkey, red fox, white-tailed deer, red-tailed hawk, mink, and belted kingfisher (see Sect. 7.1). Life history parameters used in the radiological assessment were identical to those used for the chemical data assessment (Table C.4-C.11). In addition, it was necessary to develop species-specific values for fraction of time spent above and below ground, underwater, or at the water's surface. A mink was assumed to spend $50 \%$ of its time above ground, $20 \%$ below ground (in burrows), $20 \%$ swimming at the water's surface, and, conservatively, $10 \%$ of its time immersed in water. Kingfishers were assumed to split their time equally between perching above water or soil and roosting in burrows. The short-tailed shrew, white-footed mouse, and red fox were all assumed to spend $75 \%$ of their time above ground and $25 \%$ below the soil surface in dens or burrows. White-tailed deer and wild turkeys spend $100 \%$ of their time above ground and were assigned a value of 1 . Red-tailed hawks also spend $100 \%$ of their time above ground, but much of this is flying or perched high in trees; thus, it was assumed that hawks would only be exposed to external radiation $10 \%$ of the time.

\subsubsection{Exposure models}

Terrestrial receptors may receive both external and internal doses of radiation. Internal exposures are a result of ingestion of contaminated food, soil, or water or inhalation of contaminated soil. Receptors on the ground surface receive external exposures from contaminated surface soil via direct radiation. Both above-ground and below-ground exposures are possible, depending on the habits of the receptor. Baker and Soldat (1992) provide general equations for estirnating dose rates to wildlife. An adaptation of the Blaylock et al. (1993) methodology was used in estimating radiation dose rates in the Remedial Investigation for Waste Area Grouping 5 at Oak Ridge National Laboratory (DOE 1995a). The Blaylock et al. methodology was further modified for the current assessment to account for the availability of site-specific uptake data. The general methodology and the equations specific to each exposure route used in estimation of dose rates for WOC wildlife are described in this subsection. Equations used in this assessment estimate the daily dose rates from current conditions. Dose rates from alpha, beta, and gamma emissions (only beta and gamma for external exposures) were calculated for each radionuclide, including the dose rates from all short-lived daughter products. Dose rates from each radionuclide were then summed over all exposure routes and all radionuclides to arrive at the overall dose rate received for each receptor at each site. Data on radionuclide activities in White Oak Creek water were not available in time for evaluation in this report. The models for estimating dose rates from exposure to radionuclides in water are provided in this section, and the analysis will be performed when the data become available. Mink and kingfisher are the only wildlife receptors likely to experience significant water-related exposures. 
External Exposures: Direct radiation from soil. The equation for estimating external dose rates $(\mathrm{mrad} / \mathrm{d})$ for terrestrial receptors exposed to contaminated soil uses dose coefficients was published by Eckerman and Ryman (1993). Dose rate reduction factors are used to account for the fraction of time the receptor spends above or below ground. Dose coefficients assume the source region is a smooth plane (Eckerman and Ryman 1993), but this is rarely the case in a terrestrial habitat. A representative average dose reduction factor for ground roughness is 0.7 (Eckerman and Ryman 1993). The equation for dose from external exposures for an organism above ground is written as follows:

Above soil exposures

$$
D_{\text {abovegrd }}=F_{\text {above }} F_{\text {ruf }} \sum C_{\text {soll, },} D F_{\text {grd, },} C F b \text {, }
$$

where

$D_{\text {above grd }}=$ external dose rate to receptor from above ground exposures to contaminated soil $(\mathrm{mrad} / \mathrm{d})$,

$\mathrm{F}_{\mathrm{above}}=$ dose rate reduction factor accounting for the fraction of time the receptor spends above ground (unitless),

$\mathrm{F}_{\text {nuf }}=$ dose rate reduction factor accounting for ground roughness (unitless). [representative average of 0.7 (Eckerman and Ryman 1993) used for this assessment],

$\mathrm{C}_{\text {soil, } \mathrm{i}}=$ activity of radionuclide $I$ in surface soil ( $\mathrm{pCi} / \mathrm{g}$ ),

$\mathrm{DF}_{\mathrm{grd}, \mathrm{i}}=$ dose coefficient for radionuclide $I$ in surface soil (Table III.5, Eckerman and Ryman 1993) (Sv/s per $\left.\mathrm{Bq} / \mathrm{m}^{3}\right)$,

$\mathrm{CFb}=$ conversion factor to change $\mathrm{Sv} / \mathrm{s}$ per $\mathrm{Bq} / \mathrm{m}^{3}$ to $\mathrm{mrad} \mathrm{g} / \mathrm{pCi} \mathrm{d}$ equals $5.12 \times 10^{14}$.

Dose from alpha radiation is not a concern for external sources as alpha radiation lacks penetrating power. The effective dose coefficients from Eckerman and Ryman (1993) incorporate both beta and gamma emissions. Radionuclide-specific parameters are provided in Table C.31. The lower of the 95\% UCL and the maximum detected concentration in surface soil were used in estimating the dose rate from external exposures for each radionuclide.

Below-ground exposures are calculated similarly. However, the ground roughness dose reduction factor is not used for below-ground exposure, and the exposure fraction is adjusted to reflect the fraction of time the receptor spends below ground. This mode of exposure is treated as immersion in a continuous soil medium. To account for exposures from above and below, a factor of 2 is included. Because wild turkey, white-tailed deer, and red-tailed hawks do not go below ground, they do not receive a dose via this exposure route. The equation for below-ground external exposures is written as follows:

Below ground exposures-terrestrial wildlife

$$
D_{\text {belowgrd }}=2 F_{\text {below }} \sum C_{\text {soll, }} D F_{\text {grd, }} C F b \text {, }
$$

where

$D_{\text {below grd }}=$ external dose rate to receptor in burrow from contaminated soil (mrad/d),

$2^{=}$dose addition factor to account for receptor immersed in soil (unitless), 
$\mathrm{F}_{\text {below }}=$ dose rate reduction factor accounting for the fraction of time the receptor spends below ground (unitless).

All other parameters are as defined for above-ground exposures.

External exposures for plants and earthworms are calculated using similar equations. Earthworms are assumed to spend $100 \%$ of their time below ground. Therefore, the $F_{\text {below }}$ term in the below ground equation is set to 1 . In addition, the dose coefficient is replaced with the energy for emission of beta or gamma particles for each radionuclide; and the $\mathrm{CFb}$ conversion factor is replaced with a conversion factor appropriate for converting $\mathrm{MeV}$ to $\mathrm{g} \mathrm{mrad} / \mathrm{pCi} \mathrm{d}(0.0512)$.

Below-ground-Earthworms and Plants

$$
D_{\text {belowgrd }}=2 \sum C_{\text {soil,i }} \epsilon_{i} C F a \text {, }
$$

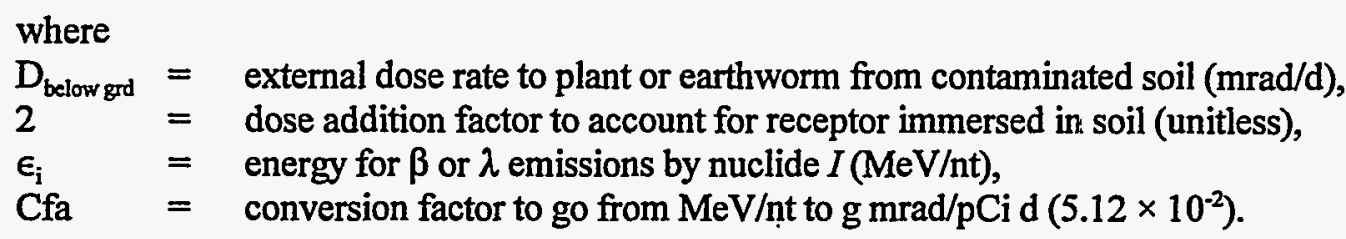

All other parameters are as defined for above-ground exposures.

Plants receive external exposures to both above- and below-ground parts. The below-ground model is identical to that for earthworms. While the above-ground parts of plants receive a lower dose rate from soil than below-ground parts, the models used in this assessment estimate only the dose rate for below-ground parts.

External Exposures: Direct radiation from water. The equation for estimating external dose rates (mrad/d) for terrestrial receptors exposed to radionuclides in water uses dose coefficients published by Eckerman and Ryman (1993) and is similar to the equation used for soil. Dose rate reduction factors are used to account for the fraction of time the receptor spends underwater or at the water's surface. The equation for dose from external exposures for an organism. immersed in water is written as follows:

Underwater exposures

$$
D_{\text {undenwater }}=F_{\text {zndenwater }} \sum C_{\text {water }, i} \frac{1}{W D} D F_{\text {water }, i} C F w,
$$

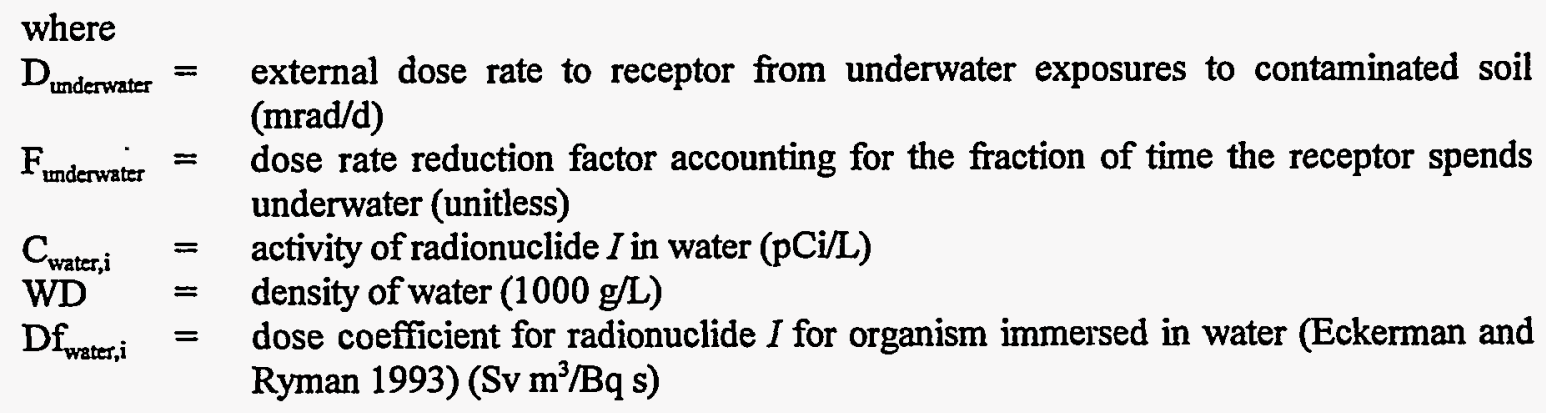


$\mathrm{CFw}=$ conversion factor to change $\mathrm{Sv} \mathrm{m}^{3} / \mathrm{Bq}$ s to $\mathrm{mrad} \mathrm{g} / \mathrm{pCi}$ d equals $3.20 \times 10^{14}$.

Dose from alpha radiation is not a concern for external sources as alpha radiation lacks penetrating power. The effective dose coefficients from Eckerman and Ryman (1993) incorporate both beta and gamma emissions. Radionuclide-specific parameters are provided in Table C.31. The mink is the only representative wildlife species likely to spend time under water.

Exposures at the water surface are calculated similarly. However, the exposure fraction is adjusted to reflect the fraction of time the receptor spends at the water surface. Because organisms at the water's surface are exposed from below instead of from above and below, a dose reduction factor of 0.5 is applied. Mink were assumed to spend $20 \%$ of their time swimming at the water surface, and kingfishers were assumed to spend $33 \%$ of their time perched close to the water surface. Other receptors were not expected to spend significant time in water, so external water exposures were not addressed. The equation for external exposures at the water surface is written:

Water surface exposures

$$
D_{\text {surface }}=F_{\text {surface }} 0.5 \sum C_{\text {water, } i} \frac{1}{W D} \quad D F_{\text {water, } i} C F w \text {, }
$$

where

$D_{\text {surfice }}=$ external dose rate to receptor from exposures at the water surface (mrad/d),

$\mathrm{F}_{\text {surface }}=$ dose rate reduction factor accounting for the fraction of time the receptor spends at the water surface (unitless),

$0.5=$ dose reduction factor to account for the difference between being immersed in water and being at the water surface (unitless).

All other parameters are the same as those defined for underwater exposures.

Internal Exposures: Ingestion. Wildlife receptors may receive internal radiation doses after ingesting contaminated prey, soil, or water or after inhaling contaminated dust. Blaylock et al. (1993) provide an equation for estimating the internal dose to fish contaminated with radionuclides. This equation can be modified to address plants, earthworms, and consumers eating a variety of prey types, ingesting soil, and drinking water.

The equation is

$$
D=\sum Q F \quad C_{\text {tissue }} E_{i} C F a
$$

where

D = internal dose rate received after ingestion of contaminated prey, soil, and water, $(\mathrm{mrad} / \mathrm{d})$ or uptake of radionuclides from soil (for plants and invertebrates).

$\mathrm{QF} \quad=\quad$ quality factor to account for the greater biological effectiveness of $\alpha$ particles (20 for $\alpha ; 1$ for $\beta$ and $\lambda$ emissions; unitless),

$\mathrm{C}_{\text {tissue }}=$ activity $(\mathrm{pCi} / \mathrm{g})$ of radionuclide $I$ in tissue of organism,

$\epsilon_{\mathrm{i}}=$ energy for $\alpha, \beta$, or $\lambda$ emissions by nuclide $I(\mathrm{MeV} / \mathrm{nt})$,

$\mathrm{Cfa}=$ Conversion factor to go from $\mathrm{MeV} / \mathrm{nt}$ to $\mathrm{g} \mathrm{mrad} / \mathrm{pCi} \mathrm{d} .\left(5.12 \times 10^{-2}\right)$. 
The primary modifications involve estimating the concentration in the consumer species and because absorbed energy fractions are generally unavailable for terrestrial wildlife, conservatively assuming that absorbed energies equaled 1 for all radionuclides and all receptors. Estimation of tissue concentrations was conducted using soil-to-tissue ratios derived from data collected in the Bear Creek watershed for three plant types (browse, canopy vegetation, and herbaceous vegetation) and small rodents; soil-to-tissue ratios for earthworms were derived from data collected at WAG 2, WAG 5, and the Bear Creek watershed. These data are likely to be more relevant to the WOC watershed than are more general literature-derived bioaccumulation factors. When site-specific uptake factors were unavailable for specific radionuclides, values were derived from those for related isotopes with measured values or from measured values of the elemental form of the radionuclide.

Dose from internal exposures was calculated for alpha, beta, and gamma energies of each radionuclide. Energies were obtained from Eckerman and Ryman (1993) and are provided in Table C.31. Because different types of radiation differ in their relative biological effectiveness per unit of absorbed dose, a quality factor derived from data on humans is normally applied (NCRP 1987). A quality factor of 1 is used for beta and gamma radiation and 20 for alpha radiation (Blaylock et al. 1993).

The lower of the 95\% UCL and the maximum detected concentration in surface soil was used in exposure calculations. Radiation energies (MeV) were obtained from Eckerman and Ryman (1993) for all radionuclides and their short-lived daughter products.

When measured soil-to-tissue uptake factors were available, tissue concentrations for plants, earthworms, short-tailed shrews, and white-footed mice were estimated by multiplying the appropriate uptake factor by soil activity levels. When site-specific data were lacking, it was necessary to use transfer factors from available literature. For plants and earthworms the literature-derived values were soil-to-tissue transfer factors, so estimation of tissue concentrations was performed as described previously. However, for mammals and birds, literature values used were bioaccumulation factors defined as the ratio of activity level in receptor tissue divided by the activity level in the receptor's food. Therefore, when site-specific data were lacking, tissue concentrations were estimated as follows:

$$
C_{\text {tissue }}=B A F_{i}\left(C_{i j} P_{j}+C_{\text {soll }} P_{\text {soll }}+C_{\text {water }} \frac{1}{W D}\right)
$$

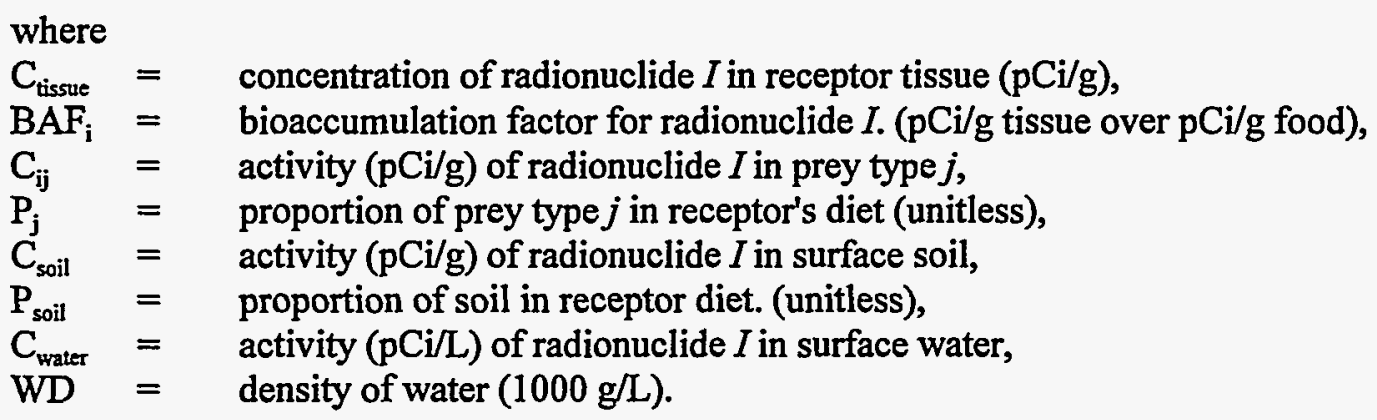

It was assumed that uptake of radionuclides from ingested food, water, and soil was similar. For predators which consume small mammals, a small mammal tissue concentration is needed to estimate the dose rate to the predator. In order to simplify the exposure models, the white-footed mouse was used as the generic prey species. Therefore, small tissue concentrations used as input to the red fox, red-tailed hawk, and mink dose rate models were based on white-footed mouse tissue concentrations 
calculated as described previously. Uptake factors used in the radiological assessment are provided in Table C.32.

Concentrations in fish will be estimated by multiplying water concentrations by fish bioconcentration factors obtained from Blaylock et al. (1993) when data on radionuclide activity in water become available.

Internal Exposures: Inhalation. Wildlife species using burrows receive an additional internal dose from inhalation of dust originating from contaminated soil. Intake of radionuclide $I$ by inhalation is estimated as follows (DOE 1995b):

$$
D_{\text {inh }}=Q F \quad F_{\text {below }} \sum C_{\text {soll, },} A \frac{1}{A D} \epsilon_{i} C F a
$$

where

$D_{\text {inh }}=$ internal dose rate from inhalation of contaminated soil (mrad/d),

$\mathrm{F}_{\exp }=$ dose reduction factor for fraction of time receptor spends below ground (unitless),

$A=$ mass of respirable dust per volume of air breathed $\left(0.1 \mathrm{~g} / \mathrm{m}^{3} ; \mathrm{DOE} 1995 \mathrm{~b}\right)$,

$\mathrm{AD}=$ air density $\left(1200 \mathrm{~g} / \mathrm{m}^{3} ;\right.$ Eckerman and Ryman 1993),

$\epsilon_{\mathrm{i}}=\alpha, \beta$, or $\gamma$ radiation energies for radionuclide $I(\mathrm{MeV} / \mathrm{nt})$,

$\mathrm{CFa}=$ conversion factor to go from $\mathrm{MeV} / \mathrm{nt}$ to $\mathrm{mrad} \mathrm{g} / \mathrm{pCi} \mathrm{d}\left(5.12 \times 10^{-2}\right)$.

Healy (1980) suggests that $0.0001 \mathrm{~g} / \mathrm{m}^{3}$ would be a conservative value when addressing human exposures to dust. Because burrowing animals are likely to spend a greater portion of their time in a confined space (burrow) than humans and are physically closer to the soil surface, an air mass loading of $0.1 \mathrm{~g} / \mathrm{m}^{3}$ was selected as a conservative estimate of the mass of respirable dust (A) to which these animals may be exposed.

Total internal exposures were obtained by adding ingestion and inhalation dose rates over all radionuclides, including all short-lived daughter products. In addition, the dose rate to a kingfisher collected near ORNL Building 4505 was estimated based on a measured body burden of $91.27 \mathrm{pCi} / \mathrm{g}$ Cs-137 (Table C.25).

\subsubsection{Effects Levels for Radionuclides}

The discharge of radioactive waste into the environment results in long-term, low dose exposure to organisms. In most cases, acute mortality can be discounted. Any potential increase in morbidity and mortality that might result from the exposure to chronic irradiation above background is unlikely to be detected because of natural fluctuations in the size of populations. The International Atomic Energy Agency (IAEA) and the Atomic Energy Act (1992) recommend limiting the dose for terrestrial organisms to $100 \mathrm{mrad} / \mathrm{d}$ (IAEA 1992). Species-specific effects data were not available, so $100 \mathrm{mrad} / \mathrm{d}$ was selected as the threshold dose for all the representative wildlife receptors. This level of exposure to the maximally exposed individual is thought to be protective of the overall receptor population (IAEA 1992, DOE 1995a).

\subsubsection{Risk Characterization for Terrestrial Receptors Exposed to Radionuclides}

Potential risks to plants, invertebrates, and selected terrestrial and semiaquatic wildlife receptors from exposures to radionuclides were estimated for each of four reaches along WOC by comparing 
estimated dose rates to the recommended dose rate limit of $100 \mathrm{mrad} / \mathrm{d}$. Dose rates were summed for all radionuclides over all exposure routes to obtain the overall dose in $\mathrm{mrad} / \mathrm{d}$ received by each receptor at each site. Tables C.33 through C.36 present overall exposures from soil for each receptor by site and identify the radionuclides contributing the majority of the dose rate. Water-related dose rates were not estimated for this assessment.

Possible radiation effects are anticipated for plants, earthworms, and wildlife receptors frequenting all four reaches of WOC as the overall dose rates in each reach exceed the effects threshold of $100 \mathrm{mrad} / \mathrm{d}$. Dose rates were generally highest for all receptors at the IHP, lower in LWC and MWC WOC, and high in LMB. Watershed-wide population level effects are likely considering herbaceous plant, earthworm, short-tailed shrew, and white-footed mouse dose rates exceeded the dose rate limit in all reaches. The primary contributors to dose rates in the IHP, MWC, and LWC were ${ }^{239,240} \mathrm{Pu},{ }^{241} \mathrm{Am}$, and ${ }^{137} \mathrm{Cs}$; and ${ }^{90} \mathrm{Sr},{ }^{239,240} \mathrm{Pu},{ }^{241} \mathrm{Am}$, and ${ }^{137} \mathrm{Cs}$ were the primary contributors in LMB.

Intermediate Holding Pond (IHP). Potential radiation effects are expected for terrestrial plant, invertebrate, and wildlife receptors at the IHP as dose rates exceeded the effects threshold of 100 $\mathrm{mrad} / \mathrm{d}$ for all receptors except the white-tailed deer and belted kingfisher (Table C.33). The kingfisher dose rate estimate was based only on external exposures to radionuclides in soil; adding likely internal exposures from ingestion of water and fish may result in a dose rate exceeding $100 \mathrm{mrad} / \mathrm{d}$. Plants, earthworms, shrews, and mice exceeded the limit by more than a factor of 10 (ranging from 21.77 for mice to 43.4 for plants). Dose rates for turkey, fox, hawk, and mink were lower (1.5 to 3.26 times the effects threshold).

Plutonium-239/240, Americium-241, and Cesium-137 were the primary contributors to estimated dose rates for plants, earthworms, shrews, and mice (Table C.33). Plutonium-239/240 accounted for greater than $40 \%$ of the dose for these receptors. Cesium- 137 was the only significant contributor to dose rates for turkey, deer, fox, hawk, mink, and kingfisher, accounting for greater than $91 \%$ of the dose rate for these receptors.

Middle White Oak Creek (MWC). Potential radiation effects are expected for terrestrial plant, invertebrate, and wildlife receptors in the vicinity of MWC as dose rates exceeded the effects threshold of $100 \mathrm{mrad} / \mathrm{d}$ for plants, earthworms, shrews, and mice (Table C.34). Dose rates for turkey, deer, fox, hawk, mink, and kingfisher were all well below the effects threshold (ranging from 3 to 17 $\mathrm{mrad} / \mathrm{d}$ ). Plants, earthworms, shrews, and mice exceeded the limit by more than a factor of 7 (ranging from 7.2 times the threshold for mice to 14 times for plants).

Plutonium-239/240 and Americium-241 were the primary contributors to estimated dose rates for plants, earthworms, shrews, and mice (Table C.34). Plutonium-239/240 accounted for greater than $62 \%$ of the dose for these receptors. Cesium- 137 was the only significant contributor to dose rates for turkey, deer, fox, hawk, mink, and kingfisher, accounting for greater than $53 \%$ of the relatively low dose rates for these receptors.

Lower White Oak Creek (LWC). Potential radiation effects are expected for terrestrial plant, invertebrate, and wildlife receptors in the vicinity of $L W C$ as dose rates exceeded the effects threshold of $100 \mathrm{mrad} / \mathrm{d}$ for plants, earthworms, shrews, and mice (Table C.35). Dose rates for turkey, deer, fox, hawk, mink, and kingfisher were all below the effects threshold (ranging from 10 to $49 \mathrm{mrad} / \mathrm{d}$ ). Plants, earthworms, shrews, and mice exceeded the limit by more than a factor of 7 (ranging from 7.2 times the threshold for mice to 13.5 times for plants). 
Plutonium-239/240 and Americium-241 were the primary contributors to estimated dose rates for plants, earthworms, shrews, and mice (Table C.35). Plutonium-239/240 accounted for greater than $51 \%$ of the dose for these receptors. Cesium- 137 was the only significant contributor to dose rates for turkey, deer, fox, hawk, mink, and kingfisher, accounting for greater than $84 \%$ of the dose rates for these receptors.

Lower Melton Branch (LMB). Potential radiation effects are expected for terrestrial plant, invertebrate, and wildlife receptors at the LMB as dose rates exceeded the effects threshold of 100 $\mathrm{mrad} / \mathrm{d}$ for all receptors except the belted kingfisher (Table C.36). The kingfisher dose rate estimate was based only on external exposures to radionuclides in soil; adding likely internal exposures from ingestion of water and fish may result in a dose rate exceeding $100 \mathrm{mrad} / \mathrm{d}$. Plants, earthworms, fox, and hawk exceeded the limit by more than a factor of 10 (ranging from 10.87 for the hawk to 30.5 for earthworms). Dose rates for shrews, mice, turkeys, deer, and mink were lower ( 2.75 to 6.22 times the effects threshold).

Plutonium-239/240 (66.6\%) and Cesium-137 (17.1\%) were the primary contributors to the estimated dose rate for plants. Strontium- 90 and Curium- 244 accounted for over $80 \%$ of the estimated dose rate for shrews and mice (Table C.36). Strontium-90 was the only significant contributor to dose rates for earthworms, turkey, deer, fox, hawk, and mink, accounting for greater than $92 \%$ of the dose rate for these receptors.

Kingfisher Tissue Data. In addition to evaluation of potential radionuclide exposures in the four reaches of WOC, the internal dose rate for a single kingfisher collected near Building 4505 at Oak Ridge National Laboratory, upstream of WOC, was estimated based on a measured body burden of $91.27 \mathrm{pCi} / \mathrm{g}$ of Cesium-137 (Table C.25) (Baron and Ashwood 1996). The model for internal ingestion exposures described in Sec. 7.2.1.1 was used to estimate a dose rate of $3.8 \mathrm{mrad} / \mathrm{d}$ for this kingfisher, a rate well below the effects threshold of $100 \mathrm{mrad} / \mathrm{d}$. Baron and Ashwood suggest that the high levels of Cesium-137 in this kingfisher indicate its foraging territory includes WOC or nearby surface impoundments. If the Cs-137 body burden found in the kingfisher from the Building 4505 area is representative of body burdens in kingfishers along WOC, the overall dose rates for kingfishers along the creek may be below $100 \mathrm{mrad} / \mathrm{d}$. Cs-137 was the primary contributor to external exposures from radionuclides in soil for kingfishers along all four reaches of WOC, and the highest dose rate (at the IHP) was estimated at $64 \mathrm{mrad} / \mathrm{d}$ (Tables C.33-C.36).

\subsubsection{Uncertainties in the Radiological Risk Assessment}

There are a number of areas of uncertainty in the estimation of risks to wildlife from exposure to radionuclides at WOC. It is believed that the methodology used in this assessment overestimates the dose rates that would be received. Whereas some of the information needed to implement the methodology is well known, much is unknown or unspecified statistically. A conservative but reasonable approach to model assumptions and radiological exposure scenarios was adopted for this assessment in order to avoid underestimating risks to biota.

- It was conservatively assumed that energy absorption by the wildlife receptors evaluated in this assessment was $100 \%$. While larger organisms are likely to absorb a greater fraction of energy than smaller organisms, it is unlikely that actual absorption would be as high as $100 \%$. Thus, radiation dose rates may be lower than those reported here.

- The dose coefficients obtained from Eckerman and Ryman (1993) used to estimate dose rates from external exposures were developed for application in determining dose rates to humans. These dose coefficients were applied directly for wildlife receptors, but the actual dose 
coefficients for wildlife, given differences in size, behavior, and general morphology, may be greater or lesser than those developed for humans. However, similar values have not been developed specifically for wildlife receptors.

- Uptake factors from soil to earthworms were not available for many radionuclides. If uptake factors were unavailable, the higher of the plant or mammal uptake factors was used for earthworms. It is unknown whether actual earthworm uptake factors for these radionuclides would be higher or lower than those used, but use of the larger of the plant and mammal values was a conservative approach.

- Mammal soil-to-tissue uptake factors were calculated from measured data on small rodents. While these clearly apply directly to white-footed mice, they were also used for the other small mammalian receptor, the short-tailed shrew. Short-tailed shrew diets differ somewhat from that of white-footed mice as shrews eat a higher proportion of invertebrates. However, it was assumed that site-specific data on mice were more applicable to shrews than literature-derived bioaccumulation factors.

- Uptake factors were not available for birds such as the red-tailed hawk. Radionuclide activities in red-tailed hawk tissues were estimated using mammal uptake factors assuming that uptake would be similar for hawks and mammals. It is unknown whether actual bird uptake factors would be higher or lower than those used here.

- Literature-derived bioaccumulation factors were used to estimate radionuclide activities in mammal and bird tissues. While these values are believed to be representative of bioaccumulation likely to observed on site, actual values may be higher or lower than used in this assessment.

- Dietary information for the wildlife receptors evaluated here vas obtained from available literature. Diets of given species in the WOC watershed may vary somewhat from those reported in the literature from other areas.

- Species-specific time budget information is lacking, so it was necessary to make a number of assumptions regarding the fraction of time each receptor spends above or below ground, underwater, or at the water's surface. The fractions used in this assessment were selected based on general knowledge of species behavior patterns, but actual fractions may be higher or lower.

- The air mass loading factor of $0.1 \mathrm{~g} / \mathrm{m}^{3}$ used in estimating exposures from inhalation of radionuclide-contaminated dust was selected as a conservative value. Healy (1980) suggested $0.0001 \mathrm{~g} / \mathrm{m}^{3}$ would be a conservative value for estimating human exposures from inhalation of dust. 


\section{SUMMARY AND CONCLUSIONS}

- This screening assessment is intended to indicate whether there are credible hazards to ecological endpoints in the WOC watershed due to contamination and whether there are data gaps that need to be filled. The following are conclusions concerning the hazards:

- Radionuclides in WAG 2 do not pose a hazard to fish or aquatic invertebrates. Strontium-90 in three seeps exceeds the screening benchmarks for aquatic life, but these seeps do not support communities of aquatic macroorganisms.

- Radionuclides in WAG 2 pose a hazard to terrestrial plants, wildlife, and soil invertebrates in all four reaches of WOC and in lower MB. Exposures were highest in the IHP reach.

- The unfiltered water in all reaches exceeded water quality criteria and other toxicological benchmarks for aquatic life.

- Water from WOC adjacent to and below ORNL was toxic in a fish embryo-larval test but not the standard subchronic tests.

- The fish community in WOC has low species richness, but this may be due to lack of recovery from past toxicity. However, the riffle invertebrate community, which is exposed primarily to chemicals in water like the fish and which has flying stages which should allow recovery, also has low species richness.

- Sediments from the IHP, MWC, and LMB are contaminated to levels that have been associated with toxic effects at other sites. Contaminants include metals, PAHs, and PCBs.

- The species richness of benthic invertebrates from WAG 2 sediments is lower than in background WOC sediments but not other reference streams. The exception is WOL, which has very low species richness; but no comparable reference lakes were characterized.

- Chromium and mercury levels in IHP and LWC soils and mercury in MWC and LMB soils exceeded levels that were reported to be toxic to earthworms.

- Multiple metals were found in IHP, MWC, LWC, and LMB soils at concentrations that have been reported to be toxic to plants.

- Metals in seep waters in the W4T and WS reaches are at concentrations that have been reported to be toxic to plants.

- Hazards to wildlife were found in all WOC reaches. However, the hazards were greatest for mercury among chemicals, for IHP among reaches, and for shrews among species.

- Kingfishers from WOC show elevated levels of contaminants, and the one adult found had tissue levels of mercury and selenium that are indicative of toxicity. Mink from WOC do not appear to be contaminated. 
The following are major uncertainties that could be addressed by additional data collection:

- Background concentrations need to be better characterized for the seeps, surface waters, sediments, and floodplain soils.

- The contamination of soil and biota on the burial grounds other than WAGs 5 and 6 are unknown.

- The bioavailable concentrations of metals in WOC watershed are unknown.

- The toxicity of soil and sediment in the watershed are unknown.

- The toxicity of water is unknown for some reaches and has been irregular in others (Table 3.4).

- The fish communities have not been quantitatively characterized for the smaller tributaries (Table 3.4).

- The chemical composition of fish is unknown for some tributaries and reaches (Table 3.4).

- Because of the high Se levels in a kingfisher, Se levels should be characterized in fish.

In sum, plausible hazards exist in all reaches of WAG 2 and to all ecological endpoints. Radionuclides, organic chemicals, and metals are all implicated. However, none of the risk estimates or observations of the state of the watershed suggest that there is a need for an accelerated response. That is, no threatened or endangered species are at risk and no wetlands or other highly valued populations or ecosystems are experiencing catastrophic effects. Sorne parts of the watershed are uncharacterized and should be surveyed and sampled before the $\mathrm{RI}$ is completed. These results imply that a more complete data set should be assembled and used to prepare a definitive ecological risk assessment for the WOC watershed. 


\section{REFERENCES}

Ables, E.D. 1969. "Home range studies of red foxes (Vulpes vulpes).”J. Mamm. 50:108-120.

Alexander, G.R. 1977. "Food of vertebrate predators on trout waters in north central lower Michigan." Mich. Acad. 10:181-195.

Ambrose, A.M., P.S. Larson, J.F. Borzelleca, and G.R. Hennigar, Jr. 1976. "Long-term toxicological assessment of nickel in rats and dogs." J. Food Sci. Tech. 13:181-187.

Andersen, D.E., and O.J. Rongstad. 1989. "Home-range estimates of red-tailed hawks based on random and systematic relocations." J. Wildl. Manage. 53:802-807.

Amold, T.W., and E.K. Fritzell. 1987. "Food habits of prairie mink during the waterfowl breeding season." Can. J. Zool. 65:2322-2234.

Ashwood, T.L. (ed.) 1993. Seventh annual report on the ORNL Biological Monitoring and Abatement Program. ORNL/TM-00000. Oak Ridge National Laboratory, Oak Ridge, TN.

Ashwood, T.L. (ed.) 1994. Eighth annual report on the ORNL Biological Monitoring and Abatement Program. ORNL/TM-12767. Oak Ridge National Laboratory, Oak Ridge, TN.

Aulerich, R. J., and R. K. Ringer. 1977. "Current status of PCB toxicity to mink and effect on their reproduction.” Arch. Environ. Contam. Toxicol. 6:279-292.

Aulerich, R.J., R.K. Ringer, M.R. Bleavins, and A. Napolitano. 1982. "Effects of supplemental dietary copper on growth, reproductive performance and kit survival of standard dark mink and the acute toxicity of copper to mink." J. Animal Sci. 55: 337-343. (Cited in ATSDR 1990).

Azar, A., H.J. Trochimowicz, and M.E. Maxwell. 1973.“Review of lead studies in animals carried out at Haskell Laboratory: two-year feeding study and response to hemmorhage study." In Environmental Health Aspects of Lead: Proceedings, International Symposium, D. Barth et al., (eds.). Commission of European Communities. pp. 199-210.

Barber, H.L. 1984. Eastern mixed forest. pp. 345-354. In Halls, L.K., (ed.) White-tailed Deer: Ecology and Managenent. Harrisburg, PA: Stackpole Books.

Baes, C. F., III, R. D. Sharp, A. L. Sjoreen, and R. W. Shor. 1984. A Review and Analysis of Parameters for Assessing Transport of Environmentally Released Radionuclides through Agriculture. ORNL-5786. Health and Safety Research Division, Oak Ridge National Laboratory, Oak Ridge, TN. 150p.

Baker, D.A., and J.K. Soldat. 1992. Methods for Estimating Doses to Organisms from Radioactive Materials Released into the Aquatic Environment. PNL-8150. Pacific Northwest Laboratory, Richland, WA.

Baron, L. A., and T. L. Ashwood. 1996. Monitoring bioaccumulation of contaminants in the belted kingfisher (Ceryle alcyon). Environmental Monitoring and Assessment. In Review. 
Barrett, G.W., and K.L. Stueck. 1976. "Caloric ingestion rate and assimilation efficiency of the shorttailed shrew, Blarina brevicauda." Ohio J. Sci. 76: 25-26.

Barsotti, D.A., R.J. Marlar, and J.R. Allen. 1976. "Reproductive dysfuction in Rhesus monkeys exposed to low levels of polychlorinated biphenyls (Aroclor 1248)." Fd. Cosmet. Toxicol. 14: 99-103.

Batzli, G.O. 1977. "Population dynamics of the white-footed mouse in flood plain and upland forests." Am. Midl. Nat. 97: 18-32.

Bent, A.C. 1940. Life histories of North American cuckoos, goat suckers, hummingbirds, and their allies. Washington, D.C.: U.S. Government Printing Office; Smithsonian Inst. U.S. Nat. Mus., Bull. 176.

Beyer, W.N., E. Conner, and S. Gerould. 1994. "Survey of soil ingestion by wildlife." J. Wildl. Mgmt. 58:375-382.

Blaylock, B.G., and J.R. Trabalka. 1978. "Evaluating the effects of ionizing radiation on aquatic organisms." pp. 103-152 in J.T. Lett and H. Alder, eds. Advances in Radiation Biology. Academic Press, New York.

Blaylock, B. G., M. L. Frank, F. O. Hoffman, L. A. Hook, G. W. Suter, and J. A. Watts. 1992. Screening of Contaminants in Waste Area Grouping 2 at Oak Rialge National Laboratory, Oak Ridge, Tennessee. ORNL/ER-62. Oak Ridge National Laboratory, Oak Ridge, Tenn.

Blaylock, B.G., M.L. Frank, and B.R. ONeal. 1993. Methodology for Estimating Radiation Dose Rates to Freshwater Biota Exposed to Radionuclides in the Environment. ES/ER/TM-78. Oak Ridge National Laboratory, Oak Ridge, Tenn.

Bleavins, M.R., and R.J. Aulerich. 1981. "Feed consumption and food passage time in mink (Mustela vison) and European ferrets (Mustela putorius furo)." Lab. Anim. Sci. 31:268-269.

Borders, D. M., D. J. Pridmore, J. J. Beauchamp, D. E. McConnell, S. T. Puruker, and T. M. Scanlon. 1996. Waste Area Grouping 2 Phase I Remedial Investigation Report: Tributary Data Assessment. ORNL/ER-362. Energy Systems Restoration Program, Oak Ridge, Tenn.

Borzelleca, J.F., L.W. Condie, Jr., and J.L. Egle, Jr. 1988. "Short-term toxicity (one-and ten-day gavage) of barium chloride in male and female rats." J. American College of Toxicology. 7:675685.

Brooks, R.P., and W.J. Davis. 1987. "Habitat selection by breeding belted kingfishers (Ceryle alcyon)." Am. Midl. Nat. 117:63-70.

Brown, L., and D. Amadon. 1968. Eagles, Hawks, and Falcons of the World, Vol. 1. McGraw-Hill. New York

Buben, J.A., and E.J. O'Flaherty. 1985. "Delineation of the role of metabolism in the hepatotoxicity of trichloroethylene and perchloroethylene: a dose-effect study." Toxicol. Appl. Pharmacol. 78:105-122. 
Buckner, C.H. 1964. "Metabolism, food capacity, and feeding behavior in four species of shrews." Can. J. Zool. 42:259-279.

Buckner, C.H. 1966. "Populations and ecological relationships of shrews in Tamarack bogs of southeastern Manitoba." J. Mamm. 74:181-194.

Burgess, S.A., and J.R. Bider. 1980. "Effects of stream habitat improvements on invertebrates, trout populations, and mink activity." J. Wildl. Manage. 44:871-880.

Burt, W.H. ,and R.P. Grossenheider. 1976. A Field Guide to the Mammals of America North of Mexico. 3rd ed., Houghton Mifflin Co., Boston.

Cain, B.W., and E.A. Pafford. 1981. "Effects of dietary nickel on survival and growth of mallard ducklings." Arch. Environm. Contam. Toxicol. 10:737-745.

Calder, W.A., and E.J. Braun. 1983. "Scaling of osmotic regulation in mammals and birds." Am. J. Physiol. 224:Rr601-R606.

Carriere, D., K. Fischer, D. Peakall, and P. Angehrn. 1986. "Effects of dietary aluminum in combination with reduced calcium and phosphorus on the ring dove (Streptopelia risoria)." Water, Air, and Soil Poll. 30:757-764.

Chew, R.M. 1951. "The water exchanges of some small mammals." Ecol. Monogr. 21(3):215-224.

Craighead, J.J., and F.C. Craighead. 1969, Hawks, Owls, and Wildlife. Dover Publ. Co. New York.

Curl, E. A., P. J. Edwards, C. Elliott, and J. P. Leahey. 1987. "The conjugation and accumulation of metabolites of cypermethrin by earthworms." Pesticide Sci. 20:207-222.

Dahlgren, R.B., R.L. Linder and C.W. Carlson. 1972. "Polychlorinated biphenyls: their effects on penned pheasants." Environmental Health Perspectives 1:89-101.

Davis, W.J. 1982. "Terrritory size in Megaceryle alcyon along a stream habitat." The Auk. 99:353362.

Davis A., R. Barale, G. Brun, et al. 1987. "Evaluation of the genetic and embryotoxic effects of bis(tri-n-butyltin)oxide (TBTO), a broad spectrum pesticide, in multiple in vivo and in vitro short-term tests." Muta. Res. 188:65-95.

DeGraaf, R.M., G.M. Witman, J.W. Lanier, B.J. Hill, and J.M. Keniston. 1981. Forest Habitat for Birds of the Northeast. U.S.D.A. Forest Service. Northeast Forest Experiment Station and Eastern Region.

DOE (U.S. Department of Energy). 1995a. Remedial Investigation Report on Waste Area Grouping 5 at Oak Ridge National Laboratory, Oak Ridge, Tennessee. DOE/OR/01-1326. U.S. Department of Energy, Oak Ridge, Tenn.

DOE (U.S. Department of Energy). 1995. Remedial Investigation Report on Waste Area Grouping 5 at Oak Ridge National Laboratory, Oak Ridge, Tennessee, Vol. 4, Appendix C-Risk Assessment, DOE/OR/01-1326\&D1/V4. U.S. Department of Energy, Oak Ridge, Tenn. 
DOE (U.S. Department of Energy). 1995b. Remedial Investigation/Feasibility Study for the Clinch River/Poplar Creek Operable Unit. DOE/OR/01-1393. U.S. Department of Energy, Oak Ridge, Tenn.

Domingo, J.L., J.L. Paternain, J.M. Llobet, and J. Corbella. 1986. "Effects of vanadium on reproduction, gestation, parturition and lactation in rats upon oral administration." Life Sci. 39:819-824.

Dowdy, S., and S. Wearden. 1983. Statistics for Research. John Wiley and Sons. New York.

Dunning, J.B. 1984. Body Weights of 686 Species of North American Birds. West. Bird Banding Assoc. Monogr. No. 1. Eldon Publ. Co. Cave Creek, Ariz.

Eckerman, K.F., and J.C. Ryman. 1993. External Exposure to Radionuclides in Air, Water, and Soil. EPA 402-R-93-081 Federal Guidance Report No. 12. Office of Radiation and Indoor Air, U.S. Environmental Protection Agency, Washington, D.C.

Edens, F.W., E. Benton, S.J. Bursian, and G.W. Morgan. 1976. "Effect of Dietary Lead on Reproductive Performance in Japanese Quail, Coturnix coturnix japonica." Toxicol. Appl. Pharmacol. 38:307-314.

EPA (U. S. Environmental Protection Agency). 1986c. 90-day Gavage Study in Albino Rats Using Acetone. Office of Solid Waste, Washington, D.C.

EPA (U. S. Environmental Protection Agency). 1993a. Wildlife Exposure Factors Handbook. Vol. I. EPA/600/R-93/187a. Office of Research and Development, Washington, D.C.

EPA (U. S. Environmental Protection Agency). 1993b. Wildlife Exposure Factors Handbook. Vol. II. EPA/600/R-93/187b. Office of Research and Development, Washington, D.C.

EPA. (U. S. Environmental Protection Agency). 1993d. Wildlife Criteria Portions of the Proposed Quality Guidance for the Great Lakes System. EPA/822/R-93/006. Office of Science and Technology, Washington, D.C.

EPA. (U.S. Environmental Protection Agency). 1995. Great Lakes Water Quality Initiative Technical Support Document for Wildlife Criteria. EPA/820/B-95/009. U.S. Environmental Protection Agency, Washington D.C.

Feron, V.J., C.F.M. Hendriksen, A.J. Speek, etal. 1981. "Lifespan oral toxicity study of vinyl chloride in rats." Food Cosmet. Toxicol. 13:633-638.

Ford, C. J., J. E. Nyquist, S. T. Puruker, and R. F. Winterfield. 1996. Characterization and Inventory of Contaminants in WAG 2 Floodplain Soils of White Oak Creek. ORNL/TM-13208. Energy Systems Restoration Program, Oak Ridge, TN.

Formigli, L., R. Scelsi, P. Poggi, C. Gregotti, A. DiNucci, E. Sabbioni, L. Gottardi, and L. Manzo. 1986. "Thallium induced testicular toxicity in the rat." Environ. Res. 40:531-539. 
Franson, J. C. 1996. "Interpretation of tissue lead residues in birds other than waterfowl." pp. 265279. In W. N. Beyer, G. H. Heinz and A. W. Redmon-Norwood (eds.), Environmental Contaminants in Wildlife. Lewis Publishers, New York.

Furness, R. W. 1996. "Cadmium in birds. pp.389-404. In W. N. Beyer, G. H. Heinz and A. W. Redmon-Norwood (eds.), Environmental Contaminants in Wildlife. Lewis Publishers, New York.

George, S.B., J.R. Choate, and H.H. Genoways. 1986. “Blarina brevicauda." Mamm. Species. 261:19.

Gerell, R. 1970. "Home ranges and movements of the mink Mustela vison Schreber in southern Sweden." Oikos 21:160-173.

Getz, L.L. 1989. “A 14-year study of Blarina brevicauda populations in east-central Illinois." J. Mamm. 70: 58-66.

Green, D.A. and J.S. Millar. 1987. "Changes in gut dimensions and capacity of Peromyscus maniculatus relative to diet quality and energy needs." Can. J. Zool. 65:2159-2162.

Hamilton, W.J.JJr. 1940. "The summer food of minks and raccoons on the Montezuma marsh." New York. J. Wildl. Manage. 4:80-84.

Hammonds, J.S., F.O. Hoffman, and S.M. Bartell. 1994. An Introductory Guide to Uncertainty Analysis in Environmental and Health Risk Assessment. ES/ER/TM-35/R1. Oak Ridge National Laboratory, Oak Ridge, Tenn.

Haseltine, S.D., L. Sileo, D.J. Hoffman, and B.D. Mulhern. 1985. "Effects of chromium on reproduction and growth in black ducks."

Healy, J.W. 1980. "Review of resuspension models."pp. 209-235. In W. C. Hanson (ed.) Transuranic Elements in the Environment. U.S. Department of Energy, Washington, D.C.

Heinz, G.H. 1979. "Methyl mercury: reproduction and behavioral effects on three generations of mallard ducks." J. Wildl. Mgmt. 43:394-401.

Heinz, G. H. 1996. "Selenium in birds." p. 447-458. In W. N. Beyer, G. H. Heinz, and A. W. Redmon-Norwood (eds.), Environmental Contaminants in Wildlife. Lewis Publishers, New York.

Heinz, G.H. , D.J. Hoffman, A.J. Krynitsky, and D.M.G. Weller. 1987. "Reprouction in mallards fed selenium." Environ. Toxicol. Chem. 6:423-433.

Hicks, D. 1996. Waste Area Grouping 2 Phase I Remedial Investigation Seep Task Data Report: Contaminant Source Area Assessment. ORNL/ER-363. Energy Systems Restoration Program, Oak Ridge, TN.

Hockman, J. G., and J. A. Chapman. 1983. "Comparative feeding habits of red foxes (Vulpes vulpes) and gray foxes (Urocyon cinereoargenteus) in Maryland." Amer. Midl. Natur. 110(2): 276-285.

IAEA (International Atomic Energy Agency). 1976. Effects of Ionizing Radiation on Aquatic Organisms and Ecosystems. IAEA Technical Report Series 172. Vienna, Austria. 
IAEA (International Atomic Energy Agency). 1982. Generic Models and Parameters for Assessing the Environmental Transfer of Radionuclides from Routine Releases: Exposures of Critical Groups. IAEA Report No 57, IAEA, Vienna, Austria.

IAEA (International Atomic Energy Agency). 1992. Effects of Ionizing Radiation on Plants and Animals at Levels Implied by Current Radiation Protection Standards. IAEA Technical Report Series 332. Vienna, Austria.

IAEA (International Atomic Energy Agency). 1994. Handbook of Parameter Values for the Prediction of Radionuclide Transfer in Temperate Environments. IAEA Technical Report Series 364, Vienna, Austria.

ICRP (International Commision on Radiological Protection). 1983. Radionuclide Transformations: Energy and Intensity of Emissions. ICRP Report No 38.

Janes, S.W. 1984. "Influences of territory compostion and interspecific competition on red-tailed hawk reproductive success.” Ecology. 65: 862-870.

Johnson, D., Jr., A.L. Mehring, Jr., and H.W. Titus. 1960. “Tolerance of chickens for barium.” Proc. Soc. Exp. Biol. Med. 104:436-438.

Korschgen, L.J. 1958. "December food habits of mink in Missouri." J. Mamm. 39:521-527.

Korschgen, L. J. 1967. Feeding habits and foods. pp. 137-198. In the wild turkey and its management. O. H. Hewitt (ed.). The Wildlife Society, Inc., Bethesda, Md.

Lackey, J.A., D.G. Huckaby, and B.G. Ormiston. 1985. "Peromyscus leucopus." Mamm. Species 247:1-10.

Lamb, J.C., IV, R.E. Chapin, J. Teague, A.D. Lawton, and J.R. Reel. 1987. "Reproductive effects of four phthalic acid esters in the mouse." Toxicol. Appl. Pharmacol. 88:255-269.

Landrum, C.L., T.L. Ashwood, and D.K. Cox. 1993. Belted Kingfishers as Ecological Monitors of Contaminations: A Review. ORNL/M-2533. Oak Ridge National Laboratory, Oak Ridge, Tenn.

Lane, R. W., B. L. Riddle, and J. F. Borzelleca. 1982. "Effects of 1,2-dichloroethane and 1,1,1trichloroethane in drinking water on reproduction and development in mice." Toxicol. Appl. Pharmacol. 63:409-421.

Laskey, J.W., G.L. Rehnberg, J.F. Hein, and S.D. Carter. 1982. "Effects of chronic manganese $\left(\mathrm{Mn}_{3} \mathrm{O}_{4}\right)$ exposure on selected reproductive parameters in rats." J. Toxicol. Environ. Health. 9:677-687.

Laskey, J.W., and F.W. Edens. 1985. "Effects of chronic high-level rnanganese exposure on male behavior in the Japanese quail (Cotirnix coturnix japonica)." Poult. Sci. 64:579-584.

Leach, R. M., K. W.-L. Wang, and D. E. Baker. 1979. "Cadmium and the food chain: the effect of dietary cadmium on tissue composition in chicks and laying hens." J. Nutr. 109:437-443. 
Lepore, P.D., and R.F. Miller, 1965. "Embryonic viability as influenced by excess molybdenum in chicken breeder diets." Proc. Soc. Exp. Biol. Med. 118:155-157

Mackenzie, K.M. and D.M. Angevine. 1981. "Infertility in mice exposed in utero to benzo[a]pyrene." Biol. Reprod. 24:183-191.

Mackenzie, R.D., R.U. Byerrum, C.F. Decker, C.A. Hoppert, and R.F. Langham. 1958. "Chronic toxicity studies, II. Hexavalent and trivalent chromium administered in drinking water to rats." Am. Med. Assoc. Arch. Ind. Health. 18:232-234.

Marathe, M.R.,and G.P. Thomas. 1986. "Embryotoxicity and teratogenicity of lithium carbonate in Wistar rat." Toxicol. Lett. 34:115-120.

Marchinton, R.L., and D.H. Hirth. 1984. "Behavior." pp. 129-168. In L. K. Halls (ed.) White-tailed Deer: Ecology and Managenent. Stackpole Books, Harrisburg, Penn.

Mautz, W.W., H. Silver, J.B. Holter, H.H. Hayes, and W.E. Urban. 1976. "Digestibility and related nutritional data for seven northern deer browse species." J. Wildl. Manage. 40(4):630-638.

Mehring, A.L., Jr., J.H. Brumbaugh, A.J. Sutherland, and H.W. Titus. 1960. "The tolerance of growing chickens for dietary copper." Poult. Sci. 39:713-719.

Miller, D.H., and L.L. Getz. 1977. "Factors influencing local distribution and species diversity of forest small mammals in New England." Can. J. Zool. 55: 806-814.

Mineau, P., B.T. Collins, and A. Baril. 1996. "On the use of scaling factors to improve interspecies extrapolation of acute toxicity in birds." Regulatory Toxicology and Pharmacology. In press.

Mitchell, J.L. 1961. “Mink movements and population on a Montana river." J. Wildl. Manage. 25:4854.

NCA (National Coffee Association). 1982. 24-month chronic toxicity and oncogenicity study of methylene chloride in rats. Final report. Hazelton Laboratories, Inc., Vienna, Va.

NCRP (National Council on Radiation Protection and Measurements). 1987. Recommendations on Limits for Exposure to Ionizing Radiation. NCRP Report No. 91, National Council on Radiation Protection and Measurements, Bethesda, Md.

NCRP (National Council on Radiation Protection and Measurements). 1989. Screening Techniques for Determining Compliance with Environmental Standards: Releases of Radionuclides to the Atmosphere. NCRP Commentary No. 3.

National Geographic Society. 1987. Field Guide to the Birds of North America. 2nd Edition.

Nawrot, P.S., and R.E. Staples. 1979. "Embryofetal toxicity and teratogenicity of benzene and toluene in the mouse." Teratology. 19:41A.

NCRP (National Council on Radiation Protection and Measurements). 1991. Effects of Ionizing Radiation on Aquatic Organisms. NCRP Report No 109. National Council on Radiation Protection and Measurements, Bethesda, Md. 
Nicholson, J. K., and D. Osborn. 1983. "Kidney lesions in pelagic seabirds with high tissue levels of cadmium and mercury." J. Zool. (Lond.) 200:99-118.

Ondreicka, R., E. Ginter, and J. Kortus. 1966. "Chronic toxicity of aluminum in rats and mice and its effects on phosphorus metabolism." Brit. J. Indust. Med. 23:305-313.

Opresko, D.M., B.E. Sample, and G.W. Suter, II. 1995. Toxicological Benchmarks for Wildlife: 1995 Revision. ES/ER/TM-86/R2. Oak Ridge National Laboratory, Oak Ridge, Tenn.

Oswald, C., P.Fonken, D. Atkinson, and M. Palladino. 1993. "Lactational water balance and recycling in white-footed mice, red-backed voles, and gerbils." J. Mammal. 74:963-970.

Palmer, A.K., A.E. Street, F.J.C. Roe, A.N. Worden, and N.J. Van Abbe. 1979. "Safety evaluation of toothpaste containing chloroform, II. Long term studies in rats." J. Environ. Pathol. Toxicol. 2:821-833.

Pattee, O.H. 1984. "Eggshell thickness and reproduction in American kestrels exposed to chronic dietary lead." Arch Environ. Contam. Toxicol. 13:29-34.

Peakall, D.B. 1974. "Effects of di-N-buylphthalate and di-2-ethylhexylphthalate on the eggs of ring doves." Bull. Environ. Contam. Toxicol. 12:698-702.

Perry, H.M., E.F. Perry, M.N. Erlanger, and S.J. Kopp. 1983. "Cardliovascular effects of chronic barium ingestion." In Proceedings of the. 17th Annual Conference on Trace Substances in Environmental Health, Vol. 17. U. of Missouri Press, Columbia, Mo..

Peterson, M. A., R. R. Petri, G. R. Southworth. 1994. "Bioaccumulation studies." In T. L. Ashwood (ed.), Eighth Annual Report on the ORNL Biological Monitoring and Abatement Program. Draft ORNL/TM-12767. Oak Ridge National Laboratory, Oak Ridge, Tenn.

Sample, B.E., L.A. Baron, and B.L. Jackson. 1995. Preliminary Assessment of the ecological risks to wide-ranging wildlife species on the Oak Ridge Reservation. DOE/OR/01-1407\&D1. Oak Ridge, Tenn.

Sargeant, A.B. 1972. "Red fox spatial characteristics in relation to waterfowl predation." J. Wildl. Manage. 36:225-236.

Sargeant, A.B. 1978. "Red fox prey demands and implications to prairie duck production." J. Wildl. Manage. 42(3):520-527.

Schlatterer, B., T.M.M. Coenen, E. Ebert, R. Grau, V. Hilbig, and R. Munk. 1993. "Effects of Bis(tri$n$-butyltin)oxide in Japanese quail exposed during egg laying period: an interlaboratory comparison study." Arch. Environ. Contam. Toxicol. 24:440-448.

Schlesinger, W.H. and G.L. Potter. 1974. "Lead, copper, and cadmium concentrations in small mammals in the Hubbard Brook experimental forest." Oikos. 25:148-152.

Schlicker, S.A., and D.H. Cox. 1968. "Maternal dietary zinc and development; zinc, iron, and copper content of the rat fetus." J. Nutr. 95:287-294. 
Schroeder, H.A., M. Mitchener, J.J. Balassa, M. Kanisawa, and A.P. Nason. 1968. "Zirconium, niobium, antimony, and fluorine in mice: effects on growth, survival and tissue levels." J. Nutr. 95:95-101.

Schroeder, H. A., and M. Mitchener. 1971. "Toxic effects on the reproduction of mice and rats." Arch. Environ. Health 23:102-106.

Schroeder, H. A., and M. Mitchener. 1975. "Life term studies in rats: effects of aluminum, barium, beryllium, and tungsten." J. Nutr. 105:421-427.

Sealander, J.A. 1943. "Winter food habits of mink in southern Michigan." J. Wildl. Manage. 7: 411417.

Skoryna, S.C. 1981. "Effects of oral supplementation with stable strontium." Can. Med. Assoc. J. 125:703-712.

Smith W.P. 1991. “Odocoileus virginianus.” Mammalian Species. 388:1-13.

Smith, G.J., and V.P. Anders. 1989. “Toxic effects of boron on mallard reproduction." Environ. Toxicol. Chem. 8:943-950.

Stahl, J.L., J.L. Greger, and M.E. Cook. 1990. "Breeding-hen and progeny performance when hens are fed excessive dietary zinc.” Poult. Sci. 69: 259-263.

Steven, J.D., L.J. Davies, E.K. Stanley, R.A. Abbott, M. Ihnat, L. Bidstrup, and J.F. Jaworski. 1976. "Effects of chromium in the Canadian environment." NRCC No. 151017.

Stevens, R.T., 1995. Heavy Metals and PCBs in Mink (Mustela vison) and Muskrat (Ondatra zibethcus) from the U.S. Department of Energy's Oak Ridge Reservation. unpubl. Masters Thesis. Tennesee Technological University. Cookville, Tenn.

Storer, N.L., and T.S. Nelson. 1968. "The effect of various aluminum compounds on chick performance." Poult. Sci. 47:244-247.

Storm, G.L., R.D. Andrews, R. L. Phillips, R.A. Bishop, D.B. Siniff, and J.R. Tester. 1976. "Morphology, reproduction, dispersal, and mortality of midwestern red fox populations." Wildl. Monogr.

Suter, G. W., B. E. Sample, D. S. Jones, and T. L. Ashwood. 1995. Approach and Strategy for Performing Ecological Risk Assessments for the U.S. Department of Energy's Oak Ridge Reservation: 1995 Revision. ES/ER/TM-33/R2, Oak Ridge National Laboratory, Oak Ridge, Tenn.

Talmage, S.S., and B.T. Walton. 1993. "Food chain transfer and potential renal toxicity to small mammals at a contaminated terrestrial field site." Ecotoxicology. 2:243-256

Tewe, O.O., and J.H. Maner. 1981 "Long-term and carry-over effect of dietary inorganic cyanide (KCN) in the life cycle performance and metabolism of rats." Toxicol. Appl. Pharmacol.58:1-7. 
Thompson, D. R. 1996."Mercury in birds and terrestrial mammals." pp. 341-356. In W. N. Beyer, G. H. Heinz, and A. W. Redmon-Norwood (eds.), Environmental Contaminants in Wildlife. Lewis Publishers, New York.

Torgerson, O., and W.R. Porath. 1984. "Midwest oak/hickory forest." pp. 411-426. In White-Tailed Deer: Ecology and Management.

U.S. Fish and Wildlife Service. 1964. "Pesticide-wildlife studies, 1963: a review of Fish and Wildlife Service investigations during the calender year." FWS Circular 199.

U.S. Fish and Wildlife Service. 1969. "Bureau of sport fisheries and wildlife." Publication 74.

van Gestel, C. A. M. 1992. "The influence of soil characteristics on the toxicity of chemicals for earthworms: a review." pp. 44-54. In Ecotoxicology of Earthworms. P. W. Grieg-Smith et al. (eds). Intercept Ltd.

van Zyll de Jong, C.G. 1983. Handbook of Canadian Mammals. National Museums of Canada.

Verschuuren, H.G., R. Kroes, E.M. Den Tonkelaar, J.M. Berkvens, P.W. Helleman, A.G. Rauws, P.L. Schuller, G.J. Van Esch. 1976c. "Toxicity of methylmercury in rats I. reproduction study." Toxicology 6:97-106.

Vogtsberger, L.M. and G.W. Barrett. 1973. "Bioenergetics of captive red foxes." J. Wildl. Manage. 37(4): $495-500$.

Washington-Allen, R.A., T.L. Ashwood, S.W. Christensen. 1995. Terrestrial Mapping of the Oak Ridge Reservation: Phase 1.ES/ER/TM-152. Oak Ridge National Laboratory, Oak Ridge, Tenn.

Weir, R.J., and R.S. Fisher. 1972. "Toxicological studies on borax and boric acid." Toxicol. Appl. Pharmacol. 23:351-364.

Whitaker, J.O., Jr., and M.G. Ferrraro. 1963. "Summer food of 220 short-tailed shrews from Ithica, New York." J. Mamm. 44:419.

Whitaker, J.O., Jr. 1966. "Food of Mus musculus, Peromyscus maniculatus bairdi, and Peromyscus leucopus in Vigo County, Indiana." J. Mamm. 47:473-486.

White, D.H. and M.P. Dieter. 1978. "Effects of dietary vanadium in mallard ducks." J. Toxicol. Environ. Health. 4:43-50.

White, D.H., and M.T. Finley. 1978. "Uptake and retention of dietary cadmium in mallard ducks." Environ. Res. 17:53-59.

Will, M. E., and G. W. Suter, II. 1995a. Toxicological Benchmarks jor Potential Contaminants of Concern for Effects on Soil and Litter Invertebrates and Heterotrophic Process. ES/ER/TM126/R2, Oak Ridge National Laboratory, Oak Ridge, Tenn.

Will, M. E., and G. W. Suter, II. 1995b. Toxicological Benchmarks jor Potential Contaminants of Concern for Effects on Terrestrial Plants. ES/ER/TM-85/R2, Oak Ridge National Laboratory, Oak Ridge, Tenn.. 
Wills, J.H., G.E. Groblewski, and F. Coulston. 1981. "Chronic and multigeneration toxicities of small concentrations of cadmium in the diet rats." Ecotoxicol. Environ. Safety. 5:452-464.

Wobeser, G., N. O. Nielsen, and B. Schiefer. 1976. "Mercury and mink. II. Experimental methylmercury intoxication." Can. J. Comp. Med. 40:34-45.

Wolff, J.O., R.D. Dueser, and K. S. Berry. 1985. "Food habits of sympatric Peromyscus leucopus and Peromyscus maniculatus" J. Mamm. 66:795-798.

Wolff, J.O. 1985. "The effects of density, food, and interspecific interference on home range size in Peromyscus leucopus and Peromyscus maniculatus." Can. J. Zool. 63:2657-2662. 
Appendix A

BENTHIC MACROINVERTEBRATE COMMUNITY STUDY OF WASTE AREA GROUPING 2 DEPOSITION AREAS 



\section{BENTHIC MACROINVERTEBRATE COMMUNITY STUDY OF WASTE AREA GROUPING 2 DEPOSITION AREAS}

November 17, 1995

Mark R. Smith and John G. Smith Biological Monitoring and Abatement Program Environmental Sciences Division Oak Ridge National Laboratory Jaycor 


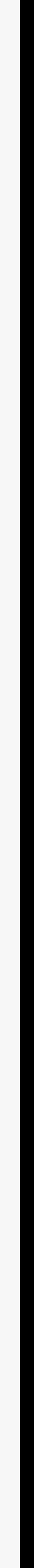




\section{INTRODUCTION}

Benthic macroinvertebrates are organisms visible to the unaided eye that inhabit the bottom substrates of aquatic systems, and include organisms such as insects, mollusks, crustaceans, annelids, bryozoans, and planarians (Platts et al. 1983). Because these organisms live in close association with the substrate and have relatively long life spans, analyses of benthic macroinvertebrate community composition can aid in assessing the role of sediment contaminants in overall system "health." Benthic macroinvertebrates have been collected from riffle areas in streams of the White Oak Creek (WOC) watershed since 1986 for the Biological Monitoring and Abatement Program (BMAP) at Oak Ridge National Laboratory (ORNL). However, deposition areas (e.g., pools, White Oak Lake) have not been sampled. It is in these areas that contaminants entering the watershed may accumulate, and therefore have a greater impact.

The objectives of this study were to evaluate the ecological condition of the benthic macroinvertebrate communities in major areas of sediment deposition in streams of the WOC watershed in Waste Area Grouping (WAG) 2, and to evaluate whether significant ecological damage would result from maintenance operations.

This study focused on major deposition areas in WOC watershed including White Oak Lake (WOL) and two weirs each on WOC and Melton Branch (MEB).

\section{DESCRIPTION OF STUDY AREAS}

Samples were collected from six sites within WAG 2 (Fig. 1) and four sites outside WAG 2 that served as references (Figs. 1 and 2). Sampling sites in WAG 2 included two each in WOL, WOC, and MEB. In WOL, the sampling sites were located approximately $100 \mathrm{~m}$ and $300 \mathrm{~m}$ upstream of WOL Dam, and were referred to as WOLLS and WOLUS, respectively. In WOC, one site was located at the X-14 weir just upstream of the confluence with MEB, and the other was located at the weir just downstream of Melton Valley Drive; these sites were referred to as WOCLS and WOCUS, respectively. In MEB, one site was located in the deposition area just upstream of the X-13 weir (MEBLS), and the other was located approximately $200 \mathrm{~m}$ downstream of the HFIR discharge tributary (MEBUS).

Artificial impoundments were selected as reference sites based on similarities in physical structure (substrate type, water depth, and width) (Table 1). Reference sites consisted of two locations within the main ORNL complex on streams just north of Bethel Valley Road; First Creek and WOC (Fig. 1). The two other reference sites were located on Clear Creek, located just southeast of Norris Dam in Norris, Tennessee (Fig. 2). The First Creek site, located $\sim 28 \mathrm{~m}$ upstream of Bethel Valley Road, was a small impoundment behind a spill dam; this site was referred to as First Creek Pool (FCP). A weir on WOC (WCK68), located approximately 6.8 kilometers above the mouth of the stream was also used as a reference site. This site was located just downstream of a reference site used in the ORNL BMAP. The two remaining reference sites (CCKLD and CCKUD) were above spill dams on Clear Creek (Fig. 2), a relatively undisturbed stream with little development from its headwaters to the mouth of the stream. 


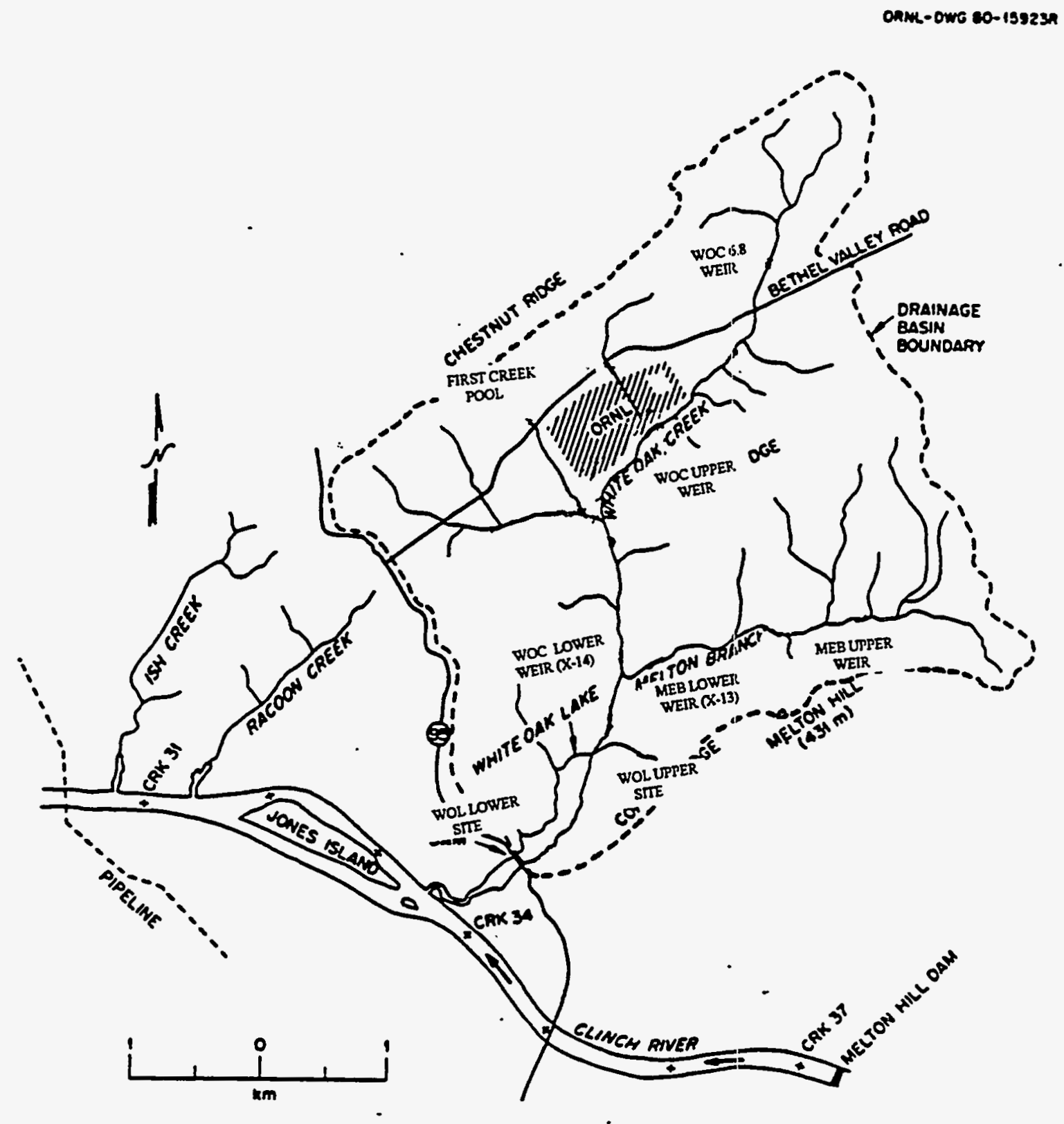

Fig. A.1. Location of benthic macroinvertebrate core sampling sites on the Oak Ridge Reservation. 


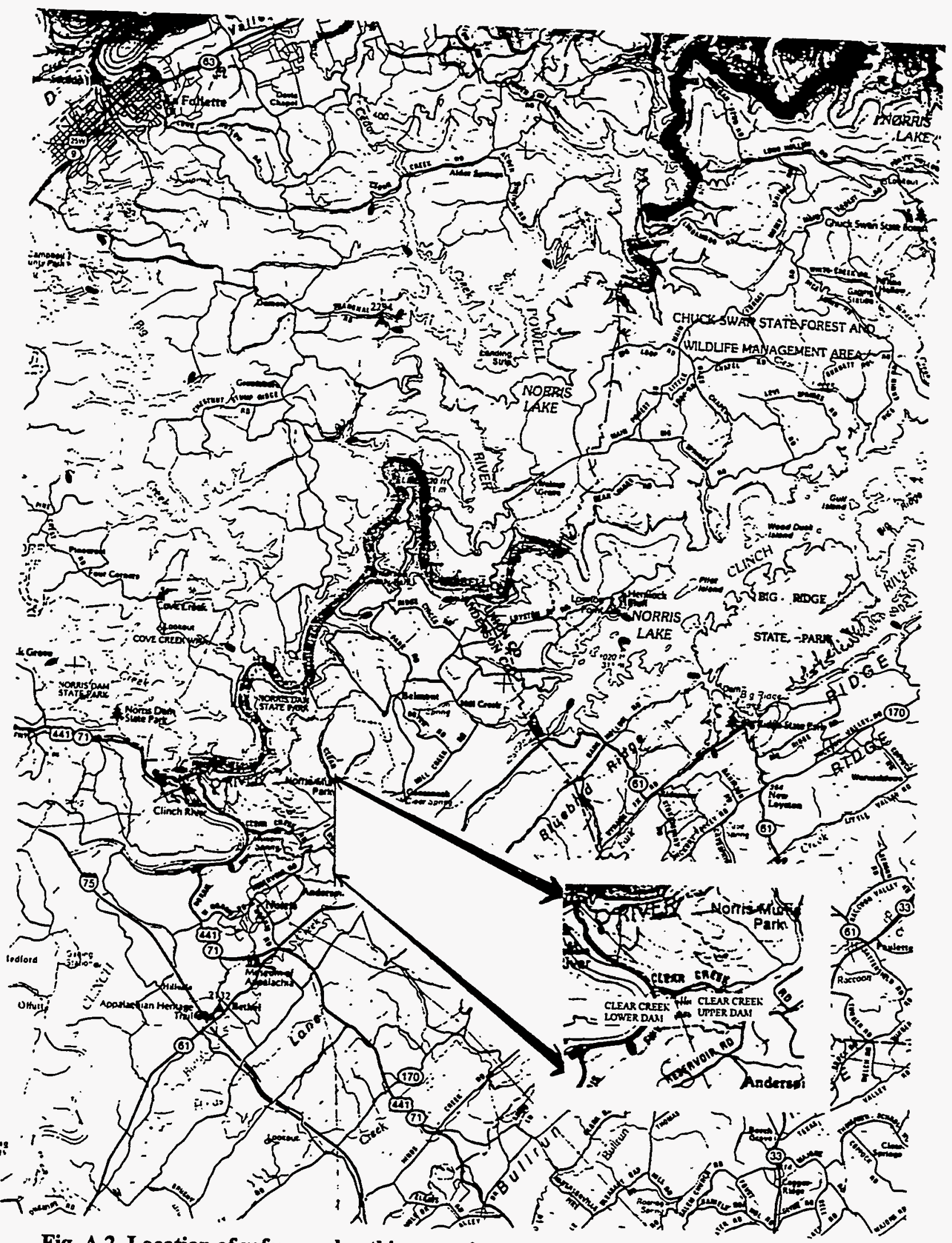

Fig. A.2. Location of reference benthic macroinvertebrate core sampling sites on Clear Creek, Anderson County, Tennessee. 


\section{A-8}

Table A.1. Summary of physical characteristics of the WAG 2 study sites and reference sites (June 1995)

\begin{tabular}{|c|c|c|c|}
\hline Site & Average depth $(\mathrm{cm})$ & Substrate type & Transect width (m) \\
\hline 1. & 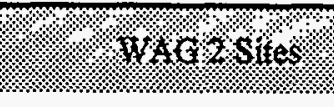 & א. & \% \\
\hline $\begin{array}{l}\text { WOC lower weir } \\
\text { (WOCLS) }\end{array}$ & 18.2 & Silt & 16.0 \\
\hline $\begin{array}{l}\text { WOC upper weir } \\
\text { (WOCUS) }\end{array}$ & 36.6 & Silt & 14.0 \\
\hline $\begin{array}{l}\text { Melton Branch } \\
\text { lower weir } \\
\text { (MEBLS) }\end{array}$ & 51.8 & Silt & 6.0 \\
\hline $\begin{array}{l}\text { Melton Branch } \\
\text { upper weir } \\
\text { (MEBUS) }\end{array}$ & 41.4 & Gravel/sand/silt & 4.3 \\
\hline $\begin{array}{l}\text { WOL' lower site } \\
\text { (WOLLS) }\end{array}$ & 100.2 & Silt: & 170.0 \\
\hline $\begin{array}{l}\text { WOL }{ }^{b} \text { upper site } \\
\text { (WOLUS) }\end{array}$ & 41.4 & Silt: & 180.0 \\
\hline (1) & ? & 1.: & (2. \\
\hline $\begin{array}{l}\text { First Creek pool } \\
\text { (FCP) }\end{array}$ & 32.2 & Silt/derritus & 19.0 \\
\hline $\begin{array}{l}\text { WOC } 6.8 \text { weir } \\
\text { (WCK 68) }\end{array}$ & 22.2 & Gravel/sand/silt & 4.0 \\
\hline $\begin{array}{l}\text { Clear Creek } \\
\text { lower dam } \\
\text { (CCKLD) }\end{array}$ & 78.8 & Gravel/sand/silt & 19.0 \\
\hline $\begin{array}{l}\text { Clear Creek } \\
\text { upper dam } \\
\text { (CCKUD) }\end{array}$ & 74.6 & Silt/detritus & 20.2 \\
\hline
\end{tabular}

${ }^{2} W O C=$ White Oak Creek; 'WOL $=$ White Oak Lake. 


\section{MATERIALS AND METHODS}

\subsection{SAMPLE COLLECTION}

Before collection of invertebrate samples, various chemical and physical aspects (D.O., conductivity, $\mathrm{pH}$, temperature, site width, and water depth) were measured at each site, in accordance with Standard Operating Procedures (SOP-3) of the BMAP Benthic Macroinvertebrate Monitoring Project Quality Assurance Plan (Q.P.) (Smith 1992). Five replicate macroinvertebrate samples were collected from each site with a hand-held coring device. The coring device had an internal diameter of $5 \mathrm{~cm}$, and was inserted into the substrate to a depth of $20.5 \mathrm{~cm}$. An aluminum skirt $(27 \times 27 \mathrm{~cm})$ attached to the corer ensured consistent sampling depths. Following procedures outlined in section 7 , SOP-5 of the Benthic Macroinvertebrate Q.P., sample replicates were taken at evenly spaced intervals along a transect running perpendicular to the shoreline at each site. After the corer was extracted from the substrate, the contents were emptied into a Surber net ( $363-\mu \mathrm{m}$ mesh), and substrate composition was determined by visual inspection, using methods described in SOP-2.

After identifying substrate composition, the Surber net containing the sample was lowered into the water and gently agitated to flush out the fine sediments. The contents of the net were then transferred into an appropriately labeled sample jar, and preserved in $80 \%$ ethanol. Prior to processing, samples were stored and maintained in a secure storage facility at ORNL, in accordance with approved quality assurance procedures (SOP-9, Smith 1992).

\subsection{LABORATORY PROCEDURES}

Appropriate procedures outlined in the BMAP Benthic Macroinvertebrate Monitoring Project Sample Processing QA Plan (Wojtowicz and Smith 1992) were followed for processing samples. Briefly, sample processing consisted of washing each sample in a $250 \mu \mathrm{m}$ sieve and sorting the remaining organisms to the lowest practical taxon. Chironomidae (midge) larvae were mounted on microscope slides for identification under compound microscopes, while the remaining organisms were identified using stereo microscopes. A reference collection was created containing two or three specimens of each taxon encountered.

The procedure normally followed for evaluating sorting efficiency (SOP- 4 in Wojtowicz and Smith 1992) was modified for processing WAG 2 samples because it was felt that the modified procedure was more rigorous. In the original procedure, half the sample material sorted by an individual is randomly selected for resorting by a different individual. If the prescribed sorting efficiency of $80 \%$ is not met, all of the future material sorted by the individual that failed is checked until that individual can consistently achieve the prescribed efficiency. In the procedure used for WAG 2 samples, if any of an individual's randomly checked samples (i.e., of the $10 \%$ checked) do not meet the prescribed sorting efficiency of $80 \%$, then all of that individuals sorted material is resorted. If an individual always sorts samples at or above the prescribed efficiency level, sorting proceeds more rapidly. The results of sorting efficiency quality control checks for the WAG 2 samples are given in WAG 2 project files in a summary report provided by the laboratory that processed the samples. No sorting failures were reported for the WAG 2 samples. 


\subsection{DATA ANALYSIS}

Data analysis was performed with the aid of Statistical Analysis System software and procedures (SAS 1985a, 1985b). Statistical analyses consisted of both descriptive and parametric techniques. Descriptive techniques included determinations of mean values for density, total richness, EPT richness (the total number of Ephemeroptera, Plecoptera, and Trichoptera taxa), and Chironomidae taxa richness for each site. A one-way analysis of the variance (ANOVA) with site as the main effect was performed on density, total richness, and Chironomidae taxa richness. Site differences were separated with a Tukey's Test, with the level of significance set as $p \leq 0.05$. Because major differences in substrate were observed among some sites while samples were collected (Table 1), the analysis was repeated on two groups based on substrate type (i.e., silt and gravel). However, this analysis gave no indication that substrate was a major factor contributing to any differences. Therefore, no further detailed consideration was given to this factor in the results. Prior to performing the ANOVAs, values for each response variable were appropriately transformed (i.e. $\log _{10}(X+1)$ for density values, and square root of $\mathrm{X}$ for total and Chironomidae taxa richness values, where $\mathrm{X}=$ the individual values for density, taxonomic richness, and Chironomidae richness; Elliot 1977).

Because Ephemeroptera, Plecoptera, and Trichoptera (EPT) taxa are generally considered sensitive to environmental disturbance (Lenat 1988), BMAP benthic macroinvertebrate studies effectively use this metric to evaluate the biological condition of stream sites (e.g., Smith 1993). However, due to the very low numbers encountered at all sites (no site had a mean EPT richness above two), it was felt this metric would not be useful for characterizing WAG 2 sites or effectively separating any site differences, and therefore not considered further in the analysis.

\section{DATA ASSESSMENT}

The sampling and analysis plan developed and approved by project management for the benthic macroinvertebrate task of the WAG 2 Remedial Investigation (RI) resulted from issues and data deficiencies identified through the data quality objectives (DQO) process (Watkins and Herbes 1994). All goals established in the DQO process for this task were met.

\subsection{SAMPLE CHAIN-OF-CUSTODY}

Sample chain-of-custody was maintained and documented from collection through their final disposition in a secure area at ORNL after processing. Copies of the sample chain-of-custody sheets are in WAG 2 project files.

\subsection{COMPLETENESS}

Having developed the most extensive and suitable benthic macroinvertebrate sampling plan possible within budget constraints, anything less than $100 \%$ completion of the plan outlined in the RI Work Plan (Watkins and Herbes 1994) was considered unacceptable. All 50 samples collected for the project were processed, and the results from these samples are included in this report. 


\subsection{PRECISION}

An acceptable sampling precision for benthic macroinvertebrate studies is often controlled by budget constraints (Resh and McElravy 1993). A high level of precision (i.e., $< \pm 20 \%$ of the mean for benthic macroinvertebrate samples) can require an astronomical number of sampling units (e.g., $>100$ sampling units per site). It has been found however, that estimates of $\pm 40 \%$ of the true mean can generally be achieved with six sampling units (Resh and McElravy 1993). Thus, depending upon sample variation, five sample units as used in this study should allow differences in site means of two to three fold to be detected.

In the laboratory, no sorting efficiency failures occurred in the $10 \%$ of samples (i.e., 5 of 50 samples) subjected to quality control checks (see summary report in WAG 2 project files).

\subsection{DATA REVIEW}

The final data set was obtained in electronic form (Lotus $)$ and in hard copy from the laboratory that processed the samples. A copy of the data as submitted by the laboratory is provided in WAG 2 project files, as part of their final report submitted to the benthic macroinvertebrate task PI. The accuracy of the data was initially validated by comparing an output of the data from the electronic copy with the copy provided in the subcontractor's report. Procedures available with the Statistical Analysis System (SAS 1985a; SAS 1985b) allowed the data to be subjected to various sorts (i.e., rearrangements) to identify inconsistencies and misspellings. Inconsistencies and misspellings were corrected, and appropriate changes were made to make the data set compatible with other data collected by the task Principal Investigator since 1984 from other projects associated with the Department of Energy's Oak Ridge Operations; these changes had no affect on data accuracy or precision. Some observations were eliminated because they included taxa not considered benthic. The observations eliminated included those with the invertebrate taxa Corixidae, Entomobryidae, and Gerridae. These three taxonomic groups live on the surface of the water or in the water column and are sometimes collected accidentally with benthic sampling devices. A copy of the final data set used to conduct all analyses is provided in WAG 2 project files.

\section{RESULTS}

\subsection{TAXONOMIC COMPOSITION}

A checklist of benthic macroinvertebrate taxa collected at each site is presented in WAG 2 project files. There were a total of 105 taxa identified, with 60 of these being in the Chironomidae (Diptera) family. Taxonomic composition varied with site, with only one major taxonomic group being present at all sites (Oligochaeta). Although most taxa identified to the genus level were collected from less than $50 \%$ of the sites, Dubiraphia sp. (Elmidae: Coleoptera), and five Chironomidae genera (Chironomus, Cryptotendipes, Cryptochironomus, Stictochironomus, and Tanytarsus) were present in at least $60 \%$ of the sites.

Plecoptera were collected from three sites only, all of which were reference sites (CCKUD, FCP, and WCK68). Conversely, Megaloptera were collected only at three study sites (WOCLS, WOLLS, and MEBUS). 


\subsection{ABUNDANCE}

\subsubsection{Total density}

Mean densities ( number of organisms $/ 0.1 \mathrm{~m}^{2}$ ) for each site are presented in Fig. 3. Statistically significant differences in densities were not detected among any sites (Tables 2 and 3). Although large differences in densities appeared to exist among some of these sites (e.g., WOCLS had 954.8 organisms $/ 0.1 \mathrm{~m}^{2}$, compared to 132.3 organisms $/ 0.1 \mathrm{~m}^{2}$ at WOLUS), high variation among samples may have limited the ability of the test to detect statistically significant differences.

\subsubsection{Relative abundance}

Oligochaetes and chironomids were the predominant taxa at all sites, and except for FCP, WOCLS, and WOCUS, the Chironomidae accounted for over $60 \%$ of the total density (Fig. 4). Oligocheates and chironomids co-dominated at FCP and both WOC sites. The relative abundance of the other taxa, which included Coleoptera (beetles), Odonata (dragonflies), Gastropods (snails), Ephemeroptera (mayflies), Plecoptera (stoneflies), and Trichoptera (caddisflies), ranged from $1.54 \%$ at WOLUS to $27.6 \%$ at FCP.

Because of the predominance of the Chironomidae at most sites (i.e., $>35 \%$ of total density at all sites), a closer examination was made of the relative abundances of the major chironomid taxa to further characterize the study sites. Three of the four major taxonomic groups examined comprised $>5 \%$ of the total community density at five of the ten sites (Fig. 4). At the extremes in relative abundance, only two of the taxonomic groups exceeded $5 \%$ of the total community density at MEBLS, WOLUS, and FCP, while at CCKUD and WCK68, all four major taxonomic groups exceeded $5 \%$ of the total density. There were no distinct or consistent differences between the reference sites and the WAG 2 study sites in predominant taxa which made the WAG 2 sites uniquely different from the reference sites. For example, the Chironomini comprised half or more of the chironomid composition at the two Melton Branch sites, CCKUD, and WCK68, while at the two WOL sites and FCP, the Tanypodinae comprised over half of the total chironomid density.

\subsection{RICHINESS}

\subsubsection{Total richness}

The reference sites WCK68 and CCKUD had significantly higher total richness values than both WOL sites, while WOCUS had significantly higher richness values than WOLUS (Tables 2 and 3). The WOL sites did not have significantly lower richness values than the remaining sites, including the reference sites FCP and CCKLD.

\subsubsection{Chironomidae taxa richness}

Chironomidae taxon represented 60 of the 105 taxa identified. Statistical analyses were performed on four major taxa of Chironomidae (Tanypodinae, Tanytarsini, Orthocladiinae, and Chironomini) to ascertain if differences may have existed between any of the sites investigated. The pattern of differences among the sites in the richness of the Chironomidae closely resembled the pattern exhibited by total richness (Fig. 3). Chironomid richness was highest at CCKUD and WCK68, and lowest at the two WOL sites, with about a 3-fold difference existing between these high and low 


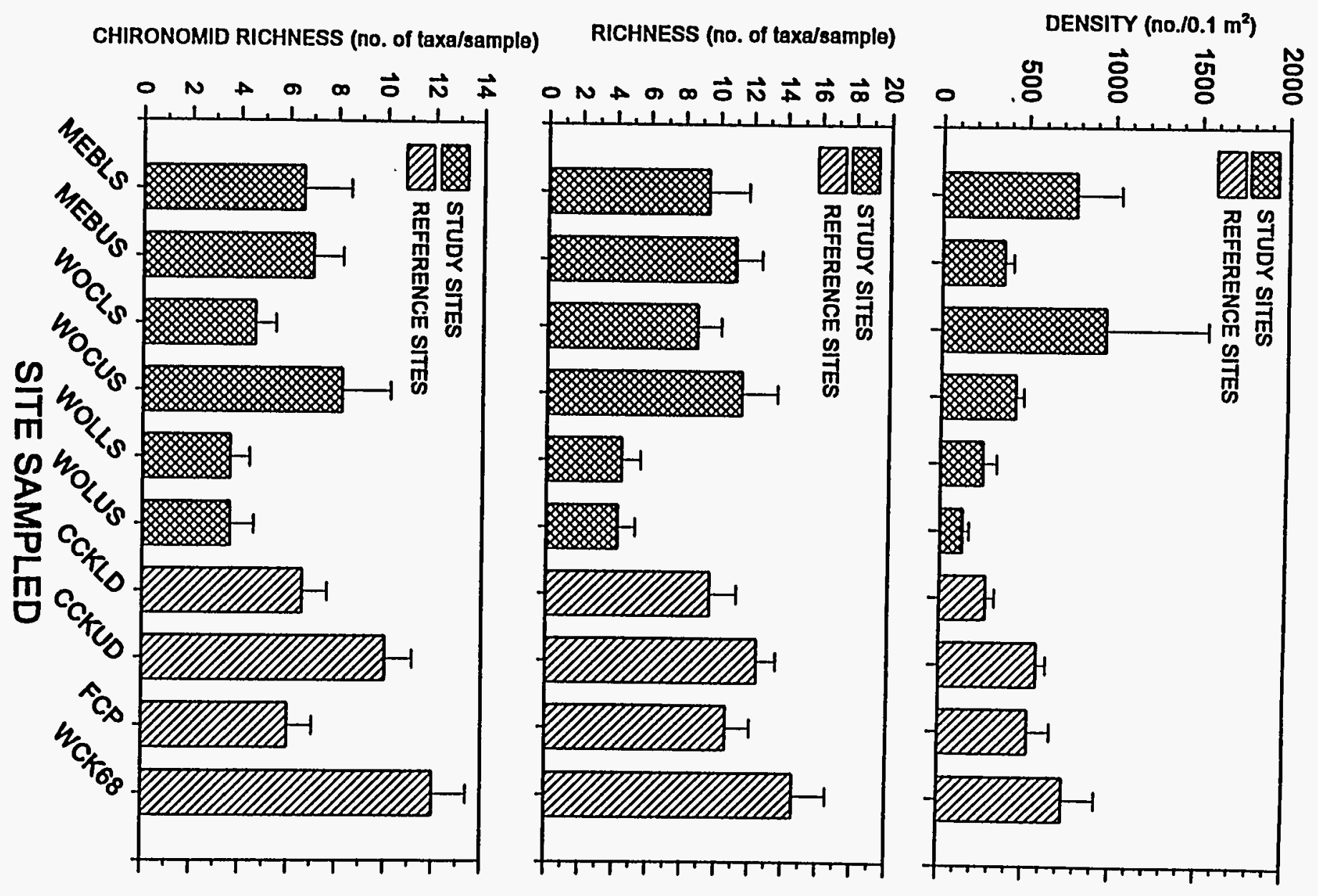


Table A.2. F-values and p-values for one-way analysis of variance (ANOVA) using therariables density, total richness, and Chironomidae taxa richness for benthic macroinvertebrate communities in WAG 2 and associated reference sites (June 1995)

\begin{tabular}{ccc}
\hline Variable $^{\mathrm{a}}$ & $f$-value & $p$-value \\
\hline Density & 1.15 & 0.3499 \\
Total Richness & 4.39 & 0.0005 \\
Chironomidae Richness & 3.63 & 0.0022 \\
\hline
\end{tabular}

Degrees of freedom $=9$ and 40 for numerator and denominator respectively.

Table A.3. Results of site comparisons with Tukey test of values for density, total richness, and Chironomidae taxa richness of the benthic macroinvertebrate communities in WAG 2 and associated reference sites, June 1995."

DENSITY

ALL

WOCLS MEBLS WCK68 WOLLS WOLUS CCKLD MEBUS FCP WOCUS CCKUD

TOTAL RICHNESS

ALL

WCK68 CCKUD WOCUS MEBUS FCP CCKLD MEBLS WOCLS WOLLS WOLUS

\section{CHIRONOMIDAE RICHINESS}

ALL

WCK68 CCKUD WOCUS MEBUS CCKLD MEBLS FCP WOCLS WOLLS WOLUS

\footnotetext{
'Sites not connected by the same line are significantly different $(p<0.05)$, based on Tukey's Studentized range test (HSD). Sites are arranged in order of highest to lowest values from left to right. $n=5$.
} 


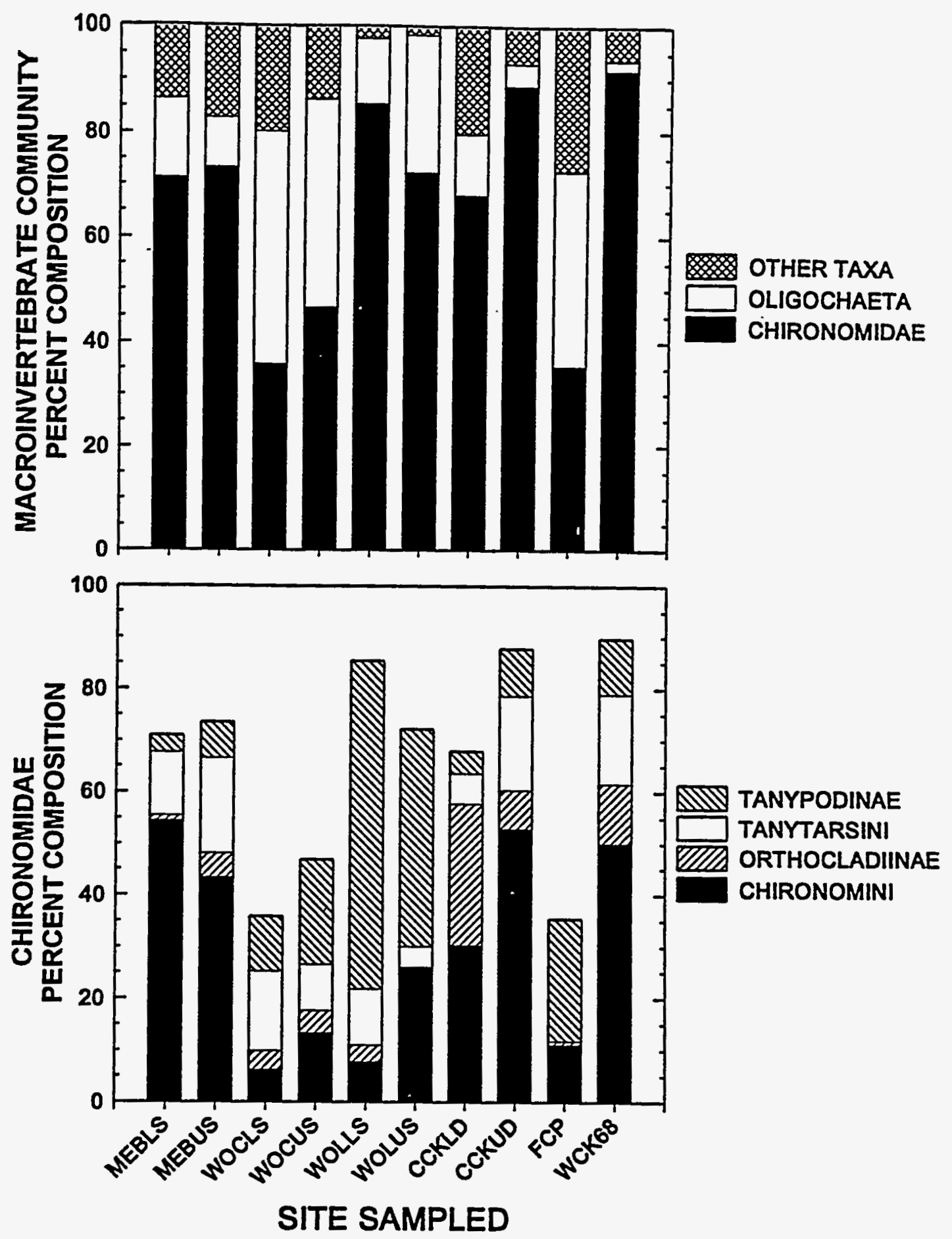

Fig. A.4. Relative abundance of selected benthic macroinvertebrate and of the major Chironomidae taxa at study sites in WAG 2 and associated reference sites, June 1995. The Chironominae were included as a separate taxonomic group because the individuals left in this group could not be further identified; further identification would have placed them within the Tanytarsini or Chironomini. 
values. However, only these site differences were statistically significant (Tables 2 and 3 ). Values for the other six sites were statistically indistinguishable from either those for CCKUD, WCK68, or the two WOL sites. This implies that chironomid richness at all WAG 2 siudy sites fell within the range that existed at the reference sites used in this study.

\section{DISCUSSION}

Several uncertainties were apparent within the benthic macroinvertebrate task. The small number of samples taken per site (five) allow only for the detection of large differences (i.e., $\geq 50 \%$ ). This was further complicated by the diverse habitat present at these sites. The resulting variability among sampling units limited the capacity to detect differences among sites. In addition, the single sampling event could not take into account the seasonal variation present in benthic macroinvertebrate communities, thus the possibility of failing to detect important site differences is increased. However, results reported in this study do provide an indication of benthic macroinvertebrate community composition at the various sites when the samples were taken. Identification of substrate composition did not include other substrate factors such as organic content. Because a majority of the organisms collected rely on organic materials in the substrate as a primary food source, organic content of the substrate at the various sites may have also influenced community composition.

There were no detectable statistically significant differences in densities among the WAG 2 and reference sites, possibly because sites with the highest densities also tended to have high variation among replicates. Relative abundance of the three categories of macroinvertebrates at each site indicated that with the exception of FCP, WOCUS, and WOCLS where oligochaetes co-dominated with the Chironomidae, chironomids were the most numerous organisms regardless of substrate type. This is not unexpected, since oligochaetes and Chironomidae use hemoglobin to aid in the uptake of oxygen, thus enabling them to inhabit areas where low oxygen levels can occur, such as areas of sediment deposition (Hynes 1974; Brinkhurst and Gelder 1991).

The two sites within WOL had the lowest values for all parameters investigated. However, these differences were only statistically significant from those of just two reference sites for total richness and Chironomidae taxa richness. White Oak Lake sites were clearly the most depauperate, although it is not possible to determine whether contaminants, habitat, or other perturbations are responsible for the condition of the benthic macroinvertebrate community. White Olak Lake impounds WOC for a substantial distance upstream of the two sampling sites, whereas at the other sites, impoundments resulting from the weirs were generally less than $50 \mathrm{~m}$ long. No reference sites were found of equivalent size , thus comparisons in benthic community composition with reference sites used in this study may not be entirely appropriate. The remaining sites within WAG 2 were generally similar to the reference sites.

The objectives of this study were to evaluate the ecological condition of the benthic macroinvertebrate community in sediment deposition areas of WAG 2, and to determine if significant ecological damage would result from routine maintenance operations. These results suggest that since no major differences existed between the MEB, WOC, and the reference sites, it appears that maintenance scheduled for the four WAG 2 weir sites will not impact any fragile or unique benthic macroinvertebrate communities, although short-term, severe impacts would occur to those communities currently existing. The presence of an apparently depauperate community in WOL also suggests that maintenance scheduled for this body of water should result in no major impacts to either a fragile or unique community. 


\section{LITERATURE CITED}

Brinkhurst, R. O., and S. R. Gelder. 1991. "Annelida: Oligochaeta and Brachiobdellida." pp 401-435. IN: J.H. Thorp and A. P. Covich (eds.), Ecology and Classification of North American Freshwater Invertebrates. Academic Press, Inc. San Diego, California.

Elliot, J. M. 1977. Some Methods for the Statistical Analysis of Samples of Benthic Invertebrates. Scientific Publication No. 25.FreshwaterBiological Association, Ambleside, England.

Hynes, H.B.N. 1974. The Biology of Polluted Waters. University of Toronto Press. Toronto, Canada.

Lenat, D. R. 1988. Water quality assessment of streams using a qualitative collection method for benthic macroinvertebrates. J. North Am. Benthol. Soc. 7:222-233.

Platts, W. W., W.F. Meghan, and G. W. Minshall. 1983. Methods for evaluating stream, riparian, and biotic conditions. U.S. Forest Service General Technical Report INT138. Intermountain Forest and Range Experimental Station, Ogden, UT.

Resh, V.H., and E. P. McElravy. 1993. "Contemporary Quantitative Approaches to Biomonitoring Using Benthic Macroinvertebrates.” pp. 159-194. IN: D. M. Rosenberg and V. H. Resh (eds.), Freshwater Biomonitoring and Benthic Macroinvertebrates. Chapman \& Hall, New York.

SAS (SAS Institute, Inc.). 1985a. SAS User's Guide: Basics, Version 5 Edition. SAS Institute, Inc., Cary, North Carolina.

SAS (SAS Institute, Inc.). 1985b. SAS User's Guide: Statistics, Version 5 Edition. SAS Institute, Inc., Cary, North Carolina.

Smith, J. G. 1992. Biological Monitoring and Abatement Program (BMAP) Benthic Macroinvertebrate Monitoring Project Sample Collection and Storage QA Plan. QAP-X-90-ES-068. Oak Ridge National Laboratory, Oak Ridge, Tennessee.

Watkins, D. R., and S. E. Herbes (eds.). 1994. FY 1995 Remedial Investigation Work Plan for Waste Area Grouping 2 at Oak Ridge National Laboratory, Oak Ridge, Tennessee. DOE/OR/01-1292\&D1, Oak Ridge National Laboratory, Oak Ridge, Tennessee.

Wojtowicz, J. A., and J. G. Smith. 1992. Biological Monitoring and Abatement Program (BMAP) Benthic Macroinvertebrate Monitoring Project Sample Processing QA Plan. QAP-X-91-ES-068. Oak Ridge National Laboratory, Oak Ridge, Tennessee. 

Appendix B

DATA TABLES FOR RISKS TO FISH, INVERTEBRATES, AND PLANTS 

Table B.1. Screening of aqueous concentrations of chemicals detected in streams against screening benchmarks for aquatic life (Suter and Mabrey 1996). All concentrations are $\mathrm{mg} / \mathrm{L}$.

\begin{tabular}{|c|c|c|c|c|c|c|c|c|}
\hline Chemical & Reach & Samples & Detects & P.L. Mean & $95 \%$ UCB & Quotient & $\begin{array}{c}\text { Benchmark } \\
\text { Value }\end{array}$ & Benchmark \\
\hline 1,1-Dichloroethane & $\begin{array}{l}\text { W4T } \\
\text { W4T } \\
\text { W4T } \\
\text { W4T } \\
\text { W4T }\end{array}$ & $\begin{array}{l}3 \\
3 \\
3 \\
3 \\
3\end{array}$ & $\begin{array}{l}9 \\
1 \\
1 \\
1 \\
1\end{array}$ & $\begin{array}{l}0.0010 \\
0.0010 \\
0.0010 \\
0.0010 \\
0.0010\end{array}$ & $\begin{array}{l}0.001 \\
0.001 \\
0.001 \\
0.001 \\
0.001\end{array}$ & $\begin{array}{l}0.0001 \\
0.0001 \\
0.0001 \\
0.0012 \\
0.0215\end{array}$ & $\begin{array}{r}14.6800 \\
14.6800 \\
8.2190 \\
0.8340 \\
0.0466\end{array}$ & $\begin{array}{l}\text { LCV_ALLO } \\
\text { LCV_FISH } \\
\text { LTV_FISH } \\
\text { S_ACU_V } \\
\text { S_CHR_V }\end{array}$ \\
\hline ALUMIKUM & 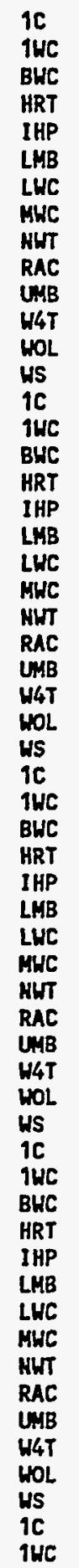 & 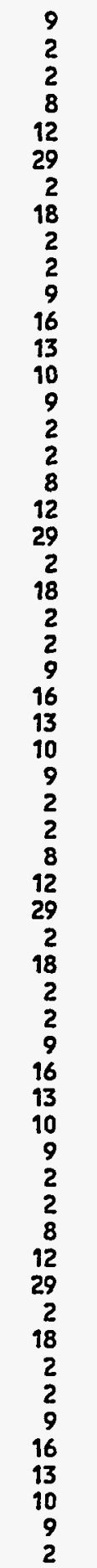 & 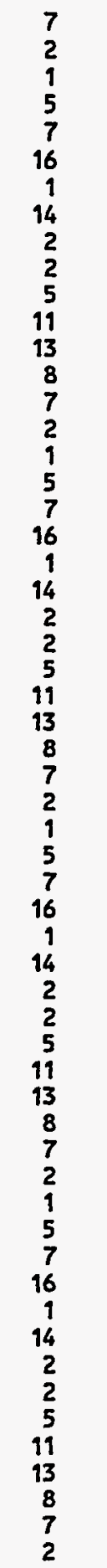 & $\begin{array}{l}0.3308 \\
0.1485 \\
0.1960 \\
0.1249 \\
0.1666 \\
0.1149 \\
0.1230 \\
0.1122 \\
0.1210 \\
0.1480 \\
0.2312 \\
0.2607 \\
0.8752 \\
0.3284 \\
0.3308 \\
0.1485 \\
0.1960 \\
0.1249 \\
0.1666 \\
0.1149 \\
0.1230 \\
0.1122 \\
0.1210 \\
0.1480 \\
0.2312 \\
0.2607 \\
0.8752 \\
0.3284 \\
0.3308 \\
0.1485 \\
0.1960 \\
0.1249 \\
0.1666 \\
0.1149 \\
0.1230 \\
0.1122 \\
0.1210 \\
0.1480 \\
0.2312 \\
0.2607 \\
0.8752 \\
0.3374 \\
0.13284 \\
0.3308 \\
0.1485 \\
0.1960 \\
0.1249 \\
0.1666 \\
0.1149 \\
0.1230 \\
0.1122 \\
0.1480 \\
0.2607 \\
0.1485\end{array}$ & $\begin{array}{l}0.503 \\
0.613 \\
0.196 \\
0.178 \\
0.306 \\
0.151 \\
0.123 \\
0.131 \\
0.481 \\
0.843 \\
0.306 \\
0.491 \\
1.102 \\
0.455 \\
0.503 \\
0.613 \\
0.196 \\
0.178 \\
0.306 \\
0.151 \\
0.123 \\
0.131 \\
0.481 \\
0.843 \\
0.306 \\
0.491 \\
1.102 \\
0.455 \\
0.503 \\
0.613 \\
0.196 \\
0.178 \\
0.306 \\
0.151 \\
0.123 \\
0.131 \\
0.481 \\
0.843 \\
0.306 \\
0.491 \\
1.102 \\
0.455 \\
0.503 \\
0.613 \\
0.196 \\
0.178 \\
0.306 \\
0.151 \\
0.123 \\
0.131 \\
0.481 \\
0.843 \\
0.306 \\
0.491 \\
1.102 \\
0.455 \\
0.503 \\
0.613\end{array}$ & $\begin{array}{l}1.0941 \\
1.3317 \\
0.4261 \\
0.3869 \\
0.6643 \\
0.3281 \\
0.2674 \\
0.2851 \\
1.0454 \\
1.8315 \\
0.6648 \\
1.0673 \\
2.3958 \\
0.9900 \\
1.0941 \\
1.3317 \\
0.4261 \\
0.3869 \\
0.6643 \\
0.3281 \\
0.2674 \\
0.2851 \\
1.0454 \\
1.8315 \\
0.6648 \\
1.0673 \\
2.3958 \\
0.9900 \\
0.2649 \\
0.3224 \\
0.1032 \\
0.0937 \\
0.1608 \\
0.0794 \\
0.0647 \\
0.0690 \\
0.2531 \\
0.4434 \\
0.1609 \\
0.2584 \\
0.5800 \\
0.2397 \\
0.1531 \\
0.1863 \\
0.0596 \\
0.0541 \\
0.0929 \\
0.0459 \\
0.0374 \\
0.0399 \\
0.1463 \\
0.2562 \\
0.0930 \\
0.1493 \\
0.3352 \\
0.1385 \\
0.9320 \\
1.1344\end{array}$ & $\begin{array}{l}0.4600 \\
0.4600 \\
0.4600 \\
0.4600 \\
0.4600 \\
0.4600 \\
0.4600 \\
0.4600 \\
0.4600 \\
0.4600 \\
0.4600 \\
0.4600 \\
0.4600 \\
0.4600 \\
0.4600 \\
0.4600 \\
0.4600 \\
0.4600 \\
0.4600 \\
0.4600 \\
0.4600 \\
0.4600 \\
0.4600 \\
0.4600 \\
0.4600 \\
0.4600 \\
0.4600 \\
0.4600 \\
1.9000 \\
1.9000 \\
1.9000 \\
1.9000 \\
1.9000 \\
1.9000 \\
1.9000 \\
1.9000 \\
1.9000 \\
1.9000 \\
1.9000 \\
1.9000 \\
1.9000 \\
1.9000 \\
3.2880 \\
3.2880 \\
3.2880 \\
3.2880 \\
3.2880 \\
3.2880 \\
3.2880 \\
3.2880 \\
3.2880 \\
3.2880 \\
3.2880 \\
3.2880 \\
3.2880 \\
3.28800 \\
0.5400 \\
0.5400\end{array}$ & $\begin{array}{l}\text { LCV_ALLO } \\
\text { LCV_ALLO } \\
\text { LCV_ALLO } \\
\text { LCV_ALLO } \\
\text { LCV_ALLO } \\
\text { LCV_ALLO } \\
\text { LCV_ALLO } \\
\text { LCV_ALLO } \\
\text { LCV_ALLO } \\
\text { LCV_ALLO } \\
\text { LCV_ALLO } \\
\text { LCV_ALLO } \\
\text { LCV_ALLO } \\
\text { LCV_ALLO } \\
\text { LCV_AQPL } \\
\text { LCV_AOPL } \\
\text { LCV_AQPL } \\
\text { LCV_AQPL } \\
\text { LCV_AQPL } \\
\text { LCV_AQPL } \\
\text { LCV_AQPL } \\
\text { LCV_AQPL } \\
\text { LCV_AOPL } \\
\text { LCV_AQPL } \\
\text { LCV_AQPL } \\
\text { LCV_AQPL } \\
\text { LCV_AQPL } \\
\text { LCV_AQPL } \\
\text { LCV_DAPH } \\
\text { LCV_DAPH } \\
\text { LCV_DAPH } \\
\text { LCV_DAPH } \\
\text { LCV_DAPH } \\
\text { LCV_DAPH } \\
\text { LCV_DAPH } \\
\text { LCV_DAPH } \\
\text { LCV_DAPH } \\
\text { LCV_DAPH } \\
\text { LCV_DAPH } \\
\text { LCV_DAPH } \\
\text { LCV_DAPH } \\
\text { LCV_DAPH } \\
\text { LCV_FISH } \\
\text { LCV_FISH } \\
\text { LCV_FISH } \\
\text { LCV_FISH } \\
\text { LCV_FISH } \\
\text { LCV_FISH } \\
\text { LCV_FISH } \\
\text { LCV_FISH } \\
\text { LCV_FISH } \\
\text { LCV_FISH } \\
\text { LCV_FISH } \\
\text { LCV_FISH } \\
\text { LCV_FISH } \\
\text { LCV_FISH } \\
\text { LTV_DAPH } \\
\text { LTV_DAPH }\end{array}$ \\
\hline
\end{tabular}


B-4

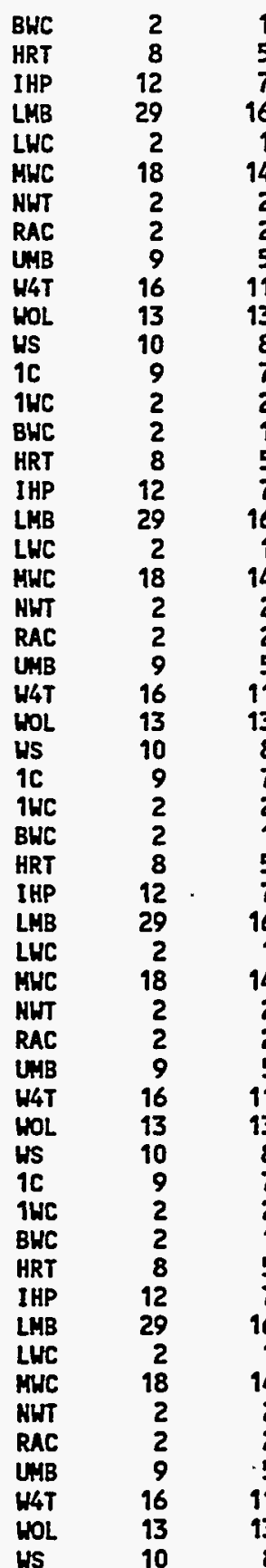

0.1960

0.1666

0.196

0.1149

0.178
0.306

0.151

0.1230

0.123

0.1122

0.1210

0.131
0.481

ANTIMONY
0.1480

0.2312

0.2607

0.8752

0.3284

0.3308

0.1485

0.1960

0.1249

0.1666

0.1149

0.1230

0.1122

0.1210

0.1480

0.2312

0.2607

0.8752

0.3284

0.3308

0.1485

0.1960

0.1249

0.1666

0.1149

0.1230

0.1122

0.1210

0.1480

0.2312

0.2607

0.8752

0.3284

0.3308

0.1485

0.1960

0.1249

0.1666

0.1149

0.1230

0.1122

0.1210

0.1480

0.2312

0.2607

0.8752

0.3284

0.843

0.306

0.491

1.102

0.455

0.503

0.613

0.198

0.178

0.306

0.151

0.123

0.131

0.481

0.843

0.306

0.491

1.102

0.455

0.503

0.613

0.196

0.178

0.306

0.151

0.123

0.131

0.481

0.843

0.306

0.491

1.102

0.455

0.503

0.613

0.196

0.178

0.306

0.151

0.123

0.131

0.481

0.843

0.306

0.491

1.102

0.455

0.0190

0.0190

0.0384

0.0190

0.0190

0.0384

0.0190

0.0190

0.0384

0.0190

0.0190

0.0384

0.0190

0.0190

0.0384

0.0190
0.019

0.019

0.039

0.019

0.019

0.039

0.019

0.019

0.039

0.019

0.019

0.039

0.019

0.019

0.039

0.019
0.3630

0.3296

0.5658

0.2795

0.2278

0.2429

0.8905

1.5602

0.5663

0.9092

2.0408

0.8433

0.1071

0.1303

0.0417

0.0379

0.0650

0.0321

0.0262

0.0279

0.1023

0.1793

0.0651

0.1045

0.2345

0.0969

0.6710

0.8167

0.2613

0.2373

0.4074

0.2012

0.1640

0.1749

0.6412

1.1234

0.4077

0.6546

1.4694

0.6072

5.7848

7.0409

2.2529

2.0455

3.5121

1.7346

1.4138

1.5074

5.5274

9.6841

3.5149

5.6431

12.6673

5.2342

0.0311

0.0311

0.0644

0.0311

0.0311

0.0644

0.0035

0.0035

0.0073

0.0119

0.0119

0.0246

0.0100

0.0100

0.0207

0.0082
0.5400

0.5400 LTV_DAPH

0.5400 LTVDAPH

0.5400 LTVDAPH

0.5400 LTV_DAPH

0.5400 LTVDAPH

0.5400 LTV_DAPH

0.5400 LTV DAPH

0.5400 LTVDAPH

0.5400 LTV_DAPH

0.5400 LTV DAPH

4.7000 LTV FISH

4.7000 LTVFISH

4.7000 LTVFISH

4.7000 LTV_FISH

4.7000 LTV_FISH

4.7000 LTVFISH

4.7000 LTV_FISH

4.7000 LTV FISH

4.7000 LTV_FISH

$$
4.7000 \text { LTV_FISH }
$$

4.7000 LTV FISH

4.7000 LTVEISH

4.7000 LTV_FISH

4.7000 LTV FISH

0.7500 HALT̃_ACU

0.7500 HAWQ ACU

0.7500 HAWQ_ACU

0.7500 NAWO ACU

0.7500 HALO_ACU

0.7500 HAWO ACU

0.7500 HAWQ_ACU

0.7500 HAWA_ACU

0.7500 HAHQ_ACU

0.7500 NALT ACU

0.7500 haLVACU

0.7500 HALE_ACU

0.7500 HAWQ ACU

0.7500 HALV_ACU

0.0870 HALN CHR

0.0870 HAWQ_CHR

0.0870 HALVECHR

0.0870 HALR CHR

0.0870 HALP_CHR

0.0870 HALO CHR

0.0870 HAHQ_CHR

0.0870 HALQ CHR

0.0870 HALQ_CHR

0.0870 HAWQ CHR

0.0870 HAWQ CHR

0.0870 HALA CHR

0.0870 HALACCHR

0.0870 NALA_CHR

0.6100 LCV_ALLO

0.6100 LCV ALLO

0.6100 LCV_ALLO

0.6100 LCV_AQPL

0.6100 LCV_AQPL

0.6100 LCV AQPL

5.4000 LCV DAPH

5.4000 LCV_DAPH

5.4000 LCVDAPH

1.6000 LCV_FISH

1.6000 LCV FISH

1.6000 LCV_FISH

1.9000 LTVDAPH

$\begin{array}{ll}1.9000 & \text { LTV_DAPH } \\ 1.9000 & \text { LTV_DAPH }\end{array}$

2.3100 LTV_FISH 
B-5

\begin{tabular}{|c|c|c|c|c|c|c|c|c|}
\hline & $\begin{array}{l}\text { LHB } \\
\text { MHC } \\
\text { HRT } \\
\text { LHB } \\
\text { MHC } \\
\text { HRT } \\
\text { LMB } \\
\text { MUC }\end{array}$ & $\begin{array}{r}29 \\
18 \\
8 \\
29 \\
18 \\
8 \\
29 \\
18\end{array}$ & $\begin{array}{l}1 \\
2 \\
1 \\
1 \\
2 \\
1 \\
1 \\
2\end{array}$ & $\begin{array}{l}0.0190 \\
0.0384 \\
0.0190 \\
0.0190 \\
0.0384 \\
0.0190 \\
0.0190 \\
0.0384\end{array}$ & $\begin{array}{l}0.019 \\
0.039 \\
0.019 \\
0.019 \\
0.039 \\
0.019 \\
0.019 \\
0.039\end{array}$ & $\begin{array}{l}0.0082 \\
0.0170 \\
0.0193 \\
0.0193 \\
0.0399 \\
0.1827 \\
0.1827 \\
0.3778\end{array}$ & $\begin{array}{l}2.3100 \\
2.3100 \\
0.9850 \\
0.9850 \\
0.9850 \\
0.1040 \\
0.1040 \\
0.1040\end{array}$ & $\begin{array}{l}\text { LTV_FISH } \\
\text { LTV_FISH } \\
\text { S_ACU_V } \\
\text { S_ACU_V } \\
\text { S_ACU_V } \\
\text { S_CHR_V } \\
\text { S_CHR_V } \\
\text { S_CHR_V }\end{array}$ \\
\hline ARSENIC & 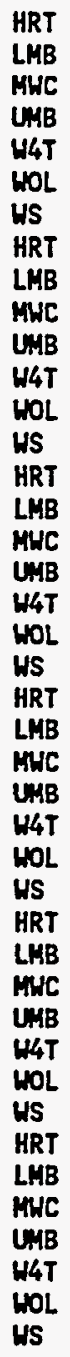 & $\begin{array}{r}7 \\
26 \\
16 \\
8 \\
9 \\
12 \\
9 \\
7 \\
26 \\
16 \\
8 \\
9 \\
12 \\
9 \\
7 \\
26 \\
16 \\
8 \\
9 \\
12 \\
9 \\
7 \\
26 \\
16 \\
8 \\
9 \\
12 \\
9 \\
7 \\
26 \\
16 \\
8 \\
9 \\
12 \\
9 \\
7 \\
26 \\
16 \\
8 \\
9 \\
12 \\
9\end{array}$ & $\begin{array}{l}1 \\
6 \\
2 \\
2 \\
1 \\
1 \\
1 \\
1 \\
6 \\
2 \\
2 \\
1 \\
1 \\
1 \\
1 \\
6 \\
2 \\
2 \\
1 \\
1 \\
1 \\
1 \\
6 \\
2 \\
2 \\
1 \\
1 \\
1 \\
1 \\
6 \\
2 \\
2 \\
1 \\
1 \\
1 \\
1 \\
6 \\
2 \\
2 \\
1 \\
1 \\
1\end{array}$ & $\begin{array}{l}0.0010 \\
0.0013 \\
0.0010 \\
0.0020 \\
0.0010 \\
0.0010 \\
0.0010 \\
0.0010 \\
0.0013 \\
0.0010 \\
0.0020 \\
0.0010 \\
0.0010 \\
0.0010 \\
0.0010 \\
0.0013 \\
0.0010 \\
0.0020 \\
0.0010 \\
0.0010 \\
0.0010 \\
0.0010 \\
0.0013 \\
0.0010 \\
0.0020 \\
0.0010 \\
0.0010 \\
0.0010 \\
0.0010 \\
0.0013 \\
0.0010 \\
0.0020 \\
0.0010 \\
0.0010 \\
0.0010 \\
0.0010 \\
0.0013 \\
0.0010 \\
0.0020 \\
0.0010 \\
0.0010 \\
0.0010\end{array}$ & $\begin{array}{l}0.001 \\
0.002 \\
0.001 \\
0.002 \\
0.001 \\
0.001 \\
0.001 \\
0.001 \\
0.002 \\
0.001 \\
0.002 \\
0.001 \\
0.001 \\
0.001 \\
0.001 \\
0.002 \\
0.001 \\
0.002 \\
0.001 \\
0.001 \\
0.001 \\
0.001 \\
0.002 \\
0.001 \\
0.002 \\
0.001 \\
0.001 \\
0.001 \\
0.001 \\
0.002 \\
0.001 \\
0.002 \\
0.001 \\
0.001 \\
0.001 \\
0.001 \\
0.002 \\
0.001 \\
0.002 \\
0.001 \\
0.001 \\
0.001\end{array}$ & $\begin{array}{l}0.0011 \\
0.0017 \\
0.0011 \\
0.0022 \\
0.0011 \\
0.0011 \\
0.0011 \\
0.0003 \\
0.0005 \\
0.0003 \\
0.0007 \\
0.0003 \\
0.0003 \\
0.0003 \\
0.0016 \\
0.0025 \\
0.0016 \\
0.0032 \\
0.0016 \\
0.0016 \\
0.0016 \\
0.0005 \\
0.0007 \\
0.0005 \\
0.0009 \\
0.0005 \\
0.0005 \\
0.0005 \\
0.0028 \\
0.0044 \\
0.0028 \\
0.0056 \\
0.0028 \\
0.0028 \\
0.0028 \\
0.0053 \\
0.0083 \\
0.0053 \\
0.0105 \\
0.0053 \\
0.0053 \\
0.0053\end{array}$ & $\begin{array}{l}0.9140 \\
0.9140 \\
0.9140 \\
0.9140 \\
0.9140 \\
0.9140 \\
0.9140 \\
2.9620 \\
2.9620 \\
2.9620 \\
2.9620 \\
2.9620 \\
2.9620 \\
2.9620 \\
0.6330 \\
0.6330 \\
0.6330 \\
0.6330 \\
0.6330 \\
0.6330 \\
0.6330 \\
2.1300 \\
2.1300 \\
2.1300 \\
2.1300 \\
2.1300 \\
2.1300 \\
2.1300 \\
0.3600 \\
0.3600 \\
0.3600 \\
0.3600 \\
0.3600 \\
0.3600 \\
0.3600 \\
0.1900 \\
0.1900 \\
0.1900 \\
0.1900 \\
0.1900 \\
0.1900 \\
0.1900\end{array}$ & 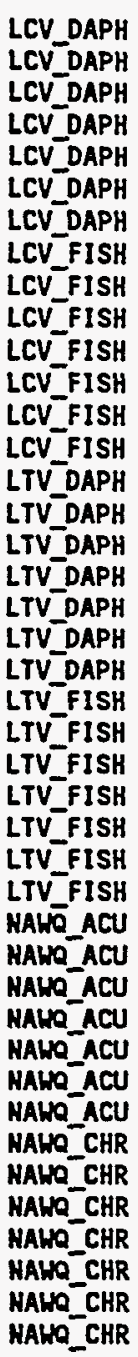 \\
\hline Acetone & $\begin{array}{l}\text { HRT } \\
\text { IHP } \\
\text { MHC } \\
\text { UNB } \\
\text { HAT } \\
\text { HOL } \\
\text { HRT } \\
\text { IHP } \\
\text { MWC } \\
\text { UMB } \\
\text { HAT } \\
\text { HOL } \\
\text { HRT } \\
\text { IHP } \\
\text { MWC } \\
\text { UMB } \\
\text { H4T } \\
\text { HOL } \\
\text { HRT }\end{array}$ & $\begin{array}{l}1 \\
1 \\
1 \\
1 \\
3 \\
1 \\
1 \\
1 \\
1 \\
1 \\
3 \\
1 \\
1 \\
1 \\
1 \\
1 \\
3 \\
1 \\
1\end{array}$ & $\begin{array}{l}1 \\
1 \\
1 \\
1 \\
1 \\
1 \\
1 \\
1 \\
1 \\
1 \\
1 \\
1 \\
1 \\
1 \\
1 \\
1 \\
1 \\
1 \\
1\end{array}$ & $\begin{array}{l}0.0010 \\
0.0030 \\
0.0050 \\
0.0030 \\
0.0020 \\
0.0030 \\
0.0010 \\
0.0030 \\
0.0050 \\
0.0030 \\
0.0020 \\
0.0030 \\
0.0010 \\
0.0030 \\
0.0050 \\
0.0030 \\
0.0020 \\
0.0030 \\
0.0010\end{array}$ & $\begin{array}{l}0.001 \\
0.003 \\
0.005 \\
0.003 \\
0.002 \\
0.003 \\
0.001 \\
0.003 \\
0.005 \\
0.003 \\
0.002 \\
0.003 \\
0.001 \\
0.003 \\
0.005 \\
0.003 \\
0.002 \\
0.003 \\
0.001\end{array}$ & $\begin{array}{l}0.0000 \\
0.0000 \\
0.0000 \\
0.0000 \\
0.0000 \\
0.0000 \\
0.0000 \\
0.0000 \\
0.0000 \\
0.0000 \\
0.0000 \\
0.0000 \\
0.0000 \\
0.0000 \\
0.0000 \\
0.0000 \\
0.0000 \\
0.0000 \\
0.0000\end{array}$ & $\begin{array}{r}507.6400 \\
507.6400 \\
507.6400 \\
507.6400 \\
507.6400 \\
507.6400 \\
3114.1820 \\
3114.1820 \\
3114.1820 \\
3114.1820 \\
3114.1820 \\
3114.1820 \\
507.6400 \\
507.6400 \\
507.6400 \\
507.6400 \\
507.6400 \\
507.6400 \\
161.8670\end{array}$ & $\begin{array}{l}\text { LCV_ALLO } \\
\text { LCV_ALLO } \\
\text { LCV_ALLO } \\
\text { LCV_ALLO } \\
\text { LCV_ALLO } \\
\text { LCV_ALLO } \\
\text { LCV_DAPH } \\
\text { LCV_DAPH } \\
\text { LCV_DAPH } \\
\text { LCV_DAPH } \\
\text { LCV_DAPH } \\
\text { LCV_DAPH } \\
\text { LCV_FISH } \\
\text { LCV_FISH } \\
\text { LCV_FISH } \\
\text { LCV_FISH } \\
\text { LCV_FISH } \\
\text { LCV_FISH } \\
\text { LTV_FISH }\end{array}$ \\
\hline
\end{tabular}


B. 6

$\begin{array}{lll}\text { IHP } & 1 & 1 \\ \text { MHC } & 1 & 1 \\ \text { UHB } & 1 & 1 \\ \text { WHT } & 3 & 1 \\ \text { WOL } & 1 & 1 \\ \text { HRT } & 1 & 1 \\ \text { IHP } & 1 & 1 \\ \text { MHC } & 1 & 1 \\ \text { UMB } & 1 & 1 \\ \text { HUT } & 3 & 1 \\ \text { HOL } & 1 & 1 \\ \text { HRT } & 1 & 1 \\ \text { IHP } & 1 & 1 \\ \text { MHC } & 1 & 1 \\ \text { UMB } & 1 & 1 \\ \text { WHT } & 3 & 1 \\ \text { WOL } & 1 & 1\end{array}$

$\begin{array}{lllll}0.0030 & 0.003 & 0.0000 & 161.8670 & \text { LTV_FISH } \\ 0.0050 & 0.005 & 0.0000 & 161.8670 & \text { LTV_FISH } \\ 0.0030 & 0.003 & 0.0000 & 161.8670 & \text { LTV_FISH } \\ 0.0020 & 0.002 & 0.0000 & 161.8670 & \text { LTV_FISH } \\ 0.0030 & 0.003 & 0.0000 & 161.8670 & \text { LTV_FISH } \\ 0.0010 & 0.001 & 0.0000 & 200.0000 & \text { S_ACU_V } \\ 0.0030 & 0.003 & 0.0000 & 200.0000 & \text { S_ACUV } \\ 0.0050 & 0.005 & 0.0000 & 200.0000 & \text { S_ACU_V } \\ 0.0030 & 0.003 & 0.0000 & 200.0000 & \text { S_ACU_V } \\ 0.0020 & 0.002 & 0.0000 & 200.0000 & \text { S_ACUV } \\ 0.0030 & 0.003 & 0.0000 & 200.0000 & \text { S_ACU_V } \\ 0.0010 & 0.001 & 0.0001 & 11.2000 & \text { S_CHR_V } \\ 0.0030 & 0.003 & 0.0003 & 11.2000 & \text { S_CHR_V } \\ 0.0050 & 0.005 & 0.0004 & 11.2000 & \text { S_CHR_V } \\ 0.0030 & 0.003 & 0.0003 & 11.2000 & \text { S_CHR_V } \\ 0.0020 & 0.002 & 0.0002 & 11.2000 & \text { S_CHR_V } \\ 0.0030 & 0.003 & 0.0003 & 11.2000 & \text { S_CHR_V }\end{array}$

BARIUM

$\begin{array}{lr}\text { IC } & 9 \\ \text { IWC } & 2 \\ \text { BWC } & 2 \\ \text { HRT } & 8 \\ \text { IHP } & 12 \\ \text { LMB } & 29 \\ \text { LWC } & 2\end{array}$

0.0412

0.046

0.0079

0.0340

0.040

0.0640

0.260

0.0580

0.063

0.0070

5.8000

5.8000

0.0448

5.8000

5.8000

0.0063

0.0511

0.037

0.0380

0.070

0.0098

5.8000

5.8000

5.8000

5.8000

5.8000

0.0440

0.044

0.0063

0.0076

0.0290

0.029

0.0526

0.065

0.0050

0.204

0.0462

0.051

0.0113

5.8000

5.8000

5.8000

5.8000

0.0087

0.0619

0.046

0.0340

0.040

0.013

5.8000

5.8000

5.8000

0.0070

5.8000

5.8000

0.0580

0.063

0.0448

0.0063

0.0349
0.0511

0.037

0.0380

0.070

0.0098

5.8000

5.8000

5.8000

5.8000

5.8000

0.0440

0.044

0.0063

0.0076

0.0290

0.029

0.0050

5.8000

5.8000

0.1646

0.204

0.0462

0.0351

0.051

0.0619

0.075

0.0412

0.046

0.0087

5.8000

5.8000

5.8000

0.0691

0.0691

0.5834

0.0691

0.0691

0.0580

0.260

3.7587

0.9145

0.037

0.5297

0.0349

0.057

0.0380

0.070

0.8251

0.0691

0.0691

0.0691

0.0691

0.0440

0.044

0.5256

0.6368

0.0290

0.029

0.0526

0.065

0.4197

0.0691

0.0691

0.0691

0.0691

0.0691

0.0462

0.051

2.9450

0.7334

0.075

0.0412

1.0878

0.046

12.0185

0.0691

0.0038

0.0038

0.0038

0.0038

0.0580

0.260

68.3490

16.6286

0.0349

9.6327

0.0511

0.057

15.0031

0.0380

0.070

0.036

18.3076

0.0348

0.044

0.0038

0.0038

0.0038

0.0038

11.5789

0.0038

0.0038

17.1754

0.0038

LCV_ALLO

LCV_ALLO

LCV_ALLO

LCV ALLO

LCV_ALLO

LCV_ALLO

LCV_ALLO

LCV_ALLO

LCV_ALLO

LCV_ALLO

LCV_ALLO

LCV_ALLO

LCV_ALLO

LCV_ALLO

LCV_DAPH

CV_DAPH

LCV_DAPH

$\angle C V D A P H$

LCV_DAPH

LCV_DAPH

LCV_DAPH

LCVDAPH

LCV DAPH

LCV_DAPH

LCV DAPH

LCV_DAPH

LCV_DAPH

LCV_DAPH

S_ACU V

SACUV

SACU_V

S_ACUIV

S_ACU V

S_ACU_V

S_ACU V

S_ACUIV

SACU $V$

SACUEV

SACUIV

S_ACU_V

SACU V

S_ACU_V

S_CHR_V

S_CHR_V

S_CHR_V

S_CHR_V

S_CHR_V

SCHR V

S_CHR_V

S_CHR_V

S_CHR_V

S_CHR_V

0.0526

0.065

S_CHR_V 
B-7

\begin{tabular}{|c|c|c|c|c|c|c|c|c|}
\hline & $\begin{array}{l}\text { W4T } \\
\text { WOL } \\
\text { WS }\end{array}$ & $\begin{array}{l}16 \\
13 \\
10\end{array}$ & $\begin{array}{l}16 \\
12 \\
10\end{array}$ & $\begin{array}{l}0.1646 \\
0.0462 \\
0.0619\end{array}$ & $\begin{array}{l}0.204 \\
0.051 \\
0.075\end{array}$ & $\begin{array}{l}53.5530 \\
13.3365 \\
19.7810\end{array}$ & $\begin{array}{l}0.0038 \\
0.0038 \\
0.0038\end{array}$ & $\begin{array}{l}\text { S_CHR_V } \\
\text { S_CHR_V } \\
\text { S_CHR_V }\end{array}$ \\
\hline BERYLLIUH & 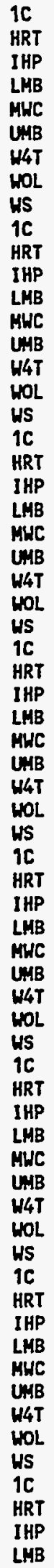 & 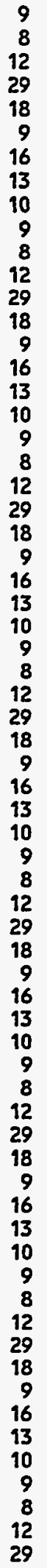 & $\begin{array}{l}1 \\
1 \\
1 \\
5 \\
2 \\
1 \\
1 \\
1 \\
1 \\
1 \\
1 \\
1 \\
5 \\
2 \\
1 \\
1 \\
1 \\
1 \\
1 \\
1 \\
1 \\
5 \\
2 \\
1 \\
1 \\
1 \\
1 \\
1 \\
1 \\
1 \\
5 \\
2 \\
1 \\
1 \\
1 \\
1 \\
1 \\
1 \\
1 \\
5 \\
2 \\
1 \\
1 \\
1 \\
1 \\
1 \\
1 \\
1 \\
5 \\
2 \\
1 \\
1 \\
1 \\
1 \\
1 \\
1 \\
1 \\
5 \\
2 \\
1 \\
1 \\
1 \\
1 \\
1 \\
1 \\
1 \\
5\end{array}$ & 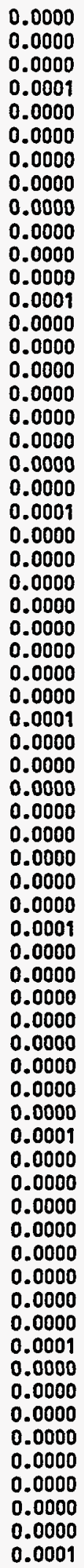 & $\begin{array}{l}0.000 \\
0.000 \\
0.000 \\
0.000 \\
0.000 \\
0.000 \\
0.000 \\
0.000 \\
0.000 \\
0.000 \\
0.000 \\
0.000 \\
0.000 \\
0.000 \\
0.000 \\
0.000 \\
0.000 \\
0.000 \\
0.000 \\
0.000 \\
0.000 \\
0.000 \\
0.000 \\
0.000 \\
0.000 \\
0.000 \\
0.000 \\
0.000 \\
0.000 \\
0.000 \\
0.000 \\
0.000 \\
0.000 \\
0.000 \\
0.000 \\
0.000 \\
0.000 \\
0.000 \\
0.000 \\
0.000 \\
0.000 \\
0.000 \\
0.000 \\
0.000 \\
0.000 \\
0.000 \\
0.000 \\
0.000 \\
0.000 \\
0.000 \\
0.000 \\
0.000 \\
0.000 \\
0.000 \\
0.000 \\
0.000 \\
0.000 \\
0.000 \\
0.000 \\
0.000 \\
0.000 \\
0.000 \\
0.000 \\
0.000 \\
0.000 \\
0.000 \\
0.000\end{array}$ & 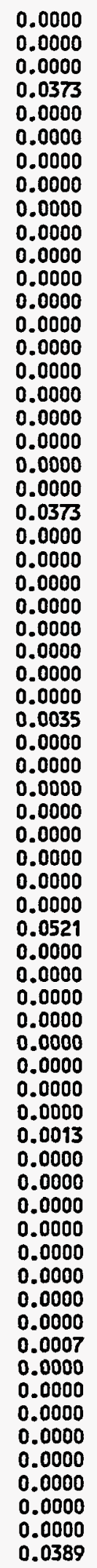 & $\begin{array}{c}0.0053 \\
0.0053 \\
0.0053 \\
0.0053 \\
0.0053 \\
0.0053 \\
0.0053 \\
0.0053 \\
0.0053 \\
100.0000 \\
100.0000 \\
100.0000 \\
100.0000 \\
100.0000 \\
100.0000 \\
100.0000 \\
100.0000 \\
100.0000 \\
0.0053 \\
0.0053 \\
0.0053 \\
0.0053 \\
0.0053 \\
0.0053 \\
0.0053 \\
0.0053 \\
0.0053 \\
0.0570 \\
0.0570 \\
0.0570 \\
0.0570 \\
0.0570 \\
0.0570 \\
0.0570 \\
0.0570 \\
0.0570 \\
0.0038 \\
0.0038 \\
0.0038 \\
0.0038 \\
0.0038 \\
0.0038 \\
0.0038 \\
0.0038 \\
0.0038 \\
0.1480 \\
0.07480 \\
0.0710 \\
0.0051 \\
0.1480 \\
0.0051 \\
0.0051 \\
0.1480 \\
0.1480 \\
0.1480 \\
0.1480 \\
0.2710 \\
0.2710 \\
0.2710 \\
0.2710 \\
0.0051\end{array}$ & 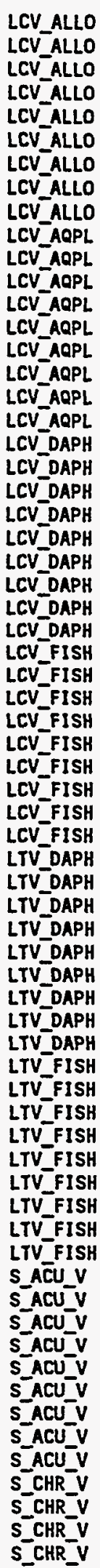 \\
\hline
\end{tabular}


BOROH

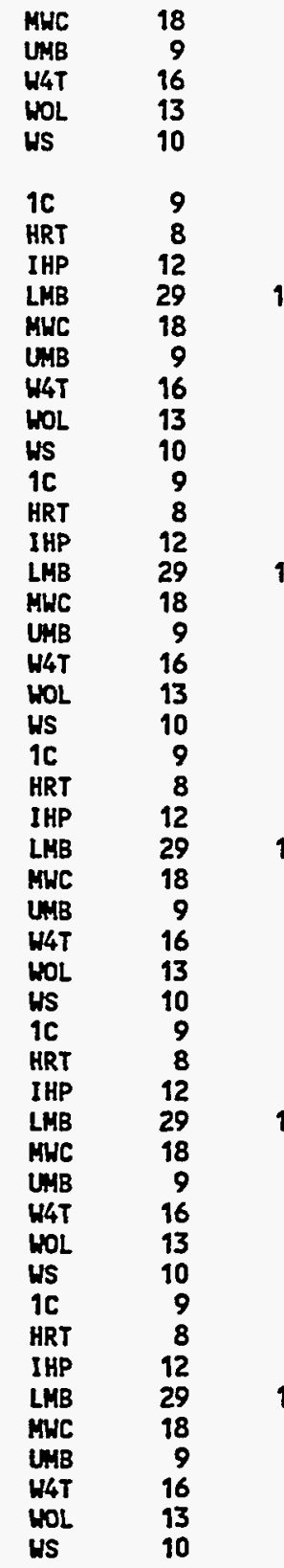

0.0000
0.0000
0.0000
0.0000
0.0000

$\begin{array}{llll}0.000 & 0.0000 & 0.0051 & \text { S_CHRV } \\ 0.000 & 0.0000 & 0.0051 & \text { S_CHR_V } \\ 0.000 & 0.0000 & 0.0051 & \text { S_CHR_V } \\ 0.000 & 0.0000 & 0.0051 & \text { S_CHR_V } \\ 0.000 & 0.0000 & 0.0051 & \text { S_CHR_V }\end{array}$

0.036

0.0041

0.0354

0.0354

0.044

0.0041

0.0498

0.0325

0.046

0.0052

0.054

0.0061

0.0394

0.055

0.1750

0.226

0.0046

0.1029

0.207

0.0062

0.0255

0.1099

0.240

0.0234

0.0218

0.036

0.0041

0.0354

0.044

0.0354

0.046

0.0050

0.0498

0.0325

0.054

0.0052

0.0394

0.1750

0.040

0.0061

0.055

0.1029

0.226

0046

0.207

0.0062

0.0255

0.0234

0.0218

0.240

0.0272

0.036

5.1193

0.0354

0.0354

0.044

6.2762

0.046

.5284

0.0498

0.054

7.7056

0.0325

0.040

0.0394

0.055

0.1029

0.226

5.7857

7.8653

0.207

32.2145

0.1099

0.240

29.5793
34.2666

0.0218

0.036

0.0033

0.0354

0.0354

0.044

0.046

0.0040

0.0042

0.0498

0.054

0.0325

0.040

0.0049

0.0037

0.0050

0.1750

0.055

0.1029

0.207

0.0205

0.1099

0.0218

0.240

0.0188

0.036

0.0354

0.0354

0.044

0.0218

0.0655

0.0803

0.046

0.0498
0.0325

0.054

0.0986

0.0394

0.040

0.0740

0.1007

0.1750

0.226

0.4123

0.207

0.3785

8.8300 LCV_ALLO

8.8300 LCVALLO

8.8300 LCVALLO

8.8300 LCV_ALLO

8.8300 LCV ALLO

8.8300 LCV_ALLO

8.8300 LCV ALLO

8.8300 LCV_ALLO

8.8300 LCV ALLO

8.8300 LCV_DAPH

8.8300 LCV_DAPH

8.8300 LCV_DAPH

8.8300 LCV_DAPH

8.8300 LCV DAPH

8.8300 LCV_DAPH

8.8300 LCVDAPH

8.8300 LCVDAPH

8.8300 LCV DAPH

0.0070 LTV_DAPH

0.0070 LTV_DAPH

0.0070 LTV_DAPH

0.0070 LTV_DAPH

0.0070 LTVDAPH

0.0070 LTV_DAPH

0.0070 LTV DAPH

0.0070 LTV_DAPH

0.0070 LTV_DAPH

11.0000 SAACU V

11.0000 S_ACU_V

11.0000 SACUV

11.0000 S_ACU_V

11.0000 SACUEV

19.0000 SAACU_V

11.0000 S_ACUEV

11.0000 SACU V

11.0000 S_ACU_V

0.5470 SCHR V

0.5470 S_CHR_V

0.5470 S_CHR_V

0.5470 S_CHR V

0.5470 SCHR V

0.5470 S_CHR V

0.5470 S_CHR_V

0.5470 S_CHR_V

$\begin{array}{lllll}0.1099 & 0.240 & 0.4385 & 0.5470 & \text { S_CHR_V }\end{array}$

CADMIUM

$\begin{array}{lll}\text { LMB } & 29 & 1 \\ \text { MHC } & 17 & 1 \\ \text { WLT } & 12 & 2 \\ \text { WOL } & 13 & 1 \\ \text { LMB } & 29 & 1 \\ \text { MHC } & 17 & 1 \\ \text { H4T } & 12 & 2 \\ \text { WOL } & 13 & 1 \\ \text { LHB } & 29 & 1 \\ \text { HWC } & 17 & 1 \\ \text { W4T } & 12 & 2 \\ \text { WOL } & 13 & 1 \\ \text { LMB } & 29 & 1 \\ \text { MHC } & 17 & 1 \\ \text { W4T } & 12 & ? \\ \text { WOL } & 13 & 1 \\ \text { LMB } & 29 & 1 \\ \text { MHC } & 17 & 1 \\ \text { W4T } & 12 & 2\end{array}$

$\begin{array}{lll}0.0000 & 0.000 & 0.0000\end{array}$

$0.0000 \quad 0.000$

0.0000

0.0000

0.0002

0.0002

LCV_ALLO

0.0011

0.001

9.1811

0.0002

0.0002

0.0000

0.0020

0.0000

0.000

0.0000

0.000

0.0000

0.0020

0.0020

0.0000

0.000

0.6886

0.0020

0.0002

0.0000

.000

0.0000

0.000

0.0000

0.0002

0.0000

0.0002

0.000

0.0000

0.0000

9.1811

0.0002

0.0017

0.0017

0.000

0.0011

0.001

0.0000

0.0000

0.0017

0.8101

0.0017

0.000

0.0000

0.0008

LCV_ALLO

LCV_ALLO

LCV_ALLO

LCV_AQPL

LCV_AQPL

LCV AQPL

LCV_AQPL

LCV_DAPH

LCV_DAPH

LCV_DAPH

LCVDAPH

LCV_FISH

LCV_FISH

0.0000

0.000

0.0000

0.0008
0.0008

LCV_FISH

LCV_FISH

LTV_DAPH

$\begin{array}{lll}0.0011 & 0.001 & 1.8362\end{array}$

LTV_DAPH 
B-9

\begin{tabular}{|c|c|c|c|c|c|c|c|c|}
\hline & $\begin{array}{l}\text { WOL } \\
\text { LMB } \\
\text { HWC } \\
\text { H4T } \\
\text { HOL } \\
\text { LMB } \\
\text { MHC } \\
\text { W4T } \\
\text { HOL } \\
\text { LKB } \\
\text { MWC } \\
\text { HAT } \\
\text { WOL }\end{array}$ & $\begin{array}{l}13 \\
29 \\
17 \\
12 \\
13 \\
29 \\
17 \\
12 \\
13 \\
29 \\
17 \\
12 \\
13\end{array}$ & $\begin{array}{l}1 \\
1 \\
1 \\
2 \\
1 \\
1 \\
1 \\
2 \\
1 \\
1 \\
1 \\
2 \\
1\end{array}$ & $\begin{array}{l}0.0000 \\
0.0000 \\
0.0000 \\
0.0011 \\
0.0000 \\
0.0000 \\
0.0000 \\
0.0011 \\
0.0000 \\
0.0000 \\
0.0000 \\
0.0011 \\
0.0000\end{array}$ & $\begin{array}{l}0.000 \\
0.000 \\
0.000 \\
0.001 \\
0.000 \\
0.000 \\
0.000 \\
0.001 \\
0.000 \\
0.000 \\
0.000 \\
0.001 \\
0.000\end{array}$ & $\begin{array}{l}0.0000 \\
0.0000 \\
0.0000 \\
0.7651 \\
0.0000 \\
0.0000 \\
0.0000 \\
0.3531 \\
0.0000 \\
0.0000 \\
0.0000 \\
1.2520 \\
0.0000\end{array}$ & $\begin{array}{l}0.0008 \\
0.0018 \\
0.0018 \\
0.0018 \\
0.0018 \\
0.0039 \\
0.0039 \\
0.0039 \\
0.0039 \\
0.0011 \\
0.0011 \\
0.0011 \\
0.0011\end{array}$ & $\begin{array}{l}\text { LTV_DAPH } \\
\text { LTV_FISH } \\
\text { LTV_FISH } \\
\text { LTV_FISH } \\
\text { LTV_FISH } \\
\text { HALO_ACU } \\
\text { HAWO_ACU } \\
\text { HALO_ACU } \\
\text { HAWO_ACU } \\
\text { HAWO_CHR } \\
\text { NAWQ_CHR } \\
\text { HALO_CHR } \\
\text { WAWO_CHR }\end{array}$ \\
\hline CALCIUH & 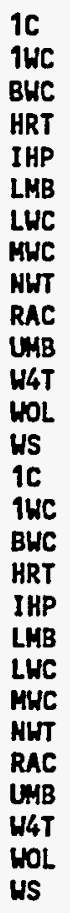 & $\begin{array}{r}9 \\
2 \\
2 \\
8 \\
12 \\
29 \\
2 \\
18 \\
2 \\
2 \\
9 \\
16 \\
13 \\
10 \\
9 \\
2 \\
2 \\
8 \\
12 \\
29 \\
2 \\
18 \\
2 \\
2 \\
9 \\
16 \\
13 \\
10\end{array}$ & $\begin{array}{r}9 \\
2 \\
2 \\
8 \\
12 \\
29 \\
2 \\
18 \\
2 \\
2 \\
9 \\
16 \\
13 \\
10 \\
9 \\
2 \\
2 \\
8 \\
12 \\
29 \\
2 \\
18 \\
2 \\
2 \\
9 \\
16 \\
13 \\
10\end{array}$ & $\begin{array}{l}43.8333 \\
40.9000 \\
23.5500 \\
41.7500 \\
44.3667 \\
58.4483 \\
44.2000 \\
43.4833 \\
48.8500 \\
84.1000 \\
63.6889 \\
76.5938 \\
44.1000 \\
37.0600 \\
43.8333 \\
40.9000 \\
23.5500 \\
41.7500 \\
44.3667 \\
58.4483 \\
44.2000 \\
43.4833 \\
48.8500 \\
84.1000 \\
63.6889 \\
76.5938 \\
44.1000 \\
37.0600\end{array}$ & $\begin{array}{r}48.460 \\
47.845 \\
80.058 \\
48.219 \\
47.985 \\
66.339 \\
58.090 \\
46.474 \\
129.350 \\
137.767 \\
82.307 \\
90.049 \\
47.219 \\
45.099 \\
48.460 \\
47.845 \\
80.058 \\
48.219 \\
47.985 \\
66.339 \\
58.090 \\
46.474 \\
129.350 \\
137.767 \\
82.307 \\
90.049 \\
47.219 \\
45.099\end{array}$ & $\begin{array}{l}0.4178 \\
0.4125 \\
0.6902 \\
0.4157 \\
0.4137 \\
0.5719 \\
0.5008 \\
0.4006 \\
1.1151 \\
1.1876 \\
0.7095 \\
0.7763 \\
0.4071 \\
0.3888 \\
0.4178 \\
0.4125 \\
0.6902 \\
0.4157 \\
0.4137 \\
0.5719 \\
0.5008 \\
0.4006 \\
1.1151 \\
1.1876 \\
0.7095 \\
0.7763 \\
0.4071 \\
0.3888\end{array}$ & $\begin{array}{l}116.0000 \\
116.0000 \\
116.0000 \\
116.0000 \\
116.0000 \\
116.0000 \\
116.0000 \\
116.0000 \\
116.0000 \\
116.0000 \\
116.0000 \\
116.0000 \\
116.0000 \\
116.0000 \\
116.0000 \\
116.0000 \\
116.0000 \\
116.0000 \\
116.0000 \\
116.0000 \\
116.0000 \\
116.0000 \\
116.0000 \\
116.0000 \\
116.0000 \\
116.0000 \\
116.0000 \\
116.0000\end{array}$ & $\begin{array}{l}\text { LCV_ALLO } \\
\text { LCV_ALLO } \\
\text { LCV_ALLO } \\
\text { LCV_ALLO } \\
\text { LCV_ALLO } \\
\text { LCV_ALLO } \\
\text { LCV_ALLO } \\
\text { LCV_ALLO } \\
\text { LCV_ALLO } \\
\text { LCV_ALLO } \\
\text { LCV_ALLO } \\
\text { LCV_ALLO } \\
\text { LCV_ALLO } \\
\text { LCV_ALLO } \\
\text { LCV_DAPH } \\
\text { LCV_DAPH } \\
\text { LCV_DAPH } \\
\text { LCV_DAPH } \\
\text { LCV_DAPH } \\
\text { LCV_DAPH } \\
\text { LCV_DAPH } \\
\text { LCV_DAPH } \\
\text { LCV_DAPH } \\
\text { LCV_DAPH } \\
\text { LCV_DAPH } \\
\text { LCV_DAPH } \\
\text { LCV_DAPH } \\
\text { LCV_DAPH }\end{array}$ \\
\hline CHROHIUN & 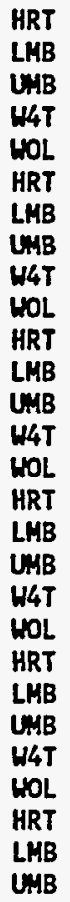 & $\begin{array}{r}8 \\
29 \\
9 \\
16 \\
13 \\
8 \\
29 \\
9 \\
16 \\
13 \\
8 \\
29 \\
9 \\
16 \\
13 \\
8 \\
29 \\
9 \\
16 \\
13 \\
8 \\
29 \\
9 \\
16 \\
13 \\
8 \\
29 \\
9\end{array}$ & $\begin{array}{l}1 \\
1 \\
2 \\
2 \\
7 \\
1 \\
1 \\
2 \\
2 \\
7 \\
1 \\
1 \\
2 \\
2 \\
7 \\
1 \\
1 \\
2 \\
2 \\
7 \\
1 \\
1 \\
2 \\
2 \\
7 \\
1 \\
1 \\
2\end{array}$ & $\begin{array}{l}0.0030 \\
0.0070 \\
0.0036 \\
0.0040 \\
0.0154 \\
0.0030 \\
0.0070 \\
0.0036 \\
0.0040 \\
0.0154 \\
0.0030 \\
0.0070 \\
0.0036 \\
0.0040 \\
0.0154 \\
0.0030 \\
0.0070 \\
0.0036 \\
0.0040 \\
0.0154 \\
0.0030 \\
0.0070 \\
0.0036 \\
0.0040 \\
0.0154 \\
0.0030 \\
0.0070 \\
0.0036\end{array}$ & $\begin{array}{l}0.003 \\
0.007 \\
0.005 \\
0.004 \\
0.019 \\
0.003 \\
0.007 \\
0.005 \\
0.004 \\
0.019 \\
0.003 \\
0.007 \\
0.005 \\
0.004 \\
0.019 \\
0.003 \\
0.007 \\
0.005 \\
0.004 \\
0.019 \\
0.003 \\
0.007 \\
0.005 \\
0.004 \\
0.019 \\
0.003 \\
0.007 \\
0.005\end{array}$ & $\begin{array}{r}1.5000 \\
3.5000 \\
2.4665 \\
2.0000 \\
9.7495 \\
1.5000 \\
3.5000 \\
2.4665 \\
2.0000 \\
9.7495 \\
0.4892 \\
1.1416 \\
0.8045 \\
0.6523 \\
3.1799 \\
0.0410 \\
0.0957 \\
0.0674 \\
0.0547 \\
0.2665 \\
6.0000 \\
14.0000 \\
9.8660 \\
8.0000 \\
38.9979 \\
0.0588 \\
0.1373 \\
0.0967\end{array}$ & $\begin{array}{l}0.0020 \\
0.0020 \\
0.0020 \\
0.0020 \\
0.0020 \\
0.0020 \\
0.0020 \\
0.0020 \\
0.0020 \\
0.0020 \\
0.0061 \\
0.0061 \\
0.0061 \\
0.0061 \\
0.0061 \\
0.0732 \\
0.0732 \\
0.0732 \\
0.0732 \\
0.0732 \\
0.0005 \\
0.0005 \\
0.0005 \\
0.0005 \\
0.0005 \\
0.0510 \\
0.0510 \\
0.0510\end{array}$ & $\begin{array}{l}\text { LCV_ALLO } \\
\text { LCV_ALLO } \\
\text { LCV_ALLO } \\
\text { LCV_ALLO } \\
\text { LCV_ALLO } \\
\text { LCV_AQPL } \\
\text { LCV_AQPL } \\
\text { LCV_AQPL } \\
\text { LCV_AQPL } \\
\text { LCV_AQPL } \\
\text { LCV_DAPH } \\
\text { LCV_DAPH } \\
\text { LCV_DAPH } \\
\text { LCV_DAPH } \\
\text { LCV_DAPH } \\
\text { LCV_FISH } \\
\text { LCV_FISH } \\
\text { LCV_FISH } \\
\text { LCV_FISH } \\
\text { LCV_FISH } \\
\text { LTV_DAPH } \\
\text { LTV_DAPH } \\
\text { LTV_DAPH } \\
\text { LTV_DAPH } \\
\text { LTV_DAPH } \\
\text { LTV_FISH } \\
\text { LTV_FISH } \\
\text { LTV_FISH }\end{array}$ \\
\hline
\end{tabular}


B-10

\begin{tabular}{|c|c|c|c|c|c|c|c|c|}
\hline & $\begin{array}{l}\text { W4T } \\
\text { HOL } \\
\text { HRT } \\
\text { LMB } \\
\text { UHB } \\
\text { H4T } \\
\text { HOL } \\
\text { HRT } \\
\text { LMB } \\
\text { UNB } \\
\text { H4T } \\
\text { WOL }\end{array}$ & $\begin{array}{r}16 \\
13 \\
8 \\
29 \\
9 \\
16 \\
13 \\
8 \\
29 \\
9 \\
16 \\
13\end{array}$ & $\begin{array}{l}2 \\
7 \\
1 \\
1 \\
2 \\
2 \\
7 \\
1 \\
1 \\
2 \\
2 \\
7\end{array}$ & $\begin{array}{l}0.0040 \\
0.0154 \\
0.0030 \\
0.0070 \\
0.0036 \\
0.0040 \\
0.0154 \\
0.0030 \\
0.0070 \\
0.0036 \\
0.0040 \\
0.0154\end{array}$ & $\begin{array}{l}0.004 \\
0.019 \\
0.003 \\
0.007 \\
0.005 \\
0.004 \\
0.019 \\
0.003 \\
0.007 \\
0.005 \\
0.004 \\
0.019\end{array}$ & $\begin{array}{l}0.0784 \\
0.3823 \\
0.1875 \\
0.4375 \\
0.3083 \\
0.2500 \\
1.2187 \\
0.2727 \\
0.6364 \\
0.4485 \\
0.3636 \\
1.7726\end{array}$ & $\begin{array}{l}0.0510 \\
0.0510 \\
0.0160 \\
0.0160 \\
0.0160 \\
0.0160 \\
0.0160 \\
0.0110 \\
0.0110 \\
0.0110 \\
0.0110 \\
0.0110\end{array}$ & $\begin{array}{l}\text { LTV_FISH } \\
\text { LTV_FISH } \\
\text { HAWQ_ACU } \\
\text { HAWQ_ACU } \\
\text { HAWQ_ACU } \\
\text { NAWQ_ACU } \\
\text { NAWQ_ACU } \\
\text { NAWQ_CHR } \\
\text { NAWQ_CHR } \\
\text { NAWQ_CHR } \\
\text { HAWQ_CHR } \\
\text { NAWQ_CHR }\end{array}$ \\
\hline COBALT & 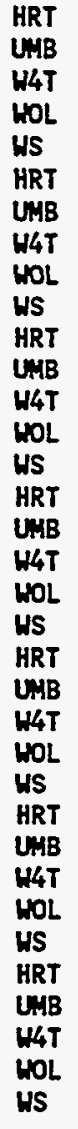 & $\begin{array}{r}8 \\
9 \\
16 \\
13 \\
10 \\
8 \\
9 \\
16 \\
13 \\
10 \\
8 \\
9 \\
16 \\
13 \\
10 \\
8 \\
9 \\
16 \\
13 \\
10 \\
8 \\
9 \\
16 \\
13 \\
10 \\
8 \\
9 \\
16 \\
13 \\
10 \\
8 \\
9 \\
16 \\
13 \\
10\end{array}$ & $\begin{array}{l}1 \\
1 \\
1 \\
1 \\
1 \\
1 \\
1 \\
1 \\
1 \\
1 \\
1 \\
1 \\
1 \\
1 \\
1 \\
1 \\
1 \\
1 \\
1 \\
1 \\
1 \\
1 \\
1 \\
1 \\
1 \\
1 \\
1 \\
1 \\
1 \\
1 \\
1 \\
1 \\
1 \\
1 \\
1\end{array}$ & $\begin{array}{l}0.0020 \\
0.0050 \\
0.0030 \\
0.0020 \\
0.0110 \\
0.0020 \\
0.0050 \\
0.0030 \\
0.0020 \\
0.0110 \\
0.0020 \\
0.0050 \\
0.0030 \\
0.0020 \\
0.0110 \\
0.0020 \\
0.0050 \\
0.0030 \\
0.0020 \\
0.0110 \\
0.0020 \\
0.0050 \\
0.0030 \\
0.0020 \\
0.0110 \\
0.0020 \\
0.0050 \\
0.0030 \\
0.0020 \\
0.0110 \\
0.0020 \\
0.0050 \\
0.0030 \\
0.0020 \\
0.0110\end{array}$ & $\begin{array}{l}0.002 \\
0.005 \\
0.003 \\
0.002 \\
0.011 \\
0.002 \\
0.005 \\
0.003 \\
0.002 \\
0.011 \\
0.002 \\
0.005 \\
0.003 \\
0.002 \\
0.011 \\
0.002 \\
0.005 \\
0.003 \\
0.002 \\
0.011 \\
0.002 \\
0.005 \\
0.003 \\
0.002 \\
0.011 \\
0.002 \\
0.005 \\
0.003 \\
0.002 \\
0.011 \\
0.002 \\
0.005 \\
0.003 \\
0.002 \\
0.011\end{array}$ & $\begin{array}{l}0.3922 \\
0.9804 \\
0.5882 \\
0.3922 \\
2.1569 \\
0.3922 \\
0.9804 \\
0.5882 \\
0.3922 \\
2.1569 \\
0.0069 \\
0.0172 \\
0.0103 \\
0.0069 \\
0.0379 \\
0.4545 \\
1.1364 \\
0.6818 \\
0.4545 \\
2.5000 \\
0.0025 \\
0.0062 \\
0.0037 \\
0.0025 \\
0.0136 \\
0.0103 \\
0.0256 \\
0.0154 \\
0.0103 \\
0.0564 \\
0.6536 \\
1.6340 \\
0.9804 \\
0.6536 \\
3.5948\end{array}$ & $\begin{array}{l}0.0051 \\
0.0051 \\
0.0051 \\
0.0051 \\
0.0051 \\
0.0051 \\
0.0051 \\
0.0051 \\
0.0051 \\
0.0051 \\
0.2900 \\
0.2900 \\
0.2900 \\
0.2900 \\
0.2900 \\
0.0044 \\
0.0044 \\
0.0044 \\
0.0044 \\
0.0044 \\
0.8100 \\
0.8100 \\
0.8100 \\
0.8100 \\
0.8100 \\
0.1950 \\
0.1950 \\
0.1950 \\
0.1950 \\
0.1950 \\
0.0031 \\
0.0031 \\
0.0031 \\
0.0031 \\
0.0031\end{array}$ & $\begin{array}{l}\text { LCV_ALLO } \\
\text { LCV_ALLO } \\
\text { LCV_ALLO } \\
\text { LCV_ALLO } \\
\text { LCV_ALLO } \\
\text { LCV_DAPH } \\
\text { LCV_DAPH } \\
\text { LCV_DAPH } \\
\text { LCV_DAPH } \\
\text { LCV_DAPH } \\
\text { LCV_FISH } \\
\text { LCV_FISH } \\
\text { LCV_FISH } \\
\text { LCV_FISH } \\
\text { LCV_FISH } \\
\text { LTV_DAPH } \\
\text { LTVDDAPH } \\
\text { LTV_DAPH } \\
\text { LTV_DAPH } \\
\text { LTV_DAPH } \\
\text { LTV_FISH } \\
\text { LTV_FISH } \\
\text { LTV_FISH } \\
\text { LTV_FISH } \\
\text { LTV_FISH } \\
\text { S_ACU_V } \\
\text { S_ACU_V } \\
\text { S_ACU_V } \\
\text { S_ACU_V } \\
\text { S_ACUIV } \\
\text { S_CHR_V } \\
\text { S_CHR_V } \\
\text { S_CHR_V } \\
\text { S_CHR_V } \\
\text { S_CHR_V }\end{array}$ \\
\hline COPPER & $\begin{array}{l}\text { IC } \\
\text { IWC } \\
\text { HRT } \\
\text { IHP } \\
\text { LHB } \\
\text { LHC } \\
\text { MUC } \\
\text { UNB } \\
\text { WHT } \\
\text { HOL } \\
\text { WS } \\
\text { IC } \\
\text { IHC } \\
\text { HRT } \\
\text { IHP } \\
\text { LHB } \\
\text { LWC } \\
\text { MHC } \\
\text { UNB } \\
\text { WHT } \\
\text { WOL } \\
\text { WS }\end{array}$ & $\begin{array}{r}9 \\
2 \\
8 \\
12 \\
29 \\
2 \\
18 \\
9 \\
16 \\
13 \\
10 \\
9 \\
2 \\
8 \\
12 \\
29 \\
2 \\
18 \\
9 \\
16 \\
13 \\
10\end{array}$ & $\begin{array}{r}4 \\
1 \\
1 \\
7 \\
18 \\
1 \\
10 \\
5 \\
6 \\
6 \\
3 \\
4 \\
1 \\
1 \\
7 \\
18 \\
1 \\
10 \\
5 \\
6 \\
6 \\
3\end{array}$ & $\begin{array}{l}0.0024 \\
0.0070 \\
0.0020 \\
0.0059 \\
0.0050 \\
0.0130 \\
0.0053 \\
0.0091 \\
0.0099 \\
0.0063 \\
0.0028 \\
0.0024 \\
0.0070 \\
0.0020 \\
0.0059 \\
0.0050 \\
0.0130 \\
0.0053 \\
0.0091 \\
0.0099 \\
0.0063 \\
0.0028\end{array}$ & $\begin{array}{l}0.004 \\
0.007 \\
0.002 \\
0.008 \\
0.006 \\
0.013 \\
0.007 \\
0.015 \\
0.014 \\
0.008 \\
0.004 \\
0.004 \\
0.007 \\
0.002 \\
0.008 \\
0.006 \\
0.013 \\
0.007 \\
0.015 \\
0.014 \\
0.008 \\
0.004\end{array}$ & $\begin{array}{r}16.1181 \\
30.4348 \\
8.6957 \\
34.9408 \\
27.3447 \\
56.5217 \\
30.1813 \\
64.5996 \\
60.9745 \\
35.1402 \\
16.9332 \\
3.7072 \\
7.0000 \\
2.0000 \\
8.0364 \\
6.2893 \\
13.0000 \\
6.9417 \\
14.8579 \\
14.0241 \\
8.0822 \\
3.8946\end{array}$ & $\begin{array}{l}0.0002 \\
0.0002 \\
0.0002 \\
0.0002 \\
0.0002 \\
0.0002 \\
0.0002 \\
0.0002 \\
0.0002 \\
0.0002 \\
0.0002 \\
0.0010 \\
0.0010 \\
0.0010 \\
0.0010 \\
0.0010 \\
0.0010 \\
0.0010 \\
0.0010 \\
0.0010 \\
0.0010 \\
0.0010\end{array}$ & $\begin{array}{l}\text { LCV_ALLO } \\
\text { LCV_ALLO } \\
\text { LCV_ALLO } \\
\text { LCV_ALLO } \\
\text { LCV_ALLO } \\
\text { LCV_ALLO } \\
\text { LCV_ALLO } \\
\text { LCV_ALLO } \\
\text { LCV_ALLO } \\
\text { LCV_ALLO } \\
\text { LCV_ALLO } \\
\text { LCV_AQPL } \\
\text { LCV_AQPL } \\
\text { LCV_AQPL } \\
\text { LCV_AQPL } \\
\text { LCV_AQPL } \\
\text { LCV_AQPL } \\
\text { LCV_AAPP } \\
\text { LCV_AQPL } \\
\text { LCV_AQPL } \\
\text { LCV_AAQPL } \\
\text { LCV_AQPL }\end{array}$ \\
\hline
\end{tabular}


B-11

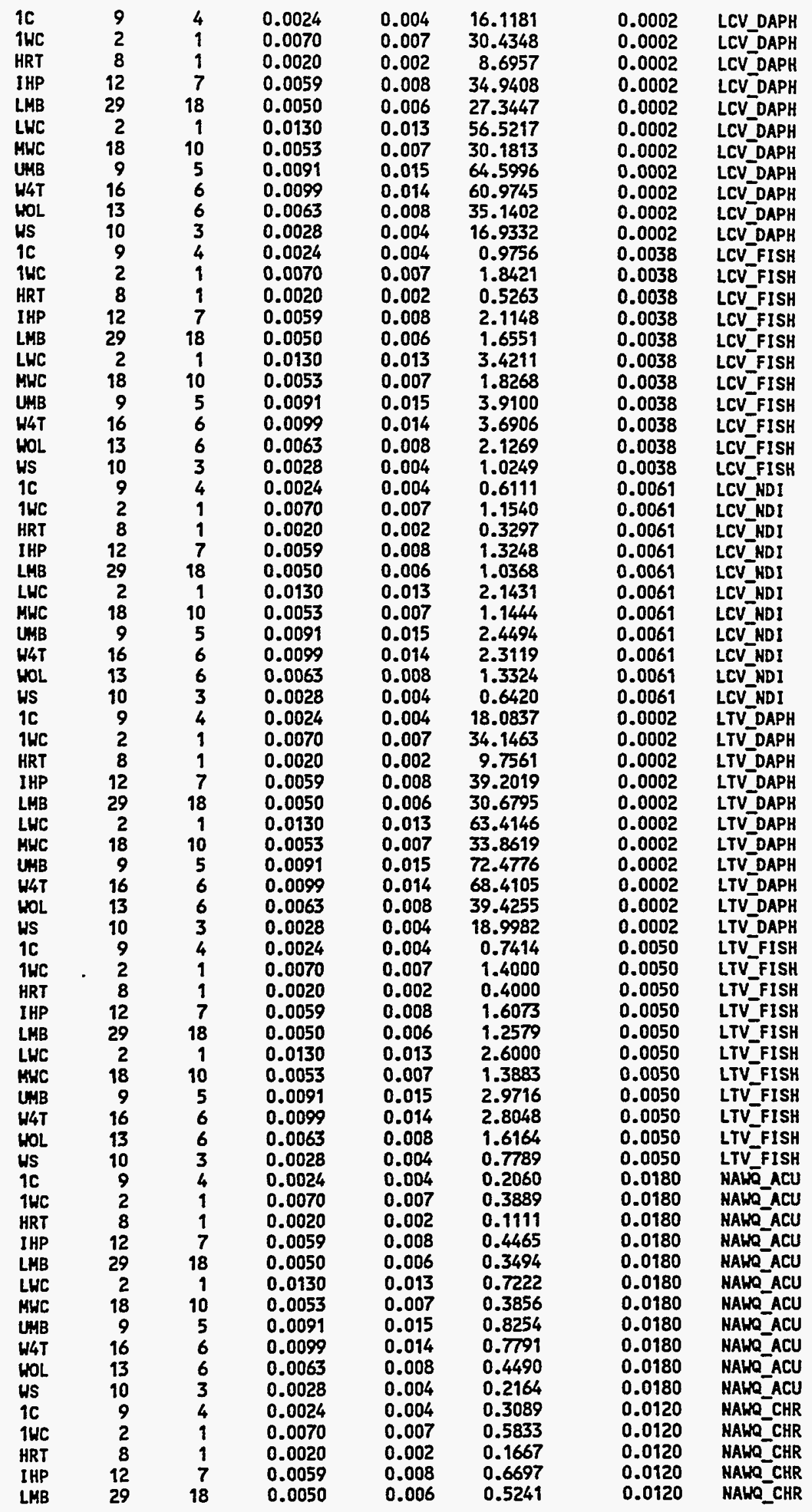


B-12

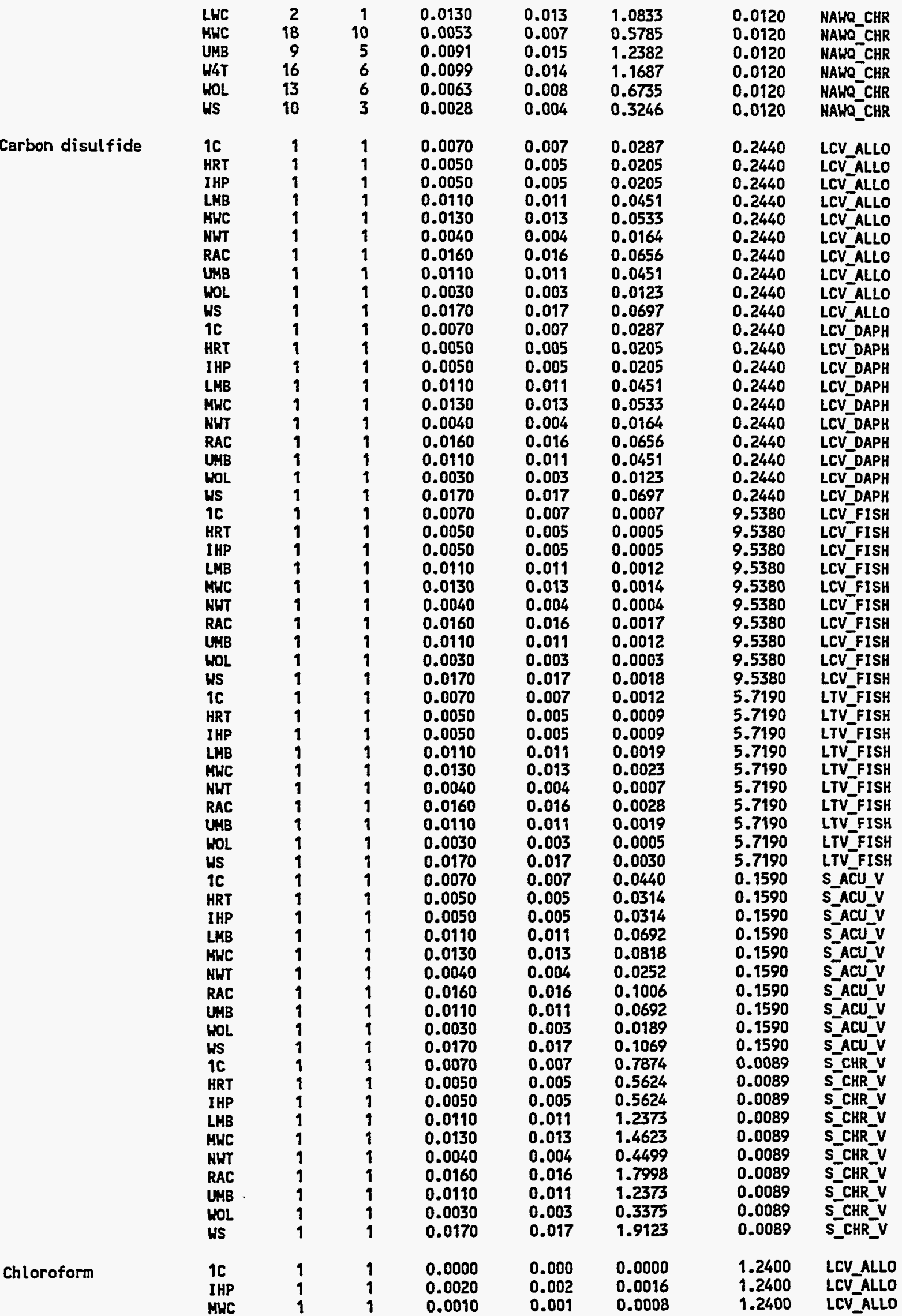


B-13

\begin{tabular}{|c|c|c|c|c|c|c|c|c|}
\hline & $\begin{array}{l}\text { HOL } \\
1 C \\
\text { IHP } \\
\text { HWC } \\
\text { HOL } \\
1 C \\
\text { IHP } \\
\text { HWC } \\
\text { HOL } \\
1 C \\
\text { IHP } \\
\text { MHC } \\
\text { WOL } \\
\text { IC } \\
\text { IHP } \\
\text { MUC } \\
\text { HOL } \\
\text { IC } \\
\text { IHP } \\
\text { MHC } \\
\text { WOL }\end{array}$ & $\begin{array}{l}1 \\
1 \\
1 \\
1 \\
1 \\
1 \\
1 \\
1 \\
1 \\
1 \\
1 \\
1 \\
1 \\
1 \\
1 \\
1 \\
1 \\
1 \\
1 \\
1 \\
1\end{array}$ & $\begin{array}{l}1 \\
1 \\
1 \\
1 \\
1 \\
1 \\
1 \\
1 \\
1 \\
1 \\
1 \\
1 \\
1 \\
1 \\
1 \\
1 \\
1 \\
1 \\
1 \\
1 \\
1\end{array}$ & $\begin{array}{l}0.0000 \\
0.0000 \\
0.0020 \\
0.0010 \\
0.0000 \\
0.0000 \\
0.0020 \\
0.0010 \\
0.0000 \\
0.0000 \\
0.0020 \\
0.0010 \\
0.0000 \\
0.0000 \\
0.0020 \\
0.0010 \\
0.0000 \\
0.0000 \\
0.0020 \\
0.0010 \\
0.0000\end{array}$ & $\begin{array}{l}0.000 \\
0.000 \\
0.002 \\
0.001 \\
0.000 \\
0.000 \\
0.002 \\
0.001 \\
0.000 \\
0.000 \\
0.002 \\
0.001 \\
0.000 \\
0.000 \\
0.002 \\
0.001 \\
0.000 \\
0.000 \\
0.002 \\
0.001 \\
0.000\end{array}$ & $\begin{array}{l}0.0000 \\
0.0000 \\
0.0004 \\
0.0002 \\
0.0000 \\
0.0000 \\
0.0016 \\
0.0008 \\
0.0000 \\
0.0000 \\
0.0002 \\
0.0001 \\
0.0000 \\
0.0000 \\
0.0006 \\
0.0003 \\
0.0000 \\
0.0000 \\
0.0106 \\
0.0053 \\
0.0000\end{array}$ & $\begin{array}{l}1.2400 \\
4.4830 \\
4.4830 \\
4.4830 \\
4.4830 \\
1.2400 \\
1.2400 \\
1.2400 \\
1.2400 \\
8.4000 \\
8.4000 \\
8.4000 \\
8.4000 \\
3.3600 \\
3.3600 \\
3.3600 \\
3.3600 \\
0.1880 \\
0.1880 \\
0.1880 \\
0.1880\end{array}$ & $\begin{array}{l}\text { LCV_ALLO } \\
\text { LCV_DAPH } \\
\text { LCV_DAPH } \\
\text { LCV_DAPH } \\
\text { LCV_DAPH } \\
\text { LCV_FISH } \\
\text { LCV_FISH } \\
\text { LCV_FISH } \\
\text { LCV_FISH } \\
\text { LTV_FISH } \\
\text { LTV_FISH } \\
\text { LTV_FISH } \\
\text { LTV_FISH } \\
\text { S_ACU_V } \\
\text { S_ACU_V } \\
\text { S_ACU_V } \\
\text { S_ACU_V } \\
\text { S_CHR_V } \\
\text { S_CHR_V } \\
\text { S_CHR_V } \\
\text { S_CHR_V }\end{array}$ \\
\hline IRON & 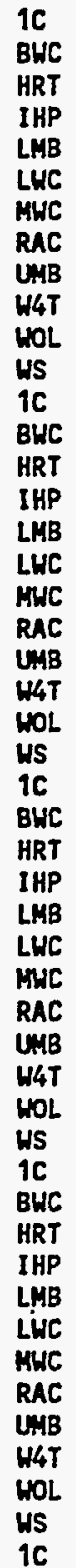 & $\begin{array}{r}9 \\
2 \\
8 \\
12 \\
29 \\
2 \\
18 \\
2 \\
9 \\
16 \\
13 \\
10 \\
9 \\
2 \\
8 \\
12 \\
29 \\
2 \\
18 \\
2 \\
9 \\
16 \\
13 \\
10 \\
9 \\
2 \\
8 \\
12 \\
29 \\
2 \\
18 \\
2 \\
9 \\
16 \\
13 \\
10 \\
9 \\
2 \\
8 \\
12 \\
29 \\
2 \\
18 \\
2 \\
9 \\
16 \\
13 \\
10 \\
9\end{array}$ & $\begin{array}{r}8 \\
1 \\
8 \\
8 \\
28 \\
2 \\
16 \\
1 \\
9 \\
15 \\
13 \\
10 \\
8 \\
1 \\
8 \\
8 \\
28 \\
2 \\
16 \\
1 \\
9 \\
15 \\
13 \\
10 \\
8 \\
1 \\
8 \\
8 \\
28 \\
2 \\
16 \\
1 \\
9 \\
15 \\
13 \\
10 \\
8 \\
1 \\
8 \\
8 \\
28 \\
2 \\
16 \\
1 \\
9 \\
15 \\
13 \\
10 \\
8\end{array}$ & $\begin{array}{l}0.3924 \\
0.1270 \\
0.2448 \\
0.2020 \\
0.1870 \\
0.1700 \\
0.1442 \\
0.2590 \\
0.3292 \\
0.5062 \\
1.0815 \\
0.6578 \\
0.3924 \\
0.1270 \\
0.2448 \\
0.2020 \\
0.1870 \\
0.1700 \\
0.1442 \\
0.2590 \\
0.3292 \\
0.5062 \\
1.0815 \\
0.6578 \\
0.3924 \\
0.1270 \\
0.2448 \\
0.2020 \\
0.1870 \\
0.1700 \\
0.1442 \\
0.2590 \\
0.3292 \\
0.5062 \\
1.0815 \\
0.6578 \\
0.3924 \\
0.1270 \\
0.2448 \\
0.2020 \\
0.1870 \\
0.1700 \\
0.1442 \\
0.2590 \\
0.3292 \\
0.5062 \\
1.0815 \\
0.6578 \\
0.3924\end{array}$ & $\begin{array}{l}0.592 \\
0.127 \\
0.305 \\
0.357 \\
0.231 \\
0.334 \\
0.166 \\
0.259 \\
0.461 \\
0.761 \\
1.346 \\
1.021 \\
0.592 \\
0.127 \\
0.305 \\
0.357 \\
0.231 \\
0.334 \\
0.166 \\
0.259 \\
0.461 \\
0.761 \\
1.346 \\
1.021 \\
0.592 \\
0.127 \\
0.305 \\
0.357 \\
0.231 \\
0.334 \\
0.166 \\
0.259 \\
0.461 \\
0.761 \\
1.346 \\
1.021 \\
0.592 \\
0.127 \\
0.305 \\
0.357 \\
0.231 \\
0.334 \\
0.166 \\
0.259 \\
0.461 \\
0.761 \\
1.346 \\
1.021 \\
0.592\end{array}$ & $\begin{array}{r}3.7449 \\
0.8038 \\
1.9294 \\
2.2619 \\
1.4639 \\
2.1149 \\
1.0498 \\
1.6392 \\
2.9168 \\
4.8151 \\
8.5173 \\
6.4590 \\
3.7449 \\
0.8038 \\
1.9294 \\
2.2619 \\
1.4639 \\
2.1149 \\
1.0498 \\
1.6392 \\
2.9168 \\
4.8151 \\
8.5173 \\
6.4590 \\
0.4552 \\
0.0977 \\
0.2345 \\
0.2749 \\
0.1779 \\
0.2570 \\
0.1276 \\
0.1992 \\
0.3545 \\
0.5852 \\
1.0352 \\
0.7850 \\
36.9811 \\
7.9375 \\
19.0530 \\
22.3365 \\
14.4561 \\
20.8848 \\
10.3667 \\
16.1875 \\
28.8034 \\
47.5493 \\
84.1088 \\
63.7822 \\
0.5917\end{array}$ & $\begin{array}{l}0.1580 \\
0.1580 \\
0.1580 \\
0.1580 \\
0.1580 \\
0.1580 \\
0.1580 \\
0.1580 \\
0.1580 \\
0.1580 \\
0.1580 \\
0.1580 \\
0.1580 \\
0.1580 \\
0.1580 \\
0.1580 \\
0.1580 \\
0.1580 \\
0.1580 \\
0.1580 \\
0.1580 \\
0.1580 \\
0.1580 \\
0.1580 \\
1.3000 \\
1.3000 \\
1.3000 \\
1.3000 \\
1.3000 \\
1.3000 \\
1.3000 \\
1.3000 \\
1.3000 \\
1.3000 \\
1.3000 \\
1.3000 \\
0.0160 \\
0.0160 \\
0.0160 \\
0.0160 \\
0.0160 \\
0.0160 \\
0.0160 \\
0.0160 \\
0.0160 \\
0.0160 \\
0.0160 \\
0.0160 \\
1.0000\end{array}$ & $\begin{array}{l}\text { LCV_ALLO } \\
\text { LCV_ALLO } \\
\text { LCV_ALLO } \\
\text { LCV_ALLO } \\
\text { LCV_ALLO } \\
\text { LCV_ALLO } \\
\text { LCV_ALLO } \\
\text { LCV_ALLO } \\
\text { LCV_ALLO } \\
\text { LCV_ALLO } \\
\text { LCV_ALLO } \\
\text { LCV_ALLO } \\
\text { LCVDDAPH } \\
\text { LCV_DAPH } \\
\text { LCVDDAPH } \\
\text { LCV_OAPH } \\
\text { LCV_DAPH } \\
\text { LCV_DAPH } \\
\text { LCV_DAPH } \\
\text { LCV_DAPH } \\
\text { LCV_DAPH } \\
\text { LCV_DAPH } \\
\text { LCV_DAPH } \\
\text { LCV_DAPH } \\
\text { LCV_FISH } \\
\text { LCV_FISH } \\
\text { LCV_FISH } \\
\text { LCV_FISH } \\
\text { LCV_FISH } \\
\text { LCV_FISH } \\
\text { LCV_FISH } \\
\text { LCV_FISH } \\
\text { LCV_FISH } \\
\text { LCV_FISH } \\
\text { LCV_FISH } \\
\text { LCV_FISH } \\
\text { LTV_DAPH } \\
\text { LTV_DAPH } \\
\text { LTV_DAPH } \\
\text { LTV_DAPH } \\
\text { LTV_DAPH } \\
\text { LTV_DAPH } \\
\text { LTV_DAPH } \\
\text { LTV_DAPH } \\
\text { LTV_DAPH } \\
\text { LTV_DAPH } \\
\text { LTV_DAPH } \\
\text { LTV_DAPH } \\
\text { HAWO_CHR }\end{array}$ \\
\hline
\end{tabular}


B-14

$\begin{array}{lrr}\text { BHC } & 2 & \\ \text { HRT } & 8 & 8 \\ \text { IHP } & 12 & 8 \\ \text { LMB } & 29 & 28 \\ \text { LHC } & 2 & 2 \\ \text { HHC } & 18 & 16 \\ \text { RAC } & 2 & 1 \\ \text { UMB } & 9 & 9 \\ \text { H4T } & 16 & 15 \\ \text { WOL } & 13 & 13 \\ \text { HS } & 10 & 10\end{array}$

0.1270
0.2448
0.2020
0.1870
0.1700
0.1442
0.2590
0.3292
0.5062
1.0815
0.6578

0.127
0.305
0.357
0.231
0.334
0.166
0.259
0.461
0.761
1.346
1.021

0.1270
0.3048
0.3574
0.2313
0.3342
0.1659
0.2590
0.4609
0.7608
1.3457
1.0205

1.0000

1.0000

1.0000

1.0000

1.0000

1.0000
1.0000

1.0000
1.0000

1.0000

0.0020

0.002
0.004

0.1631

0.0040

0.004

0.0040
0.0021

0.002

0.0020

0.0013

0.002

0.0028

0.0020

0.002

0.003

0.0020

0.0040

0.002

0.002

0.0040

0.004

0.0021

0.004

0.0020

0.002

0.0013

0.0028

0.002

0.0020

0.0020

0.0040

0.0040

0.0021

0.0020

0.0013

0.0028

0.0020

0.0020

0.0040

0.002

0.003

0.002

0.002

0.004

0.004

0.002

0.002

0.002

0.003

0.002

0.002

0.0040

0.004

0.0021

0.004

0.0020

0.002

0.0013

0.002

0.0028

0.002

0.0020

0.003

0.0020

0.002

0.0040

0.002

0.0040

0.004

0.0021

0.0020

0.004

0.0013

0.0028

0.002
0.002

0.002

0.0020

0.003

0.0020

0.002

0.0040

0.002

0.0040

0.004

0.0021

0.004

0.0020

0.002

0.0013

0.002

0.0028

0.0020

0.002

0.0020

0.003

0.002
0.002

0.0040

0.002
0.004

0.0040

0.004

0.0021

0.002

0.3263

0.3263

0.1840

0.1631

0.1740

0.2721

0.1631

0.0040

0.0080

0.0080

0.0045

0.0040

0.0043

0.0067

0.0040

0.1631

0.3263

0.3263

0.1840

0.1631

0.1740

0.2721

0.1631

0.1059

0.2119

0.2119

0.1195

0.1059

0.1130

0.1767

0.1059

0.0786

0.1571

0.1571

0.0886

0.0786

0.0838

0.1310

0.0786

0.0909

0.1818

0.1818

0.1026

0.0909

0.0970

0.1516

0.0909

1.0000

0.0123

0.0123

0.0123

0.0123

0.0123

0.0123

0.0123

0.0123

0.5000

0.5000

0.5000

0.5000

0.5000

0.5000

0.5000

0.5000

0.0123

0.0123

0.0123

0.0123

0.0123

0.0123

0.0123

0.0123

0.0189

0.0189

0.0189

0.0189

0.0189

0.0189

0.0189

0.0189

0.0255

0.0255

0.0255

0.0255

0.0255

0.0255

0.0255

0.0255

0.0220

0.0220

0.0220

0.0220

0.0220

0.0220

0.0220

0.0220

0.0244

0.0488

0.0820

0.0820

0.0488

0.0820

0.0275

0.0820

0.0820

0.0013

0.002

0.0260

0.0820

0.0820

0.0020

0.003

0.0407

0.002

0.0020

0.002

0.0244

0.0820

0.0032

1.2500

0.0032

MAHQ CHR

NAHQ_CHR

NAWQ CHR

NAWQ_CHR

NAWQ CHR

NAWQ_CHR

NAWQ CHR

NAWQ_CHR

NALO_CHR

HAWE_CHR

NAWE_CHR

LCV_ALLO

LCV ALLO

LCV_ALLO

LCV ALLO

LCV ALLO

LCV ALLO

LCV_ALLO

LCV_ALLO

LCV_AQPL

LCV_AQPL

LCV_AQPL

LCV_AQPL

LCV_AQPL

LCV_AQPL

LCV AQPL

LCV_AQPL

LCV DAPH

LCVDAPH

LCV_DAPH

LCV DAPH

LCVDAPH

LCV DAPH

LCV DAPH

LCVDAPH

LCV FISH

LCV FISH

LCV_FISH

LCV FISH

LCV_FISH

LCV_FISH

LCV_FISH

LCV_FISH

LCV_NDI

LCV_NDI

LCV NDI

LCV_HDI

LCV_NDI

LCV_NDI

LCV_NDI

LCV_NDI

LTV_FISH

LTV FISH

LTV FISH

LTV FISH

LTVFISH

LTV FISH

LTV_FISH

LTV FISH

NAWT ACU

NAWE_ACU

NALQ_ACU 
B-15

\begin{tabular}{|c|c|c|c|c|c|c|c|c|}
\hline & $\begin{array}{l}\text { LMB } \\
\text { LWC } \\
\text { W4T } \\
\text { WOL } \\
\text { WS }\end{array}$ & $\begin{array}{r}23 \\
2 \\
9 \\
12 \\
8\end{array}$ & $\begin{array}{l}2 \\
1 \\
2 \\
8 \\
1\end{array}$ & $\begin{array}{l}0.0021 \\
0.0020 \\
0.0013 \\
0.0028 \\
0.0020\end{array}$ & $\begin{array}{l}0.002 \\
0.002 \\
0.002 \\
0.003 \\
0.002\end{array}$ & $\begin{array}{l}0.7051 \\
0.6250 \\
0.6667 \\
1.0423 \\
0.6250\end{array}$ & $\begin{array}{l}0.0032 \\
0.0032 \\
0.0032 \\
0.0032 \\
0.0032\end{array}$ & $\begin{array}{l}\text { NAWQ_CHR } \\
\text { NAWQ_CHR } \\
\text { NAWQ_CHR } \\
\text { HAWQ_CHR } \\
\text { NALE_CHR }\end{array}$ \\
\hline MAGNESIUH & $\begin{array}{l}\text { IC } \\
\text { IWC } \\
\text { BHC } \\
\text { HRT } \\
\text { IHP } \\
\text { LHBB } \\
\text { LHC } \\
\text { HHC } \\
\text { HHT } \\
\text { RAC } \\
\text { UHB } \\
\text { WHT } \\
\text { WOL } \\
\text { HS } \\
\text { IC } \\
\text { IWC } \\
\text { BHC } \\
\text { HRT } \\
\text { IHP } \\
\text { LMB } \\
\text { LHC } \\
\text { HHC } \\
\text { HUT } \\
\text { RAC } \\
\text { UWB } \\
\text { WAT } \\
\text { WOL } \\
\text { HS }\end{array}$ & $\begin{array}{r}9 \\
2 \\
2 \\
8 \\
12 \\
29 \\
2 \\
18 \\
2 \\
2 \\
9 \\
16 \\
13 \\
10 \\
9 \\
2 \\
2 \\
8 \\
12 \\
29 \\
2 \\
18 \\
2 \\
2 \\
9 \\
16 \\
13 \\
10\end{array}$ & $\begin{array}{r}9 \\
2 \\
2 \\
8 \\
12 \\
29 \\
2 \\
18 \\
2 \\
2 \\
9 \\
16 \\
13 \\
10 \\
9 \\
2 \\
2 \\
8 \\
12 \\
29 \\
2 \\
18 \\
2 \\
2 \\
9 \\
16 \\
13 \\
10\end{array}$ & $\begin{array}{r}9.3944 \\
9.5050 \\
11.6500 \\
9.2375 \\
9.6750 \\
11.7938 \\
9.1950 \\
9.1383 \\
8.8550 \\
4.7600 \\
12.4356 \\
16.0956 \\
8.6508 \\
8.6190 \\
9.3944 \\
9.5050 \\
11.6500 \\
9.2375 \\
9.6750 \\
11.7938 \\
9.1950 \\
9.1383 \\
8.8550 \\
4.7600 \\
12.4356 \\
16.0956 \\
8.6508 \\
8.6190\end{array}$ & $\begin{array}{r}10.548 \\
11.936 \\
43.534 \\
10.597 \\
10.468 \\
14.053 \\
19.329 \\
9.782 \\
22.398 \\
4.886 \\
18.128 \\
17.779 \\
9.471 \\
10.216 \\
10.548 \\
11.936 \\
43.534 \\
10.597 \\
10.468 \\
14.053 \\
19.329 \\
9.782 \\
22.398 \\
4.886 \\
18.128 \\
17.779 \\
9.471 \\
10.216\end{array}$ & $\begin{array}{l}0.1286 \\
0.1456 \\
0.5309 \\
0.1292 \\
0.1277 \\
0.1714 \\
0.2357 \\
0.1193 \\
0.2731 \\
0.0596 \\
0.2211 \\
0.2168 \\
0.1155 \\
0.1246 \\
0.1286 \\
0.1456 \\
0.5309 \\
0.1292 \\
0.1277 \\
0.1714 \\
0.2357 \\
0.1193 \\
0.2731 \\
0.0596 \\
0.2211 \\
0.2168 \\
0.1155 \\
0.1246\end{array}$ & $\begin{array}{l}82.0000 \\
82.0000 \\
82.0000 \\
82.0000 \\
82.0000 \\
82.0000 \\
82.0000 \\
82.0000 \\
82.0000 \\
82.0000 \\
82.0000 \\
82.0000 \\
82.0000 \\
82.0000 \\
82.0000 \\
82.0000 \\
82.0000 \\
82.0000 \\
82.0000 \\
82.0000 \\
82.0000 \\
82.0000 \\
82.0000 \\
82.0000 \\
82.0000 \\
82.0000 \\
82.0000 \\
82.0000\end{array}$ & $\begin{array}{l}\text { LCV_ALLO } \\
\text { LCV_ALLO } \\
\text { LCV_ALLO } \\
\text { LCV_ALLO } \\
\text { LCV_ALLO } \\
\text { LCV_ALLO } \\
\text { LCV_ALLO } \\
\text { LCV_ALLO } \\
\text { LCV_ALLO } \\
\text { LCV_ALLO } \\
\text { LCV_ALLO } \\
\text { LCV_ALLO } \\
\text { LCV_ALLO } \\
\text { LCV_ALLO } \\
\text { LCV_DAPH } \\
\text { LCV_DAPH } \\
\text { LCV_DAPH } \\
\text { LCV_DAPH } \\
\text { LCV_DAPH } \\
\text { LCV_DAPH } \\
\text { LCV_DAPH } \\
\text { LCV_DAPH } \\
\text { LCV_DAPH } \\
\text { LCVDDAPH } \\
\text { LCV_DAPH } \\
\text { LCV_DAPH } \\
\text { LCV_DAPH } \\
\text { LCV_DAPH }\end{array}$ \\
\hline MAHGAHESE & 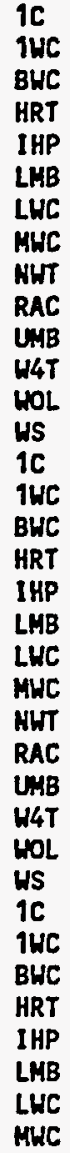 & $\begin{array}{r}9 \\
2 \\
2 \\
8 \\
12 \\
29 \\
2 \\
18 \\
2 \\
2 \\
9 \\
16 \\
13 \\
10 \\
9 \\
2 \\
2 \\
8 \\
12 \\
29 \\
2 \\
18 \\
2 \\
2 \\
9 \\
16 \\
13 \\
10 \\
9 \\
2 \\
2 \\
8 \\
12 \\
29 \\
2 \\
18\end{array}$ & $\begin{array}{r}9 \\
2 \\
1 \\
8 \\
12 \\
29 \\
2 \\
18 \\
2 \\
2 \\
9 \\
16 \\
-13 \\
10 \\
9 \\
2 \\
1 \\
8 \\
12 \\
29 \\
2 \\
18 \\
2 \\
2 \\
9 \\
16 \\
13 \\
10 \\
9 \\
2 \\
1 \\
8 \\
12 \\
29 \\
2 \\
18\end{array}$ & $\begin{array}{l}0.0258 \\
0.0195 \\
0.0080 \\
0.0444 \\
0.0248 \\
0.1169 \\
0.0345 \\
0.0292 \\
0.0350 \\
0.7330 \\
0.0552 \\
0.7425 \\
0.1461 \\
1.6078 \\
0.0258 \\
0.0195 \\
0.0080 \\
0.0444 \\
0.0248 \\
0.1169 \\
0.0345 \\
0.0292 \\
0.0350 \\
0.7330 \\
0.0552 \\
0.7425 \\
0.1461 \\
1.6078 \\
0.0258 \\
0.0195 \\
0.0080 \\
0.0444 \\
0.0248 \\
0.1169 \\
0.0345 \\
0.0292\end{array}$ & $\begin{array}{l}0.034 \\
0.023 \\
0.008 \\
0.051 \\
0.030 \\
0.138 \\
0.057 \\
0.031 \\
0.149 \\
5.323 \\
0.075 \\
1.378 \\
0.177 \\
3.223 \\
0.034 \\
0.023 \\
0.008 \\
0.051 \\
0.030 \\
0.138 \\
0.057 \\
0.031 \\
0.149 \\
5.323 \\
0.075 \\
1.378 \\
0.177 \\
3.223 \\
0.034 \\
0.023 \\
0.008 \\
0.051 \\
0.030 \\
0.138 \\
0.057 \\
0.031\end{array}$ & $\begin{array}{l}0.0308 \\
0.0206 \\
0.0073 \\
0.0462 \\
0.0270 \\
0.1255 \\
0.0515 \\
0.0284 \\
0.1351 \\
4.8392 \\
0.0678 \\
1.2531 \\
0.1608 \\
2.9304 \\
0.0308 \\
0.0206 \\
0.0073 \\
0.0462 \\
0.0270 \\
0.1255 \\
0.0515 \\
0.0284 \\
0.1351 \\
4.8392 \\
0.0678 \\
1.2531 \\
0.1608 \\
2.9304 \\
0.0191 \\
0.0128 \\
0.0045 \\
0.0287 \\
0.0168 \\
0.0780 \\
0.0320 \\
0.0177\end{array}$ & $\begin{array}{l}1.1000 \\
1.1000 \\
1.1000 \\
1.1000 \\
1.1000 \\
1.1000 \\
1.1000 \\
1.1000 \\
1.1000 \\
1.1000 \\
1.1000 \\
1.1000 \\
1.1000 \\
1.1000 \\
1.1000 \\
1.1000 \\
1.1000 \\
1.1000 \\
1.1000 \\
1.1000 \\
1.1000 \\
1.1000 \\
1.1000 \\
1.1000 \\
1.1000 \\
1.1000 \\
1.1000 \\
1.1000 \\
1.7700 \\
1.7700 \\
1.7700 \\
1.7700 \\
1.7700 \\
1.7700 \\
1.7700 \\
1.7700\end{array}$ & $\begin{array}{l}\text { LCV_ALLO } \\
\text { LCV_ALLO } \\
\text { LCV_ALLO } \\
\text { LCV_ALLO } \\
\text { LCV_ALLO } \\
\text { LCV_ALLO } \\
\text { LCV_ALLO } \\
\text { LCV_ALLO } \\
\text { LCV_ALLO } \\
\text { LCV_ALLO } \\
\text { LCV_ALLO } \\
\text { LCV_ALLO } \\
\text { LCV_ALLO } \\
\text { LCV_ALLO } \\
\text { LCV_DAPH } \\
\text { LCV_DAPH } \\
\text { LCV_DAPH } \\
\text { LCV_DAPH } \\
\text { LCV_DAPH } \\
\text { LCV_DAPH } \\
\text { LCV_DAPH } \\
\text { LCV_DAPH } \\
\text { LCV_DAPH } \\
\text { LCV_DAPH } \\
\text { LCV_DAPH } \\
\text { LCV_DAPH } \\
\text { LCV_DAPH } \\
\text { LCV_DAPH } \\
\text { LCV_FISH } \\
\text { LCV_FISH } \\
\text { LCV_FISH } \\
\text { LCV_FISH } \\
\text { LCV_FISH } \\
\text { LCV_FISH } \\
\text { LCV_FISH } \\
\text { LCV_FISH }\end{array}$ \\
\hline
\end{tabular}


B-16

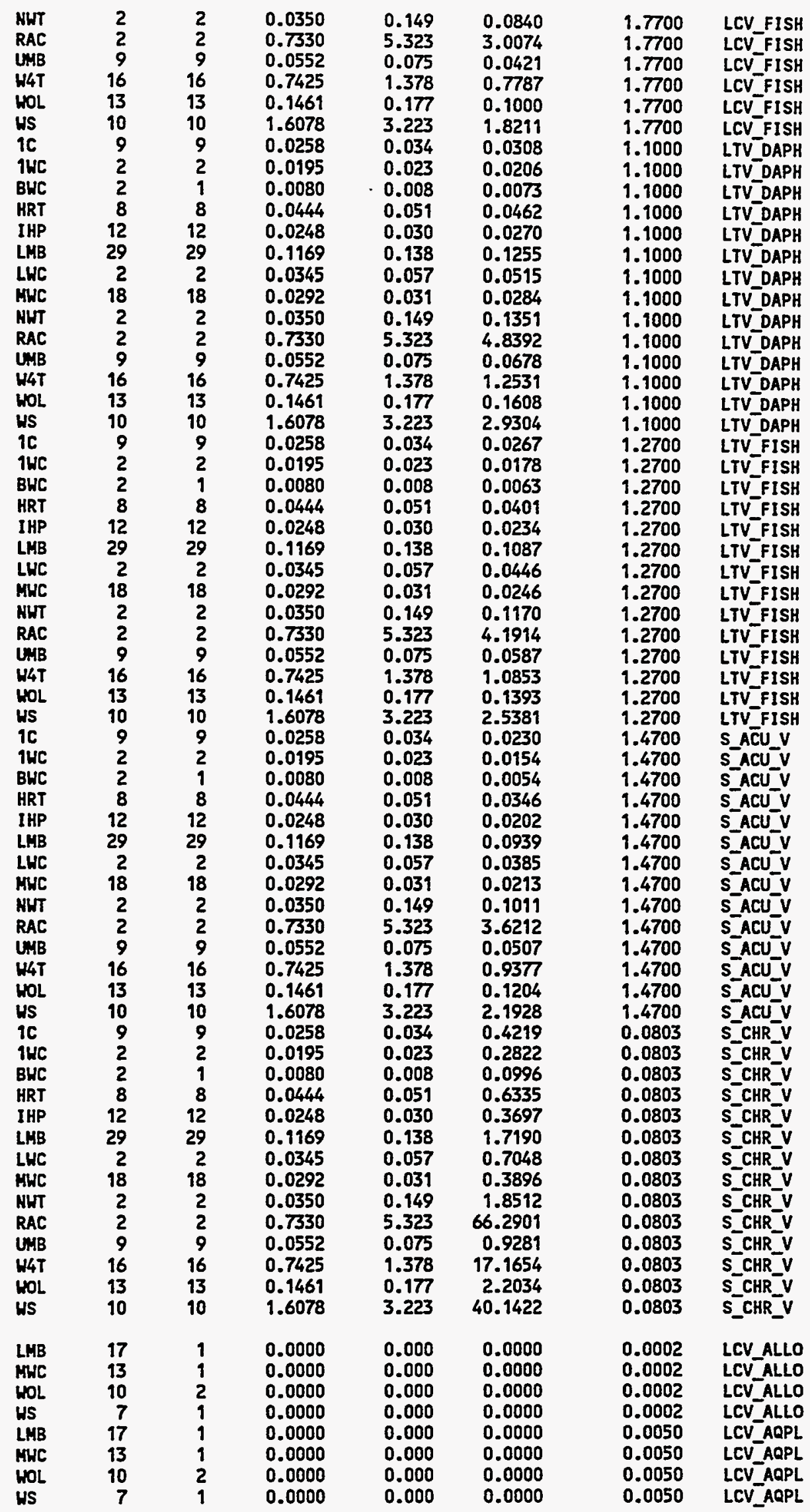




\section{B-17}

\begin{tabular}{|c|c|c|c|c|c|c|c|c|}
\hline & $\begin{array}{l}\text { LMB } \\
\text { HWC } \\
\text { HOL } \\
\text { HS } \\
\text { LHB } \\
\text { MHC } \\
\text { WOL } \\
\text { HS } \\
\text { LMB } \\
\text { HWC } \\
\text { WOL } \\
\text { HS } \\
\text { LHB } \\
\text { MHC } \\
\text { WOL } \\
\text { US } \\
\text { LMB } \\
\text { MHC } \\
\text { WOL } \\
\text { WS } \\
\text { LMB } \\
\text { MWC } \\
\text { WOL } \\
\text { WS }\end{array}$ & $\begin{array}{r}17 \\
13 \\
10 \\
7 \\
17 \\
13 \\
10 \\
7 \\
17 \\
13 \\
10 \\
7 \\
17 \\
13 \\
10 \\
7 \\
17 \\
13 \\
10 \\
7 \\
17 \\
13 \\
10 \\
7\end{array}$ & $\begin{array}{l}1 \\
1 \\
2 \\
1 \\
1 \\
1 \\
2 \\
1 \\
1 \\
1 \\
2 \\
1 \\
1 \\
1 \\
2 \\
1 \\
1 \\
1 \\
2 \\
1 \\
1 \\
1 \\
2 \\
1\end{array}$ & $\begin{array}{l}0.0000 \\
0.0000 \\
0.0000 \\
0.0000 \\
0.0000 \\
0.0000 \\
0.0000 \\
0.0000 \\
0.0000 \\
0.0000 \\
0.0000 \\
0.0000 \\
0.0000 \\
0.0000 \\
0.0000 \\
0.0000 \\
0.0000 \\
0.0000 \\
0.0000 \\
0.0000 \\
0.0000 \\
0.0000 \\
0.0000 \\
0.0000\end{array}$ & $\begin{array}{l}0.000 \\
0.000 \\
0.000 \\
0.000 \\
0.000 \\
0.000 \\
0.000 \\
0.000 \\
0.000 \\
0.000 \\
0.000 \\
0.000 \\
0.000 \\
0.000 \\
0.000 \\
0.000 \\
0.000 \\
0.000 \\
0.000 \\
0.000 \\
0.000 \\
0.000 \\
0.000 \\
0.000\end{array}$ & $\begin{array}{l}0.0000 \\
0.0000 \\
0.0000 \\
0.0000 \\
0.0000 \\
0.0000 \\
0.0000 \\
0.0000 \\
0.0000 \\
0.0000 \\
0.0000 \\
0.0000 \\
0.0000 \\
0.0000 \\
0.0000 \\
0.0000 \\
0.0000 \\
0.0000 \\
0.0000 \\
0.0000 \\
0.0000 \\
0.0000 \\
0.0000 \\
0.0000\end{array}$ & $\begin{array}{l}0.0010 \\
0.0010 \\
0.0010 \\
0.0010 \\
0.0002 \\
0.0002 \\
0.0002 \\
0.0002 \\
0.0009 \\
0.0009 \\
0.0009 \\
0.0009 \\
0.0009 \\
0.0009 \\
0.0009 \\
0.0009 \\
0.0024 \\
0.0024 \\
0.0024 \\
0.0024 \\
0.0013 \\
0.0013 \\
0.0013 \\
0.0013\end{array}$ & $\begin{array}{l}\text { LCV_DAPH } \\
\text { LCV_DAPH } \\
\text { LCV_DAPH } \\
\text { LCV_DAPH } \\
\text { LCV_FISH } \\
\text { LCV_FISH } \\
\text { LCV_FISH } \\
\text { LCV_FISH } \\
\text { LTV_DAPH } \\
\text { LTV_DAPH } \\
\text { LTV_DAPH } \\
\text { LTV_DAPH } \\
\text { LTV_FISH } \\
\text { LTV_FISH } \\
\text { LTV_FISH } \\
\text { LTV_FISH } \\
\text { HALE_ACU } \\
\text { HAWQ_ACU } \\
\text { HAWO_ACU } \\
\text { HAWQ_ACU } \\
\text { S_CHR_V } \\
\text { S_CHR_V } \\
\text { S_CHR_V } \\
\text { S_CHR_V }\end{array}$ \\
\hline MOLYBDEHUM & $\begin{array}{l}\text { RAC } \\
\text { WAT } \\
\text { RAC } \\
\text { WAT } \\
\text { RAC } \\
\text { W4T } \\
\text { RAC } \\
\text { W4T } \\
\text { RAC } \\
\text { W4T }\end{array}$ & $\begin{array}{r}2 \\
16 \\
2 \\
16 \\
2 \\
16 \\
2 \\
16 \\
2 \\
16\end{array}$ & $\begin{array}{l}1 \\
6 \\
1 \\
6 \\
1 \\
6 \\
1 \\
6 \\
1 \\
6\end{array}$ & $\begin{array}{l}0.0120 \\
0.0152 \\
0.0120 \\
0.0152 \\
0.0120 \\
0.0152 \\
0.0120 \\
0.0152 \\
0.0120 \\
0.0152\end{array}$ & $\begin{array}{l}0.012 \\
0.019 \\
0.012 \\
0.019 \\
0.012 \\
0.019 \\
0.012 \\
0.019 \\
0.012 \\
0.019\end{array}$ & $\begin{array}{l}0.0136 \\
0.0221 \\
0.0136 \\
0.0221 \\
0.0333 \\
0.0541 \\
0.0012 \\
0.0019 \\
0.0502 \\
0.0816\end{array}$ & $\begin{array}{r}0.8800 \\
0.8800 \\
0.8800 \\
0.8800 \\
0.3600 \\
0.3600 \\
10.1000 \\
10.1000 \\
0.2390 \\
0.2390\end{array}$ & $\begin{array}{l}\text { LCV_ALLO } \\
\text { LCV_ALLO } \\
\text { LCV_DAPH } \\
\text { LCV_DAPH } \\
\text { LTV_DAPH } \\
\text { LTV_DAPH } \\
\text { S_ACU_V } \\
\text { S_ACUIV } \\
\text { S_CHR_V } \\
\text { S_CHR_V }\end{array}$ \\
\hline Methylene chloride & 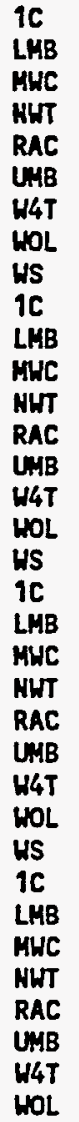 & $\begin{array}{l}1 \\
1 \\
1 \\
1 \\
1 \\
1 \\
3 \\
1 \\
1 \\
1 \\
1 \\
1 \\
1 \\
1 \\
1 \\
3 \\
1 \\
1 \\
1 \\
1 \\
1 \\
1 \\
1 \\
1 \\
3 \\
1 \\
1 \\
1 \\
1 \\
1 \\
1 \\
1 \\
1 \\
3 \\
1\end{array}$ & $\begin{array}{l}1 \\
1 \\
1 \\
1 \\
1 \\
1 \\
1 \\
1 \\
1 \\
1 \\
1 \\
1 \\
1 \\
1 \\
1 \\
1 \\
1 \\
1 \\
1 \\
1 \\
1 \\
1 \\
1 \\
1 \\
1 \\
1 \\
1 \\
1 \\
1 \\
1 \\
1 \\
1 \\
1 \\
1 \\
1\end{array}$ & $\begin{array}{l}0.0000 \\
0.0010 \\
0.0000 \\
0.0000 \\
0.0020 \\
0.0000 \\
0.0000 \\
0.0000 \\
0.0000 \\
0.0000 \\
0.0010 \\
0.0000 \\
0.0000 \\
0.0020 \\
0.0000 \\
0.0000 \\
0.0000 \\
0.0000 \\
0.0000 \\
0.0010 \\
0.0000 \\
0.0000 \\
0.0020 \\
0.0000 \\
0.0000 \\
0.0000 \\
0.0000 \\
0.0000 \\
0.0010 \\
0.0000 \\
0.0000 \\
0.0020 \\
0.0000 \\
0.0000 \\
0.0000\end{array}$ & $\begin{array}{l}0.000 \\
0.001 \\
0.000 \\
0.000 \\
0.002 \\
0.000 \\
0.000 \\
0.000 \\
0.000 \\
0.000 \\
0.001 \\
0.000 \\
0.000 \\
0.002 \\
0.000 \\
0.000 \\
0.000 \\
0.000 \\
0.000 \\
0.001 \\
0.000 \\
0.000 \\
0.002 \\
0.000 \\
0.000 \\
0.000 \\
0.000 \\
0.000 \\
0.001 \\
0.000 \\
0.000 \\
0.002 \\
0.000 \\
0.000 \\
0.000\end{array}$ & $\begin{array}{l}0.0000 \\
0.0000 \\
0.0000 \\
0.0000 \\
0.0000 \\
0.0000 \\
0.0000 \\
0.0000 \\
0.0000 \\
0.0000 \\
0.0000 \\
0.0000 \\
0.0000 \\
0.0000 \\
0.0000 \\
0.0000 \\
0.0000 \\
0.0000 \\
0.0000 \\
0.0000 \\
0.0000 \\
0.0000 \\
0.0000 \\
0.0000 \\
0.0000 \\
0.0000 \\
0.0000 \\
0.0000 \\
0.0024 \\
0.0000 \\
0.0000 \\
0.0049 \\
0.0000 \\
0.0000 \\
0.0000\end{array}$ & $\begin{array}{r}42.6670 \\
42.6670 \\
42.6670 \\
42.6670 \\
42.6670 \\
42.6670 \\
42.6670 \\
42.6670 \\
42.6670 \\
42.6670 \\
42.6670 \\
42.6670 \\
42.6670 \\
42.6670 \\
42.6670 \\
42.6670 \\
42.6670 \\
42.6670 \\
108.0000 \\
108.0000 \\
108.0000 \\
108.0000 \\
108.0000 \\
108.0000 \\
108.0000 \\
108.0000 \\
108.0000 \\
0.4100 \\
0.4100 \\
0.4100 \\
0.4100 \\
0.4100 \\
0.4100 \\
0.4100 \\
0.4100\end{array}$ & $\begin{array}{l}\text { LCV_ALLO } \\
\text { LCV_ALLO } \\
\text { LCV_ALLO } \\
\text { LCV_ALLO } \\
\text { LCV_ALLO } \\
\text { LCV_ALLO } \\
\text { LCV_ALLO } \\
\text { LCV_ALLO } \\
\text { LCV_ALLO } \\
\text { LCV_DAPH } \\
\text { LCV_DAPH } \\
\text { LCV_DAPH } \\
\text { LCV_DAPH } \\
\text { LCV_DAPH } \\
\text { LCV_DAPH } \\
\text { LCV_DAPH } \\
\text { LCV_DAPH } \\
\text { LCV_DAPH } \\
\text { LCV_FISH } \\
\text { LCV_FISH } \\
\text { LCV_FISH } \\
\text { LCV_FISH } \\
\text { LCV_FISH } \\
\text { LCV_FISH } \\
\text { LCV_FISH } \\
\text { LCV_FISH } \\
\text { LCV_FISH } \\
\text { LTV_FISH } \\
\text { LTV_FISH } \\
\text { LTV_FISH } \\
\text { LTV_FISH } \\
\text { LTV_FISH } \\
\text { LTV_FISH } \\
\text { LTV_FISH } \\
\text { LTV_FISH }\end{array}$ \\
\hline
\end{tabular}


B-18

\begin{tabular}{|c|c|c|c|c|c|c|c|c|}
\hline & $\begin{array}{l}\text { WS } \\
\text { IC } \\
\text { LMB } \\
\text { MHC } \\
\text { NHT } \\
\text { RAC } \\
\text { UMB } \\
\text { HAT } \\
\text { WOL } \\
\text { US } \\
\text { IC } \\
\text { MMB } \\
\text { HHC } \\
\text { WHT } \\
\text { RAC } \\
\text { UMB } \\
\text { WAT } \\
\text { WOL } \\
\text { HS }\end{array}$ & $\begin{array}{l}1 \\
1 \\
1 \\
1 \\
1 \\
1 \\
1 \\
3 \\
1 \\
1 \\
1 \\
1 \\
1 \\
1 \\
1 \\
1 \\
3 \\
1 \\
1\end{array}$ & $\begin{array}{l}1 \\
1 \\
1 \\
1 \\
1 \\
1 \\
1 \\
1 \\
1 \\
1 \\
1 \\
1 \\
1 \\
1 \\
1 \\
1 \\
1 \\
1 \\
1\end{array}$ & $\begin{array}{l}0.0000 \\
0.0000 \\
0.0010 \\
0.0000 \\
0.0000 \\
0.0020 \\
0.0000 \\
0.0000 \\
0.0000 \\
0.0000 \\
0.0000 \\
0.0010 \\
0.0000 \\
0.0000 \\
0.0020 \\
0.0000 \\
0.0000 \\
0.0000 \\
0.0000\end{array}$ & $\begin{array}{l}0.000 \\
0.000 \\
0.001 \\
0.000 \\
0.000 \\
0.002 \\
0.000 \\
0.000 \\
0.000 \\
0.000 \\
0.000 \\
0.001 \\
0.000 \\
0.000 \\
0.002 \\
0.000 \\
0.000 \\
0.000 \\
0.000\end{array}$ & $\begin{array}{l}0.0000 \\
0.0000 \\
0.0000 \\
0.0000 \\
0.0000 \\
0.0001 \\
0.0000 \\
0.0000 \\
0.0000 \\
0.0000 \\
0.0000 \\
0.0004 \\
0.0000 \\
0.0000 \\
0.0009 \\
0.0000 \\
0.0000 \\
0.0000 \\
0.0000\end{array}$ & $\begin{array}{r}0.4100 \\
25.6000 \\
25.6000 \\
25.6000 \\
25.6000 \\
25.6000 \\
25.6000 \\
25.6000 \\
25.6000 \\
25.6000 \\
2.2400 \\
2.2400 \\
2.2400 \\
2.2400 \\
2.2400 \\
2.2400 \\
2.2400 \\
2.2400 \\
2.2400\end{array}$ & 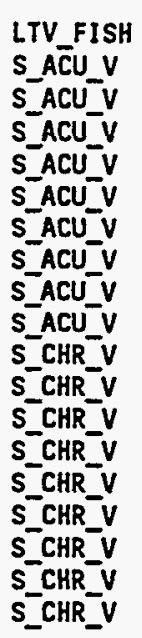 \\
\hline HICKEL & 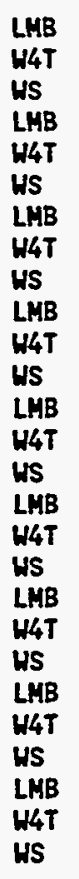 & $\begin{array}{l}29 \\
16 \\
10 \\
29 \\
16 \\
10 \\
29 \\
16 \\
10 \\
29 \\
16 \\
10 \\
29 \\
16 \\
10 \\
29 \\
16 \\
10 \\
29 \\
16 \\
10 \\
29 \\
16 \\
10 \\
29 \\
16 \\
10\end{array}$ & $\begin{array}{l}1 \\
5 \\
4 \\
1 \\
5 \\
4 \\
1 \\
5 \\
4 \\
1 \\
5 \\
4 \\
1 \\
5 \\
4 \\
1 \\
5 \\
4 \\
1 \\
5 \\
4 \\
1 \\
5 \\
4 \\
1 \\
5 \\
4\end{array}$ & $\begin{array}{l}0.0070 \\
0.0136 \\
0.0104 \\
0.0070 \\
0.0136 \\
0.0104 \\
0.0070 \\
0.0136 \\
0.0104 \\
0.0070 \\
0.0136 \\
0.0104 \\
0.0070 \\
0.0136 \\
0.0104 \\
0.0070 \\
0.0136 \\
0.0104 \\
0.0070 \\
0.0136 \\
0.0104 \\
0.0070 \\
0.0136 \\
0.0104 \\
0.0070 \\
0.0136 \\
0.0104\end{array}$ & $\begin{array}{l}0.007 \\
0.015 \\
0.014 \\
0.007 \\
0.015 \\
0.014 \\
0.007 \\
0.015 \\
0.014 \\
0.007 \\
0.015 \\
0.014 \\
0.007 \\
0.015 \\
0.014 \\
0.007 \\
0.015 \\
0.014 \\
0.007 \\
0.015 \\
0.014 \\
0.007 \\
0.015 \\
0.014 \\
0.007 \\
0.015 \\
0.014\end{array}$ & $\begin{array}{l}1.4000 \\
3.0380 \\
2.8210 \\
1.4000 \\
3.0380 \\
2.8210 \\
1.4000 \\
3.0380 \\
2.8210 \\
0.2000 \\
0.4340 \\
0.4030 \\
0.0545 \\
0.1183 \\
0.1099 \\
0.1556 \\
0.3376 \\
0.3134 \\
0.1129 \\
0.2450 \\
0.2275 \\
0.0050 \\
0.0008 \\
0.0101 \\
0.0438 \\
0.0949 \\
0.0882\end{array}$ & $\begin{array}{l}0.0050 \\
0.0050 \\
0.0050 \\
0.0050 \\
0.0050 \\
0.0050 \\
0.0050 \\
0.0050 \\
0.0050 \\
0.0350 \\
0.0350 \\
0.0350 \\
0.1284 \\
0.1284 \\
0.1284 \\
0.0450 \\
0.0450 \\
0.0450 \\
0.0620 \\
0.0620 \\
0.0620 \\
1.4000 \\
1.4000 \\
1.4000 \\
0.1600 \\
0.1600 \\
0.1600\end{array}$ & $\begin{array}{l}\text { LCV_ALLO } \\
\text { LCV_ALLO } \\
\text { LCV_ALLO } \\
\text { LCV_AOPL } \\
\text { LCV_AQPL } \\
\text { LCV_AQPL } \\
\text { LCV_DAPH } \\
\text { LCV_DAPH } \\
\text { LCV_DAPH } \\
\text { LCV_FISH } \\
\text { LCV_FISH } \\
\text { LCV_FISH } \\
\text { LCV_HDI } \\
\text { LCV_HDI } \\
\text { LCV_HDI } \\
\text { LTV_DAPH } \\
\text { LTV_DAPH } \\
\text { LTV_DAPH } \\
\text { LTV_FISH } \\
\text { LTV_FISH } \\
\text { LTV_FISH } \\
\text { HAWD_ACU } \\
\text { HAWE_ACU } \\
\text { HAHE_ACU } \\
\text { HAWE_CHR } \\
\text { HALE_CHR } \\
\text { HAWE_CHR }\end{array}$ \\
\hline POTASSIUM & $\begin{array}{l}\text { IC } \\
\text { IWC } \\
\text { BHC } \\
\text { HRT } \\
\text { IHP } \\
\text { LHB } \\
\text { LHC } \\
\text { MHC } \\
\text { NHT } \\
\text { RAC } \\
\text { UHB } \\
\text { WHT } \\
\text { HOL } \\
\text { HS } \\
\text { IC } \\
\text { IHC } \\
\text { BHC } \\
\text { HRT } \\
\text { IHP } \\
\text { LHB } \\
\text { LWC } \\
\text { WHC } \\
\text { HWT }\end{array}$ & $\begin{array}{r}9 \\
2 \\
2 \\
8 \\
12 \\
29 \\
2 \\
18 \\
2 \\
2 \\
9 \\
16 \\
13 \\
10 \\
9 \\
2 \\
2 \\
8 \\
12 \\
29 \\
2 \\
18 \\
2\end{array}$ & $\begin{array}{r}7 \\
2 \\
2 \\
1 \\
8 \\
11 \\
28 \\
1 \\
17 \\
1 \\
1 \\
9 \\
16 \\
12 \\
8 \\
7 \\
2 \\
1 \\
8 \\
11 \\
28 \\
1 \\
17 \\
1\end{array}$ & $\begin{array}{l}0.9363 \\
1.6850 \\
0.8870 \\
1.8813 \\
1.8167 \\
2.0054 \\
1.2000 \\
1.764 \\
1.5900 \\
0.8990 \\
2.5233 \\
7.0494 \\
1.7679 \\
1.7448 \\
0.9363 \\
1.6850 \\
0.8870 \\
1.8813 \\
1.8167 \\
2.0054 \\
1.2000 \\
1.7764 \\
1.5900\end{array}$ & $\begin{array}{l}1.066 \\
2.032 \\
0.887 \\
2.108 \\
2.057 \\
2.276 \\
1.200 \\
1.980 \\
1.590 \\
0.899 \\
3.478 \\
9.129 \\
2.005 \\
2.089 \\
1.066 \\
2.032 \\
0.887 \\
2.108 \\
2.057 \\
2.276 \\
1.200 \\
1.980 \\
1.590\end{array}$ & $\begin{array}{l}0.0201 \\
0.0383 \\
0.0167 \\
0.0398 \\
0.0388 \\
0.0429 \\
0.0226 \\
0.0374 \\
0.0300 \\
0.0170 \\
0.0656 \\
0.1722 \\
0.0378 \\
0.0394 \\
0.0201 \\
0.0383 \\
0.0167 \\
0.0398 \\
0.0388 \\
0.0429 \\
0.0226 \\
0.0374 \\
0.0300\end{array}$ & $\begin{array}{l}53.0000 \\
53.0000 \\
53.0000 \\
53.0000 \\
53.0000 \\
53.0000 \\
53.0000 \\
53.0000 \\
53.0000 \\
53.0000 \\
53.0000 \\
53.0000 \\
53.0000 \\
53.0000 \\
53.0000 \\
53.0000 \\
53.0000 \\
53.0000 \\
53.0000 \\
53.0000 \\
53.0000 \\
53.0000 \\
53.0000\end{array}$ & $\begin{array}{l}\text { LCV_ALLO } \\
\text { LCV_ALLO } \\
\text { LCV_ALLO } \\
\text { LCV_ALLO } \\
\text { LCV_ALLO } \\
\text { LCVALLO } \\
\text { LC_ALLO } \\
\text { LCV_ALLO } \\
\text { LCV_ALLO } \\
\text { LCV_ALLO } \\
\text { LCV_ALLO } \\
\text { LCV_ALLO } \\
\text { LCVALLO } \\
\text { LC_ALLO } \\
\text { LC_DAPH } \\
\text { LC_DAPH } \\
\text { LCV_DAPH } \\
\text { LCVDDAPH } \\
\text { LCV_DAPH } \\
\text { LCVDDAPH } \\
\text { LCVDDAPH } \\
\text { LCVDAPH } \\
\text { LCVDDAPH }\end{array}$ \\
\hline
\end{tabular}


B-19

\begin{tabular}{|c|c|c|c|c|c|c|c|c|}
\hline & $\begin{array}{l}\text { RAC } \\
\text { UNB } \\
\text { H4T } \\
\text { WOL } \\
\text { WS }\end{array}$ & $\begin{array}{r}2 \\
9 \\
16 \\
13 \\
10\end{array}$ & $\begin{array}{r}1 \\
9 \\
16 \\
12 \\
8\end{array}$ & $\begin{array}{l}0.8990 \\
2.5233 \\
7.0494 \\
1.7679 \\
1.7448\end{array}$ & $\begin{array}{l}0.899 \\
3.478 \\
9.129 \\
2.005 \\
2.089\end{array}$ & $\begin{array}{l}0.0170 \\
0.0656 \\
0.1722 \\
0.0378 \\
0.0394\end{array}$ & $\begin{array}{l}53.0000 \\
53.0000 \\
53.0000 \\
53.0000 \\
53.0000\end{array}$ & $\begin{array}{l}\text { LCV_DAPH } \\
\text { LCV_DAPH } \\
\text { LCV_DAPH } \\
\text { LCV_DAPH } \\
\text { LCV_DAPH }\end{array}$ \\
\hline SILVER & $\begin{array}{l}\text { BHC } \\
\text { IHP } \\
\text { W4T } \\
\text { BHC } \\
\text { IHP } \\
\text { W4T } \\
\text { BHC } \\
\text { IHP } \\
\text { W4T } \\
\text { BHC } \\
\text { IHP } \\
\text { W4T } \\
\text { BHC } \\
\text { IHP } \\
\text { W4T } \\
\text { BHC } \\
\text { IHP } \\
\text { W4T } \\
\text { BHC } \\
\text { IHP } \\
\text { W4T } \\
\text { BHC } \\
\text { IHP } \\
\text { W4T }\end{array}$ & $\begin{array}{r}2 \\
12 \\
16 \\
2 \\
12 \\
16 \\
2 \\
12 \\
12 \\
16 \\
2 \\
12 \\
16 \\
16 \\
2 \\
12 \\
16 \\
2 \\
12 \\
16 \\
2 \\
12 \\
16 \\
2 \\
12 \\
16\end{array}$ & $\begin{array}{l}1 \\
1 \\
1 \\
1 \\
1 \\
1 \\
1 \\
1 \\
1 \\
1 \\
1 \\
1 \\
1 \\
1 \\
1 \\
1 \\
1 \\
1 \\
1 \\
1 \\
1 \\
1 \\
1 \\
1\end{array}$ & $\begin{array}{l}0.0040 \\
0.0040 \\
0.0040 \\
0.0040 \\
0.0040 \\
0.0040 \\
0.0040 \\
0.0040 \\
0.0040 \\
0.0040 \\
0.0040 \\
0.0040 \\
0.0040 \\
0.0040 \\
0.0040 \\
0.0040 \\
0.0040 \\
0.0040 \\
0.0040 \\
0.0040 \\
0.0040 \\
0.0040 \\
0.0040 \\
0.0040\end{array}$ & $\begin{array}{l}0.004 \\
0.004 \\
0.004 \\
0.004 \\
0.004 \\
0.004 \\
0.004 \\
0.004 \\
0.004 \\
0.004 \\
0.004 \\
0.004 \\
0.004 \\
0.004 \\
0.004 \\
0.004 \\
0.004 \\
0.004 \\
0.004 \\
0.004 \\
0.004 \\
0.004 \\
0.004 \\
0.004\end{array}$ & $\begin{array}{r}33.3333 \\
33.3333 \\
33.3333 \\
0.1333 \\
0.1333 \\
0.1333 \\
1.5385 \\
1.5385 \\
1.5385 \\
33.3333 \\
33.3333 \\
33.3333 \\
7.1429 \\
7.1429 \\
7.1429 \\
20.0000 \\
20.0000 \\
20.0000 \\
0.9756 \\
0.9756 \\
0.9756 \\
11.11111 \\
11.1111 \\
11.11111\end{array}$ & $\begin{array}{l}0.0001 \\
0.0001 \\
0.0001 \\
0.0300 \\
0.0300 \\
0.0300 \\
0.0026 \\
0.0026 \\
0.0026 \\
0.0001 \\
0.0001 \\
0.0001 \\
0.0006 \\
0.0006 \\
0.0006 \\
0.0002 \\
0.0002 \\
0.0002 \\
0.0041 \\
0.0041 \\
0.0041 \\
0.0004 \\
0.0004 \\
0.0004\end{array}$ & $\begin{array}{l}\text { LCV_ALLO } \\
\text { LCV_ALLO } \\
\text { LCV_ALLO } \\
\text { LCV_AOPL } \\
\text { LCV_AOPL } \\
\text { LCV_AQPL } \\
\text { LCV_DAPH } \\
\text { LCV_DAPH } \\
\text { LCV_DAPH } \\
\text { LCV_FISH } \\
\text { LCV_FISH } \\
\text { LCV_FISH } \\
\text { LTV_DAPH } \\
\text { LTV_DAPH } \\
\text { LTV_DAPH } \\
\text { LTV_FISH } \\
\text { LTV_FISH } \\
\text { LTV_FISH } \\
\text { HALE_ACU } \\
\text { NAWQ_ACU } \\
\text { NAWQ_ACU } \\
\text { S_CHR_V } \\
\text { S_CHR_V } \\
\text { S_CHR_V }\end{array}$ \\
\hline SOOIUM & 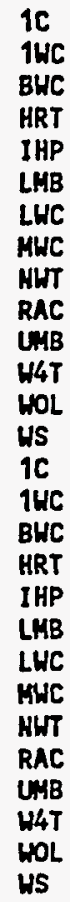 & $\begin{array}{r}9 \\
2 \\
2 \\
8 \\
12 \\
29 \\
2 \\
18 \\
2 \\
2 \\
9 \\
16 \\
13 \\
10 \\
9 \\
2 \\
2 \\
8 \\
12 \\
29 \\
2 \\
18 \\
2 \\
2 \\
9 \\
16 \\
13 \\
10\end{array}$ & $\begin{array}{r}9 \\
2 \\
1 \\
8 \\
12 \\
29 \\
2 \\
18 \\
2 \\
2 \\
9 \\
16 \\
13 \\
10 \\
9 \\
2 \\
1 \\
8 \\
12 \\
29 \\
2 \\
18 \\
2 \\
2 \\
9 \\
16 \\
13 \\
10\end{array}$ & $\begin{array}{r}4.5044 \\
18.8500 \\
0.5230 \\
5.0038 \\
16.4375 \\
7.4876 \\
17.4800 \\
15.6189 \\
3.4500 \\
2.3700 \\
7.6311 \\
13.3956 \\
13.3846 \\
26.6400 \\
4.5044 \\
18.8500 \\
0.5230 \\
5.0038 \\
16.4375 \\
7.4876 \\
17.4800 \\
15.6189 \\
3.4500 \\
2.3700 \\
7.6311 \\
13.3956 \\
13.3846 \\
26.6400\end{array}$ & $\begin{array}{r}6.144 \\
40.001 \\
0.523 \\
5.694 \\
19.317 \\
8.950 \\
72.536 \\
18.004 \\
6.354 \\
3.570 \\
11.164 \\
15.115 \\
15.932 \\
41.874 \\
6.144 \\
40.001 \\
0.523 \\
5.694 \\
19.317 \\
8.950 \\
72.536 \\
18.004 \\
6.354 \\
3.570 \\
11.964 \\
15.115 \\
15.932 \\
41.874\end{array}$ & $\begin{array}{l}0.0090 \\
0.0588 \\
0.0008 \\
0.0084 \\
0.0284 \\
0.0132 \\
0.1067 \\
0.0265 \\
0.0093 \\
0.0052 \\
0.0164 \\
0.0222 \\
0.0234 \\
0.0616 \\
0.0090 \\
0.0588 \\
0.0008 \\
0.0084 \\
0.0284 \\
0.0132 \\
0.1067 \\
0.0265 \\
0.0093 \\
0.0052 \\
0.0164 \\
0.0222 \\
0.0234 \\
0.0616\end{array}$ & $\begin{array}{l}680.0000 \\
680.0000 \\
680.0000 \\
680.0000 \\
680.0000 \\
680.0000 \\
680.0000 \\
680.0000 \\
680.0000 \\
680.0000 \\
680.0000 \\
680.0000 \\
680.0000 \\
680.0000 \\
680.0000 \\
680.0000 \\
680.0000 \\
680.0000 \\
680.0000 \\
680.0000 \\
680.0000 \\
680.0000 \\
680.0000 \\
680.0000 \\
680.0000 \\
680.0000 \\
680.0000 \\
680.0000\end{array}$ & $\begin{array}{l}\text { LCV_ALLO } \\
\text { LCV_ALLO } \\
\text { LCV_ALLO } \\
\text { LCV_ALLO } \\
\text { LCV_ALLO } \\
\text { LCV_ALLO } \\
\text { LCV_ALLO } \\
\text { LCV_ALLO } \\
\text { LCV_ALLO } \\
\text { LCV_ALLO } \\
\text { LCV_ALLO } \\
\text { LCV_ALLO } \\
\text { LCV_ALLO } \\
\text { LCV_ALLO } \\
\text { LCV_DAPH } \\
\text { LCV_DAPH } \\
\text { LCV_DAPH } \\
\text { LCV_DAPH } \\
\text { LCV_DAPH } \\
\text { LCVDDAPH } \\
\text { LCVDDAPH } \\
\text { LCV_DAPH } \\
\text { LCV_DAPH } \\
\text { LCVDDAPH } \\
\text { LCVDDAPH } \\
\text { LCVDDAPH } \\
\text { LCV_DAPH } \\
\text { LCVDDAPH }\end{array}$ \\
\hline STRONTIUH & $\begin{array}{l}\text { 1C } \\
\text { IWC } \\
\text { BWC } \\
\text { HRT } \\
\text { IHP } \\
\text { LHB } \\
\text { LWC } \\
\text { HWC } \\
\text { HWT } \\
\text { RAC } \\
\text { LWB }\end{array}$ & $\begin{array}{r}9 \\
2 \\
2 \\
8 \\
12 \\
29 \\
2 \\
18 \\
2 \\
2 \\
9\end{array}$ & $\begin{array}{r}9 \\
2 \\
1 \\
8 \\
12 \\
29 \\
2 \\
18 \\
2 \\
2 \\
9\end{array}$ & $\begin{array}{l}0.0829 \\
0.0925 \\
0.0360 \\
0.0941 \\
0.0973 \\
0.1344 \\
0.1000 \\
0.0924 \\
0.0965 \\
0.1250 \\
0.1467\end{array}$ & $\begin{array}{l}0.095 \\
0.134 \\
0.036 \\
0.107 \\
0.106 \\
0.156 \\
0.207 \\
0.100 \\
0.169 \\
0.232 \\
0.200\end{array}$ & $\begin{array}{l}0.0023 \\
0.0032 \\
0.0009 \\
0.0026 \\
0.0025 \\
0.0037 \\
0.0049 \\
0.0024 \\
0.0040 \\
0.0055 \\
0.0048\end{array}$ & $\begin{array}{l}42.0000 \\
42.0000 \\
42.0000 \\
42.0000 \\
42.0000 \\
42.0000 \\
42.0000 \\
42.0000 \\
42.0000 \\
42.0000 \\
42.0000\end{array}$ & 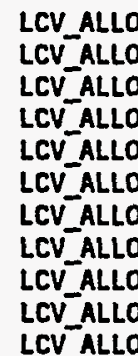 \\
\hline
\end{tabular}




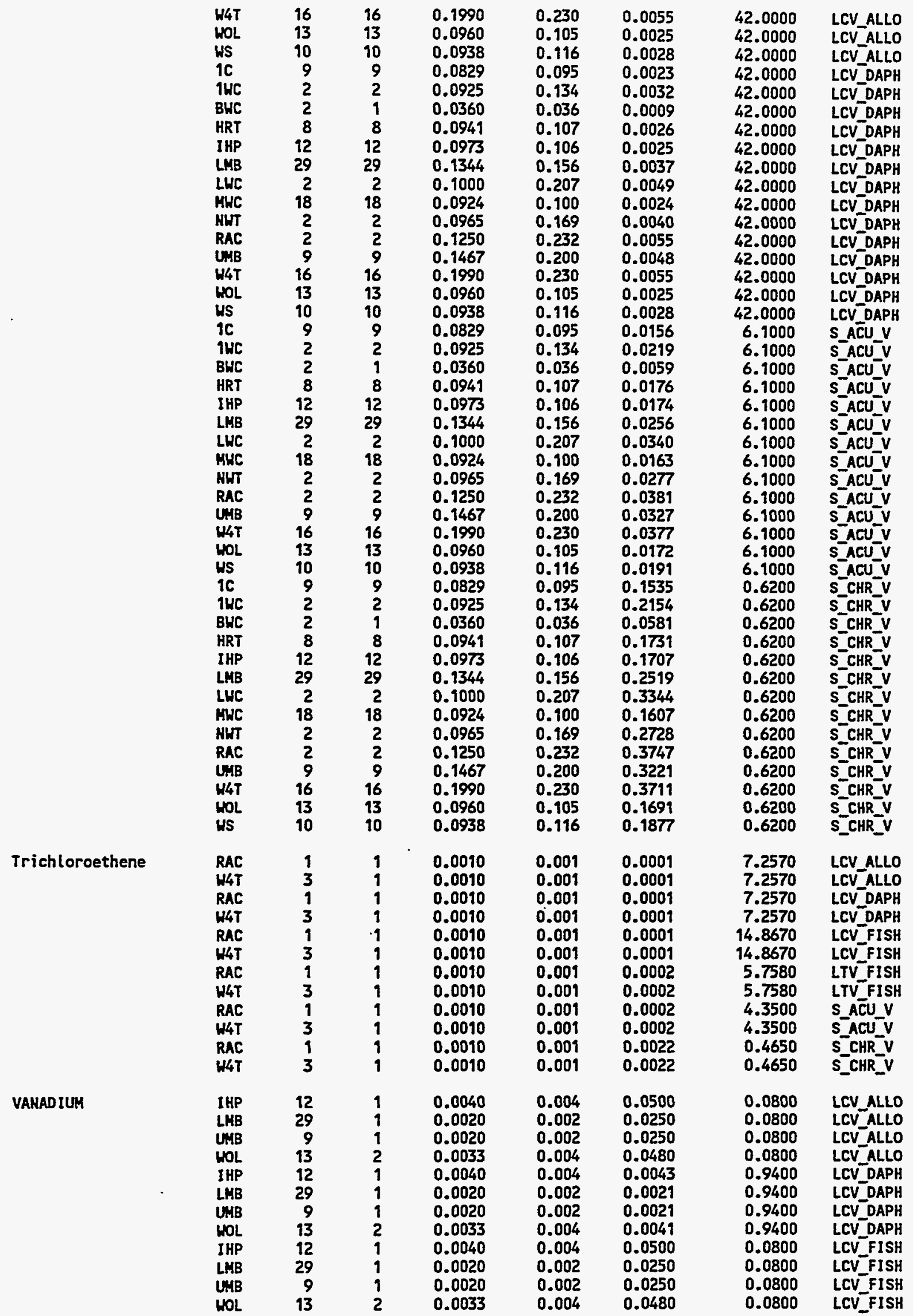


B-21

\begin{tabular}{|c|c|c|c|c|c|c|c|c|}
\hline & $\begin{array}{l}\text { IHP } \\
\text { LMB } \\
\text { UHB } \\
\text { WOL } \\
\text { IHP } \\
\text { LMB } \\
\text { UWB } \\
\text { WOL } \\
\text { IHP } \\
\text { LHB } \\
\text { UMB } \\
\text { WOL } \\
\text { IHP } \\
\text { LMB } \\
\text { UMB } \\
\text { WOL }\end{array}$ & $\begin{array}{r}12 \\
29 \\
9 \\
13 \\
12 \\
29 \\
9 \\
13 \\
12 \\
29 \\
9 \\
13 \\
12 \\
29 \\
9 \\
13\end{array}$ & $\begin{array}{l}1 \\
1 \\
1 \\
2 \\
1 \\
1 \\
1 \\
2 \\
1 \\
1 \\
1 \\
2 \\
1 \\
1 \\
1 \\
2\end{array}$ & $\begin{array}{l}0.0040 \\
0.0020 \\
0.0020 \\
0.0033 \\
0.0040 \\
0.0020 \\
0.0020 \\
0.0033 \\
0.0040 \\
0.0020 \\
0.0020 \\
0.0033 \\
0.0040 \\
0.0020 \\
0.0020 \\
0.0033\end{array}$ & $\begin{array}{l}0.004 \\
0.002 \\
0.002 \\
0.004 \\
0.004 \\
0.002 \\
0.002 \\
0.004 \\
0.004 \\
0.002 \\
0.002 \\
0.004 \\
0.004 \\
0.002 \\
0.002 \\
0.004\end{array}$ & $\begin{array}{l}0.0093 \\
0.0047 \\
0.0047 \\
0.0089 \\
0.0976 \\
0.0488 \\
0.0488 \\
0.0936 \\
0.0149 \\
0.0070 \\
0.0070 \\
0.0135 \\
0.2094 \\
0.1047 \\
0.1047 \\
0.2010\end{array}$ & $\begin{array}{l}0.4300 \\
0.4300 \\
0.4300 \\
0.4300 \\
0.0410 \\
0.0410 \\
0.0410 \\
0.0410 \\
0.2840 \\
0.2840 \\
0.2840 \\
0.2840 \\
0.0191 \\
0.0191 \\
0.0191 \\
0.0191\end{array}$ & $\begin{array}{l}\text { LTV_DAPH } \\
\text { LTV_DAPH } \\
\text { LTV_DAPH } \\
\text { LTV_DAPH } \\
\text { LTV_FISH } \\
\text { LTV_FISH } \\
\text { LTV_FISH } \\
\text { LTV_FISH } \\
\text { S_ACU_V } \\
\text { S_ACU_V } \\
\text { S_ACUV } \\
\text { S_ACU_V } \\
\text { S_CHR_V } \\
\text { S_CHR_V } \\
\text { S_CHR_V } \\
\text { S_CHR_V }\end{array}$ \\
\hline Vinyl chloride & $\begin{array}{l}\text { W4T } \\
\text { W4T } \\
\text { W4T } \\
\text { W4T } \\
\text { W4T }\end{array}$ & $\begin{array}{l}3 \\
3 \\
3 \\
3 \\
3\end{array}$ & $\begin{array}{l}1 \\
1 \\
1 \\
1 \\
1\end{array}$ & $\begin{array}{l}0.0000 \\
0.0000 \\
0.0000 \\
0.0000 \\
0.0000\end{array}$ & $\begin{array}{l}0.000 \\
0.000 \\
0.000 \\
0.000 \\
0.000\end{array}$ & $\begin{array}{l}0.0000 \\
0.0000 \\
0.0000 \\
0.0000 \\
0.0000\end{array}$ & $\begin{array}{r}28.8790 \\
28.8790 \\
14.5200 \\
1.5700 \\
0.0878\end{array}$ & $\begin{array}{l}\text { LCV_ALLO } \\
\text { LCV_FISH } \\
\text { LTV_FISH } \\
\text { S_ACU_V } \\
\text { S_CHR_V }\end{array}$ \\
\hline ZIHC & 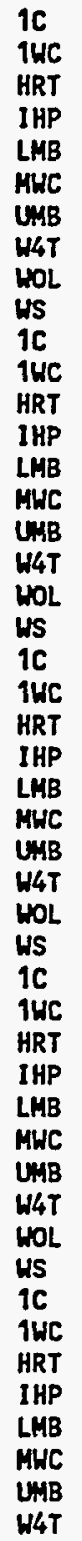 & $\begin{array}{r}9 \\
2 \\
8 \\
11 \\
28 \\
17 \\
9 \\
16 \\
12 \\
8 \\
9 \\
2 \\
8 \\
11 \\
28 \\
17 \\
9 \\
16 \\
12 \\
8 \\
9 \\
2 \\
8 \\
11 \\
28 \\
17 \\
9 \\
16 \\
12 \\
8 \\
9 \\
2 \\
8 \\
11 \\
28 \\
17 \\
9 \\
16 \\
12 \\
8 \\
9 \\
2 \\
8 \\
11 \\
28 \\
17 \\
9 \\
16\end{array}$ & $\begin{array}{r}4 \\
2 \\
3 \\
9 \\
18 \\
11 \\
6 \\
6 \\
7 \\
5 \\
4 \\
2 \\
3 \\
9 \\
18 \\
11 \\
6 \\
6 \\
7 \\
5 \\
4 \\
2 \\
3 \\
9 \\
18 \\
11 \\
6 \\
6 \\
7 \\
5 \\
4 \\
2 \\
3 \\
9 \\
18 \\
11 \\
6 \\
6 \\
7 \\
5 \\
4 \\
2 \\
3 \\
9 \\
18 \\
11 \\
6 \\
6\end{array}$ & $\begin{array}{l}0.0193 \\
0.0660 \\
0.0044 \\
0.0373 \\
0.0124 \\
0.0251 \\
0.0569 \\
0.0083 \\
0.0363 \\
0.0083 \\
0.0193 \\
0.0660 \\
0.0044 \\
0.0373 \\
0.0124 \\
0.0251 \\
0.0569 \\
0.0083 \\
0.0363 \\
0.0083 \\
0.0193 \\
0.0660 \\
0.0044 \\
0.0373 \\
0.0124 \\
0.0251 \\
0.0569 \\
0.0083 \\
0.0363 \\
0.0083 \\
0.0193 \\
0.0660 \\
0.0044 \\
0.0373 \\
0.0124 \\
0.0251 \\
0.0569 \\
0.0083 \\
0.0363 \\
0.0083 \\
0.0193 \\
0.0660 \\
0.0044 \\
0.0373 \\
0.0124 \\
0.0251 \\
0.0569 \\
0.0083\end{array}$ & $\begin{array}{l}0.028 \\
0.262 \\
0.007 \\
0.045 \\
0.014 \\
0.027 \\
0.114 \\
0.013 \\
0.053 \\
0.015 \\
0.028 \\
0.262 \\
0.007 \\
0.045 \\
0.014 \\
0.027 \\
0.114 \\
0.013 \\
0.053 \\
0.015 \\
0.028 \\
0.262 \\
0.007 \\
0.045 \\
0.014 \\
0.027 \\
0.114 \\
0.013 \\
0.053 \\
0.015 \\
0.028 \\
0.262 \\
0.007 \\
0.045 \\
0.014 \\
0.027 \\
0.114 \\
0.013 \\
0.053 \\
0.015 \\
0.028 \\
0.262 \\
0.007 \\
0.045 \\
0.014 \\
0.027 \\
0.114 \\
0.013\end{array}$ & $\begin{array}{l}0.9435 \\
8.7242 \\
0.2177 \\
1.4882 \\
0.4730 \\
0.9161 \\
3.7985 \\
0.4240 \\
1.7608 \\
0.5070 \\
0.9435 \\
8.7242 \\
0.2177 \\
1.4882 \\
0.4730 \\
0.9161 \\
3.7985 \\
0.4240 \\
1.7608 \\
0.5070 \\
0.6057 \\
5.6008 \\
0.1398 \\
0.9554 \\
0.3037 \\
0.5881 \\
2.4386 \\
0.2722 \\
1.1304 \\
0.3255 \\
0.7774 \\
7.1883 \\
0.1794 \\
1.2262 \\
0.3898 \\
0.7548 \\
3.1298 \\
0.3494 \\
1.4508 \\
0.4177 \\
0.0054 \\
0.0499 \\
0.0012 \\
0.0085 \\
0.0027 \\
0.0052 \\
0.0217 \\
0.0024\end{array}$ & $\begin{array}{l}0.0300 \\
0.0300 \\
0.0300 \\
0.0300 \\
0.0300 \\
0.0300 \\
0.0300 \\
0.0300 \\
0.0300 \\
0.0300 \\
0.0300 \\
0.0300 \\
0.0300 \\
0.0300 \\
0.0300 \\
0.0300 \\
0.0300 \\
0.0300 \\
0.0300 \\
0.0300 \\
0.0467 \\
0.0467 \\
0.0467 \\
0.0467 \\
0.0467 \\
0.0467 \\
0.0467 \\
0.0467 \\
0.0467 \\
0.0467 \\
0.0364 \\
0.0364 \\
0.0364 \\
0.0364 \\
0.0364 \\
0.0364 \\
0.0364 \\
0.0364 \\
0.0364 \\
0.0364 \\
5.2430 \\
5.2430 \\
5.2430 \\
5.2430 \\
5.2430 \\
5.2430 \\
5.2430 \\
5.2430\end{array}$ & $\begin{array}{l}\text { LCV_ALLO } \\
\text { LCV_ALLO } \\
\text { LCV_ALLO } \\
\text { LCV_ALLO } \\
\text { LCV_ALLO } \\
\text { LCV_ALLO } \\
\text { LCV_ALLO } \\
\text { LCV_ALLO } \\
\text { LCV_ALLO } \\
\text { LCV_ALLO } \\
\text { LCV_AQPL } \\
\text { LCV_AQPL } \\
\text { LCV_AOPL } \\
\text { LCV_AOPL } \\
\text { LCV_AOPL } \\
\text { LCV_AOPL } \\
\text { LCV_AAPL } \\
\text { LCV_AOPL } \\
\text { LCV_AOPL } \\
\text { LCV_AOPL } \\
\text { LCV_DAPH } \\
\text { LCV_DAPH } \\
\text { LCV_DAPH } \\
\text { LCV_DAPH } \\
\text { LCV_DAPH } \\
\text { LCV_DAPH } \\
\text { LCV_DAPH } \\
\text { LCV_DAPH } \\
\text { LCV_DAPH } \\
\text { LCV_DAPH } \\
\text { LCV_FISH } \\
\text { LCV_FISH } \\
\text { LCV_FISH } \\
\text { LCV_FISH } \\
\text { LCV_FISH } \\
\text { LCV_FISH } \\
\text { LCV_FISH } \\
\text { LCV_FISH } \\
\text { LCV_FISH } \\
\text { LCV_FISH } \\
\text { LCV_HDI } \\
\text { LCV_HDI } \\
\text { LCV_HDI } \\
\text { LCV_NDI } \\
\text { LCV_NDI } \\
\text { LCV_NDI } \\
\text { LCV_NDI } \\
\text { LCV_HDI }\end{array}$ \\
\hline
\end{tabular}


B-22

\begin{tabular}{|c|c|c|c|c|c|c|c|}
\hline 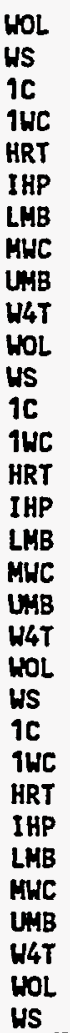 & $\begin{array}{r}12 \\
8 \\
9 \\
2 \\
8 \\
11 \\
28 \\
17 \\
9 \\
16 \\
12 \\
8 \\
9 \\
2 \\
8 \\
11 \\
28 \\
17 \\
9 \\
16 \\
12 \\
8 \\
9 \\
2 \\
8 \\
11 \\
28 \\
17 \\
9 \\
16 \\
12 \\
8\end{array}$ & $\begin{array}{r}7 \\
5 \\
4 \\
2 \\
3 \\
9 \\
18 \\
11 \\
6 \\
6 \\
7 \\
5 \\
4 \\
2 \\
3 \\
9 \\
18 \\
11 \\
6 \\
6 \\
7 \\
5 \\
4 \\
2 \\
3 \\
9 \\
18 \\
11 \\
6 \\
6 \\
7 \\
5\end{array}$ & $\begin{array}{l}0.0363 \\
0.0083 \\
0.0193 \\
0.0660 \\
0.0044 \\
0.0373 \\
0.0124 \\
0.0251 \\
0.0569 \\
0.0083 \\
0.0363 \\
0.0083 \\
0.0193 \\
0.0660 \\
0.0044 \\
0.0373 \\
0.0124 \\
0.0251 \\
0.0569 \\
0.0083 \\
0.0363 \\
0.0083 \\
0.0193 \\
0.0660 \\
0.0044 \\
0.0373 \\
0.0124 \\
0.0251 \\
0.0569 \\
0.0083 \\
0.0363 \\
0.0083\end{array}$ & $\begin{array}{l}0.053 \\
0.015 \\
0.028 \\
0.262 \\
0.007 \\
0.045 \\
0.014 \\
0.027 \\
0.114 \\
0.013 \\
0.053 \\
0.015 \\
0.028 \\
0.262 \\
0.007 \\
0.045 \\
0.014 \\
0.027 \\
0.114 \\
0.013 \\
0.053 \\
0.015 \\
0.028 \\
0.262 \\
0.007 \\
0.045 \\
0.014 \\
0.027 \\
0.114 \\
0.013 \\
0.053 \\
0.015\end{array}$ & $\begin{array}{l}0.0101 \\
0.0029 \\
0.6022 \\
5.5686 \\
0.1390 \\
0.9499 \\
0.3019 \\
0.5847 \\
2.4246 \\
0.2706 \\
1.1239 \\
0.3236 \\
0.2359 \\
2.1811 \\
0.0544 \\
0.3721 \\
0.1183 \\
0.2290 \\
0.9496 \\
0.1060 \\
0.4402 \\
0.1267 \\
0.2573 \\
2.3793 \\
0.0594 \\
0.4059 \\
0.1290 \\
0.2498 \\
1.0360 \\
0.1156 \\
0.4802 \\
0.1383\end{array}$ & $\begin{array}{l}5.2430 \\
5.2430 \\
0.0470 \\
0.0470 \\
0.0470 \\
0.0470 \\
0.0470 \\
0.0470 \\
0.0470 \\
0.0470 \\
0.0470 \\
0.0470 \\
0.1200 \\
0.1200 \\
0.1200 \\
0.1200 \\
0.1200 \\
0.1200 \\
0.1200 \\
0.1200 \\
0.1200 \\
0.1200 \\
0.1100 \\
0.1100 \\
0.1100 \\
0.1100 \\
0.1100 \\
0.1100 \\
0.1100 \\
0.1100 \\
0.1100 \\
0.1100\end{array}$ & 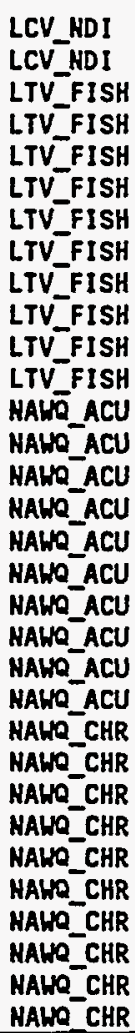 \\
\hline
\end{tabular}


Table B.2. Screening of aqueous concentrations of chemicals detected in seeps and ephemeral tributaries against chronic NALaC or Secondary Chronic Values (Suter and Mabrey 1996). All concentrations are mg/L.

\begin{tabular}{|c|c|c|c|c|c|c|c|c|c|}
\hline Chemical & Reach & Seep & Samples & Detects & P.L. Mean & $95 \%$ UCB & Quotient & $\begin{array}{c}\text { Benchmark } \\
\text { Value }\end{array}$ & Benchmark \\
\hline 1,1,1-Trichloroethane & MHC & SH2-3 & 2 & 1 & 0.0000 & 0.000 & 0.000 & 0.0621 & S_CHR_V \\
\hline 1,1-Dichloroethane & $\begin{array}{l}\text { W4T } \\
\text { LMB }\end{array}$ & $\begin{array}{l}\text { BTT } \\
\text { MID. DRAIH. }\end{array}$ & $\begin{array}{l}1 \\
1\end{array}$ & $\begin{array}{l}1 \\
1\end{array}$ & $\begin{array}{l}0.0010 \\
0.0010\end{array}$ & $\begin{array}{l}0.001 \\
0.001\end{array}$ & $\begin{array}{l}0.021 \\
0.021\end{array}$ & $\begin{array}{l}0.0466 \\
0.0466\end{array}$ & $\begin{array}{l}\text { S_CHR_V } \\
\text { S_CHR_V }\end{array}$ \\
\hline ALUMINUH & $\begin{array}{l}\text { H4T } \\
\text { LHC } \\
\text { LMB } \\
\text { LMB } \\
\text { LWC } \\
\text { UMB } \\
\text { WOL } \\
\text { WOL } \\
\text { WOL } \\
\text { MHC } \\
\text { LMB } \\
\text { Unknown } \\
\text { Unknown } \\
\text { WHT } \\
\text { LMB } \\
\text { LMB } \\
\text { WOL } \\
\text { LHC } \\
\text { LHC } \\
\text { LHC } \\
\text { LWC } \\
\text { HRT } \\
\text { H4T } \\
\text { W4T } \\
\text { LHC } \\
\text { MHC } \\
\text { EHC }\end{array}$ & $\begin{array}{l}\text { BTT } \\
\text { EAST SEEP } \\
\text { MBTRIB-3 } \\
\text { MID. DRAIH. } \\
\text { MV-1 } \\
\text { HV-3 } \\
\text { RS-1 } \\
\text { RS-3A } \\
\text { RS-3B } \\
\text { SW2-1 } \\
\text { SH2-5 } \\
\text { SH2-6 } \\
\text { SH2-7 } \\
\text { SW4-2 } \\
\text { SW5-2 } \\
\text { SW5-4 } \\
\text { SH7-2 } \\
\text { SH7-3 } \\
\text { SW7-5 } \\
\text { SH7-6 } \\
\text { SH7-8 } \\
\text { SW9-2 } \\
\text { HAG4 MS1 } \\
\text { HAG4 T2A } \\
\text { WCTRIB-1 } \\
\text { HCTRIB-2 } \\
\text { WOCET }\end{array}$ & $\begin{array}{r}7 \\
9 \\
2 \\
10 \\
2 \\
1 \\
1 \\
10 \\
2 \\
1 \\
10 \\
3 \\
4 \\
6 \\
1 \\
6 \\
2 \\
8 \\
10 \\
1 \\
1 \\
3 \\
11 \\
7 \\
2 \\
1 \\
2\end{array}$ & $\begin{array}{r}4 \\
9 \\
2 \\
6 \\
2 \\
1 \\
1 \\
10 \\
2 \\
1 \\
6 \\
2 \\
1 \\
2 \\
1 \\
2 \\
2 \\
8 \\
10 \\
1 \\
1 \\
2 \\
10 \\
7 \\
1 \\
1 \\
2\end{array}$ & $\begin{array}{r}0.0336 \\
0.8376 \\
0.1730 \\
0.0713 \\
0.1990 \\
0.1620 \\
0.2980 \\
10.0120 \\
1.3450 \\
0.1860 \\
0.0686 \\
0.0753 \\
0.0380 \\
0.0318 \\
0.0780 \\
0.0473 \\
0.5740 \\
0.4520 \\
0.8017 \\
0.7610 \\
0.4120 \\
0.9780 \\
0.1551 \\
0.4713 \\
0.9570 \\
0.1940 \\
1.0710\end{array}$ & $\begin{array}{r}0.040 \\
1.262 \\
0.735 \\
0.108 \\
0.275 \\
0.162 \\
0.298 \\
12.730 \\
1.819 \\
0.186 \\
0.098 \\
0.201 \\
0.038 \\
0.041 \\
0.078 \\
0.051 \\
1.066 \\
0.548 \\
1.122 \\
0.761 \\
0.412 \\
1.791 \\
0.313 \\
0.710 \\
0.957 \\
0.194 \\
3.780\end{array}$ & $\begin{array}{r}0.461 \\
14.508 \\
8.447 \\
1.242 \\
3.158 \\
1.862 \\
3.425 \\
146.319 \\
20.903 \\
2.138 \\
1.124 \\
2.313 \\
0.437 \\
0.477 \\
0.897 \\
0.584 \\
12.258 \\
6.299 \\
12.898 \\
8.747 \\
4.736 \\
20.581 \\
3.602 \\
8.163 \\
11.000 \\
2.230 \\
43.444\end{array}$ & $\begin{array}{l}0.0870 \\
0.0870 \\
0.0870 \\
0.0870 \\
0.0870 \\
0.0870 \\
0.0870 \\
0.0870 \\
0.0870 \\
0.0870 \\
0.0870 \\
0.0870 \\
0.0870 \\
0.0870 \\
0.0870 \\
0.0870 \\
0.0870 \\
0.0870 \\
0.0870 \\
0.0870 \\
0.0870 \\
0.0870 \\
0.0870 \\
0.0870 \\
0.0870 \\
0.0870 \\
0.0870\end{array}$ & 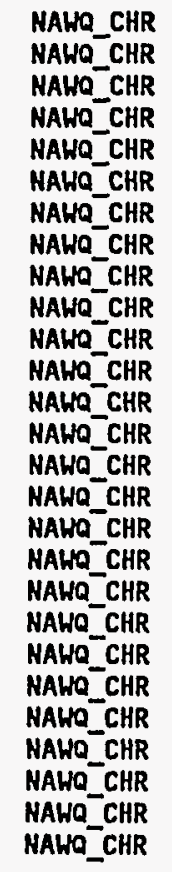 \\
\hline ANTIMOHY & H4T & SW4-1 & 2 & 1 & 0.0450 & 0.045 & 0.433 & 0.1040 & $S_{-} C H R_{-} V$ \\
\hline ARSENIC & $\begin{array}{l}\text { LWC } \\
\text { LHB } \\
\text { LHC } \\
\text { HOL } \\
\text { Unknown } \\
\text { Unknown } \\
\text { H4T } \\
\text { LHC }\end{array}$ & $\begin{array}{l}\text { EAST SEEP } \\
\text { HID. DRAIH. } \\
\text { HV-1 } \\
\text { RS-3A } \\
\text { SW2-6 } \\
\text { SW2-7 } \\
\text { SW4-1 } \\
\text { SW7-3 }\end{array}$ & $\begin{array}{l}8 \\
7 \\
2 \\
8 \\
2 \\
3 \\
2 \\
7\end{array}$ & $\begin{array}{l}2 \\
2 \\
1 \\
8 \\
1 \\
1 \\
1 \\
2\end{array}$ & $\begin{array}{l}0.0016 \\
0.0010 \\
0.0020 \\
0.0169 \\
0.0010 \\
0.0010 \\
0.0060 \\
0.0030\end{array}$ & $\begin{array}{l}0.003 \\
0.001 \\
0.002 \\
0.020 \\
0.001 \\
0.001 \\
0.006 \\
0.003\end{array}$ & $\begin{array}{l}0.016 \\
0.005 \\
0.011 \\
0.107 \\
0.005 \\
0.005 \\
0.032 \\
0.016\end{array}$ & $\begin{array}{l}0.1900 \\
0.1900 \\
0.1900 \\
0.1900 \\
0.1900 \\
0.1900 \\
0.1900 \\
0.1900\end{array}$ & $\begin{array}{l}\text { NAWQ_CHR } \\
\text { NAHQ_CHR } \\
\text { NAHQ_CHR } \\
\text { HAHQ_CHR } \\
\text { NAWQ_CHR } \\
\text { NAWQ_CHR } \\
\text { NAWQ_CHR } \\
\text { NAWQ_CHR }\end{array}$ \\
\hline
\end{tabular}




\begin{tabular}{|c|c|c|c|c|c|c|c|c|c|}
\hline Acetone & $\begin{array}{l}\text { IHP } \\
\text { LWC } \\
\text { LWC } \\
\text { MWC } \\
\text { UMC } \\
\text { MHC } \\
\text { HOL } \\
\text { LWC } \\
\text { MHC } \\
\text { EWC }\end{array}$ & $\begin{array}{l}\text { 5NNT } \\
\text { MV-1 } \\
\text { MV-2 } \\
\text { SW2-1 } \\
\text { SH2-2 } \\
\text { SW2-4 } \\
\text { SW6-1 } \\
\text { SW7-5 } \\
\text { WCTRI8-2 } \\
\text { HOCET }\end{array}$ & $\begin{array}{l}1 \\
1 \\
1 \\
1 \\
1 \\
1 \\
1 \\
1 \\
1 \\
1\end{array}$ & $\begin{array}{l}1 \\
1 \\
1 \\
1 \\
1 \\
1 \\
1 \\
1 \\
1 \\
1\end{array}$ & $\begin{array}{l}0.0080 \\
0.0010 \\
0.0030 \\
0.0110 \\
0.0010 \\
0.0140 \\
0.0030 \\
0.0140 \\
0.0020 \\
0.0090\end{array}$ & $\begin{array}{l}0.008 \\
0.001 \\
0.003 \\
0.011 \\
0.001 \\
0.014 \\
0.003 \\
0.014 \\
0.002 \\
0.009\end{array}$ & $\begin{array}{l}0.001 \\
0.000 \\
0.000 \\
0.001 \\
0.000 \\
0.001 \\
0.000 \\
0.001 \\
0.000 \\
0.001\end{array}$ & $\begin{array}{l}11.2000 \\
11.2000 \\
11.2000 \\
11.2000 \\
11.2000 \\
11.2000 \\
11.2000 \\
11.2000 \\
11.2000 \\
11.2000\end{array}$ & $\begin{array}{l}\text { S_CHR_V } \\
\text { S_CHR_V } \\
\text { S_CHR_V } \\
\text { S_CHR_V } \\
\text { S_CHR_V } \\
\text { S_CHR_V } \\
\text { S_CHR_V } \\
\text { S_CHR_V } \\
\text { S_CHR_V } \\
\text { S_CHR_V }\end{array}$ \\
\hline BARIUH & $\begin{array}{l}\text { HAT } \\
\text { LHC } \\
\text { UMB } \\
\text { LMB } \\
\text { LMB } \\
\text { LHC } \\
\text { UHB } \\
\text { HOL } \\
\text { HOL } \\
\text { HOL } \\
\text { HWC } \\
\text { UMC } \\
\text { HWC } \\
\text { MHC } \\
\text { LMB } \\
\text { UnknOWn } \\
\text { UnknOWn } \\
\text { HAT } \\
\text { HAT } \\
\text { LMB } \\
\text { LMB } \\
\text { HOL } \\
\text { HOL } \\
\text { LWC } \\
\text { LHC } \\
\text { LHC } \\
\text { LHC } \\
\text { HRT } \\
\text { HRT } \\
\text { HAT } \\
\text { HAT } \\
\text { LHC } \\
\text { MHC } \\
\text { IHP } \\
\text { ENC }\end{array}$ & $\begin{array}{l}\text { BTT } \\
\text { EAST SEEP } \\
\text { MBTRIB-2A } \\
\text { MBTRIB-3 } \\
\text { MID. DRAIN. } \\
\text { HV-1 } \\
\text { HV-3 } \\
\text { RS-1 } \\
\text { RS-3A } \\
\text { RS-3B } \\
\text { SW2-1 } \\
\text { SW2-2 } \\
\text { SW2-3 } \\
\text { SW2-4 } \\
\text { SW2-5 } \\
\text { SH2-6 } \\
\text { SW2-7 } \\
\text { SH4-1 } \\
\text { SW4-2 } \\
\text { SW5-2 } \\
\text { SW5-4 } \\
\text { SH7-1 } \\
\text { SH7-2 } \\
\text { SW7-3 } \\
\text { SH7-5 } \\
\text { SH7-6 } \\
\text { SH7-8 } \\
\text { SH9-1 } \\
\text { SH9-2 } \\
\text { HAG4 HS1 } \\
\text { HAG4 T2A } \\
\text { WCTRIB-1 } \\
\text { WCTRIB-2 } \\
\text { HCTRIB-3 } \\
\text { WOCET }\end{array}$ & $\begin{array}{r}7 \\
9 \\
1 \\
2 \\
10 \\
2 \\
1 \\
1 \\
10 \\
2 \\
1 \\
1 \\
1 \\
2 \\
10 \\
3 \\
4 \\
2 \\
6 \\
1 \\
6 \\
2 \\
2 \\
8 \\
10 \\
1 \\
1 \\
3 \\
3 \\
11 \\
7 \\
2 \\
1 \\
1 \\
2\end{array}$ & $\begin{array}{r}7 \\
7 \\
1 \\
2 \\
10 \\
2 \\
1 \\
1 \\
8 \\
1 \\
1 \\
1 \\
1 \\
2 \\
10 \\
3 \\
4 \\
2 \\
6 \\
1 \\
6 \\
2 \\
1 \\
3 \\
10 \\
1 \\
1 \\
3 \\
3 \\
10 \\
7 \\
2 \\
1 \\
1 \\
2\end{array}$ & $\begin{array}{l}0.2804 \\
0.0312 \\
0.0500 \\
0.0570 \\
0.0914 \\
0.1505 \\
0.0490 \\
0.0360 \\
0.0515 \\
0.0290 \\
0.0840 \\
0.1040 \\
0.0380 \\
0.0935 \\
0.2801 \\
0.1530 \\
0.1308 \\
0.2455 \\
0.3733 \\
0.0640 \\
0.1057 \\
0.0720 \\
0.0320 \\
0.0207 \\
0.0546 \\
0.0490 \\
0.0300 \\
0.1360 \\
0.2117 \\
0.1425 \\
0.0941 \\
0.0545 \\
0.0380 \\
0.0620 \\
0.0490\end{array}$ & $\begin{array}{l}0.309 \\
0.036 \\
0.050 \\
0.133 \\
0.113 \\
0.160 \\
0.049 \\
0.036 \\
0.061 \\
0.029 \\
0.084 \\
0.104 \\
0.038 \\
0.324 \\
0.301 \\
0.168 \\
0.140 \\
0.362 \\
0.428 \\
0.064 \\
0.127 \\
0.078 \\
0.032 \\
0.022 \\
0.070 \\
0.049 \\
0.030 \\
0.147 \\
0.287 \\
0.154 \\
0.106 \\
0.140 \\
0.038 \\
0.062 \\
0.112\end{array}$ & $\begin{array}{r}81.285 \\
9.479 \\
13.158 \\
34.938 \\
29.641 \\
42.098 \\
12.895 \\
9.474 \\
16.107 \\
7.632 \\
22.105 \\
27.368 \\
10.000 \\
85.251 \\
79.263 \\
44.256 \\
36.864 \\
95.343 \\
112.569 \\
16.842 \\
33.423 \\
20.609 \\
8.421 \\
5.771 \\
18.538 \\
12.895 \\
7.895 \\
38.560 \\
75.593 \\
40.471 \\
27.767 \\
36.773 \\
10.000 \\
16.316 \\
29.510\end{array}$ & $\begin{array}{l}0.0038 \\
0.0038 \\
0.0038 \\
0.0038 \\
0.0038 \\
0.0038 \\
0.0038 \\
0.0038 \\
0.0038 \\
0.0038 \\
0.0038 \\
0.0038 \\
0.0038 \\
0.0038 \\
0.0038 \\
0.0038 \\
0.0038 \\
0.0038 \\
0.0038 \\
0.0038 \\
0.0038 \\
0.0038 \\
0.0038 \\
0.0038 \\
0.0038 \\
0.0038 \\
0.0038 \\
0.0038 \\
0.0038 \\
0.0038 \\
0.0038 \\
0.0038 \\
0.0038 \\
0.0038 \\
0.0038\end{array}$ & 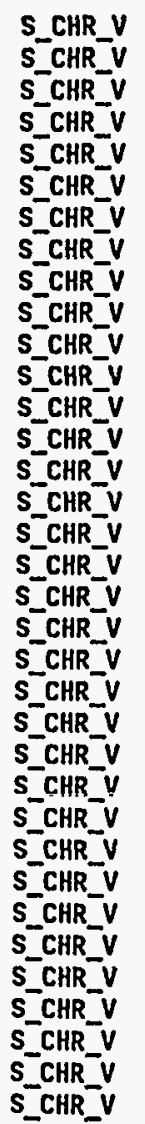 \\
\hline BERYLLIUM & $\begin{array}{l}\text { W4T } \\
\text { LHC } \\
\text { LMB } \\
\text { HOL }\end{array}$ & $\begin{array}{l}\text { BTT } \\
\text { EAST SEEP } \\
\text { MID. DRAIH. } \\
\text { RS-3A }\end{array}$ & $\begin{array}{r}7 \\
9 \\
10 \\
10\end{array}$ & $\begin{array}{l}1 \\
1 \\
2 \\
5\end{array}$ & $\begin{array}{l}0.0000 \\
0.0000 \\
0.0000 \\
0.0004\end{array}$ & $\begin{array}{l}0.000 \\
0.000 \\
0.000 \\
0.001\end{array}$ & $\begin{array}{l}0.000 \\
0.000 \\
0.000 \\
0.141\end{array}$ & $\begin{array}{l}0.0051 \\
0.0051 \\
0.0051 \\
0.0051\end{array}$ & $\begin{array}{l}\text { S_CHR_V } \\
\text { S_CHR_V } \\
\text { S_CHR_V } \\
\text { S_CHR_V }\end{array}$ \\
\hline
\end{tabular}




\begin{tabular}{|c|c|c|c|c|c|c|c|c|c|}
\hline & $\begin{array}{l}\text { LMB } \\
\text { Unknown } \\
\text { Unknown } \\
\text { H4T } \\
\text { LHC } \\
\text { LHC } \\
\text { W4T } \\
\text { W4T }\end{array}$ & $\begin{array}{l}\text { SH2-5 } \\
\text { SH2-6 } \\
\text { SW2-7 } \\
\text { SW4-2 } \\
\text { SH7-3 } \\
\text { SH7-5 } \\
\text { WAG4 MS1 } \\
\text { WAG4 T2A }\end{array}$ & $\begin{array}{r}10 \\
3 \\
4 \\
6 \\
8 \\
10 \\
11 \\
7\end{array}$ & $\begin{array}{l}2 \\
1 \\
1 \\
1 \\
1 \\
1 \\
3 \\
1\end{array}$ & $\begin{array}{l}0.0000 \\
0.0000 \\
0.0000 \\
0.0000 \\
0.0000 \\
0.0010 \\
0.0002 \\
0.0000\end{array}$ & $\begin{array}{l}0.000 \\
0.000 \\
0.000 \\
0.000 \\
0.000 \\
0.001 \\
0.001 \\
0.000\end{array}$ & $\begin{array}{l}0.000 \\
0.000 \\
0.000 \\
0.000 \\
0.000 \\
0.196 \\
0.111 \\
0.000\end{array}$ & $\begin{array}{l}0.0051 \\
0.0051 \\
0.0051 \\
0.0051 \\
0.0051 \\
0.0051 \\
0.0051 \\
0.0051\end{array}$ & $\begin{array}{l}\text { S_CHR_V } \\
\text { S_CHR_V } \\
\text { S_CHR V } \\
\text { S_CHR_V } \\
\text { S_CHR_V } \\
\text { S_CHR_V } \\
\text { S_CHR_V } \\
\text { S_CHR_V }\end{array}$ \\
\hline BOROH & $\begin{array}{l}\text { W4T } \\
\text { LWC } \\
\text { LMB } \\
\text { WOL } \\
\text { WOL } \\
\text { MWC } \\
\text { LMB } \\
\text { Unknown } \\
\text { Unknown } \\
\text { W4T } \\
\text { LMB } \\
\text { LMB } \\
\text { LWC } \\
\text { LWC } \\
\text { W4T } \\
\text { W4T } \\
\text { IHP }\end{array}$ & $\begin{array}{l}\text { BTT } \\
\text { EAST SEEP } \\
\text { HID. DRAIH. } \\
\text { RS-3A } \\
\text { RS-3B } \\
\text { SW2-1 } \\
\text { SW2-5 } \\
\text { SW2-6 } \\
\text { SW2-7 } \\
\text { SW4-2 } \\
\text { SW5-2 } \\
\text { SW5-4 } \\
\text { SW7-3 } \\
\text { SH7-5 } \\
\text { HAG4 MS1 } \\
\text { HAG4 T2A } \\
\text { WCTRIB-3 }\end{array}$ & $\begin{array}{r}7 \\
9 \\
10 \\
10 \\
2 \\
1 \\
10 \\
3 \\
4 \\
6 \\
1 \\
6 \\
8 \\
10 \\
11 \\
7 \\
1\end{array}$ & $\begin{array}{l}2 \\
4 \\
6 \\
3 \\
1 \\
1 \\
5 \\
2 \\
2 \\
3 \\
1 \\
3 \\
2 \\
4 \\
4 \\
5 \\
1\end{array}$ & $\begin{array}{l}0.0826 \\
0.0528 \\
0.1654 \\
0.0924 \\
0.0340 \\
0.0190 \\
0.1890 \\
0.1170 \\
0.1397 \\
0.1368 \\
0.1750 \\
0.1307 \\
0.0743 \\
0.0557 \\
0.1559 \\
0.1293 \\
0.1990\end{array}$ & $\begin{array}{l}0.101 \\
0.079 \\
0.201 \\
0.107 \\
0.034 \\
0.019 \\
0.237 \\
0.120 \\
0.141 \\
0.181 \\
0.175 \\
0.178 \\
0.087 \\
0.062 \\
0.174 \\
0.169 \\
0.199\end{array}$ & $\begin{array}{l}0.185 \\
0.145 \\
0.367 \\
0.195 \\
0.062 \\
0.035 \\
0.434 \\
0.219 \\
0.259 \\
0.331 \\
0.320 \\
0.325 \\
0.160 \\
0.113 \\
0.317 \\
0.309 \\
0.364\end{array}$ & $\begin{array}{l}0.5470 \\
0.5470 \\
0.5470 \\
0.5470 \\
0.5470 \\
0.5470 \\
0.5470 \\
0.5470 \\
0.5470 \\
0.5470 \\
0.5470 \\
0.5470 \\
0.5470 \\
0.5470 \\
0.5470 \\
0.5470 \\
0.5470\end{array}$ & $\begin{array}{l}\text { S_CHR_V } \\
\text { S_CHR_V } \\
\text { S_CHR_V } \\
\text { S_CHR_V } \\
\text { S_CHR_V } \\
\text { S_CHR_V } \\
\text { S_CHR_V } \\
\text { S_CHR_V } \\
\text { S_CHR_V } \\
\text { s_CHR_V } \\
\text { S_CHR_V } \\
\text { S_CHR_V } \\
\text { S_CHR_V } \\
\text { S_CHR_V } \\
\text { S_CHR_V } \\
\text { S_CHR_V } \\
\text { S_CHR_V }\end{array}$ \\
\hline CADMIUM & $\begin{array}{l}\text { W4T } \\
\text { LMB } \\
\text { WOL } \\
\text { LMB } \\
\text { W4T } \\
\text { LMB } \\
\text { LWC } \\
\text { LHC } \\
\text { W4T } \\
\text { W4T }\end{array}$ & $\begin{array}{l}\text { BTT } \\
\text { MID. DRAIH. } \\
\text { RS-3A } \\
\text { SH2-5 } \\
\text { SH4-2 } \\
\text { SH5-4 } \\
\text { SW7-3 } \\
\text { SH7-5 } \\
\text { HAG4 MS1 } \\
\text { HAG4 T2A }\end{array}$ & $\begin{array}{l}6 \\
9 \\
8 \\
7 \\
5 \\
5 \\
6 \\
7 \\
9 \\
6\end{array}$ & $\begin{array}{l}1 \\
1 \\
2 \\
1 \\
1 \\
1 \\
1 \\
1 \\
2 \\
1\end{array}$ & $\begin{array}{l}0.0000 \\
0.0000 \\
0.0005 \\
0.0000 \\
0.0000 \\
0.0020 \\
0.0000 \\
0.0000 \\
0.0000 \\
0.0000\end{array}$ & $\begin{array}{l}0.000 \\
0.000 \\
0.002 \\
0.000 \\
0.000 \\
0.002 \\
0.000 \\
0.000 \\
0.000 \\
0.000\end{array}$ & $\begin{array}{l}0.000 \\
0.000 \\
1.509 \\
0.000 \\
0.000 \\
1.818 \\
0.000 \\
0.000 \\
0.000 \\
0.000\end{array}$ & $\begin{array}{l}0.0011 \\
0.0011 \\
0.0011 \\
0.0011 \\
0.0011 \\
0.0011 \\
0.0011 \\
0.0011 \\
0.0011 \\
0.0011\end{array}$ & $\begin{array}{l}\text { NAHQ_CHR } \\
\text { NAWQ_CHR } \\
\text { NAHQ_CHR } \\
\text { NAHQ_CHR } \\
\text { HAWQ_CHR } \\
\text { HAWQ_CHR } \\
\text { HAWQ_CHR } \\
\text { HAWQ_CHR } \\
\text { HAWQ_CHR } \\
\text { NAWQ_CHR }\end{array}$ \\
\hline CHROMIUM & $\begin{array}{l}\text { WHT } \\
\text { LHC } \\
\text { LMB } \\
\text { WOL } \\
\text { LMB } \\
\text { Unknown } \\
\text { Unknown } \\
\text { LWC } \\
\text { LWC } \\
\text { W4T } \\
\text { W4T }\end{array}$ & $\begin{array}{l}\text { BTT } \\
\text { EAST SEEP } \\
\text { HID. DRAIH. } \\
\text { RS-3A } \\
\text { SH2-5 } \\
\text { SH2-6 } \\
\text { SH2-7 } \\
\text { SH7-3 } \\
\text { SW7-5 } \\
\text { WAG4 HS1 } \\
\text { HAG4 T2A }\end{array}$ & $\begin{array}{r}7 \\
9 \\
10 \\
10 \\
10 \\
3 \\
4 \\
8 \\
10 \\
11 \\
7\end{array}$ & $\begin{array}{r}1 \\
6 \\
1 \\
10 \\
2 \\
1 \\
1 \\
8 \\
2 \\
1 \\
1\end{array}$ & $\begin{array}{l}0.0030 \\
0.0176 \\
0.0060 \\
0.0784 \\
0.0033 \\
0.0080 \\
0.0060 \\
0.0561 \\
0.0053 \\
0.0060 \\
0.0350\end{array}$ & $\begin{array}{l}0.003 \\
0.023 \\
0.006 \\
0.084 \\
0.004 \\
0.008 \\
0.006 \\
0.070 \\
0.006 \\
0.006 \\
0.035\end{array}$ & $\begin{array}{l}0.273 \\
2.075 \\
0.545 \\
7.648 \\
0.367 \\
0.727 \\
0.545 \\
6.382 \\
0.549 \\
0.545 \\
3.182\end{array}$ & $\begin{array}{l}0.0110 \\
0.0110 \\
0.0110 \\
0.0110 \\
0.0110 \\
0.0110 \\
0.0110 \\
0.0110 \\
0.0110 \\
0.0110 \\
0.0110\end{array}$ & $\begin{array}{l}\text { NAHQ_CHR } \\
\text { NAHQ_CHR } \\
\text { NAHQ_CHR } \\
\text { NAHQ_CHR } \\
\text { NAHQ_CHR } \\
\text { NAHQ_CHR } \\
\text { NAHQ_CHR } \\
\text { NAHQ_CHR } \\
\text { NAHQ_CHR } \\
\text { NAHQ_CHR } \\
\text { NAWQ_CHR }\end{array}$ \\
\hline COBALT & W4T & BTT & 7 & 1 & 0.0030 & 0.003 & 0.980 & 0.0031 & S_CHR_V \\
\hline
\end{tabular}




\begin{tabular}{|c|c|c|c|c|c|c|c|c|c|}
\hline & $\begin{array}{l}\text { LWC } \\
\text { LWC } \\
\text { HOL } \\
\text { LMB } \\
\text { Unknown } \\
\text { W4T } \\
\text { W4T } \\
\text { WOL } \\
\text { LWC } \\
\text { LWC } \\
\text { W4T }\end{array}$ & $\begin{array}{l}\text { EAST SEEP } \\
\text { MV-1 } \\
\text { RS-3A } \\
\text { SH2-5 } \\
\text { SH2-6 } \\
\text { SH4-1 } \\
\text { SH4-2 } \\
\text { SH7-2 } \\
\text { SW7-3 } \\
\text { SH7-5 } \\
\text { HAG4 MS1 }\end{array}$ & $\begin{array}{r}9 \\
2 \\
10 \\
10 \\
3 \\
2 \\
6 \\
2 \\
8 \\
10 \\
11\end{array}$ & $\begin{array}{l}6 \\
1 \\
9 \\
6 \\
1 \\
1 \\
4 \\
2 \\
5 \\
5 \\
3\end{array}$ & $\begin{array}{l}0.0087 \\
0.0060 \\
0.0286 \\
0.0049 \\
0.0050 \\
0.0080 \\
0.0198 \\
0.0940 \\
0.0133 \\
0.0095 \\
0.0031\end{array}$ & $\begin{array}{l}0.011 \\
0.006 \\
0.031 \\
0.006 \\
0.005 \\
0.008 \\
0.027 \\
0.347 \\
0.017 \\
0.014 \\
0.004\end{array}$ & $\begin{array}{r}3.668 \\
1.961 \\
10.206 \\
2.086 \\
1.634 \\
2.614 \\
8.961 \\
113.252 \\
5.546 \\
4.471 \\
1.444\end{array}$ & $\begin{array}{l}0.0031 \\
0.0031 \\
0.0031 \\
0.0031 \\
0.0031 \\
0.0031 \\
0.0031 \\
0.0031 \\
0.0031 \\
0.0031 \\
0.0031\end{array}$ & $\begin{array}{l}\text { s_CHR_V } \\
\text { s_CHR_V } \\
\text { s_CHR_V } \\
\text { s_CHR_V } \\
\text { S_CHR_V } \\
\text { s_CHR_V } \\
\text { s_CHR_V } \\
\text { s_CHR_V } \\
\text { s_CHR_V } \\
\text { S_CHR_V } \\
\text { S_CHR_V }\end{array}$ \\
\hline COPPER & $\begin{array}{l}\text { H4T } \\
\text { LWC } \\
\text { UM8 } \\
\text { LMB } \\
\text { HOL } \\
\text { LMB } \\
\text { Unknown } \\
\text { Unknown } \\
\text { W4T } \\
\text { HOL } \\
\text { LWC } \\
\text { LWC } \\
\text { HRT } \\
\text { HRT } \\
\text { W4T } \\
\text { W4T }\end{array}$ & $\begin{array}{l}\text { BTT } \\
\text { EAST SEEP } \\
\text { MBTRIB-2A } \\
\text { MID. DRAIH. } \\
\text { RS-3A } \\
\text { SH2-5 } \\
\text { SH2-6 } \\
\text { SH2-7 } \\
\text { SW4-2 } \\
\text { SH7-2 } \\
\text { SW7-3 } \\
\text { SW7-5 } \\
\text { SW9-1 } \\
\text { SH9-2 } \\
\text { WAG4 MS1 } \\
\text { HAG4 T2A }\end{array}$ & $\begin{array}{r}7 \\
9 \\
1 \\
10 \\
10 \\
10 \\
3 \\
4 \\
6 \\
2 \\
8 \\
10 \\
3 \\
3 \\
11 \\
7\end{array}$ & $\begin{array}{l}2 \\
6 \\
1 \\
2 \\
8 \\
4 \\
1 \\
1 \\
2 \\
1 \\
6 \\
4 \\
1 \\
2 \\
4 \\
2\end{array}$ & $\begin{array}{l}0.0026 \\
0.0057 \\
0.0160 \\
0.0015 \\
0.0180 \\
0.0029 \\
0.0020 \\
0.0020 \\
0.0025 \\
0.0250 \\
0.0053 \\
0.0038 \\
0.0070 \\
0.0090 \\
0.0032 \\
0.0027\end{array}$ & $\begin{array}{l}0.004 \\
0.008 \\
0.016 \\
0.002 \\
0.022 \\
0.004 \\
0.002 \\
0.002 \\
0.004 \\
0.025 \\
0.006 \\
0.006 \\
0.007 \\
0.009 \\
0.004 \\
0.004\end{array}$ & $\begin{array}{l}0.335 \\
0.672 \\
1.333 \\
0.201 \\
1.802 \\
0.301 \\
0.167 \\
0.167 \\
0.317 \\
2.083 \\
0.523 \\
0.511 \\
0.583 \\
0.750 \\
0.365 \\
0.362\end{array}$ & $\begin{array}{l}0.0120 \\
0.0120 \\
0.0120 \\
0.0120 \\
0.0120 \\
0.0120 \\
0.0120 \\
0.0120 \\
0.0120 \\
0.0120 \\
0.0120 \\
0.0120 \\
0.0120 \\
0.0120 \\
0.0120 \\
0.0120\end{array}$ & $\begin{array}{l}\text { HAWO_CHR } \\
\text { HAWQ_CHR } \\
\text { HAWQ_CHR } \\
\text { HAWQ_CHR } \\
\text { NAWQ_CHR } \\
\text { NAWQ_CHR } \\
\text { HAWQ_CHR } \\
\text { NAWQ_CHR } \\
\text { NAWQ_CHR } \\
\text { NAWQ_CHR } \\
\text { HAWQ_CHR } \\
\text { HAWQ_CHR } \\
\text { NAWQ_CHR } \\
\text { NAWQ_CHR } \\
\text { NAWQ_CHR } \\
\text { NAHQ_CHR }\end{array}$ \\
\hline Carbon disulfide & $\begin{array}{l}\text { IHP } \\
\text { MHC } \\
\text { WHT } \\
\text { LWC } \\
\text { LMB } \\
\text { LMB } \\
\text { LWC } \\
\text { UMB } \\
\text { WOL } \\
\text { WOL } \\
\text { MWC } \\
\text { MWC } \\
\text { MWC } \\
\text { LWB } \\
\text { WOL } \\
\text { HOL } \\
\text { HOL } \\
\text { WOL } \\
\text { LWC } \\
\text { LWC } \\
\text { LWC } \\
\text { LWC }\end{array}$ & $\begin{array}{l}\text { 5HHT } \\
\text { 5HST } \\
\text { BTT } \\
\text { EAST SEEP } \\
\text { MBTRIB-3 } \\
\text { MID. DRAIN. } \\
\text { HW-2 } \\
\text { MV-3 } \\
\text { RS-1 } \\
\text { RS-3B } \\
\text { SW2-1 } \\
\text { SH2-3 } \\
\text { SH2-4 } \\
\text { SH2-5 } \\
\text { SW6-1 } \\
\text { SH6-2 } \\
\text { SH7-1 } \\
\text { SH7-2 } \\
\text { SH7-5 } \\
\text { SH7-6 } \\
\text { SW7-7 } \\
\text { SW7-8 }\end{array}$ & $\begin{array}{l}1 \\
1 \\
1 \\
1 \\
1 \\
1 \\
1 \\
1 \\
1 \\
1 \\
1 \\
2 \\
1 \\
1 \\
1 \\
1 \\
1 \\
1 \\
1 \\
1 \\
1 \\
1\end{array}$ & $\begin{array}{l}1 \\
1 \\
1 \\
1 \\
1 \\
1 \\
1 \\
1 \\
1 \\
1 \\
1 \\
2 \\
1 \\
1 \\
1 \\
1 \\
1 \\
1 \\
1 \\
1 \\
1 \\
1\end{array}$ & $\begin{array}{l}0.1400 \\
0.0040 \\
0.0000 \\
0.0110 \\
0.0630 \\
0.0160 \\
0.0000 \\
0.0010 \\
0.0250 \\
0.2600 \\
0.1200 \\
0.0375 \\
0.0410 \\
0.2400 \\
0.0020 \\
0.0100 \\
0.4100 \\
0.0670 \\
0.3000 \\
0.1100 \\
0.0430 \\
0.0000\end{array}$ & $\begin{array}{l}0.140 \\
0.004 \\
0.000 \\
0.011 \\
0.063 \\
0.016 \\
0.000 \\
0.001 \\
0.025 \\
0.260 \\
0.120 \\
0.274 \\
0.041 \\
0.240 \\
0.002 \\
0.010 \\
0.410 \\
0.067 \\
0.300 \\
0.110 \\
0.043 \\
0.000\end{array}$ & $\begin{array}{r}15.748 \\
0.450 \\
0.000 \\
1.237 \\
7.087 \\
1.800 \\
0.000 \\
0.112 \\
2.812 \\
29.246 \\
13.498 \\
30.851 \\
4.612 \\
26.997 \\
0.225 \\
1.125 \\
46.119 \\
7.537 \\
33.746 \\
12.373 \\
4.837 \\
0.000\end{array}$ & $\begin{array}{l}0.0089 \\
0.0089 \\
0.0089 \\
0.0089 \\
0.0089 \\
0.0089 \\
0.00689 \\
0.0089 \\
0.0089 \\
0.0089 \\
0.0089 \\
0.0089 \\
0.0089 \\
0.0089 \\
0.0089 \\
0.0089 \\
0.0089 \\
0.0089 \\
0.0089 \\
0.0089 \\
0.0089 \\
0.0089\end{array}$ & 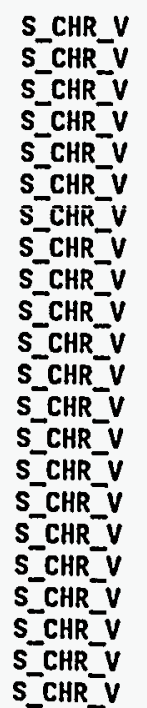 \\
\hline
\end{tabular}




\begin{tabular}{|c|c|c|c|c|c|c|c|c|c|}
\hline & $\begin{array}{l}\text { HRT } \\
\text { HRT } \\
\text { WOL } \\
\text { WOL } \\
\text { HOL } \\
\text { WOL } \\
\text { LHC } \\
\text { MWC } \\
\text { IHP } \\
\text { EWC } \\
\text { HOL }\end{array}$ & $\begin{array}{l}\text { SW9-1 } \\
\text { SH9-2 } \\
\text { HAG6 MS1 } \\
\text { HAG6 MS2 } \\
\text { HAG6 MS3A } \\
\text { HAG6 MS3B } \\
\text { HCTRIB-1 } \\
\text { WCTRIB-2 } \\
\text { HCTRIB-4 } \\
\text { WOCET } \\
\text { HSTRIB-1 }\end{array}$ & $\begin{array}{l}1 \\
2 \\
1 \\
1 \\
1 \\
1 \\
1 \\
1 \\
1 \\
1 \\
1\end{array}$ & $\begin{array}{l}1 \\
1 \\
1 \\
1 \\
1 \\
1 \\
1 \\
1 \\
1 \\
1 \\
1\end{array}$ & $\begin{array}{l}0.0870 \\
0.0030 \\
0.4600 \\
0.0170 \\
0.0020 \\
0.0080 \\
0.0250 \\
0.0010 \\
0.0370 \\
0.0010 \\
0.0140\end{array}$ & $\begin{array}{l}0.087 \\
0.003 \\
0.460 \\
0.017 \\
0.002 \\
0.008 \\
0.025 \\
0.001 \\
0.037 \\
0.001 \\
0.014\end{array}$ & $\begin{array}{r}9.786 \\
0.337 \\
51.744 \\
1.912 \\
0.225 \\
0.900 \\
2.812 \\
0.112 \\
4.162 \\
0.112 \\
1.575\end{array}$ & $\begin{array}{l}0.0089 \\
0.0089 \\
0.0089 \\
0.0089 \\
0.0089 \\
0.0089 \\
0.0089 \\
0.0089 \\
0.0089 \\
0.0089 \\
0.0089\end{array}$ & $\begin{array}{l}\text { S_CHR_V } \\
\text { s_CHR_V } \\
\text { s_CHR_V } \\
\text { s_CHR_V } \\
\text { s_CHR_V } \\
\text { s_CHR_V } \\
\text { s_CHR_V } \\
\text { s_CHR_V } \\
\text { s_CHR_V } \\
\text { s_CHR_V } \\
\text { s_CHR_V }\end{array}$ \\
\hline Chloroform & HRT & SW9-2 & 2 & 1 & 0.0010 & 0.001 & 0.005 & 0.1880 & S_CHR_V \\
\hline IROH & $\begin{array}{l}\text { HAT } \\
\text { LHC } \\
\text { UMB } \\
\text { LMB } \\
\text { LMB } \\
\text { LHC } \\
\text { UMB } \\
\text { HOL } \\
\text { HOL } \\
\text { HOL } \\
\text { HWC } \\
\text { UMC } \\
\text { MHC } \\
\text { MHC } \\
\text { LMB } \\
\text { UNknOHn } \\
\text { UnknOWn } \\
\text { HAT } \\
\text { HAT } \\
\text { LMB } \\
\text { LMB } \\
\text { HOL } \\
\text { HOL } \\
\text { LHC } \\
\text { LHC } \\
\text { LHC } \\
\text { LHC } \\
\text { HRT } \\
\text { HRT } \\
\text { HAT } \\
\text { HAT } \\
\text { LHC } \\
\text { MHC } \\
\text { IHP } \\
\text { EHC }\end{array}$ & $\begin{array}{l}\text { BTT } \\
\text { EAST SEEP } \\
\text { MBTRIB-2A } \\
\text { MBTRIB-3 } \\
\text { MID. DRAIN. } \\
\text { HV-1 } \\
\text { MV-3 } \\
\text { RS-1 } \\
\text { RS-3A } \\
\text { RS-3B } \\
\text { SH2-1 } \\
\text { SH2-2 } \\
\text { SH2-3 } \\
\text { SH2-4 } \\
\text { SH2-5 } \\
\text { SH2-6 } \\
\text { SH2-7 } \\
\text { SH4-1 } \\
\text { SH4-2 } \\
\text { SHS-2 } \\
\text { SHS-4 } \\
\text { SH7-1 } \\
\text { SH7-2 } \\
\text { SH7-3 } \\
\text { SH7-5 } \\
\text { SH7-6 } \\
\text { SH7-8 } \\
\text { SH9-1 } \\
\text { SH9-2 } \\
\text { HAG4 HS1 } \\
\text { HAG4 T2A } \\
\text { HCTRIB-1 } \\
\text { HCTRIB-2 } \\
\text { HCTRIB-3 } \\
\text { HOCET }\end{array}$ & $\begin{array}{r}7 \\
9 \\
1 \\
2 \\
10 \\
2 \\
1 \\
1 \\
10 \\
2 \\
1 \\
1 \\
1 \\
2 \\
10 \\
3 \\
4 \\
2 \\
6 \\
1 \\
6 \\
2 \\
2 \\
8 \\
10 \\
1 \\
1 \\
3 \\
3 \\
11 \\
7 \\
2 \\
1 \\
1 \\
2\end{array}$ & $\begin{array}{r}4 \\
9 \\
1 \\
2 \\
10 \\
2 \\
1 \\
1 \\
10 \\
2 \\
1 \\
1 \\
1 \\
2 \\
7 \\
3 \\
4 \\
2 \\
5 \\
1 \\
6 \\
2 \\
2 \\
8 \\
10 \\
1 \\
1 \\
3 \\
3 \\
8 \\
7 \\
2 \\
1 \\
1 \\
2\end{array}$ & $\begin{array}{l}0.1347 \\
0.6446 \\
0.2180 \\
0.2945 \\
2.0316 \\
2.1000 \\
0.1720 \\
0.6010 \\
7.7280 \\
1.0650 \\
2.3000 \\
0.3940 \\
0.2250 \\
0.5975 \\
0.3481 \\
2.8570 \\
6.8925 \\
14.8810 \\
2.4508 \\
0.0890 \\
0.4035 \\
6.3750 \\
0.5860 \\
0.3488 \\
0.8155 \\
0.4310 \\
0.3680 \\
0.3663 \\
1.8670 \\
0.2034 \\
0.4763 \\
0.4370 \\
0.1880 \\
0.3780 \\
1.0840\end{array}$ & $\begin{array}{r}0.165 \\
0.933 \\
0.218 \\
1.049 \\
3.608 \\
2.163 \\
0.172 \\
0.601 \\
9.843 \\
1.160 \\
2.300 \\
0.394 \\
0.225 \\
1.933 \\
0.679 \\
11.125 \\
15.133 \\
102.762 \\
4.671 \\
0.089 \\
0.758 \\
7.606 \\
0.940 \\
0.453 \\
1.233 \\
0.431 \\
0.368 \\
0.740 \\
4.137 \\
0.377 \\
0.807 \\
1.839 \\
0.188 \\
0.378 \\
4.405\end{array}$ & $\begin{array}{r}0.165 \\
0.933 \\
0.218 \\
1.049 \\
3.608 \\
2.163 \\
0.172 \\
0.601 \\
9.843 \\
1.160 \\
2.300 \\
0.394 \\
0.225 \\
1.933 \\
0.679 \\
11.125 \\
15.133 \\
102.762 \\
4.671 \\
0.089 \\
0.758 \\
7.606 \\
0.940 \\
0.453 \\
1.233 \\
0.431 \\
0.368 \\
0.740 \\
4.137 \\
0.377 \\
0.807 \\
1.839 \\
0.188 \\
0.378 \\
4.405\end{array}$ & $\begin{array}{l}1.0000 \\
1.0000 \\
1.0000 \\
1.0000 \\
1.0000 \\
1.0000 \\
1.0000 \\
1.0000 \\
1.0000 \\
1.0000 \\
1.0000 \\
1.0000 \\
1.0000 \\
1.0000 \\
1.0000 \\
1.0000 \\
1.0000 \\
1.0000 \\
1.0000 \\
1.0000 \\
1.0000 \\
1.0000 \\
1.0000 \\
1.0000 \\
1.0000 \\
1.0000 \\
1.0000 \\
1.0000 \\
1.0000 \\
1.0000 \\
1.0000 \\
1.0000 \\
1.0000 \\
1.0000 \\
1.0000\end{array}$ & 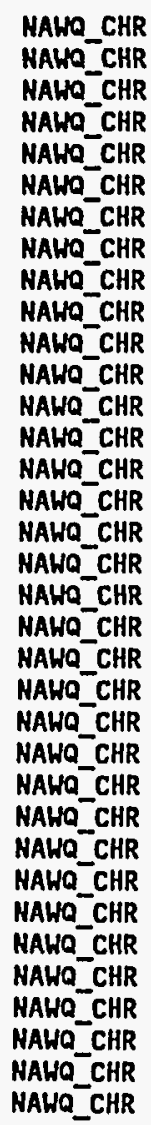 \\
\hline LEAD & W4T & BTT & 5 & 1 & 0.0020 & 0.002 & 0.625 & 0.0032 & NAWQ_CHR \\
\hline
\end{tabular}




\begin{tabular}{|c|c|c|c|c|c|c|c|c|c|}
\hline & $\begin{array}{l}\text { LWC } \\
\text { LWB } \\
\text { HOL } \\
\text { WOL } \\
\text { WOL } \\
\text { HWC } \\
\text { MHC } \\
\text { LMB } \\
\text { Unknown } \\
\text { Unknown } \\
\text { LHB } \\
\text { WOL } \\
\text { LHC } \\
\text { LWC } \\
\text { LWC } \\
\text { H4T }\end{array}$ & $\begin{array}{l}\text { EAST SEEP } \\
\text { MID. DRAIN. } \\
\text { RS-1 } \\
\text { RS-3A } \\
\text { RS-3B } \\
\text { SH2-1 } \\
\text { SH2-4 } \\
\text { SH2-5 } \\
\text { SH2-6 } \\
\text { SH2-7 } \\
\text { SH5-4 } \\
\text { SW7-2 } \\
\text { SH7-3 } \\
\text { SW7-5 } \\
\text { SH7-8 } \\
\text { HAG4 T2A }\end{array}$ & $\begin{array}{l}7 \\
5 \\
1 \\
6 \\
1 \\
1 \\
2 \\
6 \\
1 \\
2 \\
3 \\
2 \\
6 \\
8 \\
1 \\
5\end{array}$ & $\begin{array}{l}2 \\
1 \\
1 \\
4 \\
1 \\
1 \\
1 \\
3 \\
1 \\
1 \\
1 \\
1 \\
1 \\
2 \\
1 \\
1\end{array}$ & $\begin{array}{l}0.0025 \\
0.0010 \\
0.0030 \\
0.0043 \\
0.0040 \\
0.0030 \\
0.0080 \\
0.0012 \\
0.0020 \\
0.0020 \\
0.0110 \\
0.0020 \\
0.0030 \\
0.0040 \\
0.0030 \\
0.0010\end{array}$ & $\begin{array}{l}0.004 \\
0.001 \\
0.003 \\
0.006 \\
0.004 \\
0.003 \\
0.008 \\
0.002 \\
0.002 \\
0.002 \\
0.011 \\
0.002 \\
0.003 \\
0.004 \\
0.003 \\
0.001\end{array}$ & $\begin{array}{l}1.153 \\
0.313 \\
0.938 \\
1.800 \\
1.250 \\
0.938 \\
2.500 \\
0.513 \\
0.625 \\
0.625 \\
3.438 \\
0.625 \\
0.938 \\
1.250 \\
0.938 \\
0.313\end{array}$ & $\begin{array}{l}0.0032 \\
0.0032 \\
0.0032 \\
0.0032 \\
0.0032 \\
0.0032 \\
0.0032 \\
0.0032 \\
0.0032 \\
0.0032 \\
0.0032 \\
0.0032 \\
0.0032 \\
0.0032 \\
0.0032 \\
0.0032\end{array}$ & $\begin{array}{l}\text { HAWQ_CHR } \\
\text { NAWQ_CHR } \\
\text { NAWQ_CHR } \\
\text { NAWQ_CHR } \\
\text { NAWQ_CHR } \\
\text { NAWQ_CHR } \\
\text { NAWQ_CHR } \\
\text { NAWQ_CHR } \\
\text { NAWQ_CHR } \\
\text { NAWQ_CHR } \\
\text { NAWQ_CHR } \\
\text { NAWQ_CHR } \\
\text { HAWQ_CHR } \\
\text { HAWQ_CHR } \\
\text { NAWQ_CHR } \\
\text { NAWQ_CHR }\end{array}$ \\
\hline LITHIUM & H4T & SW4-2 & 1 & 1 & 0.1130 & 0.113 & 7.842 & 0.0144 & SCV_NEH \\
\hline
\end{tabular}




\begin{tabular}{|c|c|c|c|c|c|c|c|c|c|}
\hline & $\begin{array}{l}\text { MWC } \\
\text { IHP } \\
\text { ENC }\end{array}$ & $\begin{array}{l}\text { HCTRIB-2 } \\
\text { WCTRIB-3 } \\
\text { WOCET }\end{array}$ & $\begin{array}{l}1 \\
1 \\
2\end{array}$ & $\begin{array}{l}1 \\
1 \\
2\end{array}$ & $\begin{array}{l}0.0240 \\
0.5850 \\
0.3545\end{array}$ & $\begin{array}{l}0.024 \\
0.585 \\
2.214\end{array}$ & $\begin{array}{r}0.299 \\
7.285 \\
27.570\end{array}$ & $\begin{array}{l}0.0803 \\
0.0803 \\
0.0803\end{array}$ & $\begin{array}{l}S_{-} C_{H R} V \\
S_{-C H R}-V \\
\text { S_CHR_V }\end{array}$ \\
\hline MERCURY & $\begin{array}{l}\text { WOL } \\
\text { MHC } \\
\text { MHCC } \\
\text { WLT } \\
\text { LHC }\end{array}$ & $\begin{array}{l}\text { RS-3A } \\
\text { SH2-1 } \\
\text { SWL2-4 } \\
\text { SW4-2 } \\
\text { SW7-3 }\end{array}$ & $\begin{array}{r}10 \\
1 \\
2 \\
4 \\
8\end{array}$ & $\begin{array}{r}10 \\
1 \\
1 \\
1 \\
1\end{array}$ & $\begin{array}{l}0.0009 \\
0.0000 \\
0.0000 \\
0.0000 \\
0.0000\end{array}$ & $\begin{array}{l}0.001 \\
0.000 \\
0.000 \\
0.000 \\
0.000\end{array}$ & $\begin{array}{l}0.833 \\
0.000 \\
0.000 \\
0.000 \\
0.000\end{array}$ & $\begin{array}{l}0.0013 \\
0.0013 \\
0.0013 \\
0.0013 \\
0.0013\end{array}$ & $\begin{array}{l}S_{\text {S_CHR_V }} \\
\text { S_CHR_V } \\
\text { S_CHR_v } \\
\text { S_CHR } \\
\text { S_CHR_V }\end{array}$ \\
\hline MOLYBDENUM & $\begin{array}{l}\text { H4T } \\
\text { LHC } \\
\text { HOL } \\
\text { N4T } \\
\text { LHC } \\
\text { H4T }\end{array}$ & $\begin{array}{l}\text { BTT } \\
\text { EAST SEEP } \\
\text { RS-3A } \\
\text { SH4-2 } \\
\text { SH7-3 } \\
\text { HAG4 MS1 }\end{array}$ & $\begin{array}{r}7 \\
9 \\
10 \\
6 \\
8 \\
11\end{array}$ & $\begin{array}{r}5 \\
1 \\
10 \\
1 \\
3 \\
2\end{array}$ & $\begin{array}{l}0.0612 \\
0.0150 \\
0.0483 \\
0.0080 \\
0.0123 \\
0.0065\end{array}$ & $\begin{array}{l}0.114 \\
0.015 \\
0.052 \\
0.008 \\
0.014 \\
0.007\end{array}$ & $\begin{array}{l}0.479 \\
0.063 \\
0.216 \\
0.033 \\
0.059 \\
0.031\end{array}$ & $\begin{array}{l}0.2390 \\
0.2390 \\
0.2390 \\
0.2390 \\
0.2390 \\
0.2390\end{array}$ & $\begin{array}{l}\text { S_CHR_v } \\
\text { S_CHR_v } \\
\text { S_CHR_v } \\
\text { S_CRR_v } \\
\text { S_CHR_v } \\
\text { S_CHR_v }\end{array}$ \\
\hline Methylene chloride & $\begin{array}{l}\text { IHP } \\
\text { MHC } \\
\text { HAT } \\
\text { LHC } \\
\text { LMB } \\
\text { LHC } \\
\text { LHC } \\
\text { UHB } \\
\text { WOL } \\
\text { HOL } \\
\text { MHC } \\
\text { UMC } \\
\text { MHC } \\
\text { MHC } \\
\text { HOL } \\
\text { HOL } \\
\text { HOL } \\
\text { LHC } \\
\text { LHC } \\
\text { LHC } \\
\text { LHC } \\
\text { HRT } \\
\text { HAT } \\
\text { HOL } \\
\text { LHC } \\
\text { HHC } \\
\text { EHC } \\
\text { HOL }\end{array}$ & $\begin{array}{l}\text { 5NNT } \\
\text { 5NST } \\
\text { BTT } \\
\text { EAST SEEP } \\
\text { MID. DRAIH. } \\
\text { MV-1 } \\
\text { MV-2 } \\
\text { MV-3 } \\
\text { RS-1 } \\
\text { RS-3A } \\
\text { SH2-1 } \\
\text { SH2-2 } \\
\text { SH2-3 } \\
\text { SH2-4 } \\
\text { SH6-1 } \\
\text { SH6-2 } \\
\text { SH7-2 } \\
\text { SH7-3 } \\
\text { SH7-4 } \\
\text { SH7-5 } \\
\text { SH7-8 } \\
\text { SH9-2 } \\
\text { HAG4 T2A } \\
\text { HAG6 MS2 } \\
\text { HCTRIB-1 } \\
\text { HCTRIB-2 } \\
\text { HOCET } \\
\text { HSTRIB-1 }\end{array}$ & $\begin{array}{l}1 \\
1 \\
1 \\
1 \\
1 \\
1 \\
1 \\
1 \\
1 \\
1 \\
1 \\
1 \\
2 \\
1 \\
1 \\
1 \\
1 \\
2 \\
1 \\
1 \\
1 \\
2 \\
1 \\
1 \\
1 \\
1 \\
1 \\
1\end{array}$ & $\begin{array}{l}1 \\
1 \\
1 \\
1 \\
1 \\
1 \\
1 \\
1 \\
1 \\
1 \\
1 \\
1 \\
2 \\
1 \\
1 \\
1 \\
1 \\
2 \\
1 \\
1 \\
1 \\
2 \\
1 \\
1 \\
1 \\
1 \\
1 \\
1\end{array}$ & $\begin{array}{l}0.0130 \\
0.0000 \\
0.0000 \\
0.0000 \\
0.0010 \\
0.0010 \\
0.0000 \\
0.0000 \\
0.0000 \\
0.0000 \\
0.0010 \\
0.0000 \\
0.0020 \\
0.0010 \\
0.0000 \\
0.0000 \\
0.0010 \\
0.0005 \\
0.0000 \\
0.0300 \\
0.0000 \\
0.0010 \\
0.0000 \\
0.0000 \\
0.0000 \\
0.0000 \\
0.0010 \\
0.0000\end{array}$ & $\begin{array}{l}0.013 \\
0.000 \\
0.000 \\
0.000 \\
0.001 \\
0.001 \\
0.000 \\
0.000 \\
0.000 \\
0.000 \\
0.001 \\
0.000 \\
0.008 \\
0.001 \\
0.000 \\
0.000 \\
0.001 \\
0.004 \\
0.000 \\
0.030 \\
0.000 \\
0.001 \\
0.000 \\
0.000 \\
0.000 \\
0.000 \\
0.001 \\
0.000\end{array}$ & $\begin{array}{l}0.006 \\
0.000 \\
0.000 \\
0.000 \\
0.000 \\
0.000 \\
0.000 \\
0.000 \\
0.000 \\
0.000 \\
0.000 \\
0.000 \\
0.004 \\
0.000 \\
0.000 \\
0.000 \\
0.000 \\
0.002 \\
0.000 \\
0.013 \\
0.000 \\
0.000 \\
0.000 \\
0.000 \\
0.000 \\
0.000 \\
0.000 \\
0.000\end{array}$ & $\begin{array}{l}2.2400 \\
2.2400 \\
2.2400 \\
2.2400 \\
2.2400 \\
2.2400 \\
2.2400 \\
2.2400 \\
2.2400 \\
2.2400 \\
2.2400 \\
2.2400 \\
2.2400 \\
2.2400 \\
2.2400 \\
2.2400 \\
2.2400 \\
2.2400 \\
2.2400 \\
2.2400 \\
2.2400 \\
2.2400 \\
2.2400 \\
2.2400 \\
2.2400 \\
2.2400 \\
2.2400 \\
2.2400\end{array}$ & 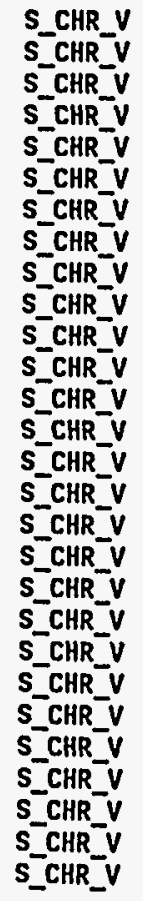 \\
\hline HICKEL & $\begin{array}{l}\text { H4T } \\
\text { LHC } \\
\text { LMB } \\
\text { HOL } \\
\text { LMB }\end{array}$ & $\begin{array}{l}\text { BTT } \\
\text { EAST SEEP } \\
\text { MID. DRAIN. } \\
\text { RS-3A } \\
\text { SH2-5 }\end{array}$ & $\begin{array}{r}7 \\
9 \\
10 \\
10 \\
10\end{array}$ & $\begin{array}{r}6 \\
8 \\
1 \\
10 \\
6\end{array}$ & $\begin{array}{l}0.0395 \\
0.0269 \\
0.0060 \\
0.0970 \\
0.0104\end{array}$ & $\begin{array}{l}0.048 \\
0.032 \\
0.006 \\
0.103 \\
0.013\end{array}$ & $\begin{array}{l}0.300 \\
0.199 \\
0.038 \\
0.645 \\
0.082\end{array}$ & $\begin{array}{l}0.1600 \\
0.1600 \\
0.1600 \\
0.1600 \\
0.1600\end{array}$ & $\begin{array}{l}\text { HAHQ_CHR } \\
\text { NAHQ_CHR } \\
\text { NAHQ_CHR } \\
\text { NAHQ_CHR } \\
\text { NAHO_CHR }\end{array}$ \\
\hline
\end{tabular}




\begin{tabular}{|c|c|c|c|c|c|c|c|c|c|}
\hline & $\begin{array}{l}\text { Unknown } \\
\text { Unknown } \\
\text { W4T } \\
\text { LMB } \\
\text { LWC } \\
\text { LWC } \\
\text { W4T } \\
\text { W4T }\end{array}$ & $\begin{array}{l}\text { SW2-6 } \\
\text { SW2-7 } \\
\text { SH4-2 } \\
\text { SW5-4 } \\
\text { SW7-3 } \\
\text { SW7-5 } \\
\text { WAG4 MS1 } \\
\text { WAG4 T2A }\end{array}$ & $\begin{array}{r}3 \\
4 \\
6 \\
6 \\
8 \\
10 \\
11 \\
7\end{array}$ & $\begin{array}{r}2 \\
1 \\
6 \\
2 \\
4 \\
4 \\
10 \\
5\end{array}$ & $\begin{array}{l}0.0095 \\
0.0080 \\
6.1700 \\
0.0118 \\
0.0253 \\
0.0161 \\
0.0345 \\
0.0230\end{array}$ & $\begin{array}{l}0.014 \\
0.008 \\
8.522 \\
0.014 \\
0.028 \\
0.021 \\
0.043 \\
0.030\end{array}$ & $\begin{array}{r}0.087 \\
0.050 \\
53.264 \\
0.086 \\
0.175 \\
0.128 \\
0.266 \\
0.189\end{array}$ & $\begin{array}{l}0.1600 \\
0.1600 \\
0.1600 \\
0.1600 \\
0.1600 \\
0.1600 \\
0.1600 \\
0.1600\end{array}$ & $\begin{array}{l}\text { HAWQ_CHR } \\
\text { NAWQ_CHR } \\
\text { HAWQ_CHR } \\
\text { HAWQ_CHR } \\
\text { HAWQ_CHR } \\
\text { NAWQ_CHR } \\
\text { NAWQ_CHR } \\
\text { NAWQ_CHR }\end{array}$ \\
\hline SELENIUM & $\begin{array}{l}\text { LWC } \\
\text { WOL } \\
\text { LHC }\end{array}$ & $\begin{array}{l}\text { EAST SEEP } \\
\text { RS-3A } \\
\text { SW7-3 }\end{array}$ & $\begin{array}{l}8 \\
7 \\
7\end{array}$ & $\begin{array}{l}1 \\
1 \\
1\end{array}$ & $\begin{array}{l}0.0010 \\
0.0020 \\
0.0030\end{array}$ & $\begin{array}{l}0.001 \\
0.002 \\
0.003\end{array}$ & $\begin{array}{l}0.200 \\
0.400 \\
0.600\end{array}$ & $\begin{array}{l}0.0050 \\
0.0050 \\
0.0050\end{array}$ & $\begin{array}{l}\text { NAWQ_CHR } \\
\text { NAHQ_CHR } \\
\text { HAWQ_CHR }\end{array}$ \\
\hline SILVER & $\begin{array}{l}\text { HOL } \\
\text { MHC }\end{array}$ & $\begin{array}{l}\text { RS-3A } \\
\text { SW2-4 }\end{array}$ & $\begin{array}{r}10 \\
2\end{array}$ & $\begin{array}{l}3 \\
1\end{array}$ & $\begin{array}{l}0.0043 \\
0.0030\end{array}$ & $\begin{array}{l}0.005 \\
0.003\end{array}$ & $\begin{array}{r}13.207 \\
8.333\end{array}$ & $\begin{array}{l}0.0004 \\
0.0004\end{array}$ & $\begin{array}{l}\text { S_CHR_V } \\
\text { S_CHR_V }\end{array}$ \\
\hline STRONTIUM & $\begin{array}{l}\text { HAT } \\
\text { LHC } \\
\text { UMB } \\
\text { LMB } \\
\text { LMB } \\
\text { LWC } \\
\text { UMB } \\
\text { HOL } \\
\text { HOL } \\
\text { HOL } \\
\text { MHC } \\
\text { UMC } \\
\text { MHC } \\
\text { MWC } \\
\text { LMB } \\
\text { UnknoWn } \\
\text { Unknown } \\
\text { W4T } \\
\text { W4T } \\
\text { LMB } \\
\text { LMB } \\
\text { HOL } \\
\text { HOL } \\
\text { LWC } \\
\text { LWC } \\
\text { LHC } \\
\text { HRT } \\
\text { HRT } \\
\text { H4T } \\
\text { H4T } \\
\text { LWC } \\
\text { MHC } \\
\text { IHP } \\
\text { EWC }\end{array}$ & $\begin{array}{l}\text { BTT } \\
\text { EAST SEEP } \\
\text { MBTRIB-2A } \\
\text { MBTRIB-3 } \\
\text { MID. DRAIH. } \\
\text { MV-1 } \\
\text { HV-3 } \\
\text { RS-1 } \\
\text { RS-3A } \\
\text { RS-3B } \\
\text { SH2-1 } \\
\text { SH2-2 } \\
\text { SW2-3 } \\
\text { SWL-4 } \\
\text { SH2-5 } \\
\text { SH2-6 } \\
\text { SH2-7 } \\
\text { SW4-1 } \\
\text { SH4-2 } \\
\text { SH5-2 } \\
\text { SW5-4 } \\
\text { SH7-1 } \\
\text { SH7-2 } \\
\text { SW7-3 } \\
\text { SH7-5 } \\
\text { SH7-8 } \\
\text { SW9-1 } \\
\text { SH9-2 } \\
\text { HAG4 MS1 } \\
\text { HAG4 T2A } \\
\text { HCTRIB-1 } \\
\text { HCTRIB-2 } \\
\text { HCTRIB-3 } \\
\text { HOCET }\end{array}$ & $\begin{array}{r}7 \\
9 \\
1 \\
2 \\
10 \\
2 \\
1 \\
1 \\
10 \\
2 \\
1 \\
1 \\
1 \\
2 \\
10 \\
3 \\
4 \\
2 \\
6 \\
1 \\
6 \\
2 \\
2 \\
8 \\
9 \\
1 \\
3 \\
3 \\
11 \\
7 \\
2 \\
1 \\
1 \\
2\end{array}$ & $\begin{array}{r}7 \\
9 \\
1 \\
2 \\
10 \\
2 \\
1 \\
1 \\
7 \\
2 \\
1 \\
1 \\
1 \\
2 \\
10 \\
3 \\
4 \\
2 \\
6 \\
1 \\
6 \\
2 \\
2 \\
8 \\
9 \\
1 \\
3 \\
3 \\
10 \\
7 \\
2 \\
1 \\
1 \\
2\end{array}$ & $\begin{array}{l}0.2347 \\
0.1127 \\
0.1880 \\
0.1570 \\
0.1871 \\
0.1560 \\
0.1450 \\
0.0670 \\
0.0144 \\
0.0525 \\
0.1890 \\
0.1240 \\
0.0670 \\
0.2500 \\
0.3168 \\
0.2220 \\
0.2033 \\
0.3330 \\
0.2592 \\
0.2010 \\
0.1838 \\
0.0850 \\
0.0265 \\
0.0279 \\
0.0890 \\
0.0690 \\
0.1050 \\
0.1483 \\
0.1841 \\
0.1871 \\
0.1120 \\
0.0610 \\
0.2100 \\
0.0755\end{array}$ & $\begin{array}{l}0.254 \\
0.132 \\
0.188 \\
0.226 \\
0.207 \\
0.169 \\
0.145 \\
0.067 \\
0.017 \\
0.062 \\
0.189 \\
0.124 \\
0.067 \\
0.597 \\
0.343 \\
0.231 \\
0.212 \\
0.503 \\
0.286 \\
0.201 \\
0.203 \\
0.091 \\
0.036 \\
0.031 \\
0.114 \\
0.069 \\
0.115 \\
0.197 \\
0.200 \\
0.204 \\
0.383 \\
0.061 \\
0.210 \\
0.154\end{array}$ & $\begin{array}{l}0.409 \\
0.213 \\
0.303 \\
0.365 \\
0.335 \\
0.272 \\
0.234 \\
0.108 \\
0.028 \\
0.100 \\
0.305 \\
0.200 \\
0.108 \\
0.963 \\
0.554 \\
0.372 \\
0.342 \\
0.812 \\
0.461 \\
0.324 \\
0.327 \\
0.147 \\
0.058 \\
0.050 \\
0.185 \\
0.111 \\
0.186 \\
0.318 \\
0.322 \\
0.329 \\
0.619 \\
0.098 \\
0.339 \\
0.249\end{array}$ & $\begin{array}{l}0.6200 \\
0.6200 \\
0.6200 \\
0.6200 \\
0.6200 \\
0.6200 \\
0.6200 \\
0.6200 \\
0.6200 \\
0.6200 \\
0.6200 \\
0.6200 \\
0.6200 \\
0.6200 \\
0.6200 \\
0.6200 \\
0.6200 \\
0.6200 \\
0.6200 \\
0.6200 \\
0.6200 \\
0.6200 \\
0.6200 \\
0.6200 \\
0.6200 \\
0.6200 \\
0.6200 \\
0.6200 \\
0.6200 \\
0.6200 \\
0.6200 \\
0.6200 \\
0.6200 \\
0.6200\end{array}$ & 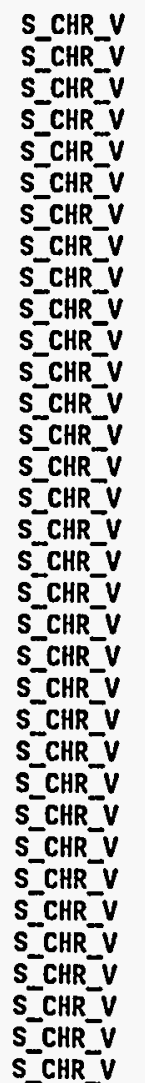 \\
\hline
\end{tabular}




\begin{tabular}{|c|c|c|c|c|c|c|c|c|c|}
\hline Tetrschloroethene & $\begin{array}{l}\text { HOL } \\
\text { LMB } \\
\text { HAT } \\
\text { WOL }\end{array}$ & $\begin{array}{l}\text { FRENCH DR S } \\
\text { MID. DRAIH. } \\
\text { HAG4 T2A } \\
\text { HAG6 MS3B }\end{array}$ & $\begin{array}{l}1 \\
1 \\
1 \\
1\end{array}$ & $\begin{array}{l}1 \\
1 \\
1 \\
1\end{array}$ & $\begin{array}{l}0.0550 \\
0.0000 \\
0.0000 \\
0.0010\end{array}$ & $\begin{array}{l}0.055 \\
0.000 \\
0.000 \\
0.001\end{array}$ & $\begin{array}{l}0.440 \\
0.000 \\
0.000 \\
0.008\end{array}$ & $\begin{array}{l}0.1250 \\
0.1250 \\
0.1250 \\
0.1250\end{array}$ & $\begin{array}{l}\text { S_CHR_V } \\
\text { S_CHR_V } \\
\text { S_CHR_V } \\
\text { S_CHR_V }\end{array}$ \\
\hline Trichloroethene & $\begin{array}{l}\text { HOL } \\
\text { LMB } \\
\text { HRT } \\
\text { WAT } \\
\text { WOL }\end{array}$ & $\begin{array}{l}\text { FRENCH DR S } \\
\text { MID. DRAIH. } \\
\text { SW9-2 } \\
\text { WAG4 T2A } \\
\text { HAG6 MS2 }\end{array}$ & $\begin{array}{l}1 \\
1 \\
2 \\
1 \\
1\end{array}$ & $\begin{array}{l}1 \\
1 \\
1 \\
1 \\
1\end{array}$ & $\begin{array}{l}1.0000 \\
0.0010 \\
0.0000 \\
0.0020 \\
0.0030\end{array}$ & $\begin{array}{l}1.000 \\
0.001 \\
0.000 \\
0.002 \\
0.003\end{array}$ & $\begin{array}{l}2.151 \\
0.002 \\
0.000 \\
0.004 \\
0.006\end{array}$ & $\begin{array}{l}0.4650 \\
0.4650 \\
0.4650 \\
0.4650 \\
0.4650\end{array}$ & $\begin{array}{l}\text { S_CHR_V } \\
\text { S_CHR_V } \\
\text { S_CHR_V } \\
\text { S_CHR_V } \\
\text { s_CHR_V }\end{array}$ \\
\hline VAHADIUM & $\begin{array}{l}\text { HOL } \\
\text { LMB } \\
\text { LWC } \\
\text { LHC }\end{array}$ & $\begin{array}{l}\text { RS-3A } \\
\text { SW2-5 } \\
\text { SW7-3 } \\
\text { SW7-5 }\end{array}$ & $\begin{array}{r}10 \\
10 \\
8 \\
9\end{array}$ & $\begin{array}{l}9 \\
1 \\
2 \\
1\end{array}$ & $\begin{array}{l}0.0217 \\
0.0030 \\
0.0040 \\
0.0020\end{array}$ & $\begin{array}{l}0.027 \\
0.003 \\
0.004 \\
0.002\end{array}$ & $\begin{array}{l}1.388 \\
0.157 \\
0.209 \\
0.105\end{array}$ & $\begin{array}{l}0.0191 \\
0.0191 \\
0.0191 \\
0.0191\end{array}$ & $\begin{array}{l}\text { S_CHR_V } \\
\text { S_CHR_V } \\
\text { s_CHR_V } \\
\text { s_CHR_V }\end{array}$ \\
\hline Vinyl chloride & $\begin{array}{l}\text { LMB } \\
\text { U4T } \\
\text { U4T } \\
\text { W4T }\end{array}$ & $\begin{array}{l}\text { MID. DRAIN. } \\
\text { SW4-2 } \\
\text { WAG4 MS1 } \\
\text { WAG4 T2A }\end{array}$ & $\begin{array}{l}1 \\
1 \\
1 \\
1\end{array}$ & $\begin{array}{l}1 \\
1 \\
1 \\
1\end{array}$ & $\begin{array}{l}0.0010 \\
0.0460 \\
0.0000 \\
0.0010\end{array}$ & $\begin{array}{l}0.001 \\
0.046 \\
0.000 \\
0.001\end{array}$ & $\begin{array}{l}0.011 \\
0.524 \\
0.000 \\
0.011\end{array}$ & $\begin{array}{l}0.0878 \\
0.0878 \\
0.0878 \\
0.0878\end{array}$ & $\begin{array}{l}\text { S_CHR_V } \\
\text { S_CHR_V } \\
\text { S_CHR_V } \\
\text { S_CHR_V }\end{array}$ \\
\hline 2INC & $\begin{array}{l}\text { WHT } \\
\text { LHC } \\
\text { LMB } \\
\text { WOL } \\
\text { HOL } \\
\text { MHC } \\
\text { LMB } \\
\text { Unknown } \\
\text { Unknown } \\
\text { H4T } \\
\text { HAT } \\
\text { LMB } \\
\text { LHC } \\
\text { LHC } \\
\text { HRT } \\
\text { HRT } \\
\text { HAT } \\
\text { H4T }\end{array}$ & $\begin{array}{l}\text { BTT } \\
\text { EAST SEEP } \\
\text { MID. DRAIH. } \\
\text { RS-3A } \\
\text { RS-3B } \\
\text { SH2-4 } \\
\text { SH2-5 } \\
\text { SH2-6 } \\
\text { SH2-7 } \\
\text { SH4-1 } \\
\text { SH4-2 } \\
\text { SW5-4 } \\
\text { SH7-3 } \\
\text { SW7-5 } \\
\text { SW9-1 } \\
\text { SW9-2 } \\
\text { HAG4 HS1 } \\
\text { HAG4 T2A } \\
\end{array}$ & $\begin{array}{r}7 \\
8 \\
10 \\
9 \\
2 \\
2 \\
10 \\
3 \\
4 \\
2 \\
6 \\
6 \\
7 \\
8 \\
3 \\
3 \\
11 \\
7 \\
\end{array}$ & $\begin{array}{l}2 \\
5 \\
3 \\
7 \\
1 \\
1 \\
6 \\
2 \\
2 \\
1 \\
4 \\
3 \\
5 \\
5 \\
2 \\
3 \\
3 \\
3 \\
\end{array}$ & $\begin{array}{l}0.0118 \\
0.0110 \\
0.0053 \\
0.0386 \\
0.0090 \\
0.0040 \\
0.0168 \\
0.0110 \\
0.0305 \\
0.0300 \\
0.0344 \\
0.0066 \\
0.0281 \\
0.0116 \\
0.0107 \\
0.1143 \\
0.0059 \\
0.0120 \\
\end{array}$ & $\begin{array}{l}0.016 \\
0.015 \\
0.006 \\
0.049 \\
0.009 \\
0.004 \\
0.024 \\
0.017 \\
0.067 \\
0.030 \\
0.056 \\
0.009 \\
0.031 \\
0.018 \\
0.033 \\
0.368 \\
0.008 \\
0.019 \\
\end{array}$ & $\begin{array}{l}0.149 \\
0.138 \\
0.052 \\
0.449 \\
0.082 \\
0.036 \\
0.220 \\
0.153 \\
0.605 \\
0.273 \\
0.512 \\
0.081 \\
0.283 \\
0.164 \\
0.301 \\
3.346 \\
0.069 \\
0.177 \\
\end{array}$ & $\begin{array}{l}0.1100 \\
0.1100 \\
0.1100 \\
0.1100 \\
0.1100 \\
0.1100 \\
0.1100 \\
0.1100 \\
0.1100 \\
0.1100 \\
0.1100 \\
0.1100 \\
0.1100 \\
0.1100 \\
0.1100 \\
0.1100 \\
0.1100 \\
0.1100 \\
\end{array}$ & 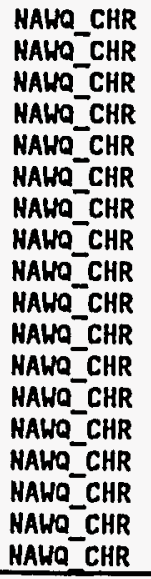 \\
\hline
\end{tabular}


Table B.3. Screening of aqueous concentrations of radionuclides detected in streams against screening benchmarks for aquatic life. Concentrations are pci/L.

Radionuclide Reach Samples Detects P.L. Mean 95\% UCB Quotient Benchmark Benchmark

\begin{tabular}{|c|c|c|c|c|c|c|c|c|}
\hline & & & & & & & Value & \\
\hline Cesium-137 & $\begin{array}{l}\text { TWC } \\
\text { IHP } \\
\text { LHB } \\
\text { LWC } \\
\text { MHC } \\
\text { WHT } \\
\text { WOL }\end{array}$ & $\begin{array}{r}5 \\
9 \\
12 \\
3 \\
12 \\
16 \\
12\end{array}$ & $\begin{array}{r}5 \\
9 \\
1 \\
2 \\
12 \\
3 \\
12\end{array}$ & $\begin{array}{r}112.62 \\
109.87 \\
15.90 \\
40.10 \\
66.95 \\
40.31 \\
67.33\end{array}$ & $\begin{array}{r}179.30 \\
134.53 \\
15.90 \\
85.62 \\
85.18 \\
50.19 \\
79.17\end{array}$ & $\begin{array}{l}0.004733 \\
0.003551 \\
0.000420 \\
0.002260 \\
0.002249 \\
0.001325 \\
0.002090\end{array}$ & $\begin{array}{l}37882.0000 \\
37882.0000 \\
37882.0000 \\
37882.0000 \\
37882.0000 \\
37882.0000 \\
37882.0000\end{array}$ & $\begin{array}{l}\text { WAT_RAD } \\
\text { WAT_RAD } \\
\text { WAT_RAD } \\
\text { WAT_RAD } \\
\text { WAT_RAD } \\
\text { WAT_RAD } \\
\text { WAT_RAD }\end{array}$ \\
\hline Cobat $t-60$ & US & 7 & 1 & 31.30 & 31.30 & 0.000061 & 510314.000 & WAT_RAD \\
\hline Curium-244 & $\begin{array}{l}\text { IHC } \\
\text { IHP }\end{array}$ & $\begin{array}{l}2 \\
1\end{array}$ & $\begin{array}{l}2 \\
1\end{array}$ & $\begin{array}{l}0.00 \\
0.00\end{array}$ & $\begin{array}{l}0.00 \\
0.00\end{array}$ & $\begin{array}{l}0.000000 \\
0.000000\end{array}$ & $\begin{array}{l}5537.0000 \\
5537.0000\end{array}$ & $\begin{array}{l}\text { HAT_RAD } \\
\text { WAT_RAD }\end{array}$ \\
\hline Plutonium-238 & $\begin{array}{l}\text { IWC } \\
\text { IHP } \\
\text { LHB }\end{array}$ & $\begin{array}{l}2 \\
1 \\
1\end{array}$ & $\begin{array}{l}2 \\
1 \\
1\end{array}$ & $\begin{array}{l}0.00 \\
0.00 \\
0.16\end{array}$ & $\begin{array}{l}0.00 \\
0.00 \\
0.16\end{array}$ & $\begin{array}{l}0.000000 \\
0.000000 \\
0.000027\end{array}$ & $\begin{array}{l}5845.0000 \\
5845.0000 \\
5845.0000\end{array}$ & $\begin{array}{l}\text { WAT_RAD } \\
\text { HAT_RAD } \\
\text { WAT_RAD }\end{array}$ \\
\hline Strontium-90 & $\begin{array}{l}\text { 1C } \\
\text { IHC } \\
\text { HRT } \\
\text { IHP } \\
\text { LMB } \\
\text { LHC } \\
\text { WHC } \\
\text { HWT } \\
\text { UWB } \\
\text { WHT } \\
\text { WOL } \\
\text { WS } \\
\text { IC } \\
\text { IWC } \\
\text { HRT } \\
\text { IHP } \\
\text { LHB } \\
\text { LHC } \\
\text { HWC } \\
\text { NWT } \\
\text { UHB } \\
\text { WHT } \\
\text { HOL } \\
\text { WS }\end{array}$ & $\begin{array}{r}2 \\
4 \\
19 \\
3 \\
21 \\
1 \\
3 \\
2 \\
2 \\
20 \\
3 \\
3 \\
7 \\
10 \\
7 \\
13 \\
32 \\
10 \\
24 \\
6 \\
4 \\
1 \\
12 \\
7\end{array}$ & $\begin{array}{r}2 \\
2 \\
19 \\
1 \\
21 \\
1 \\
2 \\
1 \\
1 \\
20 \\
3 \\
2 \\
7 \\
8 \\
7 \\
13 \\
32 \\
9 \\
24 \\
6 \\
2 \\
1 \\
12 \\
7\end{array}$ & $\begin{array}{r}477.00 \\
87.50 \\
1057.61 \\
196.00 \\
641.60 \\
326.00 \\
130.80 \\
96.00 \\
20.00 \\
9778.88 \\
224.00 \\
179.67 \\
269.80 \\
77.56 \\
947.00 \\
80.95 \\
532.49 \\
178.04 \\
105.43 \\
36.55 \\
0.00 \\
7168.00 \\
194.00 \\
135.79\end{array}$ & $\begin{array}{r}1973.36 \\
212.88 \\
1444.71 \\
196.00 \\
804.60 \\
326.00 \\
287.08 \\
96.00 \\
20.00 \\
10681.82 \\
330.21 \\
225.75 \\
411.81 \\
118.79 \\
1242.22 \\
94.42 \\
643.31 \\
212.35 \\
119.69 \\
58.92 \\
0.00 \\
7168.00 \\
213.04 \\
183.74\end{array}$ & $\begin{array}{l}0.005694 \\
0.000614 \\
0.004169 \\
0.000566 \\
0.002322 \\
0.000941 \\
0.000828 \\
0.000277 \\
0.000058 \\
0.030822 \\
0.000953 \\
0.000651 \\
0.001188 \\
0.000343 \\
0.003584 \\
0.000272 \\
0.001856 \\
0.000613 \\
0.000345 \\
0.000170 \\
0.000000 \\
0.020683 \\
0.000615 \\
0.000530\end{array}$ & $\begin{array}{l}346570.000 \\
346570.000 \\
346570.000 \\
346570.000 \\
346570.000 \\
346570.000 \\
346570.000 \\
346570.000 \\
346570.000 \\
346570.000 \\
346570.000 \\
346570.000 \\
346570.000 \\
346570.000 \\
346570.000 \\
346570.000 \\
346570.000 \\
346570.000 \\
346570.000 \\
346570.000 \\
346570.000 \\
346570.000 \\
346570.000 \\
346570.000\end{array}$ & $\begin{array}{l}\text { UAT_RAD } \\
\text { HAT_RAD } \\
\text { UAT_RAD } \\
\text { WAT_RAD } \\
\text { WAT_RAD } \\
\text { UAT_RAD } \\
\text { HAT_RAD } \\
\text { HAT_RAD } \\
\text { WAT_RAD } \\
\text { WAT_RAD } \\
\text { WAT_RAD } \\
\text { UAT_RAD } \\
\text { UAT_RAD } \\
\text { UAT_RAD } \\
\text { WAT_RAD } \\
\text { WAT_RAD } \\
\text { WAT_RAD } \\
\text { WAT_RAD } \\
\text { WAT_RAD } \\
\text { WAT_RAD } \\
\text { WAT_RAD } \\
\text { WAT_RAD } \\
\text { WAT_RAD } \\
\text { WAT_RAD }\end{array}$ \\
\hline Thorium-228 & LMB & 1 & 1 & 1.25 & 1.25 & 0.000916 & 1365.0000 & HAT_RAD \\
\hline Thorium-230 & LMB & 1 & 1 & 0.17 & 0.17 & 0.000080 & 2064.0000 & WAT_RAD \\
\hline Thorium-232 & LHB & 1 & 1 & 0.01 & 0.01 & 0.000004 & 2389.0000 & HAT_RAD \\
\hline Tritiun & $\begin{array}{l}\text { IC } \\
\text { IWC } \\
\text { BWC } \\
\text { HRT } \\
\text { IHP } \\
\text { LMB } \\
\text { LWC } \\
\text { NHC } \\
\text { HWT } \\
\text { RAC } \\
\text { UHB } \\
\text { W4T } \\
\text { WOL } \\
\text { HS } \\
\text { IC } \\
\text { IWC }\end{array}$ & $\begin{array}{r}9 \\
3 \\
2 \\
52 \\
16 \\
147 \\
24 \\
34 \\
3 \\
2 \\
15 \\
110 \\
15 \\
10 \\
1 \\
1\end{array}$ & $\begin{array}{r}9 \\
3 \\
2 \\
51 \\
16 \\
147 \\
24 \\
34 \\
3 \\
2 \\
15 \\
110 \\
15 \\
10 \\
1 \\
1\end{array}$ & $\begin{array}{r}1.15 \\
11.54 \\
1.57 \\
1784.99 \\
8.50 \\
751.34 \\
132.94 \\
28.33 \\
0.49 \\
1.34 \\
17.62 \\
11631.42 \\
156.62 \\
49.55 \\
1.68 \\
4.94\end{array}$ & $\begin{array}{r}2.03 \\
27.71 \\
6.75 \\
2190.70 \\
12.23 \\
816.59 \\
156.69 \\
33.13 \\
1.21 \\
5.25 \\
26.87 \\
13062.04 \\
191.31 \\
115.28 \\
1.68 \\
4.94\end{array}$ & $\begin{array}{l}0.000000 \\
0.000000 \\
0.000000 \\
0.000001 \\
0.000000 \\
0.000000 \\
0.000000 \\
0.000000 \\
0.000000 \\
0.000000 \\
0.000000 \\
0.000004 \\
0.000000 \\
0.000000 \\
0.000000 \\
0.000000\end{array}$ & $\begin{array}{l}3445329521 \\
3445329521 \\
3445329521 \\
3445329521 \\
3445329521 \\
3445329521 \\
3445329521 \\
3445329521 \\
3445329521 \\
3445329521 \\
3445329521 \\
3445329521 \\
3445329521 \\
3445329521 \\
3445329521 \\
3445329521\end{array}$ & $\begin{array}{l}\text { WAT_RAD } \\
\text { WAT_RAD } \\
\text { WAT_RAD } \\
\text { WAT_RAD } \\
\text { WAT_RAD } \\
\text { WAT_RAD } \\
\text { WAT_RAD } \\
\text { WAT_RAD } \\
\text { WAT_RAD } \\
\text { WAT_RAD } \\
\text { WAT_RAD } \\
\text { WAT_RAD } \\
\text { WAT_RAD } \\
\text { WAT_RAD } \\
\text { WAT_RAD } \\
\text { WAT_RAD }\end{array}$ \\
\hline
\end{tabular}


B-33

\begin{tabular}{lrrrrrrrr} 
& HRT & 1 & 1 & 1.88 & 1.88 & 0.000000 & 3445329521 & WAT_RAD \\
& IHP & 6 & 6 & 10.01 & 17.44 & 0.000000 & 3445329521 & HAT_RAD \\
& LMB & 8 & 8 & 1111.21 & 1514.15 & 0.000000 & 3445329521 & WAT_RAD \\
& MHC & 10 & 10 & 28.34 & 38.52 & 0.00000 & 3445329521 & HAT_RAD \\
& RAC & 1 & 1 & 0.81 & 0.81 & 0.000000 & 3445329521 & WAT_RAD \\
& HOL & 9 & 9 & 151.34 & 199.66 & 0.000000 & 3445329521 & HAT_RAD \\
Uranium-235 & LMB & 1 & 1 & 0.03 & 0.03 & 0.000001 & 21833.0000 & HAT_RAD \\
Uranium-238 & LMB & 1 & 1 & 0.53 & 0.53 & 0.000023 & 22727.0000 & HAT RAD \\
\hline
\end{tabular}


Table B.4. Screening of aqueous concentrations of radionuclides detected in seeps and ephemeral tributaries against screening benchmarks for aquatic life. Concentrations are $\mathrm{pCi} / \mathrm{L}$.

\begin{tabular}{|c|c|c|c|c|c|c|c|c|c|}
\hline Radionucl ide & Reach & Seep ID & Samples & Detects & P.L. Mean & $95 \%$ UCB & $\begin{array}{c}\text { Quotient } \\
\text { Value }\end{array}$ & Benchmark & Benchmark \\
\hline Cesium-137 & $\begin{array}{l}\text { LWC } \\
\text { LHC } \\
\text { LWC } \\
\text { H4T } \\
\text { W4T } \\
\text { W4T } \\
\text { HS } \\
\text { WS } \\
\text { HS }\end{array}$ & $\begin{array}{l}\text { SH7-4 } \\
\text { SH7-6 } \\
\text { HCTR1B-1 } \\
\text { BTT } \\
\text { SW4-2 } \\
\text { WAG4 T2A } \\
\text { RS-1 } \\
\text { RS-3B } \\
\text { SW7-2 }\end{array}$ & $\begin{array}{l}1 \\
2 \\
3 \\
5 \\
5 \\
4 \\
1 \\
2 \\
2\end{array}$ & $\begin{array}{l}1 \\
2 \\
1 \\
5 \\
5 \\
4 \\
1 \\
1 \\
1\end{array}$ & $\begin{array}{r}28.50 \\
304.30 \\
29.20 \\
300.29 \\
247.79 \\
254.11 \\
35.90 \\
13.30 \\
43.20\end{array}$ & $\begin{array}{r}28.50 \\
529.07 \\
29.20 \\
690.41 \\
450.83 \\
401.08 \\
35.90 \\
13.30 \\
43.20\end{array}$ & $\begin{array}{l}0.00075 \\
0.01397 \\
0.00077 \\
0.01823 \\
0.01190 \\
0.01059 \\
0.00095 \\
0.00035 \\
0.00114\end{array}$ & $\begin{array}{l}37882.0000 \\
37882.0000 \\
37882.0000 \\
37882.0000 \\
37882.0000 \\
37882.0000 \\
37882.0000 \\
37882.0000 \\
37882.0000\end{array}$ & $\begin{array}{l}\text { WAT_RAD } \\
\text { HAT_RAD } \\
\text { HAT_RAD } \\
\text { WAT_RAD } \\
\text { HAT_RAD } \\
\text { WAT_RAD } \\
\text { WAT_RAD } \\
\text { HAT_RAD } \\
\text { HAT_RAD }\end{array}$ \\
\hline Cobalt -60 & $\begin{array}{l}\text { LHC } \\
\text { LHC } \\
\text { LHC } \\
\text { LHC } \\
\text { LHC } \\
\text { WS } \\
\text { HS } \\
\text { WS } \\
\text { HS }\end{array}$ & $\begin{array}{l}\text { EAST SEEP } \\
\text { SW7-3 } \\
\text { SW7-4 } \\
\text { SW7-5 } \\
\text { HCTRIB-1 } \\
\text { RS-3A } \\
\text { RS-3B } \\
\text { SW7-2 } \\
\text { WS-2 }\end{array}$ & $\begin{array}{l}7 \\
8 \\
1 \\
6 \\
3 \\
8 \\
2 \\
2 \\
2\end{array}$ & $\begin{array}{l}6 \\
8 \\
1 \\
6 \\
2 \\
8 \\
2 \\
2 \\
1\end{array}$ & $\begin{array}{r}166.51 \\
653.45 \\
179.30 \\
2550.38 \\
65.27 \\
835.72 \\
97.05 \\
1172.20 \\
111.80\end{array}$ & $\begin{array}{r}222.17 \\
1057.22 \\
179.30 \\
5002.84 \\
89.77 \\
972.64 \\
364.44 \\
2869.34 \\
111.80\end{array}$ & $\begin{array}{l}0.00044 \\
0.00207 \\
0.00035 \\
0.00980 \\
0.00018 \\
0.00191 \\
0.00071 \\
0.00562 \\
0.00022\end{array}$ & $\begin{array}{l}510314.000 \\
510314.000 \\
510314.000 \\
510314.000 \\
510314.000 \\
510314.000 \\
510314.000 \\
510314.000 \\
510314.000\end{array}$ & $\begin{array}{l}\text { WAT_RAD } \\
\text { WAT_RAD } \\
\text { WAT_RAD } \\
\text { WAT_RAD } \\
\text { HAT_RAD } \\
\text { WAT_RAD } \\
\text { WAT_RAD } \\
\text { WAT_RAD } \\
\text { WAT_RAD }\end{array}$ \\
\hline Plutonium-238 & $\begin{array}{l}\text { LMB } \\
\text { LWC } \\
\text { W4T } \\
\text { W4T } \\
\text { W4T } \\
\text { W4T } \\
\text { WS } \\
\text { WS } \\
\text { WS }\end{array}$ & $\begin{array}{l}\text { SW5-4 } \\
\text { SW7-3 } \\
\text { BTT } \\
\text { SW4-1 } \\
\text { SW4-2 } \\
\text { WAG4 MS1 } \\
\text { RS-1 } \\
\text { RS-3A } \\
\text { RS-3B }\end{array}$ & $\begin{array}{l}1 \\
1 \\
1 \\
1 \\
1 \\
1 \\
1 \\
1 \\
1\end{array}$ & $\begin{array}{l}1 \\
1 \\
1 \\
1 \\
1 \\
1 \\
1 \\
1 \\
1\end{array}$ & $\begin{array}{l}0.45 \\
0.02 \\
0.03 \\
0.16 \\
0.00 \\
0.04 \\
0.11 \\
0.16 \\
0.23\end{array}$ & $\begin{array}{r}0.45 \\
0.02 \\
0.03 \\
0.16 \\
-0.07 \\
0.04 \\
0.11 \\
0.16 \\
0.23\end{array}$ & $\begin{array}{r}0.00008 \\
0.00000 \\
0.00000 \\
0.00003 \\
-0.00001 \\
0.00001 \\
0.00002 \\
\hat{0} .0 \overline{0} 003 \\
0.00004\end{array}$ & $\begin{array}{l}5845.0000 \\
5845.0000 \\
5845.0000 \\
5845.0000 \\
5845.0000 \\
5845.0000 \\
5845.0000 \\
5845.0000 \\
5845.0000\end{array}$ & $\begin{array}{l}\text { HAT_RAD } \\
\text { HAT_RAD } \\
\text { HAT_RAD } \\
\text { WAT_RAD } \\
\text { HAT_RAD } \\
\text { HAT_RAD } \\
\text { WAT_RAD } \\
\text { WAT_RAD } \\
\text { HAT_RAD }\end{array}$ \\
\hline Strontium-90 & $\begin{array}{l}\text { LMB } \\
\text { LMB } \\
\text { LWC } \\
\text { Unknown } \\
\text { Unknown } \\
\text { H4T } \\
\text { W4T } \\
\text { H4T } \\
\text { W4T } \\
\text { WOL } \\
\text { WS } \\
\text { LMB } \\
\text { LMB }\end{array}$ & $\begin{array}{l}\text { MID. DRAIH. } \\
\text { SW2-5 } \\
\text { EAST SEEP } \\
\text { SH2-6 } \\
\text { SH2-7 } \\
\text { BTT } \\
\text { SW4-2 } \\
\text { HAG4 MS1 } \\
\text { HAG4 T2A } \\
\text { HAG6 MS3 } \\
\text { WS-1 } \\
\text { MID. DRAIH. } \\
\text { SW5-4 }\end{array}$ & $\begin{array}{l}2 \\
3 \\
3 \\
1 \\
2 \\
1 \\
1 \\
2 \\
1 \\
1 \\
1 \\
3 \\
2\end{array}$ & $\begin{array}{l}2 \\
3 \\
1 \\
1 \\
2 \\
1 \\
1 \\
2 \\
1 \\
1 \\
1 \\
3 \\
2\end{array}$ & $\begin{array}{r}2333.25 \\
163422.33 \\
68.00 \\
564388.00 \\
186311.50 \\
19733.00 \\
13100.00 \\
11123.00 \\
9138.00 \\
248.00 \\
196.00 \\
1516.67 \\
355176.00\end{array}$ & $\begin{array}{r}2483.20 \\
176320.66 \\
68.00 \\
564388.00 \\
672088.38 \\
19733.00 \\
13100.00 \\
21250.26 \\
9138.00 \\
248.00 \\
196.00 \\
1835.79 \\
854612.69\end{array}$ & $\begin{array}{l}0.00717 \\
0.50876 \\
0.00020 \\
1.62850 \\
1.93926 \\
0.05694 \\
0.03780 \\
0.06132 \\
0.02637 \\
0.00072 \\
0.00057 \\
0.00530 \\
2.46592\end{array}$ & $\begin{array}{l}346570.000 \\
346570.000 \\
346570.000 \\
346570.000 \\
346570.000 \\
346570.000 \\
346570.000 \\
346570.000 \\
346570.000 \\
346570.000 \\
346570.000 \\
346570.000 \\
346570.000\end{array}$ & $\begin{array}{l}\text { WAT_RAD } \\
\text { HAT_RAD } \\
\text { HAT_RAD } \\
\text { WAT_RAD } \\
\text { HAT_RAD } \\
\text { WAT_RAD } \\
\text { WAT_RAD } \\
\text { HAT_RAD } \\
\text { WAT_RAD } \\
\text { WAT_RAD } \\
\text { WAT_RAD } \\
\text { WAT_RAD } \\
\text { WAT_RAD }\end{array}$ \\
\hline
\end{tabular}




\begin{tabular}{|c|c|c|c|c|c|c|c|c|c|}
\hline & $\begin{array}{l}\text { UMC } \\
\text { H4T } \\
\text { H4T } \\
\text { HS } \\
\text { HS } \\
\text { HOL } \\
\text { HS } \\
\text { HS } \\
\text { HS } \\
\text { HS }\end{array}$ & $\begin{array}{l}\text { SH2-2 } \\
\text { HAG4 MS1 } \\
\text { HAG4 T2A } \\
\text { RS-3A } \\
\text { RS-3B } \\
\text { HAG6 MS3 } \\
\text { HS-1 } \\
\text { HS-2 } \\
\text { HS-3 } \\
\text { HSTRIB-1 }\end{array}$ & $\begin{array}{l}1 \\
3 \\
3 \\
4 \\
2 \\
1 \\
3 \\
2 \\
2 \\
3\end{array}$ & $\begin{array}{l}1 \\
3 \\
3 \\
4 \\
2 \\
1 \\
3 \\
2 \\
2 \\
3\end{array}$ & $\begin{array}{r}562.00 \\
10214.67 \\
7481.83 \\
5.54 \\
28.70 \\
280.00 \\
138.97 \\
159.50 \\
196.50 \\
156.20\end{array}$ & $\begin{array}{r}562.00 \\
12498.47 \\
8923.30 \\
80.05 \\
115.83 \\
280.00 \\
210.84 \\
206.85 \\
395.38 \\
257.66\end{array}$ & $\begin{array}{l}0.00162 \\
0.03606 \\
0.02575 \\
0.0002 \\
0.00033 \\
0.00081 \\
0.00061 \\
0.00060 \\
0.00114 \\
0.00074\end{array}$ & $\begin{array}{l}346570.000 \\
346570.000 \\
346570.000 \\
346570.000 \\
346570.000 \\
346570.000 \\
346570.000 \\
346570.000 \\
346570.000 \\
346570.000\end{array}$ & $\begin{array}{l}\text { HAT_RAD } \\
\text { HAT_RAD } \\
\text { HAT_RD } \\
\text { HAT_RAD } \\
\text { HAT_RAD } \\
\text { HAT_RAD } \\
\text { HAT_RAD } \\
\text { HAT_RAD } \\
\text { HAT_RAD } \\
\text { HAT_RAD }\end{array}$ \\
\hline Thorium-228 & $\begin{array}{l}\text { LMB } \\
\text { LWC } \\
\text { H4T } \\
\text { H4T } \\
\text { H4T } \\
\text { H4T } \\
\text { WS } \\
\text { HS } \\
\text { WS }\end{array}$ & $\begin{array}{l}\text { SH5-4 } \\
\text { SH7-3 } \\
\text { BTT } \\
\text { SH4-1 } \\
\text { SH4-2 } \\
\text { HAG4 MS1 } \\
\text { RS-1 } \\
\text { RS-3A } \\
\text { RS-3B }\end{array}$ & $\begin{array}{l}1 \\
1 \\
1 \\
1 \\
1 \\
1 \\
1 \\
1 \\
1\end{array}$ & $\begin{array}{l}1 \\
1 \\
1 \\
1 \\
1 \\
1 \\
1 \\
1 \\
1\end{array}$ & $\begin{array}{l}0.68 \\
1.04 \\
2.35 \\
0.95 \\
1.30 \\
3.50 \\
0.00 \\
0.00 \\
0.00\end{array}$ & $\begin{array}{l}0.68 \\
1.04 \\
2.35 \\
0.95 \\
1.30 \\
3.50 \\
0.00 \\
0.00 \\
0.00\end{array}$ & $\begin{array}{l}0.00050 \\
0.00076 \\
0.00172 \\
0.00070 \\
0.00095 \\
0.00256 \\
0.00000 \\
0.00000 \\
0.00000\end{array}$ & $\begin{array}{l}1365.0000 \\
1365.0000 \\
1365.0000 \\
1365.0000 \\
1365.0000 \\
1365.0000 \\
1365.0000 \\
1365.0000 \\
1365.0000\end{array}$ & $\begin{array}{l}\text { HAT_RAD } \\
\text { HAT-RAD } \\
\text { HAT RAD } \\
\text { HAT-RAD } \\
\text { HAT-RAD } \\
\text { WAT-RAD } \\
\text { WAT-RAD } \\
\text { HAT RAD } \\
\text { HAT_RAD }\end{array}$ \\
\hline Thorium-230 & $\begin{array}{l}\text { LMB } \\
\text { LWC } \\
\text { H4T } \\
\text { H4T } \\
\text { H4T } \\
\text { W4T } \\
\text { HS } \\
\text { HS } \\
\text { WS }\end{array}$ & $\begin{array}{l}\text { SH5-4 } \\
\text { SH7-3 } \\
\text { BTT } \\
\text { SH4-1 } \\
\text { SH4-2 } \\
\text { HAG4 HS1 } \\
\text { RS-1 } \\
\text { RS-3A } \\
\text { RS-3B }\end{array}$ & $\begin{array}{l}1 \\
1 \\
1 \\
1 \\
1 \\
1 \\
1 \\
1 \\
1\end{array}$ & $\begin{array}{l}1 \\
1 \\
1 \\
1 \\
1 \\
1 \\
1 \\
1 \\
1\end{array}$ & $\begin{array}{l}0.08 \\
0.12 \\
0.04 \\
0.12 \\
0.14 \\
0.08 \\
0.12 \\
0.21 \\
0.09\end{array}$ & $\begin{array}{l}0.08 \\
0.12 \\
0.04 \\
0.12 \\
0.14 \\
0.08 \\
0.12 \\
0.21 \\
0.09\end{array}$ & $\begin{array}{l}0.00004 \\
0.00006 \\
0.00002 \\
0.00006 \\
0.00007 \\
0.00004 \\
0.00006 \\
0.00010 \\
0.00004\end{array}$ & $\begin{array}{l}2064.0000 \\
2064.0000 \\
2064.0000 \\
2064.0000 \\
2064.0000 \\
2064.0000 \\
2064.0000 \\
2064.0000 \\
2064.0000\end{array}$ & $\begin{array}{l}\text { HAT_RAD } \\
\text { WAT-RAD } \\
\text { HAT_RAD } \\
\text { HAT-RAD } \\
\text { HAT_RAD } \\
\text { HAT_RAD } \\
\text { HAT-RAD } \\
\text { HAT RRD } \\
\text { HAT_RAD }\end{array}$ \\
\hline Thor ium-232 & $\begin{array}{l}\text { LMB } \\
\text { LHC } \\
\text { H4T } \\
\text { W4T } \\
\text { H4T } \\
\text { H4T } \\
\text { HS } \\
\text { HS } \\
\text { HS }\end{array}$ & $\begin{array}{l}\text { SH5-4 } \\
\text { SH7-3 } \\
\text { BTT } \\
\text { SH4-1 } \\
\text { SH4-2 } \\
\text { HAG4 MS1 } \\
\text { RS-1 } \\
\text { RS-3A } \\
\text { RS-3B }\end{array}$ & $\begin{array}{l}1 \\
1 \\
1 \\
1 \\
1 \\
1 \\
1 \\
1 \\
1\end{array}$ & $\begin{array}{l}1 \\
1 \\
1 \\
1 \\
1 \\
1 \\
1 \\
1 \\
1\end{array}$ & $\begin{array}{l}0.04 \\
0.02 \\
0.00 \\
0.01 \\
0.03 \\
0.04 \\
0.00 \\
0.20 \\
0.04\end{array}$ & $\begin{array}{r}0.04 \\
0.02 \\
-0.01 \\
0.01 \\
0.03 \\
0.04 \\
0.00 \\
0.20 \\
0.04\end{array}$ & $\begin{array}{r}0.00002 \\
0.00001 \\
-0.00000 \\
0.00000 \\
0.00001 \\
0.00002 \\
0.00000 \\
0.00008 \\
0.00002\end{array}$ & $\begin{array}{l}2389.0000 \\
2389.0000 \\
2389.0000 \\
2389.0000 \\
2389.0000 \\
2389.0000 \\
2389.0000 \\
2389.0000 \\
2389.0000\end{array}$ & $\begin{array}{l}\text { HAT_RAD } \\
\text { HAT_RAD } \\
\text { HAT-RAD } \\
\text { HAT-RAD } \\
\text { HAT_RAD } \\
\text { HAT_RAD } \\
\text { HAT-RAD } \\
\text { HAT RAD } \\
\text { HAT_RAD }\end{array}$ \\
\hline Tritium & $\begin{array}{l}\text { EHC } \\
\text { IHP } \\
\text { LMB } \\
\text { LMB } \\
\text { LMB } \\
\text { LMB } \\
\text { LMB } \\
\text { LHC } \\
\text { LHC } \\
\text { LHC }\end{array}$ & $\begin{array}{l}\text { HOCET } \\
\text { HCTRIB-3 } \\
\text { MBTRIB-3 } \\
\text { MID. DRAIH. } \\
\text { SH2-5 } \\
\text { SH5-2 } \\
\text { SH5-4 } \\
\text { EAST SEEP } \\
\text { MV-1 } \\
\text { SH7-3 }\end{array}$ & $\begin{array}{r}2 \\
2 \\
3 \\
10 \\
10 \\
2 \\
7 \\
10 \\
1 \\
4\end{array}$ & $\begin{array}{r}2 \\
2 \\
3 \\
10 \\
10 \\
2 \\
7 \\
7 \\
10 \\
1 \\
4\end{array}$ & $\begin{array}{r}0.81 \\
103.19 \\
2.59 \\
7387.80 \\
9420.15 \\
20.20 \\
4792.71 \\
24.81 \\
1.80 \\
21.46\end{array}$ & $\begin{array}{r}2.96 \\
273.12 \\
3.35 \\
8140.39 \\
10890.74 \\
42.42 \\
5825.63 \\
30.86 \\
1.80 \\
29.73\end{array}$ & $\begin{array}{l}0.00000 \\
0.00000 \\
0.00000 \\
0.00000 \\
0.00000 \\
0.00000 \\
0.00000 \\
0.00000 \\
0.00000 \\
0.00000\end{array}$ & $\begin{array}{l}3445329521 \\
3445329521 \\
3445329521 \\
3445329521 \\
3445329521 \\
3445329521 \\
3445329521 \\
3445329521 \\
344529521 \\
3445329521\end{array}$ & $\begin{array}{l}\text { HAT_RAD } \\
\text { HAT-RAD } \\
\text { HAT RAD } \\
\text { HAT RAD } \\
\text { HAT_RAD } \\
\text { HAT_RAD } \\
\text { HAT_RAD } \\
\text { HAT_RAD } \\
\text { HAT_RAD } \\
\text { HAT_RAD }\end{array}$ \\
\hline
\end{tabular}




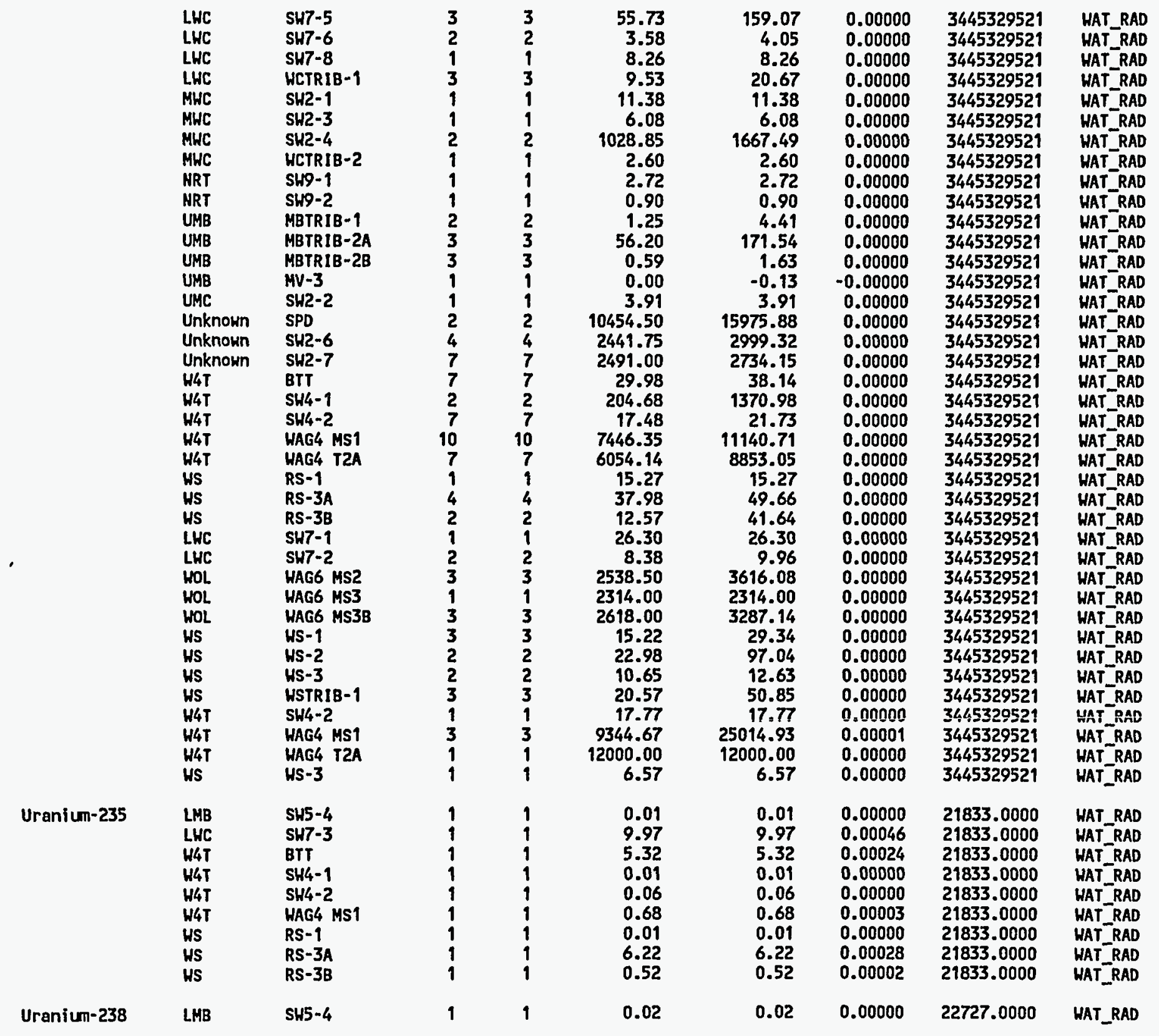




$\begin{array}{llllrrrrr}\text { LHC } & \text { SH7-3 } & 1 & 1 & 76.30 & 76.30 & 0.00336 & 22727.0000 & \text { WAT_RAD } \\ \text { W4T } & \text { BTT } & 1 & 1 & 84.20 & 84.20 & 0.00370 & 22727.0000 & \text { HAT_RAD } \\ \text { H4T } & \text { SH4-1 } & 1 & 1 & 2.43 & 2.43 & 0.00011 & 22727.0000 & \text { UAT_RAD } \\ \text { H4T } & \text { SH4-2 } & 1 & 1 & 0.41 & 0.41 & 0.00002 & 22727.0000 & \text { HAT_RAD } \\ \text { H4T } & \text { HAG4 MS1 } & 1 & 1 & 13.00 & 13.00 & 0.00057 & 22727.0000 & \text { WAT_RAD } \\ \text { WS } & \text { RS-1 } & 1 & 1 & 0.18 & 0.18 & 0.00001 & 22727.0000 & \text { HAT_RAD } \\ \text { HS } & \text { RS-3A } & 1 & 1 & 64.20 & 64.20 & 0.00282 & 22727.0000 & \text { WAT_RAD } \\ \text { HS } & \text { RS-3B } & 1 & 1 & 6.64 & 6.64 & 0.00029 & 22727.0000 & \text { HAT_RAD }\end{array}$


Table B.5. Screening of aqueous concentrations of chemicals (including radionuclides) detected in sediments against screening benchmarks for benthic invertebrates (Hull and suter 1996). All concentrations are $\mathrm{mg} / \mathrm{L}$. See Table 4.1 for definitions of benchmarks.

\begin{tabular}{|c|c|c|c|c|c|c|c|c|}
\hline Chemical & Benchmark & Reach & Samples & tects & P.L. Mean & Maximum & Quotient & $\begin{array}{c}\text { Benchmark } \\
\text { Value }\end{array}$ \\
\hline 2-Methylnaphthalene & ER_L & $\begin{array}{l}\text { IHP } \\
\text { LWC }\end{array}$ & $\begin{array}{l}5 \\
7\end{array}$ & $\begin{array}{l}2 \\
1\end{array}$ & $\begin{array}{l}0.03 \\
0.08\end{array}$ & $\begin{array}{l}0.030830 \\
0.083000\end{array}$ & $\begin{array}{l}0.440423 \\
1.185714\end{array}$ & $\begin{array}{l}0.070000 \\
0.070000\end{array}$ \\
\hline 2-Methylnaphthalene & ER_M & $\begin{array}{l}\text { IHP } \\
\text { LHC }\end{array}$ & $\begin{array}{l}5 \\
7\end{array}$ & $\begin{array}{l}2 \\
1\end{array}$ & $\begin{array}{l}0.03 \\
0.08\end{array}$ & $\begin{array}{l}0.030830 \\
0.083000\end{array}$ & $\begin{array}{l}0.046014 \\
0.123881\end{array}$ & $\begin{array}{l}0.670000 \\
0.670000\end{array}$ \\
\hline 2-Methylnaphthalene & REG_IV & $\begin{array}{l}\text { IHP } \\
\text { LWC }\end{array}$ & $\begin{array}{l}5 \\
7\end{array}$ & 2 & $\begin{array}{l}0.03 \\
0.08\end{array}$ & $\begin{array}{l}0.030830 \\
0.083000\end{array}$ & $\begin{array}{l}0.093423 \\
0.251515\end{array}$ & $\begin{array}{l}0.330000 \\
0.330000\end{array}$ \\
\hline 2-Methylnaphthalene & SED_PEL. & $\begin{array}{l}\text { IHP } \\
\text { LHC }\end{array}$ & $\begin{array}{l}5 \\
7\end{array}$ & $\begin{array}{l}2 \\
1\end{array}$ & $\begin{array}{l}0.03 \\
0.08\end{array}$ & $\begin{array}{l}0.030830 \\
0.083000\end{array}$ & $\begin{array}{l}0.153381 \\
0.412935\end{array}$ & $\begin{array}{l}0.201000 \\
0.201000\end{array}$ \\
\hline 2-Methylnaph thalene & SED_TEL & $\begin{array}{l}\text { IHP } \\
\text { LHC }\end{array}$ & $\begin{array}{l}5 \\
7\end{array}$ & $\begin{array}{l}2 \\
1\end{array}$ & $\begin{array}{l}0.03 \\
0.08\end{array}$ & $\begin{array}{l}0.030830 \\
0.083000\end{array}$ & $\begin{array}{l}1.526219 \\
4.108911\end{array}$ & $\begin{array}{l}0.020200 \\
0.020200\end{array}$ \\
\hline 4-Methylphenol & AET & IHP & 5 & 1 & 0.22 & 0.220000 & 0.328358 & 0.670000 \\
\hline$A M-241$ & SED_RAD & $\begin{array}{l}\text { IHP } \\
\text { LMB } \\
\text { LHC } \\
\text { MHC }\end{array}$ & $\begin{array}{l}\mathbf{5} \\
\mathbf{5} \\
4 \\
\mathbf{2}\end{array}$ & $\begin{array}{l}5 \\
1 \\
4 \\
2\end{array}$ & $\begin{array}{l}1.99 \\
0.13 \\
2.65 \\
2.95\end{array}$ & $\begin{array}{l}3.115066 \\
0.130000 \\
7.968475 \\
4.528438\end{array}$ & $\begin{array}{l}0.000764 \\
0.000032 \\
0.001955 \\
0.001111\end{array}$ & $\begin{array}{l}4076.000000 \\
4076.000000 \\
4076.000000 \\
4076.000000\end{array}$ \\
\hline Acenaphthene & EPASAC_A & $\begin{array}{l}\text { IHP } \\
\text { LHC } \\
\text { MHC }\end{array}$ & $\begin{array}{l}5 \\
7 \\
4\end{array}$ & $\begin{array}{l}2 \\
2 \\
1\end{array}$ & $\begin{array}{l}0.08 \\
0.06 \\
0.54\end{array}$ & $\begin{array}{l}0.187724 \\
0.125011 \\
0.540000\end{array}$ & $\begin{array}{l}0.144403 \\
0.096163 \\
0.415385\end{array}$ & $\begin{array}{l}1.300000 \\
1.300000 \\
1.300000\end{array}$ \\
\hline Acenaphthene & ER_L & $\begin{array}{l}\text { IHP } \\
\text { LWC } \\
\text { MHC }\end{array}$ & $\begin{array}{l}5 \\
7 \\
4\end{array}$ & $\begin{array}{l}2 \\
2 \\
1\end{array}$ & $\begin{array}{l}0.08 \\
0.06 \\
0.54\end{array}$ & $\begin{array}{l}0.187724 \\
0.125011 \\
0.540000\end{array}$ & $\begin{array}{r}11.732762 \\
7.813207 \\
33.750000\end{array}$ & $\begin{array}{l}0.016000 \\
0.016000 \\
0.016000\end{array}$ \\
\hline Acenaphthene & ER_M & $\begin{array}{l}\text { IHP } \\
\text { LHC } \\
\text { HWC }\end{array}$ & $\begin{array}{l}5 \\
7 \\
4\end{array}$ & $\begin{array}{l}2 \\
2 \\
1\end{array}$ & $\begin{array}{l}0.08 \\
0.06 \\
0.54\end{array}$ & $\begin{array}{l}0.187724 \\
0.125011 \\
0.540000\end{array}$ & $\begin{array}{l}0.375448 \\
0.250023 \\
1.080000\end{array}$ & $\begin{array}{l}0.500000 \\
0.500000 \\
0.500000\end{array}$ \\
\hline Acenaphthene & REG_IV & $\begin{array}{l}\text { IHP } \\
\text { LHC } \\
\text { MHC }\end{array}$ & $\begin{array}{l}5 \\
7 \\
4\end{array}$ & $\begin{array}{l}2 \\
2 \\
1\end{array}$ & $\begin{array}{l}0.08 \\
0.06 \\
0.54\end{array}$ & $\begin{array}{l}0.187724 \\
0.125011 \\
0.540000\end{array}$ & $\begin{array}{l}0.568861 \\
0.378822 \\
1.636364\end{array}$ & $\begin{array}{l}0.330000 \\
0.330000 \\
0.330000\end{array}$ \\
\hline Acenaphthene & SED_PEL & $\begin{array}{l}\text { IHP } \\
\text { LWC } \\
\text { MHC }\end{array}$ & $\begin{array}{l}5 \\
7 \\
4\end{array}$ & $\begin{array}{l}2 \\
2 \\
1\end{array}$ & $\begin{array}{l}0.08 \\
0.06 \\
0.54\end{array}$ & $\begin{array}{l}0.187724 \\
0.125011 \\
0.540000\end{array}$ & $\begin{array}{l}2.111633 \\
1.406201 \\
6.074241\end{array}$ & $\begin{array}{l}0.088900 \\
0.088900 \\
0.088900\end{array}$ \\
\hline Acenaphthene & SED_TEL. & $\begin{array}{l}\text { IHP } \\
\text { LWC } \\
\text { MWC }\end{array}$ & $\begin{array}{l}5 \\
7 \\
4\end{array}$ & $\begin{array}{l}2 \\
2 \\
1\end{array}$ & $\begin{array}{l}0.08 \\
0.06 \\
0.54\end{array}$ & $\begin{array}{l}0.187724 \\
0.125011 \\
0.540000\end{array}$ & $\begin{array}{l}27.976779 \\
18.630598 \\
80.476902\end{array}$ & $\begin{array}{l}0.006710 \\
0.006710 \\
0.006710\end{array}$ \\
\hline
\end{tabular}




\begin{tabular}{|c|c|c|c|c|c|c|c|c|}
\hline Anthracene & EQPSQB_A & $\begin{array}{l}\text { IHP } \\
\text { LWC } \\
\text { MWC }\end{array}$ & $\begin{array}{l}5 \\
7 \\
4\end{array}$ & $\begin{array}{l}2 \\
2 \\
2\end{array}$ & $\begin{array}{l}0.13 \\
0.06 \\
0.28\end{array}$ & $\begin{array}{l}0.325262 \\
0.095920 \\
0.706312\end{array}$ & $\begin{array}{r}1084.205837 \\
319.734751 \\
2354.373817\end{array}$ & $\begin{array}{l}0.000300 \\
0.000300 \\
0.000300\end{array}$ \\
\hline Anthracene & ER_L & $\begin{array}{l}\text { IHP } \\
\text { LHC } \\
\text { MHC }\end{array}$ & $\begin{array}{l}5 \\
7 \\
4\end{array}$ & $\begin{array}{l}2 \\
2 \\
2\end{array}$ & $\begin{array}{l}0.13 \\
0.06 \\
0.28\end{array}$ & $\begin{array}{l}0.325262 \\
0.095920 \\
0.706312\end{array}$ & $\begin{array}{l}3.826609 \\
1.128476 \\
8.309555\end{array}$ & $\begin{array}{l}0.085000 \\
0.085000 \\
0.085000\end{array}$ \\
\hline Anthracene & ER_M & $\begin{array}{l}\text { IHP } \\
\text { LWC } \\
\text { MHC }\end{array}$ & $\begin{array}{l}5 \\
7 \\
4\end{array}$ & $\begin{array}{l}2 \\
2 \\
2\end{array}$ & $\begin{array}{l}0.13 \\
0.06 \\
0.28\end{array}$ & $\begin{array}{l}0.325262 \\
0.095920 \\
0.706312\end{array}$ & $\begin{array}{l}0.295693 \\
0.087200 \\
0.642102\end{array}$ & $\begin{array}{l}1.100000 \\
1.100000 \\
1.100000\end{array}$ \\
\hline Anthracene & REG_IV & $\begin{array}{l}\text { IHP } \\
\text { LWC } \\
\text { MHC }\end{array}$ & $\begin{array}{l}5 \\
7 \\
4\end{array}$ & $\begin{array}{l}2 \\
2 \\
2\end{array}$ & $\begin{array}{l}0.13 \\
0.06 \\
0.28\end{array}$ & $\begin{array}{l}0.325262 \\
0.095920 \\
0.706312\end{array}$ & $\begin{array}{l}0.985642 \\
0.290668 \\
2.140340\end{array}$ & $\begin{array}{l}0.330000 \\
0.330000 \\
0.330000\end{array}$ \\
\hline Anthracene & SED_PEL & $\begin{array}{l}\text { IHP } \\
\text { LWC } \\
\text { MHC }\end{array}$ & $\begin{array}{l}5 \\
7 \\
4\end{array}$ & $\begin{array}{l}2 \\
2 \\
2\end{array}$ & $\begin{array}{l}0.13 \\
0.06 \\
0.28\end{array}$ & $\begin{array}{l}0.325262 \\
0.095920 \\
0.706312\end{array}$ & $\begin{array}{l}1.327599 \\
0.391512 \\
2.882907\end{array}$ & $\begin{array}{l}0.245000 \\
0.245000 \\
0.245000\end{array}$ \\
\hline Anthracene & SED_TEL & $\begin{array}{l}\text { IHP } \\
\text { LWC } \\
\text { MHC }\end{array}$ & $\begin{array}{l}5 \\
7 \\
4\end{array}$ & $\begin{array}{l}2 \\
2 \\
2\end{array}$ & $\begin{array}{l}0.13 \\
0.06 \\
0.28\end{array}$ & $\begin{array}{l}0.325262 \\
0.095920 \\
0.706312\end{array}$ & $\begin{array}{r}6.935218 \\
2.045212 \\
15.059960\end{array}$ & $\begin{array}{l}0.046900 \\
0.046900 \\
0.046900\end{array}$ \\
\hline Antimony & ER_L & $\begin{array}{l}\text { IHP } \\
\text { LMB } \\
\text { LWC } \\
\text { MWC }\end{array}$ & $\begin{array}{l}3 \\
5 \\
3 \\
2\end{array}$ & $\begin{array}{l}2 \\
5 \\
3 \\
2\end{array}$ & $\begin{array}{l}0.51 \\
0.92 \\
0.99 \\
0.58\end{array}$ & $\begin{array}{l}0.918798 \\
1.052792 \\
1.442676 \\
0.732844\end{array}$ & $\begin{array}{l}0.459399 \\
0.526396 \\
0.721338 \\
0.366422\end{array}$ & $\begin{array}{l}2.000000 \\
2.000000 \\
2.000000 \\
2.000000\end{array}$ \\
\hline Antimony & ER_M & $\begin{array}{l}\text { IHP } \\
\text { LMB } \\
\text { LHC } \\
\text { MHC }\end{array}$ & $\begin{array}{l}3 \\
5 \\
3 \\
2\end{array}$ & $\begin{array}{l}2 \\
5 \\
3 \\
2\end{array}$ & $\begin{array}{l}0.51 \\
0.92 \\
0.99 \\
0.58\end{array}$ & $\begin{array}{l}0.918798 \\
1.052792 \\
1.442676 \\
0.732844\end{array}$ & $\begin{array}{l}0.036752 \\
0.042112 \\
0.057707 \\
0.029314\end{array}$ & $\begin{array}{l}25.000000 \\
25.000000 \\
25.000000 \\
25.000000\end{array}$ \\
\hline Antimony & REG_IV & $\begin{array}{l}\text { IHP } \\
\text { LMB } \\
\text { LWC } \\
\text { HWC }\end{array}$ & $\begin{array}{l}3 \\
5 \\
3 \\
2\end{array}$ & $\begin{array}{l}2 \\
5 \\
3 \\
2\end{array}$ & $\begin{array}{l}0.51 \\
0.92 \\
0.99 \\
0.58\end{array}$ & $\begin{array}{l}0.918798 \\
1.052792 \\
1.442676 \\
0.732844\end{array}$ & $\begin{array}{l}0.076566 \\
0.087733 \\
0.120223 \\
0.061070\end{array}$ & $\begin{array}{l}12.000000 \\
12.000000 \\
12.000000 \\
12.000000\end{array}$ \\
\hline Aroclor-1254 & EAPSAB_A & $\begin{array}{l}\text { IHP } \\
\text { LHC }\end{array}$ & $\begin{array}{l}5 \\
7\end{array}$ & $\begin{array}{l}3 \\
1\end{array}$ & $\begin{array}{l}0.25 \\
0.05\end{array}$ & $\begin{array}{l}0.449889 \\
0.047000\end{array}$ & $\begin{array}{l}2.646404 \\
0.276471\end{array}$ & $\begin{array}{l}0.170000 \\
0.170000\end{array}$ \\
\hline Aroclor-1254 & ER_L & $\begin{array}{l}\text { IHP } \\
\text { LHC }\end{array}$ & $\begin{array}{l}5 \\
7\end{array}$ & $\begin{array}{l}3 \\
1\end{array}$ & $\begin{array}{l}0.25 \\
0.05\end{array}$ & $\begin{array}{l}0.449889 \\
0.047000\end{array}$ & $\begin{array}{r}19.560381 \\
2.043478\end{array}$ & $\begin{array}{l}0.023000 \\
0.023000\end{array}$ \\
\hline Aroclor-1254 & ER_H & $\begin{array}{l}\text { IHP } \\
\text { LHC }\end{array}$ & $\begin{array}{l}5 \\
7\end{array}$ & $\begin{array}{l}3 \\
1\end{array}$ & $\begin{array}{l}0.25 \\
0.05\end{array}$ & $\begin{array}{l}0.449889 \\
0.047000\end{array}$ & $\begin{array}{l}2.499382 \\
0.261111\end{array}$ & $\begin{array}{l}0.180000 \\
0.180000\end{array}$ \\
\hline Aroclor -1260 & EQPSQB_A & $\begin{array}{l}\text { IHP } \\
\text { LMB } \\
\text { L.WC }\end{array}$ & $\begin{array}{l}5 \\
4 \\
7\end{array}$ & $\begin{array}{l}5 \\
1 \\
3\end{array}$ & $\begin{array}{l}0.22 \\
0.04 \\
0.07\end{array}$ & $\begin{array}{l}0.381206 \\
0.038000 \\
0.152737\end{array}$ & $\begin{array}{l}0.000347 \\
0.000035 \\
0.000139\end{array}$ & $\begin{array}{l}1099.000000 \\
1099.000000 \\
1099.000000\end{array}$ \\
\hline
\end{tabular}




\begin{tabular}{|c|c|c|c|c|c|c|c|c|}
\hline & & MHC & 4 & 4 & 0.23 & 0.525667 & 0.000478 & 1099.000000 \\
\hline Aroclor-1260 & $E R \_L$ & $\begin{array}{l}\text { IHP } \\
\text { LMB } \\
\text { LHC } \\
\text { MHC }\end{array}$ & $\begin{array}{l}5 \\
4 \\
7 \\
4\end{array}$ & $\begin{array}{l}5 \\
1 \\
3 \\
4\end{array}$ & $\begin{array}{l}0.22 \\
0.04 \\
0.07 \\
0.23\end{array}$ & $\begin{array}{l}0.381206 \\
0.038000 \\
0.152737 \\
0.525667\end{array}$ & $\begin{array}{r}16.574153 \\
1.652174 \\
6.640733 \\
22.855074\end{array}$ & $\begin{array}{l}0.023000 \\
0.023000 \\
0.023000 \\
0.023000\end{array}$ \\
\hline Aroclor-1260 & ER_M & $\begin{array}{l}\text { IHP } \\
\text { LMB } \\
\text { LHC } \\
\text { MHC }\end{array}$ & $\begin{array}{l}5 \\
4 \\
7 \\
4\end{array}$ & $\begin{array}{l}5 \\
1 \\
3 \\
4\end{array}$ & $\begin{array}{l}0.22 \\
0.04 \\
0.07 \\
0.23\end{array}$ & $\begin{array}{l}0.381206 \\
0.038000 \\
0.152737 \\
0.525667\end{array}$ & $\begin{array}{l}2.117808 \\
0.211111 \\
0.848538 \\
2.920371\end{array}$ & $\begin{array}{l}0.180000 \\
0.180000 \\
0.180000 \\
0.180000\end{array}$ \\
\hline Arsenic & $E R \_L$ & $\begin{array}{l}\text { IHP } \\
\text { LMB } \\
\text { LHC } \\
\text { MHC }\end{array}$ & $\begin{array}{l}3 \\
5 \\
3 \\
2\end{array}$ & $\begin{array}{l}3 \\
5 \\
3 \\
2\end{array}$ & $\begin{array}{l}4.40 \\
5.04 \\
4.40 \\
5.80\end{array}$ & $\begin{array}{r}8.860352 \\
7.292707 \\
8.821955 \\
15.270627\end{array}$ & $\begin{array}{l}1.080531 \\
0.889355 \\
1.075848 \\
1.862272\end{array}$ & $\begin{array}{l}8.200000 \\
8.200000 \\
8.200000 \\
8.200000\end{array}$ \\
\hline Arsenic & ER_M & $\begin{array}{l}\text { IHP } \\
\text { LMB } \\
\text { LHC } \\
\text { MHC }\end{array}$ & $\begin{array}{l}3 \\
5 \\
3 \\
2\end{array}$ & $\begin{array}{l}3 \\
5 \\
3 \\
2\end{array}$ & $\begin{array}{l}4.40 \\
5.04 \\
4.40 \\
5.80\end{array}$ & $\begin{array}{r}8.860352 \\
7.292707 \\
8.821955 \\
15.270627\end{array}$ & $\begin{array}{l}0.126576 \\
0.104182 \\
0.126028 \\
0.218152\end{array}$ & $\begin{array}{l}70.000000 \\
70.000000 \\
70.000000 \\
70.000000\end{array}$ \\
\hline Arsenic & LEL_MOE & $\begin{array}{l}\text { IHP } \\
\text { LMB } \\
\text { LHC } \\
\text { MHC }\end{array}$ & $\begin{array}{l}3 \\
5 \\
3 \\
2\end{array}$ & $\begin{array}{l}3 \\
5 \\
3 \\
2\end{array}$ & $\begin{array}{l}4.40 \\
5.04 \\
4.40 \\
5.80\end{array}$ & $\begin{array}{r}8.860352 \\
7.292707 \\
8.821955 \\
15.270627\end{array}$ & $\begin{array}{l}1.476725 \\
1.215451 \\
1.470326 \\
2.545105\end{array}$ & $\begin{array}{l}6.000000 \\
6.000000 \\
6.000000 \\
6.000000\end{array}$ \\
\hline Arsenic & REG_IV & $\begin{array}{l}\text { IHP } \\
\text { LMB } \\
\text { LHC } \\
\text { MHC }\end{array}$ & $\begin{array}{l}3 \\
5 \\
3 \\
2\end{array}$ & $\begin{array}{l}3 \\
5 \\
3 \\
2\end{array}$ & $\begin{array}{l}4.40 \\
5.04 \\
4.40 \\
5.80\end{array}$ & $\begin{array}{r}8.860352 \\
7.292707 \\
8.821955 \\
15.270627\end{array}$ & $\begin{array}{l}1.107544 \\
0.911588 \\
1.102744 \\
1.908828\end{array}$ & $\begin{array}{l}8.000000 \\
8.000000 \\
8.000000 \\
8.000000\end{array}$ \\
\hline Arsenic & SED_PEL & $\begin{array}{l}\text { IHP } \\
\text { LMBB } \\
\text { LHCC } \\
\text { MHC }\end{array}$ & $\begin{array}{l}3 \\
5 \\
3 \\
2\end{array}$ & $\begin{array}{l}3 \\
5 \\
3 \\
2\end{array}$ & $\begin{array}{l}4.40 \\
5.04 \\
4.40 \\
5.80\end{array}$ & $\begin{array}{r}8.860352 \\
7.292707 \\
8.821955 \\
15.270627\end{array}$ & $\begin{array}{l}0.212989 \\
0.175305 \\
0.212066 \\
0.367082\end{array}$ & $\begin{array}{l}41.600001 \\
41.600001 \\
41.600001 \\
41.600001\end{array}$ \\
\hline Arsenic & SED_TEL & $\begin{array}{l}\text { IHP } \\
\text { LWMB } \\
\text { LWHC } \\
\text { MHC }\end{array}$ & $\begin{array}{l}3 \\
5 \\
3 \\
2\end{array}$ & $\begin{array}{l}3 \\
5 \\
3 \\
2\end{array}$ & $\begin{array}{l}4.40 \\
5.04 \\
4.40 \\
5.80\end{array}$ & $\begin{array}{r}8.860352 \\
7.292707 \\
8.821955 \\
15.270627\end{array}$ & $\begin{array}{l}1.223806 \\
1.007280 \\
1.218502 \\
2.109203\end{array}$ & $\begin{array}{l}7.240000 \\
7.240000 \\
7.240000 \\
7.240000\end{array}$ \\
\hline Bariun & REG_V_L & $\begin{array}{l}\text { IHP } \\
\text { LHB } \\
\text { LHC } \\
\text { MHC }\end{array}$ & $\begin{array}{l}3 \\
5 \\
3 \\
2\end{array}$ & $\begin{array}{l}3 \\
5 \\
3 \\
2\end{array}$ & $\begin{array}{l}102.77 \\
358.20 \\
197.33 \\
118.00\end{array}$ & $\begin{array}{l}196.451396 \\
681.723747 \\
297.160025 \\
130.627503\end{array}$ & $\begin{array}{r}9.822570 \\
34.086187 \\
14.858001 \\
6.531375\end{array}$ & $\begin{array}{l}20.000000 \\
20.000000 \\
20.000000 \\
20.000000\end{array}$ \\
\hline Barium & REG_V_M & $\begin{array}{l}\text { IHP } \\
\text { LHB } \\
\text { L.HC } \\
\text { HWC }\end{array}$ & $\begin{array}{l}3 \\
5 \\
3 \\
2\end{array}$ & $\begin{array}{l}3 \\
5 \\
3 \\
2\end{array}$ & $\begin{array}{l}102.77 \\
358.20 \\
197.33 \\
118.00\end{array}$ & $\begin{array}{l}196.451396 \\
681.723747 \\
297.160025 \\
130.627503\end{array}$ & $\begin{array}{r}3.274190 \\
11.362062 \\
4.952667 \\
2.177125\end{array}$ & $\begin{array}{l}60.000000 \\
60.000000 \\
60.000000 \\
60.000000\end{array}$ \\
\hline
\end{tabular}




\begin{tabular}{|c|c|c|c|c|c|c|c|c|}
\hline Benzo(a)anthracene & EQPSQB_A & $\begin{array}{l}\text { IHP } \\
\text { LHC } \\
\text { MHC }\end{array}$ & $\begin{array}{l}5 \\
7 \\
4\end{array}$ & $\begin{array}{l}4 \\
1 \\
2\end{array}$ & $\begin{array}{l}0.23 \\
0.03 \\
0.60\end{array}$ & $\begin{array}{l}0.546377 \\
0.032000 \\
0.995223\end{array}$ & $\begin{array}{l}5.059042 \\
0.296296 \\
9.215028\end{array}$ & $\begin{array}{l}0.108000 \\
0.108000 \\
0.108000\end{array}$ \\
\hline Benzo(a)anthracene & $E R \_L$ & $\begin{array}{l}\text { IHP } \\
\text { LHC } \\
\text { MHC }\end{array}$ & $\begin{array}{l}5 \\
7 \\
4\end{array}$ & $\begin{array}{l}4 \\
1 \\
2\end{array}$ & $\begin{array}{l}0.23 \\
0.03 \\
0.60\end{array}$ & $\begin{array}{l}0.546377 \\
0.032000 \\
0.995223\end{array}$ & $\begin{array}{l}2.101448 \\
0.123077 \\
3.827781\end{array}$ & $\begin{array}{l}0.260000 \\
0.260000 \\
0.260000\end{array}$ \\
\hline Benzo(a)anthracene & ER_M & $\begin{array}{l}\text { IHP } \\
\text { LHC } \\
\text { MHC }\end{array}$ & $\begin{array}{l}5 \\
7 \\
4\end{array}$ & $\begin{array}{l}4 \\
1 \\
2\end{array}$ & $\begin{array}{l}0.23 \\
0.03 \\
0.60\end{array}$ & $\begin{array}{l}0.546377 \\
0.032000 \\
0.995223\end{array}$ & $\begin{array}{l}0.341485 \\
0.020000 \\
0.622014\end{array}$ & $\begin{array}{l}1.600000 \\
1.600000 \\
1.600000\end{array}$ \\
\hline Benzo(a)anthracene & REG_IV & $\begin{array}{l}\text { IHP } \\
\text { LHC } \\
\text { MHC }\end{array}$ & $\begin{array}{l}5 \\
7 \\
4\end{array}$ & $\begin{array}{l}4 \\
1 \\
2\end{array}$ & $\begin{array}{l}0.23 \\
0.03 \\
0.60\end{array}$ & $\begin{array}{l}0.546377 \\
0.032000 \\
0.995223\end{array}$ & $\begin{array}{l}1.655686 \\
0.096970 \\
3.015827\end{array}$ & $\begin{array}{l}0.330000 \\
0.330000 \\
0.330000\end{array}$ \\
\hline Benzo(a)anthracene & SED_PEL & $\begin{array}{l}\text { IHP } \\
\text { LHC } \\
\text { MHC }\end{array}$ & $\begin{array}{l}5 \\
7 \\
4\end{array}$ & $\begin{array}{l}4 \\
1 \\
2\end{array}$ & $\begin{array}{l}0.23 \\
0.03 \\
0.60\end{array}$ & $\begin{array}{l}0.546377 \\
0.032000 \\
0.995223\end{array}$ & $\begin{array}{l}0.788422 \\
0.046176 \\
1.436108\end{array}$ & $\begin{array}{l}0.693000 \\
0.693000 \\
0.693000\end{array}$ \\
\hline Benzo(a)anthracene & SED_TEL & $\begin{array}{l}\text { IHP } \\
\text { LHC } \\
\text { MHC }\end{array}$ & $\begin{array}{l}5 \\
7 \\
4\end{array}$ & $\begin{array}{l}4 \\
1 \\
2\end{array}$ & $\begin{array}{l}0.23 \\
0.03 \\
0.60\end{array}$ & $\begin{array}{l}0.546377 \\
0.032000 \\
0.995223\end{array}$ & $\begin{array}{r}7.304499 \\
0.427807 \\
13.305121\end{array}$ & $\begin{array}{l}0.074800 \\
0.074800 \\
0.074800\end{array}$ \\
\hline Benzo(a)pyrene & EAPSAB_A & $\begin{array}{l}\text { IHP } \\
\text { LHC } \\
\text { MHC }\end{array}$ & $\begin{array}{l}5 \\
7 \\
4\end{array}$ & $\begin{array}{l}4 \\
3 \\
3\end{array}$ & $\begin{array}{l}0.20 \\
0.08 \\
0.47\end{array}$ & $\begin{array}{l}0.395901 \\
0.126524 \\
0.954074\end{array}$ & $\begin{array}{l}2.827864 \\
0.903744 \\
6.814816\end{array}$ & $\begin{array}{l}0.140000 \\
0.140000 \\
0.140000\end{array}$ \\
\hline Benzo(a)pyrene & ER_L & $\begin{array}{l}\operatorname{liPP}_{\text {LHC }} \\
\text { MHCC }\end{array}$ & $\begin{array}{l}5 \\
7 \\
4\end{array}$ & $\begin{array}{l}4 \\
3 \\
3\end{array}$ & $\begin{array}{l}0.20 \\
0.08 \\
0.47\end{array}$ & $\begin{array}{l}0.395901 \\
0.126524 \\
0.954074\end{array}$ & $\begin{array}{l}0.920700 \\
0.294242 \\
2.218777\end{array}$ & $\begin{array}{l}0.430000 \\
0.430000 \\
0.430000\end{array}$ \\
\hline Benzo(a)pyrene & ER_M & $\begin{array}{l}\text { IHP } \\
\text { LHCC } \\
\text { MHC }\end{array}$ & $\begin{array}{l}5 \\
7 \\
4\end{array}$ & $\begin{array}{l}4 \\
3 \\
3\end{array}$ & $\begin{array}{l}0.20 \\
0.08 \\
0.47\end{array}$ & $\begin{array}{l}0.395901 \\
0.126524 \\
0.954074\end{array}$ & $\begin{array}{l}0.247438 \\
0.079078 \\
0.596296\end{array}$ & $\begin{array}{l}1.600000 \\
1.600000 \\
1.600000\end{array}$ \\
\hline Benzo(a)pyrene & REG_IV & $\begin{array}{l}\text { IHP } \\
\text { LWWC } \\
\text { MWC }\end{array}$ & $\begin{array}{l}5 \\
7 \\
4\end{array}$ & $\begin{array}{l}4 \\
3 \\
3\end{array}$ & $\begin{array}{l}0.20 \\
0.08 \\
0.47\end{array}$ & $\begin{array}{l}0.395901 \\
0.126524 \\
0.954074\end{array}$ & $\begin{array}{l}1.199700 \\
0.383406 \\
2.891134\end{array}$ & $\begin{array}{l}0.330000 \\
0.330000 \\
0.330000\end{array}$ \\
\hline Benzo(a)pyrene & SED_PEL & $\begin{array}{l}\text { IHP } \\
\text { LHC } \\
\text { MHC }\end{array}$ & $\begin{array}{l}5 \\
7 \\
4\end{array}$ & $\begin{array}{l}4 \\
3 \\
3\end{array}$ & $\begin{array}{l}0.20 \\
0.08 \\
0.47\end{array}$ & $\begin{array}{l}0.395901 \\
0.126524 \\
0.954074\end{array}$ & $\begin{array}{l}0.518874 \\
0.165825 \\
1.250425\end{array}$ & $\begin{array}{l}0.763000 \\
0.763000 \\
0.763000\end{array}$ \\
\hline Benzo(a)pyrene & SED_TEL & $\begin{array}{l}\text { IHP } \\
\text { LHCC } \\
\text { MHC }\end{array}$ & $\begin{array}{l}5 \\
7 \\
4\end{array}$ & $\begin{array}{l}4 \\
3 \\
3\end{array}$ & $\begin{array}{l}0.20 \\
0.08 \\
0.47\end{array}$ & $\begin{array}{l}0.395901 \\
0.126524 \\
0.954074\end{array}$ & $\begin{array}{r}4.458344 \\
1.424821 \\
10.744080\end{array}$ & $\begin{array}{l}0.088800 \\
0.088800 \\
0.088800\end{array}$ \\
\hline $\mathrm{CH}-244$ & SED_RAD & $\begin{array}{l}\text { IHP } \\
\text { LMB } \\
\text { LHE }\end{array}$ & $\begin{array}{l}2 \\
5 \\
2\end{array}$ & $\begin{array}{l}2 \\
3 \\
2\end{array}$ & $\begin{array}{l}4.70 \\
0.94 \\
0.04\end{array}$ & $\begin{array}{r}13.539252 \\
1.691524 \\
0.143677\end{array}$ & $\begin{array}{l}0.001223 \\
0.000153 \\
0.000013\end{array}$ & $\begin{array}{l}069.000000 \\
369.000000 \\
369.000000\end{array}$ \\
\hline
\end{tabular}




\begin{tabular}{|c|c|c|c|c|c|c|c|c|}
\hline & & MHC & 2 & 2 & 4.50 & 6.394125 & 0.000578 & 11069.000000 \\
\hline co-60 & SED_RAD & $\begin{array}{l}\text { IHP } \\
\text { LMB } \\
\text { LWC } \\
\text { HHC }\end{array}$ & $\begin{array}{l}5 \\
7 \\
6 \\
3\end{array}$ & $\begin{array}{l}5 \\
7 \\
6 \\
3\end{array}$ & $\begin{array}{r}17.92 \\
134.34 \\
92.48 \\
24.75\end{array}$ & $\begin{array}{r}30.732834 \\
167.739634 \\
163.816332 \\
45.289069\end{array}$ & $\begin{array}{l}0.003559 \\
0.019426 \\
0.018971 \\
0.005245\end{array}$ & $\begin{array}{l}8635.000000 \\
8635.000000 \\
8635.000000 \\
8635.000000\end{array}$ \\
\hline CS-137 & SED_RAD & $\begin{array}{l}\text { IHP } \\
\text { LMB } \\
\text { LHC } \\
\text { MHC }\end{array}$ & $\begin{array}{l}5 \\
7 \\
6 \\
3\end{array}$ & $\begin{array}{l}5 \\
4 \\
4 \\
3\end{array}$ & $\begin{array}{r}2160.77 \\
66.85 \\
398.81 \\
2693.45\end{array}$ & $\begin{array}{r}3717.668177 \\
79.050725 \\
1236.907825 \\
3940.916070\end{array}$ & $\begin{array}{l}0.157348 \\
0.003346 \\
0.052351 \\
0.166797\end{array}$ & $\begin{array}{l}23627.000000 \\
23627.000000 \\
23627.000000 \\
23627.000000\end{array}$ \\
\hline Cactmium & $E R \_L$ & $\begin{array}{l}\text { IHP } \\
\text { LMB } \\
\text { LHC } \\
\text { MHC }\end{array}$ & $\begin{array}{l}3 \\
5 \\
3 \\
2\end{array}$ & $\begin{array}{l}3 \\
5 \\
3 \\
2\end{array}$ & $\begin{array}{l}0.85 \\
0.29 \\
0.29 \\
1.65\end{array}$ & $\begin{array}{l}1.681006 \\
0.324491 \\
0.334604 \\
1.965688\end{array}$ & $\begin{array}{l}1.400838 \\
0.270410 \\
0.278836 \\
1.638073\end{array}$ & $\begin{array}{l}1.200000 \\
1.200000 \\
1.200000 \\
1.200000\end{array}$ \\
\hline Cadmium & ER_M & $\begin{array}{l}\text { IHP } \\
\text { LMB } \\
\text { LHC } \\
\text { MHC }\end{array}$ & $\begin{array}{l}3 \\
5 \\
3 \\
2\end{array}$ & $\begin{array}{l}3 \\
5 \\
3 \\
2\end{array}$ & $\begin{array}{l}0.85 \\
0.29 \\
0.29 \\
1.65\end{array}$ & $\begin{array}{l}1.681006 \\
0.324491 \\
0.334604 \\
1.965688\end{array}$ & $\begin{array}{l}0.175105 \\
0.033801 \\
0.034855 \\
0.204759\end{array}$ & $\begin{array}{l}9.600000 \\
9.600000 \\
9.600000 \\
9.600000\end{array}$ \\
\hline Cachium & LEL_MOE & $\begin{array}{l}\text { IHP } \\
\text { LMB } \\
\text { LHC } \\
\text { MHC }\end{array}$ & $\begin{array}{l}3 \\
5 \\
3 \\
2\end{array}$ & $\begin{array}{l}3 \\
5 \\
3 \\
2\end{array}$ & $\begin{array}{l}0.85 \\
0.29 \\
0.29 \\
1.65\end{array}$ & $\begin{array}{l}1.681006 \\
0.324491 \\
0.334604 \\
1.965688\end{array}$ & $\begin{array}{l}2.801677 \\
0.540819 \\
0.557673 \\
3.276146\end{array}$ & $\begin{array}{l}0.600000 \\
0.600000 \\
0.600000 \\
0.600000\end{array}$ \\
\hline Codniun & REG_IV & $\begin{array}{l}\text { IHP } \\
\text { LHB } \\
\text { LHC } \\
\text { HHC }\end{array}$ & $\begin{array}{l}3 \\
5 \\
3 \\
2\end{array}$ & $\begin{array}{l}3 \\
5 \\
3 \\
2\end{array}$ & $\begin{array}{l}0.85 \\
0.29 \\
0.29 \\
1.65\end{array}$ & $\begin{array}{l}1.681006 \\
0.324491 \\
0.334604 \\
1.965688\end{array}$ & $\begin{array}{l}1.681006 \\
0.324491 \\
0.334604 \\
1.965688\end{array}$ & $\begin{array}{l}1.000000 \\
1.000000 \\
1.000000 \\
1.000000\end{array}$ \\
\hline Cactmium & SED_PEL & $\begin{array}{l}\text { IHP } \\
\text { LMB } \\
\text { LHCC } \\
\text { MHC }\end{array}$ & $\begin{array}{l}3 \\
5 \\
3 \\
2\end{array}$ & $\begin{array}{l}3 \\
5 \\
3 \\
2\end{array}$ & $\begin{array}{l}0.85 \\
0.29 \\
0.29 \\
1.65\end{array}$ & $\begin{array}{l}1.681006 \\
0.324491 \\
0.33604 \\
1.965688\end{array}$ & $\begin{array}{l}0.399289 \\
0.077076 \\
0.079478 \\
0.466909\end{array}$ & $\begin{array}{l}4.210000 \\
4.210000 \\
4.210000 \\
4.210000\end{array}$ \\
\hline Cadmium & SED_TELL & $\begin{array}{l}\text { IHP } \\
\text { LMBB } \\
\text { LHCC } \\
\text { HHC }\end{array}$ & $\begin{array}{l}3 \\
5 \\
3 \\
2\end{array}$ & $\begin{array}{l}3 \\
5 \\
3 \\
2\end{array}$ & $\begin{array}{l}0.85 \\
0.29 \\
0.29 \\
1.65\end{array}$ & $\begin{array}{l}1.681006 \\
0.324491 \\
0.34604 \\
1.965688\end{array}$ & $\begin{array}{l}2.486695 \\
0.480017 \\
0.494976 \\
2.907822\end{array}$ & $\begin{array}{l}0.676000 \\
0.676000 \\
0.676000 \\
0.676000\end{array}$ \\
\hline Chromium VI & $E R \_L$ & $\begin{array}{l}\text { IHP } \\
\text { LMB } \\
\text { LHC } \\
\text { MHC }\end{array}$ & $\begin{array}{l}3 \\
5 \\
3 \\
2\end{array}$ & $\begin{array}{l}3 \\
5 \\
3 \\
2\end{array}$ & $\begin{array}{l}56.50 \\
92.76 \\
36.90 \\
48.95\end{array}$ & $\begin{array}{r}81.452355 \\
134.772940 \\
40.547061 \\
62.524566\end{array}$ & $\begin{array}{l}1.005585 \\
1.663863 \\
0.500581 \\
0.771908\end{array}$ & $\begin{array}{l}81.000000 \\
81.000000 \\
81.000000 \\
81.000000\end{array}$ \\
\hline Chromium VI & ER_M & $\begin{array}{l}\text { IHP } \\
\text { LMB } \\
\text { LHC } \\
\text { MHC }\end{array}$ & $\begin{array}{l}3 \\
5 \\
3 \\
2\end{array}$ & $\begin{array}{l}3 \\
5 \\
3 \\
2\end{array}$ & $\begin{array}{l}56.50 \\
92.76 \\
36.90 \\
48.95\end{array}$ & $\begin{array}{r}81.452355 \\
134.772940 \\
40.547061 \\
62.524566\end{array}$ & $\begin{array}{l}0.220141 \\
0.364251 \\
0.109587 \\
0.168985\end{array}$ & $\begin{array}{l}370.000000 \\
370.000000 \\
370.000000 \\
370.000000\end{array}$ \\
\hline
\end{tabular}




\begin{tabular}{|c|c|c|c|c|c|c|c|c|}
\hline Chrysene & ER_L & $\begin{array}{l}\text { IHP } \\
\text { LHC } \\
\text { MHC }\end{array}$ & $\begin{array}{l}5 \\
7 \\
4\end{array}$ & $\begin{array}{l}5 \\
1 \\
2\end{array}$ & $\begin{array}{l}0.25 \\
0.04 \\
0.34\end{array}$ & $\begin{array}{l}0.526580 \\
0.035000 \\
0.771989\end{array}$ & $\begin{array}{l}1.385738 \\
0.092105 \\
2.031550\end{array}$ & $\begin{array}{l}0.380000 \\
0.380000 \\
0.380000\end{array}$ \\
\hline Chrysene & ER_M & $\begin{array}{l}\text { IHP } \\
\text { LHC } \\
\text { MHC }\end{array}$ & $\begin{array}{l}5 \\
7 \\
4\end{array}$ & $\begin{array}{l}5 \\
1 \\
2\end{array}$ & $\begin{array}{l}0.25 \\
0.04 \\
0.34\end{array}$ & $\begin{array}{l}0.526580 \\
0.035000 \\
0.771989\end{array}$ & $\begin{array}{l}0.188064 \\
0.012500 \\
0.275710\end{array}$ & $\begin{array}{l}2.800000 \\
2.800000 \\
2.800000\end{array}$ \\
\hline Chrysene & REG_IV & $\begin{array}{l}\operatorname{IHP}_{\text {LHC }} \\
\text { MHC }\end{array}$ & $\begin{array}{l}5 \\
7 \\
4\end{array}$ & $\begin{array}{l}5 \\
1 \\
2\end{array}$ & $\begin{array}{l}0.25 \\
0.04 \\
0.34\end{array}$ & $\begin{array}{l}0.526580 \\
0.035000 \\
0.771989\end{array}$ & $\begin{array}{l}1.595698 \\
0.106061 \\
2.339360\end{array}$ & $\begin{array}{l}0.330000 \\
0.330000 \\
0.330000\end{array}$ \\
\hline Chrysene & SED_PEL & $\begin{array}{l}\text { IHP } \\
\text { LHC } \\
\text { MHC }\end{array}$ & $\begin{array}{l}5 \\
7 \\
4\end{array}$ & $\begin{array}{l}5 \\
1 \\
2\end{array}$ & $\begin{array}{l}0.25 \\
0.04 \\
0.34\end{array}$ & $\begin{array}{l}0.526580 \\
0.035000 \\
0.771989\end{array}$ & $\begin{array}{l}0.622436 \\
0.041371 \\
0.912516\end{array}$ & $\begin{array}{l}0.846000 \\
0.846000 \\
0.846000\end{array}$ \\
\hline Chrysene & SED_TEL & $\begin{array}{l}\text { IHP } \\
\text { LWC } \\
\text { MHC }\end{array}$ & $\begin{array}{l}5 \\
7 \\
4\end{array}$ & $\begin{array}{l}5 \\
1 \\
2\end{array}$ & $\begin{array}{l}0.25 \\
0.04 \\
0.34\end{array}$ & $\begin{array}{l}0.526580 \\
0.035000 \\
0.771989\end{array}$ & $\begin{array}{l}4.875745 \\
0.324074 \\
7.148045\end{array}$ & $\begin{array}{l}0.108000 \\
0.108000 \\
0.108000\end{array}$ \\
\hline Copper & $E R_{-} L$ & $\begin{array}{l}\text { IHP } \\
\text { LMB } \\
\text { LHC } \\
\text { MHC }\end{array}$ & $\begin{array}{l}3 \\
5 \\
3 \\
2\end{array}$ & $\begin{array}{l}3 \\
5 \\
3 \\
2\end{array}$ & $\begin{array}{r}35.43 \\
23.38 \\
29.73 \\
139.00\end{array}$ & $\begin{array}{r}79.478143 \\
30.480170 \\
66.341745 \\
290.530036\end{array}$ & $\begin{array}{l}2.337592 \\
0.896476 \\
1.951228 \\
8.545001\end{array}$ & $\begin{array}{l}34.000000 \\
34.000000 \\
34.000000 \\
34.000000\end{array}$ \\
\hline Copper & ER_M & $\begin{array}{l}\text { IHP } \\
\text { LMB } \\
\text { LHC } \\
\text { HWC }\end{array}$ & $\begin{array}{l}3 \\
5 \\
3 \\
2\end{array}$ & $\begin{array}{l}3 \\
5 \\
3 \\
2\end{array}$ & $\begin{array}{r}35.43 \\
23.38 \\
29.73 \\
139.00\end{array}$ & $\begin{array}{r}79.478143 \\
30.480170 \\
66.341745 \\
290.530036\end{array}$ & $\begin{array}{l}0.294363 \\
0.112890 \\
0.245710 \\
1.076037\end{array}$ & $\begin{array}{l}270.000000 \\
270.000000 \\
270.000000 \\
270.000000\end{array}$ \\
\hline Copper & REG_IV & $\begin{array}{l}\text { IHP } \\
\text { LMB } \\
\text { LHC } \\
\text { HHC }\end{array}$ & $\begin{array}{l}3 \\
5 \\
3 \\
2\end{array}$ & $\begin{array}{l}3 \\
5 \\
3 \\
2\end{array}$ & $\begin{array}{r}35.43 \\
23.38 \\
29.73 \\
139.00\end{array}$ & $\begin{array}{r}79.478143 \\
30.480170 \\
66.341745 \\
290.530036\end{array}$ & $\begin{array}{r}2.838505 \\
1.088578 \\
2.369348 \\
10.376073\end{array}$ & $\begin{array}{l}28.000000 \\
28.000000 \\
28.000000 \\
28.000000\end{array}$ \\
\hline Copper & SED_PEL & $\begin{array}{l}\text { IHP } \\
\text { LMB } \\
\text { LHC } \\
\text { MHC }\end{array}$ & $\begin{array}{l}3 \\
5 \\
3 \\
2\end{array}$ & $\begin{array}{l}3 \\
5 \\
3 \\
2\end{array}$ & $\begin{array}{r}35.43 \\
23.38 \\
29.73 \\
139.00\end{array}$ & $\begin{array}{r}79.478143 \\
30.480170 \\
66.341745 \\
290.530036\end{array}$ & $\begin{array}{l}0.735909 \\
0.282224 \\
0.614275 \\
2.690093\end{array}$ & $\begin{array}{l}108.000000 \\
108.000000 \\
108.000000 \\
108.000000\end{array}$ \\
\hline Copper & SED_TEL. & $\begin{array}{l}\operatorname{liHP}_{\text {LMB }} \\
\text { LHCC } \\
\text { HHC }\end{array}$ & $\begin{array}{l}3 \\
5 \\
3 \\
2\end{array}$ & $\begin{array}{l}3 \\
5 \\
3 \\
2\end{array}$ & $\begin{array}{r}35.43 \\
23.38 \\
29.73 \\
139.00\end{array}$ & $\begin{array}{r}79.478143 \\
30.480170 \\
66.347745 \\
290.530036\end{array}$ & $\begin{array}{r}4.250168 \\
1.629956 \\
3.547687 \\
15.536365\end{array}$ & $\begin{array}{l}18.700000 \\
18.700000 \\
18.700000 \\
18.700000\end{array}$ \\
\hline Di-n-butylphthalate & EAPSQB_A & $\begin{array}{l}\text { IHP } \\
\text { LHCC } \\
\text { MHC }\end{array}$ & $\begin{array}{l}5 \\
7 \\
4\end{array}$ & $\begin{array}{l}4 \\
2 \\
2\end{array}$ & $\begin{array}{l}0.28 \\
0.36 \\
0.22\end{array}$ & $\begin{array}{l}0.449471 \\
0.578466 \\
0.564621\end{array}$ & $\begin{array}{l}0.010676 \\
0.013740 \\
0.013411\end{array}$ & $\begin{array}{l}42.100000 \\
42.100000 \\
42.100000\end{array}$ \\
\hline Di-n-octylphthalate & EAPSQB_A & LMB & 5 & 1 & 0.06 & 0.055000 & 0.000000 & 300000.000000 \\
\hline
\end{tabular}




\begin{tabular}{|c|c|c|c|c|c|c|c|c|}
\hline Dibenz $(a, h)$ anthracene & ER_L & $\begin{array}{l}\text { IHP } \\
\text { MHC }\end{array}$ & $\begin{array}{l}5 \\
4\end{array}$ & $\begin{array}{l}1 \\
1\end{array}$ & $\begin{array}{l}0.24 \\
0.10\end{array}$ & $\begin{array}{l}0.240000 \\
0.100500\end{array}$ & $\begin{array}{l}3.809524 \\
1.595238\end{array}$ & $\begin{array}{l}0.063000 \\
0.063000\end{array}$ \\
\hline Dibenz $(B, h)$ anthracene & ER_M & $\begin{array}{l}\text { IHP } \\
\text { MHC }\end{array}$ & $\begin{array}{l}5 \\
4\end{array}$ & $\begin{array}{l}1 \\
1\end{array}$ & $\begin{array}{l}0.24 \\
0.10\end{array}$ & $\begin{array}{l}0.240000 \\
0.100500\end{array}$ & $\begin{array}{l}0.923077 \\
0.386538\end{array}$ & $\begin{array}{l}0.260000 \\
0.260000\end{array}$ \\
\hline Dibenz $(a, h)$ anthracene & REG_IV & $\begin{array}{l}\text { IHP } \\
\text { MHC }\end{array}$ & $\begin{array}{l}5 \\
4\end{array}$ & $\begin{array}{l}1 \\
1\end{array}$ & $\begin{array}{l}0.24 \\
0.10\end{array}$ & $\begin{array}{l}0.240000 \\
0.100500\end{array}$ & $\begin{array}{l}0.727273 \\
0.304545\end{array}$ & $\begin{array}{l}0.330000 \\
0.330000\end{array}$ \\
\hline Dibenz $(a, h)$ anthracene & SED_PEL & $\begin{array}{l}\text { IHP } \\
\text { MHC }\end{array}$ & $\begin{array}{l}5 \\
4\end{array}$ & 1 & $\begin{array}{l}0.24 \\
0.10\end{array}$ & $\begin{array}{l}0.240000 \\
0.100500\end{array}$ & $\begin{array}{l}1.777778 \\
0.744444\end{array}$ & $\begin{array}{l}0.135000 \\
0.135000\end{array}$ \\
\hline Dibenz $(a, h)$ anthracene & SED_TEL & $\begin{array}{l}\text { IHP } \\
\text { MHC }\end{array}$ & $\begin{array}{l}5 \\
4\end{array}$ & $\begin{array}{l}1 \\
1\end{array}$ & $\begin{array}{l}0.24 \\
0.10\end{array}$ & $\begin{array}{l}0.240000 \\
0.100500\end{array}$ & $\begin{array}{l}38.585210 \\
16.157557\end{array}$ & $\begin{array}{l}0.006220 \\
0.006220\end{array}$ \\
\hline Dibenzofuran & EQPSAB_A & $\begin{array}{l}\text { IHP } \\
\text { LWC } \\
\text { MHC }\end{array}$ & $\begin{array}{l}5 \\
7 \\
4\end{array}$ & $\begin{array}{l}1 \\
2 \\
1\end{array}$ & $\begin{array}{l}0.07 \\
0.16 \\
0.43\end{array}$ & $\begin{array}{l}0.067000 \\
0.362266 \\
0.430000\end{array}$ & $\begin{array}{l}0.029258 \\
0.158195 \\
0.187773\end{array}$ & $\begin{array}{l}2.290000 \\
2.290000 \\
2.290000\end{array}$ \\
\hline Fluoranthene & EPASQC_A & $\begin{array}{l}\text { IHP } \\
\text { LMB } \\
\text { LHC } \\
\text { MHC }\end{array}$ & $\begin{array}{l}5 \\
5 \\
7 \\
4\end{array}$ & $\begin{array}{l}5 \\
1 \\
3 \\
3\end{array}$ & $\begin{array}{l}0.49 \\
0.11 \\
0.12 \\
0.48\end{array}$ & $\begin{array}{l}0.990234 \\
0.110000 \\
0.212802 \\
1.218625\end{array}$ & $\begin{array}{l}0.159715 \\
0.017742 \\
0.034323 \\
0.196552\end{array}$ & $\begin{array}{l}6.200000 \\
6.200000 \\
6.200000 \\
6.200000\end{array}$ \\
\hline Fluoranthene & ER_L & $\begin{array}{l}\text { IHP } \\
\text { LMB } \\
\text { LWC } \\
\text { MWC }\end{array}$ & $\begin{array}{l}5 \\
5 \\
7 \\
4\end{array}$ & $\begin{array}{l}5 \\
1 \\
3 \\
3\end{array}$ & $\begin{array}{l}0.49 \\
0.11 \\
0.12 \\
0.48\end{array}$ & $\begin{array}{l}0.990234 \\
0.110000 \\
0.212802 \\
1.218625\end{array}$ & $\begin{array}{l}1.650391 \\
0.183333 \\
0.354670 \\
2.031041\end{array}$ & $\begin{array}{l}0.600000 \\
0.600000 \\
0.600000 \\
0.600000\end{array}$ \\
\hline Fluoranthene & ER_M & $\begin{array}{l}\text { IHP } \\
\text { LMB } \\
\text { LWC } \\
\text { MWC }\end{array}$ & $\begin{array}{l}5 \\
5 \\
7 \\
4\end{array}$ & $\begin{array}{l}5 \\
1 \\
3 \\
3\end{array}$ & $\begin{array}{l}0.49 \\
0.11 \\
0.12 \\
0.48\end{array}$ & $\begin{array}{l}0.990234 \\
0.110000 \\
0.212802 \\
1.218625\end{array}$ & $\begin{array}{l}0.194164 \\
0.021569 \\
0.041726 \\
0.238946\end{array}$ & $\begin{array}{l}5.100000 \\
5.100000 \\
5.100000 \\
5.100000\end{array}$ \\
\hline Fluoranthene & REG_IV & $\begin{array}{l}\text { IHP } \\
\text { LMB } \\
\text { LWC } \\
\text { MHC }\end{array}$ & $\begin{array}{l}5 \\
5 \\
7 \\
4\end{array}$ & $\begin{array}{l}5 \\
1 \\
3 \\
3\end{array}$ & $\begin{array}{l}0.49 \\
0.11 \\
0.12 \\
0.48\end{array}$ & $\begin{array}{l}0.990234 \\
0.110000 \\
0.212802 \\
1.218625\end{array}$ & $\begin{array}{l}2.605880 \\
0.280474 \\
0.560005 \\
3.206907\end{array}$ & $\begin{array}{l}0.380000 \\
0.380000 \\
0.380000 \\
0.380000\end{array}$ \\
\hline Fluoranthene & SED_PEL & $\begin{array}{l}\text { IHP } \\
\text { LMB } \\
\text { LWC } \\
\text { HWC }\end{array}$ & $\begin{array}{l}5 \\
5 \\
7 \\
4\end{array}$ & $\begin{array}{l}5 \\
9 \\
3 \\
3\end{array}$ & $\begin{array}{l}0.49 \\
0.11 \\
0.12 \\
0.48\end{array}$ & $\begin{array}{l}0.990234 \\
0.110000 \\
0.212802 \\
1.218625\end{array}$ & $\begin{array}{l}0.662808 \\
0.073628 \\
0.142438 \\
0.815679\end{array}$ & $\begin{array}{l}1.494000 \\
1.494000 \\
1.494000 \\
1.494000\end{array}$ \\
\hline Fluoranthene & SED_TEL & $\begin{array}{l}\text { IHP } \\
\text { LMB } \\
\text { LWC } \\
\text { MWC }\end{array}$ & $\begin{array}{l}5 \\
5 \\
7 \\
4\end{array}$ & $\begin{array}{l}5 \\
1 \\
3 \\
3\end{array}$ & $\begin{array}{l}0.49 \\
0.11 \\
0.12 \\
0.48\end{array}$ & $\begin{array}{l}0.990234 \\
0.110000 \\
0.212802 \\
1.218625\end{array}$ & $\begin{array}{r}8.763137 \\
0.973451 \\
1.883203 \\
10.784288\end{array}$ & $\begin{array}{l}0.113000 \\
0.113000 \\
0.113000 \\
0.113000\end{array}$ \\
\hline Fluorene & ER_L & $\begin{array}{l}\text { IHP } \\
\text { LHC }\end{array}$ & $\begin{array}{l}5 \\
7\end{array}$ & $\begin{array}{l}2 \\
2\end{array}$ & $\begin{array}{l}0.09 \\
0.21\end{array}$ & $\begin{array}{l}0.197724 \\
0.478767\end{array}$ & $\begin{array}{l}10.406536 \\
25.198283\end{array}$ & $\begin{array}{l}0.019000 \\
0.019000\end{array}$ \\
\hline
\end{tabular}




\begin{tabular}{|c|c|c|c|c|c|c|c|c|}
\hline Fluorene & ER_M & $\begin{array}{l}\text { IHP } \\
\text { LUC }\end{array}$ & $\begin{array}{l}5 \\
7\end{array}$ & $\begin{array}{l}2 \\
2\end{array}$ & $\begin{array}{l}0.09 \\
0.21\end{array}$ & $\begin{array}{l}0.197724 \\
0.478767\end{array}$ & $\begin{array}{l}0.366156 \\
0.886606\end{array}$ & $\begin{array}{l}0.540000 \\
0.540000\end{array}$ \\
\hline Fluorene & REG_IV & $\begin{array}{l}\text { IHP } \\
\text { LHC }\end{array}$ & $\begin{array}{l}5 \\
7\end{array}$ & $\begin{array}{l}2 \\
2\end{array}$ & $\begin{array}{l}0.09 \\
0.21\end{array}$ & $\begin{array}{l}0.197724 \\
0.478767\end{array}$ & $\begin{array}{l}0.599164 \\
1.450810\end{array}$ & $\begin{array}{l}0.330000 \\
0.330000\end{array}$ \\
\hline Fluorene & SED_PEL & $\begin{array}{l}\text { IHP } \\
\text { LHC }\end{array}$ & $\begin{array}{l}5 \\
7\end{array}$ & $\begin{array}{l}2 \\
2\end{array}$ & $\begin{array}{l}0.09 \\
0.21\end{array}$ & $\begin{array}{l}0.197724 \\
0.478767\end{array}$ & $\begin{array}{l}1.373085 \\
3.324773\end{array}$ & $\begin{array}{l}0.144000 \\
0.144000\end{array}$ \\
\hline Fluorene & SED_TEL & $\begin{array}{l}\text { IHP } \\
\text { LHC }\end{array}$ & $\begin{array}{l}5 \\
7\end{array}$ & $\begin{array}{l}2 \\
2\end{array}$ & $\begin{array}{l}0.09 \\
0.21\end{array}$ & $\begin{array}{l}0.197724 \\
0.478767\end{array}$ & $\begin{array}{r}9.326612 \\
22.583366\end{array}$ & $\begin{array}{l}0.021200 \\
0.021200\end{array}$ \\
\hline Iron & LEL_MOE & $\begin{array}{l}\text { IHP } \\
\text { LMB } \\
\text { LHC } \\
\text { WHC }\end{array}$ & $\begin{array}{l}3 \\
5 \\
3 \\
2\end{array}$ & $\begin{array}{l}3 \\
5 \\
3 \\
2\end{array}$ & $\begin{array}{l}21133.33 \\
49080.00 \\
40600.00 \\
21850.00\end{array}$ & $\begin{array}{l}29098.586823 \\
67472.093481 \\
68827.869767 \\
32899.065151\end{array}$ & $\begin{array}{l}0.969953 \\
2.249070 \\
2.294262 \\
1.096636\end{array}$ & $\begin{array}{l}30000.000000 \\
30000.000000 \\
30000.000000 \\
30000.000000\end{array}$ \\
\hline iron & SEL_MOE & $\begin{array}{l}\text { IHP } \\
\text { LMB } \\
\text { LWC } \\
\text { MHC }\end{array}$ & $\begin{array}{l}3 \\
5 \\
3 \\
2\end{array}$ & $\begin{array}{l}3 \\
5 \\
3 \\
2\end{array}$ & $\begin{array}{l}21133.33 \\
49080.00 \\
40600.00 \\
21850.00\end{array}$ & $\begin{array}{l}29098.586823 \\
67472.093481 \\
68827.869767 \\
32899.065151\end{array}$ & $\begin{array}{l}0.727465 \\
1.686802 \\
1.720697 \\
0.822477\end{array}$ & $\begin{array}{l}40000.000000 \\
40000.000000 \\
40000.000000 \\
40000.000000\end{array}$ \\
\hline Lead & ER_L & $\begin{array}{l}\text { IHP } \\
\text { LMB } \\
\text { LHKC } \\
\text { MHC }\end{array}$ & $\begin{array}{l}3 \\
5 \\
3 \\
2\end{array}$ & $\begin{array}{l}3 \\
5 \\
3 \\
2\end{array}$ & $\begin{array}{l}35.03 \\
13.70 \\
15.77 \\
71.80\end{array}$ & $\begin{array}{r}64.883115 \\
19.143937 \\
22.877828 \\
121.678637\end{array}$ & $\begin{array}{l}1.380492 \\
0.407318 \\
0.45698 \\
2.588907\end{array}$ & $\begin{array}{l}47.000000 \\
47.000000 \\
47.000000 \\
47.000000\end{array}$ \\
\hline Lead & ER_M & $\begin{array}{l}\text { IHP } \\
\text { LMB } \\
\text { LHC } \\
\text { HWC }\end{array}$ & $\begin{array}{l}3 \\
5 \\
3 \\
2\end{array}$ & $\begin{array}{l}3 \\
5 \\
3 \\
2\end{array}$ & $\begin{array}{l}35.03 \\
13.70 \\
15.77 \\
71.80\end{array}$ & $\begin{array}{r}64.883115 \\
19.143937 \\
22.827828 \\
121.678637\end{array}$ & $\begin{array}{l}0.297629 \\
0.087816 \\
0.104715 \\
0.558159\end{array}$ & $\begin{array}{l}218.000000 \\
218.000000 \\
218.000000 \\
218.000000\end{array}$ \\
\hline Lead & REG_IV & $\begin{array}{l}\text { IHP } \\
\text { LMB } \\
\text { LHC } \\
\text { MHC }\end{array}$ & $\begin{array}{l}3 \\
5 \\
3 \\
2\end{array}$ & $\begin{array}{l}3 \\
5 \\
3 \\
2\end{array}$ & $\begin{array}{l}35.03 \\
13.70 \\
15.77 \\
71.80\end{array}$ & $\begin{array}{r}64.883115 \\
19.143937 \\
22.827828 \\
121.678637\end{array}$ & $\begin{array}{l}3.089672 \\
0.911616 \\
1.087039 \\
5.794221\end{array}$ & $\begin{array}{l}21.000000 \\
21.000000 \\
21.000000 \\
21.000000\end{array}$ \\
\hline Lead & SED_PEL & $\begin{array}{l}\text { IHP } \\
\text { LMB } \\
\text { LHC } \\
\text { HHC }\end{array}$ & $\begin{array}{l}3 \\
5 \\
3 \\
2\end{array}$ & $\begin{array}{l}3 \\
5 \\
3 \\
2\end{array}$ & $\begin{array}{l}35.03 \\
13.70 \\
15.77 \\
71.80\end{array}$ & $\begin{array}{r}64.883115 \\
19.143937 \\
22.827828 \\
121.678637\end{array}$ & $\begin{array}{l}0.579314 \\
0.170928 \\
0.203820 \\
1.086416\end{array}$ & $\begin{array}{l}112.000000 \\
112.000000 \\
112.000000 \\
112.000000\end{array}$ \\
\hline Lead & SED_TEL & $\begin{array}{l}\text { IHP } \\
\text { LMB } \\
\text { LHC } \\
\text { MHC }\end{array}$ & $\begin{array}{l}3 \\
5 \\
3 \\
2\end{array}$ & $\begin{array}{l}3 \\
5 \\
3 \\
2\end{array}$ & $\begin{array}{l}35.03 \\
13.70 \\
15.77 \\
71.80\end{array}$ & $\begin{array}{r}64.883115 \\
19.143937 \\
22.827828 \\
121.678637\end{array}$ & $\begin{array}{l}2.148447 \\
0.633905 \\
0.755888 \\
4.029094\end{array}$ & $\begin{array}{l}30.200000 \\
30.200000 \\
30.200000 \\
30.200000\end{array}$ \\
\hline Manganese & LEL_MOE & $\begin{array}{l}\text { IHP } \\
\text { LMB } \\
\text { LHC } \\
\text { MHC }\end{array}$ & $\begin{array}{l}3 \\
5 \\
3 \\
2\end{array}$ & $\begin{array}{l}3 \\
5 \\
3 \\
2\end{array}$ & $\begin{array}{r}803.33 \\
3211.20 \\
1760.00 \\
747.00\end{array}$ & $\begin{array}{l}1650.715184 \\
6021.788706 \\
2289.905652 \\
1018.491315\end{array}$ & $\begin{array}{r}3.588511 \\
13.090845 \\
4.978056 \\
2.214112\end{array}$ & $\begin{array}{l}460.000000 \\
460.000000 \\
460.000000 \\
460.000000\end{array}$ \\
\hline
\end{tabular}




\begin{tabular}{|c|c|c|c|c|c|c|c|c|}
\hline Manganese & SEL_MOE & $\begin{array}{l}\text { IHP } \\
\text { LMB } \\
\text { LHC } \\
\text { HHC }\end{array}$ & $\begin{array}{l}3 \\
5 \\
3 \\
2\end{array}$ & $\begin{array}{l}3 \\
5 \\
3 \\
2\end{array}$ & $\begin{array}{r}803.33 \\
3211.20 \\
1760.00 \\
747.00\end{array}$ & $\begin{array}{l}1650.715184 \\
6021.788706 \\
2289.905652 \\
1018.491315\end{array}$ & $\begin{array}{l}1.487131 \\
5.425035 \\
2.062978 \\
0.917560\end{array}$ & $\begin{array}{l}1110.000000 \\
1110.000000 \\
1110.000000 \\
1110.000000\end{array}$ \\
\hline Mercury & $E R \_L$ & $\begin{array}{l}\text { IHP } \\
\text { LHB } \\
\text { LHC } \\
\text { HWC }\end{array}$ & $\begin{array}{l}3 \\
5 \\
3 \\
2\end{array}$ & $\begin{array}{l}3 \\
5 \\
3 \\
2\end{array}$ & $\begin{array}{l}2.03 \\
0.12 \\
0.17 \\
4.60\end{array}$ & $\begin{array}{l}4.072683 \\
0.142359 \\
0.199085 \\
5.862750\end{array}$ & $\begin{array}{r}27.151220 \\
0.949060 \\
1.327235 \\
39.085002\end{array}$ & $\begin{array}{l}0.150000 \\
0.150000 \\
0.150000 \\
0.150000\end{array}$ \\
\hline Mercury & ER_M & $\begin{array}{l}\text { IHP } \\
\text { LMBB } \\
\text { LHC } \\
\text { MHC }\end{array}$ & $\begin{array}{l}3 \\
5 \\
3 \\
2\end{array}$ & $\begin{array}{l}3 \\
5 \\
3 \\
2\end{array}$ & $\begin{array}{l}2.03 \\
0.12 \\
0.17 \\
4.60\end{array}$ & $\begin{array}{l}4.072683 \\
0.142359 \\
0.199085 \\
5.862750\end{array}$ & $\begin{array}{l}5.736173 \\
0.200506 \\
0.280402 \\
8.257395\end{array}$ & $\begin{array}{l}0.710000 \\
0.710000 \\
0.710000 \\
0.710000\end{array}$ \\
\hline Mercury & REG_IV & $\begin{array}{l}\text { IHP } \\
\text { LMB } \\
\text { LHC } \\
\text { MHC }\end{array}$ & $\begin{array}{l}3 \\
5 \\
3 \\
2\end{array}$ & $\begin{array}{l}3 \\
5 \\
3 \\
2\end{array}$ & $\begin{array}{l}2.03 \\
0.12 \\
0.17 \\
4.60\end{array}$ & $\begin{array}{l}4.072683 \\
0.142359 \\
0.199085 \\
5.862750\end{array}$ & $\begin{array}{r}40.726831 \\
1.423590 \\
1.990852 \\
58.627503\end{array}$ & $\begin{array}{l}0.100000 \\
0.100000 \\
0.100000 \\
0.100000\end{array}$ \\
\hline Mercury & SED_PEL & $\begin{array}{l}\text { IHP } \\
\text { LMB } \\
\text { LHC } \\
\text { MHC }\end{array}$ & $\begin{array}{l}3 \\
5 \\
3 \\
2\end{array}$ & $\begin{array}{l}3 \\
5 \\
3 \\
2\end{array}$ & $\begin{array}{l}2.03 \\
0.12 \\
0.17 \\
4.60\end{array}$ & $\begin{array}{l}4.072683 \\
0.142359 \\
0.199085 \\
5.862750\end{array}$ & $\begin{array}{l}5.851556 \\
0.204539 \\
0.286042 \\
8.423491\end{array}$ & $\begin{array}{l}0.696000 \\
0.696000 \\
0.696000 \\
0.696000\end{array}$ \\
\hline Mercury & SED_TEL & $\begin{array}{l}\text { IHP } \\
\text { LMBB } \\
\text { LWC } \\
\text { MWC }\end{array}$ & $\begin{array}{l}3 \\
5 \\
3 \\
2\end{array}$ & $\begin{array}{l}3 \\
5 \\
3 \\
2\end{array}$ & $\begin{array}{l}2.03 \\
0.12 \\
0.17 \\
4.60\end{array}$ & $\begin{array}{l}4.072683 \\
0.142359 \\
0.199085 \\
5.862750\end{array}$ & $\begin{array}{r}31.328332 \\
1.095069 \\
1.531425 \\
45.098080\end{array}$ & $\begin{array}{l}0.130000 \\
0.130000 \\
0.130000 \\
0.130000\end{array}$ \\
\hline Naphthalene & EQPSOB_A & $\begin{array}{l}\text { IHP } \\
\text { LWC }\end{array}$ & $\begin{array}{l}5 \\
7\end{array}$ & $\begin{array}{l}2 \\
1\end{array}$ & $\begin{array}{l}0.04 \\
0.03\end{array}$ & $\begin{array}{l}0.047791 \\
0.031000\end{array}$ & $\begin{array}{l}0.117423 \\
0.076167\end{array}$ & $\begin{array}{l}0.407000 \\
0.407000\end{array}$ \\
\hline Naphthalene & ER_L & $\begin{array}{l}\text { IHP } \\
\text { LHC }\end{array}$ & $\begin{array}{l}5 \\
7\end{array}$ & $\begin{array}{l}2 \\
1\end{array}$ & $\begin{array}{l}0.04 \\
0.03\end{array}$ & $\begin{array}{l}0.047791 \\
0.031000\end{array}$ & $\begin{array}{l}0.298694 \\
0.193750\end{array}$ & $\begin{array}{l}0.160000 \\
0.160000\end{array}$ \\
\hline Naph thalene & ER_M & $\begin{array}{l}\text { IHP } \\
\text { LHC }\end{array}$ & $\begin{array}{l}5 \\
7\end{array}$ & $\begin{array}{l}2 \\
1\end{array}$ & $\begin{array}{l}0.04 \\
0.03\end{array}$ & $\begin{array}{l}0.047791 \\
0.031000\end{array}$ & $\begin{array}{l}0.022758 \\
0.014762\end{array}$ & $\begin{array}{l}2.100000 \\
2.100000\end{array}$ \\
\hline Naphthalene & REG_IV & $\begin{array}{l}\text { IHP } \\
\text { LHC }\end{array}$ & $\begin{array}{l}5 \\
7\end{array}$ & $\begin{array}{l}2 \\
1\end{array}$ & $\begin{array}{l}0.04 \\
0.03\end{array}$ & $\begin{array}{l}0.047791 \\
0.031000\end{array}$ & $\begin{array}{l}0.144821 \\
0.093939\end{array}$ & $\begin{array}{l}0.330000 \\
0.330000\end{array}$ \\
\hline Maphthalene & SED_PEL & $\begin{array}{l}\text { IHP } \\
\text { LHC }\end{array}$ & $\begin{array}{l}5 \\
7\end{array}$ & $\begin{array}{l}2 \\
1\end{array}$ & $\begin{array}{l}0.04 \\
0.03\end{array}$ & $\begin{array}{l}0.047791 \\
0.031000\end{array}$ & $\begin{array}{l}0.122228 \\
0.079284\end{array}$ & $\begin{array}{l}0.391000 \\
0.391000\end{array}$ \\
\hline Naphthalene & SED_TEL & $\begin{array}{l}\text { IHP } \\
\text { LHC }\end{array}$ & $\begin{array}{l}5 \\
7\end{array}$ & $\begin{array}{l}2 \\
1\end{array}$ & $\begin{array}{l}0.04 \\
0.03\end{array}$ & $\begin{array}{l}0.047791 \\
0.031000\end{array}$ & $\begin{array}{l}1.381245 \\
0.895954\end{array}$ & $\begin{array}{l}0.034600 \\
0.034600\end{array}$ \\
\hline Nickel & ER_L. & $\begin{array}{l}\text { IHP } \\
\text { LMB } \\
\text { LHC }\end{array}$ & $\begin{array}{l}3 \\
5 \\
3\end{array}$ & $\begin{array}{l}3 \\
5 \\
3\end{array}$ & $\begin{array}{l}45.90 \\
38.30 \\
30.23\end{array}$ & $\begin{array}{r}145.505469 \\
42.993937 \\
43.938960\end{array}$ & $\begin{array}{l}6.928832 \\
2.047330 \\
2.092331\end{array}$ & $\begin{array}{l}21.000000 \\
21.000000 \\
21.000000\end{array}$ \\
\hline
\end{tabular}




\begin{tabular}{|c|c|c|c|c|c|c|c|c|}
\hline & & MWC & 2 & 2 & 25.55 & 30.916689 & 1.472223 & 21.000000 \\
\hline Hickel & ER_M & $\begin{array}{l}\text { IHP } \\
\text { LMB } \\
\text { LWC } \\
\text { MHC }\end{array}$ & $\begin{array}{l}3 \\
5 \\
3 \\
2\end{array}$ & $\begin{array}{l}3 \\
5 \\
3 \\
2\end{array}$ & $\begin{array}{l}45.90 \\
38.30 \\
30.23 \\
25.55\end{array}$ & $\begin{array}{r}145.505469 \\
42.993937 \\
43.938960 \\
30.916689\end{array}$ & $\begin{array}{l}2.819873 \\
0.833216 \\
0.851530 \\
0.599169\end{array}$ & $\begin{array}{l}51.600000 \\
51.600000 \\
51.600000 \\
51.600000\end{array}$ \\
\hline Hickel & REG_IV & $\begin{array}{l}\text { IHP } \\
\text { LMB } \\
\text { LHC } \\
\text { MHC }\end{array}$ & $\begin{array}{l}3 \\
5 \\
3 \\
2\end{array}$ & $\begin{array}{l}3 \\
5 \\
3 \\
2\end{array}$ & $\begin{array}{l}45.90 \\
38.30 \\
30.23 \\
25.55\end{array}$ & $\begin{array}{r}145.505469 \\
42.993937 \\
43.938960 \\
30.916689\end{array}$ & $\begin{array}{l}6.961984 \\
2.057126 \\
2.102343 \\
1.479267\end{array}$ & $\begin{array}{l}20.900000 \\
20.900000 \\
20.900000 \\
20.900000\end{array}$ \\
\hline Nickel & SED_PEL & $\begin{array}{l}\text { IHP } \\
\text { LMB } \\
\text { LWC } \\
\text { MHC }\end{array}$ & $\begin{array}{l}3 \\
5 \\
3 \\
2\end{array}$ & $\begin{array}{l}3 \\
5 \\
3 \\
2\end{array}$ & $\begin{array}{l}45.90 \\
38.30 \\
30.23 \\
25.55\end{array}$ & $\begin{array}{r}145.505469 \\
42.993937 \\
43.938960 \\
30.916689\end{array}$ & $\begin{array}{l}3.399660 \\
1.004531 \\
1.026611 \\
0.722353\end{array}$ & $\begin{array}{l}42.800001 \\
42.800001 \\
42.800001 \\
42.800001\end{array}$ \\
\hline Nickel & SED_TEL & $\begin{array}{l}\text { IHP } \\
\text { LMB } \\
\text { LHC } \\
\text { MHC }\end{array}$ & $\begin{array}{l}3 \\
5 \\
3 \\
2\end{array}$ & $\begin{array}{l}3 \\
5 \\
3 \\
2\end{array}$ & $\begin{array}{l}45.90 \\
38.30 \\
30.23 \\
25.55\end{array}$ & $\begin{array}{r}145.505469 \\
42.993937 \\
43.938960 \\
30.916689\end{array}$ & $\begin{array}{l}9.151287 \\
2.704021 \\
2.763457 \\
1.944446\end{array}$ & $\begin{array}{l}15.900000 \\
15.900000 \\
15.900000 \\
15.900000\end{array}$ \\
\hline PCB, total & EAPSAB_A & $\begin{array}{l}\text { IHP } \\
\text { LMB } \\
\text { LHC } \\
\text { MHC }\end{array}$ & $\begin{array}{l}5 \\
4 \\
7 \\
4\end{array}$ & $\begin{array}{l}5 \\
1 \\
4 \\
4\end{array}$ & $\begin{array}{l}0.74 \\
0.43 \\
0.38 \\
0.65\end{array}$ & $\begin{array}{l}1.108107 \\
0.428000 \\
0.462140 \\
1.079672\end{array}$ & $\begin{array}{l}0.054001 \\
0.020858 \\
0.022521 \\
0.052616\end{array}$ & $\begin{array}{l}20.520000 \\
20.520000 \\
20.520000 \\
20.520000\end{array}$ \\
\hline PCB, total & ER_L & $\begin{array}{l}\text { IHP } \\
\text { LMB } \\
\text { LHC } \\
\text { MHC }\end{array}$ & $\begin{array}{l}5 \\
4 \\
7 \\
4\end{array}$ & $\begin{array}{l}5 \\
1 \\
4 \\
4\end{array}$ & $\begin{array}{l}0.74 \\
0.43 \\
0.38 \\
0.65\end{array}$ & $\begin{array}{l}1.108107 \\
0.428000 \\
0.462140 \\
1.079672\end{array}$ & $\begin{array}{l}48.178552 \\
18.608696 \\
20.093043 \\
46.942239\end{array}$ & $\begin{array}{l}0.023000 \\
0.023000 \\
0.023000 \\
0.023000\end{array}$ \\
\hline PCB, total & ER_M & $\begin{array}{l}\text { IHP } \\
\text { LMB } \\
\text { LHC } \\
\text { HHC }\end{array}$ & $\begin{array}{l}5 \\
4 \\
7 \\
4\end{array}$ & $\begin{array}{l}5 \\
1 \\
4 \\
4\end{array}$ & $\begin{array}{l}0.74 \\
0.43 \\
0.38 \\
0.65\end{array}$ & $\begin{array}{l}1.108107 \\
0.428000 \\
0.462140 \\
1.079672\end{array}$ & $\begin{array}{l}6.156148 \\
2.377778 \\
2.567444 \\
5.998175\end{array}$ & $\begin{array}{l}0.180000 \\
0.180000 \\
0.180000 \\
0.180000\end{array}$ \\
\hline PCB, total & REG_IV & $\begin{array}{l}\text { IHP } \\
\text { LMB } \\
\text { LHC } \\
\text { HHC }\end{array}$ & $\begin{array}{l}5 \\
4 \\
7 \\
4\end{array}$ & $\begin{array}{l}5 \\
1 \\
4 \\
4\end{array}$ & $\begin{array}{l}0.74 \\
0.43 \\
0.38 \\
0.65\end{array}$ & $\begin{array}{l}1.108107 \\
0.428000 \\
0.462140 \\
1.079672\end{array}$ & $\begin{array}{l}33.578991 \\
12.969697 \\
14.004242 \\
32.717318\end{array}$ & $\begin{array}{l}0.033000 \\
0.033000 \\
0.033000 \\
0.033000\end{array}$ \\
\hline PCB， total & SED_PEL & $\begin{array}{l}\text { IHP } \\
\text { LMB } \\
\text { LHC } \\
\text { MHC }\end{array}$ & $\begin{array}{l}5 \\
4 \\
7 \\
4\end{array}$ & $\begin{array}{l}5 \\
1 \\
4 \\
4\end{array}$ & $\begin{array}{l}0.74 \\
0.43 \\
0.38 \\
0.65\end{array}$ & $\begin{array}{l}1.108107 \\
0.428000 \\
0.462140 \\
1.079672\end{array}$ & $\begin{array}{l}5.862998 \\
2.264550 \\
2.445185 \\
5.712548\end{array}$ & $\begin{array}{l}0.189000 \\
0.189000 \\
0.189000 \\
0.189000\end{array}$ \\
\hline PCB, total & SED_TEL & $\begin{array}{l}1 \text { IHP } \\
\text { LMB } \\
\text { LHC } \\
\text { MHC }\end{array}$ & $\begin{array}{l}5 \\
4 \\
7 \\
4\end{array}$ & $\begin{array}{l}5 \\
1 \\
4 \\
4\end{array}$ & $\begin{array}{l}0.74 \\
0.43 \\
0.38 \\
0.65\end{array}$ & $\begin{array}{l}1.108107 \\
0.428000 \\
0.462140 \\
1.079672\end{array}$ & $\begin{array}{l}51.301235 \\
19.814815 \\
21.395370 \\
49.984791\end{array}$ & $\begin{array}{l}0.021600 \\
0.021600 \\
0.021600 \\
0.021600\end{array}$ \\
\hline
\end{tabular}




\begin{tabular}{|c|c|c|c|c|c|c|c|c|}
\hline PU-238 & SED_RAD & $\begin{array}{l}\text { IHP } \\
\text { LMB } \\
\text { LWC } \\
\text { MHC }\end{array}$ & $\begin{array}{l}5 \\
5 \\
4 \\
2\end{array}$ & $\begin{array}{l}5 \\
2 \\
4 \\
2\end{array}$ & $\begin{array}{l}0.31 \\
1.10 \\
0.37 \\
0.86\end{array}$ & $\begin{array}{l}0.440587 \\
1.534837 \\
1.178685 \\
1.139119\end{array}$ & $\begin{array}{l}0.000017 \\
0.000058 \\
0.000045 \\
0.000043\end{array}$ & $\begin{array}{l}26272.000000 \\
26272.000000 \\
26272.000000 \\
26272.000000\end{array}$ \\
\hline$P U-239 / 40$ & SED_RAD & $\begin{array}{l}\text { IHP } \\
\text { LHC } \\
\text { MHC }\end{array}$ & $\begin{array}{l}5 \\
4 \\
2\end{array}$ & $\begin{array}{l}5 \\
4 \\
2\end{array}$ & $\begin{array}{r}5.59 \\
18.64 \\
5.30\end{array}$ & $\begin{array}{r}8.759958 \\
59.758823 \\
7.194125\end{array}$ & $\begin{array}{l}0.000313 \\
0.002136 \\
0.000257\end{array}$ & $\begin{array}{l}27975.000000 \\
27975.000000 \\
27975.000000\end{array}$ \\
\hline Pentachlorophenol & AET & IHP & 5 & 1 & 0.03 & 0.029000 & 0.080556 & 0.360000 \\
\hline Phenanthrene & EPASAC_A & $\begin{array}{l}\text { IHP } \\
\text { LMB } \\
\text { LHC } \\
\text { MHC }\end{array}$ & $\begin{array}{l}5 \\
5 \\
7 \\
4\end{array}$ & $\begin{array}{l}5 \\
1 \\
2 \\
3\end{array}$ & $\begin{array}{l}0.31 \\
0.07 \\
0.37 \\
0.93\end{array}$ & $\begin{array}{l}0.654559 \\
0.065000 \\
0.818758 \\
2.517209\end{array}$ & $\begin{array}{l}0.363644 \\
0.036111 \\
0.454866 \\
1.398450\end{array}$ & $\begin{array}{l}1.800000 \\
1.800000 \\
1.800000 \\
1.800000\end{array}$ \\
\hline Phenanthrene & ER_L & $\begin{array}{l}\text { IHP } \\
\text { LMB } \\
\text { LHC } \\
\text { MHC }\end{array}$ & $\begin{array}{l}5 \\
5 \\
7 \\
4\end{array}$ & $\begin{array}{l}5 \\
1 \\
2 \\
3\end{array}$ & $\begin{array}{l}0.31 \\
0.07 \\
0.37 \\
0.93\end{array}$ & $\begin{array}{l}0.654559 \\
0.065000 \\
0.818758 \\
2.517209\end{array}$ & $\begin{array}{r}2.727328 \\
0.270833 \\
3.411493 \\
10.488372\end{array}$ & $\begin{array}{l}0.240000 \\
0.240000 \\
0.240000 \\
0.240000\end{array}$ \\
\hline Phenanthrene & ER_M & $\begin{array}{l}\text { IHP } \\
\text { LMB } \\
\text { LMC } \\
\text { MHC }\end{array}$ & $\begin{array}{l}5 \\
5 \\
7 \\
4\end{array}$ & $\begin{array}{l}5 \\
1 \\
2 \\
3\end{array}$ & $\begin{array}{l}0.31 \\
0.07 \\
0.37 \\
0.93\end{array}$ & $\begin{array}{l}0.654559 \\
0.065000 \\
0.818758 \\
2.517209\end{array}$ & $\begin{array}{l}0.436372 \\
0.043333 \\
0.54539 \\
1.678140\end{array}$ & $\begin{array}{l}1.500000 \\
1.500000 \\
1.550000 \\
1.500000\end{array}$ \\
\hline Phenanthrene & REG_IV & $\begin{array}{l}\text { IHP } \\
\text { LMB } \\
\text { LHC } \\
\text { MHC }\end{array}$ & $\begin{array}{l}5 \\
5 \\
7 \\
4\end{array}$ & $\begin{array}{l}5 \\
1 \\
2 \\
3\end{array}$ & $\begin{array}{l}0.31 \\
0.07 \\
0.37 \\
0.93\end{array}$ & $\begin{array}{l}0.654559 \\
0.065000 \\
0.818758 \\
2.517209\end{array}$ & $\begin{array}{l}1.983511 \\
0.196970 \\
2.481066 \\
7.627907\end{array}$ & $\begin{array}{l}0.330000 \\
0.330000 \\
0.330000 \\
0.330000\end{array}$ \\
\hline Phenanthrene & SED_PEL & $\begin{array}{l}\text { IHP } \\
\text { LMB } \\
\text { LHC } \\
\text { MHC }\end{array}$ & $\begin{array}{l}5 \\
5 \\
7 \\
4\end{array}$ & $\begin{array}{l}5 \\
1 \\
2 \\
3\end{array}$ & $\begin{array}{l}0.31 \\
0.07 \\
0.37 \\
0.93\end{array}$ & $\begin{array}{l}0.654559 \\
0.065000 \\
0.818758 \\
2.517209\end{array}$ & $\begin{array}{l}1.203233 \\
0.119485 \\
1.505070 \\
4.627223\end{array}$ & $\begin{array}{l}0.544000 \\
0.544000 \\
0.544000 \\
0.544000\end{array}$ \\
\hline Phenanthrene & SED_TEL & $\begin{array}{l}\text { IHP } \\
\text { LMB } \\
\text { LHC } \\
\text { MHC }\end{array}$ & $\begin{array}{l}5 \\
5 \\
7 \\
4\end{array}$ & $\begin{array}{l}5 \\
1 \\
2 \\
3\end{array}$ & $\begin{array}{l}0.31 \\
0.07 \\
0.37 \\
0.93\end{array}$ & $\begin{array}{l}0.654559 \\
0.065000 \\
0.818758 \\
2.517209\end{array}$ & $\begin{array}{r}7.549696 \\
0.749712 \\
9.443578 \\
29.033556\end{array}$ & $\begin{array}{l}0.086700 \\
0.086700 \\
0.086700 \\
0.086700\end{array}$ \\
\hline Pyrene & ER_L & $\begin{array}{l}\text { IHP } \\
\text { LMB } \\
\text { LHC } \\
\text { MHC }\end{array}$ & $\begin{array}{l}5 \\
5 \\
7 \\
4\end{array}$ & $\begin{array}{l}5 \\
1 \\
3 \\
4\end{array}$ & $\begin{array}{l}0.39 \\
0.09 \\
0.08 \\
0.67\end{array}$ & $\begin{array}{l}0.831804 \\
0.086000 \\
0.132275 \\
1.499339\end{array}$ & $\begin{array}{l}1.260309 \\
0.130303 \\
0.200416 \\
2.271726\end{array}$ & $\begin{array}{l}0.660000 \\
0.660000 \\
0.660000 \\
0.660000\end{array}$ \\
\hline Pyrene & ER_M & $\begin{array}{l}\text { IHP } \\
\text { LMB } \\
\text { LHC } \\
\text { MHC }\end{array}$ & $\begin{array}{l}5 \\
5 \\
7 \\
4\end{array}$ & $\begin{array}{l}5 \\
1 \\
3 \\
4\end{array}$ & $\begin{array}{l}0.39 \\
0.09 \\
0.08 \\
0.67\end{array}$ & $\begin{array}{l}0.831804 \\
0.086000 \\
0.132275 \\
1.499339\end{array}$ & $\begin{array}{l}0.319925 \\
0.033077 \\
0.050875 \\
0.576669\end{array}$ & $\begin{array}{l}2.600000 \\
2.600000 \\
2.600000 \\
2.600000\end{array}$ \\
\hline
\end{tabular}




\begin{tabular}{|c|c|c|c|c|c|c|c|c|}
\hline Pyrene & REG_IV & $\begin{array}{l}\text { IHP } \\
\text { LMB } \\
\text { LWC } \\
\text { MHC }\end{array}$ & $\begin{array}{l}5 \\
5 \\
7 \\
4\end{array}$ & $\begin{array}{l}5 \\
1 \\
3 \\
4\end{array}$ & $\begin{array}{l}0.39 \\
0.09 \\
0.08 \\
0.67\end{array}$ & $\begin{array}{l}0.831804 \\
0.086000 \\
0.132275 \\
1.499339\end{array}$ & $\begin{array}{l}2.520618 \\
0.260606 \\
0.400832 \\
4.543453\end{array}$ & $\begin{array}{l}0.330000 \\
0.330000 \\
0.330000 \\
0.330000\end{array}$ \\
\hline Pyrene & SED_PEL. & $\begin{array}{l}\text { IHP } \\
\text { LMB } \\
\text { LWC } \\
\text { MHC }\end{array}$ & $\begin{array}{l}5 \\
5 \\
7 \\
4\end{array}$ & $\begin{array}{l}5 \\
1 \\
3 \\
4\end{array}$ & $\begin{array}{l}0.39 \\
0.09 \\
0.08 \\
0.67\end{array}$ & $\begin{array}{l}0.831804 \\
0.086000 \\
0.132275 \\
1.499339\end{array}$ & $\begin{array}{l}0.594996 \\
0.061516 \\
0.094617 \\
1.072489\end{array}$ & $\begin{array}{l}1.398000 \\
1.398000 \\
1.398000 \\
1.398000\end{array}$ \\
\hline Pyrene & SED_TEL & $\begin{array}{l}\text { IHP } \\
\text { LMB } \\
\text { LWC } \\
\text { MHC }\end{array}$ & $\begin{array}{l}5 \\
5 \\
7 \\
4\end{array}$ & $\begin{array}{l}5 \\
1 \\
3 \\
4\end{array}$ & $\begin{array}{l}0.39 \\
0.09 \\
0.08 \\
0.67\end{array}$ & $\begin{array}{l}0.831804 \\
0.086000 \\
0.132275 \\
1.499339\end{array}$ & $\begin{array}{l}5.436627 \\
0.562092 \\
0.864540 \\
9.799604\end{array}$ & $\begin{array}{l}0.153000 \\
0.153000 \\
0.153000 \\
0.153000\end{array}$ \\
\hline silver & $E R \_L$ & $\begin{array}{l}\text { IHP } \\
\text { L.MB } \\
\text { LHC } \\
\text { MHC }\end{array}$ & $\begin{array}{l}3 \\
5 \\
3 \\
2\end{array}$ & $\begin{array}{l}3 \\
5 \\
3 \\
2\end{array}$ & $\begin{array}{r}7.37 \\
0.29 \\
0.29 \\
24.05\end{array}$ & $\begin{array}{r}21.870242 \\
0.324491 \\
0.332266 \\
31.310814\end{array}$ & $\begin{array}{r}21.870242 \\
0.324491 \\
0.332266 \\
31.310814\end{array}$ & $\begin{array}{l}1.000000 \\
1.000000 \\
1.000000 \\
1.000000\end{array}$ \\
\hline silver & ER_M & $\begin{array}{l}\text { IHP } \\
\text { LMB } \\
\text { LHC } \\
\text { MHC }\end{array}$ & $\begin{array}{l}3 \\
5 \\
3 \\
2\end{array}$ & $\begin{array}{l}3 \\
5 \\
3 \\
2\end{array}$ & $\begin{array}{r}7.37 \\
0.29 \\
0.29 \\
24.05\end{array}$ & $\begin{array}{r}21.870242 \\
0.324491 \\
0.332266 \\
31.310814\end{array}$ & $\begin{array}{l}5.910876 \\
0.087700 \\
0.089802 \\
8.462382\end{array}$ & $\begin{array}{l}3.700000 \\
3.700000 \\
3.700000 \\
3.700000\end{array}$ \\
\hline silver & REG_IV & $\begin{array}{l}\text { IHP } \\
\text { LMB } \\
\text { LHC } \\
\text { MHC }\end{array}$ & $\begin{array}{l}3 \\
5 \\
3 \\
2\end{array}$ & $\begin{array}{l}3 \\
5 \\
3 \\
2\end{array}$ & $\begin{array}{r}7.37 \\
0.29 \\
0.29 \\
24.05\end{array}$ & $\begin{array}{r}21.870242 \\
0.324491 \\
0.332266 \\
31.310814\end{array}$ & $\begin{array}{r}10.935121 \\
0.162246 \\
0.166133 \\
15.655407\end{array}$ & $\begin{array}{l}2.000000 \\
2.000000 \\
2.000000 \\
2.000000\end{array}$ \\
\hline silver & SED_PEL & $\begin{array}{l}\text { IHP } \\
\text { LMB } \\
\text { LWC } \\
\text { MHC }\end{array}$ & $\begin{array}{l}3 \\
5 \\
3 \\
2\end{array}$ & $\begin{array}{l}3 \\
5 \\
3 \\
2\end{array}$ & $\begin{array}{r}7.37 \\
0.29 \\
0.29 \\
24.05\end{array}$ & $\begin{array}{r}21.870242 \\
0.324491 \\
0.332266 \\
31.310814\end{array}$ & $\begin{array}{r}12.356069 \\
0.183329 \\
0.187721 \\
17.689726\end{array}$ & $\begin{array}{l}1.770000 \\
1.770000 \\
1.770000 \\
1.770000\end{array}$ \\
\hline silver & SED_TEL & $\begin{array}{l}\text { IHP } \\
\text { LMB } \\
\text { LHC } \\
\text { MHC }\end{array}$ & $\begin{array}{l}3 \\
5 \\
3 \\
2\end{array}$ & $\begin{array}{l}3 \\
5 \\
3 \\
2\end{array}$ & $\begin{array}{r}7.37 \\
0.29 \\
0.29 \\
24.05\end{array}$ & $\begin{array}{r}21.870242 \\
0.324491 \\
0.332266 \\
31.310814\end{array}$ & $\begin{array}{r}29.836617 \\
0.442690 \\
0.453297 \\
42.715979\end{array}$ & $\begin{array}{l}0.733000 \\
0.733000 \\
0.733000 \\
0.733000\end{array}$ \\
\hline TH-228 & SED_RAD & $\begin{array}{l}\text { I LPP } \\
\text { LHBB } \\
\text { LHC } \\
\text { MHC }\end{array}$ & $\begin{array}{l}5 \\
5 \\
4 \\
1\end{array}$ & $\begin{array}{l}5 \\
5 \\
4 \\
1\end{array}$ & $\begin{array}{l}1.44 \\
1.14 \\
6.03 \\
1.50\end{array}$ & $\begin{array}{l}1.759990 \\
1.602714 \\
6.720305 \\
1.500000\end{array}$ & $\begin{array}{l}0.000101 \\
0.000092 \\
0.000385 \\
0.000086\end{array}$ & $\begin{array}{l}17450.000000 \\
17450.000000 \\
17450.000000 \\
17450.000000\end{array}$ \\
\hline TH-230 & SED_RAD & $\begin{array}{l}\text { IHP } \\
\text { LMB } \\
\text { LHC } \\
\text { MHC }\end{array}$ & $\begin{array}{l}5 \\
5 \\
4 \\
1\end{array}$ & $\begin{array}{l}5 \\
5 \\
4 \\
1\end{array}$ & $\begin{array}{l}1.01 \\
0.84 \\
1.06 \\
0.88\end{array}$ & $\begin{array}{l}1.144154 \\
1.173528 \\
1.192956 \\
0.880000\end{array}$ & $\begin{array}{l}0.000004 \\
0.000004 \\
0.000004 \\
0.000003\end{array}$ & $\begin{array}{l}306208.000000 \\
306208.000000 \\
306208.000000 \\
306208.000000\end{array}$ \\
\hline TH-232 & SED_RAD & IHP & 5 & 5 & 1.17 & 1.253080 & 0.000049 & 25440.000000 \\
\hline
\end{tabular}




\begin{tabular}{|c|c|c|c|c|c|c|c|c|}
\hline & & $\begin{array}{l}\text { LMB } \\
\text { LHCC } \\
\text { MHC }\end{array}$ & $\begin{array}{l}5 \\
4 \\
1\end{array}$ & $\begin{array}{l}5 \\
4 \\
1\end{array}$ & $\begin{array}{l}1.14 \\
1.28 \\
1.10\end{array}$ & $\begin{array}{l}1.575231 \\
1.517579 \\
1.100000\end{array}$ & $\begin{array}{l}0.000062 \\
0.000060 \\
0.000043\end{array}$ & $\begin{array}{l}25440.000000 \\
25440.000000 \\
25440.000000\end{array}$ \\
\hline TOTAL RADIO-STRONTIUM & SED_RAD & $\begin{array}{l}\text { IHP } \\
\text { LMB } \\
\text { LHC } \\
\text { MHC }\end{array}$ & $\begin{array}{l}5 \\
5 \\
4 \\
2\end{array}$ & $\begin{array}{l}5 \\
4 \\
3 \\
2\end{array}$ & $\begin{array}{r}47.58 \\
28.63 \\
6.25 \\
25.50\end{array}$ & $\begin{array}{l}89.007899 \\
55.535909 \\
13.833095 \\
72.853136\end{array}$ & $\begin{array}{l}0.005099 \\
0.003182 \\
0.000793 \\
0.004174\end{array}$ & $\begin{array}{l}17455.000000 \\
17455.000000 \\
17455.000000 \\
17455.000000\end{array}$ \\
\hline$U-233 / 4$ & SED_RAD & $\begin{array}{l}\text { IHP } \\
\text { LMB } \\
\text { LWC } \\
\text { MHC }\end{array}$ & $\begin{array}{l}5 \\
5 \\
2 \\
2\end{array}$ & $\begin{array}{l}5 \\
5 \\
2 \\
2\end{array}$ & $\begin{array}{l}2.85 \\
0.81 \\
6.95 \\
4.75\end{array}$ & $\begin{array}{r}4.177064 \\
1.135598 \\
16.736315 \\
9.485314\end{array}$ & $\begin{array}{l}0.000464 \\
0.000126 \\
0.001859 \\
0.001054\end{array}$ & $\begin{array}{r}9001.000000 \\
9001.000000 \\
9001.000000 \\
9001.000000\end{array}$ \\
\hline U-235 & SED_RAD & $\begin{array}{l}\text { IHP } \\
\text { LMBB } \\
\text { LHCC } \\
\text { MHC }\end{array}$ & $\begin{array}{l}5 \\
5 \\
2 \\
2\end{array}$ & $\begin{array}{l}5 \\
5 \\
2 \\
2\end{array}$ & $\begin{array}{l}0.10 \\
0.08 \\
0.07 \\
0.08\end{array}$ & $\begin{array}{l}0.161824 \\
0.130476 \\
0.254756 \\
0.282697\end{array}$ & $\begin{array}{l}0.000018 \\
0.000014 \\
0.000028 \\
0.000031\end{array}$ & $\begin{array}{r}9207.000000 \\
9207.000000 \\
9207.000000 \\
9207.000000\end{array}$ \\
\hline U-238 & SED_RAD & $\begin{array}{l}\text { IHP } \\
\text { LMB } \\
\text { LHC } \\
\text { MHC }\end{array}$ & $\begin{array}{l}5 \\
5 \\
2 \\
2\end{array}$ & $\begin{array}{l}5 \\
5 \\
2 \\
2\end{array}$ & $\begin{array}{l}1.83 \\
0.80 \\
0.24 \\
1.70\end{array}$ & $\begin{array}{l}2.767581 \\
1.077611 \\
0.708531 \\
2.331375\end{array}$ & $\begin{array}{l}0.000331 \\
0.000129 \\
0.000085 \\
0.000279\end{array}$ & $\begin{array}{l}8351.000000 \\
8351.000000 \\
8351.000000 \\
8351.000000\end{array}$ \\
\hline Zine & ER_L & $\begin{array}{l}\text { IHP } \\
\text { LMB } \\
\text { LHC } \\
\text { MHC }\end{array}$ & $\begin{array}{l}3 \\
5 \\
3 \\
2\end{array}$ & $\begin{array}{l}3 \\
5 \\
3 \\
2\end{array}$ & $\begin{array}{r}197.50 \\
399.00 \\
70.27 \\
811.00\end{array}$ & $\begin{array}{r}393.402164 \\
554.862641 \\
88.289810 \\
1423.433897\end{array}$ & $\begin{array}{l}2.622681 \\
3.699084 \\
0.588599 \\
9.489559\end{array}$ & $\begin{array}{l}150.000000 \\
150.000000 \\
150.000000 \\
150.000000\end{array}$ \\
\hline Zine & ER_M & $\begin{array}{l}\text { IHP } \\
\text { LMB } \\
\text { LHC } \\
\text { MHC }\end{array}$ & $\begin{array}{l}3 \\
5 \\
3 \\
2\end{array}$ & $\begin{array}{l}3 \\
5 \\
3 \\
2\end{array}$ & $\begin{array}{r}197.50 \\
399.00 \\
70.27 \\
811.00\end{array}$ & $\begin{array}{r}393.402164 \\
554.862641 \\
88.289810 \\
1423.433897\end{array}$ & $\begin{array}{l}0.959517 \\
1.353324 \\
0.215341 \\
3.471790\end{array}$ & $\begin{array}{r}410.000000 \\
410.000000 \\
410.000000 \\
410.000000\end{array}$ \\
\hline Zinc & REG_IV & $\begin{array}{l}\text { IHP } \\
\text { LHR } \\
\text { LHC } \\
\text { MHC }\end{array}$ & $\begin{array}{l}3 \\
5 \\
3 \\
2\end{array}$ & $\begin{array}{l}3 \\
5 \\
3 \\
2\end{array}$ & $\begin{array}{r}197.50 \\
399.00 \\
70.27 \\
811.00\end{array}$ & $\begin{array}{r}393.402164 \\
554.862644 \\
88.289810 . \\
1423.433897\end{array}$ & $\begin{array}{r}5.785326 \\
8.159745 \\
1.298380 \\
20.932851\end{array}$ & $\begin{array}{l}68.000000 \\
68.000000 \\
68.000000 \\
68.000000\end{array}$ \\
\hline Zine & SED_PEL & $\begin{array}{l}\text { IHP } \\
\text { LMB } \\
\text { LHC } \\
\text { MHC }\end{array}$ & $\begin{array}{l}3 \\
5 \\
3 \\
2\end{array}$ & $\begin{array}{l}3 \\
5 \\
3 \\
2\end{array}$ & $\begin{array}{r}197.50 \\
399.00 \\
70.27 \\
811.00\end{array}$ & $\begin{array}{r}393.402164 \\
554.862641 \\
88.289810 \\
1423.433897\end{array}$ & $\begin{array}{l}1.451669 \\
2.047464 \\
0.325793 \\
5.252524\end{array}$ & $\begin{array}{l}271.000000 \\
271.000000 \\
271.000000 \\
271.000000\end{array}$ \\
\hline Zine & SED_TEL & $\begin{array}{l}\text { IHP } \\
\text { LMB } \\
\text { LHC } \\
\text { MHC }\end{array}$ & $\begin{array}{l}3 \\
5 \\
3 \\
2\end{array}$ & $\begin{array}{l}3 \\
5 \\
3 \\
2\end{array}$ & $\begin{array}{r}197.50 \\
399.00 \\
70.27 \\
811.00\end{array}$ & $\begin{array}{r}393.402164 \\
554.862641 \\
88.289810 \\
1423.433897\end{array}$ & $\begin{array}{r}3.172598 \\
4.474699 \\
0.712015 \\
11.479306\end{array}$ & $\begin{array}{l}124.000000 \\
124.000000 \\
124.000000 \\
124.000000\end{array}$ \\
\hline bis(2- & EQPSAB_A & $\begin{array}{l}\text { IHP } \\
\text { LMB }\end{array}$ & $\begin{array}{l}5 \\
5\end{array}$ & $\begin{array}{l}5 \\
3\end{array}$ & $\begin{array}{l}0.30 \\
0.11\end{array}$ & $\begin{array}{l}0.481422 \\
0.163751\end{array}$ & $\begin{array}{l}0.000001 \\
0.000000\end{array}$ & $\begin{array}{l}890000.000000 \\
890000.000000\end{array}$ \\
\hline
\end{tabular}




\begin{tabular}{|c|c|c|c|c|c|c|c|c|}
\hline & & $\begin{array}{l}\text { LHC } \\
\text { MHC }\end{array}$ & $\begin{array}{l}7 \\
4\end{array}$ & $\begin{array}{l}5 \\
4\end{array}$ & $\begin{array}{l}0.16 \\
0.96\end{array}$ & $\begin{array}{l}0.314450 \\
2.226516\end{array}$ & $\begin{array}{l}0.000000 \\
0.000003\end{array}$ & $\begin{array}{l}890000.000000 \\
890000.000000\end{array}$ \\
\hline bis(2-Ethylhexyl)phthalate & SED_PEL & $\begin{array}{l}\text { IHP } \\
\text { LHB } \\
\text { LHC } \\
\text { HWC }\end{array}$ & $\begin{array}{l}5 \\
5 \\
7 \\
4\end{array}$ & $\begin{array}{l}5 \\
3 \\
5 \\
4\end{array}$ & $\begin{array}{l}0.30 \\
0.11 \\
0.16 \\
0.96\end{array}$ & $\begin{array}{l}0.481422 \\
0.163751 \\
0.314450 \\
2.226516\end{array}$ & $\begin{array}{l}0.181875 \\
0.061863 \\
0.118795 \\
0.841147\end{array}$ & $\begin{array}{l}2.647000 \\
2.647000 \\
2.647000 \\
2.647000\end{array}$ \\
\hline bis(2-Ethylhexyl)phthalate & SED_TEL & $\begin{array}{l}\text { IHP } \\
\text { LMB } \\
\text { LHC } \\
\text { MHC }\end{array}$ & $\begin{array}{l}5 \\
5 \\
7 \\
4\end{array}$ & $\begin{array}{l}5 \\
3 \\
5 \\
4 \\
\end{array}$ & $\begin{array}{l}0.30 \\
0.11 \\
0.16 \\
0.96\end{array}$ & $\begin{array}{l}0.481422 \\
0.163751 \\
0.314450 \\
2.226516\end{array}$ & $\begin{array}{r}2.645178 \\
0.899729 \\
1.727748 \\
12.233605\end{array}$ & $\begin{array}{l}0.182000 \\
0.182000 \\
0.182000 \\
0.182000\end{array}$ \\
\hline
\end{tabular}


Table B.6. Comparison of above-background, maximum-detected soil contaminant concentrations to screening benchmarks for toxicity to soil invertebrates.

\begin{tabular}{|c|c|c|c|c|c|}
\hline Reach & Chemical & $\begin{array}{l}\text { Mean Conc. } \\
\text { (mg/kg) }\end{array}$ & $\begin{array}{l}\text { Maximum } \\
\text { detect. conc. } \\
\text { (mg/kg) }\end{array}$ & $\begin{array}{l}\text { Earthworm } \\
\text { benchmark } \\
\text { (mg/kg) }\end{array}$ & $\begin{array}{l}\text { Hazard } \\
\text { Quotient }\end{array}$ \\
\hline \multirow[t]{8}{*}{ IHP } & Cadmium & 1.211 & 1.5 & 20 & 0.08 \\
\hline & Chromium V12 & 48.93 & 71.60 & 0.4 & 200 \\
\hline & Copper & 28.19 & 45.1 & 50 & $\overline{0.9}$ \\
\hline & Fluorene & 0.38 & 0.14 & 30 & 0.005 \\
\hline & Lead & 59.39 & 111 & 500 & 0.2 \\
\hline & Mercury & 17.33 & 76.4 & 0.1 & 800 \\
\hline & Nickel & 53.63 & 310 & 200 & 2 \\
\hline & Zinc & 95.92 & 159 & 200 & 0.8 \\
\hline & & & & & \\
\hline \multirow[t]{7}{*}{ LWOC } & Cadmium & 0.8325 & 1 & 20 & 0.05 \\
\hline & Chromium V12 & 55.45 & 95.30 & 0.4 & 200 \\
\hline & Lead & 35.3 & 50.4 & 500 & 0.1 \\
\hline & Mercury & 2.958 & 5.1 & 0.1 & 50 \\
\hline & N-Nitrosodiphenylamine ${ }^{1}$ & 0.4275 & 0.42 & 20 & 0.021 \\
\hline & Selenium & 1.075 & 1.3 & 70 & 0.02 \\
\hline & Zinc & 104.4 & 190. & 200 & 1 \\
\hline & & & & & \\
\hline \multirow[t]{4}{*}{ MWOC } & Cadmium & 0.825 & 0.86 & 20 & 0.04 \\
\hline & Mercury & 1.555 & 2.5 & 0.1 & 30 \\
\hline & Selenium & 1.23 & 1.6 & 70 & 0.02 \\
\hline & Zinc & 83.75 & 123 & 200 & 0.6 \\
\hline & & & & & \\
\hline \multirow[t]{3}{*}{$\angle M B C /$} & Cadmium & 0.93 & 1.1 & 20 & 0.06 \\
\hline & Mercury & 0.506 & 2 & 0.1 & 20 \\
\hline & Selenium & 0.902 & 1.3 & 70 & 0.02 \\
\hline
\end{tabular}

Boldface type indicates exceedence of benchmark.

'Background concentration assumed to be zero.

${ }^{2}$ Concentrations of Chromium $\mathrm{V}$ are compared to benchmarks for total chromium. 
Table B.7. Comparison of above-background, maximum-detected soil contaminant concentrations to screening benchmarks for toxicity to plants.

\begin{tabular}{|c|c|c|c|c|c|}
\hline Reach & Chemical & $\begin{array}{l}\text { Mean Conc. } \\
\text { (mg/kg) }\end{array}$ & $\begin{array}{l}\text { Maximum } \\
\text { detect. conc. } \\
\text { (mg/kg) }\end{array}$ & $\begin{array}{c}\text { Benchmark } \\
\text { (mg/kg) }\end{array}$ & $\begin{array}{l}\text { Hazard } \\
\text { Quotient }\end{array}$ \\
\hline \multirow[t]{17}{*}{ IHP } & Barium & 180.27778 & 268 & 500 & 0.5 \\
\hline & Boron ${ }^{1}$ & 6.4055556 & 10.2 & 0.5 & 20 \\
\hline & Cadmium & 1.2111111 & 1.5 & 3 & 0.5 \\
\hline & Chromium V ${ }^{3}$ & 48.93 & 71.60 & 1 & 70 \\
\hline & Copper & 28.188889 & 45.1 & 100 & 0.5 \\
\hline & Di-n-butyl phthalate ${ }^{2}$ & 0.1494 & 0.11 & 200 & 0.0006 \\
\hline & Lead & 59.394444 & 111 & 50 & 2 \\
\hline & Lithium ${ }^{9}$ & 26.844444 & 41.4 & 2 & 20 \\
\hline & Manganese & 1260.1111 & 4150 & 500 & 8 \\
\hline & Mercury & 17.33 & 76.4 & 0.3 & 300 \\
\hline & Molybdenum ${ }^{1}$ & 4.2722222 & 5.2 & 2 & 3 \\
\hline & Nickel & 53.627778 & 310 & 30 & 10 \\
\hline & PCB, total ${ }^{2}$ & 1.0866 & 2.194 & 40 & 0.05 \\
\hline & Silver & 6.6 & 15.2 & 2 & 8 \\
\hline & Thallium & 0.8483333 & 0.91 & 1 & 0.9 \\
\hline & Tin & 10.522222 & 12.8 & 50 & 0.3 \\
\hline & Zinc & 95.916667 & 159 & 50 & 3 \\
\hline \multirow{16}{*}{ LWOC } & & & & & \\
\hline & Boron ${ }^{2}$ & 9.75 & 10.2 & 0.5 & 20 \\
\hline & Cadmium & 0.8325 & 1 & 3 & 0.3 \\
\hline & Chromium V $\mathbf{V}^{3}$ & 55.45 & 95.30 & 1 & 100 \\
\hline & Di-n-butyi phthalate ${ }^{2}$ & 0.18975 & 0.17 & 200 & 0.0009 \\
\hline & Lead & 35.3 & 50.4 & 50 & 1 \\
\hline & Lithium ${ }^{1}$ & 13.95 & 16.2 & 2 & 8 \\
\hline & Manganese & 969.25 & 1280 & 500 & 3 \\
\hline & Mercury & 2.9575 & 5.1 & 0.3 & 20 \\
\hline & Molybdenum ${ }^{1}$ & 3.6 & 3.8 & 2 & 2 \\
\hline & PCB, total ${ }^{2}$ & 0.5115 & 0.736 & 40 & 0.02 \\
\hline & Selenium & 1.075 & 1.3 & 1 & 1 \\
\hline & \begin{tabular}{|l} 
Silver \\
\end{tabular} & 3.7 & 6.8 & 2 & 3 \\
\hline & Tin & 6.95 & 7.3 & 50 & 0.1 \\
\hline & Zinc & 104.35 & 190 & 50 & 4 \\
\hline & & & & & \\
\hline \multirow[t]{8}{*}{ MWOC } & Boron' & 10.45 & 10.9 & 0.5 & 20 \\
\hline & Cadmium & 0.825 & 0.86 & 3 & 0.3 \\
\hline & Di-n-butyl phthalate ${ }^{2}$ & 0.042 & 0.049 & 200 & 0.0002 \\
\hline & Lithium ${ }^{3}$ & 11.2 & 13 & 2 & 7 \\
\hline & Mercury & 1.555 & 2.5 & 0.3 & 8 \\
\hline & Molybdenum ${ }^{4}$ & 3.85 & 4 & 2 & 2 \\
\hline & $\mathrm{PCB}$ total $^{2}$ & 0.633 & 0.94 & 40 & 0.02 \\
\hline & Selenium & 1.23 & 1.6 & 1 & 2 \\
\hline
\end{tabular}




\begin{tabular}{|c|c|c|c|c|c|}
\hline & Silver & 2.5 & 3.9 & 2 & 2 \\
\hline & Tin & 7.4 & 7.7 & 50 & 0.2 \\
\hline & Zinc & 83.75 & 123 & 50 & 2 \\
\hline & & & & & \\
\hline \multirow[t]{15}{*}{$\angle \mathrm{MBC} /$} & Antimony & 10.66 & 12.1 & 5 & 2 \\
\hline & Barium & 220.6 & 409 & 500 & 0.8 \\
\hline & Boron ${ }^{1}$ & 6.36 & 9.4 & 0.5 & 20 \\
\hline & Cadmium & 0.93 & 1.1 & 3 & 0.4 \\
\hline & Di-n-butyl phthalate ${ }^{2}$ & 0.1635714 & 0.42 & 200 & 0.002 \\
\hline & Lead & 16.36 & 18.8 & 50 & 0.4 \\
\hline & Lithium ${ }^{1}$ & 20.02 & 25.9 & 2 & 10 \\
\hline & Manganese & 4502 & 9400 & 500 & 20 \\
\hline & Mercury & 0.506 & 2 & 0.3 & 7 \\
\hline & Molybdenum ${ }^{7}$ & 5.56 & 7.3 & 2 & 4 \\
\hline & $\overline{P C B}$, total $^{2}$ & 0.3752857 & 0.315 & 40 & 0.008 \\
\hline & Selenium & 0.902 & 1.3 & 1 & 1 \\
\hline & Silver & 1.208 & 1.4 & 2 & 0.7 \\
\hline & Thallium & 1.11 & 1.4 & 1 & 1 \\
\hline & Tin & 8.78 & 11.3 & 50 & 0.2 \\
\hline
\end{tabular}

Boldface type indicates exceedence of benchmark.

${ }^{1}$ Background concentration not available.

${ }^{2}$ Background concentration assumed to be zero.

${ }^{3}$ Concentrations of Chromium Vl are compared to benchmarks for total chromium. 

Table B.8. Comparison of above-background, maximum-detected contaminant concentrations in seeps or springs to screening benchmarks for toxicity
to plants in solution.

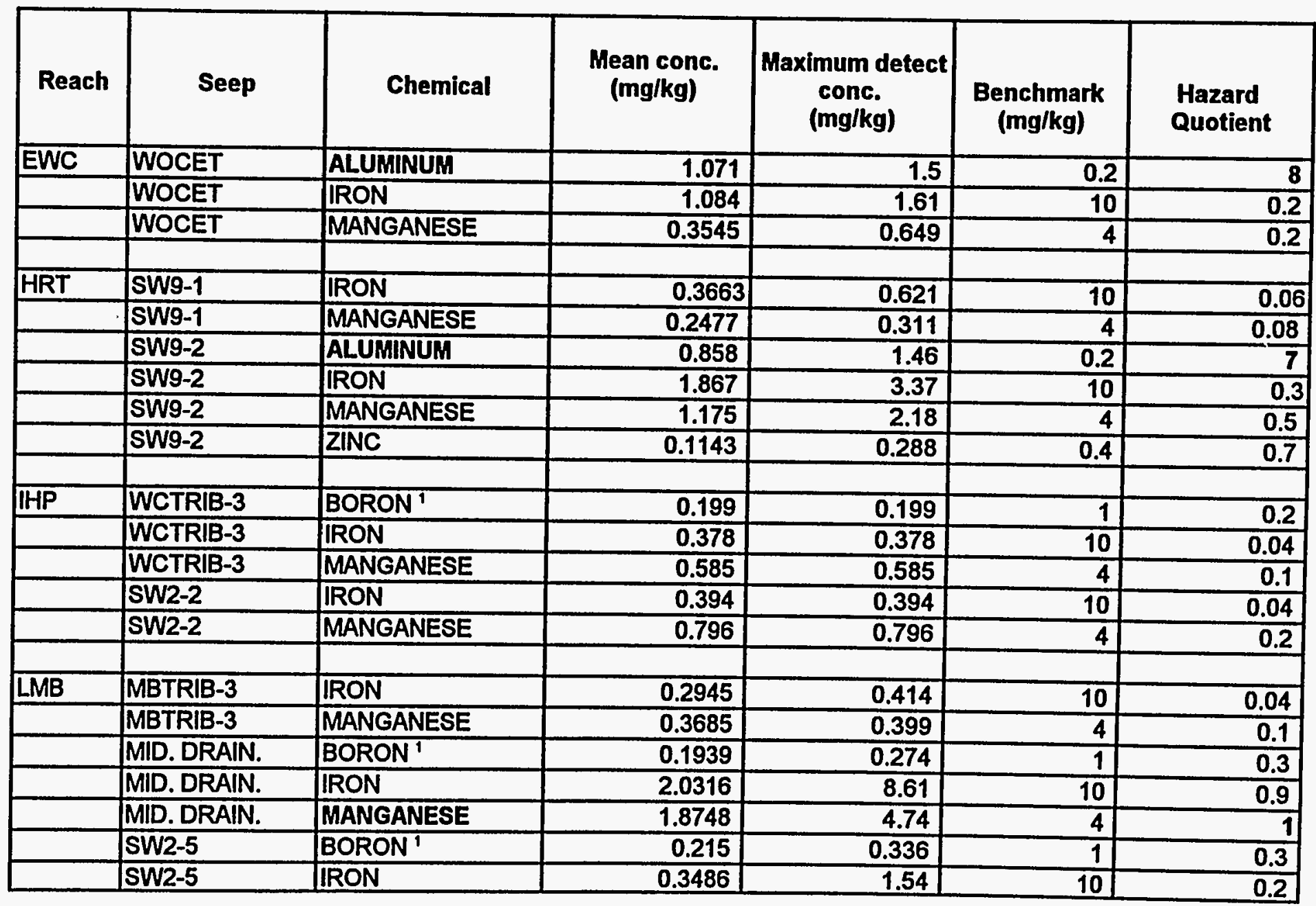




\begin{tabular}{|c|c|c|c|c|c|c|}
\hline & SW2-5 & MANGANESE & 0.945 & 3.06 & 4 & 0.7 \\
\hline & sW5-2 & BORON $^{1}$ & 0.175 & 0.175 & 1 & 0.2 \\
\hline & SW5-2 & IRON & 0.089 & 0.089 & 10 & 0.009 \\
\hline & SW5-4 & BORON $^{1}$ & 0.1457 & 0.234 & 1 & 0.2 \\
\hline & SW5-4 & IRON & 0.4035 & 1.11 & 10 & 0.1 \\
\hline & SW5-4 & MANGANESE & 0.7902 & 2.62 & 4 & 0.7 \\
\hline & & & & & & \\
\hline LWC & EAST SEEP & ALUMINUM & 0.8376 & 2.41 & 0.2 & 10 \\
\hline & EAST SEEP & ARSENIC & 0.0275 & 0.004 & 0.001 & 4 \\
\hline & EAST SEEP & BORON ${ }^{1}$ & 0.08756 & 0.14 & 1 & 0.1 \\
\hline & EAST SEEP & CHROMIUM & 0.015 & 0.033 & 0.05 & 0.7 \\
\hline & EAST SEEP & IRON & 0.6446 & 1.7 & 10 & 0.2 \\
\hline & EAST SEEP & MANGANESE & 0.2593 & 0.552 & 4 & 0.1 \\
\hline & EAST SEEP & MOLYBDENUM ${ }^{\prime}$ & 0.01467 & 0.015 & 0.5 & 0.03 \\
\hline & EAST SEEP & NICKEL & 0.02767 & 0.04 & 0.2 & 0.2 \\
\hline & MV-1 & IRON & 2.1 & 2.11 & 10 & 0.2 \\
\hline & $M V-1$ & MANGANESE & 3.965 & 3.99 & 4 & 1 \\
\hline & sw7-3 & ALUMINUM & 0.452 & 0.775 & 0.2 & 4 \\
\hline & SW7-3 & BORON ${ }^{1}$ & 0.08713 & 0.101 & 1 & 0.1 \\
\hline & SW7-3 & CHROMIUM & 0.056 & 0.091 & 0.05 & 2 \\
\hline & SW7-3 & IRON & 0.3488 & 0.693 & 10 & 0.07 \\
\hline & SW7-3 & MOLYBDENUM ${ }^{1}$ & 0.014 & 0.017 & 0.5 & 0.03 \\
\hline & SW7-5 & ALUMINUM & 0.8017 & 2.10 & 0.2 & 10 \\
\hline & sw7-5 & BORON ${ }^{1}$ & 0.0951 & 0.077 & 1 & 0.08 \\
\hline & SW7-5 & IRON & 0.8155 & 2.73 & 10 & 0.3 \\
\hline & SW7-5 & MANGANESE & 0.2711 & 2.35 & 4 & 0.6 \\
\hline & SW7-6 & ALUMINUM & 0.761 & 0.761 & 0.2 & 4 \\
\hline & SW7-6 & IRON & 0.431 & 0.431 & 10 & 0.04 \\
\hline & SW7-8 & ALUMINUM & 0.412 & 0.412 & 0.2 & 2 \\
\hline & SW7-8 & IRON & 0.368 & 0.368 & 10 & 0.04 \\
\hline & SW7-8 & MANGANESE & 0.126 & 0.126 & 4 & 0.03 \\
\hline & WCTRIB-1 & ALUMINUM & \begin{tabular}{l|l}
0.572 \\
\end{tabular} & 0.957 & 0.2 & 5 \\
\hline & WCTRIB-1 & IRON & 0.437 & 0.659 & 10 & 0.07 \\
\hline
\end{tabular}




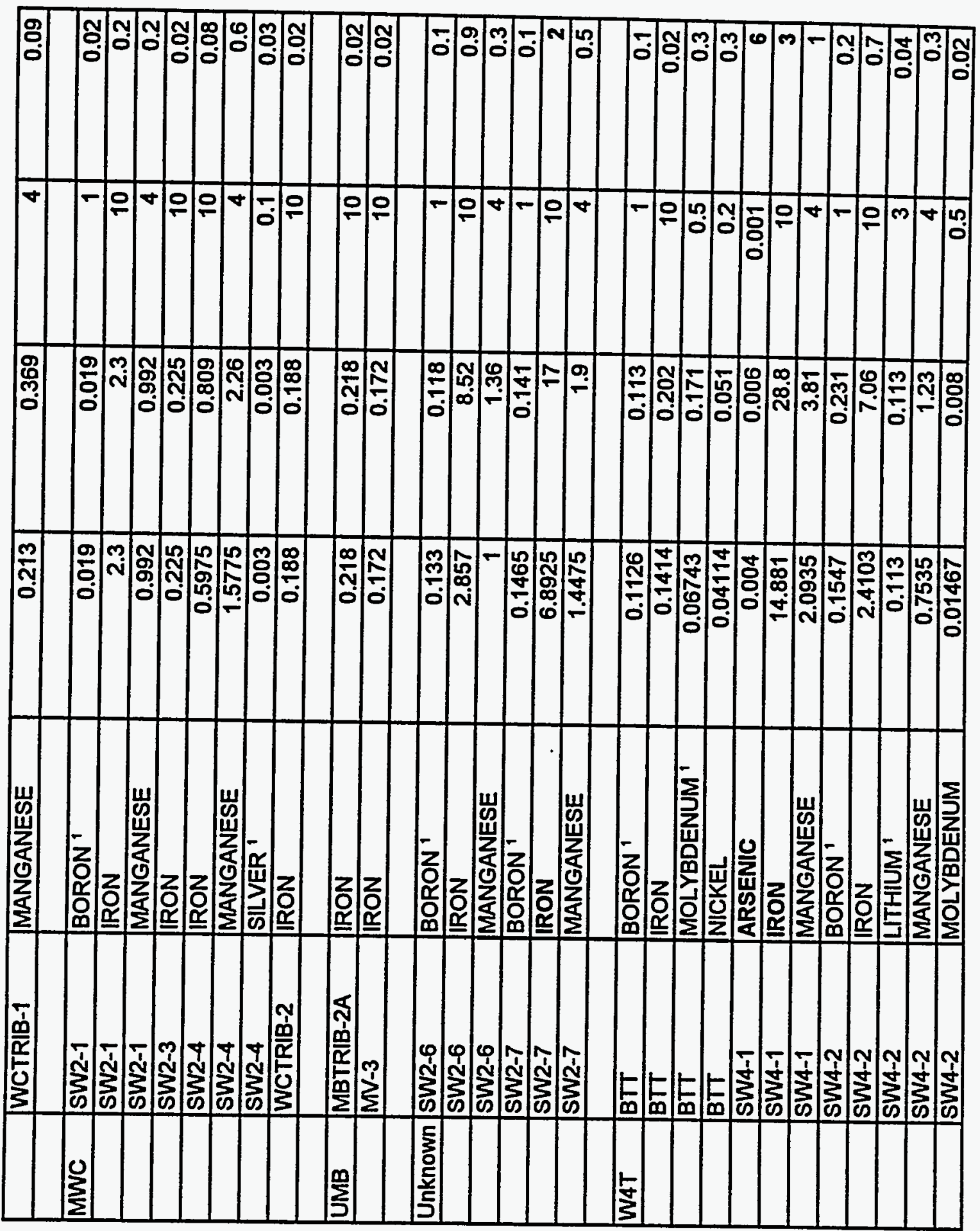




\begin{tabular}{|c|c|c|c|c|c|c|}
\hline & SW4-2 & NICKEL & 6.17 & 9.46 & 0.2 & 50 \\
\hline & WAG4 MS1 & ALUMINUM & 0.1535 & 1.02 & 0.2 & 5 \\
\hline & WAG4 MS1 & BERYLLIUM & 0.000909 & 0.002 & 0.5 & 0.004 \\
\hline & WAG4 MS1 & BORON ${ }^{1}$ & 0.1735 & 0.196 & 1 & 0.2 \\
\hline & WAG4 MS1 & IRON & 0.1947 & 1.12 & 10 & 0.1 \\
\hline & WAG4 MS1 & MANGANESE & 0.2095 & 0.644 & 4 & 0.2 \\
\hline & WAG4 MS1 & MOLYBDENUM $^{1}$ & 0.01418 & 0.007 & 0.5 & 0.01 \\
\hline & WAG4 MS1 & NICKEL & 0.03364 & 0.067 & 0.2 & 0.3 \\
\hline & WAG4 T2A & ALUMINUM & 0.4713 & 1 & 0.2 & 5 \\
\hline & WAG4 T2A & BORON ${ }^{1}$ & 0.1456 & 0.206 & 1 & 0.2 \\
\hline & WAG4 T2A & CHROMIUM & $\overline{0.008}$ & 0.035 & 0.05 & 1 \\
\hline & WAG4 T2A & IRON & 0.4763 & 1.43 & 10 & 0.1 \\
\hline & WAG4 T2A & MANGANESE & 0.1254 & 0.41 & 4 & 0.1 \\
\hline WOL & & IRON & & & & \\
\hline WUL & $\frac{\mathrm{RS}-1}{\mathrm{RS}-1}$ & $\begin{array}{l}\text { IRON } \\
\text { MANGANESE }\end{array}$ & 0.601 & 0.601 & 10 & 0.06 \\
\hline & $\frac{R S-1}{R S-3 A}$ & MANGANESE & 1.35 & 1.35 & 4 & 0.3 \\
\hline & & & 10.012 & 17.7 & 0.2 & 90 \\
\hline & & & 0.01688 & 0.024 & 0.001 & 20 \\
\hline & & & 0.1521 & 0.118 & 1 & 0.1 \\
\hline & ת) & CHROMIUM & 0.078 & 0.096 & 0.05 & 2 \\
\hline & RS-3A & COPPER & 0.0194 & 0.028 & 0.03 & 0.9 \\
\hline & RS-3A & IRON & 7.728 & 13.9 & 10 & 1 \\
\hline & R̂S-3Â & INIANVAAANESE & 0.2344 & 0.531 & 4 & $\overline{0} . \bar{j}$ \\
\hline & RS-3A & MOLYBDENUM ${ }^{1}$ & 0.0483 & 0.056 & 0.5 & 0.1 \\
\hline & RS-3A & NICKEL & 0.097 & 0.108 & 0.2 & 0.5 \\
\hline & RS-3A & SILVER ${ }^{1}$ & 0.0046 & 0.006 & 0.1 & 0.06 \\
\hline & RS-3A & VANADIUM & 0.022 & 0.034 & 0.2 & 0.2 \\
\hline & RS-3B & ALUMINUM & 1.345 & 1.42 & 0.2 & $\overline{7}$ \\
\hline & RS-3B & BORON ${ }^{1}$ & 0.077 & 0.034 & 1 & 0.03 \\
\hline & RS-3B & IRON & 1.065 & 1.08 & 10 & 0.1 \\
\hline & SW7-1 & IRON & 6.375 & 6.57 & 10 & 0.7 \\
\hline & SW7-1 & MANGANESE & 6.39 & 6.4 & 4 & 2 \\
\hline & SW7-2 & ALUMINUM & 0.574 & 0.652 & 0.2 & $\overline{3}$ \\
\hline
\end{tabular}




\begin{tabular}{|l|l|l|r|r|r|r|}
\hline & SW7-2 & COBALT & 0.094 & 0.134 & 0.06 & 2 \\
\hline & SW7-2 & COPPER & 0.015 & 0.025 & 0.03 & 0.8 \\
\hline & SW7-2 & IRON & 0.586 & 0.642 & 10 & 0.06 \\
\hline & FRENCH DR S & TETRACHLOROETHENE & 0.055 & 0.055 & 10 & 0.006 \\
\hline WAG6 MS3B & TETRACHLOROETHENE & 0.001 & 0.001 & 10 & 0.0001 \\
\hline
\end{tabular}

Boldface type indicates exceedence of benchmark.

'Background concentration not available. 


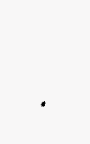


Appendix C

DATA TABLES FOR RISKS TO WILDLIFE 


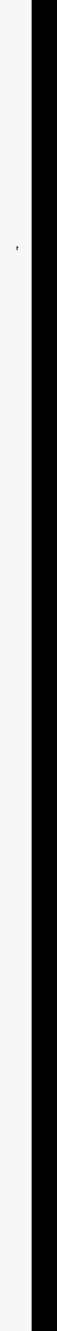




\section{C-3}

Table C.1. Point Estimates of Contaminant Exposure of Mink to Fish from White Oak Creek.

\begin{tabular}{llrrr}
\hline Location & Contaminant & $\begin{array}{r}\text { Dietary } \\
\text { Exposure } \\
\text { (mo/kg/d) }\end{array}$ & $\begin{array}{r}\text { NOAEL } \\
\text { HQ }\end{array}$ & $\begin{array}{r}\text { LOAEL } \\
\text { HQ }\end{array}$ \\
\hline HIINDSCR ${ }^{1}$ & Mercury & 0.005 & 0.33 & 0.20 \\
NTK0.2 & Mercury & 0.010 & 0.64 & 0.38 \\
WCK3.5 & Mercury & 0.014 & 0.91 & 0.55 \\
WCK2.9 & Mercury & 0.023 & 1.51 & 0.91 \\
MEK0.2 & Mercury & 0.007 & 0.45 & 0.27 \\
WCK2.3 & Mercury & 0.015 & 0.98 & 0.59 \\
WOL & Mercury & 0.009 & 0.58 & 0.35 \\
WCK0.9 & Mercury & 0.006 & 0.37 & 0.22 \\
WCK0.3 & Mercury & 0.010 & 0.64 & 0.38 \\
HINDSCR & PCB-1260 & 0.003 & 0.02 & 0.00 \\
NTK0.2 & PCB-1260 & 0.049 & 0.35 & 0.07 \\
WCK3.5 & PCB-1260 & 0.080 & 0.57 & 0.12 \\
WCK2.9 & PCB-1260 & 0.093 & 0.66 & 0.13 \\
MEK0.2 & PCB-1260 & 0.039 & 0.28 & 0.06 \\
WCK2.3 & PCB-1260 & 0.099 & 0.70 & 0.14 \\
WOL & PCB-1260 & 0.129 & 0.92 & 0.19 \\
WCK0.9 & PCB-1260 & 0.052 & 0.37 & 0.08 \\
WCK0.3 & PCB-1260 & 0.058 & 0.41 & 0.08 \\
\hline
\end{tabular}

'Reference location. 
Table C.2. Point Estimates of Contaminant Exposure of Belted Kingfisher to Fish from White Oak Creek.

\begin{tabular}{|c|c|c|c|c|}
\hline Location & Contaminant & $\begin{array}{r}\text { Dietary } \\
\text { Exposure }\end{array}$ & $\begin{array}{r}\text { NOAEL } \\
\mathrm{HO} \\
\end{array}$ & $\begin{array}{r}\text { LOAEL } \\
\mathrm{HO}\end{array}$ \\
\hline $\mathrm{HINDSCR}{ }^{1}$ & Mercury & 0.033 & 5.54 & 0.52 \\
\hline NTK0.2 & Mercury & 0.065 & 10.80 & 1.01 \\
\hline WCK3.5 & Mercury & 0.092 & 15.41 & 1.44 \\
\hline WCK2.9 & Mercury & 0.154 & 25.60 & 2.40 \\
\hline MEK0.2 & Mercury & 0.046 & 7.69 & 0.72 \\
\hline WCK2.3 & Mercury & 0.100 & 16.66 & 1.56 \\
\hline WOL & Mercury & 0.059 & 9.83 & 0.92 \\
\hline WCK0.9 & Mercury & 0.038 & 6.26 & 0.59 \\
\hline WCK0.3 & Mercury & 0.065 & 10.77 & 1.01 \\
\hline $\mathrm{HINDSCR}^{1}$ & PCB-1260 & 0.022 & 0.12 & 0.01 \\
\hline NTK0.2 & PCB-1260 & 0.335 & 1.86 & 0.19 \\
\hline WCK3.5 & PCB-1260 & 0.543 & 3.02 & 0.30 \\
\hline WCK2.9 & PCB-1260 & 0.630 & 3.50 & 0.35 \\
\hline MEK0.2 & PCB-1260 & 0.263 & 1.46 & 0.15 \\
\hline WCK2.3 & PCB-1260 & 0.668 & 3.71 & 0.37 \\
\hline WOL & PCB-1260 & 0.875 & 4.86 & 0.49 \\
\hline WCK0.9 & PCB-1260 & 0.354 & 1.97 & 0.20 \\
\hline WCK0.3 & PCB-1260 & 0.391 & 2.17 & 0.22 \\
\hline
\end{tabular}

'Reference location. 
C-5

Table C.3. Summary Statistics for Soil-Biota Uptake Factors

\begin{tabular}{|c|c|c|c|c|c|c|c|}
\hline Contaminant & Media & Detects & Mean & $\begin{array}{r}\text { Standard } \\
\text { Error } \\
\end{array}$ & UCL95 & Maximum & Minimum \\
\hline Aluminum & Browse & 12 & 0.004 & 0.001 & 0.007 & 0.016 & 0.001 \\
\hline Americium-241 & Browse & 4 & 1.875 & 0.346 & 2.553 & 2.489 & 0.894 \\
\hline Arsenic & Browse & 6 & 0.008 & 0.002 & 0.012 & 0.015 & 0.001 \\
\hline Barium & Browse & 12 & 0.090 & 0.021 & 0.131 & 0.241 & 0.010 \\
\hline Beryllium & Browse & 1 & 0.002 & 0.000 & 0.000 & 0.002 & 0.002 \\
\hline Cadmium & Browse & 8 & 1.158 & 0.761 & 2.650 & 5.951 & 0.002 \\
\hline Calcium & Browse & 12 & 1.717 & 0.376 & 2.455 & 4.257 & 0.117 \\
\hline Chromium & Browse & 12 & 0.024 & 0.005 & 0.033 & 0.065 & 0.001 \\
\hline Cobalt & Browse & 12 & 0.003 & 0.001 & 0.005 & 0.010 & 0.001 \\
\hline Copper & Browse & 12 & 0.305 & 0.071 & 0.443 & 0.864 & 0.001 \\
\hline Iron & Browse & 12 & 0.001 & 0.000 & 0.002 & 0.002 & 0.000 \\
\hline Lead & Browse & 12 & 0.007 & 0.002 & 0.011 & 0.022 & 0.000 \\
\hline Lithium & Browse & 10 & 0.005 & 0.001 & 0.008 & 0.010 & 0.000 \\
\hline Magnesium & Browse & 10 & 0.980 & 0.198 & 1.368 & 2.350 & 0.489 \\
\hline Manganese & Browse & 10 & 0.118 & 0.049 & 0.215 & 0.414 & 0.015 \\
\hline Mercury & Browse & 9 & 0.040 & 0.010 & 0.059 & 0.086 & 0.007 \\
\hline Nickel & Browse & 12 & 0.051 & 0.018 & 0.085 & 0.200 & 0.001 \\
\hline Plutonium-239/240 & Browse & 1 & 1.800 & 0.000 & 0.000 & 1.800 & 1.800 \\
\hline Potassium & Browse & 10 & 6.596 & 1.062 & 8.677 & 12.285 & 2.744 \\
\hline Selenium & Browse & 3 & 0.409 & 0.395 & 1.184 & 1.200 & 0.011 \\
\hline Silver & Browse & 1 & 0.001 & 0.000 & 0.000 & 0.001 & 0.001 \\
\hline Sodium & Browse & 11 & 0.352 & 0.060 & 0.470 & 0.693 & 0.011 \\
\hline Uranium & Browse & 1 & 0.000 & 0.000 & 0.000 & 0.000 & 0.000 \\
\hline Vanadium & Browse & 1 & 0.026 & 0.000 & 0.000 & 0.026 & 0.026 \\
\hline Zine & Browse & 12 & 0.365 & 0.094 & 0.550 & 1.203 & 0.004 \\
\hline Aluminum & Canopy & 12 & 0.006 & 0.001 & 0.009 & 0.016 & 0.000 \\
\hline Americium-241 & Canopy & 6 & 2.774 & 1.493 & 5.700 & 10.194 & 0.748 \\
\hline Arsenic & Canopy & 6 & 0.017 & 0.006 & 0.029 & 0.039 & 0.001 \\
\hline Barium & Canopy & 12 & 0.153 & 0.045 & 0.241 & 0.471 & 0.010 \\
\hline Beryllium & Canopy & 5 & 0.017 & 0.010 & 0.036 & 0.055 & 0.002 \\
\hline Cadmium & Canopy & 7 & 0.136 & 0.083 & 0.299 & 0.621 & 0.003 \\
\hline Calcium & Canopy & 12 & 2.511 & 0.505 & 3.501 & 5.808 & 0.081 \\
\hline Chromium & Canopy & 12 & 0.033 & 0.011 & 0.055 & 0.147 & 0.001 \\
\hline Cobalt & Canopy & 12 & 0.003 & 0.001 & 0.004 & 0.009 & 0.001 \\
\hline Copper & Canopy & 12 & 0.118 & 0.021 & 0.160 & 0.258 & 0.001 \\
\hline Curium-244 & Canopy & 1 & 1.067 & 0.000 & 0.000 & 1.067 & 1.067 \\
\hline Iron & Canopy & 12 & 0.003 & 0.001 & 0.006 & 0.019 & 0.000 \\
\hline Lead & Canopy & 12 & 0.032 & 0.015 & 0.062 & 0.177 & 0.000 \\
\hline Lithium & Canopy & 10 & 0.016 & 0.011 & 0.037 & 0.113 & 0.000 \\
\hline Magnesium & Canopy & 10 & 1.147 & 0.206 & 1.550 & 2.615 & 0.443 \\
\hline Manganese & Canopy & 10 & 0.177 & 0.068 & 0.310 & 0.733 & 0.015 \\
\hline
\end{tabular}


Table 6.3 (Continued)

\begin{tabular}{|c|c|c|c|c|c|c|c|}
\hline Contaminant & Media & Detects & Mean & $\begin{array}{r}\text { Standard } \\
\text { Error }\end{array}$ & UCL95 & Maximum & Minimum \\
\hline Mercury & Canopy & 9 & 0.044 & 0.012 & 0.068 & 0.128 & 0.009 \\
\hline Nickel & Canopy & 12 & 0.076 & 0.026 & 0.126 & 0.248 & 0.003 \\
\hline Plutonium-239/240 & Canopy & 2 & 4.025 & 1.175 & 6.328 & 5.200 & 2.850 \\
\hline Potassium & Canopy & 10 & 3.205 & 0.581 & 4.345 & 5.691 & 0.288 \\
\hline Selenium & Canopy & 4 & 0.024 & 0.006 & 0.035 & 0.040 & 0.017 \\
\hline Silver & Canopy & 3 & 0.020 & 0.010 & 0.040 & 0.036 & 0.001 \\
\hline Sodium & Canopy & 11 & 0.336 & 0.059 & 0.452 & 0.700 & 0.012 \\
\hline Uranium & Canopy & 1 & 0.001 & 0.000 & 0.000 & 0.001 & 0.001 \\
\hline Zinc & Canopy & 12 & 0.216 & 0.043 & 0.301 & 0.521 & 0.019 \\
\hline Aluminum & Herbacious & 12 & 0.019 & 0.004 & 0.027 & 0.050 & 0.002 \\
\hline Americium-241 & Herbacious & 3 & 1.497 & 0.394 & 2.269 & 2.178 & 0.813 \\
\hline Arsenic & Herbacious & 11 & 0.015 & 0.002 & 0.018 & 0.023 & 0.007 \\
\hline Barium & Herbacious & 12 & 0.096 & 0.016 & 0.126 & 0.188 & 0.019 \\
\hline Beryllium & Herbacious & 6 & 0.014 & 0.003 & 0.019 & 0.020 & 0.004 \\
\hline Cadmium & Herbacious & 8 & 0.202 & 0.096 & 0.390 & 0.709 & 0.013 \\
\hline Calcium & Herbacious & 12 & 0.725 & 0.179 & 1.076 & 1.983 & 0.024 \\
\hline Chromium & Herbacious & 12 & 0.043 & 0.007 & 0.057 & 0.081 & 0.002 \\
\hline Cobalt & Herbacious & 12 & 0.007 & 0.001 & 0.010 & 0.014 & 0.002 \\
\hline Copper & Herbacious & 12 & 0.137 & 0.028 & 0.191 & 0.316 & 0.001 \\
\hline Curium-244 & Herbacious & 1 & 1.093 & 0.000 & 0.000 & 1.093 & 1.093 \\
\hline Iron & Herbacious & 12 & 0.009 & 0.002 & 0.012 & 0.022 & 0.001 \\
\hline Lead & Herbacious & 12 & 0.017 & 0.004 & 0.025 & 0.052 & 0.000 \\
\hline Lithrum & Herbacious & 10 & 0.015 & 0.003 & 0.020 & 0.029 & 0.002 \\
\hline Magnesium & Herbacious & 10 & 0.681 & 0.124 & 0.923 & 1.481 & 0.244 \\
\hline Manganese & Herbacious & 10 & 0.027 & 0.007 & 0.040 & 0.080 & 0.011 \\
\hline Mercury & Herbacious & 8 & 0.031 & 0.008 & 0.045 & 0.067 & 0.005 \\
\hline Nickel & Herbacious & 12 & 0.026 & 0.008 & 0.043 & 0.103 & 0.001 \\
\hline Plutonium-239/240 & Herbacious & 2 & 4.200 & 0.800 & 5.768 & 5.000 & 3.400 \\
\hline Potassium & Herbacious & 10 & 3.971 & 1.054 & 6.036 & 13.008 & 1.517 \\
\hline Selenium & Herbacious & 2 & 0.012 & 0.002 & 0.015 & 0.014 & 0.011 \\
\hline Silver & Herbacious & 3 & 0.006 & 0.005 & 0.016 & 0.016 & 0.001 \\
\hline Sodium & Herbacious & 11 & 0.364 & 0.0654 & 0.490 & 0.707 & 0.013 \\
\hline Thallium & Herbacious & 1 & 0.006 & 0.000 & 0.000 & 0.006 & 0.006 \\
\hline Uranium & Herbacious & 1 & 0.002 & 0.000 & 0.000 & 0.002 & 0.002 \\
\hline Vanadium & Herbacious & 4 & 0.041 & 0.005 & 0.050 & 0.052 & 0.030 \\
\hline Zinc & Herbacious & 12 & 0.367 & 0.071 & 0.507 & 0.769 & 0.016 \\
\hline Aluminum & $\begin{array}{l}\text { Small } \\
\text { Mammal }\end{array}$ & 9 & 0.003 & 0.000 & 0.004 & 0.005 & 0.001 \\
\hline Americium-241 & $\begin{array}{l}\text { Small } \\
\text { Mammal }\end{array}$ & 5 & 1.484 & 0.400 & 2.268 & 2.889 & 0.735 \\
\hline Arsenic & $\begin{array}{l}\text { Small } \\
\text { Mammal }\end{array}$ & 9 & 0.004 & 0.001 & 0.006 & 0.008 & 0.001 \\
\hline
\end{tabular}




\section{C-7}

Table 6.3 (Continued)

\begin{tabular}{|c|c|c|c|c|c|c|c|}
\hline Contaminant & Media & Detects & Mean & $\begin{array}{r}\text { Standard } \\
\text { Error } \\
\end{array}$ & UCL95 & Maximum & Minimum \\
\hline Barium & $\begin{array}{l}\text { Small } \\
\text { Mammal }\end{array}$ & 9 & 0.030 & 0.008 & 0.045 & 0.075 & 0.004 \\
\hline Cadmium & $\begin{array}{l}\text { Small } \\
\text { Mammal }\end{array}$ & 6 & 0.069 & 0.051 & 0.168 & 0.320 & 0.004 \\
\hline Calcium & $\begin{array}{l}\text { Small } \\
\text { Mammal }\end{array}$ & 9 & 3.610 & 1.141 & 5.846 & 9.378 & 0.243 \\
\hline Chromium & $\begin{array}{l}\text { Small } \\
\text { Mammal }\end{array}$ & 9 & 0.044 & 0.023 & 0.088 & 0.221 & 0.001 \\
\hline Cobalt & $\begin{array}{l}\text { Small } \\
\text { Mammal }\end{array}$ & 9 & 0.006 & 0.002 & 0.010 & 0.020 & 0.003 \\
\hline Copper & $\begin{array}{l}\text { Small } \\
\text { Mammal }\end{array}$ & 9 & 0.313 & 0.076 & 0.461 & 0.749 & 0.001 \\
\hline Curium-244 & $\begin{array}{l}\text { Small } \\
\text { Mammal }\end{array}$ & 1 & 2.693 & 0.000 & 0.000 & 2.693 & 2.693 \\
\hline Iron & $\begin{array}{l}\text { Small } \\
\text { Mammal }\end{array}$ & 9 & 0.004 & 0.001 & 0.005 & 0.006 & 0.001 \\
\hline Lead & $\begin{array}{l}\text { Small } \\
\text { Mammal }\end{array}$ & 9 & 0.015 & 0.006 & 0.027 & 0.047 & 0.000 \\
\hline Lithium & $\begin{array}{l}\text { Small } \\
\text { Mammal }\end{array}$ & 8 & 0.007 & 0.004 & 0.015 & 0.033 & 0.001 \\
\hline Magnesium & $\begin{array}{l}\text { Small } \\
\text { Mammal }\end{array}$ & 7 & 0.484 & 0.085 & 0.651 & 0.916 & 0.308 \\
\hline Manganese & $\begin{array}{l}\text { Small } \\
\text { Mammal }\end{array}$ & 7 & 0.003 & 0.001 & 0.005 & 0.006 & 0.002 \\
\hline Mercury & $\begin{array}{l}\text { Small } \\
\text { Mammal }\end{array}$ & 7 & 0.282 & 0.146 & 0.569 & 1.085 & 0.009 \\
\hline Nickel & $\begin{array}{l}\text { Small } \\
\text { Mammal }\end{array}$ & 9 & 0.070 & 0.021 & 0.112 & 0.196 & 0.003 \\
\hline PCB-1260 & $\begin{array}{l}\text { Small } \\
\text { Mammal }\end{array}$ & 8 & 1.831 & 0.676 & 3.157 & 5.220 & 0.072 \\
\hline Plutonium-239/240 & $\begin{array}{l}\text { Small } \\
\text { Mammal }\end{array}$ & 2 & 2.267 & 0.467 & 3.181 & 2.733 & 1.800 \\
\hline Potassium & $\begin{array}{l}\text { Small } \\
\text { Mammal }\end{array}$ & 7 & 2.967 & 0.494 & 3.935 & 5.112 & 1.812 \\
\hline Selenium & $\begin{array}{l}\text { Small } \\
\text { Mammal }\end{array}$ & 7 & 0.162 & 0.021 & 0.204 & 0.263 & 0.098 \\
\hline Silver & $\begin{array}{l}\text { Small } \\
\text { Mammal }\end{array}$ & 1 & 0.000 & 0.000 & 0.000 & 0.000 & 0.000 \\
\hline Sodium & $\begin{array}{l}\text { Small } \\
\text { Mammal }\end{array}$ & 8 & 5.275 & 1.201 & 7.630 & 10.223 & 0.269 \\
\hline Uranium & $\begin{array}{l}\text { Small } \\
\text { Mammal }\end{array}$ & 2 & 0.000 & 0.000 & 0.000 & 0.000 & 0.000 \\
\hline Zinc & $\begin{array}{l}\text { Small } \\
\text { Mammal }\end{array}$ & 9 & 0.868 & 0.197 & 1.254 & 1.863 & 0.016 \\
\hline Aluminum & Earthworm & 20 & 0.053 & 0.010 & 0.073 & 0.197 & 0.008 \\
\hline
\end{tabular}




\section{C-8}

Table 6.3 (Continued)

\begin{tabular}{|c|c|c|c|c|c|c|c|}
\hline Contaminant & Media & Detects & Mean & $\begin{array}{r}\text { Standard } \\
\text { Error } \\
\end{array}$ & UCL95 & Maximum & Minimum \\
\hline Americium-241 & Earthworm & 4 & 1.970 & 0.601 & 3.148 & 3.644 & 0.800 \\
\hline Aroclor- 1254 & Earthworm & 3 & 0.470 & 0.154 & 0.772 & 0.625 & 0.162 \\
\hline Aroclor -1260 & Earthworm & 13 & 4.256 & 1.778 & 7.740 & 22.500 & 0.000 \\
\hline Arsenic & Earthworm & 17 & 0.243 & 0.070 & 0.380 & 0.909 & 0.006 \\
\hline Barium & Earthworm & 20 & 0.088 & 0.016 & 0.119 & 0.310 & 0.005 \\
\hline Beryllium & Earthworm & 10 & 0.296 & 0.170 & 0.628 & 1.429 & 0.000 \\
\hline BetaParticle & Earthworm & 6 & 0.078 & 0.036 & 0.148 & 0.240 & 0.004 \\
\hline$C O-60$ & Earthworm & 1 & 0.000 & & & 0.000 & 0.000 \\
\hline CS-137 & Earthworm & 5 & 0.005 & 0.003 & 0.011 & 0.015 & 0.000 \\
\hline Cadmium & Earthworm & 14 & 6.004 & 3.018 & 11.919 & 44.553 & 0.253 \\
\hline Calcium & Earthworm & 20 & 0.689 & 0.157 & 0.997 & 2.513 & 0.023 \\
\hline Chromium & Earthworm & 19 & 2.087 & 0.710 & 3.479 & 11.416 & 0.065 \\
\hline Cobalt & Earthworm & 17 & 0.139 & 0.021 & 0.181 & 0.321 & 0.031 \\
\hline Copper & Earthworm & 20 & 0.538 & 0.266 & 1.060 & 5.498 & 0.002 \\
\hline Curium-244 & Earthworm & 4 & 0.587 & 0.162 & 0.905 & 0.886 & 0.152 \\
\hline Iron & Earthworm & 20 & 0.038 & 0.006 & 0.049 & 0.100 & 0.006 \\
\hline $\mathrm{K}-40$ & Earthworm & 6 & 0.139 & 0.04 .0 & 0.217 & 0.269 & 0.056 \\
\hline Lead & Earthworm & 19 & 0.171 & 0.107 & 0.381 & 2.087 & 0.000 \\
\hline Lithium & Earthworm & 12 & 0.083 & 0.024 & 0.131 & 0.253 & 0.008 \\
\hline Magnesium & Earthworm & 18 & 0.220 & $0.03 \cdot 1$ & 0.281 & 0.539 & 0.069 \\
\hline Manganese & Earthworm & 18 & 0.060 & 0.009 & 0.077 & 0.127 & 0.012 \\
\hline Mercury & Earthworm & 15 & 1.909 & 1.068 & 4.002 & 16.250 & 0.030 \\
\hline Molybdenum & Earthworm & 2 & 1.939 & 0.153 & 2.238 & 2.091 & 1.786 \\
\hline Nickel & Earthworm & 14 & 2.551 & 0.63 .5 & 3.796 & 7.802 & 0.038 \\
\hline Plutonium-239 & Earthworm & 1 & 2.500 & & & 2.500 & 2.500 \\
\hline Potassium & Earthworm & 18 & 3.016 & 0.535 & 4.064 & 8.372 & 0.567 \\
\hline Selenium & Earthworm & 14 & 1.798 & 0.92 .2 & 3.606 & 13.733 & 0.301 \\
\hline Silver & Earthworm & 10 & 4.527 & 2.027 & 8.500 & 19.500 & 0.001 \\
\hline Sodium & Earthworm & 19 & 20.976 & 7.285 & 35.254 & 122.388 & 0.146 \\
\hline Strontium & Earthworm & 2 & 0.212 & 0.066 & 0.342 & 0.278 & 0.146 \\
\hline Thallium & Earthworm & 2 & 0.000 & 0.000 & 0.000 & 0.000 & 0.000 \\
\hline Total Radio Strontium & Earthworm & 1 & 0.169 & & & 0.169 & 0.169 \\
\hline Uranium & Earthworm & 2 & 0.033 & 0.030 & 0.092 & 0.063 & 0.003 \\
\hline Vanadium & Earthworm & 6 & 0.039 & 0.014 & 0.067 & 0.088 & 0.000 \\
\hline Zinc & Earthworm & 20 & 2.419 & 0.518 & 3.435 & 7.305 & 0.032 \\
\hline
\end{tabular}


Table C.4. Life history parameters for the short-tailed shrew (Blarina brevicauda)

\begin{tabular}{|c|c|c|c|}
\hline Parameter & Value $^{a}$ & Comments & Reference \\
\hline Body Weight & $0.015 \pm 0.00078 \mathrm{~kg}$ & New Hampshire (field) & $\begin{array}{l}\text { Schlessinger and Potter } \\
1974\end{array}$ \\
\hline Food Consumption Rate & $\begin{array}{l}0.01 \mathrm{~kg} / \mathrm{d} \\
0.00795 \pm 0.00017 \mathrm{~kg} / \mathrm{d} \\
\text { mean }=0.009 \mathrm{~kg} / \mathrm{d}\end{array}$ & $\begin{array}{l}\text { larch sawfly diet (lab) } \\
\text { mealworm diet (lab) }\end{array}$ & $\begin{array}{l}\text { Buckner } 1964 \\
\text { Barrett and Stueck } 1976\end{array}$ \\
\hline Water Consumption Rate & $\begin{array}{l}0.223 \mathrm{ml} / \mathrm{g} \mathrm{bw} / \mathrm{d} \\
0.033 \mathrm{~L} / \mathrm{d}\end{array}$ & assuming a $0.015 \mathrm{~kg} \mathrm{bw}$ & Chew 1951 \\
\hline Soil Consumption Rate & $\begin{array}{l}13 \% \text { of diet } \\
0.00117 \mathrm{~kg} / \mathrm{d}\end{array}$ & $\begin{array}{l}\text { assuming diet of } 0.009 \\
\mathrm{~kg} / \mathrm{d}\end{array}$ & Talmage and Walton 1993 \\
\hline Diet Composition & $\begin{array}{l}\text { earthworms } 31.4 \% \\
\text { slugs/snails } 27.1 \% \\
\text { soil/litter invert } 13.2 \% \\
\text { fungi } 8.4 \% \\
\text { misc. animals } 8.1 \% \\
\text { coleoptera } 5.9 \% \\
\text { vegetation } 5.4 \% \\
\end{array}$ & $\begin{array}{l}\text { percent volume in diet in } \\
\text { summer in New York }\end{array}$ & $\begin{array}{l}\text { Whitaker and Ferraro } \\
1963\end{array}$ \\
\hline Home Range & $0.39 \pm 0.036 \mathrm{ha}$ & Manitoba bog & Buckner 1966 \\
\hline Habitat Requirements & $\begin{array}{l}\text { broad and variable but } \\
\text { requires }>50 \% \\
\text { herbaceous cover } \\
\text { forest, wetlands, and } \\
\text { grasslands. most } \\
\text { abundant in hardwood } \\
\text { forests with deep litter } \\
\text { and humus. }\end{array}$ & & $\begin{array}{l}\text { Miller and Getz } 1977 \\
\text { van Zyll de Jong } 1983\end{array}$ \\
\hline Population Density & $\begin{array}{l}2.3 / \mathrm{ha} \text { - winter } \\
5.2 / \mathrm{ha} \text { - spring } \\
9.3 / \mathrm{ha} \text {-summer } \\
8.1 / \mathrm{ha} \text { - fall } \\
2.5-45 / \mathrm{ha} \\
\end{array}$ & $\begin{array}{l}\text { Illinois - alfalfa, tallgrass, } \\
\text { and bluegrass; } \\
\text { means derived from } \\
\text { graph. } \\
\text { Depending on habitat }\end{array}$ & Getz 1989 \\
\hline Behavior & $\begin{array}{l}\text { nocturnal, semifossorial, } \\
\text { spends little time above } \\
\text { surface } \\
\text { active year-round - does } \\
\text { not hibernate }\end{array}$ & & $\begin{array}{l}\text { George et al. } 1986 \\
\text { EPA 1993a }\end{array}$ \\
\hline
\end{tabular}


Other

appear to be unpalatable to most predators due to

van Zyll de Jong 1983 lateral gland

${ }^{a}$ Suggested values for use in exposure assessment are in bold. 


\section{C-11}

Table C.5. Life history parameters for the white-footed mouse (Peromyscus leucopus)

\begin{tabular}{|c|c|c|c|}
\hline Parameter & Value & Comments & Reference \\
\hline Body Weight & $0.022 \mathrm{~kg}$ & & Green and Millar 1987 \\
\hline Food Consumption Rate & $0.0034 \mathrm{~kg} / \mathrm{d}$ & lab study & Green and Millar 1987 \\
\hline Water Consumption Rate & $0.0066 \mathrm{~L} / \mathrm{d}$ & nonreproductive $\&$ (ab) & Oswald et al. 1993 \\
\hline \multirow[t]{2}{*}{ Soil Consumption Rate } & $<2 \%$ & & Beyer et al. 1994 \\
\hline & $0.000068 \mathrm{~kg} / \mathrm{d}$ & $\begin{array}{l}\text { assuming diet of } 0.0034 \\
\mathrm{~kg} / \mathrm{d} \text { and a } 2 \% \text { soil } \\
\text { consumption rate }\end{array}$ & \\
\hline \multirow[t]{4}{*}{ Diet Composition } & $\begin{array}{l}\text { omnivorous and } \\
\text { opportunistic }\end{array}$ & & \\
\hline & $\begin{array}{l}\text { arthropods }-57 \% \\
\text { seeds, fruit, vegetation - } \\
34 \%\end{array}$ & Virginia & Wolff et al. 1985 \\
\hline & $\begin{array}{l}\text { arthropods - } 30 \% \\
\text { seeds, fruit, vegetation - } \\
67 \%\end{array}$ & Indiana & Whitaker 1966 \\
\hline & $\begin{array}{l}\text { arthropods - } 50 \% \\
\text { seeds, fruit, vegetation - } \\
48 \%\end{array}$ & Illinois & Batzli 1977 \\
\hline Home Range & $0.059 \mathrm{ha}$ & $\begin{array}{l}\text { mean: } 0^{2}+9 \text {; Virginia, } \\
\text { mixed deciduous forest }\end{array}$ & Wolff 1985 \\
\hline Habitat Requirements & $\begin{array}{l}\text { wooded, brushy areas; } \\
\text { sometimes open areas }\end{array}$ & & $\begin{array}{l}\text { Burt and Grossenheider } \\
1976\end{array}$ \\
\hline Population Density & $6-57 / \mathrm{ha}$ & $\begin{array}{l}\text { Virginia, mixed deciduous } \\
\text { forest }\end{array}$ & Wolff 1985 \\
\hline \multirow[t]{2}{*}{ Behavior } & $\begin{array}{l}\text { while semi-arboreal, } \\
\text { spends most of time on } \\
\text { ground. } \\
\text { primarily nocturnal }\end{array}$ & & Lackey et al. 1985 \\
\hline & $\begin{array}{l}\text { enters torpor to reduce } \\
\text { metabolic demands in } \\
\text { winter and during food } \\
\text { stress }\end{array}$ & & EPA 1993a \\
\hline
\end{tabular}

a Suggested values for use in exposure assessment are in bold. 


\section{C-12}

Table C.6. Life history parameters for white-tailed deer (Odocoileus virginianus)

\begin{tabular}{|c|c|c|c|}
\hline Parameter & Value $^{\mathrm{a}}$ & Comments & Reference \\
\hline Body Weight & $\begin{array}{l}68 \mathrm{~kg}\left(\sigma^{7}\right) \\
45 \mathrm{~kg}(f) \\
56.5 \mathrm{~kg}\left(\text { mean } \sigma^{2}+f\right) \\
\end{array}$ & & Smith 1991 \\
\hline Food Consumption Rate & $1.74 \mathrm{~kg} / \mathrm{d}$ & & Mautz et al. 1976 \\
\hline Water Consumption Rate & $3.7 \mathrm{~L} / \mathrm{d}$ & $\begin{array}{l}\text { Estimated using allometric } \\
\text { equation }{ }^{\mathrm{b}} \text { assuming } 56.5 \\
\mathrm{~kg} \mathrm{bw}\end{array}$ & Calder and Braun 1983 \\
\hline \multirow[t]{2}{*}{ Soil Consumption Rate } & $<2 \%$ & & Beyer et al. 1994 \\
\hline & $0.0348 \mathrm{~kg} / \mathrm{d}$ & $\begin{array}{l}\text { assuming } 2 \% \text { soil and } \\
1.74 \mathrm{~kg} / \mathrm{d} \text { food } \\
\text { consumption mates }\end{array}$ & \\
\hline
\end{tabular}

Diet Composition

exclusively herbivorous

diet diverse and variable, depends on availability.

Martin et al. 1951

major foods:

- buds and twigs of

Smith 1991

trees and shrubs

- grasses and forbs

(summer)

- mast and fruits (fall)

\begin{tabular}{|c|c|c|c|}
\hline Home Range & $59-520$ ha & & $\begin{array}{l}\text { Marchinton and Hirth } \\
1984\end{array}$ \\
\hline Habitat Requirements & $\begin{array}{l}\text { uses a wide variety of } \\
\text { habitats; favors forest- } \\
\text { field-farmland mosaic; } \\
\text { population density directly } \\
\text { related to number and } \\
\text { distribution of forest } \\
\text { openings }\end{array}$ & & Smith 1991 \\
\hline \multirow[t]{3}{*}{ Population Density } & $0.06 / \mathrm{ha}$ & $\begin{array}{l}\text { eastern mixed deciduous } \\
\text { forest - Tennessee }\end{array}$ & Barber 1984 \\
\hline & $0.39-0.78 / \mathrm{ha}$ & $\begin{array}{l}\text { oak-hickory forest - } \\
\text { midwest }\end{array}$ & $\begin{array}{l}\text { Torgerson and Porath } \\
1984\end{array}$ \\
\hline & $0.1704 / \mathrm{ha}$ & $\begin{array}{l}\text { (calculated based upon } \\
2000 \text { deer on the ORR } \\
\text { and available habitat) }\end{array}$ & $\begin{array}{l}\text { J. Evans } \\
\text { (pers. comm., 1995) }\end{array}$ \\
\hline Behavior & $\begin{array}{l}\text { generally crepuscular } \\
\text { active year-round; does } \\
\text { not hibernate }\end{array}$ & & Smith 1991 \\
\hline
\end{tabular}




\section{C-13}

a Suggested values for use in exposure assessment are in bold.

b Allometric equation for estimation of water consumption by mammals is:

$\mathrm{W}=0.099(\mathrm{bw})^{0.90}$

where: $\mathrm{W}=$ water consumption $(\mathrm{L} / \mathrm{d})$

bw $=$ body weight $(\mathrm{kg})$ 


\section{C-14}

Table C.7. Life history parameters for red fox: (Vulpes fulva)

Parameter

Value

Comments

Reference

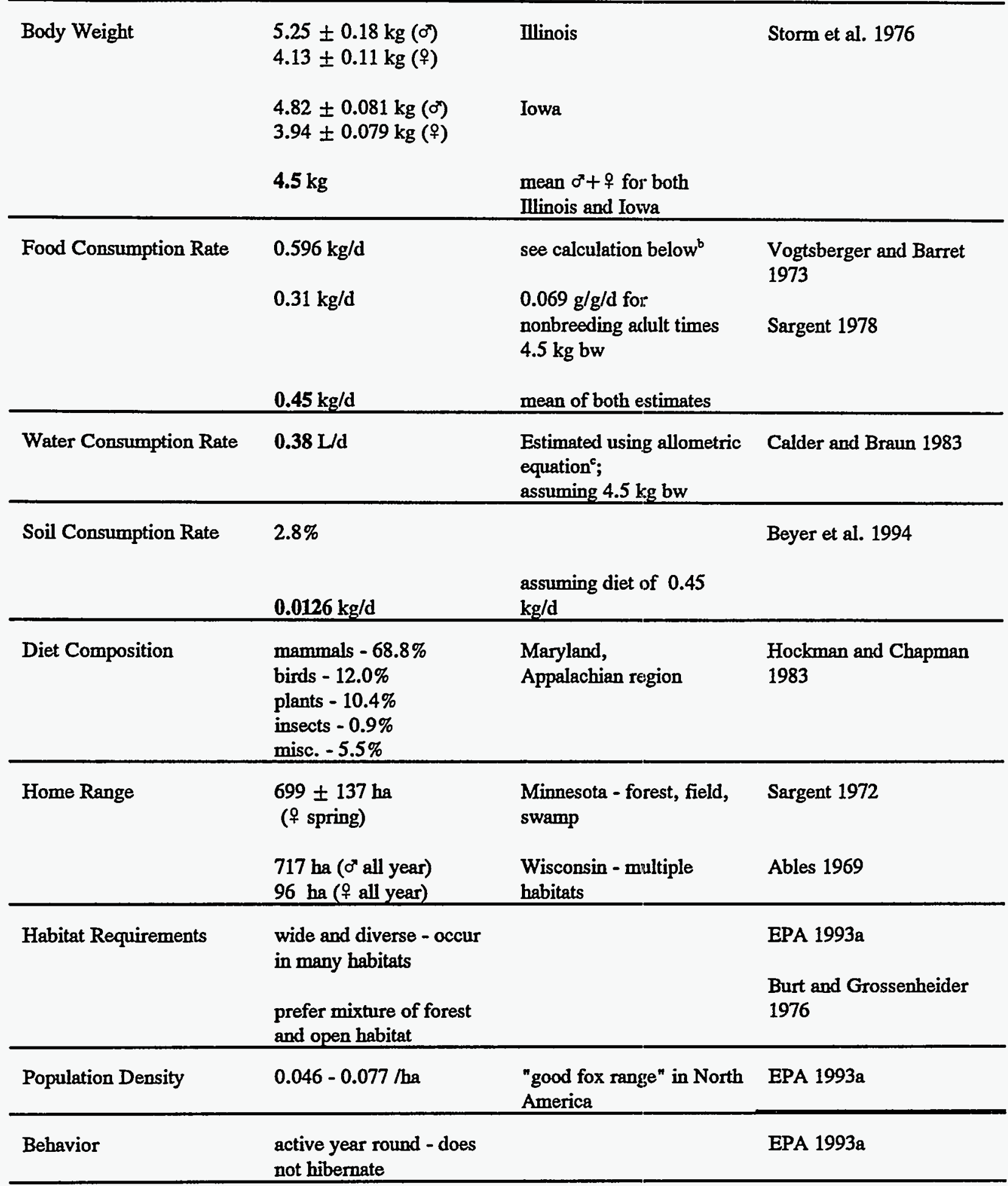

Suggested values for use in exposure assessment are in bold.

'The following parameters were presented by Vogtsberger and Barret (1973):

food ingestion

energy content of vertebrate food

wet-dry weight conversion

$\begin{array}{ll}= & 223 \mathrm{kcal} / \mathrm{kg} \mathrm{bw} / \mathrm{d} \\ = & 5.606 \mathrm{kcal} / \mathrm{g} \mathrm{dry} \mathrm{wt} . \\ = & 1 \mathrm{~g} \mathrm{wet} \mathrm{wt}=0.3 \mathrm{~g} \mathrm{dry} \mathrm{wt}\end{array}$




\section{C-15}

therefore:

$223 \mathrm{kcal} / \mathrm{kg} \mathrm{bw} / \mathrm{d} \times 4.5 \mathrm{~kg} \mathrm{bw}=1003.5 \mathrm{kcal} / \mathrm{d}$

$1003.5 \mathrm{kcal} / \mathrm{d} \times 1 \mathrm{~g} \mathrm{dry} \mathrm{wt.} / 5.606 \mathrm{kcal}=179 \mathrm{~g} \mathrm{dry} / \mathrm{d}$

$179 \mathrm{~g} \mathrm{dry} / \mathrm{d} \times 1 \mathrm{~g}$ wet $/ 0.3 \mathrm{~g}$ dry (wet-dry conversion) $=596 \mathrm{~g} / \mathrm{d}$

' Allometric equation for estimation of water consumption by mammals is:

where: $\mathrm{W}=$ water consumption $(\mathrm{L} / \mathrm{d})$

bw $\quad=\quad$ body weight $(\mathrm{kg})$ 
Table C.8. Life History parameters for red-tailed hawks (Buteo jamaicensis)

\begin{tabular}{|c|c|c|c|}
\hline Parameter & Value $^{\mathrm{a}}$ & Comments & Reference \\
\hline Body Weight & $\begin{array}{l}1.028 \mathrm{~kg}\left(\sigma^{\prime}\right) \\
1.224 \mathrm{~kg}(+) \\
1.126 \mathrm{~kg}\left(\text { meano } \sigma^{\pi}+q\right) \\
\end{array}$ & & Dunning 1984 \\
\hline Food Consumption Rate & $0.109 \mathrm{~kg} / \mathrm{d}$ & & $\begin{array}{l}\text { Craighead and Craighead } \\
1969\end{array}$ \\
\hline Water Consumption Rate & $0.064 \mathrm{~L} / \mathrm{d}$ & $\begin{array}{l}\text { Estimated using allometric } \\
\text { equation } ; \\
\text { assuming } 1.126 \mathrm{~kg} \mathrm{bw}\end{array}$ & Calder and Braun 1983 \\
\hline Soil Consumption Rate & $\begin{array}{l}\text { while some soil attached } \\
\text { to prey may be ingested, } \\
\text { amount is assumed to } \\
\text { negligible }\end{array}$ & & \\
\hline \multirow[t]{2}{*}{ Diet Composition } & $\begin{array}{l}\text { predominantly small } \\
\text { mammals }\end{array}$ & & EPA 1993a \\
\hline & $\begin{array}{l}\text { small mammal }-78.5 \% \\
\text { bird }-8.5 \% \\
\text { snake }-13.0 \%\end{array}$ & $\begin{array}{l}\text { Oregon - pasturre and } \\
\text { wheat fields }\end{array}$ & Janes 1984 \\
\hline \multirow[t]{2}{*}{ Home Range } & 233 ha & $\begin{array}{l}\text { Oregon - pasture and } \\
\text { wheat fields }\end{array}$ & Janes 1984 \\
\hline & $\begin{array}{l}1936 \text { ha } \\
\text { (957 - } 2465 \text { ha range) }\end{array}$ & $\begin{array}{l}\text { Colorado - } \\
\text { prairie-pinyon/juniper } \\
\text { woodland; } \\
\text { mean of } 4 \text { birds; } 95 \% \\
\text { ellipse and systematic } \\
\text { relocation }\end{array}$ & $\begin{array}{l}\text { Anderson and Rongstad } \\
1989\end{array}$ \\
\hline
\end{tabular}

\begin{tabular}{|c|c|c|}
\hline Habitat Requirements & $\begin{array}{l}\text { use wide range of } \\
\text { habitats. prefer } \\
\text { landscapes containing } \\
\text { mixture of oldfields, } \\
\text { wetlands and pasture for } \\
\text { foraging with trees } \\
\text { interspersed for perching } \\
\text { and nesting }\end{array}$ & $\begin{array}{l}\text { EPA 1993a } \\
\text { DeGraaf et al. } 1981\end{array}$ \\
\hline Population Density & $0.03->0.005$ pairs/ha & EPA 1993a \\
\hline \multirow[t]{2}{*}{ Behavior } & territorial throughout year & Brown and Amadon $1968^{b}$ \\
\hline & $\begin{array}{l}\text { northerly populations } \\
\text { migrate; those in the south } \\
\text { do not }\end{array}$ & $\begin{array}{l}\text { National Geographic } \\
\text { Society } 1987\end{array}$ \\
\hline
\end{tabular}

\footnotetext{
Suggested values for use in exposure assessment are in bold.
} 
- Allometric equation for estimation of water consumption by birds is:

where: $\mathrm{W}=$ water consumption (L/d)

bw $=$ body weight $(\mathrm{kg})$ 
Table C.9. Life history parameters for mink

\begin{tabular}{|c|c|c|c|}
\hline Parameter & Value & Comments & Reference \\
\hline Body Weight & $1.0 \mathrm{~kg}\left(\right.$ mean $\left.\sigma^{*}+q\right)$ & & EPA 1993b \\
\hline Food Consumption Rate & $0.137 \mathrm{~kg} / \mathrm{d}\left(\right.$ mean $\left.o^{x}+q\right)$ & & $\begin{array}{l}\text { Bleavins and Aulerich } \\
1981\end{array}$ \\
\hline Water Consumption Rate & $0.099 \mathrm{~L} / \mathrm{d}$ & $\begin{array}{l}\text { estimated using } \\
\text { allometric equation } \\
\text { assuming } 1.0 \mathrm{~kg} \mathrm{bw}\end{array}$ & Calder and Braun 1983 \\
\hline \multirow[t]{3}{*}{ Diet Composition } & $\begin{array}{l}\text { Diverse diet includes: } \\
\text { mammals, fish, } \\
\text { aquatic invertebrates, } \\
\text { amphibians, } \\
\text { and birds }\end{array}$ & & $\begin{array}{l}\text { Hamilton 1940, Sealander } \\
\text { 1943, Korschgen 1958, } \\
\text { Burgess and Bider } 1980 \\
\text { Alexander } 1977\end{array}$ \\
\hline & $\begin{array}{l}\text { Proportion of aquatic prey } \\
\text { (fish, amphibians, inverts, } \\
\text { etc.) }=0.546 \pm 0.21\end{array}$ & $\begin{array}{l}\text { Proportion represents } \\
\text { means of values from five } \\
\text { studies }\end{array}$ & \\
\hline & $\begin{array}{l}\text { fish sizes: } \\
0-10 \mathrm{~cm}=72 \% \\
11-20 \mathrm{~cm}=28 \%\end{array}$ & & \\
\hline \multirow[t]{3}{*}{ Home Range } & $\begin{array}{l}2.63 \mathrm{~km}\left(0^{7}\right) \\
1.85 \mathrm{~km}(\%)\end{array}$ & stream - Sweden & Gerell 1970 \\
\hline & 770 ha $\left(0^{\circ}\right)$ & prairie potholes, Manitoba & Arnold and Fritzell 1987 \\
\hline & & $\begin{array}{l}\text { range size and shape } \\
\text { depends on habitat - linear } \\
\text { along streams, circular in } \\
\text { marshes }\end{array}$ & EPA 1993a. \\
\hline Habitat Requirements & $\begin{array}{l}\text { aquatic habitats - streams, } \\
\text { lakes, marshes; }\end{array}$ & & $\begin{array}{l}\text { Burt and Grossenheider } \\
1976\end{array}$ \\
\hline \multirow[t]{2}{*}{ Population Density } & $0.03-0.085 / \mathrm{ha}$ & river - Montana & Mitchell 1961 \\
\hline & $0.6 / \mathrm{km}$ & river - Michigan & EPA 1993a \\
\hline Behavior & $\begin{array}{l}\text { nocturnal } \\
\text { active year-round, } \\
\text { does not hibernate }\end{array}$ & & EPA $1993 a$ \\
\hline
\end{tabular}

\footnotetext{
Allometric equation for estimation of water consumption by mammals is: $\mathrm{W}=0.099(\mathrm{bw})^{0.90}$
}

where: $\mathrm{W} \quad=\quad$ water consumption $(\mathrm{L} / \mathrm{d})$

bw $=$ body weight $(\mathrm{kg})$ 


\section{C-19}

Table C.10. Life history parameters for belted kingfisher

Parameter

\begin{tabular}{|c|c|c|c|}
\hline Parameter & Value & Comments & Reference \\
\hline Body Weight & $0.148 \mathrm{~kg}$ & & Dunning 1984 \\
\hline \multirow[t]{2}{*}{ Food Consumption Rate } & $50 \%$ bw & & Alexander 1977 \\
\hline & $0.075 \mathrm{~kg} / \mathrm{d}$ & assuming $0.148 \mathrm{~kg} \mathrm{bw}$ & \\
\hline Water Consumption Rate & $0.016 \mathrm{~L} / \mathrm{d}$ & $\begin{array}{l}\text { estimated using } \\
\text { allometric equation } \\
\text { assuming } 0.148 \mathrm{~kg} \mathrm{bw} \\
\end{array}$ & Calder and Braun 1983 \\
\hline Soil Consumption Rate & $\begin{array}{l}\text { as a piscivore, assumed to } \\
\text { be negligible }\end{array}$ & & \\
\hline \multirow[t]{2}{*}{ Diet Composition } & $\begin{array}{l}\text { Cyprinids }-76.4 \% \\
\text { other fish }-10.2 \% \\
\text { crayfish }-13.3 \%\end{array}$ & Ohio - creek & Davis 1982 \\
\hline & $\begin{array}{l}\text { lizards, small snakes, } \\
\text { frogs, salamanders, and } \\
\text { insects may be consumed } \\
\text { if fish are unavailable }\end{array}$ & & Landrum et al. 1993 \\
\hline \multirow[t]{2}{*}{ Home Range } & $\begin{array}{l}1.03 \mathrm{~km} \text { (breeding) } \\
0.39 \mathrm{~km} \text { (non-breeding) }\end{array}$ & Ohio - creek & Davis 1982 \\
\hline & $2.19 \mathrm{~km}$ (breeding) & $\begin{array}{l}\text { Pennsylvania - stream } \\
\text { summer }\end{array}$ & Brooks and Davis 1987 \\
\hline \multirow[t]{3}{*}{ Habitat Requirements } & $\begin{array}{l}\text { uses a diverse aquatic } \\
\text { habitats (stream, river, } \\
\text { lake, marsh, coastline) }\end{array}$ & & Brooks and Davis 1987 \\
\hline & $\begin{array}{l}\text { require high vertical } \\
\text { banks composed of } \\
>75 \% \text { sand and }<7 \% \\
\text { clay for nest construction }\end{array}$ & & \\
\hline & $\begin{array}{l}\text { prefer relatively clear } \\
\text { waters free of thick } \\
\text { vegetation }\end{array}$ & & Bent 1940. \\
\hline Population Density & $\begin{array}{l}0.11-0.19 \text { pairs } / \mathrm{km} \\
\text { shore }\end{array}$ & $\begin{array}{l}\text { Pennsylvania - stream } \\
\text { summer }\end{array}$ & Brooks and Davis 1987 \\
\hline Behavior & $\begin{array}{l}\text { while most migrate from } \\
\text { northern parts of range, } \\
\text { some may stay in areas } \\
\text { where water remains ice- } \\
\text { free }\end{array}$ & & Bent 1940. \\
\hline
\end{tabular}

Allometric equation for estimation of water consumption by birds is:

$$
\mathrm{W}=0.059(\mathrm{bw})^{0.6}
$$

where: $\mathrm{W}=$ water consumption (L/d)

bw $\quad=\quad$ body weight $(\mathrm{kg})$ 
Table C.11. Life History Parameters for the Wild Turkey (Meleagris gallopavo)

\begin{tabular}{|c|c|c|c|}
\hline Parameter & Value & Comments & Reference \\
\hline Body Weight & $\begin{array}{l}7.400 \mathrm{~kg}\left(\sigma^{7}\right) \\
4.222 \mathrm{~kg}(q) \\
5.8 \mathrm{~kg}\left(\text { mean } \sigma^{7}+q\right)\end{array}$ & & Dunning 1984 \\
\hline Food Consumption Rate & $\begin{array}{l}13.6 \mathrm{~g} / \mathrm{b} \mathrm{bw} / \mathrm{d} \\
0.174 \mathrm{~kg} / \mathrm{d}\end{array}$ & assuming $5.8 \mathrm{~kg}$ bw & Korschgen 1967 \\
\hline Water Consumption Rate & $0.19 \mathrm{~L} / \mathrm{d}$ & $\begin{array}{l}\text { estimated using } \\
\text { allometric equation } \\
\text { assuming } 5.8 \mathrm{~kg} \text { bw }\end{array}$ & Calder and Braun 1983 \\
\hline Soil Consumption Rate & $\begin{array}{l}9.3 \% \\
0.0162 \mathrm{~kg} / \mathrm{d}\end{array}$ & $\begin{array}{l}\text { assuming } 0.174 \mathrm{~kg} / \mathrm{d} \text { food } \\
\text { consumption rates }\end{array}$ & Beyer et al. 1994 \\
\hline Diet Composition & $\begin{array}{l}\text { plant material (mast, fruit, } \\
\text { seeds, some foliage) - } \\
90.3 \% \\
\text { animal material (insects, } \\
\text { crayfish, snails, } \\
\text { salamanders) - } 9.7 \%\end{array}$ & & Korschgen 1967 \\
\hline Home Range & $150-190 \mathrm{ha}$ & & Pough $1951^{\mathrm{b}}$ \\
\hline Habitat Requirements & $\begin{array}{l}\text { mast-producing } \\
\text { woodlands with associated } \\
\text { fields and abundant water }\end{array}$ & & Schorger $1966^{\circ}$ \\
\hline Population Density & $\begin{array}{l}0.03 / \mathrm{ha} \\
0.06-0.076 / \mathrm{ha}\end{array}$ & $\begin{array}{l}\text { West Virginia } \\
\text { in 'ideal' habital }\end{array}$ & $\begin{array}{l}\text { Uhling } 1950^{b} \\
\text { Pough } 1951^{b}\end{array}$ \\
\hline & $\begin{array}{l}\text { 0.0426 /ha (calculated } \\
\text { based on @ } 500 \text { turkey } \\
\text { observed on ORR and } \\
\text { suitable habitat) } \\
\end{array}$ & Oak Ridge Reservation & $\begin{array}{l}\text { Personal Communication, } \\
\text { Jim Evans } 1995\end{array}$ \\
\hline Behavior & $\begin{array}{l}\text { forage primarily on the } \\
\text { ground } \\
\text { roost in trees at night } \\
\text { year-round resident; does } \\
\text { not migrate }\end{array}$ & & $\begin{array}{l}\text { National Geographic } \\
\text { Society } 1987\end{array}$ \\
\hline
\end{tabular}

a Suggested values for use in exposure assessment are in bold.

${ }^{b}$ Cited in DeGraaf et al. 1981. 


\section{C-21}

c Allometric equation for estimation of water consumption for birds is:

where:

$$
\text { WIR }=0.059(B W)^{0.67}
$$

$\mathrm{WIR}=$ water ingestion rate $(\mathrm{L}$ water/individual/day). 


\section{$\mathrm{C}-22$}

Table C.12. Point Estimates of Contaminant Exposure for Short-tailed Shrews in WAG2.

\begin{tabular}{|c|c|c|c|c|}
\hline Location & Contaminant & $\begin{array}{c}\text { Total } \\
\text { Exposure }\end{array}$ & $\begin{array}{r}\text { NOAEL } \\
\mathrm{HO} \\
\end{array}$ & $\begin{array}{r}\text { LOAEL } \\
\text { HO } \\
\end{array}$ \\
\hline IHP & Acetone & 0.007 & 0.00 & 0.00 \\
\hline MWC & Acetone & 0.011 & 0.00 & 0.00 \\
\hline IHP & Aluminum & 2816.097 & 1226.96 & 122.70 \\
\hline $\mathrm{LMB}$ & Aluminum & 3187.367 & 1388.72 & 138.87 \\
\hline LWC & Aluminum & 1649.656 & 718.75 & 71.87 \\
\hline MWC & Aluminum & 2302.725 & 1003.29 & 100.33 \\
\hline backg & Aluminum & 6078.748 & 2648.48 & 264.85 \\
\hline LMB & Antimony & 0.917 & 0.40 & 0.04 \\
\hline MWC & Antimony & 0.086 & 0.58 & 0.06 \\
\hline backg & Antimony & 0.166 & 1.12 & 0.11 \\
\hline LMB & Aroclor-1248 & 0.002 & 0.05 & 0.01 \\
\hline IHP & Aroclor- 1254 & 0.897 & 13.42 & 1.34 \\
\hline LMB & Aroclor-1254 & 0.028 & 0.42 & 0.04 \\
\hline IHP & Aroclor-1260 & 2.190 & 32.76 & 3.28 \\
\hline LWC & Aroclor -1260 & 2.098 & 31.39 & 3.14 \\
\hline MWC & Aroclor-1260 & 10.206 & 152.70 & 15.27 \\
\hline IHP & Arsenic & 1.918 & 12.80 & 1.28 \\
\hline LMB & Arsenic & 3.194 & 21.31 & 2.13 \\
\hline MWC & Arsenic & 0.002 & 0.01 & 0.00 \\
\hline backg & Arsenic & 3.981 & 26.57 & 2.66 \\
\hline IHP & Barium & 32.507 & 2.75 & 0.75 \\
\hline LMB & Barium & 53.811 & 4.55 & 1.24 \\
\hline LWC & Barium & 21.347 & 1.80 & 0.49 \\
\hline MWC & Barium & 27.967 & 2.36 & 0.64 \\
\hline backg & Barium & 36.051 & 3.05 & 0.83 \\
\hline IHP & Benzo(a)pyrene & 0.027 & 0.02 & 0.00 \\
\hline LWC & Benzo(a)pyrene & 0.012 & 0.01 & 0.00 \\
\hline MWC & Benzo(a)pyrene & 0.009 & 0.01 & 0.00 \\
\hline backg & Beryllium & 0.168 & 0.12 & \\
\hline IHP & Beryllium & 0.645 & 0.44 & \\
\hline LMB & Beryllium & 0.558 & 0.38 & \\
\hline LWC & Beryllium & 0.456 & 0.31 & \\
\hline MWC & Beryllium & 0.594 & 0.41 & \\
\hline IHP & Boron & 0.685 & 0.01 & 0.00 \\
\hline LMB & Boron & 0.869 & 0.01 & 0.00 \\
\hline LWC & Boron & 0.792 & 0.01 & 0.00 \\
\hline MWC & Boron & 1.126 & 0.02 & 0.01 \\
\hline IHP & Cadmium & 9.444 & 31.59 & 3.16 \\
\hline LMB & Cadmium & 8.043 & 26.90 & 2.69 \\
\hline LWC & Cadmium & 7.000 & 23.41 & 2.34 \\
\hline MWC & Cadmium & 7.564 & 25.30 & 2.53 \\
\hline
\end{tabular}


Table 12 (Continued)

\begin{tabular}{|c|c|c|c|c|}
\hline Location & Contaminant & $\begin{array}{c}\text { Total } \\
\text { Exposure }\end{array}$ & $\begin{array}{r}\text { NOAEL } \\
\mathrm{HO} \\
\end{array}$ & $\begin{array}{r}\text { LOAEL } \\
\mathrm{HO}\end{array}$ \\
\hline backg & Cadmium & 3.200 & 10.70 & 1.07 \\
\hline IIHP & Chloroform & 0.004 & 0.00 & 0.00 \\
\hline MWC & Chloroform & 0.002 & 0.00 & 0.00 \\
\hline backg & Chromium & 110.474 & 15.32 & 3.83 \\
\hline IHP & Chromium & 127.246 & 17.65 & 4.41 \\
\hline LMB & Chromium & 88.251 & 12.24 & 3.06 \\
\hline LWC & Chromium & 198.547 & 27.54 & 6.88 \\
\hline MWC & Chromium & 215.309 & 29.87 & 7.46 \\
\hline IHP & Copper & 24.044 & 0.72 & 0.56 \\
\hline LMB & Copper & 18.564 & 0.56 & 0.43 \\
\hline LWC & Copper & 24.379 & 0.73 & 0.56 \\
\hline MWC & Copper & 68.843 & 2.06 & 1.59 \\
\hline backg & Copper & 27.183 & 0.81 & 0.63 \\
\hline backg & Cyanide & 0.038 & 0.00 & \\
\hline IHP & Di-n-butylphthalate & 0.009 & 0.00 & 0.00 \\
\hline LMB & Di-n-butylphthalate & 0.020 & 0.00 & 0.00 \\
\hline LWC & Di-n-butylphthalate & 0.014 & 0.00 & 0.00 \\
\hline MWC & Di-n-butylphthalate & 0.007 & 0.00 & 0.00 \\
\hline IHP & Lead & 24.109 & 1.37 & 0.14 \\
\hline LMB & Lead & 5.833 & 0.33 & 0.03 \\
\hline LWC & Lead & 15.684 & 0.89 & 0.09 \\
\hline MWC & Lead & 27.456 & 1.56 & 0.16 \\
\hline backg & Lead & 13.513 & 0.77 & 0.08 \\
\hline IIPP & Lithium & 4.986 & 0.24 & 0.12 \\
\hline LMB & Lithium & 3.945 & 0.19 & 0.10 \\
\hline LWC & Lithium & 2.463 & 0.12 & 0.06 \\
\hline MWC & Lithium & 3.530 & 0.17 & 0.09 \\
\hline backg & Manganese & 0.462 & 0.00 & 0.00 \\
\hline IHP & Manganese & 241.392 & $\cdot \quad 1.25$ & 0.39 \\
\hline LMB & Manganese & 1021.870 & 5.28 & 1.64 \\
\hline LWC & Manganese & 170.370 & 0.88 & 0.27 \\
\hline MWC & Manganese & 141.617 & 0.73 & 0.23 \\
\hline IHP & Mercury & 85.769 & 1219.52 & 243.90 \\
\hline LMB & Mercury & 3.296 & 46.86 & 9.37 \\
\hline LWC & Mercury & 13.084 & 186.03 & 37.21 \\
\hline MWC & Mercury & 18.647 & 265.13 & 53.03 \\
\hline backg & Mercury & 1.471 & 20.91 & 4.18 \\
\hline LMB & Methylene chloride & 0.002 & 0.00 & 0.00 \\
\hline MWC & Methylene chloride & 0.000 & 0.00 & 0.00 \\
\hline IHP & Molybdenum & 6.425 & 20.78 & 2.08 \\
\hline
\end{tabular}


C-24

\begin{tabular}{|c|c|c|c|c|}
\hline Location & Contaminant & $\begin{array}{c}\text { Total } \\
\text { Exposure }^{2}\end{array}$ & $\begin{array}{r}\text { NOAEL } \\
\mathrm{HO} \\
\end{array}$ & $\begin{array}{r}\text { LOAEL } \\
\text { HO }\end{array}$ \\
\hline LMB & Molybdenum & 10.608 & 34.31 & 3.43 \\
\hline LWC & Molybdenum & 5.352 & 17.31 & 1.73 \\
\hline MWC & Molybdenum & 6.818 & 22.05 & 2.21 \\
\hline IHP & Nickel & 266.737 & 3.03 & 1.52 \\
\hline LMB & Nickel & 100.067 & 1.14 & 0.57 \\
\hline LWC & Nickel & 49.278 & 0.56 & 0.28 \\
\hline MWC & Nickel & 119.102 & 1.35 & 0.68 \\
\hline backg & Nickel & 136.708 & 1.56 & 0.78 \\
\hline IHP & Selenium & 1.355 & 14.99 & 1.50 \\
\hline LMB & Selenium & 2.505 & 27.72 & 2.77 \\
\hline LWC & Selenium & 2.965 & 32.81 & 3.28 \\
\hline MWC & Selenium & 7.994 & 88.45 & 8.85 \\
\hline backg & Selenium & 2.924 & 32.35 & 3.24 \\
\hline $\mathbb{I H P}$ & Strontium & 6.628 & 0.01 & \\
\hline LMB & Strontium & 5.660 & 0.01 & \\
\hline LWC & Strontium & 3.257 & 0.01 & \\
\hline MWC & Strontium & 7.717 & 0.01 & \\
\hline IHP & Thallium & 0.067 & 4.08 & 0.41 \\
\hline LMB & Thallium & 0.113 & 6.88 & 0.69 \\
\hline LWC & Thallium & 0.063 & 3.84 & 0.38 \\
\hline MWC & Thallium & 0.082 & 4.98 & 0.50 \\
\hline backg & Thallium & 0.068 & 4.13 & 0.41 \\
\hline IHP & Tin & 0.869 & 0.03 & 0.02 \\
\hline LMB & Tin & 0.846 & 0.03 & 0.02 \\
\hline LWC & Tin & 0.566 & 0.02 & 0.01 \\
\hline MWC & Tin & 0.725 & 0.03 & 0.02 \\
\hline IHP & Vanadium & 3.551 & 8.29 & 0.83 \\
\hline LMB & Vanadium & 4.729 & 11.04 & 1.10 \\
\hline LWC & Vanadium & 2.402 & 5.61 & 0.56 \\
\hline MWC & Vanadium & 3.431 & 8.01 & 0.80 \\
\hline backg & Vanadium & 9.032 & 21.08 & 2.11 \\
\hline IHP & Zinc & 242.420 & 0.69 & 0.34 \\
\hline LMB & Zinc & 165.616 & 0.47 & 0.24 \\
\hline LWC & Zinc & 380.413 & 1.08 & 0.54 \\
\hline MWC & Zinc & 709.220 & 2.02 & 1.01 \\
\hline backg & Zinc & 257.140 & 0.73 & 0.37 \\
\hline LMB & bis(2-Ethylhexyl)phthalate & 0.020 & 0.00 & 0.00 \\
\hline LWC & bis(2-Ethylhexyl)phthalate & 0.008 & 0.00 & 0.00 \\
\hline MWC & bis(2-Ethylhexvl)phthalate & 0.016 & 0.00 & 0.00 \\
\hline
\end{tabular}

Biota estimates $=$ UCL soil $x$ UCL uptake factor. 


\section{C-25}

Table C.13. Point Estimates of Contaminant Exposure for White-footed Mice in WAG 2.

\begin{tabular}{|c|c|c|c|c|}
\hline Location & Contaminant & $\begin{array}{c}\text { Total } \\
\text { Exposure }\end{array}$ & $\begin{array}{r}\text { NOAEL } \\
\mathrm{HO} \\
\end{array}$ & $\begin{array}{r}\text { LOAEL } \\
\mathrm{HO} \\
\end{array}$ \\
\hline IHP & Acetone & 0.001 & 0.00 & 0.00 \\
\hline MWC & Acetone & 0.002 & 0.00 & 0.00 \\
\hline IHP & Aluminum & 249.575 & 119.67 & 11.97 \\
\hline LMB & Aluminum & 282.459 & 135.43 & 13.54 \\
\hline LWC & Aluminum & 146.194 & 70.10 & 7.01 \\
\hline MWC & Aluminum & 204.066 & 97.84 & 9.78 \\
\hline backg & Aluminum & 538.693 & 258.29 & 25.83 \\
\hline LMB & Antimony & 0.040 & 0.02 & 0.00 \\
\hline MWC & Antimony & 0.012 & 0.09 & 0.01 \\
\hline backg & Antimony & 0.019 & 0.14 & 0.01 \\
\hline LMB & Aroclor-1248 & 0.000 & 0.00 & 0.00 \\
\hline $\mathbb{I H P}$ & Aroclor-1254 & 0.104 & 1.71 & 0.17 \\
\hline LMB & Aroclor-1254 & 0.003 & 0.05 & 0.01 \\
\hline IHP & Aroclor- 1260 & 0.279 & 4.59 & 0.46 \\
\hline LWC & Aroclor -1260 & 0.267 & 4.40 & 0.44 \\
\hline MWC & Aroclor-1260 & 1.299 & 21.40 & 2.14 \\
\hline IHP & Arsenic & 0.212 & 1.56 & 0.16 \\
\hline LMB & Arsenic & 0.353 & 2.59 & 0.26 \\
\hline MWC & Arsenic & 0.000 & 0.00 & 0.00 \\
\hline backg & Arsenic & 0.440 & 3.23 & 0.32 \\
\hline IHP & Barium & 4.791 & 0.45 & 0.12 \\
\hline LMB & Barium & 7.930 & 0.74 & 0.20 \\
\hline LWC & Barium & 3.145 & 0.29 & 0.08 \\
\hline MWC & Barium & 4.121 & 0.38 & 0.10 \\
\hline backg & Barium & 5.312 & 0.49 & 0.13 \\
\hline $\mathrm{IHP}$ & Benzo(a)pyrene & 0.001 & 0.00 & 0.00 \\
\hline LWC & Benzo(a)pyrene & 0.000 & 0.00 & 0.00 \\
\hline MWC & Benzo(a)pyrene & 0.000 & 0.00 & 0.00 \\
\hline backg & Beryllium & 0.007 & 0.01 & \\
\hline IHP & Beryllium & 0.075 & 0.06 & \\
\hline LMB & Beryllium & 0.065 & 0.05 & * \\
\hline LWC & Beryllium & 0.053 & 0.04 & \\
\hline MWC & Beryllium & 0.069 & 0.05 & \\
\hline IHP & Boron & 0.037 & 0.00 & 0.00 \\
\hline LMB & Boron & 0.046 & 0.00 & 0.00 \\
\hline LWC & Boron & 0.031 & 0.00 & 0.00 \\
\hline MWC & Boron & 0.053 & 0.00 & 0.00 \\
\hline IHP & Cadmium & 1.247 & 4.58 & 0.46 \\
\hline LMB & Cadmium & 1.061 & 3.90 & 0.39 \\
\hline LWC & Cadmium & 0.924 & 3.40 & 0.34 \\
\hline MWC & Cadmium & 0.999 & 3.67 & 0.37 \\
\hline
\end{tabular}


Table12 (Continued)

\begin{tabular}{|c|c|c|c|c|}
\hline Location & Contaminant & $\begin{array}{c}\text { Total } \\
\text { Exposure }\end{array}$ & $\begin{array}{r}\text { NOAEL } \\
\mathrm{HO}\end{array}$ & $\begin{array}{r}\text { LOAEL } \\
\text { HO }\end{array}$ \\
\hline backg & Cadmium & 0.422 & 1.55 & 0.16 \\
\hline IHP & Chloroform & 0.001 & 0.00 & 0.00 \\
\hline MWC & Chloroform & 0.000 & 0.00 & 0.00 \\
\hline backg & Chromium & 14.099 & 2.15 & 0.54 \\
\hline IHP & Chromium & 16.240 & 2.48 & 0.62 \\
\hline LMB & Chromium & 11.264 & 1.72 & 0.43 \\
\hline LWC & Chromium & 25.340 & 3.87 & 0.97 \\
\hline MWC & Chromium & 27.480 & 4.19 & 1.05 \\
\hline IHP & Copper & 3.360 & 0.11 & 0.09 \\
\hline LMB & Copper & 2.594 & 0.09 & 0.07 \\
\hline LWC & Copper & 3.407 & 0.11 & 0.09 \\
\hline MWC & Copper & 9.621 & 0.32 & 0.24 \\
\hline backg & Copper & 3.799 & 0.13 & 0.10 \\
\hline backg & Cyanide & 0.002 & 0.00 & \\
\hline IHP & Di-n-butylphthalate & 0.000 & 0.00 & 0.00 \\
\hline LMB & Di-n-butylphthalate & 0.001 & 0.00 & 0.00 \\
\hline LWC & Di-n-butylphthalate & 0.001 & 0.00 & 0.00 \\
\hline MWC & Di-n-butylphthalate & 0.000 & 0.00 & 0.00 \\
\hline IHP & Lead & 2.712 & 0.17 & 0.02 \\
\hline LMB & Lead & 0.656 & 0.04 & 0.00 \\
\hline LWC & Lead & 1.764 & 0.11 & 0.01 \\
\hline MWC & Lead & 3.089 & 0.19 & 0.02 \\
\hline backg & Lead & 1.521 & 0.10 & 0.01 \\
\hline IHP & Lithium & 0.469 & 0.02 & 0.01 \\
\hline LMB & Lithium & 0.371 & 0.02 & 0.01 \\
\hline LWC & Lithium & 0.232 & 0.01 & 0.01 \\
\hline MWC & Lithium & 0.332 & 0.02 & 0.01 \\
\hline backg & Manganese & 0.063 & 0.00 & 0.00 \\
\hline IHP & Manganese & 23.641 & 0.13 & 0.04 \\
\hline LMB & Manganese & 100.080 & 0.57 & 0.18 \\
\hline LWC & Manganese & 16.688 & 0.09 & 0.03 \\
\hline MWC & Manganese & 13.871 & 0.08 & 0.02 \\
\hline IHP & Mercury & 10.927 & 170.97 & 34.20 \\
\hline LMB & Mercury & 0.420 & 6.57 & 1.31 \\
\hline LWC & Mercury & 1.667 & 26.08 & 5.22 \\
\hline MWC & Mercury & 2.375 & 37.17 & 7.43 \\
\hline backg & Mercury & 0.188 & 2.94 & 0.59 \\
\hline LMB & Methylene chloride & 0.000 & 0.00 & 0.00 \\
\hline MWC & Methylene chloride & 0.000 & 0.00 & 0.00 \\
\hline IHP & Molybdenum & 0.796 & 2.83 & 0.28 \\
\hline
\end{tabular}


Table12 (Continued)

\begin{tabular}{|c|c|c|c|c|}
\hline Location & Contaminant & $\begin{array}{c}\text { Total } \\
\text { Exposure }\end{array}$ & $\begin{array}{r}\text { NOAEL } \\
\mathrm{HO} \\
\end{array}$ & $\begin{array}{r}\text { LOAEL } \\
\mathrm{HO}\end{array}$ \\
\hline LMB & Molybdenum & 1.314 & 4.68 & 0.47 \\
\hline LWC & Molybdenum & 0.663 & 2.36 & 0.24 \\
\hline MWC & Molybdenum & 0.845 & 3.01 & 0.30 \\
\hline IHP & Nickel & 33.937 & 0.42 & 0.21 \\
\hline LMB & Nickel & 12.732 & 0.16 & 0.08 \\
\hline LWC & Nickel & 6.270 & 0.08 & 0.04 \\
\hline MWC & Nickel & 15.153 & 0.19 & 0.09 \\
\hline backg & Nickel & 17.395 & 0.22 & 0.11 \\
\hline IHP & Selenium & 0.171 & 2.08 & 0.21 \\
\hline LMB & Selenium & 0.316 & 3.85 & 0.39 \\
\hline LWC & Selenium & 0.374 & 4.56 & 0.46 \\
\hline MWC & Selenium & 1.009 & 12.28 & 1.23 \\
\hline backg & Selenium & 0.369 & 4.49 & 0.45 \\
\hline IHP & Strontium & 0.698 & 0.00 & \\
\hline LMB & Strontium & 0.601 & 0.00 & \\
\hline LWC & Strontium & 0.354 & 0.00 & \\
\hline MWC & Strontium & 0.811 & 0.00 & \\
\hline IIPP & Thallium & 0.003 & 0.18 & 0.02 \\
\hline LMB & Thallium & 0.004 & 0.30 & 0.03 \\
\hline LWC & Thallium & 0.003 & 0.17 & 0.02 \\
\hline MWC & Thallium & 0.003 & 0.22 & 0.02 \\
\hline backg & Thallium & 0.003 & 0.18 & 0.02 \\
\hline IHP & Tin & 0.034 & 0.00 & 0.00 \\
\hline LMB & Tin & 0.034 & 0.00 & 0.00 \\
\hline LWC & Tin & 0.022 & 0.00 & 0.00 \\
\hline MWC & Tin & 0.029 & 0.00 & 0.00 \\
\hline IHP & Vanadium & 0.366 & 0.94 & 0.09 \\
\hline LMB & Vanadium & 0.487 & 1.25 & 0.12 \\
\hline LWC & Vanadium & 0.247 & 0.63 & 0.06 \\
\hline MWC & Vanadium & 0.353 & 0.91 & 0.09 \\
\hline backg & Vanadium & 0.931 & 2.39 & 0.24 \\
\hline IHP & Zinc & 34.870 & 0.11 & 0.05 \\
\hline LMB & Zinc & 23.823 & 0.07 & 0.04 \\
\hline LWC & Zinc & 54.719 & 0.17 & 0.09 \\
\hline MWC & Zinc & 102.015 & 0.32 & 0.16 \\
\hline backg & Zinc & 36.984 & 0.12 & 0.06 \\
\hline LMB & bis(2-Ethylhexyl)phthalate & 0.001 & 0.00 & 0.00 \\
\hline LWC & bis(2-Ethylhexyl)phthalate & 0.000 & 0.00 & 0.00 \\
\hline MWC & bis(2-Ethylhexyl)phthalate & 0.001 & 0.00 & 0.00 \\
\hline
\end{tabular}

- Biota estimates = UCL soil $\times$ UCL uptake factor. 
C-28

Table C.14. Point Estimates of Contaminant Exposure for White-tailed Deer in WAG 2.

\begin{tabular}{|c|c|c|c|c|}
\hline Location & Contaminant & $\begin{array}{c}\text { Total } \\
\text { Exposure }^{\mathbf{a}}\end{array}$ & $\begin{array}{c}\text { NOAEL } \\
\text { HO }\end{array}$ & $\begin{array}{c}\text { LOAEL } \\
\text { HO }\end{array}$ \\
\hline IHP & Acetone & 0.000 & 0.00 & 0.00 \\
\hline MWC & Acetone & 0.000 & 0.00 & 0.00 \\
\hline IHP & Aluminum & 24.289 & 82.91 & 8.29 \\
\hline LMB & Aluminum & 27.482 & 93.81 & 9.38 \\
\hline LWC & Aluminum & 14.226 & 48.56 & 4.86 \\
\hline MWC & Aluminum & 19.856 & 67.77 & 6.78 \\
\hline backg & Aluminum & 52.415 & 178.91 & 17.89 \\
\hline LMB & Antimony & 0.008 & 0.03 & 0.00 \\
\hline MWC & Antimony & 0.003 & 0.14 & 0.01 \\
\hline backg & Antimony & 0.004 & 0.22 & 0.02 \\
\hline LMB & Aroclor-1248 & 0.000 & 0.00 & 0.00 \\
\hline IHP & Aroclor-1254 & 0.001 & 0.12 & 0.01 \\
\hline LMB & Aroclor-1254 & 0.000 & 0.00 & 0.00 \\
\hline $\mathbb{I H P}$ & Aroclor-1260 & 0.000 & 0.03 & 0.00 \\
\hline LWC & Aroclor- 1260 & 0.000 & 0.03 & 0.00 \\
\hline MWC & Aroclor -1260 & 0.001 & 0.16 & 0.02 \\
\hline IHP & Arsenic & 0.008 & 0.40 & 0.04 \\
\hline LMB & Arsenic & 0.013 & 0.67 & 0.07 \\
\hline MWC & Arsenic & 0.000 & 0.00 & 0.00 \\
\hline backg & Arsenic & 0.016 & 0.84 & 0.08 \\
\hline IHP & Barium & 1.234 & 0.82 & 0.22 \\
\hline LMB & Barium & 2.042 & 1.35 & 0.37 \\
\hline LWC & Barium & 0.809 & 0.54 & 0.15 \\
\hline MWC & Barium & 1.061 & 0.70 & 0.19 \\
\hline backg & Barium & 1.367 & 0.91 & 0.25 \\
\hline $\mathbb{I H P}$ & Benzo(a)pyrene & 0.000 & 0.00 & 0.00 \\
\hline LWC & Benzo(a)pyrene & 0.000 & 0.00 & 0.00 \\
\hline MWC & Benzo(a)pyrene & 0.000 & 0.00 & 0.00 \\
\hline backg & Beryllium & 0.001 & 0.01 & \\
\hline IHP & Beryllium & 0.002 & 0.01 & \\
\hline LMB & Beryllium & 0.001 & 0.01 & \\
\hline LWC & Beryllium & 0.001 & 0.01 & \\
\hline MWC & Beryllium & 0.002 & 0.01 & \\
\hline IHP & Boron & 0.008 & 0.00 & 0.00 \\
\hline LMB & Boron & 0.009 & 0.00 & 0.00 \\
\hline LWC & Boron & 0.006 & 0.00 & 0.00 \\
\hline MWC & Boron & 0.011 & 0.00 & 0.00 \\
\hline IHP & Cadmium & 0.045 & 1.18 & 0.12 \\
\hline LMB & Cadmium & 0.038 & 1.00 & 0.10 \\
\hline LWC & Cadmium & 0.034 & 0.88 & 0.09 \\
\hline MWC & Cadmium & 0.036 & 0.95 & 0.09 \\
\hline backg & Cadmium & 0.016 & 0.42 & 0.04 \\
\hline
\end{tabular}


Table14 (Continued)

\begin{tabular}{|c|c|c|c|c|}
\hline Location & Contaminant & $\begin{array}{c}\text { Total } \\
\text { Exposure }\end{array}$ & $\begin{array}{c}\text { NOAEL } \\
\text { HO }\end{array}$ & $\begin{array}{c}\text { LOAEL } \\
\text { HO }\end{array}$ \\
\hline IHP & Chloroform & 0.000 & 0.00 & 0.00 \\
\hline MWC & Chloroform & 0.000 & 0.00 & 0.00 \\
\hline backg & Chromium & 0.108 & 0.12 & 0.03 \\
\hline IHP & Chromium & 0.124 & 0.13 & 0.03 \\
\hline LMB & Chromium & 0.086 & 0.09 & 0.02 \\
\hline LWC & Chromium & 0.193 & 0.21 & 0.05 \\
\hline MWC & Chromium & 0.209 & 0.23 & 0.06 \\
\hline IFP & Copper & 0.293 & 0.07 & 0.05 \\
\hline LMB & Copper & 0.226 & 0.05 & 0.04 \\
\hline LWC & Copper & 0.297 & 0.07 & 0.05 \\
\hline MWC & Copper & 0.838 & 0.20 & 0.15 \\
\hline backg & Copper & 0.332 & 0.08 & 0.06 \\
\hline backg & Cyanide & 0.000 & 0.00 & \\
\hline IHPP & Di-n-butylphthalate & 0.000 & 0.00 & 0.00 \\
\hline LMB & Di-n-butylphthalate & 0.000 & 0.00 & 0.00 \\
\hline LWC & Di-n-butylphthalate & 0.000 & 0.00 & 0.00 \\
\hline MWC & Di-n-butylphthalate & 0.000 & 0.00 & 0.00 \\
\hline IFP & Lead & 0.127 & 0.06 & 0.01 \\
\hline LMB & Lead & 0.031 & 0.01 & 0.00 \\
\hline LWC & Lead & 0.082 & 0.04 & 0.00 \\
\hline MWC & Lead & 0.144 & 0.06 & 0.01 \\
\hline backg & Lead & 0.072 & 0.03 & 0.00 \\
\hline IHP & Lithium & 0.041 & 0.02 & 0.01 \\
\hline LMB & Lithium & 0.032 & 0.01 & 0.01 \\
\hline LWC & Lithium & 0.020 & 0.01 & 0.00 \\
\hline MWC & Lithium & 0.029 & 0.01 & 0.01 \\
\hline backg & Manganese & 0.014 & 0.00 & 0.00 \\
\hline IFP & Manganese & 12.328 & 0.50 & 0.15 \\
\hline LMB & Manganese & 52.187 & 2.11 & 0.65 \\
\hline LWC & Manganese & 8.699 & 0.35 & 0.11 \\
\hline MWC & Manganese & 7.232 & 0.29 & 0.09 \\
\hline IHP & Mercury & 0.082 & 9.11 & 1.82 \\
\hline LMB & Mercury & 0.003 & 0.35 & 0.07 \\
\hline LWC & Mercury & 0.013 & 1.39 & 0.28 \\
\hline MWC & Mercury & 0.018 & 1.98 & 0.40 \\
\hline backg & Mercury & 0.002 & 0.18 & 0.04 \\
\hline LMB & Methylene chloride & 0.000 & 0.00 & 0.00 \\
\hline MWC & Methylene chloride & 0.000 & 0.00 & 0.00 \\
\hline IIPP & Molybdenum & 0.003 & 0.07 & 0.01 \\
\hline LMB & Molybdenum & 0.005 & 0.12 & 0.01 \\
\hline
\end{tabular}




\section{C-30}

Table14 (Continued)

\begin{tabular}{|c|c|c|c|c|}
\hline Location & Contaminant & $\begin{array}{c}\text { Total } \\
\text { Exposure }\end{array}$ & $\begin{array}{c}\text { NOAEL } \\
\text { HO }\end{array}$ & $\begin{array}{c}\text { LOAEL } \\
\mathrm{HO} \\
\end{array}$ \\
\hline LWC & Molybdenum & 0.002 & 0.06 & 0.01 \\
\hline MWC & Molybdenum & 0.003 & 0.07 & 0.01 \\
\hline IHP & Nickel & 0.362 & 0.03 & 0.02 \\
\hline LMB & Nickel & 0.136 & 0.01 & 0.01 \\
\hline LWC & Nickel & 0.067 & 0.01 & 0.00 \\
\hline MWC & Nickel & 0.162 & 0.01 & 0.01 \\
\hline backg & Nickel & 0.188 & 0.02 & 0.01 \\
\hline IIPP & Selenium & 0.008 & 0.69 & 0.07 \\
\hline LMB & Selenium & 0.015 & 1.28 & 0.13 \\
\hline LWC & Selenium & 0.017 & 1.51 & 0.15 \\
\hline MWC & Selenium & 0.047 & 4.06 & 0.41 \\
\hline backg & Selenium & 0.017 & 1.51 & 0.15 \\
\hline IHP & Strontium & 0.021 & 0.00 & \\
\hline LMB & Strontium & 0.022 & 0.00 & \\
\hline LWC & Strontium & 0.020 & 0.00 & \\
\hline MWC & Strontium & 0.023 & 0.00 & \\
\hline $\mathbb{I} \mathbf{P P}$ & Thallium & 0.001 & 0.25 & 0.03 \\
\hline LMB & Thallium & 0.001 & 0.43 & 0.04 \\
\hline LWC & Thallium & 0.000 & 0.24 & 0.02 \\
\hline MWC & Thallium & 0.001 & 0.31 & 0.03 \\
\hline backg & Thallium . & 0.001 & 0.26 & 0.03 \\
\hline IHP & Tin & 0.007 & 0.00 & 0.00 \\
\hline LMB & Tin & 0.007 & 0.00 & 0.00 \\
\hline LWC & Tin & 0.004 & 0.00 & 0.00 \\
\hline MWC & Tin & 0.006 & 0.00 & 0.00 \\
\hline IHP & Vanadium & 0.034 & 0.62 & 0.06 \\
\hline LMB & Vanadium & 0.045 & 0.83 & 0.08 \\
\hline LWC & Vanadium & 0.023 & 0.42 & 0.04 \\
\hline MWC & Vanadium & 0.033 & 0.60 & 0.06 \\
\hline backg & Vanadium & 0.087 & 1.59 & 0.16 \\
\hline IHP & Zinc & 1.636 & 0.04 & 0.02 \\
\hline LMB & Zinc & 1.117 & 0.02 & 0.01 \\
\hline LWC & Zinc & 2.564 & 0.06 & 0.03 \\
\hline MWC & Zinc & 4.781 & 0.11 & 0.05 \\
\hline backg & Zinc & 1.744 & 0.04 & 0.02 \\
\hline LMB & bis(2-Ethylhexyl)phthalate & 0.000 & 0.00 & 0.00 \\
\hline LWC & bis(2-Ethylhexyl)phthalate & 0.000 & 0.00 & 0.00 \\
\hline MWC & bis(2-Ethvlhexyl)phthalate & 0.000 & 0.00 & 0.00 \\
\hline
\end{tabular}


C-31

Table C.15. Point Estimates of Contaminant Exposure for Red Fox in WAG 2.

\begin{tabular}{|c|c|c|c|c|}
\hline Location & Contaminant & $\begin{array}{c}\text { Total } \\
\text { Exposure }^{\mathrm{a}}\end{array}$ & $\begin{array}{r}\text { NOAEL } \\
\text { HO }\end{array}$ & $\begin{array}{r}\text { LOAEL } \\
\text { HO }\end{array}$ \\
\hline IHP & Acetone & 0.000 & 0.00 & 0.00 \\
\hline MWC & Acetone & 0.000 & 0.00 & 0.00 \\
\hline IHP & Aluminum & 88.024 & 159.61 & 15.96 \\
\hline LMB & Aluminum & 99.626 & 180.65 & 18.07 \\
\hline LWC & Aluminum & 51.563 & 93.50 & 9.35 \\
\hline MWC & Aluminum & 71.975 & 130.51 & 13.05 \\
\hline backg & Aluminum & 190.001 & 344.53 & 34.45 \\
\hline LMB & Antimony & 0.033 & 0.06 & 0.01 \\
\hline MWC & Antimony & 0.003 & 0.09 & 0.01 \\
\hline backg & Antimony & 0.006 & 0.18 & 0.02 \\
\hline LMB & Aroclor-1248 & 0.000 & 0.01 & 0.00 \\
\hline $\operatorname{IHP}$ & Aroclor-1254 & 0.016 & 0.17 & 0.03 \\
\hline LMB & Aroclor-1254 & 0.000 & 0.01 & 0.00 \\
\hline IHP & Aroclor- 1260 & 0.151 & 1.57 & 0.32 \\
\hline LWC & Aroclor-1260 & 0.145 & 1.51 & 0.31 \\
\hline MWC & Aroclor- 1260 & 0.705 & 7.33 & 1.49 \\
\hline $\mathbb{I H P}$ & Arsenic & 0.043 & 1.18 & 0.12 \\
\hline LMB & Arsenic & 0.071 & 1.97 & 0.20 \\
\hline MWC & Arsenic & 0.000 & 0.00 & 0.00 \\
\hline backg & Arsenic & 0.088 & 2.46 & 0.25 \\
\hline IHP & Barium & 1.923 & 0.68 & 0.18 \\
\hline LMB & Barium & 3.184 & 1.12 & 0.30 \\
\hline LWC & Barium & 1.261 & 0.44 & 0.12 \\
\hline MWC & Barium & 1.654 & 0.58 & 0.16 \\
\hline backg & Barium & 2.131 & 0.75 & 0.20 \\
\hline IHP & Benzo(a)pyrene & 0.001 & 0.00 & 0.00 \\
\hline LWC & Benzo(a)pyrene & 0.000 & 0.00 & 0.00 \\
\hline MWC & Benzo(a)pyrene & 0.000 & 0.00 & 0.00 \\
\hline backg & Beryllium & 0.006 & 0.02 & \\
\hline IHP & Beryllium & 0.012 & 0.03 & \\
\hline LMB & Beryllium & 0.010 & 0.03 & \\
\hline LWC & Beryllium & 0.008 & 0.02 & \\
\hline MWC & Beryllium & 0.011 & 0.03 & \\
\hline IHP & Boron & 0.025 & 0.00 & 0.00 \\
\hline LMB & Boron & 0.031 & 0.00 & 0.00 \\
\hline LWC & Boron & 0.028 & 0.00 & 0.00 \\
\hline MWC & Boron & 0.041 & 0.00 & 0.00 \\
\hline $\mathbb{I H P}$ & Cadmium & 0.194 & 2.70 & 0.27 \\
\hline LMB & Cadmium & 0.166 & 2.30 & 0.23 \\
\hline LWC & Cadmium & 0.144 & 2.01 & 0.20 \\
\hline MWC & Cadmium & 0.156 & 2.17 & 0.22 \\
\hline
\end{tabular}


Table 15 (Continued)

\begin{tabular}{|c|c|c|c|c|}
\hline Location & Contaminant & $\begin{array}{c}\text { Total } \\
\text { Exposure }\end{array}$ & $\begin{array}{r}\text { NOAEL } \\
\mathrm{HO}\end{array}$ & $\begin{array}{r}\text { LOAEL } \\
\mathrm{HO} \\
\end{array}$ \\
\hline backg & Cadmium & 0.066 & 0.92 & 0.09 \\
\hline IHP & Chloroform & 0.000 & 0.00 & 0.00 \\
\hline MWC & Chloroform & 0.000 & 0.00 & 0.00 \\
\hline backg & Chromium & 2.088 & 1.21 & 0.30 \\
\hline $\operatorname{IHP}$ & Chromium & 2.405 & 1.39 & 0.35 \\
\hline LMB & Chromium & 1.668 & 0.96 & 0.24 \\
\hline LWC & Chromium & 3.752 & 2.17 & 0.54 \\
\hline MWC & Chromium & 4.069 & 2.35 & 0.59 \\
\hline IHP & Copper & 1.817 & 0.23 & 0.17 \\
\hline LMB & Copper & 1.403 & 0.17 & 0.13 \\
\hline LWC & Copper & 1.842 & 0.23 & 0.18 \\
\hline MWC & Copper & 5.204 & 0.65 & 0.50 \\
\hline backg & Copper & 2.053 & 0.26 & 0.20 \\
\hline backg & Cyanide & 0.001 & 0.00 & \\
\hline IHP & Di-n-butylphthalate & 0.000 & 0.00 & 0.00 \\
\hline LMB & Di-n-butylphthalate & 0.001 & 0.00 & 0.00 \\
\hline LWC & Di-n-butylphthalate & 0.001 & 0.00 & 0.00 \\
\hline MWC & Di-n-butylphthalate & 0.000 & 0.00 & 0.00 \\
\hline IHP & Lead & 0.663 & 0.16 & 0.02 \\
\hline LMB & Lead & 0.160 & 0.04 & 0.00 \\
\hline LWC & Lead & 0.431 & 0.10 & 0.01 \\
\hline MWC & Lead & 0.755 & 0.18 & 0.02 \\
\hline backg & Lead & 0.372 & 0.09 & 0.01 \\
\hline IHP & Lithium & 0.166 & 0.03 & 0.02 \\
\hline LMB & Lithium & 0.131 & 0.03 & 0.01 \\
\hline LWC & Lithium & 0.082 & 0.02 & 0.01 \\
\hline MWC & Lithium & 0.117 & 0.02 & 0.01 \\
\hline backg & Manganes & 0.018 & 0.00 & 0.00 \\
\hline IHP & Manganese & 11.836 & 0.25 & 0.08 \\
\hline LMB & Manganese & 50.104 & 1.08 & 0.33 \\
\hline LWC & Manganese & 8.353 & 0.18 & 0.06 \\
\hline MWC & Manganese & 6.943 & 0.15 & 0.05 \\
\hline $\operatorname{IHP}$ & Mercury & 2.926 & 284.05 & 170.50 \\
\hline LMB & Mercury & 0.112 & 10.92 & 6.55 \\
\hline LWC & Mercury & 0.446 & 43.33 & 26.01 \\
\hline MWC & Mercury & 0.636 & 61.75 & 37.06 \\
\hline backg & Mercury & 0.050 & 4.87 & 2.92 \\
\hline LMB & Methylene chloride & 0.000 & 0.00 & 0.00 \\
\hline MWC & Methylene chloride & 0.000 & 0.00 & 0.00 \\
\hline IHP & Molybdenum & 0.102 & 1.37 & 0.14 \\
\hline
\end{tabular}


Table 15 (Continued)

\begin{tabular}{|c|c|c|c|c|}
\hline Location & Contaminant & $\begin{array}{c}\text { Total } \\
\text { Exposure }\end{array}$ & $\begin{array}{r}\text { NOAEL } \\
\mathrm{HO}\end{array}$ & $\begin{array}{r}\text { LOAEL } \\
\text { HO }\end{array}$ \\
\hline LMB & Molybdenum & 0.168 & 2.26 & 0.23 \\
\hline LWC & Molybdenum & 0.085 & 1.14 & 0.11 \\
\hline MWC & Molybdenum & 0.108 & 1.45 & 0.15 \\
\hline IHP & Nickel & 5.220 & 0.25 & 0.12 \\
\hline LMB & Nickel & 1.959 & 0.09 & 0.05 \\
\hline LWC & Nickel & 0.965 & 0.05 & 0.02 \\
\hline MWC & Nickel & 2.331 & 0.11 & 0.06 \\
\hline backg & Nickel & 2.677 & 0.13 & 0.06 \\
\hline IHP & Selenium & 0.038 & 1.76 & 0.18 \\
\hline LMB & Selenium & 0.071 & 3.25 & 0.33 \\
\hline LWC & Selenium & 0.084 & 3.86 & 0.39 \\
\hline MWC & Selenium & 0.226 & 10.39 & 1.04 \\
\hline backg & Selenium & 0.083 & 3.81 & 0.38 \\
\hline IHP & Strontium & 0.140 & 0.00 & \\
\hline LMB & Strontium & 0.122 & 0.00 & \\
\hline LWC & Strontium & 0.075 & 0.00 & \\
\hline MWC & Strontium & 0.162 & 0.00 & \\
\hline IFIP & Thallium & 0.002 & 0.61 & 0.06 \\
\hline LMB & Thallium & 0.004 & 1.03 & 0.10 \\
\hline LWC & Thallium & 0.002 & 0.57 & 0.06 \\
\hline MWC & Thallium & 0.003 & 0.74 & 0.07 \\
\hline backg & Thallium & 0.002 & 0.62 & 0.06 \\
\hline IFP & Tin & 0.031 & 0.00 & 0.00 \\
\hline LMB & Tin & 0.030 & 0.00 & 0.00 \\
\hline LWC & $\operatorname{Tin}$ & 0.020 & 0.00 & 0.00 \\
\hline MWC & Tin & 0.026 & 0.00 & 0.00 \\
\hline IHP & Vanadium & 0.102 & 0.99 & 0.10 \\
\hline LMB & Vanadium & 0.136 & 1.32 & 0.13 \\
\hline LWC & Vanadium & 0.069 & 0.67 & 0.07 \\
\hline MWC & Vanadium & 0.098 & 0.96 & 0.10 \\
\hline backg & Vanadium & 0.259 & 2.52 & 0.25 \\
\hline IHP & Zinc & 15.871 & 0.19 & 0.09 \\
\hline LMB & Zinc & 10.844 & 0.13 & 0.06 \\
\hline LWC & Zinc & 24.910 & 0.29 & 0.15 \\
\hline MWC & Zinc & 46.438 & 0.55 & 0.27 \\
\hline backg & Zinc & 16.825 & 0.20 & 0.10 \\
\hline LMB & bis(2-Ethylhexyl)phthalate & 0.001 & 0.00 & 0.00 \\
\hline LWC & bis(2-Ethylhexyl)phthalate & 0.000 & 0.00 & 0.00 \\
\hline MWC & bis(2-Ethylhexyl)phthalate & 0.001 & 0.00 & 0.00 \\
\hline
\end{tabular}

${ }^{2}$ Biota estimates=UCL soil $x$ UCL uptake factor. 
Table C.16. Point Estimates of Contaminant Exposure Hawk.

\begin{tabular}{|c|c|c|c|c|}
\hline Location & Contaminant & $\begin{array}{c}\text { Total } \\
\text { Exposure }\end{array}$ & $\begin{array}{r}\text { NOAEL } \\
\text { HO }\end{array}$ & $\begin{array}{r}\text { LOAEL } \\
\text { HO } \\
\end{array}$ \\
\hline IHP & Acetone & 0.000 & & \\
\hline MWC & Acetone & 0.000 & & \\
\hline IHP & Aluminum & 8.089 & 0.07 & 0.18 \\
\hline LMB & Aluminum & 9.145 & 0.08 & 0.21 \\
\hline LWC & Aluminum & 4.736 & 0.04 & 0.11 \\
\hline MWC & Aluminum & 6.608 & 0.06 & 0.15 \\
\hline backg & Aluminum & 17.444 & 0.16 & 0.39 \\
\hline LMB & Antimony & 0.001 & 0.00 & 0.00 \\
\hline MWC & Antimony & 0.002 & & \\
\hline backg & Antimony & 0.003 & & \\
\hline LMB & Aroclor-1248 & 0.000 & & \\
\hline IHP & Aroclor-1254 & 0.000 & 0.00 & 0.00 \\
\hline LMB & Aroclor-1254 & 0.000 & 0.00 & 0.00 \\
\hline IHP & Aroclor-1260 & 0.142 & 0.79 & 0.08 \\
\hline LWC & Aroclor -1260 & 0.136 & 0.75 & 0.08 \\
\hline MWC & Aroclor- 1260 & 0.660 & 3.67 & 0.37 \\
\hline IHP & Arsenic & 0.004 & 0.00 & 0.00 \\
\hline LMB & Arsenic & 0.006 & 0.00 & 0.00 \\
\hline MWC & Arsenic & 0.000 & 0.00 & 0.00 \\
\hline backg & Arsenic & 0.008 & 0.00 & 0.00 \\
\hline IHP & Barium & 0.947 & 0.05 & 0.02 \\
\hline LMB & Barium & 1.568 & 0.08 & 0.04 \\
\hline LWC & Barium & 0.622 & 0.03 & 0.01 \\
\hline MWC & Barium & 0.815 & 0.04 & 0.02 \\
\hline backg & Barium & 1.050 & 0.05 & 0.03 \\
\hline IHP & Benzo(a)pyrene & 0.000 & & \\
\hline LWC & Benzo(a)pyrene & 0.000 & & \\
\hline MWC & Benzo(a)pyrene & 0.000 & & \\
\hline backg & Beryllium & 0.000 & & \\
\hline IHP & Beryllium & 0.000 & & \\
\hline LMB & Beryllium & 0.000 & & \\
\hline LWC & Beryllium & 0.000 & & \\
\hline MWC & Beryllium & 0.000 & & \\
\hline IHP & Boron & 0.003 & 0.00 & 0.00 \\
\hline LMB & Boron & 0.003 & 0.00 & 0.00 \\
\hline LWC & Boron & 0.000 & 0.00 & 0.00 \\
\hline MWC & Boron & 0.002 & 0.00 & 0.00 \\
\hline IHP & Cadmium & 0.021 & 0.01 & 0.00 \\
\hline LMB & Cadmium & 0.018 & 0.01 & 0.00 \\
\hline LWC & Cadmium & 0.016 & 0.01 & 0.00 \\
\hline MWC & Cadmium & 0.017 & 0.01 & 0.00 \\
\hline
\end{tabular}


Table16 (Continued)

\begin{tabular}{|c|c|c|c|c|}
\hline Location & Contaminant & $\begin{array}{c}\text { Total } \\
\text { Exposure }\end{array}$ & $\begin{array}{r}\text { NOAEL } \\
\text { HO }\end{array}$ & $\begin{array}{r}\text { LOAEL } \\
\text { HO }\end{array}$ \\
\hline backg & Cadmium & 0.008 & 0.01 & 0.00 \\
\hline IHP & Chloroform & 0.000 & & \\
\hline MWC & Chloroform & 0.000 & & \\
\hline backg & Chromium & 0.438 & 0.44 & 0.09 \\
\hline IHP & Chromium & 0.504 & 0.50 & 0.10 \\
\hline LMB & Chromium & 0.350 & 0.35 & 0.07 \\
\hline LWC & Chromium & 0.786 & 0.79 & 0.16 \\
\hline MWC & Chromium & 0.853 & 0.85 & 0.17 \\
\hline IHP & Copper & 1.501 & 0.03 & 0.02 \\
\hline LMB & Copper & 1.159 & 0.02 & 0.02 \\
\hline LWC & Copper & 1.522 & 0.03 & 0.02 \\
\hline MWC & Copper & 4.301 & 0.09 & 0.07 \\
\hline backg & Copper & 1.696 & 0.04 & 0.03 \\
\hline backg & Cyanide & 0.000 & & \\
\hline IHP & Di-n-butylphthalate & 0.000 & 0.00 & 0.00 \\
\hline LMB & Di-n-butylphthalate & 0.000 & 0.00 & 0.00 \\
\hline LWC & Di-n-butylphthalate & 0.000 & 0.00 & 0.00 \\
\hline MWC & Di-n-butylphthalate & 0.000 & 0.00 & 0.00 \\
\hline IHP & Lead & 0.204 & 0.18 & 0.02 \\
\hline LMB & Lead & 0.049 & 0.04 & 0.00 \\
\hline LWC & Lead & 0.132 & 0.12 & 0.01 \\
\hline MWC & Lead & 0.232 & 0.20 & 0.02 \\
\hline backg & Lead & 0.115 & 0.10 & 0.01 \\
\hline IHP & Lithium & 0.045 & & \\
\hline LMB & Lithium & 0.035 & & \\
\hline LWC & Lithium & 0.022 & & \\
\hline MWC & Lithrum & 0.032 & & \\
\hline backg & Manganes & 0.012 & 0.00 & \\
\hline IHP & Manganese & 0.903 & 0.00 & \\
\hline LMB & Manganese & 3.822 & 0.00 & \\
\hline LWC & Manganese & 0.639 & 0.00 & \\
\hline MWC & Manganese & 0.530 & 0.00 & \\
\hline IHP & Mercury & 1.904 & 317.34 & 29.75 \\
\hline LMB & Mercury & 0.073 & 12.20 & 1.14 \\
\hline LWC & Mercury & 0.290 & 48.40 & 4.54 \\
\hline MWC & Mercury & 0.414 & 68.99 & 6.47 \\
\hline backg & Mercury & 0.033 & 5.44 & 0.51 \\
\hline LMB & Methylene chloride & 0.000 & & \\
\hline MWC & Methylene chloride & 0.000 & & \\
\hline IHP & Molybdenum & 0.000 & 0.00 & 0.00 \\
\hline
\end{tabular}


Table16 (Continued)

\begin{tabular}{|c|c|c|c|c|}
\hline Location & Contaminant & $\begin{array}{c}\text { Total } \\
\text { Exposure }\end{array}$ & $\begin{array}{r}\text { NOAEL } \\
\text { HO }\end{array}$ & $\begin{array}{r}\text { LOAEL } \\
\mathrm{HO} \\
\end{array}$ \\
\hline LMB & Molybdenum & 0.000 & 0.00 & 0.00 \\
\hline LWC & Molybdenum & 0.000 & 0.00 & 0.00 \\
\hline MWC & Molybdenum & 0.000 & 0.00 & 0.00 \\
\hline IHP & Nickel & 1.222 & 0.02 & 0.01 \\
\hline LMB & Nickel & 0.459 & 0.01 & 0.00 \\
\hline LWC & Nickel & 0.226 & 0.00 & 0.00 \\
\hline MWC & Nickel & 0.546 & 0.01 & 0.01 \\
\hline backg & Nickel & 0.628 & 0.01 & 0.01 \\
\hline IHP & Selenium & 0.012 & 0.02 & 0.01 \\
\hline LMB & Selenium & 0.022 & 0.04 & 0.02 \\
\hline LWC & Selenium & 0.026 & 0.05 & 0.03 \\
\hline MWC & Selenium & 0.070 & 0.14 & 0.07 \\
\hline backg & Selenium & 0.026 & 0.05 & 0.03 \\
\hline IHP & Strontium & 0.006 & & \\
\hline LMB & Strontium & 0.009 & & \\
\hline LWC & Strontium & 0.012 & & \\
\hline MWC & Strontium & 0.006 & & \\
\hline IHP & Thallium & 0.000 & & \\
\hline LMB & Thallium & 0.000 & & \\
\hline LWC & Thallium & 0.000 & & \\
\hline MWC & Thallinm & 0.000 & & \\
\hline backg & Thallium & 0.000 & & \\
\hline IHP & Tin & 0.000 & 0.00 & 0.00 \\
\hline LMB & Tin & 0.000 & 0.00 & 0.00 \\
\hline LWC & Tin & 0.000 & 0.00 & 0.00 \\
\hline MWC & Tin & 0.000 & 0.00 & 0.00 \\
\hline IHP & Vanadium & 0.000 & 0.00 & \\
\hline LMB & Vanadium & 0.000 & 0.00 & \\
\hline LWC & Vanadium & 0.000 & 0.00 & \\
\hline MWC & Vanadium & 0.000 & 0.00 & \\
\hline backg & Vanadium & 0.001 & 0.00 & \\
\hline IHP & Zinc & 13.754 & 0.95 & 0.10 \\
\hline LMB & Zinc & 9.397 & 0.65 & 0.07 \\
\hline LWC & Zinc & 21.587 & 1.49 & 0.16 \\
\hline MWC & Zinc & 40.244 & 2.78 & 0.31 \\
\hline backg & Zinc & 14.577 & 1.01 & 0.11 \\
\hline LMB & bis(2-Ethylhexyl)phthalate & 0.000 & 0.00 & \\
\hline LWC & bis(2-Ethylhexyl)phthalate & 0.000 & 0.00 & \\
\hline MWC & bis(2-Ethylhexyl)phthalate & 0.000 & 0.00 & \\
\hline
\end{tabular}

'Biota estimates=UCL soil x UCL uptake factor. 
Table C.17. Point Estimates of Contaminant Exposoure for Wild Turkey in WAG 2.

\begin{tabular}{|c|c|c|c|c|}
\hline Location & Contaminant & $\begin{array}{c}\text { Total } \\
\text { Exposure }\end{array}$ & $\begin{array}{r}\text { NOAEL } \\
\mathrm{HO} \\
\end{array}$ & $\begin{array}{r}\text { LOAEL } \\
\mathrm{HO}\end{array}$ \\
\hline IHP & Acetone & 0.000 & & \\
\hline MWC & Acetone & 0.000 & & \\
\hline IIIP & Aluminum & 75.241 & 0.69 & 1.69 \\
\hline LMB & Aluminum & 85.165 & 0.78 & 1.91 \\
\hline LWC & Aluminum & 44.077 & 0.40 & 0.99 \\
\hline MWC & Aluminum & 61.527 & 0.56 & 1.38 \\
\hline backg & Aluminum & 162.420 & 1.48 & 3.65 \\
\hline LMB & Antimony & 0.032 & 0.00 & 0.00 \\
\hline MWC & Antimony & 0.001 & & \\
\hline backg & Antimony & 0.003 & & \\
\hline LMB & Aroclor-1248 & 0.000 & & \\
\hline IHP & Aroclor-1254 & 0.008 & 0.05 & 0.00 \\
\hline LMB & Aroclor-1254 & 0.000 & 0.00 & 0.00 \\
\hline IHP & Aroclor-1260 & 0.012 & 0.07 & 0.01 \\
\hline LWC & Aroclor- 1260 & 0.011 & 0.06 & 0.01 \\
\hline MWC & Aroclor- 1260 & 0.055 & 0.30 & 0.03 \\
\hline IHP & Arsenic & 0.029 & 0.01 & 0.00 \\
\hline LMB & Arsenic & 0.049 & 0.01 & 0.00 \\
\hline MWC & Arsenic & 0.000 & 0.00 & 0.00 \\
\hline backg & Arsenic & 0.061 & 0.01 & 0.00 \\
\hline IHP & Barium & 2.096 & 0.10 & 0.05 \\
\hline LMB & Barium & 3.470 & 0.17 & 0.08 \\
\hline LWC & Barium & 1.371 & 0.07 & 0.03 \\
\hline MWC & Barium & 1.803 & 0.09 & 0.04 \\
\hline backg & Barium & 2.320 & 0.11 & 0.06 \\
\hline IHP & Benzo(a)pyrene & 0.001 & & \\
\hline LWC & Benzo(a)pyrene & 0.000 & & \\
\hline MWC & Benzo(a)pyrene & 0.000 & & \\
\hline backg & Beryllium & 0.006 & & \\
\hline $\mathbb{I H P}$ & Beryllium & 0.008 & & \\
\hline LMB & Beryllium & 0.007 & & \\
\hline LWC & Beryllium & 0.006 & & \\
\hline MWC & Beryllium & 0.007 & & \\
\hline IHP & Boron & 0.022 & 0.00 & 0.00 \\
\hline LMB & Boron & 0.029 & 0.00 & 0.00 \\
\hline LWC & Boron & 0.028 & 0.00 & 0.00 \\
\hline MWC & Boron & 0.038 & 0.00 & 0.00 \\
\hline IHP & Cadmium & 0.060 & 0.04 & 0.00 \\
\hline LMB & Cadmium & 0.051 & 0.03 & 0.00 \\
\hline LWC & Cadmium & 0.044 & 0.03 & 0.00 \\
\hline MWC & Cadmium & 0.048 & 0.03 & 0.00 \\
\hline
\end{tabular}


Table 17 (Continued)

\begin{tabular}{|c|c|c|c|c|}
\hline Location & Contaminant & $\begin{array}{c}\text { Total } \\
\text { Exposure }\end{array}$ & $\begin{array}{r}\text { NOAEL } \\
\text { HO } \\
\end{array}$ & $\begin{array}{r}\text { LOAEL } \\
\mathrm{HO} \\
\end{array}$ \\
\hline backg & Cadmium & 0.020 & 0.01 & 0.00 \\
\hline IHP & Chloroform & 0.000 & & \\
\hline MWC & Chloroform & 0.000 & & \\
\hline backg & Chromium & 0.735 & 0.73 & 0.15 \\
\hline IHP & Chromium & 0.847 & 0.85 & 0.17 \\
\hline LMB & Chromium & 0.587 & 0.59 & 0.12 \\
\hline LWC & Chromium & 1.321 & 1.32 & 0.26 \\
\hline MWC & Chromium & 1.433 & 1.43 & 0.29 \\
\hline $\operatorname{IHP}$ & Copper & 0.344 & 0.01 & 0.01 \\
\hline LMB & Copper & 0.265 & 0.01 & 0.00 \\
\hline LWC & Copper & 0.349 & 0.01 & 0.01 \\
\hline MWC & Copper & 0.985 & 0.02 & 0.02 \\
\hline backg & Copper & 0.389 & 0.01 & 0.01 \\
\hline backg & Cyanide & 0.001 & & \\
\hline IHP & Di-n-butylphthalate & 0.000 & 0.00 & 0.00 \\
\hline LMB & Di-n-butylphthalate & 0.001 & 0.01 & 0.00 \\
\hline LWC & Di-n-butylphthalate & 0.001 & 0.00 & 0.00 \\
\hline MWC & Di-n-butylphthalate & 0.000 & 0.00 & 0.00 \\
\hline IHP & Lead & 0.438 & 0.39 & 0.04 \\
\hline LMB & Lead & 0.106 & 0.09 & 0.01 \\
\hline LWC & Lead & 0.285 & 0.25 & 0.03 \\
\hline MWC & Lead & 0.499 & 0.44 & 0.04 \\
\hline backg & Lead & 0.246 & 0.22 & 0.02 \\
\hline IHP & Lithium & 0.133 & & \\
\hline LMB & Lithium & 0.105 & & \\
\hline LWC & Lithium & 0.066 & & \\
\hline MWC & Lithium & 0.094 & & \\
\hline backg & Manganes & 0.007 & 0.00 & \\
\hline IHP & Manganese & 22.130 & 0.02 & \\
\hline LMB & Manganese & 93.679 & 0.10 & \\
\hline LWC & Manganese & 15.613 & 0.02 & \\
\hline MWC & Manganese & 12.981 & 0.01 & \\
\hline IHP & Mercury & 0.563 & 93.82 & 8.80 \\
\hline LMB & Mercury & 0.022 & 3.61 & 0.34 \\
\hline LWC & Mercury & 0.086 & 14.33 & 1.34 \\
\hline MWC & Mercury & 0.122 & 20.40 & 1.91 \\
\hline backg & Mercury & 0.010 & 1.62 & 0.15 \\
\hline LMB & Methylene chloride & 0.000 & & \\
\hline MWC & Methylene chloride & 0.000 & & \\
\hline $\mathbb{I H P}$ & Molybdenum & 0.042 & 0.01 & 0.00 \\
\hline
\end{tabular}


Table 17 (Continued)

\begin{tabular}{|c|c|c|c|c|}
\hline Location & Contaminant & $\begin{array}{c}\text { Total } \\
\text { Exposure }\end{array}$ & $\begin{array}{r}\text { NOAEL } \\
\mathrm{HO} \\
\end{array}$ & $\begin{array}{r}\text { LOAEL } \\
\mathrm{HO}\end{array}$ \\
\hline LMB & Molybdenum & 0.069 & 0.02 & 0.00 \\
\hline LWC & Molybdenum & 0.035 & 0.01 & 0.00 \\
\hline MWC & Molybdenum & 0.045 & 0.01 & 0.00 \\
\hline IHP & Nickel & 1.953 & 0.03 & 0.02 \\
\hline LMB & Nickel & 0.733 & 0.01 & 0.01 \\
\hline LWC & Nickel & 0.361 & 0.00 & 0.00 \\
\hline MWC & Nickel & 0.872 & 0.01 & 0.01 \\
\hline backg & Nickel & 1.001 & 0.01 & 0.01 \\
\hline IHP & Selenium & 0.009 & 0.02 & 0.01 \\
\hline LMB & Selenium & 0.016 & 0.03 & 0.02 \\
\hline LWC & Selenium & 0.019 & 0.04 & 0.02 \\
\hline MWC & Selenium & 0.051 & 0.10 & 0.05 \\
\hline backg & Selenium & 0.019 & 0.04 & 0.02 \\
\hline IHP & Strontium & 0.089 & & \\
\hline LMB & Strontium & 0.076 & & \\
\hline LWC & Strontium & 0.044 & & \\
\hline MWC & Strontium & 0.104 & & \\
\hline IHP & Thallium & 0.002 & & \\
\hline LMB & Thallium & 0.004 & & \\
\hline LWC & Thallium & 0.002 & & \\
\hline MWC & Thallium & 0.003 & & \\
\hline backg & Thallium & 0.002 & & \\
\hline IHP & Tin & 0.031 & 0.00 & 0.00 \\
\hline LMB & Tin & 0.030 & 0.00 & 0.00 \\
\hline LWC & Tin & 0.020 & 0.00 & 0.00 \\
\hline MWC & Tin & 0.026 & 0.00 & 0.00 \\
\hline IHP & Vanadium & 0.090 & 0.01 & \\
\hline LMB & Vanadium & 0.119 & 0.01 & \\
\hline LWC & Vanadium & 0.061 & 0.01 & \\
\hline$M W C$ & Vanadium & 0.087 & 0.01 & \\
\hline backg & Vanadium & 0.228 & 0.02 & \\
\hline IHP & Zinc & 2.375 & 0.16 & 0.02 \\
\hline LMB & Zinc & 1.622 & 0.11 & 0.01 \\
\hline LWC & Zinc & 3.726 & 0.26 & 0.03 \\
\hline MWC & Zinc & 6.946 & 0.48 & 0.05 \\
\hline backg & Zinc & 2.521 & 0.17 & 0.02 \\
\hline LMB & bis(2-Ethylhexyl)phthalate & 0.001 & 0.00 & \\
\hline LWC & bis(2-Ethylhexyl)phthalate & 0.000 & 0.00 & \\
\hline MWC & bis(2-Ethylhexyl)phthalate & 0.001 & 0.00 & \\
\hline
\end{tabular}

" Biota estimates = UCL soil $x$ UCL uptake factor. 
Table C.18. Point Estimates of Contaminant Exposure of Mink to Small Mammals in WAG2.

\begin{tabular}{|c|c|c|c|c|}
\hline Location & Contaminant & $\begin{array}{c}\text { Total } \\
\text { Exnosure }\end{array}$ & $\begin{array}{r}\text { NOAEL } \\
\mathrm{HO} \\
\end{array}$ & $\begin{array}{r}\text { LOAEL } \\
\text { HO } \\
\end{array}$ \\
\hline IHP & Acetone & 0.000 & 0.00 & 0.00 \\
\hline MWC & Acetone & 0.000 & 0.00 & 0.00 \\
\hline IHP & Aluminum & 5.216 & 6.49 & 0.65 \\
\hline LMB & Aluminum & 5.885 & 7.33 & 0.73 \\
\hline LWC & Aluminum & 3.050 & 3.80 & 0.38 \\
\hline MWC & Aluminum & 4.254 & 5.30 & 0.53 \\
\hline backg & Aluminum & 11.229 & 13.98 & 1.40 \\
\hline LMB & Antimony & 0.002 & 0.00 & 0.00 \\
\hline MWC & Antimony & 0.004 & 0.07 & 0.01 \\
\hline backg & Antimony & 0.006 & 0.11 & 0.01 \\
\hline LMB & Aroclor-1248 & 0.000 & 0.00 & 0.00 \\
\hline IHP & Aroclor-1254 & 0.000 & 0.00 & 0.00 \\
\hline LMB & Aroclor-1254 & 0.000 & 0.00 & 0.00 \\
\hline IHP & Aroclor-1260 & 0.091 & 0.65 & 0.13 \\
\hline LWC & Aroclor-1260 & 0.087 & 0.62 & 0.13 \\
\hline MWC & Aroclor- 1260 & 0.424 & 3.03 & 0.62 \\
\hline IHP & Arsenic & 0.002 & 0.05 & 0.00 \\
\hline LMB & Arsenic & 0.004 & 0.08 & 0.01 \\
\hline MWC & Arsenic & 0.000 & 0.00 & 0.00 \\
\hline backg & Arsenic & 0.005 & 0.10 & 0.01 \\
\hline IHP & Barium & 0.611 & 0.15 & 0.04 \\
\hline $\mathrm{LMB}$ & Barium & 1.011 & 0.24 & 0.07 \\
\hline LWC & Barium & 0.404 & 0.10 & 0.03 \\
\hline MWC & Barium & 0.526 & 0.13 & 0.03 \\
\hline backg & Barium & 0.680 & 0.16 & 0.04 \\
\hline IHP & Benzo(a)pyrene & 0.000 & 0.00 & 0.00 \\
\hline LWC & Benzo(a)pyrene & 0.000 & 0.00 & 0.00 \\
\hline MWC & Benzo(a)pyrene & 0.000 & 0.00 & 0.00 \\
\hline backg & Beryllium & 0.000 & 0.00 & \\
\hline IHP & Beryllium & 0.000 & 0.00 & \\
\hline LMB & Beryllium & 0.000 & 0.00 & \\
\hline LWC & Beryllium & 0.000 & 0.00 & \\
\hline MWC & Beryllium & 0.000 & 0.00 & \\
\hline IHP & Boron & 0.005 & 0.00 & 0.00 \\
\hline LMB & Boron & 0.005 & 0.00 & 0.00 \\
\hline LWC & Boron & 0.000 & 0.00 & 0.00 \\
\hline MWC & Boron & 0.004 & 0.00 & 0.00 \\
\hline IHP & Cadmium & 0.014 & 0.13 & 0.01 \\
\hline LMB & Cadmium & 0.012 & 0.11 & 0.01 \\
\hline LWC & Cadmium & 0.010 & 0.10 & 0.01 \\
\hline MWC & Cadmium & 0.011 & 0.10 & 0.01 \\
\hline
\end{tabular}


Table18 (Continued)

\begin{tabular}{|c|c|c|c|c|}
\hline Location & Contaminant & $\begin{array}{c}\text { Total } \\
\text { Exposure }\end{array}$ & $\begin{array}{r}\text { NOAEL } \\
\mathrm{HO} \\
\end{array}$ & $\begin{array}{r}\text { LOAEL } \\
\mathrm{HO} \\
\end{array}$ \\
\hline backg & Cadmium & 0.006 & 0.05 & 0.01 \\
\hline IHP & Chloroform & 0.000 & 0.00 & 0.00 \\
\hline MWC & Chloroform & 0.000 & 0.00 & 0.00 \\
\hline backg & Chromium & 0.282 & 0.11 & 0.03 \\
\hline IHP & Chromium & 0.324 & 0.13 & 0.03 \\
\hline LMB & Chromium & 0.225 & 0.09 & 0.02 \\
\hline LWC & Chromium & 0.505 & 0.20 & 0.05 \\
\hline MWC & Chromium & 0.548 & 0.22 & 0.05 \\
\hline IHP & Copper & 0.965 & 0.08 & 0.06 \\
\hline LMB & Copper & 0.745 & 0.06 & 0.05 \\
\hline LWC & Copper & 0.979 & 0.08 & 0.06 \\
\hline MWC & Copper & 2.764 & 0.24 & 0.18 \\
\hline backg & Copper & 1.091 & 0.09 & 0.07 \\
\hline backg & Cyanide & 0.000 & 0.00 & \\
\hline IHP & Di-n-butylphthalate & 0.000 & 0.00 & 0.00 \\
\hline LMB & Di-n-butylphthalate & 0.000 & 0.00 & 0.00 \\
\hline LWC & Di-n-butylphthalate & 0.000 & 0.00 & 0.00 \\
\hline MWC & Di-n-butylphthalate & 0.000 & 0.00 & 0.00 \\
\hline IHP & Lead & 0.131 & 0.02 & 0.00 \\
\hline LMB & Lead & 0.032 & 0.01 & 0.00 \\
\hline LWC & Lead & 0.085 & 0.01 & 0.00 \\
\hline MWC & Lead & 0.149 & 0.02 & 0.00 \\
\hline backg & Lead & 0.074 & 0.01 & 0.00 \\
\hline IHP & Lithium & 0.029 & 0.00 & 0.00 \\
\hline LMB & Lithium & 0.023 & 0.00 & 0.00 \\
\hline LWC & Lithium & 0.014 & 0.00 & 0.00 \\
\hline MWC & Lithium & 0.020 & 0.00 & 0.00 \\
\hline backg & Manganes & 0.021 & 0.00 & 0.00 \\
\hline IHP & Manganese & 0.582 & 0.01 & 0.00 \\
\hline LMB & Manganese & 2.465 & 0.04 & 0.01 \\
\hline LWC & Manganese & 0.414 & 0.01 & 0.00 \\
\hline MWC & Manganese & 0.343 & 0.01 & 0.00 \\
\hline IHP & Mercury & 1.223 & 81.56 & 48.93 \\
\hline LMB & Mercury & 0.047 & 3.13 & 1.88 \\
\hline LWC & Mercury & 0.187 & 12.44 & 7.46 \\
\hline MWC & Mercury & 0.266 & 17.73 & 10.64 \\
\hline backg & Mercury & 0.021 & 1.42 & 0.85 \\
\hline LMB & Methylene chloride & 0.000 & 0.00 & 0.00 \\
\hline MWC & Methylene chloride & 0.000 & 0.00 & 0.00 \\
\hline IHP & Molybdenum & 0.000 & 0.00 & 0.00 \\
\hline
\end{tabular}


Table18 (Continued)

\begin{tabular}{|c|c|c|c|c|}
\hline Location & Contaminant & $\begin{array}{c}\text { Total } \\
\text { Exposure }\end{array}$ & $\begin{array}{r}\text { NOAEL } \\
\mathrm{HO} \\
\end{array}$ & $\begin{array}{r}\text { LOAEL } \\
\text { HO } \\
\end{array}$ \\
\hline LMB & Molybdenum & 0.000 & 0.00 & 0.00 \\
\hline LWC & Molybdenum & 0.000 & 0.00 & 0.00 \\
\hline MWC & Molybdenum & 0.000 & 0.00 & 0.00 \\
\hline IHP & Nickel & 0.785 & 0.03 & 0.01 \\
\hline LMB & Nickel & 0.295 & 0.01 & 0.00 \\
\hline LWC & Nickel & 0.145 & 0.00 & 0.00 \\
\hline MWC & Nickel & 0.351 & 0.01 & 0.01 \\
\hline backg & Nickel & 0.406 & 0.01 & 0.01 \\
\hline IHP & Selenium & 0.008 & 0.24 & 0.02 \\
\hline $\mathrm{LMB}$ & Selenium & 0.014 & 0.45 & 0.04 \\
\hline LWC & Selenium & 0.017 & 0.53 & 0.05 \\
\hline MWC & Selenium & 0.045 & 1.43 & 0.14 \\
\hline backg & Selenium & 0.017 & 0.53 & 0.05 \\
\hline IHP & Strontium & 0.010 & 0.00 & \\
\hline LMB & Strontium & 0.015 & 0.00 & \\
\hline LWC & Strontium & 0.021 & 0.00 & \\
\hline MWC & Strontium & 0.010 & 0.00 & \\
\hline IHP & Thallium & 0.000 & 0.00 & 0.00 \\
\hline LMB & Thallium & 0.000 & 0.00 & 0.00 \\
\hline LWC & Thallium & 0.000 & 0.00 & 0.00 \\
\hline MWC & Thallium & 0.000 & 0.00 & 0.00 \\
\hline backg & Thallium & 0.000 & 0.00 & 0.00 \\
\hline IHP & Tin & 0.000 & 0.00 & 0.00 \\
\hline LMB & Tin & 0.000 & 0.00 & 0.00 \\
\hline LWC & Tin & 0.000 & 0.00 & 0.00 \\
\hline MWC & Tin & 0.000 & 0.00 & 0.00 \\
\hline IHP & Vanadium & 0.000 & 0.00 & 0.00 \\
\hline LMB & Vanadium & 0.000 & 0.00 & 0.00 \\
\hline LWC & Vanadium & 0.000 & 0.00 & 0.00 \\
\hline MWC & Vanadium & 0.000 & 0.00 & 0.00 \\
\hline backg & Vanadium & 0.002 & 0.01 & 0.00 \\
\hline $\mathbb{I H P}$ & Zinc & 8.840 & 0.07 & 0.04 \\
\hline LMB & Zinc & 6.039 & 0.05 & 0.02 \\
\hline LWC & Zinc & 13.870 & 0.11 & 0.06 \\
\hline MWC & Zinc & 25.859 & 0.21 & 0.11 \\
\hline backg & Zinc & 9.380 & 0.08 & 0.04 \\
\hline LMB & bis(2-Ethylhexyl)phthalate & 0.000 & 0.00 & 0.00 \\
\hline LWC & bis(2-Ethylhexyl)phthalate & 0.000 & 0.00 & 0.00 \\
\hline MWC & bis(2-Ethylhexyl)phthalate & 0.000 & 0.00 & 0.00 \\
\hline
\end{tabular}

- Biota estimates = UCL soil $\times$ UCL uptake factor. 
Table C.19. Results of Monte Carlo Simulation of Exposure for wildlife in WAG 2

\begin{tabular}{|c|c|c|c|c|c|c|}
\hline Species & Analyte & Mean & STD & $\begin{array}{l}\text { 80th } \\
\text { Percen. }\end{array}$ & $\%>$ NOAEL & $\%>$ LOAEL \\
\hline \multirow[t]{13}{*}{ Short-tailed Shrew } & Aroclor 1260 & 0.624 & 0.265 & 0.823 & $>95 \%$ & $35-40 \%$ \\
\hline & Arsenic & 0.976 & 0.177 & 1.126 & $>95 \%$ & $<5 \%$ \\
\hline & Barium & 20.617 & 2.437 & 22.551 & $>95 \%$ & $<5 \%$ \\
\hline & Cadmium & 3.475 & 0.856 & 4.222 & $>95 \%$ & $70 \%$ \\
\hline & Chromium & 56.165 & 11.929 & 65.749 & $>95 \%$ & $>95 \%$ \\
\hline & Copper & 9.414 & 2.423 & 11.387 & $<5 \%$ & $<5 \%$ \\
\hline & Manganese & 214.645 & 51.290 & 258.606 & $65 \%$ & $<5 \%$ \\
\hline & Mercury & 6.753 & 4.272 & 9.921 & $>95 \%$ & $>95 \%$ \\
\hline & Molybdenum & 5.362 & 0.351 & 5.661 & $<5 \%$ & $<5 \%$ \\
\hline & Nickel & 48.614 & 15.456 & 60.623 & $<5 \%$ & $<5 \%$ \\
\hline & Selenium & 1.093 & 0.297 & 1.335 & $>95 \%$ & $75 \%$ \\
\hline & Vanadium & 2.341 & 0.175 & 2.486 & $>95 \%$ & $<5 \%$ \\
\hline & Zinc & 134.327 & 24.675 & 154.142 & $<5 \%$ & $<5 \%$ \\
\hline \multirow[t]{4}{*}{ White-footed Mice } & Aroclor 1260 & 0.084 & 0.041 & 0.117 & $70 \%$ & $<5 \%$ \\
\hline & Chromium & 7.054 & 1.482 & 8.246 & $60-65 \%$ & $<5 \%$ \\
\hline & Mercury & 0.856 & 0.546 & 1.264 & $>95 \%$ & $80-85 \%$ \\
\hline & Selenium & 0.135 & 0.037 & 0.165 & $90-95 \%$ & $<5 \%$ \\
\hline \multirow[t]{3}{*}{ Red Fox } & Aroclor 1260 & 0.049 & 0.022 & 0.066 & $<5 \%$ & $<5 \%$ \\
\hline & Mercury & 0.241 & 0.126 & 0.337 & $>95 \%$ & $65-70 \%$ \\
\hline & Selenium & 0.034 & 0.006 & 0.039 & $>95 \%$ & $<5 \%$ \\
\hline Mink $^{1}$ & Mercury & 0.011 & 0.005 & 0.015 & $\sim 20 \%$ & $<5 \%$ \\
\hline Mink $^{2}$ & Mercury & 0.098 & 0.061 & 0.145 & $>95 \%$ & $90-95 \%$ \\
\hline White-tailed Deer & Mercury & 0.010 & 0.004 & 0.013 & $55-60 \%$ & $<5 \%$ \\
\hline Belted Kingfisher ${ }^{1}$ & Mercury & 0.072 & 0.011 & 0.080 & $>95 \%$ & $70-75 \%$ \\
\hline Red-tailed Hawk & Mercury & 0.153 & 0.092 & 0.229 & $>95 \%$ & $80-85 \%$ \\
\hline Wild Turkey & Mercury & 0.055 & 0.028 & 0.075 & $>95 \%$ & $30-35 \%$ \\
\hline
\end{tabular}

${ }^{1}$ Exposure through consumption of fish only.

${ }^{2}$ Exposure through consumption of small mammals, vegetation, invertegrates, and soil. 
Table C.20. Experimental Information for Derivation of Mammalian NOAEL's and LOAEL's

\begin{tabular}{|c|c|c|c|c|c|c|}
\hline Contaminant & Form & $\begin{array}{l}\text { Test } \\
\text { Species }\end{array}$ & $\begin{array}{c}\text { NOAEL } \\
\text { (mg/kg/d) } \\
\text { and Duration }\end{array}$ & $\begin{array}{c}\text { LOAEL } \\
\text { (mg/kg/d) } \\
\text { and Duration }\end{array}$ & Endpoint & Citation \\
\hline Acetone & NA & rat & $\begin{array}{r}10^{2} \\
90 \mathrm{~d}\end{array}$ & $\begin{array}{l}50^{2} \\
90 \mathrm{~d}\end{array}$ & $\begin{array}{l}\text { liver, kidney } \\
\text { damage }\end{array}$ & EPA 1986c \\
\hline Aluminum & $\mathrm{AlCl3}$ & mouse & $\begin{array}{l}1.93^{1} \\
3 \text { gen. }\end{array}$ & $\begin{array}{r}19.3 \\
3 \text { gen. }\end{array}$ & reproduction & Ondreicka et al. 1966 \\
\hline Antimony & $\begin{array}{c}\text { potassium } \\
\text { tartrate }\end{array}$ & mouse & $\begin{array}{l}0.125 \\
\text { lifetime }\end{array}$ & $\begin{array}{l}1.25 \\
\text { lifetime }\end{array}$ & reproduction & Schroeder et al. 1968 \\
\hline Aroclor-1248 & $\mathrm{NA}$ & $\begin{array}{l}\text { rhesus } \\
\text { monkey }\end{array}$ & $\begin{aligned} 0.01^{1} \\
14 \mathrm{mo}\end{aligned}$ & $\begin{array}{c}0.1 \\
14 \mathrm{mo}\end{array}$ & reproduction & Barsotti et al. 1976 \\
\hline Aroclor-1254 & NA & $\operatorname{mink}$ & $\begin{array}{c}0.14 \\
4.5 \mathrm{mo}\end{array}$ & $\begin{array}{c}0.69 \\
4.5 \mathrm{mo}\end{array}$ & reproduction & Aulerich and Ringer 1977 \\
\hline Arsenic & Ast3 & mouse & $\begin{array}{l}0.126^{1} \\
3 \text { gen. }\end{array}$ & $\begin{array}{l}1.26 \\
3 \text { gen. }\end{array}$ & reproduction & $\begin{array}{l}\text { Schroeder and Mitchner } \\
1971\end{array}$ \\
\hline Barium & chloride & rat & $\begin{array}{c}5.1 \\
16 \mathrm{mo}\end{array}$ & & $\begin{array}{l}\text { growth, } \\
\text { hypertension }\end{array}$ & Perry et al. 1983 \\
\hline Barium & chloride & rat & & $\begin{array}{l}19.8^{2} \\
10 \mathrm{~d}\end{array}$ & mortality & Borzelleca et al. 1988 \\
\hline Benzene & NA & mouse & $\begin{array}{c}26.36^{1} \\
6-12 \mathrm{~d}, \text { gest. }\end{array}$ & $\begin{array}{c}263.6 \\
6-12 \mathrm{~d}, \text { gest. }\end{array}$ & reproduction & Nawrot and Staples 1979 \\
\hline Benzo(a)pyrene & NA & mouse & ${ }_{7-16}^{1} d$, gest & $\begin{array}{c}10 \\
7-16 d, \text { gest }\end{array}$ & reproduction & $\begin{array}{l}\text { Mackenzie and Angevine } \\
1981\end{array}$ \\
\hline Beryllium & sulfate & rat & $\begin{array}{c}0.66 \\
1126 \mathrm{~d}\end{array}$ & & $\begin{array}{l}\text { longevity/ } \\
\text { wt. loss }\end{array}$ & Schroeder and Mitchner 1975 \\
\hline
\end{tabular}


Table 6.20 (Continued)

\begin{tabular}{|c|c|c|c|c|c|c|}
\hline Contaminant & Form & $\begin{array}{c}\text { Test } \\
\text { Species }\end{array}$ & $\begin{array}{c}\text { NOAEL } \\
\text { (mg/kg/d) } \\
\text { and Duration }\end{array}$ & $\begin{array}{c}\text { LOAEL } \\
\text { (mg/kg/d) } \\
\text { and Duration }\end{array}$ & Endpoint & Citation \\
\hline Bis(2-ethylhexyl) phthalate & NA & mouse & $\begin{array}{c}18.3 \\
105 \mathrm{~d} .\end{array}$ & $\begin{array}{c}183 \\
105 \mathrm{~d}\end{array}$ & reproduction & Lamb et al. 1987 \\
\hline Boron & $\begin{array}{l}\text { boric acid, } \\
\text { borax }\end{array}$ & rat & $\begin{array}{c}28 \\
3 \text { gen. }\end{array}$ & $\begin{array}{l}93.6 \\
3 \text { gen. }\end{array}$ & reproduction & Weir and Fisher 1972 \\
\hline Cadmium & $\mathrm{CdCl}_{2}$ & mouse & $\begin{array}{l}2.518 \\
2 \text { gen. }\end{array}$ & $\begin{array}{l}0.1913 \\
2 \text { gen. }\end{array}$ & reproduction & $\begin{array}{c}\text { Schroeder and Mitchner } \\
1971\end{array}$ \\
\hline Chloroform & NA & rat & $\begin{array}{c}15^{2} \\
13 \mathrm{wk}\end{array}$ & $\begin{array}{c}41^{2} \\
13 \mathrm{wk} .\end{array}$ & $\begin{array}{l}\text { liver, kidney, gonad } \\
\text { cond. }\end{array}$ & Palmer et al. 1979 \\
\hline Chromium & $\mathrm{Cr}^{+6}$ & rat & $\begin{array}{l}3.28 \\
1 \mathrm{yr} .\end{array}$ & & $\begin{array}{l}\text { wt. loss, food } \\
\text { consumption }\end{array}$ & Mackenzie et al. 1958 \\
\hline Chromium & $\mathrm{Cr}^{+6}$ & rat & & $\begin{array}{l}13.14^{2} \\
3 \mathrm{mo} .\end{array}$ & Mortality & Steven et al. 1976 \\
\hline Copper & sulfate & $\operatorname{mink}$ & $\begin{array}{l}11.71 \\
1 \mathrm{yr} .\end{array}$ & $\begin{array}{l}15.14 \\
1 \mathrm{yr} .\end{array}$ & reproduction & Aulerich et al. 1982 \\
\hline Cyanide & $\begin{array}{l}\text { potassium } \\
\text { cyanide }\end{array}$ & rat & $\begin{array}{l}\quad 68.7 \\
\text { gest. lact. }\end{array}$ & & reproduction & Tewe and Maner 1981 \\
\hline 1,2 Dichloroethene & NA & mouse & $\begin{array}{l}45.2^{2} \\
90 \mathrm{~d} .\end{array}$ & & $\begin{array}{l}\text { body, organ weight, } \\
\text { blood chem. } \\
\text { hepatic function }\end{array}$ & Palmer et al. 1979 \\
\hline Di-n-butylphthalate & NA & mouse & $\begin{array}{c}550 \\
105 \mathrm{~d} .\end{array}$ & $\begin{array}{r}1833 \\
105 \mathrm{~d} .\end{array}$ & reproduction & Lamb et al. 1987 \\
\hline Lead & acetate & rat & $\begin{array}{c}8 \\
3 \text { gen. }\end{array}$ & $\begin{array}{l}80 \\
3 \text { gen. }\end{array}$ & reproduction & Azar et al. 1973 \\
\hline Lithium & carbonate & rat & $\begin{array}{l}9.4 \\
\text { gest. }\end{array}$ & $\begin{array}{l}18.8 \\
\text { gest. }\end{array}$ & reproduction & Marathe and Thomas 1986 \\
\hline
\end{tabular}


Table 6.20 (Continued)

\begin{tabular}{|c|c|c|c|c|c|c|}
\hline Contaminant & Form & $\begin{array}{c}\text { Test } \\
\text { Species }\end{array}$ & $\begin{array}{c}\text { NOAEL } \\
\text { (mg/kg/d) } \\
\text { and Duration }\end{array}$ & $\begin{array}{c}\text { LOAEL } \\
\text { (mg/kg/d) } \\
\text { and Duration } \\
\end{array}$ & Endpoint & Citation \\
\hline Manganese & oxide & rat & $\begin{array}{c}88 \\
224 \text { d., gest. }\end{array}$ & $\begin{array}{c}284 \\
224 \text { d., gest. }\end{array}$ & reproduction & Laskey et al. 1982 \\
\hline Mercury & methyl & $\operatorname{mink}$ & $\begin{array}{l}0.015^{2} \\
93 \mathrm{~d}\end{array}$ & $93 \mathrm{~d}$. & mortality & Wobeser et al. 1976 \\
\hline Mercury & methyl & rat & 3 gen. & $\begin{array}{l}0.16 \\
3 \text { gen. }\end{array}$ & reproduction & Verschuuren et al. 1976 \\
\hline Methylene Chloride & NA & rat & $\begin{array}{l}5.85 \\
2 \mathrm{yr}\end{array}$ & $\begin{array}{l}50 \\
2 \mathrm{yr}\end{array}$ & Liver Histology & NCA 1982 \\
\hline Molybdenum & molybdate & mouse & $\begin{array}{l}0.26^{1} \\
3 \text { gen. }\end{array}$ & $\begin{array}{c}2.6 \\
3 \text { gen. }\end{array}$ & reproduction & $\begin{array}{l}\text { Schroeder and Mitchner } \\
1971\end{array}$ \\
\hline Nickel & sulfate & rat & $\begin{array}{c}40 \\
3 \text { gen. }\end{array}$ & $\begin{array}{c}80 \\
3 \text { gen. }\end{array}$ & reproduction & Ambrose et al. 1976 \\
\hline Selenium & selenate & mouse & $\begin{array}{l}0.075^{1} \\
3 \text { gen. }\end{array}$ & $\begin{array}{l}0.75 \\
3 \text { gen. }\end{array}$ & reproduction & $\begin{array}{c}\text { Schroeder and Mitchner } \\
1971\end{array}$ \\
\hline Strontium & chloride & rat & $\begin{array}{l}263 \\
3 \mathrm{yr} .\end{array}$ & $3 \mathrm{yr}$. & $\begin{array}{l}\text { body weight, bone } \\
\text { changes }\end{array}$ & Skoryna 1981 \\
\hline 1,1,2,2-Tetrachloroethene & $\mathrm{NA}$ & mouse & $\begin{array}{r}1.4^{2} \\
6 \mathrm{wk}\end{array}$ & $\begin{array}{c}7^{2} \\
6 \mathrm{wk}\end{array}$ & Hepatotoxicity & Buben and O'Flaherty 1985 \\
\hline Thallium & sulfate & rat & $\begin{array}{l}0.0074^{1,2} \\
60 \mathrm{~d}\end{array}$ & $\begin{array}{l}0.074^{1,2} \\
60 \mathrm{~d}\end{array}$ & reproduction & Formigli et al. 1986 \\
\hline Tin & (TBTO) & mouse & $\begin{array}{c}23.4 \\
6-15 \mathrm{~d}, \text { gest. }\end{array}$ & $\begin{array}{c}35 \\
6-15 \mathrm{~d}, \text { gest. }\end{array}$ & reproduction & Davis et al. 1987 \\
\hline Trichloroethene & NA & mouse & $\begin{array}{l}0.7^{1,2} \\
6 \mathrm{wk}\end{array}$ & $\begin{array}{c}7^{2} \\
6 \mathrm{wk}\end{array}$ & hepatotoxicity & Buben and O'Flaherty 1985 \\
\hline
\end{tabular}


Table 6.20 (Continued)

\begin{tabular}{|c|c|c|c|c|c|c|}
\hline Contaminant & Form & $\begin{array}{c}\text { Test } \\
\text { Species }\end{array}$ & $\begin{array}{c}\text { NOAEL } \\
\text { (mg/kg/d) } \\
\text { and Duration }\end{array}$ & $\begin{array}{c}\text { LOAEL } \\
\text { (mg/kg/d) } \\
\text { and Duration }\end{array}$ & Endpoint & Citation \\
\hline 1,1,1 Trichloroethane & NA & mouse & $\begin{array}{l}1000 \\
3 \text { gen. }\end{array}$ & 3 gen. & reproduction & Lane et al. 1982 \\
\hline Vanadium & $\mathrm{NaVO} 3$ & rat & $\begin{array}{c}0.21^{\prime} \\
60 \mathrm{~d} .+ \text { gest. }\end{array}$ & $\begin{array}{c}2.1 \\
60 \mathrm{~d} .+ \text { gest. }\end{array}$ & reproduction & Domingo et al. 1986 \\
\hline Vinyl chloride & NA & rat & $\begin{array}{c}0.17^{1} \\
\text { lifetime }\end{array}$ & $\begin{array}{c}1.7 \\
\text { lifetime }\end{array}$ & longevity, mortality & Feron et al. 1981 \\
\hline Zinc & oxide & rat & $\begin{array}{l}160 \\
\text { gest. }\end{array}$ & $\begin{array}{l}320 \\
\text { gest. }\end{array}$ & reproduction & Schlicker and Cox 1968 \\
\hline
\end{tabular}

1 Estimated NOAEL: LOAEL to NOAEL factor of 10 applied.

${ }^{2}$ Estimated NOAEL: subchronic to chronic factor of 10 applied. 
Table C.21. Estimated NOAELs and LOAELs for Mammalian Endpoints.

\begin{tabular}{|c|c|c|c|c|c|c|c|c|c|c|}
\hline \multirow{2}{*}{ Contaminant } & \multicolumn{5}{|c|}{ Estimated NOAEL's } & \multicolumn{5}{|c|}{ Estimated LOAEL's } \\
\hline & Shrew & Mouse & Mink & Fox & Deer & Shrew & Mouse & Mink & Fox & Deer \\
\hline Acetone & 21.978 & 19.972 & 7.692 & 5.281 & 2.806 & 109.892 & 99.858 & 38.458 & 26.405 & 14.028 \\
\hline Aluminum & 2.295 & 2.086 & 0.803 & 0.551 & 0.293 & 22.952 & 20.856 & 8.032 & 5.515 & 2.930 \\
\hline Antimony & 0.149 & 0.135 & 0.052 & 0.036 & 0.019 & 1.487 & $1.351^{\circ}$ & 0.520 & 0.357 & 0.190 \\
\hline Aroclor 1248 & 0.043 & 0.039 & 0.015 & 0.010 & 0.005 & 0.427 & 0.388 & 0.150 & 0.103 & 0.055 \\
\hline Aroclor 1254 & 0.067 & 0.061 & 0.140 & 0.096 & 0.009 & 0.668 & 0.607 & 0.690 & 0.474 & 0.085 \\
\hline Arsenic & 0.150 & 0.136 & 0.052 & 0.036 & 0.019 & 1.498 & 1.362 & 0.524 & 0.360 & 0.191 \\
\hline Barium & 11.835 & 10.754 & 4.142 & 2.844 & 1.511 & 43.517 & 39.544 & 15.229 & 10.456 & 5.555 \\
\hline Benzo(a)pyrene & 1.189 & 1.081 & 0.416 & 0.286 & 0.152 & 11.892 & 10.806 & 4.162 & 2.857 & 1.518 \\
\hline Beryllium & 1.451 & 1.318 & 0.508 & 0.349 & 0.185 & & & & & \\
\hline Bis(2-ethylhexyl)phthalate & 21.763 & 19.775 & 7.616 & 5.229 & 2.778 & 217.625 & 197.753 & 76.161 & 52.290 & 27.779 \\
\hline Boron & 61.539 & 55.920 & 21.536 & 14.787 & 7.855 & 205.717 & 186.933 & 71.993 & 49.430 & 26.259 \\
\hline Cadmium & 0.299 & 0.272 & 0.105 & 0.072 & 0.038 & 2.994 & 2.721 & 1.048 & 0.719 & 0.382 \\
\hline Chloroform & 32.967 & 29.957 & 11.537 & 7.922 & 4.208 & 90.111 & 81.883 & 31.536 & 21.652 & 11.503 \\
\hline Chromium (Cr+6) & 7.209 & 6.551 & 2.523 & 1.732 & 0.920 & 28.879 & 26.243 & 10.107 & 6.939 & 3.686 \\
\hline Copper & 33.432 & 30.380 & 11.700 & 8.033 & 4.267 & 43.262 & 39.312 & 15.140 & 10.395 & 5.522 \\
\hline Cyanide & 141.890 & 128.941 & 49.659 & 34.095 & 18.113 & & & & & \\
\hline 1,2-Dichloroethene & 53.752 & 48.844 & 18.811 & 12.915 & 6.861 & & & & & \\
\hline Di-n-butyl phthalate & 654.066 & 594.341 & 228.899 & 157.157 & 83.490 & 2179.822 & 1980.776 & 762.858 & 523.761 & 278.249 \\
\hline Lead & 17.583 & 15.977 & 6.153 & 4.225 & 2.244 & 175.826 & 159.772 & 61.533 & 42.248 & 22.444 \\
\hline Lithium & 20.660 & 18.773 & 7.230 & 4.964 & 2.637 & 41.319 & 37.546 & 14.460 & 9.928 & 5.274 \\
\hline Manganese & 193.409 & 175.749 & 67.686 & 46.473 & 24.688 & 624.140 & 567.191 & 218.441 & 149.980 & 79.676 \\
\hline Methylmercury & 0.070 & 0.064 & 0.015 & 0.010 & 0.009 & 0.352 & 0.320 & 0.123 & 0.085 & 0.045 \\
\hline Methylene Chloride & 12.857 & 11.683 & 4.500 & 3.089 & 1.641 & 109.892 & 99.858 & 38.458 & 26.405 & 14.028 \\
\hline Molybdenum & 0.309 & 0.281 & 0.108 & 0.074 & 0.039 & 3.092 & 2.810 & 1.082 & 0.743 & 0.395 \\
\hline Nickel & 87.913 & 79.886 & 30.766 & 21.124 & 11.222 & 175.826 & 159.772 & 61.533 & 42.248 & 22.444 \\
\hline $\begin{array}{l}\text { Selenium } \\
\text { (Sodium selenite) }\end{array}$ & 0.090 & 0.082 & 0.032 & 0.022 & 0.012 & 0.904 & 0.821 & 0.316 & 0.217 & 0.115 \\
\hline Strontium & 578.029 & 525.250 & 202.289 & 138.890 & 73.785 & & & & & \\
\hline
\end{tabular}




$\begin{array}{lrrrrrrrrrr}\text { 1,1,2,2-Tetrachloroethene } & 1.665 & 1.513 & 0.583 & 0.400 & 0.213 & 8.324 & 7.564 & 2.913 & 2.000 & 1.063 \\ \text { Thallium } & 0.016 & 0.015 & 0.006 & 0.004 & 0.002 & 0.164 & 0.149 & 0.058 & 0.039 & 0.021 \\ \text { Tin } & 27.828 & 25.287 & 9.739 & 6.686 & 3.552 & 41.622 & 37.822 & 14.566 & 10.001 & 5.313 \\ \text { 1,1,1-Trichloroethane } & 1235.930 & 1123.080 & 432.530 & 296.970 & 157.760 & & & & & \\ \text { Trichloroethene } & 0.832 & 0.756 & 0.291 & 0.200 & 0.106 & 8.324 & 7.564 & 2.913 & 2.000 & 1.063 \\ \text { Vanadium } & 0.428 & 0.389 & 0.150 & 0.103 & 0.055 & 4.285 & 3.894 & 1.500 & 1.030 & 0.547 \\ \text { Vinyl Chloride } & 0.374 & 0.340 & 0.131 & 0.090 & 0.048 & 3.736 & 3.395 & 1.308 & 0.898 & 0.477 \\ \text { Zinc } & 351.653 & 319.544 & 123.066 & 84.496 & 44.888 & 703.306 & 639.088 & 246.131 & 168.992 & 89.776\end{array}$


Table C.22 Estimated NOAEL's and LOAEL's for Avian Endpoints

\begin{tabular}{|c|c|c|c|c|c|c|c|c|}
\hline Contaminant & Form & Test Species & $\begin{array}{c}\text { NOAEL } \\
\text { (mg/kg/d) } \\
\text { and Duration }\end{array}$ & $\begin{array}{c}\text { LOAEL } \\
\text { (mg/kg/d) } \\
\text { and Duration }\end{array}$ & Endpoint & Citation & $\begin{array}{c}\text { Estimated } \\
\text { NOAEL } \\
(\mathrm{mg} / \mathrm{kg} / \mathrm{d})\end{array}$ & $\begin{array}{c}\text { Estimated } \\
\text { LOAEL } \\
(\mathrm{mg} / \mathrm{kg} / \mathrm{d})\end{array}$ \\
\hline Aluminum & $\mathrm{Al}_{2}\left(\mathrm{SO}_{4}\right)_{3}$ & ringed dove & $\begin{array}{l}109.7 \\
4 \mathrm{mo} .\end{array}$ & & reproduction & Carriere et al. 1986 & 109.7 & \\
\hline Aluminum & chloride & $\begin{array}{l}\text { day-old white } \\
\text { leghorn chicks }\end{array}$ & 2 wks. & $\begin{array}{l}44.5^{2} \\
2 \text { wks. }\end{array}$ & mortality & Storer and Nelson 1968 & & 44.5 \\
\hline Aroclor 1254 & NA & $\begin{array}{c}\text { Ring-necked } \\
\text { pheasant }\end{array}$ & $\begin{array}{c}0.18^{2} \\
17 \mathrm{wk}\end{array}$ & $\begin{array}{c}1.8 \\
17 \mathrm{wk}\end{array}$ & reproduction & Dahlgren et al. 1972 & 0.18 & 1.8 \\
\hline Arsenic & arsenite & mallard duck & $\begin{array}{l}5.14 \\
128 \mathrm{~d}\end{array}$ & $\begin{array}{l}12.84 \\
128 \mathrm{~d}\end{array}$ & mortality & USFWS 1964 & 5.14 & 12.84 \\
\hline Arsenic & Paris Green & $\begin{array}{l}\text { brown-headed } \\
\text { cowbird }\end{array}$ & $\begin{array}{l}2.46 \\
7 \mathrm{mo}\end{array}$ & $\begin{array}{l}7.38 \\
7 \mathrm{mo} .\end{array}$ & mortality & USFWS 1969 & 2.46 & 7.38 \\
\hline Barium & hydroxide & $\begin{array}{l}\text { 1-day old } \\
\text { chicks }\end{array}$ & $\begin{array}{l}20.8^{2} \\
4 \text { wks. }\end{array}$ & $\begin{array}{l}41.7^{2} \\
4 \text { wks. }\end{array}$ & mortality & Johnson et al. 1960 & 20.8 & 41.7 \\
\hline $\begin{array}{l}\text { bis(2-ethylhexyl) } \\
\text { Phthalate }\end{array}$ & NA & ringed dove & $\begin{array}{c}1.1 \\
4 \text { wks. }\end{array}$ & 4 wks. & reproduction & Peakall 1974 & 1.1 & \\
\hline Boron & boric acid & mailard duck & $\begin{array}{c}28.8 \\
3 \text { wks. prior, } \\
\text { during, } 3 \text { wks. } \\
\text { post reprod. }\end{array}$ & $\begin{array}{c}100 \\
3 \text { wks.prior, } \\
\text { during, } 3 \text { wks. } \\
\text { post reprod. }\end{array}$ & reproduction & Smith and Ànders 1989 & 28.8 & 100 \\
\hline Cadmium & $\mathrm{CdCl}_{2}$ & mallard duck & $\begin{array}{l}1.45 \\
90 \mathrm{~d} \\
\end{array}$ & $\begin{array}{c}20 \\
90 \mathrm{~d} \\
\end{array}$ & reproduction & White and Finley 1978 & 1.45 & 20 \\
\hline
\end{tabular}


Table 6.22 (Continued)

\begin{tabular}{|c|c|c|c|c|c|c|c|c|}
\hline Contaminant & Form & Test Species & $\begin{array}{c}\text { NOAEL } \\
\text { (mg/kg/d) } \\
\text { and Duration }\end{array}$ & $\begin{array}{c}\text { LOAEL } \\
\text { (mg/kg/d) } \\
\text { and Duration }\end{array}$ & Endpoint & Citation & $\begin{array}{c}\text { Estimated } \\
\text { NOAEL } \\
(\mathrm{mg} / \mathrm{kg} / \mathrm{d}) \\
\end{array}$ & $\begin{array}{c}\text { Estimated } \\
\text { LOAEL } \\
\text { (mg/kg/d) }\end{array}$ \\
\hline Chromium & $\mathrm{Cr}^{+3}$ & black duck & $\begin{array}{c}1 \\
10 \mathrm{mo} .\end{array}$ & $\begin{array}{c}5 \\
10 \mathrm{mo} .\end{array}$ & reproduction & $\begin{array}{l}\text { Haseltine et al., } \\
\text { unpubl. data }\end{array}$ & 1 & 5 \\
\hline Copper & oxide & chicken & $\begin{array}{c}33.2 \\
10 \mathrm{wk}\end{array}$ & $\begin{array}{l}46.97 \\
10 \mathrm{wk}\end{array}$ & $\begin{array}{l}\text { growth/ } \\
\text { mortality }\end{array}$ & Mehring et al. 1960 & 33.2 & 46.97 \\
\hline Di-n-butylphthalate & NA & ringed dove & $\begin{array}{l}0.11^{1} \\
4 \text { wks. }\end{array}$ & $\begin{array}{c}1.1 \\
4 \text { wks. }\end{array}$ & reproduction & Peakall 1974 & 0.11 & \\
\hline Lead & metal & $\begin{array}{c}\text { American } \\
\text { Kestrel }\end{array}$ & $\begin{array}{l}3.85 \\
7 \mathrm{mo} .\end{array}$ & & reproduction & Pattee 1984 & 3.85 & \\
\hline Lead & acetate & Japanese quail & & $\begin{array}{c}11.3 \\
12 \mathrm{wk}\end{array}$ & reproduction & Edens et al. 1976 & & 11.3 \\
\hline Manganese & oxide & Japanese quail & $\begin{array}{l}977 \\
75 \mathrm{~d} .\end{array}$ & $75 \mathrm{~d}$. & $\begin{array}{l}\text { growth, } \\
\text { aggresiveness }\end{array}$ & Laskey and Edens 1985 & 977 & \\
\hline Mercury & methyl & mallard duck & $\begin{array}{l}0.0064^{2} \\
3 \text { gen. }\end{array}$ & $\begin{array}{l}0.064 \\
3 \text { gen. }\end{array}$ & reproduction & Heinz 1979 & 0.0064 & 0.064 \\
\hline Molybdenum & sodium Mo & chicken & $\begin{array}{l}3.5^{1} \\
21 \mathrm{~d}\end{array}$ & $\begin{array}{l}35.3 \\
21 \mathrm{~d} .\end{array}$ & reproduction & Lepore and Miller 1965 & 3.5 & 35.3 \\
\hline Nickel & sulfate & mallard duck & $\begin{array}{l}77.4 \\
90 \mathrm{~d}\end{array}$ & $\begin{array}{l}107 \\
90 d\end{array}$ & $\begin{array}{l}\text { mortality, } \\
\text { growth, } \\
\text { behavior }\end{array}$ & Cain and Pafford 1981 & 77.4 & 107 \\
\hline Selenium & selenite & mallard duck & $\begin{array}{c}0.5 \\
10 \mathrm{wk}\end{array}$ & $\begin{array}{c}1.0 \\
10 \mathrm{wk}\end{array}$ & reproduction & Heinz et al. 1987 & 0.5 & 1.0 \\
\hline $\operatorname{Tin}$ & (TBTO) & Japanese quail & $\begin{array}{c}6.8 \\
6 \mathrm{wks} .\end{array}$ & $\begin{array}{c}16.9 \\
6 \text { wks. }\end{array}$ & reproduction & Schlatterer et al. 1993 & 6.8 & 16.9 \\
\hline
\end{tabular}


Table 6.22 (Continued)

\begin{tabular}{|c|c|c|c|c|c|c|c|c|}
\hline Contaminant & Form & Test Species & $\begin{array}{c}\text { NOAEL } \\
\text { (mg/kg/d) } \\
\text { and Duration }\end{array}$ & $\begin{array}{c}\text { LOAEL } \\
\text { (mg/kg/d) } \\
\text { and Duration }\end{array}$ & Endpoint & Citation & $\begin{array}{c}\text { Estimated } \\
\text { NOAEL } \\
(\mathrm{mg} / \mathrm{kg} / \mathrm{d}) \\
\end{array}$ & $\begin{array}{c}\text { Estimated } \\
\text { LOAEL } \\
(\mathrm{mg} / \mathrm{kg} / \mathrm{d})\end{array}$ \\
\hline Vanadium & $\begin{array}{l}\text { vanadyl } \\
\text { sulfate }\end{array}$ & mallard duck & $\begin{array}{c}11.4 \\
12 \text { wks. }\end{array}$ & 12 wks. & $\begin{array}{l}\text { mortality, } \\
\text { body weight, } \\
\text { blood chem. }\end{array}$ & White and Dieter 1978 & 11.4 & \\
\hline Zinc & zinc sulfate & chicken & $\begin{array}{c}14.5 \\
44 \mathrm{wk}\end{array}$ & $\begin{array}{l}130.9 \\
44 \mathrm{wk}\end{array}$ & reproduction & Stahl et al. 1990 & 14.5 & 1309 \\
\hline
\end{tabular}


Table C.23 Water Benchmamark Values for Wildlife Endpoints

\begin{tabular}{|c|c|c|c|c|c|c|c|c|c|c|c|c|c|c|}
\hline \multirow{2}{*}{ Contaminant } & \multicolumn{7}{|c|}{ Estimated NOAEL's } & \multicolumn{7}{|c|}{ Estimated LOAEL's } \\
\hline & Shrew & Mouse & Mink & Fox & Deer & Kingfisher & Hawk & Shrew & Mouse & Mink & Fox & Deer & Kingfisher & Hawk \\
\hline Acetone & 99.90 & 66.57 & 77.69 & 62.54 & 42.84 & & & 499.51 & 332.86 & 388.47 & 312.69 & 214.20 & & \\
\hline Aluminum & 10.43 & 6.95 & 8.11 & 6.53 & 4.47 & 1014.70 & 1930.03 & 104.33 & 69.52 & 81.13 & 65.31 & 44.74 & 411.63 & 782.92 \\
\hline Antimony & 0.68 & 0.45 & 0.53 & 0.42 & 0.29 & & & 6.76 & 4.50 & 5.26 & 4.23 & 2.90 & & \\
\hline Aroclor 1248 & 0.19 & 0.13 & 0.15 & 0.12 & 0.08 & & & 1.94 & 1.29 & 1.51 & 1.22 & 0.83 & & \\
\hline Aroclor 1254 & 0.30 & 0.20 & 1.41 & 1.14 & 0.13 & 1.67 & 3.17 & 3.08 & 2.02 & 6.97 & 5.61 & 1.30 & 16.65 & 31.67 \\
\hline Arsenic(Sodium Arsenite) & 0.68 & 0.45 & 0.53 & 0.43 & 0.29 & 47.50 & 90.34 & 6.81 & 4.54 & 5.30 & 4.26 & 2.92 & 118.77 & 225.90 \\
\hline Barium & 53.80 & 35.85 & 41.84 & 33.68 & 23.07 & 192.40 & 365.95 & 197.81 & 131.81 & 153.83 & 123.83 & 84.83 & 385.73 & 733.66 \\
\hline Benzo(a)pyrene & 5.41 & 3.60 & 4.20 & 3.38 & 2.32 & & & 54.06 & 36.02 & 42.04 & 33.84 & 23.18 & & \\
\hline Beryllium & 6.59 & 4.39 & 5.13 & 4.13 & 2.83 & & & & & & & & & \\
\hline Bis(2-ethylhexyl)phthalate & 98.92 & 65.92 & 76.93 & 61.92 & 42.42 & 10.18 & 19.35 & 989.21 & 659.18 & 769.30 & 619.23 & 424.20 & & \\
\hline Boron & 279.72 & 186.40 & 217.54 & 175.11 & 119.95 & 266.40 & 506.70 & 935.08 & 623.11 & 727.21 & 585.36 & 400.99 & 925.00 & 1759.38 \\
\hline Cadmium & 0.08 & 0.05 & 0.06 & 0.05 & 0.03 & 13.41 & 25.51 & 0.10 & 0.07 & 0.08 & 0.06 & 0.04 & 185.00 & 351.88 \\
\hline Carbon Tetrachloride & 159.84 & 106.52 & 124.31 & 100.06 & 68.55 & & & & & & & & & \\
\hline Chloroform & 149.85 & 99.86 & 116.54 & 93.81 & 64.26 & & & 409.60 & 272.94 & 318.54 & 256.41 & 175.65 & & \\
\hline Chromium $(\mathrm{Cr}+3)$ & 27343.00 & 18220.70 & 21264.60 & 17116.70 & 11725.50 & 9.25 & 17.59 & & & & & & 46.25 & 87.97 \\
\hline Chromium $(\mathrm{Cr}+6)$ & 32.77 & 21.84 & 25.48 & 20.51 & 14.05 & & & 131.27 & 87.48 & 102.09 & 82.18 & 56.29 & & \\
\hline Copper & 151.96 & 101.27 & 118.18 & 95.13 & 65.17 & 434.75 & 826.91 & 196.64 & 131.04 & 152.93 & 123.10 & 84.33 & 570.73 & 1085.53 \\
\hline 1,2-Dichloroethene & 244.33 & 162.81 & 190.01 & 152.95 & 104.78 & & & & & & & & & \\
\hline Di-n-butyl phthalate & 2973.03 & 1981.14 & 2312.11 & 1861.07 & 1274.92 & 1.02 & 1.94 & 9908.28 & 6602.58 & 7705.64 & 6202.44 & 4248.94 & 10.18 & 19.35 \\
\hline Lead (Metal) & 79.92 & 53.26 & 62.15 & 50.03 & 34.27 & 35.61 & 67.74 & & & & & & & \\
\hline Lead (Acetate) & & & & & & 10.45 & 19.88 & 799.21 & 532.57 & 621.54 & 500.31 & 342.73 & 104.53 & 198.81 \\
\hline Lithium & 93.91 & 62.58 & 73.03 & 58.79 & 40.27 & & & 187.82 & 125.16 & 146.06 & 117.57 & 80.54 & & \\
\hline Manganese & 879.13 & 585.83 & 683.70 & 550.34 & 377.00 & 9037.30 & 17189.10 & 2837.20 & 1890.64 & 2206.48 & 1776.08 & 1216.68 & & \\
\hline Methylmercury & 0.32 & 0.21 & 0.15 & 0.12 & 0.14 & 0.06 & 0.11 & 1.60 & 1.07 & 1.24 & 1.00 & 0.69 & 0.59 & 1.13 \\
\hline Methylene Chloride & 58.44 & 38.94 & 45.45 & 36.59 & 25.06 & & & 499.51 & 332.86 & 388.47 & 312.69 & 214.20 & & \\
\hline Molybdenum & 1.41 & 0.94 & 1.09 & 0.88 & 0.60 & 32.38 & 61.58 & 14.05 & 9.37 & 10.93 & 8.80 & 6.03 & 326.53 & 621.06 \\
\hline Nickel & 399.61 & 266.29 & 310.77 & 250.15 & 171.36 & 715.95 & 1361.76 & 799.21 & 532.57 & 621.54 & 500.31 & 342.73 & 989.75 & 1882.53 \\
\hline Selenium(Sodium Selenite) & 0.41 & 0.27 & 0.32 & 0.26 & 0.18 & 4.63 & 8.80 & 4.11 & 2.74 & 3.20 & 2.57 & 1.76 & 9.25 & 17.59 \\
\hline Strontium & 2627.41 & 1750.84 & 2043.32 & 1644.75 & 1126.71 & & & & & & & & & \\
\hline 1,1,2,2-Tetrachloroethene & 7.57 & 5.04 & 5.89 & 4.74 & 3.25 & & & 37.84 & 25.21 & 29.43 & 23.69 & 16.23 & & \\
\hline Thallium & 0.08 & 0.05 & 0.06 & 0.05 & 0.03 & & & 0.75 & 0.50 & 0.58 & 0.47 & 0.32 & & \\
\hline
\end{tabular}


Tin

1,1,1-Trichloroethane

Trichloroethene

Vanadium

Vinyl Chloride

Zinc

Zirconium

$\begin{array}{rrrrr}126.49 & 84.29 & 98.37 & 79.18 & 54.24 \\ 5617.86 & 3743.60 & 4368.99 & 3516.75 & 2409.04 \\ 3.78 & 2.52 & 2.94 & 2.37 & 1.62 \\ 1.95 & 1.30 & 1.52 & 1.22 & 0.84 \\ 1.70 & 1.13 & 1.32 & 1.06 & 0.73 \\ 1598.42 & 1065.15 & 1243.09 & 1000.61 & 685.45 \\ 9.41 & 6.27 & 7.32 & 5.89 & 4.03\end{array}$

$105.45 \quad 200.57$

37.84

19.48

16.98

$134.13 \quad 255.11$

$\begin{array}{rrrrr}189.19 & 126.07 & 147.13 & 118.43 & 1.13 \\ & & & & \\ 37.84 & 25.21 & 29.43 & 23.69 & 16.23 \\ 19.48 & 12.98 & 15.15 & 12.19 & 8.35 \\ 16.98 & 11.32 & 13.21 & 10.63 & 7.23 \\ 196.84 & 2130.29 & 2486.17 & 2001.22 & 1370.90\end{array}$

$156.33 \quad 297.33$

8.23

.03 
Table C.24 Contaminant concentrations ( $\mathrm{mg} / \mathrm{kg}$ ) found in Kingfisher egg shells and feathers found on the ORR.

\begin{tabular}{lcccccccc}
\hline Matrix & Burrow a & As & Cd & Se & Pb & Hg & $\begin{array}{c}{ }_{60 C o} \\
(\mathbf{p C i} / \mathrm{g})\end{array}$ & $\begin{array}{c}{ }^{137} \mathrm{Cs} \\
\text { (pCi/g) }\end{array}$ \\
\hline egg shell & CRD & 0.135 & $<0.0333_{\mathrm{b}}$ & 1.58 & 2.0 & $<0.020$ & $<7.45$ & $<9.09$ \\
egg shell & WOC & 0.0536 & 0.0583 & 1.41 & 5.31 & 0.182 & $<1.89$ & $58.1-1.7$ \\
feathers & CRU & 0.074 & 0.0132 & 5.72 & 0.657 & 1.03 & $<0.21$ & $<0.18$ \\
feathers & CRU & 0.0449 & $<0.0102$ & 6.54 & 1.42 & 1.01 & $<0.18$ & $<0.19$ \\
feathers & CRU & 0.052 & $<0.010$ & 5.72 & 1.67 & 1.04 & $<0.17$ & $<0.18$ \\
feathers & CRU & 0.0755 & 0.0755 & 6.83 & 1.91 & 0.726 & $<0.25$ & $<0.16$ \\
\hline
\end{tabular}

$\mathrm{CRD}=$ Clinch River downstream of WOL Embayment; WOC = White Oak Creek downstream of WCK 3.5; $\mathrm{CRU}=$ Clinch River upstream of Oak Ridge Reservation.

b Less than values are below minimum detection limit. 


$$
\text { C-56 }
$$

Table C.25. Contaminant concentrations in tissues of the three kingfishers found on the ORR

\begin{tabular}{|c|c|c|c|c|c|c|c|}
\hline $\begin{array}{l}\text { Bird } \\
\text { No. }\end{array}$ & $\begin{array}{l}\text { Watershed } \\
\text { and Location }\end{array}$ & Organ & $\begin{array}{c}{ }_{137} \mathrm{Cs} \\
(\mathrm{pCi} / \mathrm{g})\end{array}$ & $\begin{array}{c}C d \\
(\mathrm{mg} / \mathrm{kg})^{2}\end{array}$ & $\begin{array}{c}\mathbf{P b} \\
(\mathrm{mg} / \mathrm{kg}) \mathbf{a}\end{array}$ & $\begin{array}{c}\mathrm{Se} \\
(\mathrm{mg} / \mathrm{kg})\end{array}$ & $\underset{(\mathbf{m g} / \mathbf{k g})}{\mathbf{H g}}$ \\
\hline \multirow[t]{5}{*}{1} & \multirow[t]{5}{*}{$\begin{array}{l}\text { East Fork } \\
\text { Poplar Creek, } \\
\text { Lake Reality }\end{array}$} & $\begin{array}{c}\text { whole body } \\
\text { feathers }\end{array}$ & $<2$ & $\mathrm{ND}$ & 2.67 & 5.38 & 13.9 \\
\hline & & kidney & & 4.04 & $\mathrm{ND}$ & 5.81 & 8.65 \\
\hline & & liver & & 0.95 & $\mathrm{ND}$ & 2.71 & 3.69 \\
\hline & & heart & & ND & $\mathrm{ND}$ & 1.25 & 1.1 \\
\hline & & muscle & & ND & $\mathrm{ND}$ & $\mathrm{ND}$ & 0.572 \\
\hline \multirow[t]{5}{*}{2} & \multirow{5}{*}{$\begin{array}{l}\text { East Fork } \\
\text { Poplar Creek }\end{array}$} & feathers & & 7.21 & 1.86 & 5.63 & 4.55 \\
\hline & & kidney & & 0.40 & $\mathrm{ND}$ & 3.14 & 1.46 \\
\hline & & liver & & 0.23 & ND & 3.45 & 0.955 \\
\hline & & heart & & ND & ND & 2.01 & 0.594 \\
\hline & & muscle & 3 & $\mathrm{ND}$ & $\mathrm{ND}$ & 1.04 & 0.805 \\
\hline \multirow[t]{5}{*}{3} & \multirow[t]{5}{*}{$\begin{array}{l}\text { White Oak } \\
\text { Creek, } \\
\text { Bldg. } 4505\end{array}$} & $\begin{array}{c}\text { whole body } \\
\text { feathers }\end{array}$ & 13,690 & 0.34 & 4.88 & 7.29 & 2.72 \\
\hline & & kidney & 69 & 1.53 & 0.42 & 6.01 & 26.8 \\
\hline & & liver & 76 & 0.90 & 0.40 & 7.5 & 17.6 \\
\hline & & heart & 81 & $\mathrm{ND}$ & ND & 2.2 & 9.52 \\
\hline & & muscle & 151 & ND & 0.58 & 1.84 & 6.34 \\
\hline
\end{tabular}

${ }^{2} \mathrm{ND}=$ Nondetect: As- $<0.40 \mathrm{mg} / \mathrm{kg}, \mathrm{Cd}-<0.20 \mathrm{mg} / \mathrm{kg}, \mathrm{Pb}-<0.40 \mathrm{mg} / \mathrm{kg}$, and Se- $<0.40 \mathrm{mg} / \mathrm{kg}$. 


\section{C-57}

Table C.26 Estimated Densities of Wildlife Populations within WAG 2

\begin{tabular}{|c|c|c|c|}
\hline Endpoint & Population Density ${ }^{1}$ & $\begin{array}{c}\text { Amount of } \\
\text { Suitable Habitat }\end{array}$ & $\begin{array}{c}\text { Estimated } \\
\text { Population Size } \\
\end{array}$ \\
\hline Short-tailed Shrew & $23 \mathrm{ha}$ & $60.56 \mathrm{ha}$ & 1393 \\
\hline White-footed Mouse & $57 \mathrm{ha}$ & $60.62 \mathrm{ha}$ & 3455 \\
\hline White-tailed Deer & $0.1704 \mathrm{ha}$ & $60.62 \mathrm{ha}$ & 10 \\
\hline Red Fox & $0.077 \mathrm{ha}$ & $60.62 \mathrm{ha}$ & 5 \\
\hline Red-Tailed Hawk & $0.03 \mathrm{ha}$ & $60.62 \mathrm{ha}$ & 2 \\
\hline Wild Turkey & $0.0426 \mathrm{ha}$ & $60.62 \mathrm{ha}$ & 3 \\
\hline Mink & 0.6 stream $\mathbf{~ k m}$ & 6.4 stream $\mathrm{km}$ & 4 \\
\hline Belted Kingfisher & 0.4 stream $\mathrm{km}$ & 6.4 stream $\mathrm{km}$ & 3 \\
\hline
\end{tabular}

'Number of individuals 
Table 6.27. Summary of the number of individuals of wildlife endpoints estimated to be experiencing adverse effects in WAG 2

\begin{tabular}{|c|c|c|c|c|c|}
\hline Species & Analyte & $\%>$ LOAEL & $\begin{array}{c}\text { Number in } \\
\text { Area }\end{array}$ & $\begin{array}{c}\text { Number } \\
\text { Adversely } \\
\text { Affected }\end{array}$ & $\begin{array}{l}\text { Percent } \\
\text { Adversely } \\
\text { Affected }\end{array}$ \\
\hline \multirow[t]{13}{*}{ Short-tailed Shrew } & Aroclor 1260 & $35-40 \%$ & 1393 & $488-557$ & $35-40 \%$ \\
\hline & Arsenic & $<5 \%$ & 1393 & 0 & $0 \%$ \\
\hline & Barium & $<5 \%$ & 1393 & 0 & $0 \%$ \\
\hline & Cadmium & $70 \%$ & 1393 & 975 & $70 \%$ \\
\hline & Chromium & $>95 \%$ & 1393 & 1393 & $100 \%$ \\
\hline & Copper & $<5 \%$ & 1393 & 0 & $0 \%$ \\
\hline & Manganese & $<5 \%$ & 1393 & 0 & $0 \%$ \\
\hline & Mercury & $>95 \%$ & 1393 & 1393 & $100 \%$ \\
\hline & Molybdenum & $<5 \%$ & 1393 & 0 & $0 \%$ \\
\hline & Nickel & $<5 \%$ & 1393 & 0 & $0 \%$ \\
\hline & Selenium & $75 \%$ & 1393 & 1045 & $75 \%$ \\
\hline & Vanadium & $<5 \%$ & 1393 & 0 & $0 \%$ \\
\hline & Zinc & $<5 \%$ & 1393 & 0 & $0 \%$ \\
\hline \multirow[t]{4}{*}{ White-footed Mice } & Aroclor 1260 & $<5 \%$ & 3455 & 0 & $0 \%$ \\
\hline & Chromium & $<5 \%$ & 3455 & 0 & $.0 \%$ \\
\hline & Mercury & $80-85 \%$ & 3455 & 3455 & $100 \%$ \\
\hline & Selenium & $<5 \%$ & 3455 & 0 & $0 \%$ \\
\hline \multirow[t]{3}{*}{ Red Fox } & Aroclor 1260 & $<5 \%$ & 5 & 0 & $0 \%$ \\
\hline & Mercury & $65-70 \%$ & 5 & 3 & $60 \%$ \\
\hline & Selenium & $<5 \%$ & 5 & 0 & $0 \%$ \\
\hline Mink $^{1}$ & Mercury & $<5 \%$ & 4 & 0 & $0 \%$ \\
\hline Mink $^{2}$ & Mercury & $90-95 \%$ & 4 & 4 & $100 \%$ \\
\hline White-tailed Deer & Mercury & $<5 \%$ & 10 & 0 & $0 \%$ \\
\hline Belted Kingfisher ${ }^{1}$ & Mercury & $70-75 \%$ & 3 & 2 & $66 \%$ \\
\hline Red-tailed Hawk & Mercury & $80-85 \%$ & 2 & 2 & $100 \%$ \\
\hline Wild Turkey & Mercury & $30-35 \%$ & 3 & 1 & $33 \%$ \\
\hline
\end{tabular}

'Exposure through consumption of fish only.

${ }^{2}$ Exposure through consumption of small mammals, vegetation, invertegrates, and soil. 
Table 6.28. NOAEL hazard quotients for water contaminants in White Oak Creek reaches.

\begin{tabular}{|c|c|c|c|c|c|c|c|c|c|c|}
\hline Location & Contaminant & $\begin{array}{l}95 \% \\
\text { UCL }\end{array}$ & Shrew & Mouse & Mink & Fox & Deer & Turkey & Kingfisher & Hawk \\
\hline $1 \mathrm{C}$ & ALUMINUM & 0.503 & 0.048 & 0.072 & 0.062 & 0.077 & 0.112 & 0.000 & 0.000 & 0.000 \\
\hline IWC & ALUMINUM & 0.613 & 0.059 & 0.088 & 0.076 & 0.094 & 0.137 & 0.000 & 0.001 & 0.000 \\
\hline BWC & ALUMINUM & 0.196 & 0.019 & 0.028 & 0.024 & 0.030 & 0.044 & 0.000 & 0.000 & 0.000 \\
\hline HRT & ALUMTNUM & 0.178 & 0.017 & 0.026 & 0.022 & 0.027 & 0.040 & 0.000 & 0.000 & 0.000 \\
\hline NWT & ALUMINUM & 0.481 & 0.046 & 0.069 & 0.059 & 0.074 & 0.108 & 0.000 & 0.000 & 0.000 \\
\hline RAC & ALUMMNUM & 0.843 & 0.081 & 0.121 & 0.104 & 0.129 & 0.188 & 0.000 & 0.001 & 0.000 \\
\hline UMB & ALUMMUM & 0.306 & 0.029 & 0.044 & 0.038 & 0.047 & 0.068 & 0.000 & 0.000 & 0.000 \\
\hline W4T & ALUMINUM & 0.491 & 0.047 & 0.071 & 0.061 & 0.075 & 0.110 & 0.000 & 0.000 & 0.000 \\
\hline WOL & ALUMTNUM & 1.102 & 0.106 & 0.159 & 0.136 & 0.169 & 0.246 & 0.000 & 0.001 & 0.001 \\
\hline WOL & ALUMINUM & 0.455 & 0.044 & 0.065 & 0.056 & 0.070 & 0.102 & 0.000 & 0.000 & 0.000 \\
\hline HRT & ANTIMONY & 0.019 & 0.028 & 0.042 & 0.036 & 0.045 & 0.066 & & & \\
\hline HRT & ARSENIC & 0.001 & 0.001 & 0.002 & 0.002 & 0.002 & 0.003 & 0.000 & 0.000 & 0.000 \\
\hline UMB & ARSENIC & 0.002 & 0.003 & 0.004 & 0.004 & 0.005 & 0.007 & 0.000 & 0.000 & 0.000 \\
\hline W4T & ARSENIC & 0.001 & 0.001 & 0.002 & 0.002 & 0.002 & 0.003 & 0.000 & 0.000 & 0.000 \\
\hline WOL & ARSENIC & 0.001 & 0.001 & 0.002 & 0.002 & 0.002 & 0.003 & 0.000 & 0.000 & 0.000 \\
\hline WOL & ARSENIC & 0.001 & 0.001 & 0.002 & 0.002 & 0.002 & 0.003 & 0.000 & 0.000 & 0.000 \\
\hline HRT & Acetone & 0.001 & 0.000 & 0.000 & 0.000 & 0.000 & 0.000 & & & \\
\hline UMB & Acetone & 0.003 & 0.000 & 0.000 & 0.000 & 0.000 & 0.000 & & & \\
\hline W4T & Acetone & 0.002 & 0.000 & 0.000 & 0.000 & 0.000 & 0.000 & & & \\
\hline WOL & Acetone & 0.003 & 0.000 & 0.000 & 0.000 & 0.000 & 0.000 & & & \\
\hline IC & BARIUM & 0.046 & 0.001 & 0.001 & 0.001 & 0.001 & 0.002 & 0.000 & 0.000 & 0.000 \\
\hline $1 W C$ & BARIUM & 0.04 & 0.001 & 0.001 & 0.001 & 0.001 & 0.002 & 0.000 & 0.000 & 0.000 \\
\hline BWC & BARIUM & 0.26 & 0.005 & 0.007 & 0.006 & 0.008 & 0.011 & 0.000 & 0.001 & 0.001 \\
\hline HRT & BARIUM & 0.063 & 0.001 & 0.002 & 0.002 & 0.002 & 0.003 & 0.000 & 0.000 & 0.000 \\
\hline NWT & BARIUM & 0.044 & 0.001 & 0.001 & 0.001 & 0.001 & 0.002 & 0.000 & 0.000 & 0.000 \\
\hline RAC & BARIUM & 0.029 & 0.001 & 0.001 & 0.001 & 0.001 & 0.001 & 0.000 & 0.000 & 0.000 \\
\hline UMB & BARIUM & 0.065 & 0.001 & 0.002 & 0.002 & 0.002 & 0.003 & 0.000 & 0.000 & 0.000 \\
\hline W4T & BARIUM & 0.204 & 0.004 & 0.006 & 0.005 & 0.006 & 0.009 & 0.000 & 0.001 & 0.001 \\
\hline WOL & BARIUM & 0.051 & 0.001 & 0.001 & 0.001 & 0.002 & 0.002 & 0.000 & 0.000 & 0.000 \\
\hline WOL & BARIUM & 0.075 & 0.001 & 0.002 & 0.002 & 0.002 & 0.003 & 0.000 & 0.000 & 0.000 \\
\hline $1 \mathrm{C}$ & BORON & 0.036 & 0.000 & 0.000 & 0.000 & 0.000 & 0.000 & 0.000 & 0.000 & 0.000 \\
\hline HRT & BORON & 0.044 & 0.000 & 0.000 & 0.000 & 0.000 & 0.000 & 0.000 & 0.000 & 0.000 \\
\hline UMB & BORON & 0.055 & 0.000 & 0.000 & 0.000 & 0.000 & 0.000 & 0.000 & 0.000 & 0.000 \\
\hline W4T & BORON & 0.226 & 0.001 & 0.001 & 0.001 & 0.001 & 0.002 & 0.000 & 0.001 & 0.000 \\
\hline WOL & BORON & 0.207 & 0.001 & 0.001 & 0.001 & 0.001 & 0.002 & 0.000 & 0.001 & 0.000 \\
\hline WOL & BORON & 0.24 & 0.001 & 0.001 & 0.001 & 0.001 & 0.002 & 0.000 & 0.001 & 0.000 \\
\hline W4T & CADMIUM & 0.001 & 0.013 & 0.019 & 0.016 & 0.020 & 0.029 & 0.000 & 0.000 & 0.000 \\
\hline HRT & CHROMIUM & 0.003 & 0.000 & 0.000 & 0.000 & 0.000 & 0.000 & 0.000 & 0.000 & 0.000 \\
\hline UMB & CHROMIUM & 0.005 & 0.000 & 0.000 & 0.000 & 0.000 & 0.000 & 0.000 & 0.001 & 0.000 \\
\hline W4T & CHROMIUM & 0.004 & 0.000 & 0.000 & 0.000 & 0.000 & 0.000 & 0.000 & 0.000 & 0.000 \\
\hline WOL & CHROMIUM & 0.019 & 0.001 & 0.001 & 0.001 & 0.001 & 0.001 & 0.001 & 0.002 & 0.001 \\
\hline
\end{tabular}


Table 6.28 (Continued)

\begin{tabular}{|c|c|c|c|c|c|c|c|c|c|c|}
\hline Location & Contaminant & $\begin{array}{l}95 \% \\
\text { UCL }\end{array}$ & Shrew & Mouse & Mink & Fox & Deer & Turkey & Kingfisher & Hawk \\
\hline $1 \mathrm{C}$ & COPPER & 0.0037 & 0.000 & 0.000 & 0.000 & 0.000 & 0.000 & 0.000 & 0.000 & 0.000 \\
\hline $1 \mathrm{WC}$ & COPPER & 0.007 & 0.000 & 0.000 & 0.000 & 0.000 & 0.000 & 0.000 & 0.000 & 0.000 \\
\hline HRT & COPPER & 0.002 & 0.000 & 0.000 & 0.000 & 0.000 & 0.000 & 0.000 & 0.000 & 0.000 \\
\hline UMB & COPPER & 0.0149 & 0.000 & 0.000 & 0.000 & 0.000 & 0.000 & 0.000 & 0.000 & 0.000 \\
\hline W4T & COPPER & 0.014 & 0.000 & 0.000 & 0.000 & 0.000 & 0.000 & 0.000 & 0.000 & 0.000 \\
\hline WOL & COPPER & 0.0081 & 0.000 & 0.000 & 0.000 & 0.000 & 0.000 & 0.000 & 0.000 & 0.000 \\
\hline WOL & COPPER & 0.0039 & 0.000 & 0.000 & 0.000 & 0.000 & 0.000 & 0.000 & 0.000 & 0.000 \\
\hline $1 \mathrm{C}$ & LEAD & 0.002 & 0.000 & 0.000 & 0.000 & 0.000 & 0.000 & 0.000 & 0.000 & 0.000 \\
\hline BWC & LEAD & 0.004 & 0.000 & 0.000 & 0.000 & 0.000 & 0.000 & 0.000 & 0.000 & 0.000 \\
\hline W4T & LEAD & 0.0021 & 0.000 & 0.000 & 0.000 & 0.000 & 0.000 & 0.000 & 0.000 & 0.000 \\
\hline WOL & LEAD & 0.0033 & 0.000 & 0.000 & 0.000 & 0.000 & 0.000 & 0.000 & 0.000 & 0.000 \\
\hline WOL & LEAD & 0.002 & 0.000 & 0.000 & 0.000 & 0.000 & 0.000 & 0.000 & 0.000 & 0.000 \\
\hline $1 \mathrm{C}$ & MANGANESE & 0.0339 & 0.000 & 0.000 & 0.000 & 0.000 & 0.000 & 0.000 & 0.000 & 0.000 \\
\hline IWC & MANGANESE & 0.0227 & 0.000 & 0.000 & 0.000 & 0.000 & 0.000 & 0.000 & 0.000 & 0.000 \\
\hline $\mathrm{BWC}$ & MANGANESE & 0.008 & 0.000 & 0.000 & 0.000 & 0.000 & 0.000 & 0.000 & 0.000 & 0.000 \\
\hline HRT & MANGANESE & 0.0509 & 0.000 & 0.000 & 0.000 & 0.000 & 0.000 & 0.000 & 0.000 & 0.000 \\
\hline NWT & MANGANESE & 0.1486 & 0.000 & 0.000 & 0.000 & 0.000 & 0.000 & 0.000 & 0.000 & 0.000 \\
\hline $\mathrm{RAC}$ & MANGANESE & 5.3231 & 0.006 & 0.009 & 0.008 & 0.010 & 0.014 & 0.000 & 0.001 & 0.000 \\
\hline UMB & MANGANESE & 0.0745 & 0.000 & 0.000 & 0.000 & 0.000 & 0.000 & 0.000 & 0.000 & 0.000 \\
\hline W4T & MANGANESE & 1.3784 & 0.002 & 0.002 & 0.002 & 0.003 & 0.004 & 0.000 & 0.000 & 0.000 \\
\hline WOL & MANGANESE & 0.1769 & 0.000 & 0.000 & 0.000 & 0.000 & 0.000 & 0.000 & 0.000 & 0.000 \\
\hline WOL & MANGANESE & 3.2234 & 0.004 & 0.006 & 0.005 & 0.006 & 0.009 & 0.000 & 0.000 & 0.000 \\
\hline RAC & MOLYBDENUM & 0.012 & 0.009 & 0.013 & 0.011 & 0.014 & 0.020 & 0.000 & 0.000 & 0.000 \\
\hline W4T & MOLYBDENUM & 0.0195 & 0.014 & 0.021 & 0.018 & 0.022 & 0.032 & 0.000 & 0.001 & 0.000 \\
\hline RAC & Methylene chloride & 0.002 & 0.000 & 0.000 & 0.000 & 0.000 & 0.000 & & & \\
\hline W4T & NICKEL & 0.0152 & 0.000 & 0.000 & 0.000 & 0.000 & 0.000 & 0.000 & 0.000 & 0.000 \\
\hline WOL & NICKEL & 0.0141 & 0.000 & 0.000 & 0.000 & 0.000 & 0.000 & 0.000 & 0.000 & 0.000 \\
\hline $1 \mathrm{C}$ & STRONTIUM & 0.0952 & 0.000 & 0.000 & 0.000 & 0.000 & 0.000 & & & \\
\hline IWC & STRONTIUM & 0.1335 & 0.000 & 0.000 & 0.000 & 0.000 & 0.000 & & & \\
\hline $\mathrm{BWC}$ & STRONTIUM & 0.036 & 0.000 & 0.000 & 0.000 & 0.000 & 0.000 & & & \\
\hline HRT & STRONTIUM & 0.1074 & 0.000 & 0.000 & 0.000 & 0.000 & 0.000 & & & \\
\hline NWT & STRONTIUM & 0.1691 & 0.000 & 0.000 & 0.000 & 0.000 & 0.000 & & & \\
\hline RAC & STRONTIUM & 0.2323 & 0.000 & 0.000 & 0.000 & 0.000 & 0.000 & & & \\
\hline UMB & STRONTIUM & 0.1997 & 0.000 & 0.000 & 0.000 & 0.000 & 0.000 & & & \\
\hline W4T & STRONTIUM & 0.2301 & 0.000 & 0.000 & 0.000 & 0.000 & 0.000 & & & \\
\hline WOL & STRONTIUM & 0.1048 & 0.000 & 0.000 & 0.000 & 0.000 & 0.000 & & & \\
\hline WOL & STRONTIUM & 0.1164 & 0.000 & 0.000 & 0.000 & 0.000 & 0.000 & & & \\
\hline RAC & Trichloroethene & 0.001 & 0.000 & 0.000 & 0.000 & 0.000 & 0.001 & & & \\
\hline W4T & Trichloroethene & 0.001 & 0.000 & 0.000 & 0.000 & 0.000 & 0.001 & & & \\
\hline UMB & VANADIUM & 0.002 & 0.001 & 0.002 & 0.001 & 0.002 & 0.002 & 0.000 & 0.000 & 0.000 \\
\hline
\end{tabular}




\section{C-61}

\begin{tabular}{llrllllllll}
\hline Location & Contaminant & $\begin{array}{r}95 \% \\
\text { UCL }\end{array}$ & Shrew & Mouse & Mink & Fox & Deer & Turkey & Kingfisher Hawk \\
\hline WOL & VANADIUM & 0.0038 & 0.002 & 0.003 & 0.003 & 0.003 & 0.005 & 0.000 & 0.000 & 0.000 \\
IC & ZINC & 0.0283 & 0.000 & 0.000 & 0.000 & 0.000 & 0.000 & 0.000 & 0.000 & 0.000 \\
IWC & ZINC & 0.2617 & 0.000 & 0.000 & 0.000 & 0.000 & 0.000 & 0.001 & 0.002 & 0.001 \\
HRT & ZINC & 0.0065 & 0.000 & 0.000 & 0.000 & 0.000 & 0.000 & 0.000 & 0.000 & 0.000 \\
UMB & ZINC & 0.114 & 0.000 & 0.000 & 0.000 & 0.000 & 0.000 & 0.000 & 0.001 & 0.000 \\
W4T & ZINC & 0.0127 & 0.000 & 0.000 & 0.000 & 0.000 & 0.000 & 0.000 & 0.000 & 0.000 \\
WOL & ZINC & 0.0528 & 0.000 & 0.000 & 0.000 & 0.000 & 0.000 & 0.000 & 0.000 & 0.000 \\
WOL & ZINC & 0.0152 & 0.000 & 0.000 & 0.000 & 0.000 & 0.000 & 0.000 & 0.000 & 0.000 \\
W4T & cis-1,2-Dichloroethene & 0.0029 & 0.000 & 0.000 & 0.000 & 0.000 & 0.000 & & & \\
\hline
\end{tabular}


Table C.29. NOAEL hazard quotients for water contaminants in White Oak Creek seeps.

\begin{tabular}{|c|c|c|c|c|c|c|c|c|c|c|}
\hline Location & Contaminant & $\begin{array}{l}95 \% \\
\text { UCL }\end{array}$ & Shrew & Mouse & Mink & Fox & Deer & Turkey & Kingfisher & Hawk \\
\hline WOCET & ALUMMNUM & 3.7796 & 0.362 & 0.544 & 0.466 & 0.579 & 0.845 & 0.001 & 0.004 & 0.002 \\
\hline MBTRIB-3 & ALUMINUM & 0.7349 & 0.070 & 0.106 & 0.091 & 0.113 & 0.164 & 0.000 & 0.001 & 0.000 \\
\hline MID. DRAIN. & ALUMINUM & 0.1081 & 0.010 & 0.016 & 0.013 & 0.017 & 0.024 & 0.000 & 0.000 & 0.000 \\
\hline SW2-5 & ALUMINUM & 0.0977 & 0.009 & 0.014 & 0.012 & 0.015 & 0.022 & 0.000 & 0.000 & 0.000 \\
\hline SW5-2 & ALUMINUM & 0.078 & 0.007 & 0.011 & 0.010 & 0.012 & 0.017 & 0.000 & 0.000 & 0.000 \\
\hline SW5-4 & ALUMINUM & 0.0508 & 0.005 & 0.007 & 0.006 & 0.008 & 0.011 & 0.000 & 0.000 & 0.000 \\
\hline EAST SEEP & ALUMMNUM & 1.2622 & 0.121 & 0.182 & 0.156 & 0.193 & 0.282 & 0.000 & 0.001 & 0.001 \\
\hline MV-1 & ALUMINUM & 0.2748 & 0.026 & 0.040 & 0.034 & 0.042 & 0.061 & 0.000 & 0.000 & 0.000 \\
\hline SW7-3 & ALUMINUM & 0.548 & 0.053 & 0.079 & 0.068 & 0.084 & 0.122 & 0.000 & 0.001 & 0.000 \\
\hline SW7-5 & ALUMINUM & 1.1221 & 0.108 & 0.161 & 0.138 & 0.172 & 0.251 & 0.000 & 0.001 & 0.001 \\
\hline SW7-6 & ALUMINUM & 0.761 & 0.073 & 0.109 & 0.094 & 0.117 & 0.170 & 0.000 & 0.001 & 0.000 \\
\hline SW7-8 & ALUMINUM & 0.412 & 0.039 & 0.059 & 0.051 & 0.063 & 0.092 & 0.000 & 0.000 & 0.000 \\
\hline WCTRIB-1 & ALUMINUM & 0.957 & 0.092 & 0.138 & 0.118 & 0.147 & 0.214 & 0.000 & 0.001 & 0.000 \\
\hline SW2-1 & ALUMINUM & 0.186 & 0.018 & 0.027 & 0.023 & 0.028 & 0.042 & 0.000 & 0.000 & 0.000 \\
\hline WCTRIB-2 & ALUMINUM & 0.194 & 0.019 & 0.028 & 0.024 & 0.030 & 0.043 & 0.000 & 0.000 & 0.000 \\
\hline SW9-2 & ALUMINUM & 1.7906 & 0.172 & 0.258 & 0.221 & 0.274 & 0.400 & 0.001 & 0.002 & 0.001 \\
\hline MV-3 & ALUMmUM & 0.162 & 0.016 & 0.023 & 0.020 & 0.025 & 0.036 & 0.000 & 0.000 & 0.000 \\
\hline SW2-6 & ALUMINUM & 0.2012 & 0.019 & 0.029 & 0.025 & 0.031 & 0.045 & 0.000 & 0.000 & 0.000 \\
\hline SW2-7 & ALUMINUM & 0.038 & 0.004 & 0.005 & 0.005 & 0.006 & 0.008 & 0.000 & 0.000 & 0.000 \\
\hline BTT & ALUMINUM & 0.0401 & 0.004 & 0.006 & 0.005 & 0.006 & 0.009 & 0.000 & 0.000 & 0.000 \\
\hline SW4-2 & ALUMINUM & 0.0415 & 0.004 & 0.006 & 0.005 & 0.006 & 0.009 & 0.000 & 0.000 & 0.000 \\
\hline WAG4 MS1 & ALUMINUM & 0.3133 & 0.030 & 0.045 & 0.039 & 0.048 & 0.070 & 0.000 & 0.000 & 0.000 \\
\hline WAG4 T2A & ALUMINUM & 0.7102 & 0.068 & 0.102 & 0.088 & 0.109 & 0.159 & 0.000 & 0.001 & 0.000 \\
\hline RS-1 & ALUMINUM & 0.298 & 0.029 & 0.043 & 0.037 & 0.046 & 0.067 & 0.000 & 0.000 & 0.000 \\
\hline RS-3A & ALUMINUM & 12.7297 & 1.220 & 1.831 & 1.569 & 1.949 & 2.845 & 0.004 & 0.013 & 0.007 \\
\hline RS-3B & ALUMINUM & 1.8185 & 0.174 & 0.262 & 0.224 & 0.278 & 0.406 & 0.001 & 0.002 & 0.001 \\
\hline SW7-2 & ALUMINUM & 1.0665 & 0.102 & 0.153 & 0.131 & 0.163 & 0.238 & 0.000 & 0.001 & 0.001 \\
\hline SW4-1 & ANTIMONY & 0.045 & 0.067 & 0.100 & 0.086 & 0.106 & 0.155 & & & \\
\hline MID. DRAIN. & ARSENIC & 0.001 & 0.001 & 0.002 & 0.002 & 0.002 & 0.003 & 0.000 & 0.000 & 0.000 \\
\hline EAST SEEP & ARSENIC & 0.003 & 0.004 & 0.007 & 0.006 & 0.007 & 0.010 & 0.000 & 0.000 & 0.000 \\
\hline MV-1 & ARSENIC & 0.002 & 0.003 & 0.004 & 0.004 & 0.005 & 0.007 & 0.000 & 0.000 & 0.000 \\
\hline SW7-3 & ARSENIC & 0.003 & 0.004 & 0.007 & 0.006 & 0.007 & 0.010 & 0.000 & 0.000 & 0.000 \\
\hline SW2-6 & ARSENIC & 0.001 & 0.001 & 0.002 & 0.002 & 0.002 & 0.003 & 0.000 & 0.000 & 0.000 \\
\hline SW2-7 & ARSENIC & 0.001 & 0.001 & 0.002 & 0.002 & 0.002 & 0.003 & 0.000 & 0.000 & 0.000 \\
\hline SW4-1 & ARSENIC & 0.006 & 0.009 & 0.013 & 0.011 & 0.014 & 0.021 & 0.000 & 0.000 & 0.000 \\
\hline RS-3A & ARSENIC & 0.0202 & 0.030 & 0.044 & 0.038 & 0.047 & 0.069 & 0.000 & 0.000 & 0.000 \\
\hline WOCET & Acetone & 0.009 & 0.000 & 0.000 & 0.000 & 0.000 & 0.000 & & & \\
\hline $5 N N T$ & Acetone & 0.008 & 0.000 & 0.000 & 0.000 & 0.000 & 0.000 & & & \\
\hline MV-1 & Acetone & 0.001 & 0.000 & 0.000 & 0.000 & 0.000 & 0.000 & & & \\
\hline MV-2 & Acetone & 0.003 & 0.000 & 0.000 & 0.000 & 0.000 & 0.000 & & & \\
\hline SW7-5 & Acetone & 0.014 & 0.000 & 0.000 & 0.000 & 0.000 & 0.000 & & & \\
\hline
\end{tabular}


Table 6.29. (Continued)

\begin{tabular}{|c|c|c|c|c|c|c|c|c|c|c|}
\hline Location & Contaminant & $\begin{array}{l}95 \% \\
\text { UCL }\end{array}$ & Shrew & Mouse & Mink & Fox & Deer & Turkey & Kingfisher & Hawk \\
\hline SW2-1 & Acetone & 0.011 & 0.000 & 0.000 & 0.000 & 0.000 & 0.000 & & & \\
\hline SW2-4 & Acetone & 0.014 & 0.000 & 0.000 & 0.000 & 0.000 & 0.000 & & & \\
\hline WCTRIB-2 & Acetone & 0.002 & 0.000 & 0.000 & 0.000 & 0.000 & 0.000 & & & \\
\hline SW2-2 & Acetone & 0.001 & 0.000 & 0.000 & 0.000 & 0.000 & 0.000 & & & \\
\hline SW6-1 & Acetone & 0.003 & 0.000 & 0.000 & 0.000 & 0.000 & 0.000 & & & \\
\hline WOCET & BARIUM & 0.1121 & 0.002 & 0.003 & 0.003 & 0.003 & 0.005 & 0.000 & 0.001 & 0.000 \\
\hline WCTRIB-3 & BARIUM & 0.062 & 0.001 & 0.002 & 0.001 & 0.002 & 0.003 & 0.000 & 0.000 & 0.000 \\
\hline MBTRIB-3 & BARIUM & 0.1328 & 0.002 & 0.004 & 0.003 & 0.004 & 0.006 & 0.000 & 0.001 & 0.000 \\
\hline MID. DRAIN. & BARIUM & 0.1126 & 0.002 & 0.003 & 0.003 & 0.003 & 0.005 & 0.000 & 0.001 & 0.000 \\
\hline SW2-5 & BARIUM & 0.3012 & 0.006 & 0.008 & 0.007 & 0.009 & 0.013 & 0.000 & 0.002 & 0.001 \\
\hline SW5-2 & BARIUM & 0.064 & 0.001 & 0.002 & 0.002 & 0.002 & 0.003 & 0.000 & 0.000 & 0.000 \\
\hline SW5-4 & BARIUM & 0.127 & 0.002 & 0.004 & 0.003 & 0.004 & 0.006 & 0.000 & 0.001 & 0.000 \\
\hline EAST SEEP & BARIUM & 0.036 & 0.001 & 0.001 & 0.001 & 0.001 & 0.002 & 0.000 & 0.000 & 0.000 \\
\hline MV-1 & BARIUM & 0.16 & 0.003 & 0.004 & 0.004 & 0.005 & 0.007 & 0.000 & 0.001 & 0.000 \\
\hline SW7-3 & BARIUM & 0.0219 & 0.000 & 0.001 & 0.001 & 0.001 & 0.001 & 0.000 & 0.000 & 0.000 \\
\hline SW7-5 & BARIUM & 0.0704 & 0.001 & 0.002 & 0.002 & 0.002 & 0.003 & 0.000 & 0.000 & 0.000 \\
\hline SW7-6 & BARIUM & 0.049 & 0.001 & 0.001 & 0.001 & 0.001 & 0.002 & 0.000 & 0.000 & 0.000 \\
\hline SW7-8 & BARIUM & 0.03 & 0.001 & 0.001 & 0.001 & 0.001 & 0.001 & 0.000 & 0.000 & 0.000 \\
\hline WCTRIB-I & BARIUM & 0.13974 & 0.003 & 0.004 & 0.003 & 0.004 & 0.006 & 0.000 & 0.001 & 0.000 \\
\hline SW2-1 & BARIUM & 0.084 & 0.002 & 0.002 & 0.002 & 0.002 & 0.004 & 0.000 & 0.000 & 0.000 \\
\hline SW2-3 & BARIUM & 0.038 & 0.001 & 0.001 & 0.001 & 0.001 & 0.002 & 0.000 & 0.000 & 0.000 \\
\hline SW2-4 & BARIUM & 0.32395 & 0.006 & 0.009 & 0.008 & 0.010 & 0.014 & 0.001 & 0.002 & 0.001 \\
\hline WCTRIB-2 & BARIUM & 0.038 & 0.001 & 0.001 & 0.001 & 0.001 & 0.002 & 0.000 & 0.000 & 0.000 \\
\hline SW9-1 & BARIUM & 0.14653 & 0.003 & 0.004 & 0.004 & 0.004 & 0.006 & 0.000 & 0.001 & 0.000 \\
\hline SW9-2 & BARIUM & 0.28725 & 0.005 & 0.008 & 0.007 & 0.009 & 0.012 & 0.000 & 0.001 & 0.001 \\
\hline MBTRIB-2A & BARIUM & 0.05 & 0.001 & 0.001 & 0.001 & 0.001 & 0.002 & 0.000 & 0.000 & 0.000 \\
\hline MV-3 & BARIUM & 0.049 & 0.001 & 0.001 & 0.001 & 0.001 & 0.002 & 0.000 & 0.000 & 0.000 \\
\hline SW2-2 & BARIUM & 0.104 & 0.002 & 0.003 & 0.002 & 0.003 & 0.005 & 0.000 & 0.001 & 0.000 \\
\hline SW2-6 & BARIUM & 0.16817 & 0.003 & 0.005 & 0.004 & 0.005 & 0.007 & 0.000 & 0.001 & 0.000 \\
\hline SW2-7 & BARIUM & 0.14008 & 0.003 & 0.004 & 0.003 & 0.004 & 0.006 & 0.000 & 0.001 & 0.000 \\
\hline BTT & BARIUM & 0.30888 & 0.006 & 0.009 & 0.007 & 0.009 & 0.013 & 0.000 & 0.002 & 0.001 \\
\hline SW4-1 & BARIUM & 0.3623 & 0.007 & 0.010 & 0.009 & 0.011 & 0.016 & 0.001 & 0.002 & 0.001 \\
\hline SW4-2 & BARIUM & 0.42776 & 0.008 & 0.012 & 0.010 & 0.013 & 0.019 & 0.001 & 0.002 & 0.001 \\
\hline WAG4 MSl & BARIUM & 0.15379 & 0.003 & 0.004 & 0.004 & 0.005 & 0.007 & 0.000 & 0.001 & 0.000 \\
\hline WAG4 T2A & BARIUM & 0.10552 & 0.002 & 0.003 & 0.003 & 0.003 & 0.005 & 0.000 & 0.001 & 0.000 \\
\hline RS-1 & BARIUM & 0.036 & 0.001 & $0.001^{\circ}$ & 0.001 & 0.001 & 0.002 & 0.000 & 0.000 & 0.000 \\
\hline RS-3A & BARIUM & 0.0612 & 0.001 & 0.002 & 0.001 & 0.002 & 0.003 & 0.000 & 0.000 & 0.000 \\
\hline RS-3B & BARIUM & 0.029 & 0.001 & 0.001 & 0.001 & 0.001 & 0.001 & 0.000 & 0.000 & 0.000 \\
\hline SW7-1 & BARIUM & 0.07831 & 0.001 & 0.002 & 0.002 & 0.002 & 0.003 & 0.000 & 0.000 & 0.000 \\
\hline SW7-2 & BARIUM & 0.032 & 0.001 & 0.001 & 0.001 & 0.001 & 0.001 & 0.000 & 0.000 & 0.000 \\
\hline
\end{tabular}


Table 6.29. (Continued)

\begin{tabular}{|c|c|c|c|c|c|c|c|c|c|c|}
\hline Location & Contaminant & $\begin{array}{l}95 \% \\
\text { UCL }\end{array}$ & Shrew & Mouse & Mink & Fox & Deer & Turkey & Kingfisher & Hawk \\
\hline SW7-5 & BERYLLIUM & 0.001 & 0.000 & 0.000 & 0.000 & 0.000 & 0.000 & & & \\
\hline WAG4 MS1 & BERYLLIUM & 0.00057 & 0.000 & 0.000 & 0.000 & 0.000 & 0.000 & & & \\
\hline RS-3A & BERYLLIUM & 0.00072 & 0.000 & 0.000 & 0.000 & 0.000 & 0.000 & & & \\
\hline WCTRIB-3 & BORON & 0.199 & 0.001 & 0.001 & 0.001 & 0.001 & 0.002 & 0.000 & 0.001 & 0.000 \\
\hline MID. DRAIN. & BORON & 0.20051 & 0.001 & 0.001 & 0.001 & 0.001 & 0.002 & 0.000 & 0.001 & 0.000 \\
\hline SW2-5 & BORON & 0.23719 & 0.001 & 0.001 & 0.001 & 0.001 & 0.002 & 0.000 & 0.001 & 0.000 \\
\hline SW5-2 & BORON & 0.175 & 0.001 & 0.001 & 0.001 & 0.001 & 0.001 & 0.000 & 0.001 & 0.000 \\
\hline SW5-4 & BORON & 0.17771 & 0.001 & 0.001 & 0.001 & 0.001 & 0.001 & 0.000 & 0.001 & 0.000 \\
\hline EAST SEEP & BORON & 0.07909 & 0.000 & 0.000 & 0.000 & 0.000 & 0.001 & 0.000 & 0.000 & 0.000 \\
\hline SW7-3 & BORON & 0.08738 & 0.000 & 0.000 & 0.000 & 0.000 & 0.001 & 0.000 & 0.000 & 0.000 \\
\hline SW7-5 & BORON & 0.06204 & 0.000 & 0.000 & 0.000 & 0.000 & 0.001 & 0.000 & 0.000 & 0.000 \\
\hline SW2-1 & BORON & 0.019 & 0.000 & 0.000 & 0.000 & 0.000 & 0.000 & 0.000 & 0.000 & 0.000 \\
\hline SW2-6 & BORON & 0.11992 & 0.000 & 0.001 & 0.001 & 0.001 & 0.001 & 0.000 & 0.000 & 0.000 \\
\hline SW2-7 & BORON & 0.14148 & 0.001 & 0.001 & 0.001 & 0.001 & 0.001 & 0.000 & 0.001 & 0.000 \\
\hline BTT & BORON & 0.10128 & 0.000 & 0.001 & 0.000 & 0.001 & 0.001 & 0.000 & 0.000 & 0.000 \\
\hline SW4-2 & BORON & 0.18083 & 0.001 & 0.001 & 0.001 & 0.001 & 0.002 & 0.000 & 0.001 & 0.000 \\
\hline WAG4 MS1 & BORON & 0.17358 & 0.001 & 0.001 & 0.001 & 0.001 & 0.001 & 0.000 & 0.001 & 0.000 \\
\hline WAG4 T2A & BORON & 0.16904 & 0.001 & 0.001 & 0.001 & 0.001 & 0.001 & 0.000 & 0.001 & 0.000 \\
\hline RS-3A & BORON & 0.10653 & 0.000 & 0.001 & 0.000 & 0.001 & 0.001 & 0.000 & 0.000 & 0.000 \\
\hline RS-3B & BORON & 0.034 & 0.000 & 0.000 & 0.000 & 0.000 & 0.000 & 0.000 & 0.000 & 0.000 \\
\hline SW5-4 & CADMIUM & 0.002 & 0.025 & 0.038 & 0.032 & 0.040 & 0.059 & 0.000 & 0.000 & 0.000 \\
\hline $\mathrm{RS}-3 \mathrm{~A}$ & CADMIUM & 0.00166 & 0.021 & 0.031 & 0.027 & 0.033 & 0.049 & 0.000 & 0.000 & 0.000 \\
\hline MID. DRAIN. & CHROMIUM & 0.006 & 0.000 & 0.000 & 0.000 & 0.000 & 0.000 & 0.000 & 0.001 & 0.000 \\
\hline SW2-5 & CHROMIUM & 0.004 & 0.000 & 0.000 & 0.000 & 0.000 & 0.000 & 0.000 & 0.000 & 0.000 \\
\hline EAST SEEP & CHROMIUM & 0.023 & 0.001 & 0.001 & 0.001 & 0.001 & 0.002 & 0.001 & 0.002 & 0.001 \\
\hline SW7-3 & CHROMIUM & 0.07 & 0.002 & 0.003 & 0.003 & 0.003 & 0.005 & 0.002 & 0.008 & 0.004 \\
\hline SW7-5 & CHROMIUM & 0.006 & 0.000 & 0.000 & 0.000 & 0.000 & 0.000 & 0.000 & 0.001 & 0.000 \\
\hline SW2-6 & CHROMIUM & 0.008 & 0.000 & 0.000 & 0.000 & 0.000 & 0.001 & 0.000 & 0.001 & 0.000 \\
\hline SW2-7 & CHROMIUM & 0.006 & 0.000 & 0.000 & 0.000 & 0.000 & 0.000 & 0.000 & 0.001 & 0.000 \\
\hline BTT & CHROMIUM & 0.003 & 0.000 & 0.000 & 0.000 & 0.000 & 0.000 & 0.000 & 0.000 & 0.000 \\
\hline WAG4 MS1 & CHROMIUM & 0.006 & 0.000 & 0.000 & 0.000 & 0.000 & 0.000 & 0.000 & 0.001 & 0.000 \\
\hline WAG4 T2A & CHROMIUM & 0.035 & 0.001 & 0.002 & 0.001 & 0.002 & 0.002 & 0.001 & 0.004 & 0.002 \\
\hline RS-3A & CHROMIUM & 0.084 & 0.003 & 0.004 & 0.003 & 0.004 & 0.006 & 0.003 & 0.009 & 0.005 \\
\hline MID. DRAIN. & COPPER & 0.002 & 0.000 & 0.000 & 0.000 & 0.000 & 0.000 & 0.000 & 0.000 & 0.000 \\
\hline SW2-5 & COPPER & 0.004 & 0.000 & 0.000 & 0.000 & 0.000 & 0.000 & 0.000 & 0.000 & 0.000 \\
\hline EAST SEEP & COPPER & 0.008 & 0.000 & 0.000 & 0.000 & 0.000 & 0.000 & 0.000 & 0.000 & 0.000 \\
\hline SW7-3 & COPPER & 0.006 & 0.000 & 0.000 & 0.000 & 0.000 & 0.000 & 0.000 & 0.000 & 0.000 \\
\hline SW7-5 & COPPER & 0.00613 & 0.000 & 0.000 & 0.000 & 0.000 & 0.000 & 0.000 & 0.000 & 0.000 \\
\hline SW9-1 & COPPER & 0.007 & 0.000 & 0.000 & 0.000 & 0.000 & 0.000 & 0.000 & 0.000 & 0.000 \\
\hline SW9-2 & COPPER & 0.009 & 0.000 & 0.000 & 0.000 & 0.000 & 0.000 & 0.000 & 0.000 & 0.000 \\
\hline
\end{tabular}


Table 6.29. (Continued)

\begin{tabular}{|c|c|c|c|c|c|c|c|c|c|c|}
\hline Location & Contaminant & $\begin{array}{l}95 \% \\
\text { UCL }\end{array}$ & Shrew & Mouse & Mink & Fox & Deer & Turkey & Kingfisher & Hawk \\
\hline MBTRIB-2A & COPPER & 0.016 & 0.000 & 0.000 & 0.000 & 0.000 & 0.000 & 0.000 & 0.000 & 0.000 \\
\hline SW2-6 & COPPER & 0.002 & 0.000 & 0.000 & 0.000 & 0.000 & 0.000 & 0.000 & 0.000 & 0.000 \\
\hline SW2-7 & COPPER & 0.002 & 0.000 & 0.000 & 0.000 & 0.000 & 0.000 & 0.000 & 0.000 & 0.000 \\
\hline BTT & COPPER & 0.00403 & 0.000 & 0.000 & 0.000 & 0.000 & 0.000 & 0.000 & 0.000 & 0.000 \\
\hline SW4-2 & COPPER & 0.0038 & 0.000 & 0.000 & 0.000 & 0.000 & 0.000 & 0.000 & 0.000 & 0.000 \\
\hline WAG4 MS1 & COPPER & 0.00438 & 0.000 & 0.000 & 0.000 & 0.000 & 0.000 & 0.000 & 0.000 & 0.000 \\
\hline WAG4 T2A & COPPER & 0.00434 & 0.000 & 0.000 & 0.000 & 0.000 & 0.000 & 0.000 & 0.000 & 0.000 \\
\hline RS-3A & COPPER & 0.02162 & 0.000 & 0.000 & 0.000 & 0.000 & 0.000 & 0.000 & 0.000 & 0.000 \\
\hline SW7-2 & COPPER & 0.025 & 0.000 & 0.000 & 0.000 & 0.000 & 0.000 & 0.000 & 0.000 & 0.000 \\
\hline SW9-2 & Chloroform & 0.001 & 0.000 & 0.000 & 0.000 & 0.000 & 0.000 & & & \\
\hline MID. DRAIN. & LEAD & 0.001 & 0.000 & 0.000 & 0.000 & 0.000 & 0.000 & 0.000 & 0.000 & 0.000 \\
\hline SW2-5 & LEAD & 0.002 & 0.000 & 0.000 & 0.000 & 0.000 & 0.000 & 0.000 & 0.000 & 0.000 \\
\hline SW5-4 & LEAD & 0.011 & 0.000 & 0.000 & 0.000 & 0.000 & 0.000 & 0.000 & 0.000 & 0.000 \\
\hline EAST SEEP & LEAD & 0.004 & 0.000 & 0.000 & 0.000 & 0.000 & 0.000 & 0.000 & 0.000 & 0.000 \\
\hline SW7-3 & LEAD & 0.003 & 0.000 & 0.000 & 0.000 & 0.000 & 0.000 & 0.000 & 0.000 & 0.000 \\
\hline SW7-5 & LEAD & 0.004 & 0.000 & 0.000 & 0.000 & 0.000 & 0.000 & 0.000 & 0.000 & 0.000 \\
\hline SW7-8 & LEAD & 0.003 & 0.000 & 0.000 & 0.000 & 0.000 & 0.000 & 0.000 & 0.000 & 0.000 \\
\hline SW2-1 & LEAD & 0.003 & 0.000 & 0.000 & 0.000 & 0.000 & 0.000 & 0.000 & 0.000 & 0.000 \\
\hline SW2-4 & LEAD & 0.008 & 0.000 & 0.000 & 0.000 & 0.000 & 0.000 & 0.000 & 0.000 & 0.000 \\
\hline SW2-6 & LEAD & 0.002 & 0.000 & 0.000 & 0.000 & 0.000 & 0.000 & 0.000 & 0.000 & 0.000 \\
\hline SW2-7 & LEAD & 0.002 & 0.000 & 0.000 & 0.000 & 0.000 & 0.000 & 0.000 & 0.000 & 0.000 \\
\hline BTT & LEAD & 0.002 & 0.000 & 0.000 & 0.000 & 0.000 & 0.000 & 0.000 & 0.000 & 0.000 \\
\hline WAG4 T2A & LEAD & 0.001 & 0.000 & 0.000 & 0.000 & 0.000 & 0.000 & 0.000 & 0.000 & 0.000 \\
\hline RS-I & LEAD & 0.003 & 0.000 & 0.000 & 0.000 & 0.000 & 0.000 & 0.000 & 0.000 & 0.000 \\
\hline RS-3A & LEAD & 0.006 & 0.000 & 0.000 & 0.000 & 0.000 & 0.000 & 0.000 & 0.000 & 0.000 \\
\hline RS-3B & LEAD & 0.004 & 0.000 & 0.000 & 0.000 & 0.000 & 0.000 & 0.000 & 0.000 & 0.000 \\
\hline SW7-2 & LEAD & 0.002 & 0.000 & 0.000 & 0.000 & 0.000 & 0.000 & 0.000 & 0.000 & 0.000 \\
\hline SW4-2 & LITHIUM & 0.113 & 0.001 & 0.002 & 0.002 & 0.002 & 0.003 & & & \\
\hline WOCET & MANGANESE & 2.2139 & 0.003 & 0.004 & 0.003 & 0.004 & 0.006 & 0.000 & 0.000 & 0.000 \\
\hline WCTRIB-3 & MANGANESE & 0.585 & 0.001 & 0.001 & 0.001 & 0.001 & 0.002 & 0.000 & 0.000 & 0.000 \\
\hline MBTRIB-3 & MANGANESE & 0.5611 & 0.001 & 0.001 & 0.001 & 0.001 & 0.001 & 0.000 & 0.000 & 0.000 \\
\hline MID. DRAIN. & MANGANESE & 3.0002 & 0.003 & 0.005 & 0.004 & 0.005 & 0.008 & 0.000 & 0.000 & 0.000 \\
\hline SW2-5 & MANGANESE & 1.4228 & 0.002 & 0.002 & 0.002 & 0.003 & 0.004 & 0.000 & 0.000 & 0.000 \\
\hline SW5-2 & MANGANESE & 0.017 & 0.000 & 0.000 & 0.000 & 0.000 & 0.000 & 0.000 & 0.000 & 0.000 \\
\hline SW5-4 & MANGANESE & 1.5463 & 0.002 & 0.003 & 0.002 & 0.003 & 0.004 & 0.000 & 0.000 & 0.000 \\
\hline EAST SEEP & MANGANESE & 0.3575 & 0.000 & 0.001 & 0.001 & 0.001 & 0.001 & 0.000 & 0.000 & 0.000 \\
\hline MV-1 & MANGANESE & 4.1228 & 0.005 & 0.007 & 0.006 & 0.007 & 0.011 & 0.000 & 0.000 & 0.000 \\
\hline SW7-3 & MANGANESE & 0.0062 & 0.000 & 0.000 & 0.000 & 0.000 & 0.000 & 0.000 & 0.000 & 0.000 \\
\hline SW7-5 & MANGANESE & 0.703 & 0.001 & 0.001 & 0.001 & 0.001 & 0.002 & 0.000 & 0.000 & 0.000 \\
\hline SW7-6 & MANGANESE & 0.071 & 0.000 & 0.000 & 0.000 & 0.000 & 0.000 & 0.000 & 0.000 & 0.000 \\
\hline
\end{tabular}


Table 6.29. (Continued)

\begin{tabular}{|c|c|c|c|c|c|c|c|c|c|c|}
\hline Location & Contaminant & $\begin{array}{l}95 \% \\
\text { UCL }\end{array}$ & Shrew & Mouse & Mink & Fox & Deer & Turkey & Kingfisher & Hawk \\
\hline SW7-8 & MANGANESE & 0.126 & 0.000 & 0.000 & 0.000 & 0.000 & 0.000 & 0.000 & 0.000 & 0.000 \\
\hline WCTRIB-1 & MANGANESE & 1.1979 & 0.001 & 0.002 & 0.002 & 0.002 & 0.003 & 0.000 & 0.000 & 0.000 \\
\hline SW2-1 & MANGANESE & 0.992 & 0.001 & 0.002 & 0.001 & 0.002 & 0.003 & 0.000 & 0.000 & 0.000 \\
\hline SW2-3 & MANGANESE & 0.093 & 0.000 & 0.000 & 0.000 & 0.000 & 0.000 & 0.000 & 0.000 & 0.000 \\
\hline SW2-4 & MANGANESE & 5.8866 & 0.007 & 0.010 & 0.009 & 0.011 & 0.016 & 0.000 & 0.001 & 0.000 \\
\hline WCTRIB-2 & MANGANESE & 0.024 & 0.000 & 0.000 & 0.000 & 0.000 & 0.000 & 0.000 & 0.000 & 0.000 \\
\hline SW9-1 & MANGANESE & 0.3602 & 0.000 & 0.001 & 0.001 & 0.001 & 0.001 & 0.000 & 0.000 & 0.000 \\
\hline SW9-2 & MANGANESE & 2.7056 & 0.003 & 0.005 & 0.004 & 0.005 & 0.007 & 0.000 & 0.000 & 0.000 \\
\hline MBTRIB-2A & MANGANESE & 0.142 & 0.000 & 0.000 & 0.000 & 0.000 & 0.000 & 0.000 & 0.000 & 0.000 \\
\hline MV-3 & MANGANESE & 0.019 & 0.000 & 0.000 & 0.000 & 0.000 & 0.000 & 0.000 & 0.000 & 0.000 \\
\hline SW2-2 & MANGANESE & 0.796 & 0.001 & 0.001 & 0.001 & 0.001 & 0.002 & 0.000 & 0.000 & 0.000 \\
\hline SW2-6 & MANGANESE & 1.5626 & 0.002 & 0.003 & 0.002 & 0.003 & 0.004 & 0.000 & 0.000 & 0.000 \\
\hline SW2-7 & MANGANESE & 1.9677 & 0.002 & 0.003 & 0.003 & 0.004 & 0.005 & 0.000 & 0.000 & 0.000 \\
\hline BTT & MANGANESE & 0.0117 & 0.000 & 0.000 & 0.000 & 0.000 & 0.000 & 0.000 & 0.000 & 0.000 \\
\hline SW4-1 & MANGANESE & 12.9311 & 0.015 & 0.022 & 0.019 & 0.024 & 0.034 & 0.000 & 0.001 & 0.001 \\
\hline SW4-2 & MANGANESE & 1.0607 & 0.001 & 0.002 & 0.002 & 0.002 & 0.003 & 0.000 & 0.000 & 0.000 \\
\hline WAG4 MS1 & MANGANESE & 0.3384 & 0.000 & 0.001 & 0.000 & 0.001 & 0.001 & 0.000 & 0.000 & 0.000 \\
\hline WAG4 T2A & MANGANESE & 0.2263 & 0.000 & 0.000 & 0.000 & 0.000 & 0.001 & 0.000 & 0.000 & 0.000 \\
\hline RS-1 & MANGANESE & 1.35 & 0.002 & 0.002 & 0.002 & 0.002 & 0.004 & 0.000 & 0.000 & 0.000 \\
\hline RS-3A & MANGANESE & 0.3108 & 0.000 & 0.001 & 0.000 & 0.001 & 0.001 & 0.000 & 0.000 & 0.000 \\
\hline RS-3B & MANGANESE & 0.1381 & 0.000 & 0.000 & 0.000 & 0.000 & 0.000 & 0.000 & 0.000 & 0.000 \\
\hline SW7-1 & MANGANESE & 6.4531 & 0.007 & 0.011 & 0.009 & 0.012 & 0.017 & 0.000 & 0.001 & 0.000 \\
\hline SW7-2 & MANGANESE & 0.2533 & 0.000 & 0.000 & 0.000 & 0.000 & 0.001 & 0.000 & 0.000 & 0.000 \\
\hline RS-3A & MERCURY & 0.0011 & 0.003 & 0.005 & 0.007 & 0.009 & 0.008 & 0.006 & 0.019 & 0.010 \\
\hline EAST SEEP & MOLYBDENUM & 0.015 & 0.011 & 0.016 & 0.014 & 0.017 & 0.025 & 0.000 & 0.000 & 0.000 \\
\hline SW7-3 & MOLYBDENUM & 0.0142 & 0.010 & 0.015 & 0.013 & 0.016 & 0.024 & 0.000 & 0.000 & 0.000 \\
\hline BTT & MOLYBDENUM & 0.1145 & 0.081 & 0.122 & 0.105 & 0.130 & 0.190 & 0.001 & 0.004 & 0.002 \\
\hline SW4-2 & MOLYBDENUM & 0.008 & 0.006 & 0.009 & 0.007 & 0.009 & 0.013 & 0.000 & 0.000 & 0.000 \\
\hline WAG4 MS1 & MOLYBDENUM & 0.0074 & 0.005 & 0.008 & 0.007 & 0.008 & 0.012 & 0.000 & 0.000 & 0.000 \\
\hline RS-3A & MOLYBDENUM & 0.0517 & 0.037 & 0.055 & 0.04 .7 & 0.059 & 0.086 & 0.000 & 0.002 & 0.001 \\
\hline WOCET & Methylene chloride & 0.001 & 0.000 & 0.000 & 0.000 & 0.000 & 0.000 & & & \\
\hline $5 \mathrm{NNT}$ & Methylene chloride & 0.013 & 0.000 & 0.000 & 0.000 & 0.000 & 0.001 & & & \\
\hline MID. DRAIN. & Methylene chloride & 0.001 & 0.000 & 0.000 & 0.000 & 0.000 & 0.000 & & & \\
\hline MV-1 & Methylene chloride & 0.001 & 0.000 & 0.000 & 0.000 & 0.000 & 0.000 & & & \\
\hline SW7-3 & Methylene chloride & 0.0037 & 0.000 & 0.000 & 0.000 & 0.000 & 0.000 & & & \\
\hline SW7-5 & Methylene chloride & 0.03 & 0.001 & 0.001 & 0.001 & 0.001 & 0.001 & & & \\
\hline SW2-1 & Methylene chloride & 0.001 & 0.000 & 0.000 & 0.000 & 0.000 & 0.000 & & & \\
\hline SW2-3 & Methylene chloride & 0.0083 & 0.000 & 0.000 & 0.000 & 0.000 & 0.000 & & & \\
\hline SW2-4 & Methylene chloride & 0.001 & 0.000 & 0.000 & 0.000 & 0.000 & 0.000 & & & \\
\hline SW9-2 & Methylene chloride & 0.001 & 0.000 & 0.000 & 0.000 & 0.000 & 0.000 & & & \\
\hline
\end{tabular}


Table 6.29. (Continued)

\begin{tabular}{|c|c|c|c|c|c|c|c|c|c|c|}
\hline Location & Contaminant & $\begin{array}{l}95 \% \\
\text { UCL }\end{array}$ & Shrew & Mouse & Mink & Fox & Deer & Turkey & Kingfisher & Hawk \\
\hline SW7-2 & Methylene chloride & 0.001 & 0.000 & 0.000 & 0.000 & 0.000 & 0.000 & & & \\
\hline MID. DRAIN. & NICKEL & 0.006 & 0.000 & 0.000 & 0.000 & 0.000 & 0.000 & 0.000 & 0.000 & 0.000 \\
\hline SW2-5 & NICKEL & 0.013 & 0.000 & 0.000 & 0.000 & 0.000 & 0.000 & 0.000 & 0.000 & 0.000 \\
\hline SW5-4 & NICKEL & 0.0138 & 0.000 & 0.000 & 0.000 & 0.000 & 0.000 & 0.000 & 0.000 & 0.000 \\
\hline EAST SEEP & NICKEL & 0.0319 & 0.000 & 0.000 & 0.000 & 0.000 & 0.000 & 0.000 & 0.000 & 0.000 \\
\hline SW7-3 & NICKEL & 0.028 & 0.000 & 0.000 & 0.000 & 0.000 & 0.000 & 0.000 & 0.000 & 0.000 \\
\hline SW7-5 & NICKEL & 0.0206 & 0.000 & 0.000 & 0.000 & 0.000 & 0.000 & 0.000 & 0.000 & 0.000 \\
\hline SW2-6 & NICKEL & 0.0139 & 0.000 & 0.000 & 0.000 & 0.000 & 0.000 & 0.000 & 0.000 & 0.000 \\
\hline SW2-7 & NICKEL & 0.008 & 0.000 & 0.000 & 0.000 & 0.000 & 0.000 & 0.000 & 0.000 & 0.000 \\
\hline BTT & NICKEL & 0.048 & 0.000 & 0.000 & 0.000 & 0.000 & 0.000 & 0.000 & 0.000 & 0.000 \\
\hline SW4-2 & NICKEL & 8.5222 & 0.021 & 0.032 & 0.027 & 0.034 & 0.050 & 0.004 & 0.012 & 0.006 \\
\hline WAG4 MSI & NICKEL & 0.0426 & 0.000 & 0.000 & 0.000 & 0.000 & 0.000 & 0.000 & 0.000 & 0.000 \\
\hline WAG4 T2A & NICKEL & 0.0303 & 0.000 & 0.000 & 0.000 & 0.000 & 0.000 & 0.000 & 0.000 & 0.000 \\
\hline RS-3A & NICKEL & 0.1031 & 0.000 & 0.000 & 0.000 & 0.000 & 0.001 & 0.000 & 0.000 & 0.000 \\
\hline EAST SEEP & SELENIUM & 0.001 & 0.002 & 0.004 & 0.003 & 0.004 & 0.006 & 0.000 & 0.000 & 0.000 \\
\hline SW7-3 & SELENIUM & 0.003 & 0.007 & 0.011 & 0.009 & 0.012 & 0.017 & 0.000 & 0.001 & 0.000 \\
\hline RS-3A & SELENIUM & 0.002 & 0.005 & 0.007 & 0.006 & 0.008 & 0.011 & 0.000 & 0.000 & 0.000 \\
\hline WOCET & STRONTIUM & 0.154 & 0.000 & 0.000 & 0.000 & 0.000 & 0.000 & & & \\
\hline WCTRIB-3 & STRONTIUM & 0.21 & 0.000 & 0.000 & 0.000 & 0.000 & 0.000 & & & \\
\hline MBTRIB-3 & STRONTIUM & 0.226 & 0.000 & 0.000 & 0.000 & 0.000 & 0.000 & & & \\
\hline MID. DRAIN. & STRONTIUM & 0.207 & 0.000 & 0.000 & 0.000 & 0.000 & 0.000 & & & \\
\hline SW2-5 & STRONTIUM & 0.343 & 0.000 & 0.000 & 0.000 & 0.000 & 0.000 & & & \\
\hline SW5-2 & STRONTIUM & 0.201 & 0.000 & 0.000 & 0.000 & 0.000 & 0.000 & & & \\
\hline SW5-4 & STRONTIUM & 0.203 & 0.000 & 0.000 & 0.000 & 0.000 & 0.000 & & & \\
\hline EAST SEEP & STRONTIUM & 0.132 & 0.000 & 0.000 & 0.000 & 0.000 & 0.000 & & & \\
\hline$M V-1$ & STRONTIUM & 0.169 & 0.000 & 0.000 & 0.000 & 0.000 & 0.000 & & & \\
\hline SW7-3 & STRONTIUM & 0.031 & 0.000 & 0.000 & 0.000 & 0.000 & 0.000 & & & \\
\hline SW7-5 & STRONTIUM & 0.114 & 0.000 & 0.000 & 0.000 & 0.000 & 0.000 & & & \\
\hline SW7-8 & STRONTIUM & 0.069 & 0.000 & 0.000 & 0.000 & 0.000 & 0.000 & & & \\
\hline WCTRIB-1 & STRONTIUM & 0.383 & 0.000 & 0.000 & 0.000 & 0.000 & 0.000 & & & \\
\hline SW2-1 & STRONTIUM & 0.189 & 0.000 & 0.000 & 0.000 & 0.000 & 0.000 & & & \\
\hline SW2-3 & STRONTIUM & 0.067 & 0.000 & 0.000 & 0.000 & 0.000 & 0.000 & & & \\
\hline SW2-4 & STRONTIUM & 0.597 & 0.000 & 0.000 & 0.000 & 0.000 & 0.001 & & & \\
\hline WCTRIB-2 & STRONTIUM & 0.061 & 0.000 & 0.000 & 0.000 & 0.000 & 0.000 & & & \\
\hline SW9-1 & STRONTIUM & 0.115 & 0.000 & 0.000 & 0.000 & 0.000 & 0.000 & & & \\
\hline SW9-2 & STRONTIUM & 0.197 & 0.000 & 0.000 & 0.000 & 0.000 & 0.000 & & & \\
\hline MBTRIB-2A & STRONTIUM & 0.188 & 0.000 & 0.000 & 0.000 & 0.000 & 0.000 & & & \\
\hline MV-3 & STRONTIUM & 0.145 & 0.000 & 0.000 & 0.000 & 0.000 & 0.000 & & & \\
\hline SW2-2 & STRONTIUM & 0.124 & 0.000 & 0.000 & 0.000 & 0.000 & 0.000 & & & \\
\hline SW2-6 & STRONTIUM & 0.231 & 0.000 & 0.000 & 0.000 & 0.000 & 0.000 & & & \\
\hline
\end{tabular}


Table 6.29. (Continued)

\begin{tabular}{|c|c|c|c|c|c|c|c|c|c|c|}
\hline Location & Contaminant & $\begin{array}{l}95 \% \\
\text { UCL }\end{array}$ & Shrew & Mouse & Mink & Fox & Deer & Turkey & Kingfisher & Hawk \\
\hline SW2-7 & STRONTIUM & 0.212 & 0.000 & 0.000 & 0.000 & 0.000 & 0.000 & & & \\
\hline BTT & STRONTIUM & 0.254 & 0.000 & 0.000 & 0.000 & 0.000 & 0.000 & & & \\
\hline SW4-1 & STRONTIUM & 0.503 & 0.000 & 0.000 & 0.000 & 0.000 & 0.000 & & & \\
\hline SW4-2 & STRONTIUM & 0.286 & 0.000 & 0.000 & 0.000 & 0.000 & 0.000 & & & \\
\hline WAG4 MS1 & STRONTIUM & 0.2 & 0.000 & 0.000 & 0.000 & 0.000 & 0.000 & & & \\
\hline WAG4 T2A & STRONTIUM & 0.204 & 0.000 & 0.000 & 0.000 & 0.000 & 0.000 & & & \\
\hline RS-I & STRONTIUM & 0.067 & 0.000 & 0.000 & 0.000 & 0.000 & 0.000 & & & \\
\hline RS-3A & STRONTIUM & 0.017 & 0.000 & 0.000 & 0.000 & 0.000 & 0.000 & & & \\
\hline RS-3B & STRONTIUM & 0.062 & 0.000 & 0.000 & 0.000 & 0.000 & 0.000 & & & \\
\hline SW7-1 & STRONTIUM & 0.091 & 0.000 & 0.000 & 0.000 & 0.000 & 0.000 & & & \\
\hline SW7-2 & STRONTIUM & 0.036 & 0.000 & 0.000 & 0.000 & 0.000 & 0.000 & & & \\
\hline FRENCHDR S & Tetrachloroethene & 0.055 & & & & & & & & \\
\hline WAG6 MS3B & Tetrachloroethene & 0.001 & & & & & & & & \\
\hline MID. DRAIN. & Trichloroethene & 0.001 & 0.000 & 0.000 & 0.000 & 0.000 & 0.001 & & & \\
\hline WAG4 T2A & Trichloroethene & 0.002 & 0.001 & 0.001 & 0.001 & 0.001 & 0.001 & & & \\
\hline FRENCHDR S & Trichloroethene & 1 & 0.264 & 0.397 & 0.340 & 0.422 & 0.616 & & & \\
\hline WAG6 MS2 & Trichloroethene & 0.003 & 0.001 & 0.001 & 0.001 & 0.001 & 0.002 & & & \\
\hline SW2-5 & VANADIUM & 0.003 & 0.002 & 0.002 & 0.002 & 0.002 & 0.004 & 0.000 & 0.000 & 0.000 \\
\hline SW7-3 & VANADIUM & 0.004 & 0.002 & 0.003 & 0.003 & 0.003 & 0.005 & 0.000 & 0.000 & 0.000 \\
\hline SW7-5 & VANADIUM & 0.002 & 0.001 & 0.002 & 0.001 & 0.002 & 0.002 & 0.000 & 0.000 & 0.000 \\
\hline RS-3A & VANADIUM & 0.0265 & 0.014 & 0.020 & 0.017 & 0.022 & 0.032 & 0.000 & 0.000 & 0.000 \\
\hline MID. DRAIN. & Vinyl chloride & 0.001 & 0.001 & 0.001 & 0.001 & 0.001 & 0.001 & & & \\
\hline SW4-2 & Vinyl chloride & 0.046 & 0.027 & 0.041 & 0.035 & 0.043 & 0.063 & & & \\
\hline WAG4 T2A & Vinyl chloride & 0.001 & 0.001 & 0.001 & 0.001 & 0.001 & 0.001 & & & \\
\hline MID. DRAIN. & ZINC & 0.00574 & 0.000 & 0.000 & 0.000 & 0.000 & 0.000 & 0.000 & 0.000 & 0.000 \\
\hline SW2-5 & ZINC & 0.02417 & 0.000 & 0.000 & 0.000 & 0.000 & 0.000 & 0.000 & 0.000 & 0.000 \\
\hline SW5-4 & ZNNC & 0.00887 & 0.000 & 0.000 & 0.000 & 0.000 & 0.000 & 0.000 & 0.000 & 0.000 \\
\hline EAST SEEP & ZINC & 0.01518 & 0.000 & 0.000 & 0.000 & 0.000 & 0.000 & 0.000 & 0.000 & 0.000 \\
\hline SW7-3 & ZNNC & 0.03116 & 0.000 & 0.000 & 0.000 & 0.000 & 0.000 & 0.000 & 0.000 & 0.000 \\
\hline SW7-5 & ZINC & 0.01799 & 0.000 & 0.000 & 0.000 & 0.000 & 0.000 & 0.000 & 0.000 & 0.000 \\
\hline SW2-4 & ZINC & 0.004 & 0.000 & 0.000 & 0.000 & 0.000 & 0.000 & 0.000 & 0.000 & 0.000 \\
\hline SW9-1 & ZINC & 0.03314 & 0.000 & 0.000 & 0.000 & 0.000 & 0.000 & 0.000 & 0.000 & 0.000 \\
\hline SW9-2 & ZINC & 0.36805 & 0.000 & 0.000 & 0.000 & 0.000 & 0.001 & 0.001 & 0.003 & 0.001 \\
\hline SW2-6 & ZINC & 0.01684 & 0.000 & 0.000 & 0.000 & 0.000 & 0.000 & 0.000 & 0.000 & 0.000 \\
\hline SW2-7 & ZINC & 0.06653 & 0.000 & 0.000 & 0.000 & 0.000 & 0.000 & 0.000 & 0.000 & 0.000 \\
\hline BTT & ZINC & 0.01643 & 0.000 & 0.000 & 0.000 & 0.000 & 0.000 & 0.000 & 0.000 & 0.000 \\
\hline SW4-1 & ZINC & 0.03 & 0.000 & 0.000 & 0.000 & 0.000 & 0.000 & 0.000 & 0.000 & 0.000 \\
\hline SW4-2 & ZINC & 0.05635 & 0.000 & 0.000 & 0.000 & 0.000 & 0.000 & 0.000 & 0.000 & 0.000 \\
\hline WAG4 MSI & ZINC & 0.00762 & 0.000 & 0.000 & 0.000 & 0.000 & 0.000 & 0.000 & 0.000 & 0.000 \\
\hline WAG4 T2A & ZINC & 0.01943 & 0.000 & 0.000 & 0.000 & 0.000 & 0.000 & 0.000 & 0.000 & 0.000 \\
\hline
\end{tabular}


Table 6.29. (Continued)

\begin{tabular}{llrllllllll}
\hline Location & Contaminant & 95\% & Shrew & Mouse & Mink & Fox & Deer & Turkey & Kingfisher Hawk \\
\hline RS-3A & ZINC & 0.04944 & 0.000 & 0.000 & 0.000 & 0.000 & 0.000 & 0.000 & 0.000 & 0.000 \\
RS-3B & ZINC & 0.009 & 0.000 & 0.000 & 0.000 & 0.000 & 0.000 & 0.000 & 0.000 & 0.000 \\
MID. DRAIN. & cis-1,2-Dichloroethene & 0.005 & 0.000 & 0.000 & 0.000 & 0.000 & 0.000 & & & \\
SW4-1 & cis-1,2-Dichloroethene & 0.047 & 0.000 & 0.000 & 0.000 & 0.000 & 0.000 & & & \\
SW4-2 & cis-1,2-Dichloroethene & 0.066 & 0.000 & 0.000 & 0.000 & 0.000 & 0.001 & & & \\
WAG4 MS1 & cis-1,2-Dichloroethene & 0.002 & 0.000 & 0.000 & 0.000 & 0.000 & 0.000 & & & \\
WAG4 T2A & cis-1,2-Dichloroethene & 0.014 & 0.000 & 0.000 & 0.000 & 0.000 & 0.000 & & & \\
FRENCH DR S & cis-1,2-Dichloroethene & 0.14 & 0.001 & 0.001 & 0.001 & 0.001 & 0.001 & & & \\
WAG6 MS2 & cis-1,2-Dichloroethene & 0.001 & 0.000 & 0.000 & 0.000 & 0.000 & 0.000 & & & \\
WAG6MS3B & cis-1,2-Dichloroethene & 0.001 & 0.000 & 0.000 & 0.000 & 0.000 & 0.000 & & & \\
\hline
\end{tabular}




$$
\text { C-70 }
$$

Table C.30. LOAEL hazard quotients for water contaminants in White Oak Creek seeps.

\begin{tabular}{llrllllllllll}
\hline Location & Contaminant & $\begin{array}{r}95 \% \\
\text { UCL }\end{array}$ & Shrew & Mouse & Mink & Fox & Deer & Turkey Kingfisher Hawk \\
\hline RS-3A & ALUMMNUM & 12.7297 & 0.122 & 0.183 & 0.157 & 0.195 & 0.285 & 0.009 & 0.031 & 0.016 \\
\hline
\end{tabular}




\begin{tabular}{|c|c|c|c|c|c|c|c|}
\hline \multirow[b]{2}{*}{ Radionuclide [a] } & \multicolumn{2}{|c|}{ Dose coefficients } & \multicolumn{2}{|c|}{ Half lives (d) } & \multicolumn{3}{|c|}{ Energies (MoV/nt) } \\
\hline & $\begin{array}{l}\text { DFgrd 0-5 } \\
(\mathrm{Sv} \mathrm{m3/s} \mathrm{Bq)})\end{array}$ & $\begin{array}{c}\text { DFwater } \\
\text { (Sv m3/s Bq) }\end{array}$ & rad. $1 / 2$ life & biol. $1 / 2$ life & alpha & beta & gamma \\
\hline Americium-241 & $2.18 \mathrm{e}-19$ & $1.88 \mathrm{e}-18$ & $1.58 \mathrm{e}+05$ & $2.00 \mathrm{e}+04$ & $5.48 \mathrm{e}+00$ & $5.20 \mathrm{e}-02$ & $3.30 \mathrm{e}-02$ \\
\hline Cesium-137 & $3.07 \mathrm{e}-21$ & $1.49 \mathrm{e}-20$ & $1.10 e+04$ & $1.15 e+02$ & $0.00 e+00$ & $1.87 \mathrm{e}-01$ & $0.00 e+00$ \\
\hline Barium-137m & $1.09 \mathrm{e}-17$ & $6.26 \mathrm{e}-17$ & $1.77 \mathrm{e}-03$ & $6.50 \mathrm{e}+01$ & $0.00 \mathrm{e}+00$ & $6.50 \mathrm{e}-02$ & $5.97 \mathrm{e}-01$ \\
\hline Cobalt -60 & $4.45 \mathrm{e}-17$ & $2.74 \mathrm{e}-16$ & $1.92 e+03$ & $9.50 \mathrm{e}+00$ & $0.00 e+00$ & $9.70 \mathrm{e}-02$ & $2.500+00$ \\
\hline Curium-244 & $6.74 \mathrm{e}-22$ & $1.15 \mathrm{e}-20$ & $6.61 e+03$ & $2.40 \mathrm{e}+04$ & $5.80 \mathrm{e}+00$ & $9.00 \mathrm{e}-03$ & $2.00 \mathrm{e}-03$ \\
\hline Plutonium-238 & $7.60 \mathrm{e}-22$ & $1.14 \mathrm{e}-20$ & $3.20 e+04$ & $6.50 e+04$ & $5.49 e+00$ & $1.10 \mathrm{e}-02$ & $2.00 \mathrm{e}-03$ \\
\hline Plutonium-239/240 & $9.47 \mathrm{e}-22$ & $1.04 \mathrm{e}-20$ & $2.39 e+06$ & $6.50 \mathrm{e}+04$ & $5.15 e+00$ & $9.00 \mathrm{e}-03$ & $1.00 \mathrm{e}-03$ \\
\hline Strontium-90 & $2.95 \mathrm{e}-21$ & $1.46 \mathrm{e}-20$ & $1.06 \theta+04$ & $4.00 e+03$ & $0.00 e+00$ & $1.96 \mathrm{e}-01$ & $0.00 \mathrm{e}+00$ \\
\hline Yttrium-90 & $8.31 \mathrm{e}-20$ & $3.63 e-19$ & $2.67 \mathrm{e}+00$ & $1.40 \mathrm{e}+04$ & $0.00 \mathrm{e}+00$ & $9.35 \mathrm{e}-01$ & $0.00 e+00$ \\
\hline Technetium-99 & $5.74 \mathrm{e}-22$ & $3.14 \mathrm{e}-21$ & $7.77 e+07$ & $1.00 e+00$ & $0.000+00$ & $1.01 \mathrm{e}-01$ & $0.00 \mathrm{e}+00$ \\
\hline Thorium-228 & $3.14 \mathrm{e}-20$ & $2.05 \mathrm{e}-19$ & $6.98 \mathrm{e}+02$ & $5.70 e+04$ & $5.40 e+00$ & $2.10 \mathrm{e}-02$ & $3.00 \mathrm{e}-03$ \\
\hline Radium-224 & $1.78 \mathrm{e}-19$ & $1.03 \mathrm{e}-18$ & $3.66 \mathrm{e}+00$ & $8.10 \theta+03$ & $5.67 e+00$ & $2.00 \mathrm{e}-03$ & $1.00 \mathrm{e}-02$ \\
\hline Radon-220 & $7.08 \mathrm{e}-21$ & $4.03 \mathrm{e}-20$ & $6.44 \mathrm{e}-04$ & $0.00 \mathrm{e}+00$ & $6.290+00$ & $0.000+00$ & $0.00 e+00$ \\
\hline Polonium-216 & $3.07 e-22$ & $1.80 \mathrm{e}-21$ & $1.74 \mathrm{e}-06$ & $3.000+01$ & $6.78 \theta+00$ & $0.000+00$ & $0.00 \mathrm{e}+00$ \\
\hline Lead-212 & $2.53 \mathrm{e}-18$ & $1.52 \mathrm{e}-17$ & $4.43 e-01$ & $1.46 e+03$ & $0.00 \mathrm{e}+00$ & $1.76 \mathrm{e}-01$ & $1.48 \mathrm{e}-01$ \\
\hline Bismuth-212 & $3.34 \mathrm{e}-18$ & $2.00 \mathrm{e}-17$ & $4.20 \mathrm{e}-02$ & $5.00 \mathrm{e}+00$ & $2.17 \mathrm{e}+00$ & $4.72 \mathrm{e}-01$ & $1.86 \mathrm{e}-01$ \\
\hline Thallium-208 & $5.79 \mathrm{e}-17$ & $3.84 \mathrm{e}-16$ & $2.13 e-03$ & $5.00 \mathrm{e}+00$ & $0.00 \mathrm{e}+00$ & $5.98 \mathrm{e}-01$ & $3.38 \mathrm{e}+00$ \\
\hline Polonium-212 & $0.00 \mathrm{e}+00$ & $0.00 \mathrm{e}+00$ & $3.53 e-12$ & $3.00 e+01$ & $8.79 e+00$ & $0.00 e+00$ & $0.00 e+00$ \\
\hline Thorium-230 & $5.22 \mathrm{e}-21$ & $3.94 \mathrm{e}-20$ & $2.81 e+07$ & $5.70 \mathrm{e}+04$ & $4.67 e+00$ & $1.50 \mathrm{e}-02$ & $2.00 \mathrm{e}-03$ \\
\hline Thorium-232 & $2.36 \mathrm{e}-21$ & $1.99 \mathrm{e}-20$ & $5.13 e+12$ & $5.70 \mathrm{e}+04$ & $4.00 e+00$ & $1.20 \mathrm{e}-02$ & $1.00 \mathrm{e}-03$ \\
\hline Radium-228 & $0.00 \mathrm{e}+00$ & $0.00 e+00$ & $2.10 \mathrm{e}+03$ & $8.10 e+03$ & $0.00 e+00$ & $1.70 \mathrm{e}-02$ & $0.00 e+00$ \\
\hline Actinium-228 & $1.73 \mathrm{e}-17$ & $1.04 \mathrm{e}-16$ & $2.55 \mathrm{e}-01$ & $2.40 \mathrm{e}+04$ & $0.00 \mathrm{e}+00$ & $4.75 \mathrm{e}-01$ & $9.71 \mathrm{e}-01$ \\
\hline Uranium-233/234 & $3.56 \mathrm{e}-21$ & $2.70 \mathrm{e}-20$ & $5.79 \mathrm{e}+07$ & $1.00 e+02$ & $4.79 e+00$ & $9.50 \mathrm{e}-03$ & $1.50 \mathrm{e}-03$ \\
\hline Uranium-235 & $2.65 \mathrm{e}-18$ & $1.59 \mathrm{e}-17$ & $2.57 e+11$ & $1.000+02$ & $4.40 e+00$ & $4.90 \mathrm{e}-02$ & $1.56 \mathrm{e}-01$ \\
\hline Thorium-231 & $1.59 \mathrm{e}-19$ & $1.18 \mathrm{e}-18$ & $1.06 \theta+00$ & $5.70 \mathrm{e}+04$ & $0.00 e+00$ & $1.65 e-01$ & $2.60 \mathrm{e}-02$ \\
\hline Uranium-238 & $5.45 \mathrm{e}-22$ & $7.95 \mathrm{e}-21$ & $1.63 e+12$ & $1.00 \mathrm{e}+02$ & $4.19 e+00$ & $1.00 \mathrm{e}-02$ & $1.00 \mathrm{e}-03$ \\
\hline Thorium-234 & $1.07 e-19$ & $7.64 \mathrm{e}-19$ & $2.41 e+01$ & $5.70 e+04$ & $0.00 \mathrm{e}+00$ & $6.00 \mathrm{e}-02$ & $9.00 \mathrm{e}-03$ \\
\hline Protactinium-234m & $2.70 \mathrm{e}-19$ & $1.52 \mathrm{e}-18$ & $8.13 e-04$ & $4.100+04$ & $0.00 e+00$ & $8.22 \mathrm{e}-01$ & $1.20 \mathrm{e}-02$ \\
\hline
\end{tabular}




\begin{tabular}{|l|r|r|r|r|r|r|r|}
\hline Protactinium-234 & $3.41 \mathrm{e}-17$ & $2.03 \mathrm{e}-16$ & $2.79 \mathrm{e}-01$ & $4.10 \mathrm{e}+04$ & $0.00 \mathrm{e}+00$ & $4.94 \mathrm{e}-01$ & $1.92 \mathrm{e}+00$ \\
\hline & & & & & & & \\
\hline & & & & & & \\
\hline
\end{tabular}


Table C.32. Literature-derived bioaccumulation factors for mammals (MammBAF) and Oak Ridge Reservation-specific soil-to-tissue uptake factors for plants (browse, canopy, and herbaceous vegetation), earthworms, and small mammals (MammUF) used in estimation of dose rates in the White Oak Creek radiological

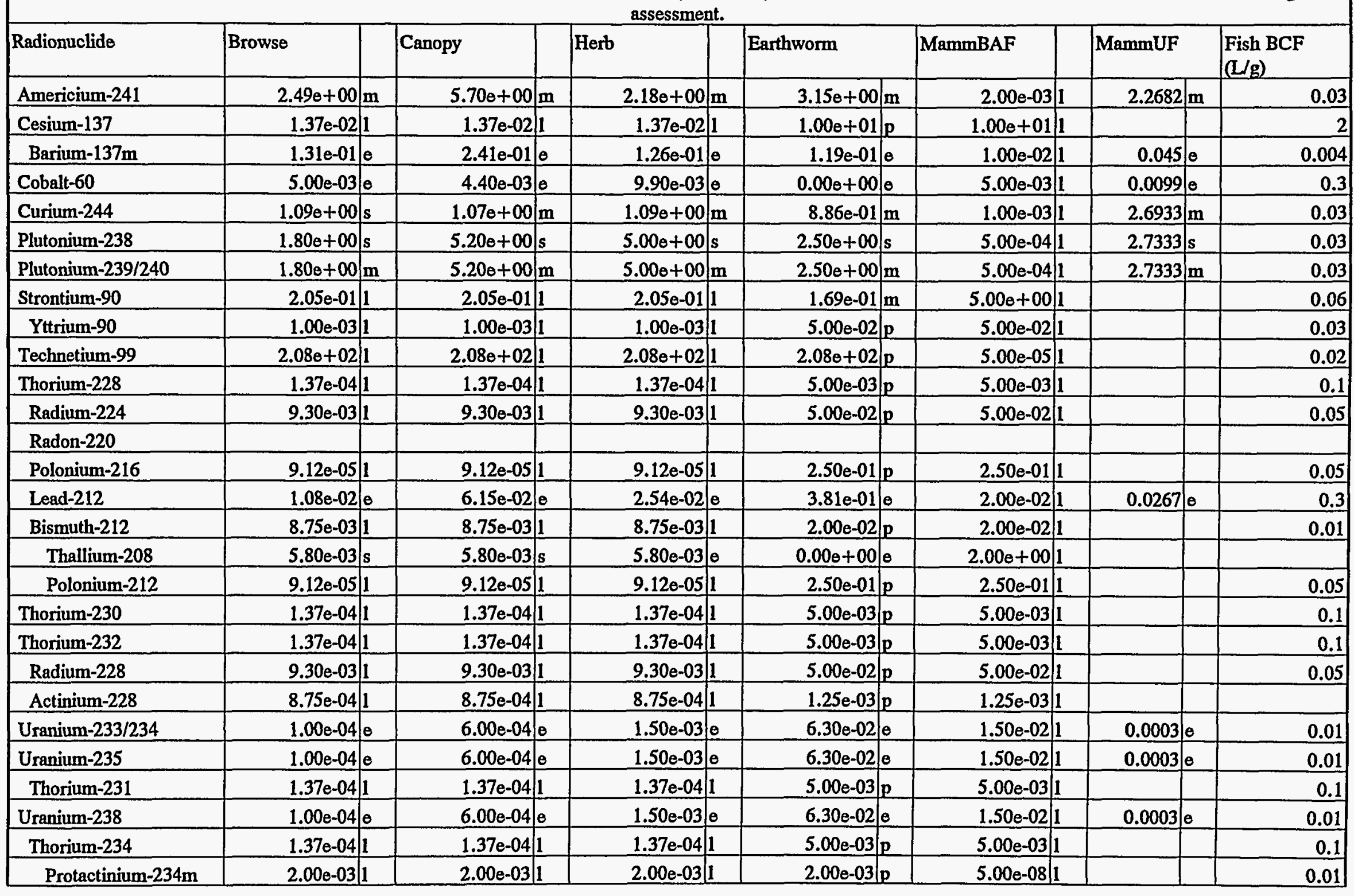


$\mathrm{m}=$ Uptake factor measured for given radionuclide

$\mathrm{s}=$ Assumed uptake is same as that for related isotope for which measured value was available

e = Uptake factor for elemental form used for radionuclide

1 = Literature value from IAEA (1994), NCRP (1989), or Baes et al. (1984). Literature biotransfer factors (d/kg)

have been converted to unitless uptake factors assuming a cow ingestion rate of $50 \mathrm{~kg} w e t$ food/d.

$\mathrm{p}=$ Uptake factor for earthworms was unavailable. Used the larger of the herbaceous plant and small mammal values.

See Sec. 6.1 for further discussion of derivation of uptake factors. 
Table C.33. Overall dose rates from internal and external exposures for plants, earthworms, and terrestrial wildlife exposed to radionuclides in soil at WAG2 Intermediate Holding Pond (IHP).

\begin{tabular}{|c|c|c|c|}
\hline Receptor & $\begin{array}{l}\text { Dose rate } \\
\text { (pCi/g) }\end{array}$ & \multicolumn{2}{|c|}{ Primary contributors ( $\%$ of total dose rate) } \\
\hline Plants & 4340 & $\begin{array}{l}\text { Plutonium-239/240 } \\
\text { Cesium-137 } \\
\text { Americium-241 } \\
\text { Plutonium-238 }\end{array}$ & $\begin{array}{l}(66.6 \%) \\
(17.1 \%) \\
(10.7 \%) \\
(3.0 \%)\end{array}$ \\
\hline Earthworms & 2850 & $\begin{array}{l}\text { Plutonium-239/240 } \\
\text { Cesium-137 } \\
\text { Americium-241 } \\
\text { Plutonium-238 }\end{array}$ & $\begin{array}{l}(43.9 \%) \\
(26.0 \%) \\
(22.5 \%) \\
(2.3 \%)\end{array}$ \\
\hline Short-tailed shrew & 2283 & $\begin{array}{l}\text { Plutonium-239/240 } \\
\text { Americium-241 } \\
\text { Cesium-137 } \\
\text { Curium-244 }\end{array}$ & $\begin{array}{l}(60.1 \%) \\
(20.3 \%) \\
(8.7 \%) \\
(7.1 \%)\end{array}$ \\
\hline White-footed mouse & 2177 & $\begin{array}{l}\text { Plutonium-239/240 } \\
\text { Americium-241 } \\
\text { Curium-244 } \\
\text { Cesium-137 }\end{array}$ & $\begin{array}{l}(63.0 \%) \\
(21.2 \%) \\
(7.4 \%) \\
(4.7 \%)\end{array}$ \\
\hline Wild turkey & 150 & Cesium-137 & $(91.3 \%)$ \\
\hline White-tailed deer & 84 & Cesium-137 & $(91.4 \%)$ \\
\hline Red fox & 326 & Cesium-137 & $(94.6 \%)$ \\
\hline Red-tailed hawk & 283 & Cesium-137 & $(94.0 \%)$ \\
\hline Mink & 180 & Cesium-137 & $(95.3 \%)$ \\
\hline Belted kingfisher ${ }^{1}$ & 64 & Cesium-137 & $(98.7 \%)$ \\
\hline
\end{tabular}

${ }^{\mathrm{I}}$ Kingfisher dose rate estimate is based on external exposures to radionuclides in soil. Water-related exposures (water and fish ingestion) will be added when water data become available. 
Table C.34. Overall dose rates from internal and external exposures for plants, earthworms, and terrestrial wildlife exposed to radionuclides in soil at WAG2 Middle White Oak Creek (MWC).

\begin{tabular}{|c|c|c|c|}
\hline Receptor & $\begin{array}{l}\text { Dose rate } \\
\text { (pCi/g) }\end{array}$ & \multicolumn{2}{|c|}{ Primary contributors ( $\%$ of total dose rate) } \\
\hline Plants & 1400 & $\begin{array}{l}\text { Plutonium-239/240 } \\
\text { Americium-241 } \\
\text { Plutonium-238 }\end{array}$ & $\begin{array}{l}(83.1 \%) \\
(9.8 \%) \\
(3.0 \%)\end{array}$ \\
\hline Earthworms & 800 & $\begin{array}{l}\text { Plutonium-239/240 } \\
\text { Americium-241 } \\
\text { Cesium-137 }\end{array}$ & $\begin{array}{l}(62.9 \%) \\
(23.7 \%) \\
(4.0 \%)\end{array}$ \\
\hline Short-tailed shrew & 734 & $\begin{array}{l}\text { Plutonium-239/240 } \\
\text { Americium-241 } \\
\text { Plutonium-238 }\end{array}$ & $\begin{array}{l}(75.0 \%) \\
(18.6 \%) \\
(3.3 \%)\end{array}$ \\
\hline White-footed mouse & 723 & $\begin{array}{l}\text { Plutonium-239/240 } \\
\text { Americium-241 } \\
\text { Plutonium-238 }\end{array}$ & $\begin{array}{l}(76.1 \%) \\
(18.8 \%) \\
(3.4 \%)\end{array}$ \\
\hline Wild turkey & 11 & Cesium-137 & $(53.8 \%)$ \\
\hline White-tailed deer & 5 & Cesium-137 & $(63.4 \%)$ \\
\hline Red fox & 17 & Cesium-137 & $(77.3 \%)$ \\
\hline Red-tailed hawk & 14 & Cesium-137 & $(81.2 \%)$ \\
\hline Mink & 9 & Cesium-137 & $(84.3 \%)$ \\
\hline Belted kingfisher ${ }^{l}$ & 3 & Cesium-137 & $(93.4 \%)$ \\
\hline
\end{tabular}

${ }^{1}$ Kingfisher dose rate estimate is based on external exposures to radionuclides in soil. Water-related exposures (water and fish ingestion) will be added when water data become available. 
Table C.35. Overall dose rates from internal and external exposures for plants, earthworms, and terrestrial wildlife exposed to radionuclides in soil at WAG2 Lower White Oak Creek (LWC).

\begin{tabular}{|c|c|c|c|}
\hline Receptor & $\begin{array}{l}\text { Dose rate } \\
(\mathrm{pCi} / \mathrm{g})\end{array}$ & \multicolumn{2}{|c|}{ Primary contributors ( $\%$ of total dose rate) } \\
\hline Plants & 1350 & $\begin{array}{l}\text { Plutonium-239/240 } \\
\text { Americium-241 } \\
\text { Cesium- } 137\end{array}$ & $\begin{array}{l}(74.0 \%) \\
(12.2 \%) \\
(8.1 \%)\end{array}$ \\
\hline Earthworms & 846 & $\begin{array}{l}\text { Plutonium-239/240 } \\
\text { Americium-241 } \\
\text { Cesium-137 }\end{array}$ & $\begin{array}{l}(51.4 \%) \\
(27.2 \%) \\
(13.0 \%)\end{array}$ \\
\hline Short-tailed shrew & 739 & $\begin{array}{l}\text { Plutonium-239/240 } \\
\text { Americium-241 } \\
\text { Curium-244 }\end{array}$ & $\begin{array}{l}(64.3 \%) \\
(22.4 \%) \\
(6.2 \%)\end{array}$ \\
\hline White-footed mouse & 722 & $\begin{array}{l}\text { Plutonium-239/240 } \\
\text { Americium-241 } \\
\text { Curium-244 }\end{array}$ & $\begin{array}{l}(65.8 \%) \\
(22.9 \%) \\
(6.3 \%)\end{array}$ \\
\hline Wild turkey & 24 & Cesium-137 & $(84.2 \%)$ \\
\hline White-tailed deer & 13 & Cesium-137 & $(85.6 \%)$ \\
\hline Red fox & 49 & Cesium-137 & $(92.9 \%)$ \\
\hline Red-tailed hawk & 42 & Cesium-137 & $(93.7 \%)$ \\
\hline Mink & 27 & Cesium-137 & $(94.3 \%)$ \\
\hline Belted kingfisher ${ }^{1}$ & 10 & Cesium-137 & $(95.7 \%)$ \\
\hline
\end{tabular}

${ }^{1}$ Kingfisher dose rate estimate is based on external exposures to radionuclides in soil. Water-related exposures (water and fish ingestion) will be added when water data become available. 
Table C.36. Overall dose rates from internal and external exposures for plants, earthworms, and terrestrial wildlife exposed to radionuclides in soil at WAG2 Lower Melton Branch (LMB).

\begin{tabular}{|c|c|c|c|}
\hline Receptor & $\begin{array}{l}\text { Dose rate } \\
\text { (pCi/g) }\end{array}$ & Primary contributors $(\%$ & of total dose rate) \\
\hline Plants & 3010 & $\begin{array}{l}\text { Plutonium-239/240 } \\
\text { Cesium-137 } \\
\text { Americium-241 } \\
\text { Plutonium-238 }\end{array}$ & $\begin{array}{l}(66.6 \%) \\
(17.1 \%) \\
(10.7 \%) \\
(3.0 \%)\end{array}$ \\
\hline Earthworms & 3050 & $\begin{array}{l}\text { Strontium-90 } \\
\text { Americium-241 }\end{array}$ & $\begin{array}{l}(92.1 \%) \\
(2.1 \%)\end{array}$ \\
\hline Short-tailed shrew & 622 & $\begin{array}{l}\text { Strontium-90 } \\
\text { Curium-244 } \\
\text { Americium-241 (7.5\%) }\end{array}$ & $\begin{array}{l}(58.3 \%) \\
(26.7 \%)\end{array}$ \\
\hline White-footed mouse & 498 & $\begin{array}{l}\text { Strontium-90 } \\
\text { Curium-244 } \\
\text { Americium-241 (9.4\%) }\end{array}$ & $\begin{array}{l}(49.7 \%) \\
(33.4 \%)\end{array}$ \\
\hline Wild turkey & 366 & Strontium-90 & $(96.2 \%)$ \\
\hline White-tailed deer & 275 & Strontium-90 & $(96.9 \%)$ \\
\hline $\operatorname{Red}$ fox & 1087 & Strontium-90 & $(97.6 \%)$ \\
\hline Red-tailed hawk & 1235 & Strontium-90 & $(98.4 \%)$ \\
\hline Mink & 568 & Strontium-90 & $(97.3 \%)$ \\
\hline Belted kingfisher ${ }^{1}$ & 9 & $\begin{array}{l}\text { Cesium-137 } \\
\text { Cobalt- } 60\end{array}$ & $\begin{array}{l}(47.3 \%) \\
(37.5 \%)\end{array}$ \\
\hline
\end{tabular}

${ }^{1}$ Kingfisher dose rate estimate is based on external exposures to radionuclides in soil. Water-related exposures (water and fish ingestion) will be added when water data become available. 


\section{DISTRIBUTION}

1. T. L. Ashwood

2. L. V. Asplund

3. D. M. Borders

4. H. L. Boston

5. W.D. Brickeen

6. B. B. Burgoa

7. R. B. Clapp

8. A. H. Curtis

9. M. F. P. DeLozier

10. A. F. Diefendorf

11. R. A Efroymson

12. C. J. Ford

13. S. B. Garland

14. C. S. Haase

15. D. S. Hicks

16. S. G. Hildebrand

17. D. D. Huff

18. D. S. Jones

19. K. L. Kaiser

20. R. H. Ketelle

21. E. A. Krispin
22. A. J. Kuhaida, Jr

23. D. M. Matteo

24. W. L. McCalla

25. P. L. Osborne

26-27. P. T. Owen

28. S. T. Puraker

29. D. E. Reichle

30. C. T. Rightmire

31. B. E. Sample

32. P. A. Schrandt

33. J. A. Shaakir-Ali

34. J. G. Smith

35. M. R. Smith

36. S. H. Stow

37-41. G. W. Suter

42. D. R. Watkins

43 C. J. E. Welsh

44. A. S. Will

45. Central Research Library

46. ER Document Management

Center-RC

47. Office of Scientific and Technical Information, P. O. Box 62, Oak Ridge, TN 37831

48. P. A. Hoffmann, DOE Oak Ridge Operations Office, P. O. Box 2001, Oak Ridge, TN 37831-8541

49. G. D. Reed, University of Tennessee, Department of Civil and Environmental Engineering, 223 Perkins Hall, Knoxville, TN 37996-2010 